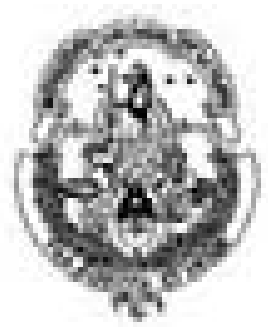

Universidad Nacional de la Plata

Facultad de Ciencias Exactas

Departamento de Química

Trabajo de Tesis Doctoral

\title{
Estudio DE INTERFASES \\ Metal-Tiol en Superficies \\ Planas Y NANOPARTÍCULAS
}

\author{
Gastón Corthey
}

Director: Mariano H. Fonticelli

Codirector: Roberto C. SAlvarezza 
El presente trabajo se llevó a cabo en el Instituto de Investigaciones Fisicoquímicas Teóricas y Aplicadas (INIFTA) del Departamento de Química de la Facultad de Ciencias Exactas, Universidad Nacional de La Plata, bajo la dirección del Prof. Dr. Mariano H. Fonticelli y el Dr. Roberto C. Salvarezza. El mismo se presenta a consideración de las autoridades de dicha Facultad para acceder al grado académico de Doctor de la Facultad de Ciencias Exactas.

La Plata, agosto de 2012.

Lic. Gastón Corthey

e-mail: gcorthey@inifta.unlp.edu.ar 
A mis padres $y$ mis hermanos

A Sole 



\section{Agradecimientos}

Esta tesis es la conjunción del trabajo de muchas personas sin las cuales no podría haberse realizado. Quiero expresar aquí mi agradecimiento hacia ellas y hacia las que olvido incluir.

A mis directores, Mariano Fonticelli y Roberto Salvarezza, por haber estado presentes en cada momento de mi trabajo de tesis y por la libertad que me han dado en el desarrollo del trabajo. Por todas las enseñanzas que me han trasmitido durante estos años y por la lectura y corrección del manuscrito de la tesis. A Mariano, por impulsarme a que siempre empecemos cosas nuevas en el laboratorio y por su mirada crítica de los resultados. A Roberto, por su constante motivación, sobre todo cuando las cosas no salían como uno quería.

A todos los integrantes del grupo de Nanoscopías del INIFTA. En especial, a Julio Azcárate, Alejandra Floridia y Aldo Rubert, por todas las charlas compartidas, que han nutrido este trabajo. A Julio, por la síntesis de algunas de las nanopartículas de oro utilizadas en este trabajo y a Alejandra, por las medidas realizadas para el sistema Pd-tiol. A Aldo Rubert y Guillermo Benitez, por las medidas de XPS y por todas sus explicaciones respecto al análisis de los datos. A Lorena Picone, por las medidas de espectroscopía infrarroja. A Germán Kürten, Matias Calderón, Celeste Dalfovo, Francisco Ibañez, Emiliano Cortés, Evangelina Pensa, Constanza Flores, Maria Elena Vela, Alejandro Ramirez, Antonieta Daza Millone, Carolina Vericat, Federico Castez, Doris Grumelli, Bárbara Blum y Patricia Schilardi, por toda la ayuda en este tiempo y la buena disposición.

A Eugenia Zelaya, por haberse dedicado desinteresadamente durante un mes entero sólo a enseñarme microscopía electrónica. Por ayudarnos con las medidas en cada visita al Centro Atómico Bariloche y por llevarnos de paseo. Por todas las charlas compartidas y su gran disposición siempre.

A Alfredo Tolley, por haber confiado en mi y haber sido el nexo para poder realizar una estadía de investigación en Berkeley, que se la debo a él. Por todo el apoyo recibido.

A Francisco Lovey, Carlos Espinoza, Victoria Castro, Liliana Mogni y todos los miembros de Materiales del Centro Atómico Bariloche. Por toda la ayuda en las visitas.

Muchas gracias a Marita Mirífico, José Caram, Nelson Rodriguez Arroyo, Esther Svartman, Fernanda Rozas, Mauro Banera, Coco Rodriguez Nieto, Miguel Pascuale, Marcelo Ceolín y Agustín Picco, por toda la ayuda que me han dado durante estos años en el INIFTA y por su generosidad para compartir los elementos de laboratorio y el lugar de trabajo.

A Jimena Olmos-Asar y Marcelo Mariscal, por las simulaciones de dinámica de Langevin y por brindarme los elementos para la compaginación de ellas en este informe. 
A Pilar Carro, por los cálculos de teoría del funcional de densidad y por toda su ayuda.

A los miembros del NCEM, Berkeley, por su ayuda durante mi estadía de investigación. Especialmente a Chengyu Song, Markus Boese y Peter Ercius, por el entrenamiento con los microscopios. A Abhay Gautam por su ayuda con las medidas y a Colin Ophus, con el análisis de los datos. A Martin Linck, Jim Ciston y Alpha N'Diaye, por las charlas compartidas. A Velimir Radmilovic, por la dirección allí y a Uli Dahmen, por haberme permitido realizar esta estadía. A Jane Cavlina, por su ayuda en la parte administrativa.

A Jong Min Yuk y Jian-Hao Chen, por las muestras de grafeno.

A Gilberto Garcia, Arturo Ponce, Miguel José-Yacamán y todos los integrantes del laboratorio del Dr. Yacamán, por toda la colaboración en mi estadía allí.

A José Ramallo-López, Lisandro Giovanetti y Félix Requejo, por las medidas de absorción de rayos $\mathrm{X}$ y dispersión de rayos $\mathrm{X}$ a bajo ángulo.

A Sergio Mejía-Rosales, Oscar Oviedo, Ezequiel Leiva y Luca Floreano, por las charlas o e-mails compartidos, que nutrieron mi trabajo.

A José Luis Vicente, por su gran disposición para nuestras consultas.

A Ricardo Faccio por la lectura de parte de la tesis y sus comentarios.

A Carolina Vericat y Gustavo Andreasen, por las imágenes de STM.

A Olga López-Acevedo, por facilitarme las coordenadas de los clusters de oro y por las charlas que aportaron ingredientes a este informe.

A los compañeros de la cátedra Fisicoquímica de la Facultad de Ciencias Exactas, por los reemplazos en los momentos finales de la tesis.

A todo el personal del INIFTA, en especial a Coco Formoso, Jorge Massarutti, Ana y Diego Celi, por toda su ayuda en estos años.

Al Consejo Nacional de Investigaciones Científicas y Técnicas (CONICET), Swiss National Science Foundation (SNSF), Comisión Fulbright y Fundación Bunge y Born, Universidad Nacional de La Plata (UNLP) y Departamento de Química de la Facultad de Ciencias Exactas, UNLP por el financiamiento para realizar esta tesis y las estadías de investigación en otros laboratorios.

A mis compañeros de las tertulias de los jueves, por saber comprender mis ausencias en el último período de escritura.

A la familia de mi novia, que considero parte de mi familia, por todo su apoyo. En especial a Juan, por las ayudas con $\mathrm{LAT}_{\mathrm{E}} \mathrm{X}$ y a Laura, por las ayudas gramaticales.

Por último, quiero agradecer especialmente a mi familia. A La Nona, por estar siempre pendiente de todos sus nietos. A mis padres, Carlos y Mary, por saber que siempre están al lado mío para cualquier cosa y porque les debo a ellos haber llegado hasta aquí. Por todas las cosas lindas que compartimos siempre y por todos los valores que me trasmitieron. A mis hermanos, Euge e Ito, por todo lo que siempre compartimos juntos y por su aliento cuando parecía que no iba a terminar nunca la escritura del manuscrito. Y a mi novia, Sole, por ser mi compañera, por muchas de las figuras de este informe, por su paciencia durante la escritura de la tesis y porque es gracias a ella que pude terminarla...

G. C.

La Plata, agosto de 2012. 


\section{Resumen}

Las nanopartículas (NPs) de metales nobles presentan gran interés tanto por sus propiedades básicas como por la amplia variedad de aplicaciones en las que se utilizan activamente. Para obtener NPs estables y evitar su aglomeración, es necesario utilizar agentes estabilizantes durante la síntesis. Estas moléculas se adsorben sobre la superficie de las NPs y evitan que estas interaccionen directamente con las partículas vecinas. Si bien existen diversas moléculas que pueden ser utilizadas para este fin, uno de los únicos tipos de NPs metálicas cuya distribución de tamaños es estrecha, son estables a lo largo del tiempo y pueden ser obtenidas en forma de polvo, lavadas, y utilizadas como si se tratase de un compuesto químico tradicional, son las NPs cubiertas por tioles. La gran estabilidad de estas partículas está dada por la alta energía del enlace que se forma entre el azufre del grupo tiol y el metal. Resulta, entonces, particularmente interesante estudiar la interfase entre la superficie metálica y las moléculas adsorbidas.

En este trabajo se presenta un estudio de la interfase $\mathrm{Au}$-tiol y $\mathrm{Pd}$-tiol en diferentes sistemas que van desde monocapas autoensambladas (SAMs) de tioles sobre superficies planas hasta compuestos poliméricos de tiolatos metálicos, con especial énfasis en las NPs metálicas cubiertas por tioles. El estudio de estos sistemas fue realizado mediante la utilización de diversas técnicas. En todos los experimentos se controlaron las condiciones de medida de manera tal de minimizar los daños producidos sobre las muestras. En los casos en que esto no fue posible, se intentó elucidar qué tipo de daño se estaba produciendo para realizar el análisis de los resultados teniendo en cuenta estos efectos o bien descartar los datos que hayan sido afectados por los mismos.

En primer lugar, se analizó la interfase $\mathrm{Au}$-tiol, sistema considerado modelo en este campo de investigación. En este caso, se estudió la síntesis de NPs de Au protegidas con tioles mediante los métodos de Brust-Schiffrin de una y dos fases. Actualmente, el mecanismo relacionado a estas síntesis es motivo de discusión en la literatura, por lo que resulta interesante analizar las diferencias en las NPs producidas por cada ruta. Uno de los tioles que se utilizó con el método de Brust-Schiffrin de una fase es el ácido tiomálico. En esta síntesis se encontró una reducción parcial de los intermediarios de reacción que, en este caso, consisten en tiolatos de oro $\left(\mathrm{Au}^{\mathrm{I}}-\mathrm{SR}\right)$.. Por tal motivo, los productos obtenidos consistieron en NPs formadas por un núcleo de Au metálico rodeado por tiomalato de Au, en una estructura del tipo carozo-coraza (core-shell). Si bien este comportamiento ha sido planteado en trabajos anteriores como un hecho posible para comprender las propiedades de lo productos obtenidos, su caracterización completa mediante diferentes métodos no ha sido informada anteriormente en la bibliografía. Adicionalmente, se presentó un 
procedimiento para la reducción del tiomalato de Au mediante la inmersión de las NPs en una solución de quinhidrona y iones $\mathrm{Ag}^{+}$, proceso mediante el cual se formaron NPs bimetálicas de $\mathrm{Au}-\mathrm{Ag}$.

Respecto a la interfase $\mathrm{Pd}$-tiol, se dividió el estudio entre superficies planas y NPs. Este sistema, a diferencia del $\mathrm{Au}$, no ha sido estudiado tan extensamente por lo que son muy pocos los trabajos previos sobre aspectos básicos referidos a esta interfase.

En primer término, se llevó a cabo el análisis de la adsorción de alcanotioles sobre superficies planas de Pd. Mediante espectroscopía de fotoelectrones generados por rayos X (XPS) se determinó la composición química luego de realizar la adsorción. La superficie resultante puede describirse como una capa mixta formada por sulfuro, con un cubrimiento $\theta_{\text {sulfuro }} \approx 0,4$ sobre la que se adsorbe una capa de moléculas de tiolato con un cubrimiento $\theta_{\text {tiolato }} \approx 0,3$. Luego, mediante medidas de la capacidad de interfase, se estudió la estabilidad electroquímica de esta capa mixta en soluciones acuosas alcalinas. Los resultados muestran que estos sistemas permanecen estables hasta potenciales más negativos que los sistemas análogos de Au o Ag. Aún más, el potencial al que ocurre la desorción de esta capa no depende de la longitud de la cadena hidrocarbonada del alcanotiol. Se estudió también la adsorción de tioles sobre superficies bimetálicas de $\mathrm{Pd}-\mathrm{Au}$ y los resultados fueron contrastados con las superficies monometálicas. En último lugar para las superficies planas, se realizó un estudio de este sistema en el marco de la teoría del funcional de densidad (DFT) y la termodinámica estadística a partir de primeros principios. Se plantearon 5 estructuras diferentes, constituidas por sulfuro, tiolato o sulfuro + tiolato adsorbidos sobre $\operatorname{Pd}(111)$ y se comparó la estabilidad relativa de estas interfases mediante el análisis de la energía libre superficial en función del potencial químico (y, por ende, la presión y temperatura) de las especies precursoras de los adsorbatos en fase gaseosa, en equilibrio termodinámico con las especies adsorbidas. Para las condiciones experimentales accesibles, se determinó que las únicas estructuras posibles (termodinámicamente estables frente a las demás) son las que comprenden una capa mixta de sulfuro y tiolato. Sin embargo, alguna de las otras estructuras podría encontrarse experimentalmente si permaneciera atrapada cinéticamente. Además, mediante el análisis de la estructura electrónica de estos sistemas, se propuso un mecanismo que explica el origen del sulfuro en estos sistemas, basado en el análisis de la interacción adsorbato-sustrato.

En segundo lugar, se estudiaron NPs de Pd protegidas por alcanotioles. Estas NPs fueron preparadas mediante el método de Brust-Schiffrin bifásico y mediante intercambio de ligandos de NPs protegidas con alquilaminas, previamente sintetizadas. Además de un estudio detallado de las condiciones de síntesis, se estudió la composición química y estructura de estas NPs mediante diferentes técnicas como XPS (convencional y con radiación de luz sincrotrón), espectroscopía infrarroja, espectroscopía de absorción de rayos X y microscopía electrónica de barrido por transmisión (STEM). Se encontró que la composición de las NPs preparadas por los dos métodos es similar a la encontrada en las superficies planas de Pd modificadas con alcanotioles. A partir de los resultados obtenidos, se planteó un modelo para estas partículas que consiste en un núcleo de Pd metálico sobre el que se encuentra una capa de sulfuro con cubrimientos en el orden de submonocapas y, sobre esta, se ubican los alcanotiolatos. Se propuso también un posible esquema de reacción para 
la síntesis de estas NPs en base a los productos obtenidos y al análisis de la estructura electrónica de las superficies planas de Pd, comentado anteriormente. Luego, se estudió la influencia de las moléculas protectoras en el orden de los átomos metálicos que componen las NPs en base al análisis de imágenes de STEM. Se ha observado que las NPs cubiertas con tioles presentan una estructura desordenada mientras que en las partículas protegidas con aminas, los átomos metálicos siguen un orden establecido. Estas diferencias fueron interpretadas en base a simulaciones atomísticas de dinámica de Langevin. Los resultados indican que el desorden de los átomos es causado por la presencia de la capa de sulfuro en estas partículas debido a la gran energía de enlace de estas especies al Pd. Por último, se estudió el daño producido sobre estas NPs al ser analizadas mediante microscopía electrónica de transmisión de alta resolución (HRTEM). 


\section{Abstract}

Title: Study of Thiol-Metal Interfaces in Planar Surfaces and Nanoparticles

Noble metal nanoparticles (NPs) are very interesting because of their fundamental properties and their applications. In order to obtain stable NPs and avoid their agglomeration, it is necessary to use stabilizing agents during the synthesis. These molecules are adsorbed on the surface of the NPs and avoid the interaction between the metal cores of adjacent particles. While there are different molecules which can be used with this purpose, one of the only types of metal NPs which have a narrow size distribution, are stable over time, can be obtained as a powder, rinsed and used as a chemical compound, are the thiolateprotected NPs. The high stability of these particles is given by the strong S-metal bond. Therefore, it is particularly interesting to study the interface between metallic surfaces and the adsorbed molecules.

In this work, we present a study of the $\mathrm{Au}$-thiol and $\mathrm{Pd}$-thiol interfaces in different systems, from thiolate self-assembled monolayers (SAMs) on planar metal surfaces to metal thiolates polymeric compounds, with special interest in thiolate-protected metal NPs. The study of these systems was done by means of different experimental and theoretical techniques. In all the experiments the measurement conditions were controlled in order to minimize the damage produced to the samples.

In the first place, we studied the $\mathrm{Au}$-thiol interface, which is considered a model system in this field of research. We analyzed the synthesis of thiolate-protected Au NPs using the one- and two-phase Brust-Schiffrin methods. Nowadays, the mechanism involved in these synthesis routes are a subject of discussion in the literature. Therefore, it is interesting to study the differences in the NPs produced by each method. One of the thiols used with the one-phase Brust-Schiffrin method was the thiomalic acid (TMA). In this synthesis we found a partial reduction of the reaction intermediates which are gold thiolates $\left(\mathrm{Au}^{\mathrm{I}}-\mathrm{SR}\right)$. Because of that, the obtained products consisted of NPs composed by a metallic Au core covered by gold thiomalate, in a core-shell structure $\left(\mathrm{Au} @ \mathrm{Au}^{\mathrm{I}}-\mathrm{TM}\right)$. Although this behavior was previously proposed to explain different properties of the obtained products, the complete characterization by different techniques have not been reported before. Additionally, we presented a procedure for the reduction of gold thiomalate by immersion of the NPs in a solution containing quinhydrone and $\mathrm{Ag}^{+}$ions, a process which produced $\mathrm{Au}-\mathrm{Ag}$ bimetallic NPs.

With respect to the $\mathrm{Pd}$-thiol interface, we studied planar surfaces and NPs. In opposition to $\mathrm{Au}$, this system have not been studied very extensively and, therefore, there are 
a few works on fundamental aspects of this interface in the literature. In the first place, we analyzed the adsorption of alkanethiols on planar Pd surfaces. We determined the chemical composition after the adsorption process, by X-ray photoelectron spectroscopy (XPS). The prepared surface can be described as a mixed layer composed by sulfide (with a coverage $\theta_{\text {sulfide }} \approx 0.4$ ) onto which a thiolate monolayer is adsorbed $\left(\theta_{\text {thiolate }} \approx 0.3\right)$. After that, we studied the electrochemical stability of this mixed layer in aqueous alkaline solutions, by interfacial capacity measurements. The results show that these systems are stable up to more negative potentials than the analogous Au or Ag systems. Moreover, the desorption potential of this layer does not depend on the thiol hydrocarbon chain length. The adsorption of thiols on bimetallic $\mathrm{Pd}-\mathrm{Au}$ surfaces was also studied and the results were contrasted to the ones obtained in the monometallic case. In the last place for planar surfaces, we performed calculations on the level of density functional theory (DFT) and first-principles statistical thermodynamics. We proposed different surfaces with sulfide, thiolate or sulfide and thiolate on $\operatorname{Pd}(111)$ and the relative stability of these structures was compared by the analysis of the surface free energy as a function of the chemical potential (and, hence, the temperature and pressure) of the adsorbate precursor species in gas phase, in thermodynamic equilibrium with the adsorbed species. For the accessible experimental conditions, it was determined that the only possible structures (thermodynamically stable compared to the others) are the ones that comprise a mixed sulfide and thiolate layer. However, some of the other structures could be experimentally found if they were kinetically trapped. Also, by the study of the electronic structure of the these systems and the analysis in terms of the adsorbate-substrate interaction we proposed a mechanism which explains the origin of sulfide in these structures.

In the second place, we studied alkanethiolate-protected Pd NPs. These NPs were prepared by the two-phase Brust-Schiffrin method and by ligand interchange of alkyl amine-protected Pd NPs. In addition to a detailed study of the synthesis conditions, we studied the chemical composition and structure of these NPs by different techniques such as XPS (conventional and with synchrotron radiation), infrared spectroscopy, X-ray absorption spectroscopy (XAS) and scanning transmission electron microscopy (STEM). We found that the composition of the NPs prepared by both routes is similar to the one found for planar Pd surfaces modified with alkanethiols. We proposed a model for these particles which comprises a metallic Pd core covered by a sulfide layer (with a sub-monolayer coverage) and an alkanethiolate monolayer. We also proposed a possible reaction scheme for the synthesis of these NPs. Then, we studied the influence of the protecting molecules on the order of the metal atoms by STEM. It was observed that, while thiolate-protected Pd NPs show a disordered structure, the metal atoms in amineprotected Pd NPs have an ordered structure. These differences were interpreted with atomistic Langevin dynamics simulations. The results indicate that the disorder of the metal atoms is caused by the sulfide layer in the particles because of the strong bond of these species to Pd. Finally, we studied the damage produce by the electron beam to these NPs when they are studied by high-resolution transmission electron microscopy (HRTEM). 


\section{Índice general}

$\begin{array}{lll}\text { Resumen } & \text { VII }\end{array}$

$\begin{array}{lll}\text { Abstract } & \text { XI }\end{array}$

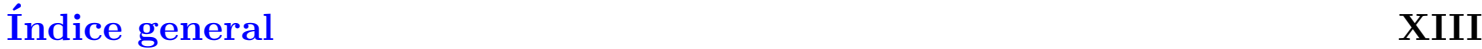

$\begin{array}{lll}\text { Índice de figuras } & \text { XVII }\end{array}$

$\begin{array}{ll}\text { Índice de tablas } & \text { XXI }\end{array}$

1 Introducción $\quad 1$

1.1 Lugar de trabajo y trabajo en colaboración . . . . . . . . . . . . . . . . 3

1.2 Estructura y contenidos . . . . . . . . . . . . . . . 3

I Métodos 5

2 Métodos experimentales y teóricos $\quad 7$

2.1 Materiales . . . . . . . . . . . . . . . . . . 7

2.1 .1 Agua . . . . . . . . . . . . . . . . 7

2.1 .2 Limpieza del material . . . . . . . . . . . . . . . . 7

2.1 .3 Reactivos generales . . . . . . . . . . . . . . 8

2.1 .4 Síntesis de $\mathrm{HAuCl}_{4} \ldots \ldots \ldots \ldots \ldots$

2.2 Voltamperometría cíclica . . . . . . . . . . . . . . . . . . . 9

2.2.1 Cálculo del área real de un electrodo . . . . . . . . . . . . . . . 10

2.3 Espectroscopía ultravioleta-visible (UV-Vis) ～. . . . . . . . . . . . . . 10

2.4 Espectroscopía infrarroja por transformada de Fourier (FTIR) . . . . . . . 10

2.5 Espectroscopía de fotoelectrones generados por rayos X (XPS) . . . . . . . 11

2.5.1 Principios básicos . . . . . . . . . . . . . . . . . 11

2.5 .2 Disposición experimental . . . . . . . . . . . . . . . 14

2.5.3 Análisis de los resultados . . . . . . . . . . . . . . . 16

2.6 Espectroscopía de absorción de rayos X (XAS) . . . . . . . . . . . . 20

2.6.1 Consideraciones experimentales . . . . . . . . . . . . . . . 21

2.7 Dispersión de rayos X a bajo ángulo (SAXS) . . . . . . . . . . . . . . . . . . 22

2.7.1 Consideraciones experimentales . . . . . . . . . . . . . 22 
2.8 Microscocopía electrónica de transmisión $(\mathrm{TEM}) \ldots \ldots$. . . . . . . . . 22

2.9 Microscopía electrónica de barrido por transmisión (STEM) . . . . . . . . . . 32

2.10 Distribución de tamaños de las nanopartículas . . . . . . . . . . . . . . . 34

2.11 Teoría del funcional de densidad (DFT) . . . . . . . . . . . . . 34

2.11 .1 Implementación computacional . . . . . . . . . . . . . 36

$\begin{array}{lll}\text { II } & \text { Interfase Au-tiol } & 37\end{array}$

3 Nanopartículas de Au protegidas por tioles $\quad 39$

3.1 Introducción . . . . . . . . . . . . . . . . . . . . 39

3.2 Monocapas autoensambladas de tioles sobre $\mathrm{Au}(111) \ldots \ldots$. . . . . . . . . . . . . . . . 40

3.3 Nanopartículas y clusters de Au protegidos por tioles . . . . . . . . . . . . . 42

3.4 Método de Brust-Schiffrin de dos fases . . . . . . . . . . . . . . . . . . . . . . 44

3.4 .1 Síntesis . . . . . . . . . . . . . . . . . 44

3.4.2 Estudio de la composición química de las nanopartículas mediante espectroscopía de fotoelectrones generados por rayos X . . . . . . 47

3.5 Método de Brust-Schiffrin de una fase . . . . . . . . . . . . . . . . . . 50

3.6 Tiolatos de $\mathrm{Au} \ldots \ldots \ldots \ldots \ldots$. . . . . . . . . . . . . . . . 52

3.7 Comportamiento de las AuNPs cubiertas por alcanotiolatos sobre grafeno . 52

3.8 Conclusiones . . . . . . . . . . . . . . . . . 59

4 Nanopartículas de Au protegidas por tiomalato de Au $\mathbf{6 1}$

4.1 Introducción . . . . . . . . . . . . . . . . . . . . . 61

4.2 Características generales de las nanopartículas y composición química . . . 62

4.3 Estudio de la resistencia del tiomalato de Au hacia la reducción . . . . . . . 65

4.3.1 Post reducción del tiomalato de Au . . . . . . . . . . . 65

4.3.2 Electrorreducción de Au sobre grafito . . . . . . . . . . . . . 66

4.3.3 Variación de la energía libre asociada al proceso de reducción del tiomalato de $\mathrm{Au} \ldots \ldots \ldots$. . . . . . . . . . . . 68

4.4 Estructura geométrica de las nanopartículas . . . . . . . . . . . . . . . . . . . . . . . . . . 70

4.5 Tamaño de las nanopartículas . . . . . . . . . . . . . . . . . 73

4.5.1 Microscopía electrónica de transmisión (TEM) . . . . . . . . . 73

4.5.2 Microscopía electrónica de barrido por transmisión (HAADF-STEM) 74

4.5.3 Comparación entre el tamaño determinado mediante microscopía electrónica y dispersión de rayos X a bajo ángulo . . . . . . . . . . 75

4.6 Estructura cristalina de las nanopartículas . . . . . . . . . . . . . . 76

4.7 Estabilidad de las nanopartículas . . . . . . . . . . . . . . . . 77

4.8 Nanopartículas bimetálicas de Au-Ag preparadas a partir de nanopartículas de Au protegidas por tiomalato de $\mathrm{Au} \ldots \ldots . \ldots 78$

4.9 Conclusiones . . . . . . . . . . . . . . . 81 
$5 \quad$ Adsorción de alcanotioles sobre superficies planas de $\mathrm{Pd} \quad \mathbf{8 7}$

5.1 Introducción . . . . . . . . . . . . . . . . . . . . . . . 87

5.2 Preparación de los sustratos de paladio . . . . . . . . . . . . 88

5.3 Preparación de las superficies cubiertas con alcanotioles . . . . . . . . . . . 91

5.4 Caracterización de las superficies de paladio modificadas con alcanotioles . 92

5.4.1 Caracterización mediante XPS . . . . . . . . . . . . . . 92

5.4 .2 Caracterización mediante voltamperometría cíclica . . . . . . . . . 94

5.4.3 Transferencia de carga a través de la capa de sulfuro-tiolato . . . . . 95

5.5 Estudio electroquímico de la estabilidad de la capa de sulfuro-tiolato . . . . 97

5.6 Adsorción de azufre sobre $\mathrm{Pd} \ldots \ldots$. . . . . . . . . . . . . . . . 99

5.7 Adsorción de alcanotioles sobre superficies de $\mathrm{Pd}-\mathrm{Au}$. . . . . . . . . . . 102

5.7.1 Preparación de los sustratos . . . . . . . . . . . . . . . 103

5.7 .2 Composición química superficial . . . . . . . . . . . . . 103

5.8 Discusión general de los resultados experimentales . . . . . . . . . . . 105

5.9 Estudio teórico de la adsorción de tioles sobre $\mathrm{Pd}$. . . . . . . . . . . . 107

5.9.1 Características de los modelos propuestos y parámetros estructurales

obtenidos . . . . . . . . . . . . . . . . . 108

5.9.2 Estabilidad termodinámica de los diferentes modelos . . . . . . . . . 111

5.9.3 Análisis de la estructura electrónica . . . . . . . . . . . . . . . . . . 114

5.9.4 Comparación entre resultados experimentales y cálculos computacionales . . . . . . . . . . . . . . . . . . . 118

5.10 Conclusiones . . . . . . . . . . . . . . . . . . . . . . . . 121

6 Nanopartículas de $\mathrm{Pd}$ protegidas por alcanotioles $\quad \mathbf{1 2 5}$

6.1 Introducción . . . . . . . . . . . . . . . . . . . . . . 125

6.2 Síntesis de las nanopartículas . . . . . . . . . . . . . . . . . 127

6.3 Naturaleza química de las nanopartículas . . . . . . . . . . . . . . . 129

6.3.1 Distribución de tamaños . . . . . . . . . . . . . . . . . 129

6.3.2 Caracterización del agente protector de las nanopartículas de Pd protegidas por alcanotioles . . . . . . . . . . . . . 131

6.3.3 Aspectos estructurales de las nanopartículas . . . . . . . . . . . . . . 134

6.3.4 Composición química de las nanopartículas . . . . . . . . . . . . 136

6.3.5 Esquema del proceso de síntesis . . . . . . . . . . . . . . . . . 140

6.4 Influencia del ligando en el orden de los átomos metálicos de las nano-

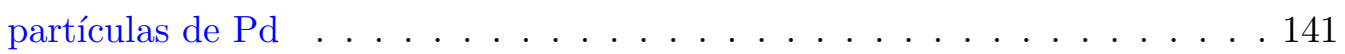

6.5 Efecto del daño por radiación en la caracterización de las nanopartículas mediante microscopía electrónica . . . . . . . . . . . . . . . . . . . 152

6.6 Conclusiones . . . . . . . . . . . . . . . . . . . . . . . . 157 
$\begin{array}{ll}\text { IV Parte final } & 159\end{array}$

7 Conclusiones generales y perspectivas $\quad 161$

A Cálculo del potencial químico a partir de la función de partición $\quad \mathbf{1 6 7}$

A.1 Potencial químico de $\left(\mathrm{CH}_{3} \mathrm{~S}\right)_{2}$ en fase gaseosa . . . . . . . . . . . . . 167

A.2 Potencial químico de $\left(\mathrm{CH}_{3} \mathrm{~S}\right)_{2}$ en solución . . . . . . . . . . . . . . 172

B Detalles experimentales de las síntesis de nanopartículas $\quad \mathbf{1 7 5}$

B.1 Síntesis de nanopartículas de Au cubiertas con dodecanotiol . . . . . . . . 175

B.1.1 Nanopartículas de $\mathrm{Au} @ \mathrm{SC}_{12}$ de $\langle D\rangle=3,9 \pm 0,6 \mathrm{~nm} \ldots \ldots . . . . . .175$

B.1.2 Nanopartículas de $\mathrm{Au} @ \mathrm{SC}_{12}$ de $\langle D\rangle=3,0 \pm 0,9 \mathrm{~nm} \ldots \ldots . . . .176$

B.1.3 Nanopartículas de $\mathrm{Au}_{\mathrm{S}} \mathrm{SC}_{12}$ de $\langle D\rangle=2,5 \pm 0,6 \mathrm{~nm} \ldots \ldots . . . . .176$

B.2 Síntesis de nanopartículas de Au cubiertas con ácido p-mercaptobenzoico . 176

B.3 Síntesis de nanopartículas de de Au cubiertas con tiomalato de Au . . . . . 177

B.4 Síntesis de nanopartículas de Pd cubiertas con dodecanotiol . . . . . . . . 177

B.5 Síntesis de nanopartículas de Pd cubiertas con dodecilamina . . . . . . . . . 178

$\begin{array}{lr}\text { C Abreviaturas, siglas, acrónimos y constantes físicas } & \mathbf{1 7 9}\end{array}$

C.1 Abreviaturas, siglas y acrónimos ． . . . . . . . . . . . . . . . . 179

C.2 Constantes físicas . . . . . . . . . . . . . . . . . . . . 180

$\begin{array}{ll}\text { D Trabajos publicados } & 181\end{array}$

$\begin{array}{ll}\text { Bibliografía } & 183\end{array}$ 


\section{Índice de figuras}

2.1 Esquema del proceso de fotoemisión y emisión Auger . . . . . . . . . . . . . 11

2.2 Diagrama de niveles de energía de una muestra metálica en equilibrio eléctrico con un espectrómetro . . . . . . . . . . . . . . . . . . . . . 12

2.3 Espectro XPS de una superficie de Pd-Au tomado con una fuente de $\operatorname{Mg} K \alpha \quad 14$

2.4 Fotografías de las cámaras de ultra alto vacío (UHV) utilizadas en los experimentos de XPS . . . . . . . . . . . . . . . . 15

2.5 Esquema del proceso de atenuación de la intensidad de los fotoelectrones eyectados . . . . . . . . . . . . . . . . . 17

2.6 Esquema de la disposición experimental para las medidas de absorción de rayos X por transmisión . . . . . . . . . . . . . . . . . . . 21

2.7 Esquema de un microscopio electrónico de transmisión (TEM) . . . . . . 23

2.8 Diagrama de los diferentes modos de imagen en TEM . . . . . . . . . . 24

2.9 La transferencia de la información en un TEM para la formación de una imagen de HRTEM, bajo la aproximación de weak-phase object . . . . . . . 25

2.10 Funciones de transferencia de contraste coherentes para microscopios con y sin corrección de aberración esférica . . . . . . . . . . . . 28

2.11 Aberración esférica y cromática en un microscopio electrónico de transmisión 29

2.12 Comparación de imágenes de HRTEM y sus transformadas de Fourier, tomadas con diferentes tipos de microscopios . . . . . . . . . . . . . 31

2.13 Diagrama de un TEM con corrección de aberración: TEAM 0.5 . . . . . . 33

2.14 Detectores en STEM y dispersión de electrones por un átomo aislado . . . . 34

3.1 Esquema de los diferentes sistemas compuestos por la interfase $\mathrm{Au}-\mathrm{S}$, clasificados por la cantidad de átomos que los forman . . . . . . . . . . . 40

3.2 Imágenes de STM de una SAM de alcanotiolatos sobre $\mathrm{Au}(111)$. . . . . . . 41

3.3 Espectros XPS de una SAM de dodecanotiolato sobre $\mathrm{Au}(111) \ldots \ldots$

3.4 Cluster de $\mathrm{Au}_{102}(p-\mathrm{MBA})_{44} \ldots \ldots \ldots \ldots \ldots \ldots$

3.5 Algunos de los tioles utilizados en la síntesis de AuNPs mediante el método de Brust-Schiffrin de una y dos fases. . . . . . . . . . . . . . . . 44

3.6 Comparación del tamaño de AuNPs protegidas con dodecanotiolato preparadas por el método bifásico de Brust-Schiffrin utilizando diferentes relaciones molares de tiol:Au . . . . . . . . . . . . . . . . . . 4 48 
3.7 Espectros XPS de AuNPs protegidas con dodecanotiolato de $3 \mathrm{~nm}$ de diámetro preparadas por el método bifásico de Brust-Schiffrin . . . . . . . . . . . 49

3.8 Distribución de tamaños e imágenes de TEM y HRTEM de AuNPs protegidas con $p$-MBA . . . . . . . . . . . . . . . . . 51

3.9 Espectros XPS de AuNPs protegidas con $p$-MBA preparadas por el método de Brust-Schiffrin de una fase . . . . . . . . . . . . . . . . . . . . . 52

3.10 Energías de adsorción de átomos de Au en diferentes sitios de grafeno . . . 54

3.11 Nanopartículas de Au sobre grafeno . . . . . . . . . . . . . 55

3.12 Evolución de nanopartículas de Au sobre grafeno . . . . . . . . . . 56

3.13 Evolución de nanopartículas de Au sobre grafeno . . . . . . . . . . . . . 57

4.1 Espectros UV-vis de reactivos, intermediarios y productos de la síntesis de AuNPs cubiertas por Au ${ }^{\mathrm{I}}-\mathrm{TM} . \ldots \ldots . \ldots . \ldots 63$

4.2 Espectros de XPS y XANES de las AuNPs cubiertas por Au ${ }^{\mathrm{I}}-\mathrm{TM}$. . . . . . 64

4.3 Espectros XPS y XANES de las AuNPs cubiertas por Au ${ }^{\mathrm{I}}-\mathrm{TM}$ luego del tratamiento de post reducción. . . . . . . . . . . . . 66 66

4.4 Diagrama de densidad de corriente vs. potencial para la electrodeposición de Au sobre HOPG. . . . . . . . . . . . . . . . . . . . . . 67

4.5 Transformada de Fourier del espectro EXAFS del borde $L_{3}$ del Au . . . . . 71

4.6 Curvas de SAXS para Au@Au $\mathrm{I}-\mathrm{TM}$ NPs antes y después del tratamiento de post reducción . . . . . . . . . . . . . . . . . . . . 73

4.7 Imágenes de HAADF-STEM con corrección de aberración de $\mathrm{Au} @ \mathrm{Au}^{\mathrm{I}}-\mathrm{TM}$ NPs. . . . . . . . . . . . . . . . . . . . 75

4.8 Comparación entre el tamaño determinado por SAXS y TEM para NPs de

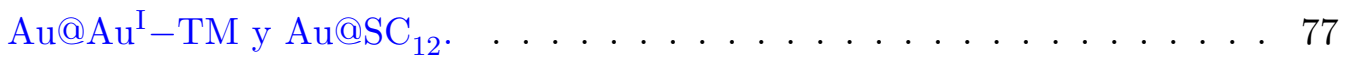

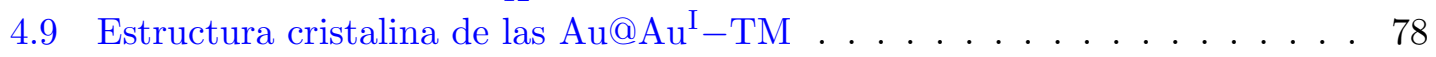

4.10 Octaedros truncados utilizados para la simulación de las imágenes de HRTEM 78

4.11 Simulaciones de las imágenes de HRTEM de Au@Au ${ }^{\mathrm{I}}-\mathrm{TM}$ NPs . . . . . . . 79

4.12 Estabilidad de las Au@Au ${ }^{\mathrm{I}}-\mathrm{TM}$ NPs. . . . . . . . . . . . . . . . . . . . . 79

4.13 Espectros UV-vis de diferentes muestras . . . . . . . . . . . . . . 80

4.16 Esquema de las reacciones involucradas en los dos métodos de Brust-Schiffrin para su comparación. . . . . . . . . . . . . . . . . . . . 83

5.1 Voltamperograma típico de electrodeposición y redisolución de Pd sobre $\mathrm{Au}(111) \ldots \ldots \ldots \ldots \ldots \ldots$

5.2 Películas de $\mathrm{Pd}$ electrodepositadas sobre $\mathrm{Au}(111) \ldots \ldots$. . . . . . . . . . 90

5.3 Caracterización de las películas de Pd depositadas sobre Au(111) mediante XPS y voltamperometría cíclica . . . . . . . . . . . . . . . . . . 91

5.4 Caracterización por XPS de las superficies de Pd modificadas con tioles . . 93

5.5 Voltamperograma de electrodo de Pd modificado con dodecanotiol . . . . . 94

5.6 Voltamperograma de un electrodo de $\mathrm{Pd}$ modificado con dodecanotiol en

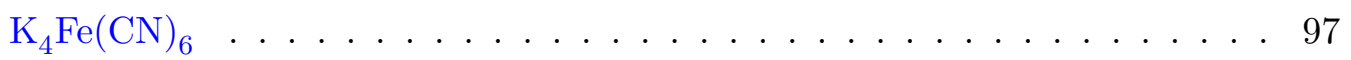

5.7 Voltamperogramas de un electrodo de Pd cubierto con propanotiol . . . . . 98 
5.8 Cubrimiento remanente de sulfuro-tiolato $\left(\theta_{\text {rem }}\right)$ en función del potencial aplicado para tioles de diferente largo de cadena . . . . . . . . . . . . 99

5.9 Espectros XPS de S $2 p$ de propanotiol $\left(\mathrm{SC}_{3}\right)$ adsorbido sobre $\mathrm{Pd} \ldots . . . .100$

5.10 Espectros XPS de superficies de Pd modificadas con sulfuro . . . . . . . . . 101

5.11 Adsorción de sulfuro sobre $\mathrm{Pd}$. . . . . . . . . . . . . . . . . . 102

5.12 Voltamperograma de deposición a subpotenciales (UPD) y redisolución de Pd sobre $\mathrm{Au}(111) \ldots \ldots \ldots$. . . . . . . . . . . . . . . . . . . . . . . . . . .

5.13 Espectro de $\mathrm{Pd} 3 d$ y $\mathrm{Au} 4 d$ de $\mathrm{Pd}$ electrodepositado sobre $\mathrm{Au}(111)$ en la zona de subpotenciales . . . . . . . . . . . . . . . . . . . . 104

5.14 Espectros de XPS de diferentes superficies modificadas con Pd . . . . . . 105

5.15 Potenciales de desorción para alcanotioles de distinto largo de cadena en diferentes metales . . . . . . . . . . . . . . 106

5.16 Estructuras optimizadas de los diferentes modelos propuestos para la adsorción de azufre y metanotiol sobre $\operatorname{Pd}(111) \ldots .109$

5.17 Estructuras iniciales y optimizadas de los modelos 4 y 5 . . . . . . . . 110

5.18 Energía libre de Gibbs de adsorción de las diferentes estructuras sobre $\operatorname{Pd}(111)$ en función del potencial químico de metanotiol (MT) . . . . . . . 115

5.19 Esquema de las interacciones entre el adsorbato y la superficie en términos del análisis de orbitales de frontera . . . . . . . . . . . . 116

5.20 Densidad de estados (DOS) de los diferentes modelos estudiados comparado con Pd limpio y metanotiol libre . . . . . . . . . . . . . . . . . 119

5.21 Densidad de estados del sistema $(\sqrt{3} \times \sqrt{3})$ R30 - MT sobre $\mathrm{Au}(111)$ y $\mathrm{Au}(111)$ limpio . . . . . . . . . . . . . . . . . . . . . . 120

6.1 Esquema de las diferentes rutas para la síntesis de PdNPs y complejos de $\mathrm{Pd}^{\mathrm{II}}-\mathrm{RSH} \ldots \ldots \ldots \ldots \ldots \ldots \ldots \ldots \ldots \ldots$

6.2 Efecto de la relación molar tiol:Pd en los productos obtenidos durante la

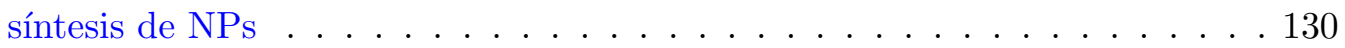

6.3 Imágenes de HAADF-STEM de PdNPs . . . . . . . . . . . . . . . . . 131

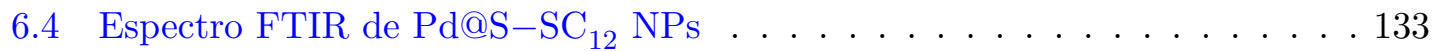

6.5 Transformada de Fourier (FT) experimental y ajustes correspondientes de la señal de EXAFS para una lámina de $\mathrm{Pd}$ y $\mathrm{Pd} @ S-\mathrm{SC}_{12} \mathrm{NPs}$. . . . . . . 134

6.6 Espectro XPS de $\mathrm{S} 2 p$ de $\mathrm{Pd} @ \mathrm{~S}-\mathrm{SC}_{12}$ NPs luego del experimento de EXAFS136

6.7 Espectros XPS de S $2 p$ de diferentes sistemas Pd-tiol . . . . . . . . . . . 138

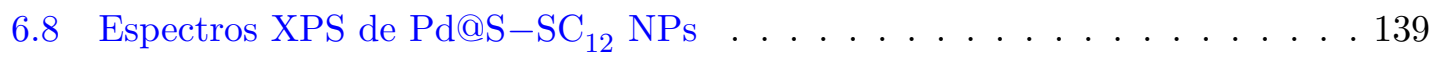

6.9 Espectro de la banda de valencia de Pd@S-SC ${ }_{12}$ NPs y Au@SC ${ }_{12}$ NPs . . 140

6.10 Imágenes representativas de HAADF-STEM con corrección de aberración de $\mathrm{Pd} @ \mathrm{NC}_{12}$ NPs y Pd@S-SC 12 NPs . . . . . . . . . . . . . . . . . . . . 142

6.11 Diferentes geometrías utilizadas para describir los núcleos de Pd en las NPs simuladas. . . . . . . . . . . . . . . . . . . . . . 144

6.12 Diferentes casquetes en los que se calculó la función de distribución de pares en las NPs. . . . . . . . . . . . . . . . . . . . . . . 146 
6.13 Simulación de nanopartículas de $\mathrm{Pd}$ protegidas con butilamina $\left(\mathrm{Pd} @ \mathrm{NC}_{4}\right.$ $\mathrm{NPs}) \ldots \ldots \ldots \ldots \ldots \ldots \ldots$

6.14 Simulación de nanopartículas de Pd protegidas con sulfuro (Pd@S NPs) . . 149

6.15 Simulación de nanopartículas de $\mathrm{Pd}$ protegidas con butanotiolato $\left(\mathrm{Pd} @ \mathrm{SC}_{4}\right.$

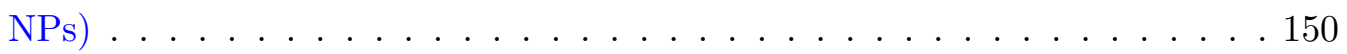

6.16 Simulación de nanopartículas de Pd protegidas con sulfuro y butanotiolato

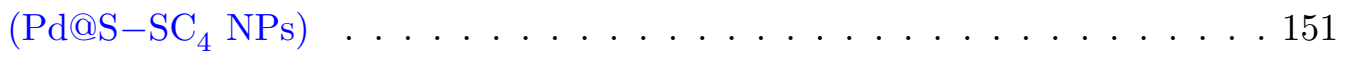

6.17 Comparación de las simulaciones de PdNPs con diferentes adsorbatos . . . 152

6.18 Evolución de las $\mathrm{Pd} @ \mathrm{~S}-\mathrm{SC}_{12} \mathrm{NPs}$ bajo un haz de electrones . . . . . . . . 153

6.19 Energía máxima transferida por dispersión y sección eficaz de desplazamiento de átomos de la superficie . . . . . . . . . . . . . . . . . . . 154

6.20 Efecto del daño por radiación sobre $\mathrm{Pd} @ \mathrm{~S}-\mathrm{SC}_{12} \mathrm{NPs}$ estudiado por HAADFSTEM . . . . . . . . . . . . . . . . . 156 


\section{Índice de tablas}

4.1 Parámetros estructurales de $\mathrm{Au} @ \mathrm{Au}^{\mathrm{I}}$-TM NPs antes y después del tratamiento de post reducción, obtenidos por EXAFS. . . . . . . . . . . . 72

4.2 Parámetros obtenidos del ajuste de las curvas de SAXS . . . . . . . . . 73

5.1 Asignación de las diferentes componentes de la señal de S $2 p$ para alcanotiolatos sobre $\mathrm{Pd}$ y energía de enlace de las mismas. . . . . . . . . . . 93

5.2 Capacidad de la interfase y cubrimiento total de especies de azufre $\left(\theta_{\mathrm{S}}\right)$ de electrodos de $\mathrm{Pd}$ y $\mathrm{Au}$ limpios y luego de su modificación con $\mathrm{Na}_{2} \mathrm{~S}$ (adsorción de sulfuro), propanotiol $\left(\mathrm{SC}_{3}\right)$ y dodecanotiol $\left(\mathrm{SC}_{12}\right) \ldots \ldots$. . . 95

5.3 Parámetros estructurales para los diferentes modelos (1-5) obtenidos de los cálculos de DFT . . . . . . . . . . . . . . . . . . . 110

5.4 Posición del centro de la banda $d$ con respecto al nivel de Fermi $\left(\epsilon_{d}\right)$ y cargas de Bader calculadas para los diferentes modelos. . . . . . . . . . . . . 118

5.5 Comparación entre los cubrimientos de sulfuro, tiolato y $\mathrm{S}$ total obtenidos mediante XPS (adsorción de propanotiol sobre Pd) y los resultantes de los modelos propuestos para los cálculos de DFT . . . . . . . . . . . . . . . 121

6.1 Parámetros estructurales de Pd@S-SC 12 NPs obtenidos por EXAFS . . . . 135

6.2 Contribución relativa de las diferentes componentes a la señal de $\mathrm{S} 2 p$ para SAMs de dodecanotiol sobre Pd plano, Pd@S-SC 12 NPs y Pd@NC $12-\mathrm{SC}_{12}$ NPs. . . . . . . . . . . . . . . . . . . . . . . . . 138

6.3 Parámetros obtenidos para el ajuste del potencial Pd-tiolato y Pd-amina . . 145 


\section{Capítulo 1}

\section{Introducción}

Las nanopartículas (NPs) metálicas son conocidas desde la antigüedad y existen informes sobre sus propiedades y usos desde el siglo XVII [1]. No obstante, la conferencia de M. Faraday de 1857 [2] donde disertó acerca del oro coloidal generado por reducción de sales de Au, es considerada un hito en la historia de las NPs. En 1988 J. M. Thomas reveló, mediante microscopía electrónica, que las muestras producidas utilizando un protocolo similar contienen NPs de Au (AuNPs) con tamaños entre 3 y $30 \mathrm{~nm}$ [3]. Casi un siglo después de la conferencia de Faraday, J. Turkevich publicó el método de síntesis de AuNPs protegidas por citrato [4], que ha sido utilizado extensamente. Incluso en la actualidad, es motivo de interés el estudio del mecanismo mediante el cual estas partículas son producidas [5]. La investigación de la composición y estructura de las NPs es interesante tanto para poder comprender mejor la variación de distintos fenómenos físicos por la restricción del tamaño a la escala nanométrica como así también por la gran variedad de aplicaciones que estas poseen en campos tan diversos como el tratamiento médico [6], diagnóstico en química clínica [7] y en medicina [8], catálisis [9-11] y fabricación de sensores [12] y biosensores [13]. Aunque el área de aplicación de las NPs es muy amplia, importantes aspectos que involucran a estos materiales se encuentran aún lejos de ser comprendidos y controlados.

Para obtener NPs estables y evitar su aglomeración, es necesario utilizar agentes estabilizantes durante la síntesis. Existe gran variedad de moléculas que pueden ser usadas con este fin como, por ejemplo, el citado ejemplo del citrato, polímeros como polivinilpirrolidona (PVP), aminas primarias y sales de amonio cuaternarias. Sin embargo, uno de los únicos tipos de NPs metálicas cuya distribución de tamaños es estrecha, son estables a lo largo del tiempo y pueden ser obtenidas en forma de polvo, lavadas, y utilizadas como si se tratase de un compuesto químico tradicional, son las NPs cubiertas por tioles. Estas NPs tomaron gran relevancia desde la publicación de los métodos de Brust-Schiffrin para la síntesis de AuNPs cubiertas por tioles hidrofóbicos [14] o hidrofílicos [15] y fue extendido luego a otros metales y diferentes tioles. Estos métodos fueron inspirados en las monocapas autoensambladas (SAMs) de alcanotioles sobre metales. La alta energía del enlace entre el azufre y el metal confiere a estas NPs una gran estabilidad. Por otro lado, la elección del grupo terminal del tiol utilizado, abre la posibilidad de modificar estas partículas con diversos compuestos mediante enlaces covalentes y cambiar así sus propiedades como la 
solubilidad en diferentes solventes.

Las NPs metálicas protegidas por tioles son los análogos tridimensionales a las SAMs de tioles sobre superficies metálicas planas. Por lo tanto, es muy interesante el estudio en conjunto de estos dos sistemas ya que los resultados que se obtienen en ambos casos son complementarios y permiten realizar una aproximación unificada al problema. Ciertas técnicas son útiles para el estudio de NPs pero no lo son para superficies planas y viceversa. Por ejemplo, el estudio de NPs mediante espectroscopía de fotoelectrones generados por rayos X (XPS) generará una señal con una contribución superficial mucho mayor que en una superficie plana, lo que facilitaría el análisis de la interfase metal-adsorbato, si no se cuenta con una fuente de luz sincrotrón para disminuir la energía de los fotones incidentes. Por otro lado, sólo recientemente fue posible realizar cálculos teóricos en el marco de la teoría del funcional de densidad (DFT) sobre NPs con algunos cientos de átomos [16] y, aún actualmente, este sigue siendo un problema de un alto costo computacional. Sin embargo, el estudio de superficies metálicas extendidas es de un costo mucho menor ya que se genera un sistema periódico formado por pocos átomos.

Por estos motivos, en este trabajo se abarcó el estudio de superficies metálicas planas y NPs modificadas con tioles de manera conjunta. Los sistemas analizados involucran la interfase $\mathrm{Au}$-tiol y $\mathrm{Pd}$-tiol. En el caso del $\mathrm{Au}$, nos centramos en la investigación de las NPs modificadas con tioles debido a que en el grupo de trabajo donde se realizó esta tesis existe gran experiencia en el estudio de SAMs de tioles sobre Au plano [17]. En el caso del $\mathrm{Pd}$, comenzamos el estudio con superficies planas - sistema conocido en menor medida que las SAMs de tioles sobre $\mathrm{Au}-$ para luego introducirnos en el estudio de NPs de Pd (PdNPs) modificadas con alcanotioles.

Esta tesis fue desarrollada en un grupo dedicado históricamente a la electroquímica y fisicoquímica de superficies extendidas. Esto requirió, en la parte inicial del trabajo, la evaluación de diferentes rutas de síntesis de NPs metálicas, varias de las cuales no se comentan en este informe ya sea porque no aportan datos relevantes a la discusión o bien por tratarse de protocolos que no han funcionado satisfactoriamente. Asimismo, se avanzó en la caracterización de estos sistemas, haciendo particular énfasis en los efectos adversos que las técnicas de medida producen en las muestras. En prácticamente todos los métodos experimentales utilizados hemos observado que el sistema de medida afecta, de alguna manera, a la medida que se está realizando. Por ejemplo, la microscopía electrónica es una técnica que históricamente se ha utilizado en gran medida para el estudio de muestras masivas (en general en metalurgia) y los daños producidos sobre estas muestras son conocidos. Sin embargo, al utilizar esta técnica para el estudio de sistemas con tamaños nanométricos, donde la superficie adquiere gran importancia, aparecen nuevos tipos de daños que limitan el estudio de estos sistemas, como veremos más adelante. Otro ejemplo lo constituyen las técnicas que involucran la irradiación de la muestra con rayos $\mathrm{X}$. Debido a la gran sensibilidad de las moléculas orgánicas, que son objeto de nuestro estudio, es necesario minimizar la dosis de rayos $\mathrm{X}$ para disminuir el daño. Durante todos los experimentos que detallamos en este informe, hemos tenido especial atención en utilizar condiciones de medida que minimizaran estos daños. En los casos en que esto no fue posible, se intentó elucidar qué tipo daño se estaba produciendo para realizar el análisis 
de los resultados teniendo en cuenta estos efectos o bien descartar los datos que hayan sido afectados por los mismos.

\subsection{Lugar de trabajo y trabajo en colaboración}

La mayor parte de los resultados presentados en este informe han sido obtenidos en el Laboratorio de Nanoscopías y Fisicoquímica de Superficies del Instituto de Investigaciones Fisicoquímicas Teóricas y Aplicadas (INIFTA). Sin embargo, una parte importante de ellos son producto del trabajo en colaboración con diferentes grupos de investigación y de estadías en diferentes laboratorios. En todos los casos se participó activamente en el análisis de los resultados.

Las medidas de XPS con fuente de $\mathrm{Mg} \mathrm{K} \alpha$ fueron realizadas por los Dres. A. A. Rubert y G. A. Benítez del grupo de Nanoscopías del INIFTA.

Los experimentos de XPS con radiación de luz sincrotrón fueron realizadas en el Laboratório Nacional do Luz Síncrotron (LNLS), Campinas, Brasil.

Las medidas de microscopía electrónica de transmisión convencional (TEM) (microscopio Phillips CM 200 UT) se realizaron en la División Metales del Centro Atómico Bariloche, Argentina, en colaboración con la Dra. E. Zelaya.

Los experimentos de absorción de rayos $\mathrm{X}$ (XAS) y dispersión de rayos $\mathrm{X}$ a bajo ángulo (SAXS) y el ajuste de los datos fueron realizados por los Dres. J. M. Ramallo-López, L. J. Giovanetti y F. G. Requejo, del INIFTA.

Los cálculos basados en DFT del sistema Pd-tiol y de termodinámica estadística desde primeros principios fueron realizados por la Dra. P. Carro, de la Universidad de La Laguna, Tenerife, España.

Las medidas de microscopía electrónica de barrido por transmisión con corrección de aberración (STEM) fueron realizadas en colaboración con G. Casillas durante una estadía realizada en el grupo del Dr. M. José-Yacamán, de la Universidad de San Antonio, Texas, Estados Unidos.

Los experimentos de microscopía electrónica de transmisión de alta resolución (HRTEM) con corrección de aberración (microscopio TEAM 0.5) y algunas sin corrección (microscopio Phillips CM 300 UT-FE) fueron realizados durante una estadía de investigación en el National Center for Electron Microscopy, del Lawrence Berkeley National Laboratory, Berkeley, California, Estados Unidos, bajo la dirección del Dr. V. Radmilovic, con el apoyo de la Comisión Fulbright y la Fundación Bunge y Born.

Los cálculos de dinámica de Langevin de las PdNPs fueron realizados por J. OlmosAsar y el Dr. M. M. Mariscal, de la Universidad Nacional de Córdoba, Argentina.

\subsection{Estructura y contenidos}

Este trabajo se divide en 4 partes. La primera, Métodos, está compuesta por un capítulo (Capítulo 2) en el que se realiza una breve descripción de los métodos experimentales y teóricos que se utilizaron.

En la segunda parte, Interfase Au-tiol, se discuten los resultados obtenidos con 
sistemas en los que está involucrada la interfase Au-tiol. En el Capítulo 3 se discuten los aspectos generales de los diferentes sistemas de este tipo y se tratan los dos métodos de síntesis de NPs cubiertas con tioles más utilizados: los métodos de Brust-Schiffrin de una y dos fases. Se presentan los lineamientos generales de estos métodos y además se discuten los resultados de XPS y HRTEM obtenidos para estas NPs. En el caso de AuNPs protegidas con alcanotioles se detallan experimentos acerca de su comportamiento sobre superficies de grafeno. El Capítulo 4 trata un caso particular de AuNPs preparadas por el método de Brust-Schiffrin de una fase, utilizando ácido tiomálico. Estas NPs son interesantes debido a que están formadas por núcleos de Au metálico y se encuentran rodeadas de especies poliméricas de tiomalato de $\mathrm{Au}$.

En la tercera parte, Interfase Pd-tiol, se cambia el metal para estudiar la interfase Pd-tiol en sistemas planos y NPs. En el Capítulo 5 se presentan, en primer término, los resultados experimentales de XPS y electroquímica acerca de la composición química de las SAMs de alcanotioles sobre Pd plano. Luego, se realiza un estudio de la estabilidad electroquímica de estos sistemas en soluciones acuosas básicas y se comparan estos resultados con los de superficies de Pd modificadas con sulfuro. En segundo lugar, se realiza un estudio teórico de la interfase $\mathrm{Pd}$-tiol en el marco de DFT. Se proponen diferentes estructuras con distintos adsorbatos sobre $\mathrm{Pd}(111)$ para estudiar sus características geométricas y electrónicas. Por último, estos resultados son utilizados para realizar un estudio de termodinámica estadística desde primeros principios y comparar así la estabilidad relativa de los diferentes sistemas en base al análisis de energía libre superficial en función del potencial químico de los adsorbatos en fase gaseosa. En el Capítulo 6 se aborda el sistema análogo al anterior pero sobre NPs. Se estudia la síntesis de PdNPs utilizando alcanotioles mediante diferentes rutas y se realiza una caracterización exhaustiva de su composición química mediante diferentes técnicas. Posteriormente, se realiza un análisis de la influencia del agente protector de las PdNPs en el orden de los átomos metálicos que las componen, mediante la combinación de STEM y cálculos de dinámica de Langevin. Por último, se discute el daño producido por un haz de electrones sobre estas partículas.

En la Parte final se presentan las conclusiones generales del trabajo y perspectivas (Capítulo 7) y 4 apéndices. En el Apéndice A se describe el cálculo del potencial químico del dimetil disulfuro en fase gaseosa y líquida, necesario para los cálculos realizados en el Capítulo 5. En el Apéndice B se enumeran los detalles experimentales de todas las síntesis de NPs descritas en este trabajo. En el Apéndice $\mathbf{C}$ se aglomeran las abreviaturas, siglas y acrónimos como así también los valores de las constantes físicas utilizados en este manuscrito. Por último, en el Apéndice $\mathbf{D}$ se presenta una lista con los trabajos que fueron publicados a partir de los resultados discutidos en este informe.

La Bibliografía se presenta al final del documento en una única lista enumerada por orden de aparición de la citas en el texto. 
Parte I

Métodos 



\section{Capítulo 2}

\section{Métodos experimentales y teóricos}

En este capítulo comentaremos brevemente las características generales de las diferentes técnicas experimentales que hemos utilizado en este trabajo. Discutiremos con un grado mayor de detalle las técnicas más relevantes para esta tesis y en las que se trabajó activamente. En el caso de las técnicas de uso común o las que fueron llevadas a cabo mediante el trabajo en colaboración sólo enumeraremos las condiciones particulares de medida de los experimentos discutidos en este informe. Primeramente, detallaremos algunos aspectos relacionados con la limpieza del material y los reactivos generales utilizados.

\subsection{Materiales}

\subsubsection{Agua}

El agua utilizada en todos los procesos mencionados en este trabajo es agua ultra pura Milli-Q (Millipore). Esta agua es generada mediante el tratamiento de agua previamente destilada utilizando filtros de distintos tipos y tamaños. El agua obtenida tiene una resistividad $\geq 18 \mathrm{M} \Omega \mathrm{cm}$ a $25^{\circ} \mathrm{C}$.

\subsubsection{Limpieza del material}

En todos los experimentos donde fue posible se utilizó material de vidrio para asegurar la limpieza del mismo. El material fue lavado antes de uso mediante alguno de los procedimientos siguientes, según su historia previa.

\section{Permanganato de potasio}

El permanganato de potasio $\left(\mathrm{KMnO}_{4}\right)$ es un agente oxidante fuerte. Permite eliminar la materia orgánica presente en el material utilizado. El material se lava llevando a ebullición solución saturada de $\mathrm{KMnO}_{4}$ en medio básico. Luego, se enjuaga con solución ácida de $\mathrm{H}_{2} \mathrm{O}_{2}$ para eliminar los restos de $\mathrm{MnO}_{2}$. Finalmente, se enjuaga varias veces con agua Milli-Q. 


\section{Solución "piraña"}

La solución "piraña" se utilizó para lavar el material de vidrio y ciertos sustratos metálicos. Esta es una solución fuertemente oxidante, compuesta por $\mathrm{H}_{2} \mathrm{SO}_{4}$ concentrado y $\mathrm{H}_{2} \mathrm{O}_{2}$ 100 vol en una relación volumétrica de $\mathrm{H}_{2} \mathrm{SO}_{4}: \mathrm{H}_{2} \mathrm{O}_{2}$ de 3:1. Se prepara antes de ser usada, agregando lentamente el ácido sobre el peróxido en baño de hielo. Esta solución ataca violentamente los materiales orgánicos, por lo que se debe manipular con extrema precaución.

\section{Agua regia}

El material que ha estado en contacto con NPs es lavado con agua regia, que consiste en una mezcla de $\mathrm{HCl}$ y $\mathrm{HNO}_{3}$ concentrados en una relación volumétrica de $\mathrm{HCl}: \mathrm{HNO}_{3}$ $=3: 1$. El agua regia se prepara momentos antes de ser utilizada y debe ser manipulada bajo campana. Esta solución disuelve los metales que se encuentren adheridos al material. Luego, se enjuaga con agua Milli-Q y se lava el material con $\mathrm{KMnO}_{4}$ o solución "piraña" para eliminar los restos de materia orgánica.

\subsubsection{Reactivos generales}

Los tioles utilizados tanto en las síntesis de las nanopartículas como en la formación de las SAMs sobre superficies planas fueron empleados tal como fueron recibidos. Se utilizaron solventes de grado analítico o HPLC en todos los casos. Los precursores de los metales utilizados fueron en el caso de $\mathrm{Pd}$ : $\mathrm{PdCl}_{2}$ (Aldrich, purum) o $\mathrm{K}_{2} \mathrm{PdCl}_{4}$ (Aldrich, 99,99\%) y en el caso de $\mathrm{Au}: \mathrm{HAuCl}_{4}$ (Aldrich, puriss) o sintetizado en el laboratorio como se explica a continuación.

\subsubsection{Síntesis de $\mathrm{HAuCl}_{4}$}

La síntesis se realizó según Block [18]. Como fuente de Au se utilizó alambre de Au de $99,9 \%$ o 99,999\%. Éste fue limpiado con etanol, en ultrasonido, para desprender contaminantes. Luego se sumergió en solución piraña por unos minutos y se enjuagó con agua Milli-Q. Se colocó aproximadamente $1 \mathrm{~g}$ de alambre de $\mathrm{Au}$ en $12,5 \mathrm{~mL}$ de agua regia de preparación reciente. Se dejó disolver durante una noche; el alambre se disolvió totalmente y la solución quedó color amarillo fuerte. Luego, se llevó a ebullición bajo campana, evaporándose el agua regia hasta alcanzar un volumen final de aproximadamente $2 \mathrm{~mL}$. El color de la solución cambió a anaranjado. Se dejó enfriar durante unas horas y se agregó suficiente $\mathrm{HCl}$ concentrado para alcanzar el volumen inicial de líquido. Se calentó hasta ebullición la solución nuevamente hasta llegar a $2 \mathrm{~mL}$. Este paso se repitió otras dos veces. Una vez que se alcanzó nuevamente el nivel de $2 \mathrm{~mL}$, se continuó calentando hasta que el color de la solución pasó de anaranjado a rojo sangre. Se removió de la fuente de calentamiento y los cristales se disolvieron en $250 \mathrm{~mL}$ de agua Milli-Q. La solución obtenida resultó de coloración amarilla. Esta solución se mantuvo en heladera y se tomaron diferentes porciones de ella para cada síntesis. La concentración final de la solución preparada fue obtenida mediante espectroscopía de absorción atómica. 


\subsection{Voltamperometría cíclica}

Los experimentos electroquímicos consisten en controlar ciertas variables de una celda electroquímica manteniéndolas constantes o bien variándolas en forma predeterminada mientras se observa cómo varían otras al aplicar cambios en las variables controladas. En la voltamperometría cíclica (cyclic voltammetry, CV) se utiliza una celda de tres electrodos: el electrodo de trabajo, el electrodo de referencia y el electrodo auxiliar (o contraelectrodo). Estos electrodos están conectados a los terminales de un potenciostato. Los potenciostatos utilizados para realizar experiencias de voltamperometría cíclica permiten aplicar una rampa de potencial (generalmente una onda triangular) entre el electrodo de trabajo y el electrodo de referencia. Es decir, controla el potencial del electrodo de trabajo referido al de referencia, utilizando una impedancia muy grande de manera tal que no circule corriente por el electrodo de referencia. La función que se aplica tiene la siguiente forma

$$
E=E_{i}+v t
$$

donde $E$ es el potencial en el instante de tiempo $t, E_{i}$ es el potencial inicial y $v$ es la velocidad de barrido del potencial.

El barrido lineal se genera entre diferentes límites, los que se designan aquí como límite mayor de potencial, $E_{\text {may }}$, y límite menor, $E_{\text {men }}$. Los valores típicos de $v$ van de $1 \times 10^{-3}$ a $1 \mathrm{~V} \mathrm{~s}^{-1}$. A medida que se modifica el potencial, se registra la corriente que circula entre el electrodo de trabajo y el auxiliar. Con los datos registrados por el potenciostato se crea un gráfico de densidad de corriente $j(j=i / A)$ en función del potencial $E$ denominado voltamperograma, donde $A$ es el área real del electrodo, calculada como se explica más adelante. En estos gráficos se observan diferentes procesos como los de transferencia de carga con especies electroactivas y los de carga de la denominada doble capa eléctrica. Un análisis detallado de esta técnica puede encontrarse en el texto de Bard y Faulkner [19].

En este trabajo se utilizó un potenciostato EG\&G PAR Princeton Applied Research Modelo 362 con un adquisidor de datos WinPcChrom y un potenciostato de fabricación nacional marca TEQ, conectado directamente a una computadora mediante interfaz serial. El primero realiza todas las operaciones en forma analógica. Si bien por ello presenta la desventaja de necesitar un dispositivo de conversión analógica-digital para adquirir los voltamperogramas, tiene la ventaja de generar rampas de potencial continuas. En cambio, los potenciostatos cuyo funcionamiento se basa en generaciones de rampas por pasos finitos de potencial podrían generar rampas de calidad deficiente para experiencias en las que se realizan barridos a muy baja velocidad, tales como las experiencias de deposición a subpotenciales (underpotential deposition, UPD).

$\mathrm{Al}$ realizar experimentos electroquímicos es de especial importancia la limpieza del material utilizado, ya que cualquier sustancia extraña puede causar interferencias en las medidas debido a la alta sensibilidad de estas técnicas. Para asegurar la ausencia de contaminantes se lavó el material de vidrio con solución de permanganato de potasio en ebullición y luego con solución ácida de peróxido de hidrógeno o con solución "piraña". Luego, los materiales fueron enjuagados varias veces con agua Milli-Q. 


\subsubsection{Cálculo del área real de un electrodo}

El área aparente (geométrica) de un electrodo es una medida macroscópica que considera que la superficie del electrodo es totalmente lisa y que no existen huecos entre los átomos que la componen. Además, es posible calcular el área real de un electrodo, que tiene en cuenta todas las imperfecciones de la superficie. Es importante la medida del área real para poder luego calcular densidades de corriente $(j)$.

En varias determinaciones realizadas en este trabajo se utilizaron superficies metálicas que presentaron marcada textura. Puesto que las caras más densamente empaquetadas de los metales $f c c-\mathrm{Au}$ y $\mathrm{Pd}-$ es la $\{111\}$, y la que se presenta en mayor proporción en las superficies de los electrodos, se ha utilizado su densidad superficial de átomos para estimar los factores de rugosidad.

En el caso del Au, se siguió el método de Michri et ál. [20] que consiste en realizar un voltamperograma en medio ácido eligiendo el $E_{\text {may }}$ correspondiente al mínimo de Burshtein para formar así una monocapa de AuO. Luego, se analiza la carga involucrada en la reducción del $\mathrm{AuO}$ (proceso de 2 electrones). Considerando que el parámetro de red del Au masivo es 0,4080 nm [21], una superficie de $\mathrm{Au}(111)$ contiene $1,39 \times 10^{15}$ átomos cm ${ }^{-2}$. Por lo tanto, la densidad de carga requerida para reducir una monocapa de $\mathrm{AuO}\left(q_{\text {mono }}\right)$ es $444 \mathrm{\mu C} \mathrm{cm}^{-2}$. El área real $A$ se calcula como $A=q_{\exp } / q_{\text {mono }}$, donde $q_{\exp }$ es la densidad de carga medida experimentalmente.

Para el caso el Pd, se utilizó el método descrito por Grdeń et ál. [22] y se realizó una voltamperometría cíclica en $\mathrm{NaOH} 0,1 \mathrm{M}$ tomando como $E_{\text {may }}=0,40 \mathrm{~V}$ [23]. Considerando que el parámetro de red del $\mathrm{Pd}$ es $0,389 \mathrm{~nm}$ [21], en una superficie de $\operatorname{Pd}(111)$ existen $1,52 \times 10^{15}$ átomos $\mathrm{cm}^{-2} \mathrm{y}$, entonces, la carga necesaria para reducir una monocapa de $\mathrm{PdO}$ es $q_{\text {mono }}=487 \mu \mathrm{C} \mathrm{cm}^{-2}$.

\subsection{Espectroscopía ultravioleta-visible (UV-Vis)}

Los espectros ultravioleta-visible (UV-Vis) fueron medidos con un espectrómetro Perkin Elmer Lambda 35, equipado con doble haz. Como referencia se utilizó hexano, tolueno o agua, dependiendo de la muestra medida.

\subsection{Espectroscopía infrarroja por transformada de Fourier (FTIR)}

La espectroscopía infrarroja por transformada de Fourier (Fourier transform infrared spectrosocpy, FTIR) fue utilizada en la caracterización de las PdNPs (Cap. 6). Los espectros fueron tomados con un espectrómetro VARIAN 660 equipado con un detector de sulfato de triglicina deuterada (deuterated triglycine sulfate, DTGS). El espectrómetro fue purgado con nitrógeno previo a su utilización para disminuir las señales de dióxido de carbono y agua en los espectros. Se depositó una película de la muestra sobre una ventana de KBr desde una suspensión de las NPs en tolueno que luego se secó con corriente de nitrógeno. Los espectros se tomaron en modo transmisión con una resolución de $4 \mathrm{~cm}^{-1}$ acumulando 


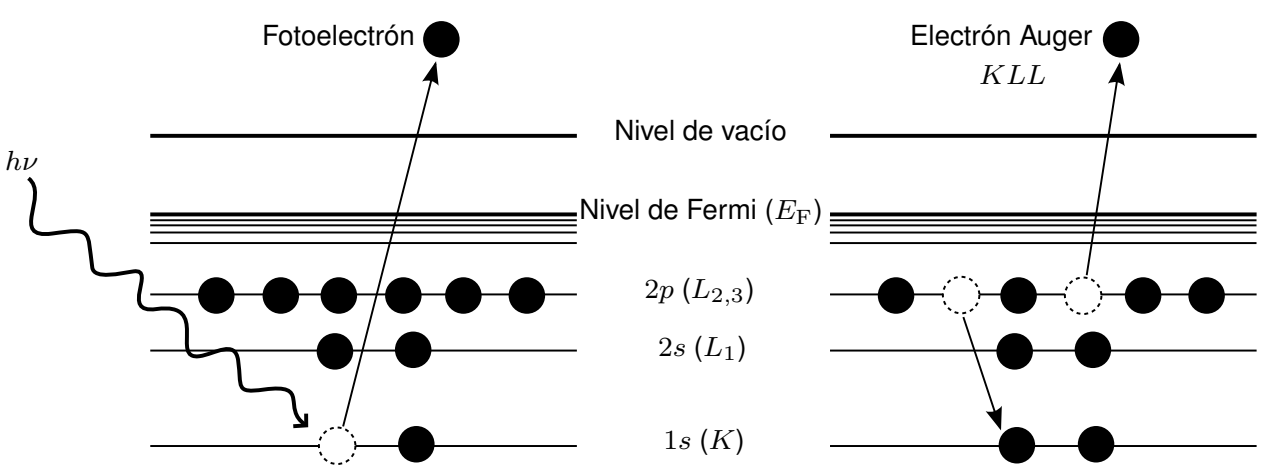

Figura 2.1: Esquema del proceso de fotoemisión y emisión Auger. Al generar un fotoelectrón se genera un hueco que puede ser llenado por un electrón de un nivel superior, lo que provoca la emisión de un segundo electrón llamado Auger.

128 barridos. Las líneas de base de los espectros fueron corregidas mediante el programa asociado al espectrómetro.

\subsection{Espectroscopía de fotoelectrones generados por rayos $\mathrm{X}$ (XPS)}

La espectroscopía de fotoelectrones generados por rayos X ( $X$-ray photoelectron spectroscopy, XPS), llamada en sus inicios espectroscopía electrónica para análisis químico (electron espectroscopy for chemical analysis, ESCA), se basa en el efecto fotoeléctrico, descubierto en 1887 por H. R. Hertz y cuyas bases teóricas fueron explicadas por A. Einstein en 1905. Sin embargo, recién en la década de 1960 se desarrolló su uso analítico, gracias a los trabajos pioneros del grupo de K. M. Siegbahn, quién obtuvo por ello el Premio Nobel de Física en 1981.

La capacidad de detectar diferencias en los estados químicos junto con la sensibilidad superficial ha hecho que esta técnica espectroscópica sea la más aplicada para el análisis general de superficies. Puede detectar todos los elementos, excepto el hidrógeno y el helio y las muestras pueden ser gaseosas, líquidas o sólidas. La profundidad de análisis de los materiales sólidos varía desde las 2 últimas capas atómicas hasta aproximadamente 10 capas. Es aplicable a materiales orgánicos, biológicos y poliméricos como así también metales, semiconductores y cerámicos. Es una técnica no destructiva aunque hay casos en los que el haz de rayos X puede dañar la muestra, sobre todo si ésta es orgánica como los tioles.

\subsubsection{Principios básicos}

Un fotón de una longitud de onda lo suficientemente baja interacciona con un electrón de un nivel electrónico interno (core) o de la banda de valencia de un material y produce un electrón libre eyectado, llamado fotoelectrón (Fig. 2.1). La energía cinética $E_{\mathrm{K}}$ del fotoelectrón depende de la energía del fotón incidente $h \nu$ a través de la ecuación de Einstein 


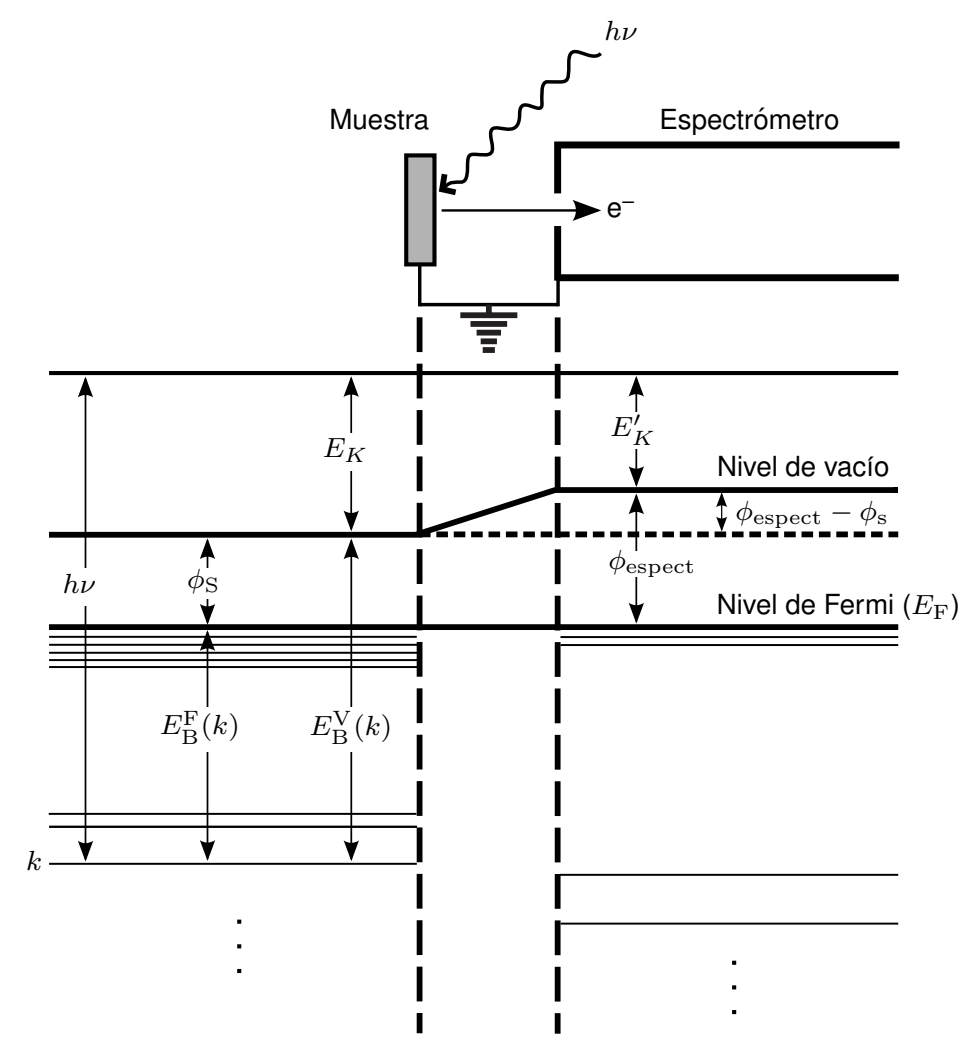

Figura 2.2: Diagrama de niveles de energía de una muestra metálica en equilibrio eléctrico con un espectrómetro. Los niveles electrónicos en la cercanías del nivel de Fermi $\left(E_{\mathrm{F}}\right)$ representan la porción llena de la banda de valencia en la muestra y el espectrómetro. Los niveles más profundos son los niveles internos. Un diagrama similar es aplicable a muestras semiconductoras o aislantes, con la única diferencia que $E_{\mathrm{F}}$ se ubica entre la porción llena de la banda de valencia y la banda de conducción vacía. Adaptado de ref. [24].

para el efecto fotoeléctrico:

$$
h \nu=E_{\mathrm{B}}^{\mathrm{V}}(k)+E_{\mathrm{K}}
$$

donde $E_{B}^{V}(k)$ es la energía de enlace (binding energy) o potencial de ionización del electrón en el nivel $k$-ésimo, referido al nivel del vacío [24]. Debido a que $h \nu$ se conoce, ya que es la energía de la fuente de rayos X, la medida de $E_{\mathrm{K}}$ determina $E_{\mathrm{B}}^{\mathrm{V}}(k)$. El hueco generado por la eyección del fotoelectrón puede ser llenado por un electrón de un nivel superior, lo que provoca la liberación de un segundo electrón, proceso que se conoce como emisión Auger (Fig. 2.1). Estos electrones también son detectados en el espectro de XPS y pueden ser identificados mediante la variación de la energía de los fotones incidentes. Si la energía cinética del pico no cambia al variar la energía incidente, se trata de un electrón Auger.

En realidad, la situación es algo más compleja. Si se conecta una muestra sólida al espectrómetro, como se muestra en la Fig. 2.2, los potenciales químicos de sus electrones - $\mathrm{o}$ sus niveles de Fermi $\left(E_{\mathrm{F}}\right)$ - se igualan. La función trabajo $\phi_{\mathrm{S}}$ de un sólido se define como la energía de separación entre el nivel de vacío y el nivel de Fermi. En un caso como el de la Fig. 2.2, los respectivos niveles de vacío pueden no ser iguales. Por lo tanto, 
un fotoelectrón que sale de la muestra al llegar al espectrómetro sufre los efectos de un potencial de aceleración o retardo que es igual a $\phi_{\mathrm{s}}-\phi_{\text {espect }}$, donde $\phi_{\mathrm{s}}$ es la función trabajo de la muestra y $\phi_{\text {espect }}$ la del espectrómetro. Entonces, la energía cinética del fotoelectrón que se medirá será diferente a su energía cinética en la superficie de la muestra, disparidad que debe ser tenida en cuenta al calcular la energía de enlace. Si llamamos $E_{\mathrm{K}}$ a la energía cinética del fotoelectrón en la superficie de la muestra (como en la Ec. 2.2) y $E_{\mathrm{K}}^{\prime}$ a la energía cinética del fotoelectrón dentro del espectrómetro, obtenemos

$$
E_{\mathrm{K}}=E_{\mathrm{K}}^{\prime}+\phi_{\text {espect }}-\phi_{\mathrm{s}}
$$

Reemplazando esta ecuación en la anterior, es posible medir las energías de enlace en un sólido metálico respecto a los niveles de Fermi del espectrómetro y de la muestra, que son equivalentes:

$$
h \nu=E_{\mathrm{B}}^{\mathrm{F}}(k)+E_{\mathrm{K}}^{\prime}+\phi_{\mathrm{espect}}
$$

donde el superíndice $\mathrm{F}$ indica que la energía de enlace se mide referida al nivel de Fermi, $E_{\mathrm{B}}^{\mathrm{V}}(k)=E_{\mathrm{B}}^{\mathrm{F}}(k)+\phi_{\mathrm{s}}$. Las energías de enlace informadas en este trabajo corresponden a $E_{\mathrm{B}}^{\mathrm{F}}$.

La determinación de $E_{\mathrm{B}}^{\mathrm{F}}(k)$ permite no sólo identificar los elementos presentes en la muestra sino también analizar el estado químico de ellos debido a que se genera un corrimiento en las energías de enlace de acuerdo al entorno, lo que se denomina corrimiento químico (chemical shift, CS). Este fenómeno fue indicado por primera vez por Siegbahn [25] y permite distinguir entre diferentes estados de oxidación de un elemento. Por ejemplo, en el litio metálico $\left(\mathrm{Li}^{0}\right)$ los electrones $2 s$ se encuentran formando parte del sistema metálico. En el óxido de litio $\left(\mathrm{Li}_{2} \mathrm{O}\right)$, sin embargo, los átomos de litio donan sus electrones $2 s$ al oxígeno, quien obtiene una capa llena $2 p^{6}$. Por esta razón, los electrones $1 s$ del litio sufren los efectos de una carga coulómbica mayor en el óxido de litio que en el metal. Por lo tanto, la energía de enlace del nivel $1 s$ del $\mathrm{Li}$ es mayor en el $\mathrm{Li}_{2} \mathrm{O}$ que en el Li metálico y se observa un corrimiento químico entre los dos compuestos [26]. Si bien esta aproximación es útil en muchos casos para interpretar los corrimientos químicos, en ciertas situaciones el análisis es menos intuitivo y más complejo como, por ejemplo, en la Ag y sus óxidos [27].

Es importante notar que las intensidades de los picos de los diferentes niveles energéticos no son iguales debido a que la probabilidad de fotoeyección desde cada nivel -llamada sección eficaz de fotoionización, $\sigma$ - es diferente. Esta probabilidad también varía para un nivel dado en diferentes átomos y depende de la energía de los rayos $\mathrm{X}$ utilizados. Los valores de $\sigma$ para los diferentes elementos y energías de fotones incidentes pueden encontrarse tabulados en la ref. [28].

En la Fig. 2.3 se presenta un espectro XPS de una muestra sólida de Pd depositado sobre un sustrato de Au. El número de picos en el espectro corresponde al número de niveles de energía ocupados en los átomos cuyas energías de enlace son menores que la energía de los rayos $\mathrm{X}$ incidentes, $h \nu$, además de los picos Auger y de plasmones. Las intensidades de los picos dependen del número de átomos presentes y del valor de $\sigma$ para el nivel estudiado, además de otros parámetros que veremos más adelante. Cada pico presenta un fondo aproximadamente constante en el lado de baja energía de enlace que se 


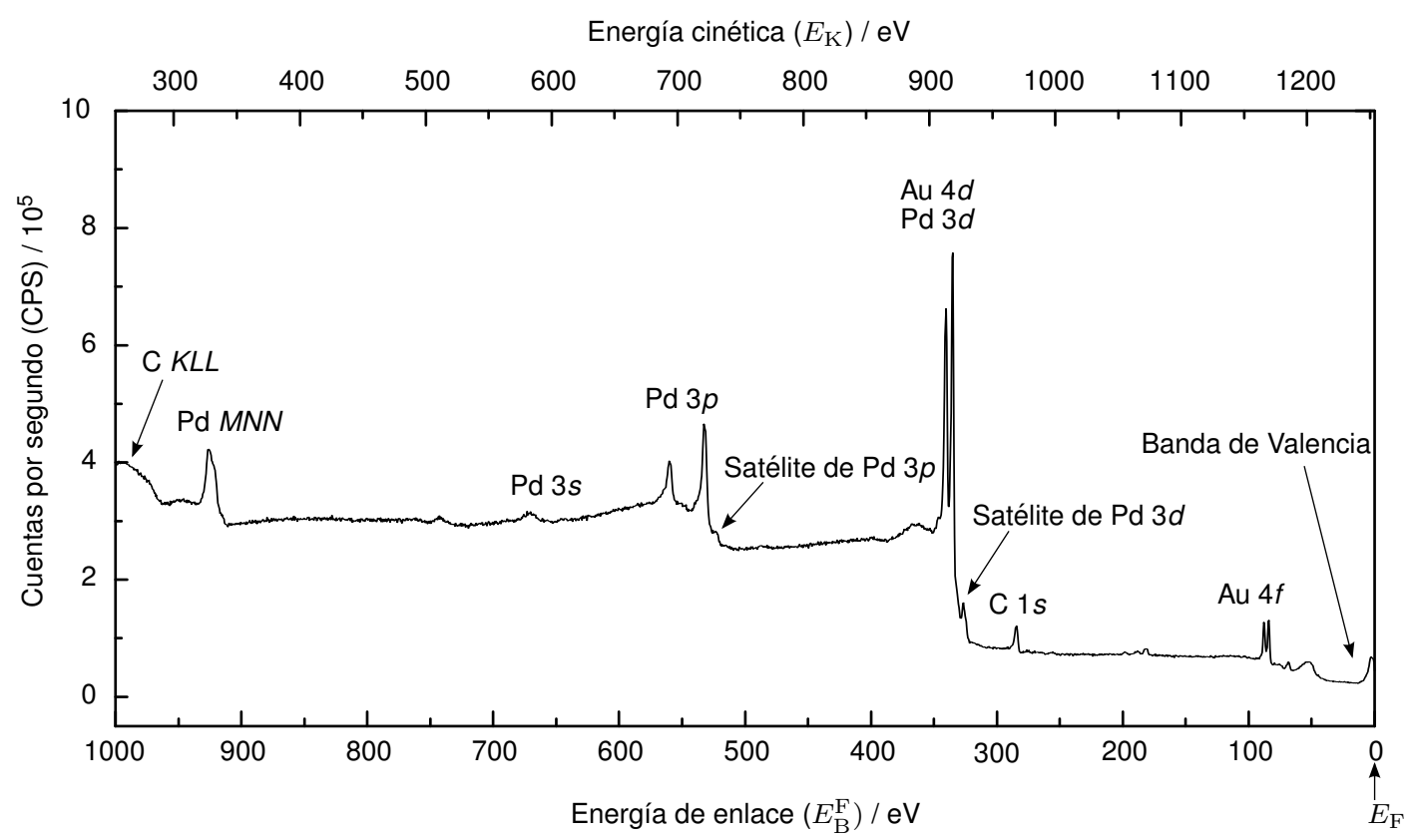

Figura 2.3: Espectro XPS de una superficie de Pd-Au tomado con una fuente de $\operatorname{Mg} K \alpha$ $(h \nu=1253,6 \mathrm{eV})$. Se nombran los principales picos que aparecen en el espectro.

debe a la dispersión inelástica. Es decir, los fotoelectrones que producen los picos agudos sin pérdida notable de energía también pueden ser dispersados de forma inelástica en el proceso de escape del material, produciéndose dicho fondo [24].

\subsubsection{Disposición experimental}

Los equipos de XPS constan de diferentes componentes. Se utiliza una cámara de ultra alto vacío (ultra-high vacuum, UHV) con presiones del orden de $10^{-9}$ mbar para disminuir la cantidad de contaminantes superficiales y asegurar a los electrones eyectados un camino libre medio lo suficientemente grande como para alcanzar el analizador. La cámara está construida de acero inoxidable y posee ventanas de vidrio para poder observar su interior. A ella se acoplan diferentes elementos necesarios para el análisis superficial como la fuente de rayos X, el analizador de electrones, el cañón de iones, etc. En la Fig. 2.4 se muestran las cámaras utilizadas en este trabajo.

La fuente de rayos $\mathrm{X}$ puede consistir en un tubo de rayos $\mathrm{X}$ o radiación de luz sincrotrón. En el caso de un tubo estándar, la radiación proviene del bombardeo de $\mathrm{Mg}$ o $\mathrm{Al}$ con un cañón de electrones. Los huecos formados en las capas electrónicas internas de estos elementos son luego llenados por transiciones radiativas desde niveles más altos, lo que produce la emisión de rayos X. Este espectro de rayos $\mathrm{X}$ generados está dominado por un doblete intenso, no resuelto, $K \alpha_{1}-K \alpha_{2}$. Adicionalmente, se producen líneas de rayos $\mathrm{X}$ menos intensas, denominadas satélites. Los satélites más intensos son los correspondientes a los picos $K \alpha_{3}$ y $K \alpha_{4}$. Para $\mathrm{Mg}$-la fuente utilizada en todos los espectros presentados en este trabajo-, $K \alpha_{3}$ y $K \alpha_{4}$ se ubican a $8,4 \mathrm{eV}$ y $10,2 \mathrm{eV}$ por encima del pico de $K \alpha_{1,2}$, respectivamente. Las intensidades de los picos $K \alpha_{3}$ y $K \alpha_{4}$ son 8,0 \% y 4,1 \% del valor del 

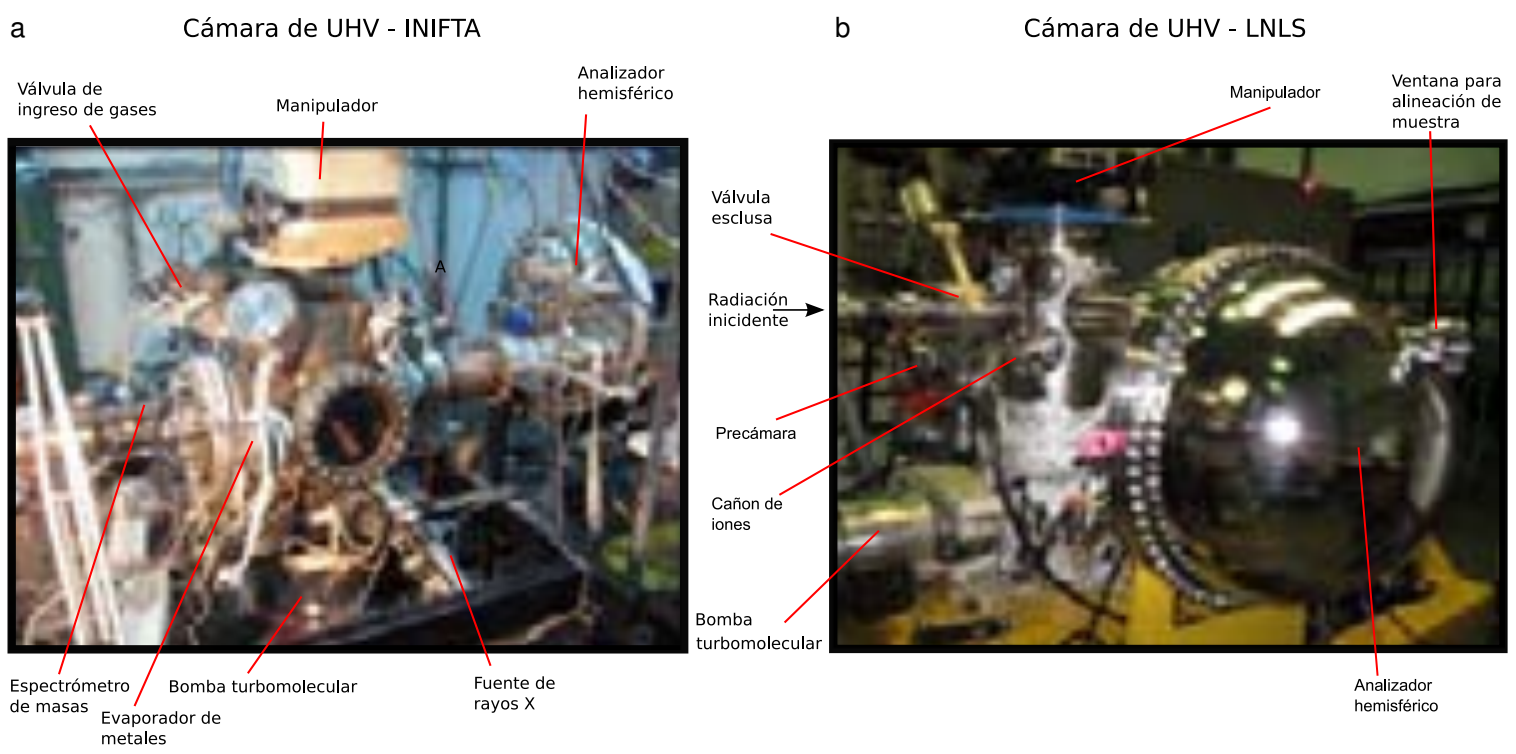

Figura 2.4: Fotografías de las cámaras de ultra alto vacío (UHV) utilizadas en los experimentos de XPS convencional y con radiación de luz sincrotrón.

pico $K \alpha_{1,2}$, respectivamente [29]. Estos satélites producen fotoelectrones con una energía cinética que excede a la de los producidos por el pico principal en los mismos valores señalados. De esta manera, en el espectro que se informa en función de la energía de enlace (calculada considerando $h \nu$ correspondiente al pico $K \alpha_{1,2}$ ) aparecen dos picos a menores energías de enlace que el pico principal y cuyas intensidades siguen los porcentajes señalados. La energía de los rayos X emitidos en el caso del $\mathrm{Mg} K \alpha$ es de $1253,6 \mathrm{eV}{ }^{1}$

Cuando se utiliza radiación de luz sincrotrón, los rayos X son generados por aceleración de electrones relativísticos dentro de un campo magnético. Existen básicamente 3 dispositivos para generar radiación en un sincrotrón: bending magnets, undulators y wigglers. En las medidas realizadas en este trabajo se utilizó radiación generada por bending magnets, que provocan una trayectoria curva en los electrones generándose un cono de radiación estrecho en dirección tangencial a la trayectoria de los electrones [30]. Lo interesante para las medidas de XPS -además del intenso flujo y la monocromaticidad de la radiaciónes la posibilidad de variar la energía de los fotones incidentes. De esta manera es posible estudiar la composición de la muestra en función de la profundidad. Disminuyendo la energía de los rayos X se puede obtener información de las primeras capas atómicas sin interferencia de las capas más profundas, ya que se disminuye el camino libre medio de los fotoelectrones generados.

La medida de la energía de los electrones eyectados se realiza mediante el análisis de su deflexión en campos magnéticos. El sistema de detección de los electrones está basado en la ganancia producida por multiplicadores de electrones, llamados channeltrons.

Las medidas de XPS realizadas en esta Tesis se llevaron a cabo en el INIFTA y en el Laboratório Nacional do Luz Síncrotron (LNLS), Campinas, Brasil. En el laboratorio se utilizó una fuente de $\operatorname{Mg} K \alpha$ (XR50, Specs GmbH) y un analizador hemisférico (PHOIBOS

\footnotetext{
${ }^{1}$ Por simplicidad, nos referiremos al pico $K \alpha_{1,2}$ emitido por $\mathrm{Mg}$ como $\mathrm{Mg} K \alpha$
} 
100, Specs $\mathrm{GmbH})$. La presión dentro de la cámara de UHV fue menor a $1 \times 10^{-9} \mathrm{mbar}$. El ángulo entre la fuente de rayos X y el eje del analizador está fijado en $54^{\circ} 44^{\prime}$, denominado ángulo mágico. Los valores de sección eficaz de fotoionización están tabulados para esta geometría. Se realizó una calibración de la escala de energía de dos puntos utilizando Au evaporado $\left(E_{B}\right.$ de $\left.\mathrm{Au} 4 f_{7 / 2}=84,00 \mathrm{eV}\right)$ y $\mathrm{Cu}\left(E_{B}\right.$ de $\left.\mathrm{Cu} 2 p_{3 / 2}=932,67 \mathrm{eV}\right)$.

En el caso de luz sincrotrón, las medidas se realizaron en la línea SGM del LNLS ${ }^{2}$, equipada con un bending magnet y un monocromador esférico de rejillas que permite variar la energía de los fotones incidentes entre 250 y $1000 \mathrm{eV}$. La estación de trabajo consta de una cámara de UHV (presión de base: $1 \times 10^{-8}$ mbar) donde se ubica un analizador hemisférico (PHOIBOS 150, Specs GmbH). El ángulo entre el haz de rayos X incidente y el eje del analizador es $90^{\circ}$. La muestra se introduce a través de una precámara y se traslada a la cámara principal utilizando un manipulador.

En ambos casos el vacío se logra mediante una bomba turbomolecular ubicada en la parte inferior de la cámara, que se encuentra conectada a un sistema de vacío previo evacuado por bombas mecánicas.

\subsubsection{Análisis de los resultados}

Para la cuantificación de los espectros de XPS es preciso conocer, en principio, dos cantidades: la intensidad de los picos utilizados en el análisis -obtenida a partir de la integración de los picos luego de sustraer una linea de base lineal o tipo Shirley- y su sección eficaz de fotoionización, $\sigma$, comentada anteriormente. De esta forma se puede obtener la relación atómica entre los diferentes elementos que componen la muestra. Sin embargo, es necesario tener en cuenta también la atenuación que sufren las señales debido a la dispersión elástica e inelástica de los fotoelectrones.

Al generarse un fotoelectrón en un sólido, este debe atravesar las capas atómicas del material hasta llegar a la superficie. La intensidad $I$ de la señal de fotoelectrones luego de atravesar una distancia $x$ de la muestra, está dada por la ley de Lambert-Beer [31]:

$$
I=I_{0} \exp \left(-\frac{x}{\lambda \cos \alpha}\right)
$$

donde $I_{0}$ es la intensidad de la señal sin atenuar, $\alpha$ es el ángulo de emisión -medido entre la dirección del electrón al salir del sólido y la normal a la superficie- y $\lambda$ es el camino libre medio inelástico de los electrones, también llamado IMFP por las siglas del inglés inelastic mean free path.

$\mathrm{Si}$ consideramos un sólido semi infinito y lo dividimos en capas de espesor $d$ (Fig. 2.5), la intensidad generada por este sólido - denominada $I^{\infty}$ - estará dada por la suma de las intensidades de cada capa de espesor $d$. La primera capa no sufre atenuación, y llamaremos $I_{d}$ a la intensidad de los fotoelectrones generados en ella. Las siguientes capas sufrirán la atenuación de las capas superiores, por lo que podemos escribir la expresión

\footnotetext{
${ }^{2}$ http://www.lnls.br/uvsoftx/sgm-technical-specifications/
} 


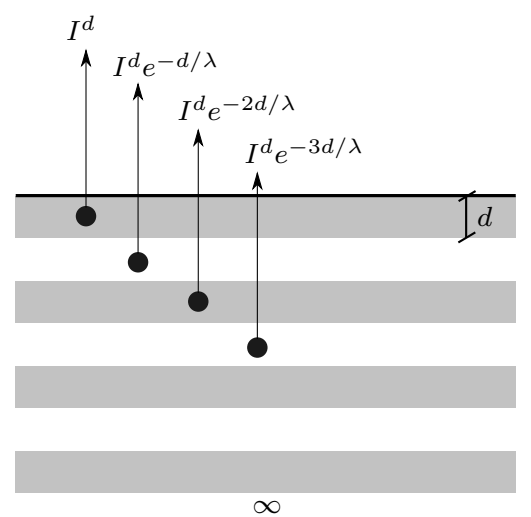

Figura 2.5: Esquema del proceso de atenuación de la intensidad de los fotoelectrones eyectados. Las intensidades corresponden a la contribución de cada capa de espesor $d$ a la intensidad total del sólido semi infinito.

para $I^{\infty}$ como: $^{3}$

$$
\begin{aligned}
I^{\infty} & =I^{d}+I^{d} e^{-d / \lambda}+I^{d} e^{-2 d / \lambda}+I^{d} e^{-3 d / \lambda}+\ldots \\
& =I^{d}\left(1+e^{-d / \lambda}+e^{-2 d / \lambda}+e^{-3 d / \lambda}+\ldots\right) \\
& =I^{d}\left(1+e^{-d / \lambda}+\left(e^{-d / \lambda}\right)^{2}+\left(e^{-d / \lambda}\right)^{3}+\ldots\right) \\
& =I^{d} \sum_{i=0}^{\infty}\left(e^{-d / \lambda}\right)^{i} \\
& =I^{d}\left(\frac{1}{1-e^{-d / \lambda}}\right)
\end{aligned}
$$

donde se aplicó el desarrollo en serie $\sum_{i=0}^{\infty} x^{i}=\frac{1}{1-x}$ para $|x|<1$, con $x=e^{-d / \lambda}$. Por lo tanto, la intensidad de los fotoelectrones producidos por una capa de espesor $d$ estará dada por la siguiente expresión:

$$
I^{d}=I^{\infty}\left[1-\exp \left(-\frac{d}{\lambda}\right)\right]
$$

Debido a que además las dispersiones inélasticas existen dispersiones elásticas que afectan a la señal medida, es apropiado utilizar una longitud de atenuación efectiva (electron effective attenuation length, EAL) en lugar del IMFP. Existen diversas definiciones de EALs y distintas formas de ser calculados que pueden encontrarse en el artículo de Jablonski y Powell [32] y en las referencias que allí se presentan. En este trabajo hemos utilizado la ecuación de Cumpson y Seah para calcular el EAL de electrones con una energía cinética $E_{\mathrm{K}}$ en un sólido de un elemento con número atómico $Z$ [33, 34]:

$$
\mathrm{EAL}[\mathrm{nm}]=0,316 a^{3 / 2}\left\{\frac{E_{\mathrm{K}}}{Z^{0,45}\left[\ln \left(E_{\mathrm{K}} / 27\right)+3\right]}+4\right\}
$$

\footnotetext{
${ }^{3}$ Consideramos aquí un ángulo de emisión $\alpha=0^{\circ}$ para simplificar las ecuaciones.
} 
donde $a$ es el parámetro de red promedio (en $\mathrm{nm}$ ) calculado como

$$
a=10^{8}\left(\frac{A_{w}}{\rho N_{\mathrm{Av}}}\right)^{1 / 3}
$$

donde $A_{w}$ es la masa atómica (en g), $\rho$ es la densidad (en $\mathrm{kg} \mathrm{m}^{-3}$ ) y $N_{\mathrm{Av}}=6,022 \times 10^{23} \mathrm{~mol}^{-1}$ es el número de Avogadro. Para calcular el EAL en unidades de número de capas atómicas (MLs) sólo hay que dividir el valor calculado con la Ec. 2.12 por el valor de $a$. Los EALs calculados con esta ecuación son útiles para estimar el cubrimiento de un elemento sobre un metal utilizando ángulos de emisión $\alpha$ ente 0 a $63^{\circ}$. En adelante, utilizaremos el símbolo $\lambda$ para referirnos a EAL en lugar de IMFP.

Para calcular el espesor $d$ de una capa de un elemento $A$ sobre un metal $B$ semi infinito, consideraremos que la intensidad de la capa de $A$ está dada por la ecuación equivalente a la 2.11:

$$
I_{A}=I_{A}^{\infty}\left[1-\exp \left(\frac{-d}{\lambda_{A, A} \cos \alpha}\right)\right]
$$

donde $\lambda_{A, A}$ señala el EAL del electrón de A en el elemento A y $I_{A}^{\infty}$ corresponde a la señal que se obtendría de un sólido $A$ semi infinito. La señal de $B$ en la interfase B-A es $I_{B}^{\infty}$, entonces la señal de $B$ a la salida de la superficie de $A$ será

$$
I_{B}=I_{B}^{\infty} \exp \left(\frac{-d}{\lambda_{B, A} \cos \alpha}\right)
$$

donde $\lambda_{B, A}$ se refiere al EAL del fotoelectrón de $\mathrm{B}$ en el elemento A. Tomando el cociente entre ambas señales

$$
\begin{aligned}
\frac{I_{A}}{I_{B}} & =\frac{I_{A}^{\infty}}{I_{B}^{\infty}} \frac{\left[1-\exp \left(-d / \lambda_{A, A} \cos \alpha\right)\right]}{\exp \left(-d / \lambda_{B, A} \cos \alpha\right)} \\
& =\frac{I_{A}^{\infty}}{I_{B}^{\infty}}\left\{\exp \left(\frac{d}{\lambda_{B, A} \cos \alpha}\right)-\exp \left[\frac{d}{\cos \alpha}\left(\frac{1}{\lambda_{B, A}}-\frac{1}{\lambda_{A, A}}\right)\right]\right\}
\end{aligned}
$$

Si $\lambda_{A, A}=\lambda_{B, A}=\lambda_{A},{ }^{4}$ entonces

$$
\frac{I_{A}}{I_{B}}=\frac{I_{A}^{\infty}}{I_{B}^{\infty}}\left[\exp \left(\frac{d}{\lambda_{A} \cos \alpha}\right)-1\right]
$$

Reordenando y tomando logaritmo natural, obtenemos

$$
\ln \left(1+\frac{I_{A}}{I_{B}} \frac{I_{B}^{\infty}}{I_{A}^{\infty}}\right)=\frac{d}{\lambda_{A} \cos \alpha}
$$

Entonces

$$
d=\lambda_{A} \cos \alpha \ln \left(1+\frac{I_{A}}{I_{B}} \frac{I_{B}^{\infty}}{I_{A}^{\infty}}\right)
$$

En las medidas presentadas en este informe $\alpha=0^{\circ}$, por lo tanto

$$
d=\lambda_{A} \ln \left(1+\frac{I_{A}}{I_{B}} \frac{I_{B}^{\infty}}{I_{A}^{\infty}}\right)
$$

\footnotetext{
${ }^{4}$ Esto se cumple si los fotoelectrones de ambas capas tienen aproximadamente la misma energía cinética.
} 
La intensidad $I$ de un pico de un espectro XPS de un sólido homogéneo está dada por [31]:

$$
I=J \rho \sigma K \lambda
$$

donde $J$ es el flujo de fotones incidentes, $\rho$ es la concentración de átomos en el sólido, $\sigma$ es la sección eficaz de fotoionización, $K$ describe factores instrumentales y $\lambda$ es la longitud eficaz de atenuación. Por lo tanto, el cociente $I_{B}^{\infty} / I_{A}^{\infty}$ será

$$
\frac{I_{B}^{\infty}}{I_{A}^{\infty}}=\frac{\rho_{B} \sigma_{B} \lambda_{B}}{\rho_{A} \sigma_{A} \lambda_{A}}
$$

De esta forma, obtenemos

$$
d=\lambda_{A} \ln \left(1+\frac{I_{A}}{I_{B}} \frac{\rho_{B} \sigma_{B} \lambda_{B}}{\rho_{A} \sigma_{A} \lambda_{A}}\right)
$$

Las unidades de $d$ están dadas por las unidades de $\lambda$, que puede estar en nm o en capas atómicas, como se explicó anteriormente.

Esta ecuación es válida si $d \gtrsim 0,2 \mathrm{~nm}$, es decir para cubrimientos mayores o iguales a 1 monocapa [33]. En los casos de cubrimientos de fracciones de monocapa, por ejemplo $\mathrm{S}$ sobre $\mathrm{Pd}(111)$, hemos utilizado el siguiente procedimiento. La intensidad del adsorbato $A$ se considera que no es atenuada, y la intensidad que correspondería a la primer monocapa atómica del sustrato $\left(I_{B}^{1 \mathrm{ML}}\right)$ se calcula utilizando la Ec. 2.11:

$$
I_{B}^{1 \mathrm{ML}}=I_{B}^{\infty}\left[1-\exp \left(\frac{1}{\lambda_{B, B}}\right)\right]
$$

donde $\lambda$ se encuentra en unidades de monocapas, $I_{B}^{\infty}$ es la intensidad de $B$ medida y se consideró $\alpha=0^{\circ}$. Por lo tanto, el cubrimiento de $A$ sobre $B$ se calcula como

$$
\theta_{A}=\frac{I_{A}}{I_{B}^{1 \mathrm{ML}}} \frac{\rho_{B} \sigma_{B} \lambda_{B}}{\rho_{A} \sigma_{A} \lambda_{A}}=\frac{I_{A}}{I_{B}^{\infty}\left[1-\exp \left(1 / \lambda_{B, B}\right)\right]} \frac{\rho_{B} \sigma_{B} \lambda_{B}}{\rho_{A} \sigma_{A} \lambda_{A}}
$$

En esta aproximación se considera que las señales del sustrato y del adsorbato son atenuadas en la misma magnitud por las otras especies que se pueden encontrar por encima como, por ejemplo, las cadenas hidrocarbonadas de los tiolatos. Esto es razonable si la energía cinética de los fotoelectrones de ambos materiales es similar, lo cual se cumple en el caso de $\mathrm{Au}, \mathrm{Pd}$ y $\mathrm{S}$ utilizando una fuente de $\mathrm{Mg} K \alpha$.

En los casos en los que los picos no se resuelven, generalmente por tratarse del mismo elemento en diferentes estados de oxidación, es posible realizar una descomposición de la señal en diferentes componentes, proceso denominado deconvolución. En este trabajo hemos utilizado el programa XPSPEAK 4.1 para realizar este análisis.

La deconvolución se realiza en los espectros tomados con alta resolución y es necesaria la medición de estándares con el mismo equipo para poder elegir los parámetros a introducir en las funciones utilizadas. Estas funciones consisten en un producto de una función gaussiana y una lorentziana. Primeramente se traza una línea de base en el espectro y luego se agregan los picos correspondientes. Los parámetros que se ajustan son: posición, intensidad, ancho a media altura y porcentaje gaussiana y lorentziana. Con este programa 
es posible elegir el tipo de pico que se está analizando $(s, p, d, f)$ con lo cual las intensidades relativas de los dobletes son fijadas. Solamente se debe ingresar un valor para la separación entre los picos de los dobletes denominada separación spín órbita (spin-orbit splitting, SOS).

En el caso del S $2 p$, la SOS entre los picos de S $2 p_{3 / 2}$ y S $2 p_{1 / 2}$, se fijó en $1,18 \mathrm{eV}$, el porcentaje gaussiana y lorentziana se fijó en $50 \%$ y el ancho en 1,1 eV. En la deconvolución de los picos de $\mathrm{Pd} 3 d$ y Au $4 d$, se fijó la SOS en $5,25 \mathrm{eV}$ para los picos de $\mathrm{Pd} 3 d_{5 / 2}$ y $\mathrm{Pd}$ $3 d_{3 / 2}$ y $18,1 \mathrm{eV}$ para los picos de $\mathrm{Au} 4 d_{5 / 2}$ y Au $4 d_{3 / 2}$. Se agregaron en este caso también los picos correspondientes a los satélites de la fuente de $\mathrm{Mg} K \alpha$ restringiendo sus posiciones e intensidades relativas a los picos principales. En el Au $4 f$, la separación entre los picos de $\mathrm{Au} 4 f_{5 / 2}$ y Au $4 f_{7 / 2}$ fue fijada en $3,65 \mathrm{eV}$ y el ancho en $1 \mathrm{eV}$.

\subsection{Espectroscopía de absorción de rayos X (XAS)}

La espectroscopía de absorción de rayos X (X-ray absorption spectroscopy, XAS) se basa en la irradiación de una muestra con una fuente de rayos $\mathrm{X}$ de energía variable y el registro de la intensidad absorbida por la muestra en función de la energía de los fotones incidentes. Esto se realiza en la zonas donde los elementos estudiados presentan un borde de absorción que está dado por una transición electrónica desde un nivel interno hasta un nivel desocupado (por encima del nivel de Fermi) o por encima del nivel de vacío, generándose un fotoelectrón. En XAS se estudia la absorción de radiación cuya energía abarca la zona de rayos $\mathrm{X}$ blandos (desde $\sim 250 \mathrm{eV}$ ) y duros.

En principio, es posible diferenciar dos zonas diferentes en los espectros de absorción. La primera es la región que abarca la zona cercana al punto de inflexión del borde de absorción y da lugar a la espectroscopia conocida como XANES, por sus siglas del inglés $X$ ray absorption near edge spectroscopy. Aquí se producen transiciones desde niveles internos hasta niveles desocupados por encima del nivel de Fermi [35]. Esta técnica, permite -de forma similar a XPS pero con un menor nivel de resolución- el estudio del estado químico del elemento considerado en base al análisis de la posición del borde de absorción.

El estudio de la zona del espectro desde $\sim 10 \mathrm{eV}$ por encima del borde de absorción da lugar a la espectroscopía EXAFS, por sus siglas del inglés extended X-ray absorption fine structure. Cuando se genera un fotoelectrón, este puede interaccionar con los átomos vecinos produciéndose una dispersión del mismo. Esto se evidencia por una oscilación en esta zona del espectro conocida como oscilación EXAFS. El análisis de estas oscilaciones permite obtener información estructural del entorno del elemento cuyo borde de absorción se está estudiando. La intensidad en la región correspondiente a EXAFS puede describirse mediante la siguiente fórmula, conocida como ecuación EXAFS [35]:

$$
\chi(k)=S_{0}^{2} \sum_{i}\left\{N_{i} \frac{f_{i}(k)}{k R_{i}^{2}} e^{-2 k^{2} \sigma_{i}^{2}} e^{-2 R_{i} / \lambda} \operatorname{sen}\left[2 k R_{i}+\delta_{i}(k)\right]\right\}
$$

donde $k=2 \pi / \lambda$ es el módulo del vector de onda del fotoelectrón, $S_{0}^{2}$ es un factor que tiene en cuenta el apantallamiento del electrón eyectado por la nube de los demás electrones del átomo y se estima midiendo un compuesto estándar, $N_{i}$ es la cantidad de átomos en 


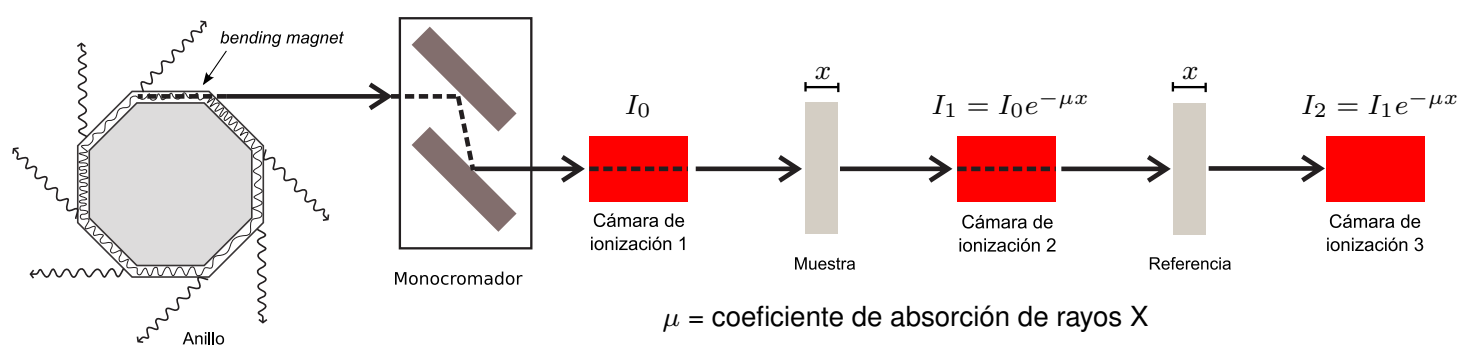

Figura 2.6: Esquema de la disposición experimental para las medidas de absorción de rayos X por transmisión en la línea XAFS-1.

la capa considerada, que se encuentra a una distancia $R_{i}$ del átomo que absorbió el fotón, $f_{i}$ y $\delta_{i}(k)$ son la amplitud y cambio de fase de la dispersión, $\lambda$ es la longitud de onda del fotoelectrón y $\sigma_{i}^{2}$ es la desviación cuadrática media de las distancias respecto al promedio $R_{i}$. Este último parámetro se denomina factor de Debye-Waller y da una idea del grado de desorden estructural del sistema.

Los parámetros de la Ec. 2.27 son variados para ajustar los datos experimentales de $\chi(k)$ a esta ecuación. En este trabajo se informa la trasformada de Fourier de $\chi(k), \mathcal{F}[\chi(k)]$.

\subsubsection{Consideraciones experimentales}

Las medidas de XAS en el borde $K$ del S se realizaron en la línea SXS del LNLS ${ }^{5}$, equipada con un monocromador de $\mathrm{Si}(111)$ y un bending magnet como fuente de radiación. Debido a que en este caso la radiación utilizada es de rayos $\mathrm{X}$ blandos $(\sim 2500 \mathrm{eV})$ las medidas se realizaron en una cámara de UHV. La cámara utilizada es la misma que se utilizó en las medidas de XPS (Fig. 2.4b). La muestra de NPs se depositó sobre una cinta de grafito y se evaporó el solvente a temperatura ambiente antes de introducirla en la cámara. Las medidas de absorción se realizaron utilizando el método TEY (total electron yield) que consiste en medir la corriente de reposición de carga a la muestra (debido a los huecos generados por la radiación incidente) y a una lámina delgada de Au colocada antes de la muestra, en el eje del haz incidente.

Las medidas de XAS en el borde $L_{3}$ del $\mathrm{Au}(7112 \mathrm{eV})$ fueron realizadas en la línea XAFS- $1^{6}$ del LNLS en aire, a temperatura ambiente, en modo transmisión, utilizando una celda para líquidos con ventanas de Kapton (poli(4,4'-difenil-eter-piromelitimida)) como portamuestra. Se utilizaron 3 cámaras de ionización como detectores: una antes de la muestra, para medir la radiación incidente $\left(I_{0}\right)$, otra después de la muestra y antes de la lámina de Au de referencia, para medir la intensidad luego de la muestra $\left(I_{1}\right)$, y la tercera luego de esta lámina para medir la intensidad $I_{2}$ (Fig. 2.6). El espectro de absorción de la muestra y del metal de referencia se expresó como $\log \left(I_{0} / I_{1}\right)$ y $\log \left(I_{1} / I_{2}\right)$, respectivamente. El espectro de la lámina de Au se utilizó para calibrar la escala de energía.

En el caso de las PdNPs, las medidas de XAS en el borde K del Pd (24350 eV) se realizaron utilizando un espectrómetro de laboratorio RIGAKU R-XAS Looper en modo

\footnotetext{
${ }^{5}$ http://www.Inls.br/uvsoftx/soft-x-rays-spectroscopy/sxs-technical-specifications/

${ }^{6}$ http://www.lnls.br/xafs/beamlines/xafs1/
} 
transmisión. Se utilizaron cámaras de ionización con Xe para medir la radiación incidente y un detector de estado sólido para medir la intensidad de la radiación transmitida. La calibración de la escala de energía se realizó con una lámina de Pd.

El análisis cuantitativo de los resultados se realizó mediante modelado y ajuste de los espectros de EXAFS. Las estructuras fueron modeladas utilizando el código FEEF y el ajuste fue realizado utilizando los programas ATHENA y ARTEMIS [36].

\subsection{Dispersión de rayos $\mathrm{X}$ a bajo ángulo (SAXS)}

De forma equivalente a la difracción de rayos $\mathrm{X}$ debido a la separación interplanar en un cristal, un conjunto de objetos de dimensiones nanométricas producirá una dispersión de rayos X a ángulos menores, debido a la relación recíproca entre ambas cantidades [37]. $\mathrm{El}$ análisis de esta región da lugar a la técnica de dispersión de rayos $\mathrm{X}$ a bajo ángulo (small-angle X-ray scattering, SAXS).

La aplicación de esta técnica al estudio de NPs permite estudiar su forma y su tamaño. En el caso de partículas en las que su composición no es homogénea sino que presenta diferencias en la densidad electrónica de las diferentes partes que la componen, es posible modelar su estructura mediante el ajuste de las curvas de dispersión generadas por el modelo a las curvas experimentales. De esta forma, con esta técnica es posible obtener información estructural de los objetos nanométricos.

\subsubsection{Consideraciones experimentales}

Las medidas de SAXS fueron realizadas en la línea SAXS-2 del LNLS. Esta linea está equipada con un monocromador de $\operatorname{Si}(111)$ que permite la obtención de un haz enfocado horizontal y verticalmente, con una longitud de onda $\lambda=0,161 \mathrm{~nm}$. Se utilizó una cámara CCD (charge-coupled device) como detector de los rayos X dispersados. Las muestras de NPs se dispersaron en agua y se midieron a temperatura ambiente en una celda para líquidos con ventanas de mica. Se utilizó behenato de plata para determinar la distancia entre la muestra y el detector $(607,4 \pm 0,1 \mathrm{~mm})$.

El análisis de los resultados se realizó con el paquete Fit2D [38]. Se sustrajo la dispersión parásita proveniente de las rendijas de colimación utilizando una curva obtenida con agua, sin NPs, en las mismas condiciones de medida.

\subsection{Microscocopía electrónica de transmisión (TEM)}

La microscopía electrónica de transmisión (TEM) es una técnica que ha sido fundamental para el desarrollo de la nanociencia y nanotecnología. Su invención se debe al trabajo de M. Knoll y E. Ruska que, en 1931, dio lugar a la construcción del primer microscopio electrónico. Dada la pequeña longitud de onda de los electrones bajo el efecto del altos voltajes de aceleración, la creación de un microscopio electrónico tenía en sus principales objetivos mejorar la resolución de un microscopio óptico, limitada en última instancia por la longitud de onda de la luz visible o ultravioleta. En el año 1933 se obtuvo, por primera 


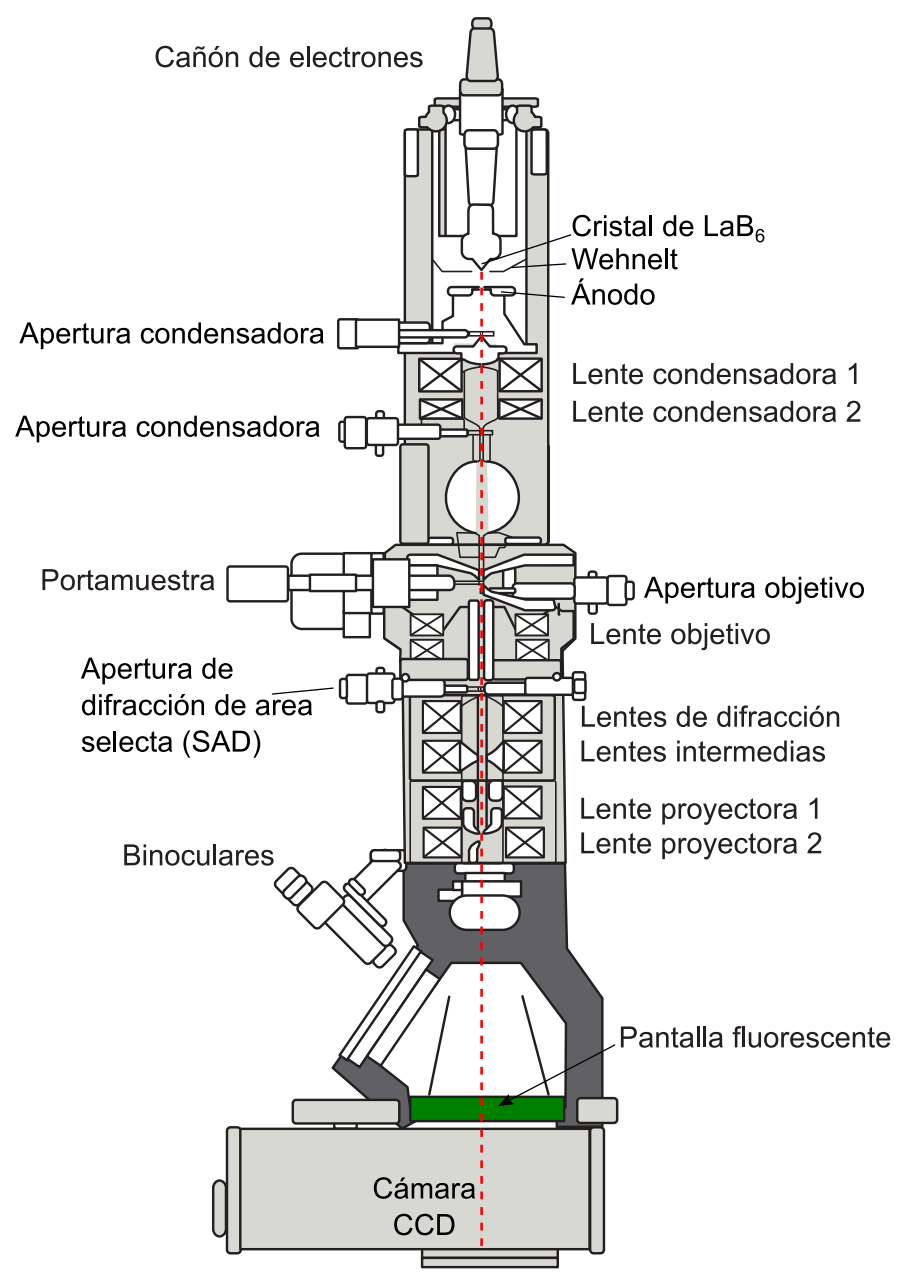

Figura 2.7: Esquema de un microscopio electrónico de transmisión (TEM) convencional con cañón de electrones de emisión termoiónica de $\mathrm{LaB}_{6}$.

vez, un microscopio electrónico con una resolución superior a la de un microscopio óptico [39]. A partir de ese momento, el límite de resolución del microscopio electrónico fue aumentando a lo largo de los años. Sin embargo el límite máximo alcanzable no está determinado por la corta longitud de onda de los electrones. Las aberraciones de las lentes magnéticas utilizadas en el microscopio limitan la resolución del mismo por encima de $0,1 \mathrm{~nm}$.

En la Fig. 2.7 se muestra un esquema de un microscopio electrónico convencional. Una descripción detallada del funcionamiento de estos equipos puede encontrarse en el texto de Williams y Carter [40]. El TEM está compuesto por un sistema de iluminación, una plataforma para la muestra, una lente objetivo, un sistema de magnificación y un sistema de recolección de datos. Las lentes son magnéticas y al variar la corriente que circula por ellas se cambia el campo magnético generado por la lente $\mathrm{y}$, por lo tanto, se modifica la deflexión de la trayectoria de los electrones que pasen por ella. La fuente de electrones es la parte principal del sistema de iluminación. Típicamente se utiliza un cañón de emisión termoiónica de $\mathrm{LaB}_{6}$ o un cañón de emisión de campo (field emission 


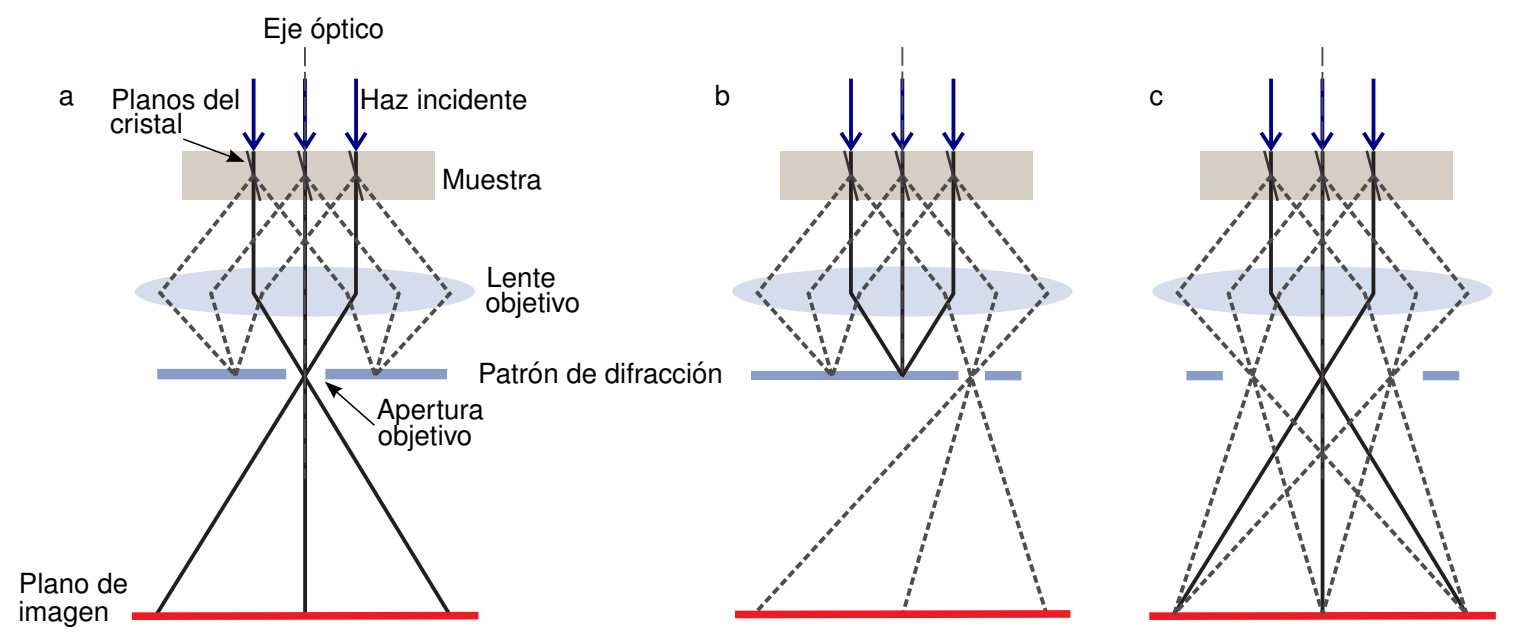

Figura 2.8: Diagrama de los diferentes modos de imagen en TEM. (a) Campo claro. (b) Campo oscuro. (c) Contraste de fase (HRTEM).

gun, FEG). Prácticamente todos los microscopios actuales se fabrican con cañones FEG ya que el brillo y coherencia de estos es muy superior a los de emisión termoiónica.

El sistema de iluminación también incluye las lentes condensadoras que controlan el haz que sale de la fuente de electrones y llega a la muestra. Puede producir un haz paralelo (para utilizar el modo TEM) o bien un haz convergente, como veremos más adelante. La lente objetivo es una de las partes más importantes del TEM ya que determina el límite de la resolución de la imagen. Consiste en piezas polares que se ubican en el nivel de la muestra. El sistema de magnificación consiste de lentes intermedias y lentes de proyección y dan una magnificación de hasta 1,5 millones. El sistema de recolección de datos puede ser una pantalla fluorescente o bien un dispositivo CCD.

La señal en TEM es formada por los electrones no deflectados y los deflectados que penetran el grosor de la muestra. Las imágenes son dominadas por tres tipos de contrastes. Primero, el contraste de difracción, que es producido debido a la disposición general de los átomos en el cristal, por lo que la intensidad difractada del haz incidente de electrones es perturbado, produciendo el contraste observado en imágenes de campo claro (bright field, BF) si se selecciona la porción del haz transmitido, no deflectado (Fig. 2.8a) o las imágenes de campo oscuro (dark field, DF) si se selecciona el haz deflectado (Fig. 2.8b). En segundo lugar, el grosor de la muestra debido a la masa o el número atómico produce contraste. Sin embargo, en lo que sigue consideraremos que este tipo de absorción es insignificante. Este tipo de contraste es útil en muestras biológicas o al utilizar otro tipo de detectores, como veremos en la siguiente sección. Por último, el contraste de fase, que es producido por la modulación de fase de la onda de electrones incidentes cuando son transmitidas a través del potencial del cristal (Fig. 2.8c). Este tipo de contraste es sensible a la distribución atómica en la muestra y es la base de la microscopía electrónica de transmisión de alta resolución (high-resolution TEM, HRTEM), que discutiremos con mayor detalle a continuación, donde realizaremos un resumen del desarrollo realizado en el texto de R. Erni [41]. 


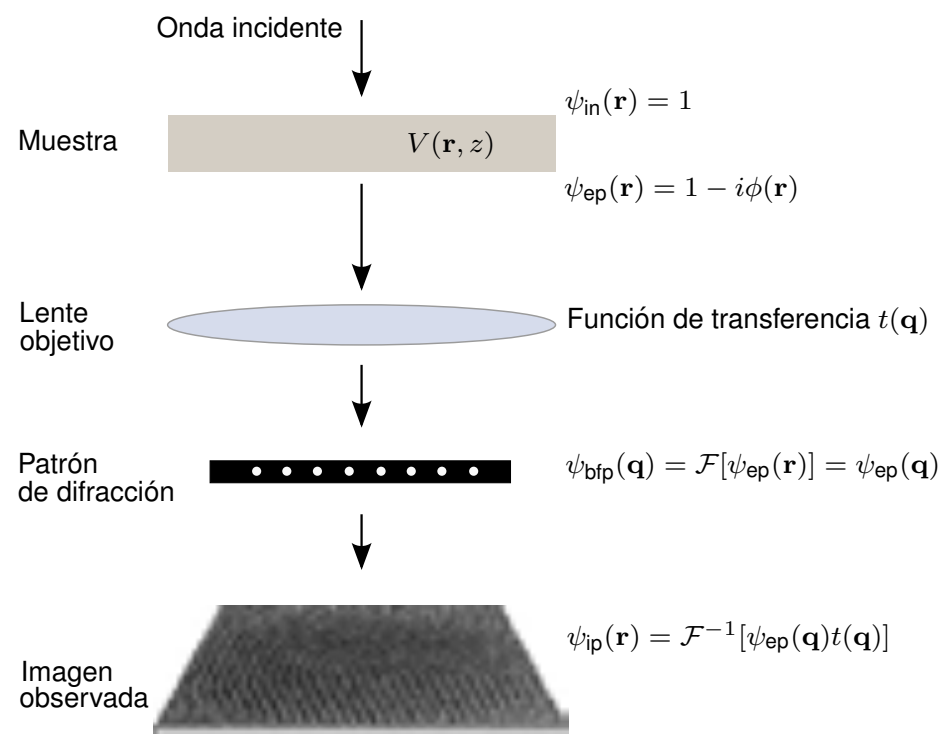

Figura 2.9: La transferencia de la información en un TEM para la formación de una imagen de HRTEM, bajo la aproximación de weak-phase object. Adaptado de [41].

Cuando una onda electrónica incidente, $\psi_{\text {in }}(\mathbf{r}),{ }^{7}$ pasa a través de un campo de potencial de un cristal, $V(\mathbf{r}, z)$, esta es modulada por este potencial produciéndose una onda en el plano de salida de la muestra, conocida como exit-plane wave (Fig. 2.9). Esta modulación está determinada por la función de objeto $\phi(\mathbf{r})$ que es proporcional a $V(\mathbf{r}, z)$. Si consideramos que la muestra es muy delgada y que solo produce cambios en la fase de la onda incidente, sin producirse absorción, nos encontramos dentro de la aproximación de weak-phase object. Entonces, si $\psi_{\text {in }}(\mathbf{r})=1$, dentro de esta aproximación $\phi \ll 1$ y se cumple que la onda en el plano de salida de la muestra es

$$
\psi_{\mathrm{ep}}(\mathbf{r})=e^{-i \phi(\mathbf{r})} \approx 1-i \phi(\mathbf{r})
$$

Si consideramos que la onda en el plano de salida está constituida por un conjunto de rayos difractados por el cristal según la ley de Bragg, como vemos en la Fig. 2.8c, cada rayo difractado es enfocado en un punto por la lente objetivo formando el patrón de difracción en el plano conocido como back focal plane. La función de onda en este plano puede ser descrita como la transformada de Fourier de la onda en el plano de salida de la muestra:

$$
\psi_{\text {bfp }}(\mathbf{q})=\mathcal{F}\left[\psi_{\text {ep }}(\mathbf{r})\right]=\psi_{\text {ep }}(\mathbf{q})
$$

aquí $\mathbf{q}$ es un vector bidimensional del espectro de las frecuencias espaciales, i. e. del espacio recíproco. La intensidad del patrón de difracción está dada por:

$$
I_{d}(\mathbf{q})=\left|\psi_{\mathrm{ep}}(\mathbf{q})\right|^{2}=\psi_{\mathrm{ep}}(\mathbf{q}) \psi_{\mathrm{ep}}^{*}(\mathbf{q})
$$

donde el asterisco se refiere al complejo conjugado.

\footnotetext{
${ }^{7} \mathbf{r}=(x, y)$ es un vector de 2 dimensiones en el plano de la muestra.
} 
Al propagar la onda hasta el plano de imagen, uno podría pensar que aquí la onda estará dada por la transformada de Fourier inversa de la onda en el plano de salida de la muestra, es decir

$$
\psi_{\text {ip }}(\mathbf{r})=\mathcal{F}^{-1}\left[\psi_{\text {ep }}(\mathbf{q})\right]
$$

Sin embargo, esto no es lo que ocurre. En cambio, la función de onda en el plano de imagen está determinada por

$$
\psi_{\mathrm{ip}}(\mathbf{r})=\mathcal{F}^{-1}\left[\psi_{\mathrm{ep}}(\mathbf{q}) t(\mathbf{q})\right]
$$

donde $t(\mathbf{q})$ es una función de transferencia compleja que describe las características de imagen del microscopio. ${ }^{8}$ Esta función consta de una parte real $\Re[t(\mathbf{q})]$ y una parte imaginaria $\Im[t(\mathbf{q})]$. La multiplicación de dos funciones en el espacio recíproco equivale a la convolución de las funciones en el espacio real. Por lo tanto, la función de onda en el plano de imagen es la convolución de la función de onda en el plano de salida de la muestra con la función de transferencia

$$
\psi_{\mathrm{ip}}(\mathbf{r})=\psi_{\mathrm{ep}}(\mathbf{r}) \otimes t(\mathbf{r})
$$

Esta expresión es válida independientemente de la aproximación seguida. Si sustituimos en esta ecuación la expresión para $\psi_{\text {ep }}(\mathbf{r})$ de un objeto bajo la aproximación de weak-phase object, obtenemos

$$
\psi_{\mathrm{ip}}(\mathbf{r})=1+\phi(\mathbf{r}) \otimes \Im[t(\mathbf{r})]-i \phi(\mathbf{r}) \otimes \Re[t(\mathbf{r})]
$$

Por lo tanto, la intensidad de la imagen $I(\mathbf{r})$ para un objeto que cumple con la aproximación de weak-phase object, despreciando los términos cuadráticos, es

$$
I(\mathbf{r})=|\psi(\mathbf{r})|^{2}=1+2\{\phi(\mathbf{r}) \otimes \Im[t(\mathbf{r})]\}
$$

Llamamos función de transferencia de contraste de fase a la transformada de Fourier de $\Im[t(\mathbf{r})]$ :

$$
\mathcal{F}[\Im[t(\mathbf{r})]] \equiv \Im[t(\mathbf{q})]
$$

Esta función determina cómo se transfiere cada frecuencia espacial $\mathbf{q}$ desde el plano de salida de la muestra hasta el plano de imagen [41].

Entonces, una función de transferencia de contraste ideal sería una función con un valor constante. Sin embargo, esto no es lo que sucede en un microscopio y cada frecuencia espacial en el plano de salida de la muestra es transferida de forma diferente a la imagen. Diferentes contribuciones definen a la función de transferencia de contraste $\Im[t(\mathbf{q})]$. Las aberraciones de las lentes, como el defoco $\left(C_{1}\right)$, la aberración esférica de tercer orden $\left(C_{3}\right)$, etc., producen un cambio de fase en la onda. Estos efectos están representados por la siguiente función de transferencia:

$$
t_{\mathrm{L}}(\mathbf{q})=\exp \left[\frac{2 \pi i}{\lambda} \chi(\mathbf{q})\right]=\cos \left[\frac{2 \pi}{\lambda} \chi(\mathbf{q})\right]+i \operatorname{sen}\left[\frac{2 \pi}{\lambda} \chi(\mathbf{q})\right]
$$

\footnotetext{
${ }^{8}$ También por este motivo, la transformada de Fourier de una imagen no es exactamente equivalente al patrón de difracción.
} 
Como vimos anteriormente, lo que nos interesa es la parte imaginaria de la función de transferencia, que llamamos $t_{\mathrm{c}}(\mathbf{q}) \equiv \Im\left[t_{\mathrm{L}}(\mathbf{q})\right]$. La función $\chi(\mathbf{q})$ se denomina función de aberración y tiene la siguiente forma ${ }^{9}$

$$
\chi(\mathbf{q})=\chi(q)=\frac{1}{2} q^{2} \lambda^{2} C_{1}+\frac{1}{4} q^{4} \lambda^{4} C_{3}+\frac{1}{6} q^{6} \lambda^{6} C_{5}
$$

donde $C_{5}$ es la aberración esférica de quinto grado y hemos reemplazado q por $q$ debido a que consideramos solo aberraciones isotrópicas.

$$
\begin{aligned}
t_{\mathrm{c}}(q)=\Im\left[t_{\mathrm{L}}(q)\right] & =\operatorname{sen}\left[\frac{2 \pi}{\lambda} \chi(q)\right] \\
& =\operatorname{sen}\left[\pi\left(q^{2} \lambda C_{1}+\frac{1}{2} q^{4} \lambda^{3} C_{3}+\frac{1}{3} q^{6} \lambda^{5} C_{5}\right)\right]
\end{aligned}
$$

En la Fig. 2.10 hemos representado esta función para dos microscopios diferentes, uno convencional, sin corrección de aberración esférica y otro con corrección de aberración (que veremos más adelante). La función $t_{\mathrm{c}}(q)$ es la función de transferencia de contraste coherente. Es decir, considerando que la onda de electrones incidentes es completamente coherente. En realidad, esta onda tiene una coherencia espacial y temporal parcial debido al tamaño de la fuente de electrones y a la distribución de energía de los electrones del haz. Esto puede ser representado mediante envolventes en los gráficos (no mostradas aquí), que tienen la función de modular la función de transferencia en la zona de altas frecuencias.

La resolución puntual de un microscopio es la máxima frecuencia espacial (mínima distancia en el espacio real) que puede ser transferida por el microscopio desde el plano de salida de la muestra al plano de imagen de manera tal que pueda realizarse una correlación directa entre el objeto y la imagen. En la Fig. 2.10 puede observarse para el microscopio sin corrección que para estas condiciones se obtiene una función de transferencia con un pasabanda ancho en la zona de bajas frecuencias que cruza el cero en aproximadamente $5 \mathrm{~nm}^{-1}$. Ese punto determina la resolución puntual de este microscopio. En esa condición, las frecuencias menores (distancias mayores) pueden ser interpretadas directamente. Debido a que la función oscila entre 0 y 1 a frecuencias mayores a la resolución puntual, la información de estas frecuencias no puede ser interpretada directamente.

En un microscopio con una fuente $\mathrm{LaB}_{6}$, las envolventes debidas a la baja coherencia del haz de electrones hace que la función caiga a 0 prácticamente en la frecuencia de la resolución puntual. En un microscopio FEG, donde la coherencia es mayor, las frecuencias por encima de este punto también afectan a la imagen, lo que aumenta la resolución pero dificulta la interpretación de altas frecuencias.

Como comentamos anteriormente, la resolución de un microscopio electrónico está limitada por la aberración de las lentes. ${ }^{10}$ Por este motivo, en la década de 1990 -y sobre

\footnotetext{
${ }^{9}$ Utilizamos aquí la expresión informada por Lentzen et ál. [42]. Existen diversas aberraciones que habría que considerar en la Ec. 2.38 (veáse Cap. 7 de ref. [41]). Sin embargo, consideraremos aquí sólo estas 3, lo que es suficiente para nuestro análisis comparativo.

${ }^{10}$ Las condiciones ambientales en donde se encuentra el microscopio como la temperatura, vibraciones, campos electromagnéticos, etc. pueden ser un limitante importante de la resolución de un microscopio, de manera que deben ser controladas de forma muy precisa.
} 


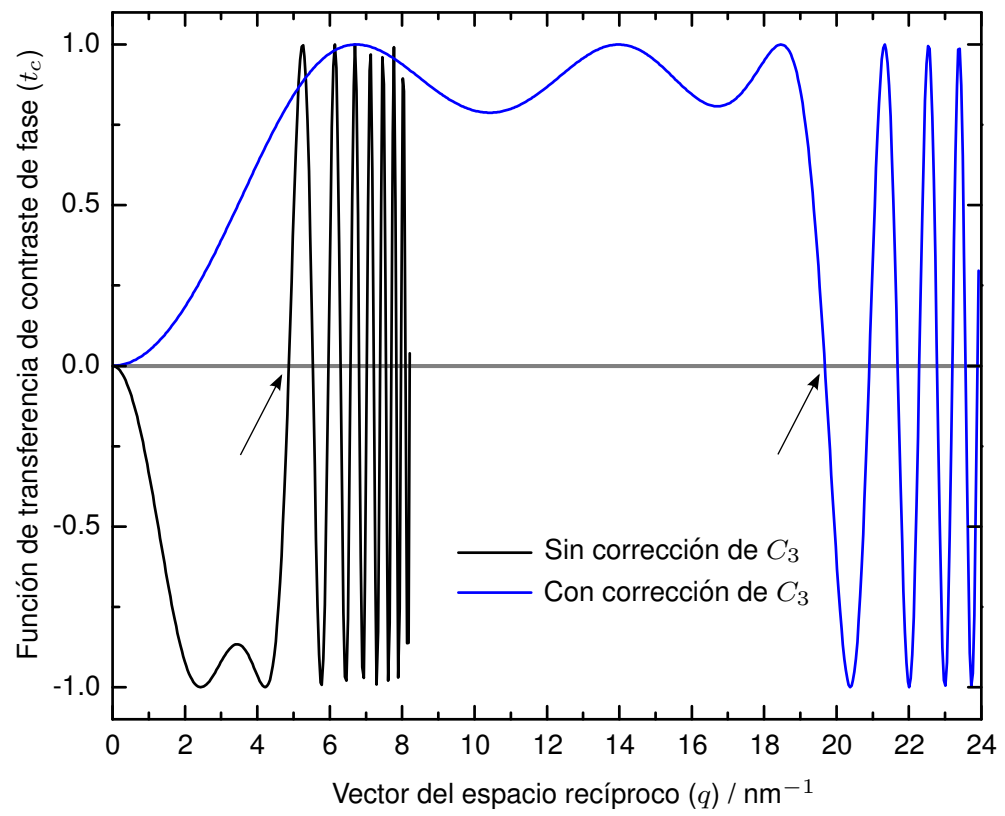

Figura 2.10: Funciones de transferencia de contraste coherentes para microscopios con y sin corrección de aberración esférica $C_{3}$ con las siguientes condiciones. Línea azul: Microscopio con corrección en condiciones óptimas según Letzen et ál. [42]: $C_{1}=+6 \mathrm{~nm}$, $C_{3}=-12,2 \mu \mathrm{m}, C_{5}=+5 \mathrm{~mm}$. Línea negra: defoco de Scherzer para un microscopio convencional, sin corrección: $C_{1}=-44,8 \mathrm{~nm}, C_{3}=+0,6 \mathrm{~mm}, C_{5}=0 \mathrm{~mm}$, se representó sólo hasta $20 \mathrm{mrad}$ para mayor claridad. $\lambda=2,5 \mathrm{~nm}(200 \mathrm{kV})$. Las flechas indican la resolución puntual $\left(\rho_{r}\right)$ en cada caso. Para el microscopio con corrección $\rho_{r} \approx 50 \mathrm{pm}$ y para el microscopio sin corrección, $\rho_{r} \approx 0,2 \mathrm{~nm}$.

todo luego del año 2000- se han comenzado a desarrollar microscopios electrónicos de transmisión con corrección de aberración. En principio, estos instrumentos agregan un corrector de aberración esférica $C_{3}$ (Fig. 2.11b) (que es un tipo de aberración geométrica), disminuyendo así el tamaño límite de resolución alcanzable por un TEM. Estos correctores ya se encuentran disponibles en versiones comerciales. Actualmente también se desarrollan correctores de aberración cromática $C_{C}$ (Fig. 2.11b), para poder aumentar la resolución en sistemas en los cuales esta aberración es particularmente importante. La aberración cromática se produce debido a la distribución de energía de los electrones $(\Delta E)$ en el haz incidente $\mathrm{y}$, además, por la pérdida de energía de los electrones al atravesar la muestra. Esta aberración es mucho menos importante que la aberración esférica. Existen otros tipos de aberraciones como el defoco $\left(C_{1}\right)$, el astigmatismo $\left(A_{1}\right)$, el coma $\left(B_{2}\right)$ que se corrigen manualmente en cualquier microscopio convencional.

Un análisis en profundidad de este campo escapa a los alcances de este trabajo, por lo que nos centraremos en comentar sólo aspectos generales de la corrección de aberración esférica y sus beneficios prácticos en la microscopía de alta resolución. El lector interesado es referido al libro de R. Erni [41].

Se podrían plantear dos mecanismos, en principio, para aumentar el poder resolutivo de un microscopio limitado por la aberración esférica. El primero consiste en acortar la 

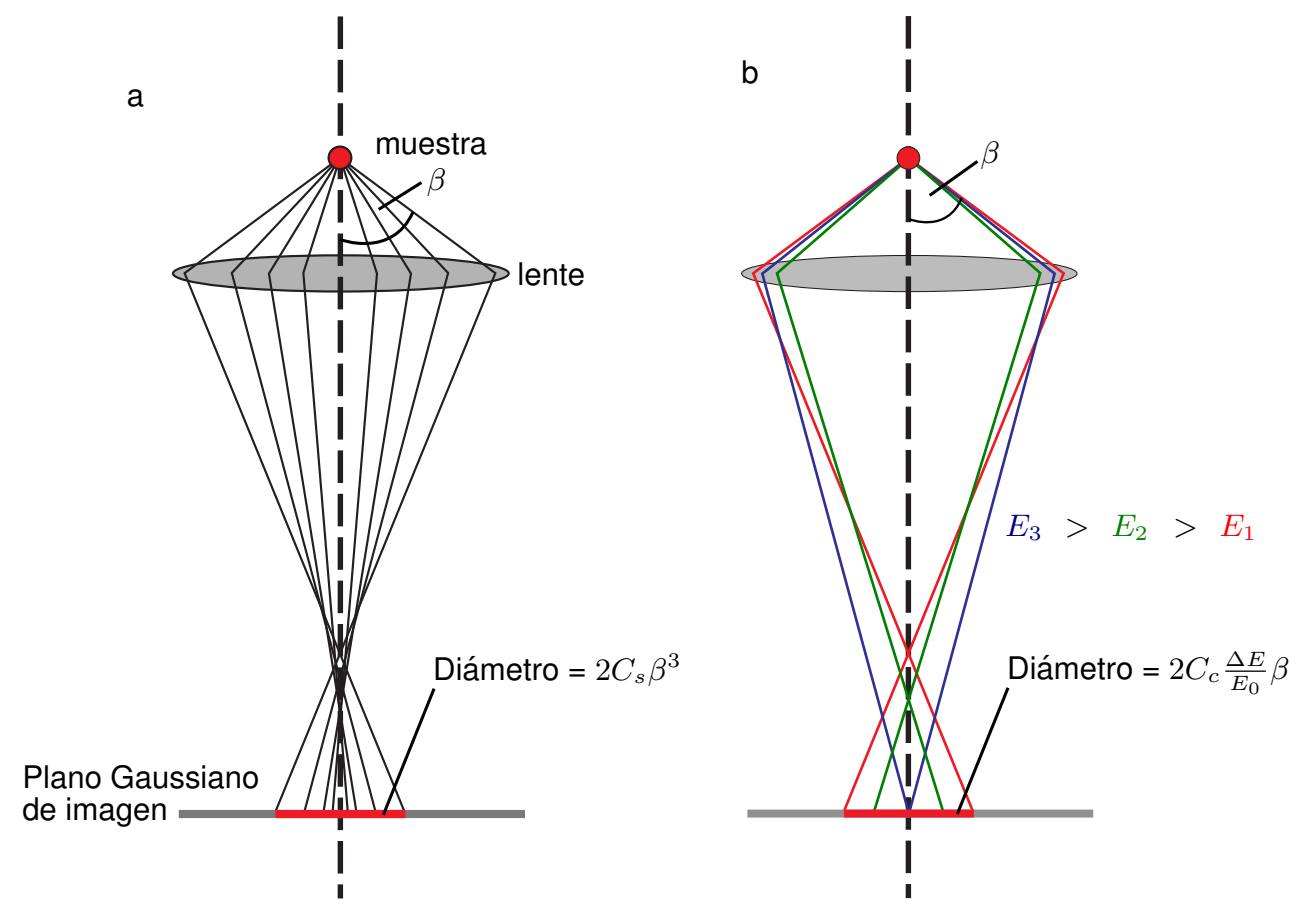

Figura 2.11: (a) Aberración esférica. (b) Aberración cromática.

distancia focal $f$ de las lentes más relevantes. La aberración esférica de una lente objetivo de distancia focal $f_{0}$ es del orden de $C_{3} \approx f_{0} / 4$. Por lo tanto, la disminución de la distancia focal, disminuye la aberración esférica. La segunda opción consiste en disminuir la longitud de onda del haz incidentes ya que esto produce que el impacto de la aberración esférica en la imagen sea menor debido a que se disminuyen los ángulos de dispersión $\theta$ para una dada frecuencia $q(\theta=q \lambda)$. Esto significa que es más sencillo obtener alta resolución a altos voltajes de aceleración [41].

Aunque los efectos perjudiciales de $C_{3}$ pueden ser reducidos con estas estrategias, ambas llevan consigo importantes limitaciones. Primeramente, el daño por radiación conocido como knock-on -que produce el desplazamiento de los átomos por trasferencia de energía y aumenta al incrementarse la energía del haz ${ }^{-11}$ puede ser crítico para ciertos materiales. Por otro lado, una lente objetivo de corta distancia focal implica que la separación entre las piezas polares sea muy pequeña.

La estrategia posible para combatir la aberración esférica, es la construcción de lentes multi-polares. Los correctores de aberración esférica están construidos con elementos de óptica electrónica no circulares que adicionan una aberración esférica negativa y entonces pueden contrarrestar la aberración esférica de la lente objetivo. Los correctores de aberración contienen dos lentes hexapolares y los electrones son deflectados asimétricamente en estas lentes.

La principal ventaja de la corrección de aberración esférica radica en trasladar la resolución puntual de un microscopio hasta el límite de información. ${ }^{12}$ Es decir, en un

\footnotetext{
${ }^{11}$ En la Sec. 6.5 discutiremos este tipo de daño.

${ }^{12}$ El límite de información representa la mayor frecuencia espacial que contribuye a la imagen. Mientras
} 
microscopio con corrección de aberración la resolución puntual prácticamente coincide con el límite de información. En un microscopio completamente libre de aberración, la función de transferencia de contraste de fase (Ec. 2.40) se vuelve igual a 0 y, por lo tanto, no existe contraste de fase. Entonces, es necesario modular las aberraciones de manera que la correspondiente función de transferencia de contraste provea de un contraste de imagen que refleje directamente las características principales de la muestra con la mayor resolución posible. De esta forma, se ajusta $C_{3}$ y el defoco $C_{1}$ para que se obtenga un pasabanda ancho que permita una simple visualización del objeto en un rango grande de frecuencias espaciales. De esta forma, se pueden obtener imágenes interpretables de forma directa para las frecuencias menores a la resolución puntual. La función de transferencia de contraste para un microscopio convencional en el defoco de Scherzer ${ }^{13}$ conduce a un pasabanda como el mostrado en la Fig. 2.10, que se extiende hasta $\sim 5 \mathrm{~nm}^{-1}$, que equivale a un contraste de fase positivo, es decir que las columnas atómicas se ven oscuras en un fondo claro. En el caso de un microscopio con las aberraciones corregidas (Fig. 2.10), la función de transferencia de contraste da lugar a un pasabanda muy amplio que produce un contraste de fase negativo con las columnas atómicas brillantes en un fondo oscuro en la imagen de HRTEM. En la representación de la función de transferencia de contraste de fase es notable la diferencia que existe en la resolución puntual de un microscopio con corrección de aberración comparado con un microscopio sin corrección. El uso de $C_{3}$ negativa en conjunto con $C_{5}$ positiva, para formar un pasabanda ancho en la función de transferencia de contraste se conoce como negative spherical aberration imaging (NCSI).

El primer paso en la utilización de un TEM con corrección de aberración luego de la alineación general del haz de electrones, es el diagnóstico de las aberraciones y la corrección de ellas. Esto se realiza con el programa de control del microscopio, que utiliza el método de Zemlin-tableau para medir las aberraciones y poder corregirlas. Este método consiste en medir el patrón de difracción (en realidad la transformada de Fourier de la imagen) de una muestra amorfa como puede ser el carbono que cubre las grillas TEM a diferentes ángulos de inclinación del haz [41].

En la Fig. 2.12 se presentan imágenes de HRTEM de una NP de Au-Ag tomadas con microscopios con diferentes características. Todas las imágenes fueron tomadas utilizando la misma muestra de NPs de Au-Ag. En todas ellas es posible observar contraste producido por las columnas atómicas; sin embargo, el nivel detalle que se obtiene de cada una es muy diferente. La imagen tomada con un microscopio con fuente de $\mathrm{LaB}_{6}$ (Fig. 2.12a) presenta un nivel detalle acotado ya que la resolución puntual de este microscopio es cercana a $0,2 \mathrm{~nm}$ y las funciones de modulación envolventes debido a las limitaciones de coherencia espacial y temporal del haz de electrones hacen que el límite de información de este microscopio sea cercano a la resolución puntual, como comentamos anteriormente. La imagen tomada con un microscopio FEG (Fig. 2.12b) presenta contribución de mayores

que en un microscopio con una fuente de $\mathrm{LaB}_{6}$ el límite de información prácticamente coincide con la resolución puntual, en un microscopio FEG existe una brecha entre estas dos cantidades y frecuencias mayores a la resolución puntual contribuyen a la imagen.

${ }^{13} \mathrm{El}$ defoco de Scherzer es el valor de $C_{1}$ para el cual se optimiza la función de transferencia del microscopio, está dado por: $C_{1}^{\text {Scherzer }}=-\left(\frac{4}{3} \lambda C_{3}\right)^{1 / 2}$. [41] 
a
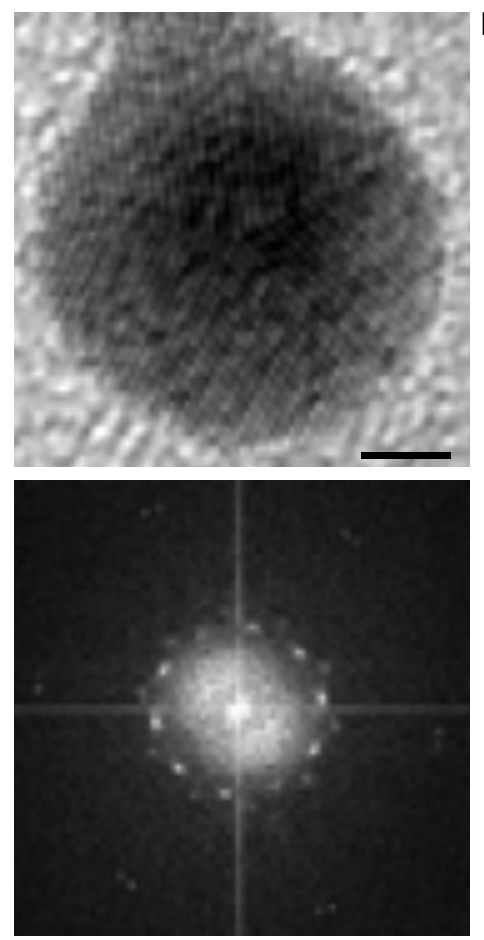
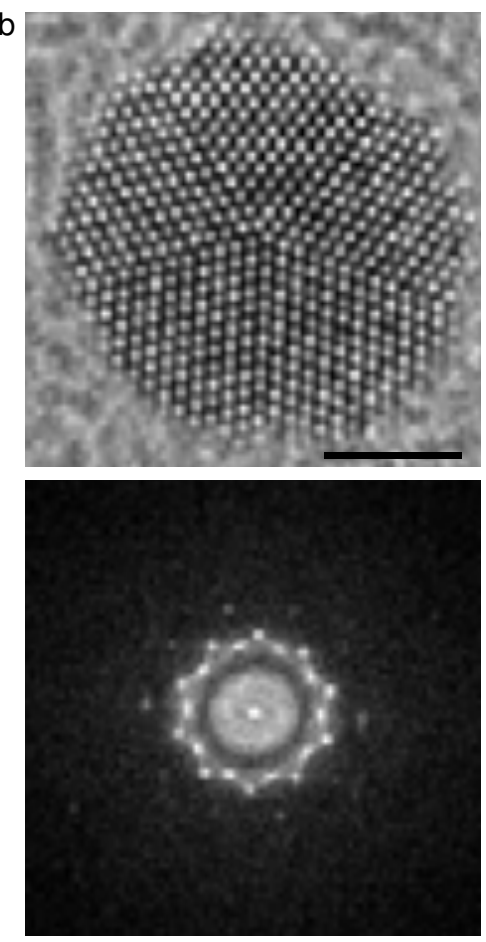
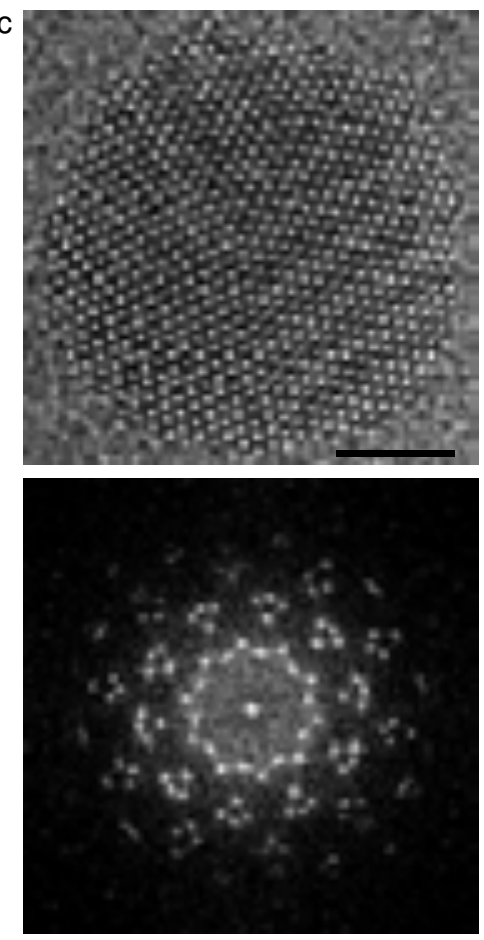

Figura 2.12: Comparación de imágenes de HRTEM y sus transformadas de Fourier de NPs individuales de Au-Ag decaédricas en el eje de zona [110], tomadas con diferentes tipos de microscopios. (a) Microscopio Phillips CM 200 UT (CAB-CNEA) con fuente de $\mathrm{LaB}_{6}$ a $200 \mathrm{kV}\left(C_{3} \approx+0,5 \mathrm{~mm}\right)$. (b) Microscopio OÅM (NCEM) con cañón de emisión de campo (FEG) a $300 \mathrm{kV}\left(C_{3} \approx+0,6 \mathrm{~mm}\right)$ (c) Microscopio TEAM 0.5 (NCEM) con cañón FEG de alto brillo, monocromador y corrector de aberración esférica a $300 \mathrm{kV}\left(C_{1} \approx+5 \mathrm{~nm}\right.$, $\left.C_{3} \approx-20 \mu \mathrm{m}, C_{5} \approx+6 \mathrm{~mm}\right)$. Escalas: $2 \mathrm{~nm}$.

frecuencias debido a la alta coherencia del haz. La interpretación de esta imagen no es inmediata debido, justamente, a la gran influencia de las altas frecuencias moduladas por la transferencia de contraste oscilatoria en la región de $q$ mayores a la resolución puntual. Estas oscilaciones producen el fenómeno de deslocalización en las imágenes que provoca - especialmente en las interfases como los bordes de las NPs- que los detalles observados en la imagen estén corridos de su posición original. La tercera imagen (Fig. 2.12c) corresponde a la misma muestra tomada con un microscopio con corrección de aberración esférica. El hecho de trasladar la resolución puntual hasta valores de frecuencias muy altos, haciendo que esta sea muy cercana al límite de información del microscopio, permite obtener imágenes con gran cantidad de información. Esto es evidente también en la transformada de Fourier de la imagen donde se observa la contribución de las altas frecuencias. Por otro lado, al controlar las condiciones de imagen como se explicó antes, es posible la interpretación directa de las imágenes hasta altas frecuencias ya que la función de transferencia de contraste está formada por un pasabanda muy ancho que abarca una región de frecuencias muy amplia.

En este trabajo hemos utilizado diferentes microscopios electrónicos para estudiar 
muestras de NPs metálicas. Los microscopios utilizados se enumeran a continuación:

- Phillips CM 200 UT. Este microscopio, ubicado en el Laboratorio de Materiales del Centro Atómico Bariloche es un microscopio con un cañón de electrones de $\mathrm{LaB}_{6} \mathrm{y}$ una lente objetivo UltraTwin, que permite la obtención imágenes de alta resolución. La aberración esférica es $C_{3}=0,5 \mathrm{~mm}$. Se utilizó con un voltaje de aceleración de $200 \mathrm{kV}$.

- OÅM (One-Angstrom Microscope $)^{14}$. Éste es un microscopio Phillips CM 300 UT-Fe modificado, con un cañón de electrones FEG y una lente objetivo UltraTwin. Además posee fuentes de poder especiales, de alta estabilidad y se encuentra ubicado sobre una plataforma construida especialmente para evitar que las vibraciones influyan en la medida. Se opera a $300 \mathrm{kV}$ y $C_{3}=0,6 \mathrm{~mm}$. Este fue el primer microscopio en que el límite de información superó la barrera de $1 \AA$ [43]. Se encuentra ubicado en NCEM, Berkeley.

- TEAM 0.5 (Transmission Electron Aberration-Corrected Microscope) ${ }^{15}$. Este microscopio, ubicado en NCEM, es un microscopio FEI Titan modificado, con un cañon FEG de alto brillo, un monocromador, una lente UltraTwin y dos correctores de aberración esférica CEOS: uno para el haz de electrones y otro para modo imagen. Las imágenes de TEM son tomadas con una cámara CCD de $2048 \times 2048$ píxeles. Este microscopio permite ser operado entre 80 y $300 \mathrm{kV}$. El microscopio se encuentra en una habitación especial equipada con un sistema de control de temperatura y humedad sin convección como así también de vibraciones y es manejado desde otra habitación. Un esquema de este microscopio se presenta en la Fig. 2.13.

Las imágenes de HRTEM presentadas en este informe son imágenes sin ningún tratamiento posterior a su adquisición, excepto en los casos en los que se indica la aplicación del algún tipo de filtro.

\subsection{Microscopía electrónica de barrido por transmisión (STEM)}

El microscopio electrónico de barrido por transmisión (scanning transmission electron microscope, STEM) es muy similar a un TEM. De hecho, actualmente, prácticamente todos TEMs permiten ser operados en modo TEM o STEM. La primera diferencia es que en un STEM el haz de electrones que incide sobre la muestra es un haz convergente en lugar de paralelo. Esto se logra a través de las lentes condensadoras del sistema de iluminación. El tamaño del haz convergente en el plano de la muestra, denominado spot size puede ser del orden de 0,1 nm. En modo STEM se realiza un barrido del haz por la muestra y los electrones pueden ser detectados en la parte inferior de la misma mediante diferentes detectores, como se muestra en la Fig 2.14a. En este trabajo hemos realizado las medidas utilizando el detector anular de campo oscuro de alto ángulo (high-angle annular dark field, HAADF). Este detector se ubica típicamente a ángulos del orden de 50 mrad.

\footnotetext{
${ }^{14}$ http://ncem.lbl.gov/frames/oam.htm

${ }^{15}$ http://ncem.lbl.gov/frames/TEAMO.5.htm
} 

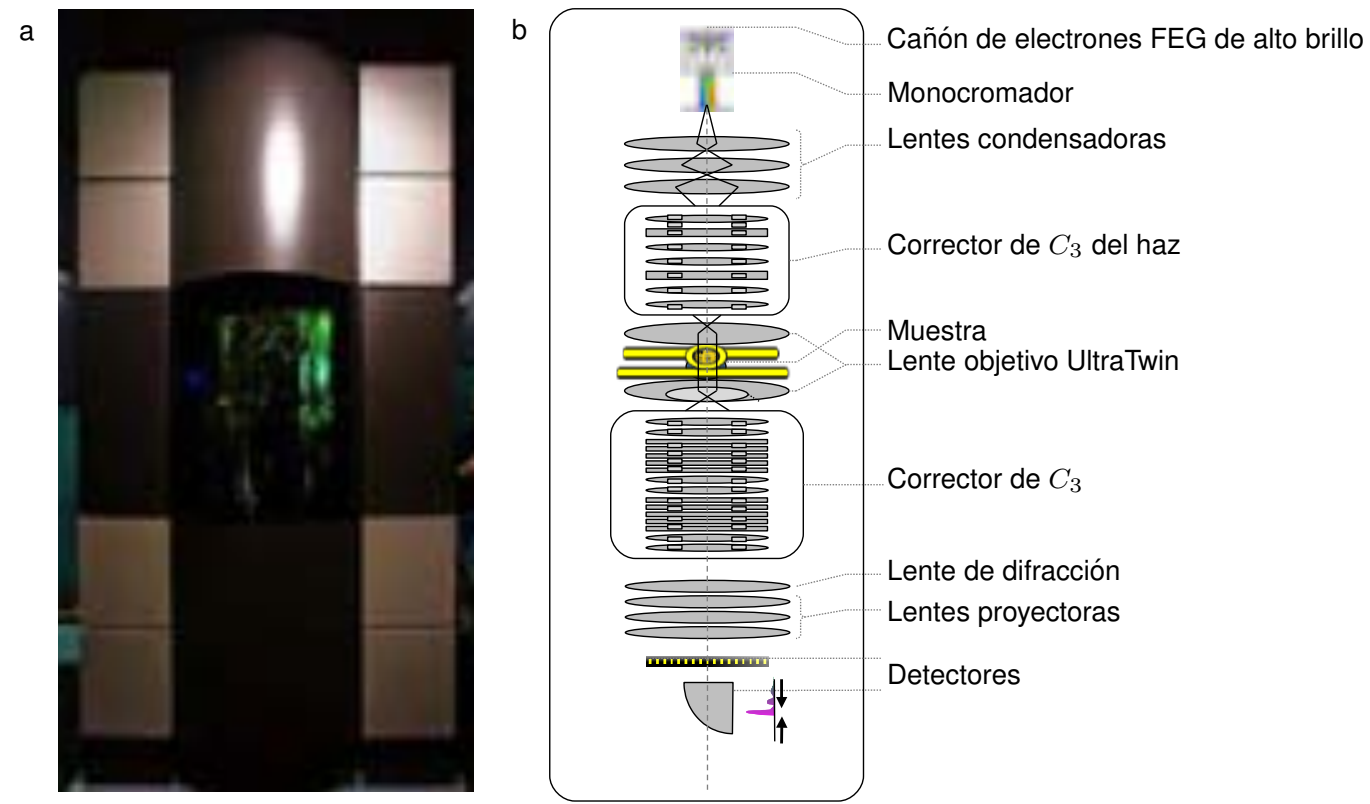

Figura 2.13: TEM con corrección de aberración esférica $\left(C_{3}\right)$ TEAM 0.5, NCEM, Berkeley. (a) Fotografía del microscopio, tomada del sitio web de NCEM. (b) Diagrama del microscopio, construido en base al cedido por M. Linck.

Al utilizar esta configuración, se detectan los electrones que han sido dispersados por la muestra a altos ángulos, lo que se denomina dispersión de Rutherford (Fig. 2.14b), debido a que la interacción núcleo-electrón es análoga a la retrodispersión de partículas $\alpha$ por una lámina delgada de un metal [40]. La sección eficaz diferencial para la dispersión de Rutherford sigue la siguiente relación [44]:

$$
d \sigma_{\mathrm{R}}=\frac{1-v^{2} / c^{2}}{v^{4} / c^{4}} \frac{Z^{2} r_{0}^{2}}{4} \frac{2 \pi \operatorname{sen} \theta}{\operatorname{sen}^{4}(\theta / 2)} d \theta
$$

donde $v$ es la velocidad de los electrones incidentes, $Z$ es el número atómico, $r_{0}=$ $\left(4 \pi \epsilon_{0}\right)^{-1}\left(e^{2} / m_{0} c^{2}\right)=2,8179 \times 10^{-15} \mathrm{~m}$ es el radio clásico del electrón y $\theta$ es el ángulo de la dispersión. Lo interesante de esta ecuación es la dependencia de la sección eficaz con el cuadrado del número atómico $Z$. Esto significa que la intensidad registrada en el detector HAADF será proporcional a $Z^{2}$. Por este motivo, este método de imagen en STEM es también llamado método de contraste en Z (Z-contrast) [40]. Esta configuración permite diferenciar elementos en una muestra.

En este trabajo utilizamos el microscopio JEOL JEM-ARM200F con corrección de aberración esférica de la fuente, ubicado en la University of Texas at San Antonio, Texas. Este microscopio cuenta con un cañón de electrones FEG y un corrector de aberración esférica CEOS. El spot size utilizado fue de 0,095 $\mathrm{nm}$. La alineación del microscopio fue verificada con el programa CESCOR asociado al microscopio. Las imágenes de HAADFSTEM fueron adquiridas utilizando una longitud de cámara de $120 \mathrm{~mm}$ y un ángulo de colección de 33-125 mrad. La muestra de las NPs fue depositada sobre una grilla de carbono desde una suspensión. 

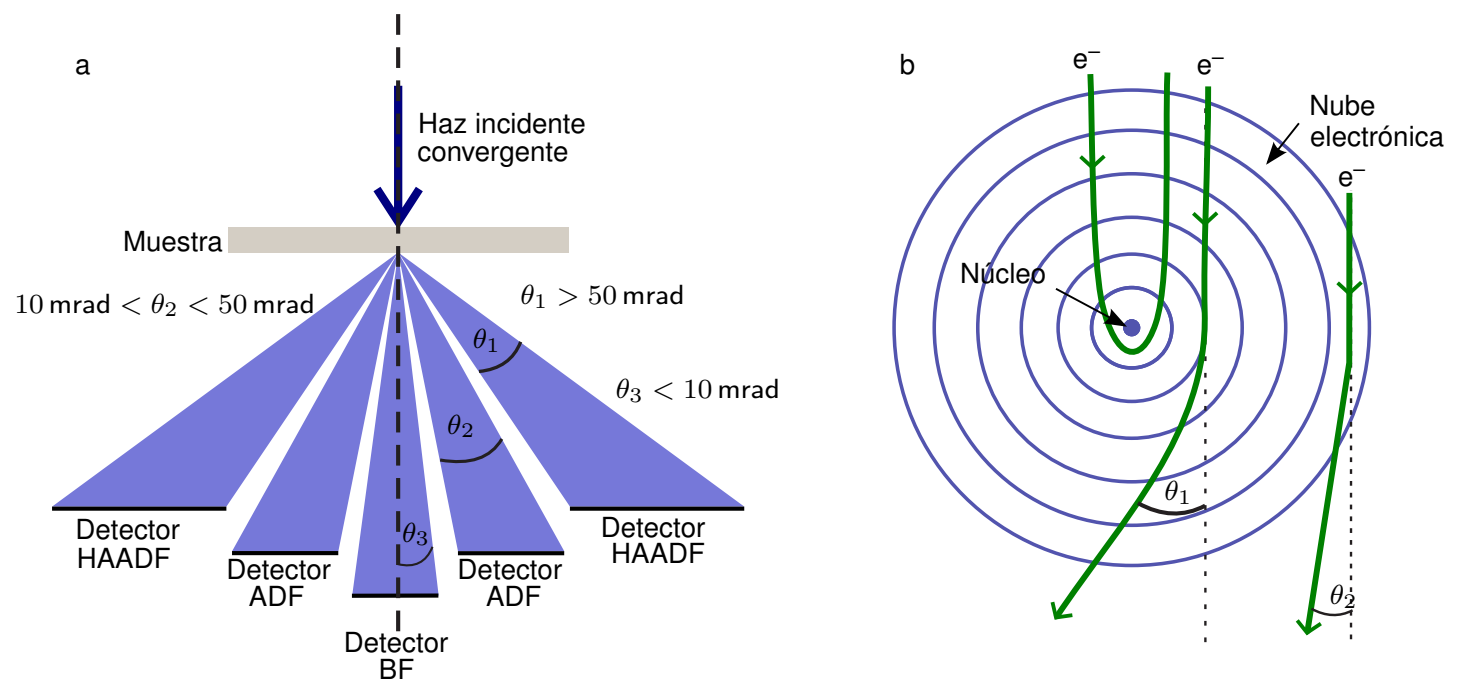

Figura 2.14: (a) Detectores utilizados en modo STEM. (b) Dispersión de electrones por un átomo aislado mediante dos mecanismos: interacción coulómbica con la nube electrónica o con el núcleo. Adaptado de ref. [40].

\subsection{Distribución de tamaños de las nanopartículas}

Las distribuciones de tamaños de las NPs fueron realizadas mediante el análisis de las imágenes de TEM o HAADF-STEM con los algoritmos disponibles en los programas de análisis de imágenes, como Digital Micrograph o ImageJ. Se ajustó el umbral de intensidad en cada imagen para que el algoritmo detecte las partículas y luego se consideraron sólo las partículas con diámetros entre 0 y $10 \mathrm{~nm}$ y una razón menor a 1,2 entre el diámetro mayor y el menor, para evitar contar 2 partículas juntas. Al histograma obtenido se ajustó una función de distribución log-normal, de acuerdo a la ref. [45]. La ecuación utilizada fue la siguiente:

$$
f(d)=\frac{1}{(2 \pi)^{1 / 2} \sigma d} \exp \left\{-\frac{[\ln (d)-\mu]^{2}}{2 \sigma^{2}}\right\}
$$

donde $\mu$ y $\sigma$ son la media y la desviación estándar del logaritmo del diámetro $d$, respectivamente. La media aritmética del diámetro, $\langle D\rangle$, y su desviación estándar, s.d., fueron calculadas como

$$
\langle D\rangle=e^{\mu+1 / 2 \sigma^{2}} \quad \text { s.d. }=\left(e^{\sigma^{2}}-1\right)^{1 / 2} e^{\mu+1 / 2 \sigma^{2}}
$$

\subsection{Teoría del funcional de densidad (DFT)}

La teoría de los funcionales de la densidad electrónica o teoría del funcional de densidad (density functional theory, DFT) es una aproximación al cálculo de la estructura electrónica de átomos y moléculas que ha tenido gran aplicación en el estudio de la fisicoquímica de superficies. Sus fundamentos indican que es posible calcular la energía total y todas las propiedades moleculares de un sistema mediante el conocimiento de la densidad electrónica 
del estado fundamental, $\rho(\mathbf{r})$. El funcional ${ }^{16}$ de energía en DFT está dado por

$$
E[\rho(\mathbf{r})]=\int v(\mathbf{r}) \rho(\mathbf{r}) d r+F[\rho(\mathbf{r})]
$$

donde el primer término se debe a la interacción de los electrones con un campo externo, como por ejemplo el que dan los carozos nucleares y el segundo es la suma de la energía cinética de los electrones y las interacciones electrónicas. El teorema de Hohenberg-Kohn indica que es posible calcular todas las propiedades moleculares del estado fundamental a partir de $\rho(\mathbf{r})$. La dificultad radica en que no conocemos la forma del funcional $F[\rho(\mathbf{r})]$. En este aspecto, Kohn y Sham sugirieron que $F[\rho(\mathbf{r})]$ puede ser aproximado mediante la suma de 3 términos:

$$
F[\rho(\mathbf{r})]=E_{K}[\rho(\mathbf{r})]+E_{H}[\rho(\mathbf{r})]+E_{x c}[\rho(\mathbf{r})]
$$

donde $E_{K}[\rho(\mathbf{r})]$ es el funcional de energía cinética del sistema de electrones no interactuantes, $E_{H}[\rho(\mathbf{r})]$ es el funcional de energía de interacción electrónica y $E_{x c}[\rho(\mathbf{r})]$ es el funcional de correlación e intercambio. Combinando las expresiones para cada uno de estos funcionales y la interacción electrón-núcleo obtenemos, para un sistema de $n$ electrones, la expresión para el funcional de la energía total:

$$
\begin{aligned}
E[\rho(\mathbf{r})]=-\sum_{I} Z_{I} \int \frac{\rho\left(\mathbf{r}_{1}\right)}{\left|\mathbf{r}_{1}-\mathbf{R}_{I}\right|} d \mathbf{r}_{1}- & \frac{1}{2} \sum_{i=1}^{n}\left\langle\psi_{i}\left|\nabla^{2}\right| \psi_{i}\right\rangle \\
& +\frac{1}{2} \iint \frac{\rho\left(\mathbf{r}_{1}\right) \rho\left(\mathbf{r}_{2}\right)}{\left|\mathbf{r}_{1}-\mathbf{r}_{2}\right|} d \mathbf{r}_{1} d \mathbf{r}_{2}+E_{x c}[\rho(\mathbf{r})]
\end{aligned}
$$

Entonces, podemos calcular $E[\rho(\mathbf{r})]$ si conocemos $\rho(\mathbf{r})$ y los orbitales de Kohn-Sham $\left(\psi_{i}\right)$. Esto puede realizarse gracias al teorema variacional de Hohenberg-Kohn que indica que es posible obtener la energía del estado fundamental variando $\rho(\mathbf{r})$ de manera de minimizar el funcional $E[\rho(\mathbf{r})]$. Puede demostrarse que los orbitales de Kohn-Sham que minimizan la Ec. 2.46 satisfacen la siguiente expresión

$$
\left[-\frac{1}{2} \nabla^{2}-\sum_{I} \frac{Z_{i}}{\left|\mathbf{r}_{1}-\mathbf{R}_{I}\right|}+\int \frac{\rho\left(\mathbf{r}_{2}\right)}{\left|\mathbf{r}_{1}-\mathbf{r}_{2}\right|} d \mathbf{r}_{2}+v_{e x}\right] \psi_{i}=\epsilon_{i} \psi_{i}
$$

donde $\epsilon_{i}$ son las energías de los orbitales y $v_{e x}$ es el potencial de correlación e intercambio que se define como:

$$
v_{e x}=\frac{\delta E_{e x}[\rho(\mathbf{r})]}{\delta \rho(\mathbf{r})}
$$

Para resolver las ecuaciones de Kohn-Sham se utiliza un método de autoconsistencia. Se genera un primer valor de $\rho(\mathbf{r})$, se construyen los potenciales y se deriva el conjunto de orbitales a partir de la Ec. 2.47, generando finalmente un valor mejorado de la densidad. Este proceso iterativo se continúa hasta alcanzar un punto con una densidad de entrada igual a la de salida, bajo cierto criterio de tolerancia. La energía total se calcula luego con la Ec. 2.46.

\footnotetext{
${ }^{16}$ Un funcional es una regla que asocia un número a una función.
} 
Un tratamiento detallado del desarrollo de estas ecuaciones puede encontrarse en la ref. [46] o en la [47], donde también se se trata la aplicación de este método a sistemas periódicos.

En este trabajo hemos utilizado DFT para optimizar diferentes geometrías propuestas para la interfase $\mathrm{Pd}(111)$-tiol y calcular diferentes propiedades, que se detallan en la Sec. 5.9. Los resultados para los sistemas estudiados fueron utilizadas luego en el análisis de termodinámica estadística desde primeros principios (Sec. 5.9.2 y Apéndice A).

\subsubsection{Implementación computacional}

Los cálculos referidos a la adsorción de sulfuro y tioles sobre Pd fueron realizados mediante el código VASP (versión 4.6) [48, 49] y las superficies fueron modeladas como superceldas periódicas en dos dimensiones con 5 capas atómicas del metal (slabs). Se permitió la relajación de las 3 capas atómicas más externas y de las coordenadas atómicas de las moléculas de metanotiol (MT). Las celdas se separaron por un espacio vacío de $\sim 0,1 \mathrm{~nm}$. La energía total y la geometría optimizada para todas las estructuras fueron obtenidas utilizando la implementación de Perdew-Wang (PW91) de la aproximación del gradiente generalizado (generalized gradient approximation, GGA) para el potencial de correlación e intercambio [50]. Las funciones de onda de un electrón fueron expandidas en un conjunto de base con un corte (cutoff) de $420 \mathrm{eV}$ para la energía cinética. El muestreo de la zona de Brillouin fue realizado de acuerdo al esquema de Monkhorst-Pack [51] con una grilla de puntos $k$ de $5 \times 5 \times 1$ para la celda unidad de $(\sqrt{7} \times \sqrt{7}) \mathrm{R} 19,1^{\circ}$ y de $9 \times 9 \times 1$ para la celda unidad de $(\sqrt{3} \times \sqrt{3}) \mathrm{R} 30^{\circ}$. Se empleó el método de ondas planas (projector augmented-wave, PAW) [52] para describir el efecto de los electrones internos de los átomos sobre los electrones de valencia. La tolerancia utilizada para definir la autoconsistencia fue $1 \times 10^{-5} \mathrm{eV}$ para la energía total de los cálculos de single-point y $1 \times 10^{-4} \mathrm{eV}$ para los de optimización geométrica.

Se realizó un test de convergencia referido a la energía de corte tanto para las ondas planas como para la grilla de puntos $k$, siendo la diferencia en la energía electrónica $0,1 \mathrm{eV}$. Por lo tanto, el error en la energía libre superficial es $\sim 3 \mathrm{meV} / \AA^{2}$. La minimización de energía (relajación de la densidad electrónica) para una configuración nuclear dada fue realizada utilizando un esquema de iteración de Davinson-Bloch. Para minimizar efectos de polarización causados por la asimetría de las celdas se aplicó la corrección de dipolo. El parámetro de red calculado para Pd masivo fue $0,396 \mathrm{~nm}$, que difiere en $\sim 2 \%$ del valor experimental. 


\section{Parte II}

\section{Interfase Au-tiol}





\section{Capítulo 3}

\section{Nanopartículas de Au protegidas por tioles}

\subsection{Introducción}

Las NPs metálicas cubiertas por tioles son uno de los tipos de NPs mas amplia y detalladamente estudiados y discutidos en la literatura. Entre los metales estudiados, el Au es el más utilizado ya que se lo considera como modelo para comprender la estructura y composición general de los sistemas tiol-metal. Este hecho se debe a la naturaleza inerte del Au que facilita tanto la obtención de superficies limpias bien definidas, como la comprensión del enlace $\mathrm{S}-$ metal. Sin embargo, esto no significa que todo lo que se estudie en el sistema $\mathrm{Au}$-tiol pueda ser extrapolado a otros metales como Ag, Pd, Pt, Cu o Ni. De hecho, se ha encontrado que el comportamiento de los tioles sobre estos metales puede ser muy diferente, lo que dificulta aún más la comprensión de estos sistemas en un marco general. Incluso, importantes aspectos del sistema modelo son motivo de discusión en el presente y, durante los años en que se desarrolló este trabajo, ha existido una importante cantidad de publicaciones que han propuesto nuevas interpretaciones para estos sistemas $[16,53-55]$.

En este capítulo discutiremos las características generales de la interfase $\mathrm{Au}$-tiol en diferentes sistemas para luego centrarnos en el estudio de las AuNPs protegidas por tioles. Discutiremos los diferentes métodos de síntesis de estas NPs como así también los resultados referidos a su composición química, estudiada mediante XPS, y su tamaño y estructura, estudiados mediante microscopía electrónica.

Es posible clasificar los sistemas $\mathrm{Au-tiol} \mathrm{en} \mathrm{base} \mathrm{al} \mathrm{número} \mathrm{de} \mathrm{átomos} \mathrm{que} \mathrm{los} \mathrm{compo-}$ nen y al estado químico de los mismos, como se muestra en la Fig. 3.1. En este esquema se observa que para un número de átomos muy grande, que corresponde a una superficie de Au plana, nos encontramos en el régimen correspondiente a SAMs de tiolatos sobre Au. Si reducimos el número de átomos entre aproximadamente 150 y unos miles de átomos (1 a $10 \mathrm{~nm}$ ) estamos en presencia de las AuNPs cubiertas por tiolatos. Recientemente ha tenido mucha importancia el estudio de partículas compuestas por un número de átomos entre 13 y 150 aproximadamente $(\leq 2 \mathrm{~nm})$, que reciben el nombre especial de clusters. 


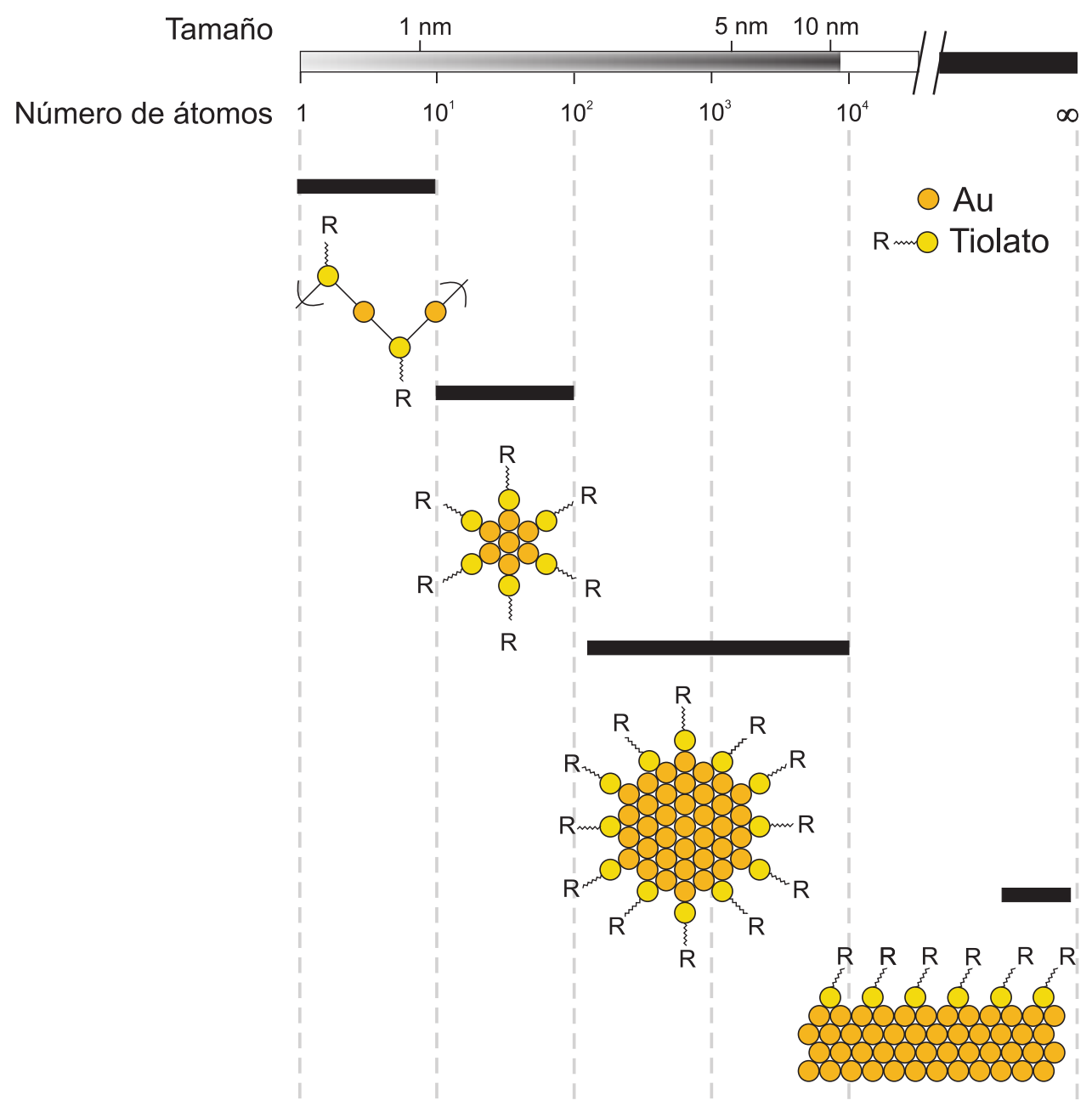

Figura 3.1: Esquema de los diferentes sistemas compuestos por la interfase $\mathrm{Au}-\mathrm{S}$, clasificados por la cantidad de átomos que los forman. Adaptado de ref. [56].

Por último, con todos los átomos de $\mathrm{Au}$ en estado de oxidación +1 , se encuentran los tiolatos de $\mathrm{Au}\left(\mathrm{Au}^{\mathrm{I}}-\mathrm{SR}\right)$. Si bien el estado de oxidación de los átomos de Au en los demás sistemas requiere un análisis más detallado, desde los clusters hasta las SAMs de tiolatos sobre superficies planas existen -al menos algunos- átomos de $\mathrm{Au}$ metálico $\left(\mathrm{Au}^{0}\right)$.

\subsection{Monocapas autoensambladas de tioles sobre $\mathrm{Au}(111)$}

En esta sección describiremos brevemente los aspectos salientes de las SAMs de tioles sobre $\mathrm{Au}(111)$. El lector interesado puede dirigirse a las refs. [17, 57] donde este sistema se describe detalladamente.

Las SAMs de tioles sobre Au pueden ser preparadas fácilmente en el laboratorio mediante inmersión de un sustrato en una solución etanólica que contiene el tiol de interés. Las moléculas de tiol se adsorben sobre la superficie del metal y, gracias a las interacciones intermoleculares, forman estructuras altamente organizadas en la superficie del Au. Pos- 
a

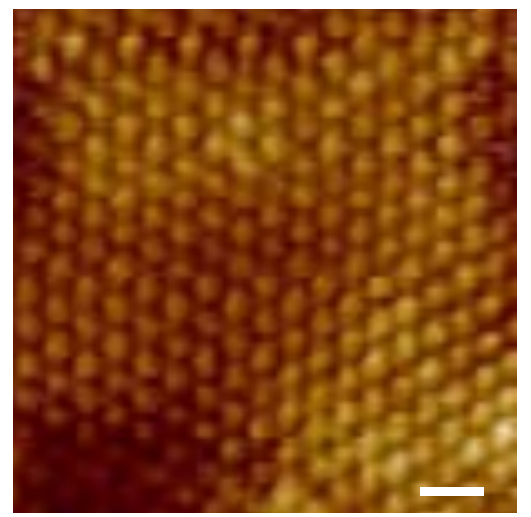

b

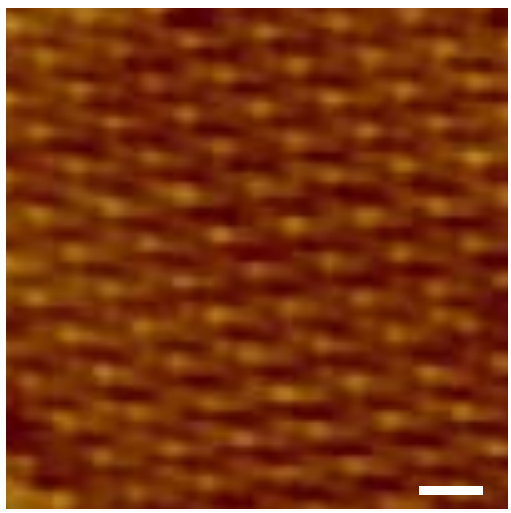

Figura 3.2: Imágenes de microscopía de barrido de efecto túnel (STM) de una SAM de alcanotiolatos sobre $\mathrm{Au}(111)$. (a) Red $(\sqrt{3} \times \sqrt{3}) \mathrm{R} 30^{\circ}$ de decanotiolato, cedida por $\mathrm{C}$. Vericat. (b) Red c $(4 \times 2)$ de hexanotiolato, cedida por G. Andreasen. Escalas: $1 \mathrm{~nm}$.

teriormente, se lava la superficie con etanol reiteradas veces para eliminar las moléculas de tiol libre. También es posible crear estas estructuras en una cámara de ultra alto vacío mediante evaporación de un tiol en fase gaseosa. Mientras que la primera ruta tiene la ventaja de poder ser implementada en cualquier laboratorio, la segunda permite el control preciso del estado de la superficie metálica antes de agregar el tiol y la ulterior caracterización mediante técnicas de análisis superficial sin necesidad de exponer la muestra a condiciones atmosféricas. La reacción formal de adsorción puede escribirse de la siguiente manera:

$$
\begin{gathered}
\mathrm{RSH}+\mathrm{Au} \longrightarrow \mathrm{RSH}-\mathrm{Au} \\
\mathrm{RSH}-\mathrm{Au} \longrightarrow \mathrm{RS}-\mathrm{Au}+\frac{1}{2} \mathrm{H}_{2}
\end{gathered}
$$

En la primera etapa, las moléculas de tioles (RSH) se fisisorben sobre la superficie de Au y luego pierden el átomo de $\mathrm{H}$ del grupo tiol, generando el radical tiil (RS') para formar una unión tiolato $(\mathrm{S}-\mathrm{Au})$. Este es considerado un enlace covalente por su alta energía de unión $\left(\sim 200 \mathrm{~kJ} \mathrm{~mol}^{-1}\right)$ [58].

Estas moléculas se ordenan en redes del tipo $(\sqrt{3} \times \sqrt{3})$ R30 $($ Fig. 3.2a) y c $(4 \times 2)($ Fig. $3.2 \mathrm{~b}$ ) que pueden coexistir en la superficie, con un cubrimiento $\theta=0,33$ en ambos casos. Cuando se trata de tioles cortos, este cubrimiento es, en general, menor. La presencia de la unión tiolato es evidente en el espectro de XPS de S $2 p$ de estos sistemas [59], como el mostrado en la Fig. 3.3a. La señal de S $2 p$ aparece en $\sim 162 \mathrm{eV}$, una energía de enlace menor que la correspondiente a $\mathrm{S}$ elemental $(164 \mathrm{eV})$, hecho que marca un incremento de densidad de carga negativa sobre el átomo de S. Correspondientemente, se esperaría que la señal de $\mathrm{Au} 4 f$ presente un comportamiento inverso: mayores energías enlace por exceso de carga positiva en los átomos superficiales. Sin embargo, en las técnicas de XPS convencional, la profundidad del sustrato analizada produce que la contribución a la señal por parte de los átomos de $\mathrm{Au}$ en el seno del metal sea muy grande y no se observen cambios en la señal de $\mathrm{Au} 4 f$. Diversos trabajos han abordado este estudio, incrementando la sensibilidad superficial de XPS mediante diferentes métodos. Sin embargo, han aparecido 

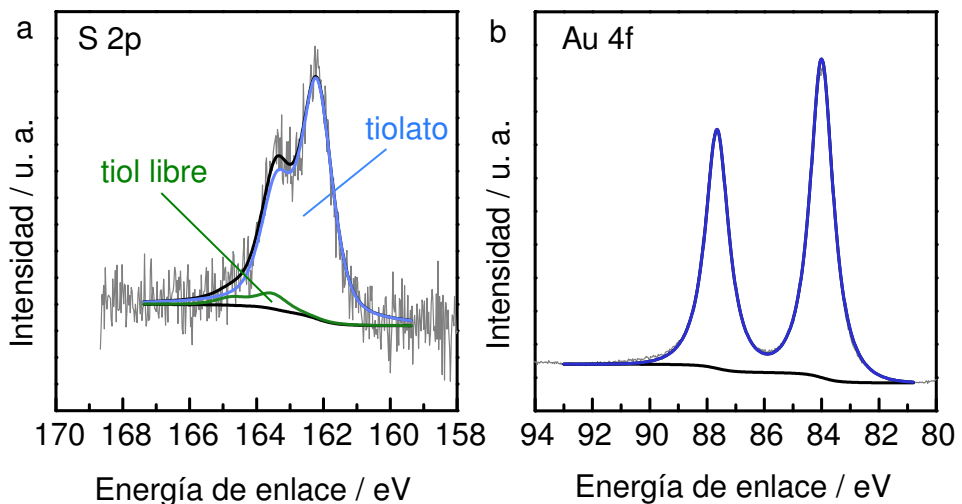

Figura 3.3: Espectros XPS de una SAM de dodecanotiolato sobre $\mathrm{Au}(111)$. (a) Espectro de S $2 p$. (a) Espectro de Au $4 f$.

controversias relacionadas con la interpretación de estos resultados, tema que discutiremos más adelante en este capítulo. La Fig. 3.3b muestra un espectro de $\mathrm{Au} 4 f$ de una SAM de dodecanotiolato sobre $\mathrm{Au}(111)$. La posición del pico es 84,0 eV y el ancho del mismo, 1,0 eV. En la señal de $\mathrm{S} 2 p$ también puede aparecer una componente en $\sim 163 \mathrm{eV}$, correspondiente a moléculas de tiol libre, como se observa en la Fig. 3.3a. Esta señal desaparece si se continúa el lavado de la superficie y es más difícil de eliminar cuanto más larga sea la cadena hidrocarbonada del tiol debido al aumento de las fuerzas intermoleculares.

Durante mucho tiempo se describió la interfase tiol-Au(111) como una superficie de $\mathrm{Au}(111)$ sobre la que se adsorben las moléculas de tiol en huecos tetraédricos, posiciones puente o sitios intermedios sin causar cambios en la superficie metálica. Sin embargo, actualmente se conoce que la adsorción de tioles sobre Au produce una fuerte reconstrucción superficial del metal. Se han propuesto diferentes modelos para describir esta interfase, algunos de los cuales se basan en resultados obtenidos con clusters de $\mathrm{Au}$, descritos más adelante. Varios de estos modelos proponen la presencia de especies del tipo RS-Au-SR, donde las moléculas de tiolato se encuentran unidas a adátomos de Au que se generan en el proceso de formación de la SAM [60, 61].

\subsection{Nanopartículas y clusters de Au protegidos por tioles}

En el año 1994, M. Brust et ál. publicaron un método para la síntesis de AuNPs cubiertas por alcanotioles, conocido actualmente como método de Brust-Schiffrin de dos fases [14]. Luego, en el año 1995, fue publicada una variante de este método para la preparación de AuNPs hidrofílicas, que se lleva a cabo en una sola fase de un solvente polar (en general metanol/agua) [15]. Este método de síntesis es conocido como método de Brust-Schiffrin de una fase. Desde la publicación de estos métodos, los cuales discutiremos en detalle más adelante, han aparecido un sinnúmero de trabajos en los que se utilizaron estas rutas para la preparación de AuNPs y se han extendido también a otros metales como Ag [62, 63], $\mathrm{Cu}$ [64], Pd [65] y $\mathrm{Pt}$ [66].

Mediante el control de las condiciones de síntesis y la separación de las partículas 


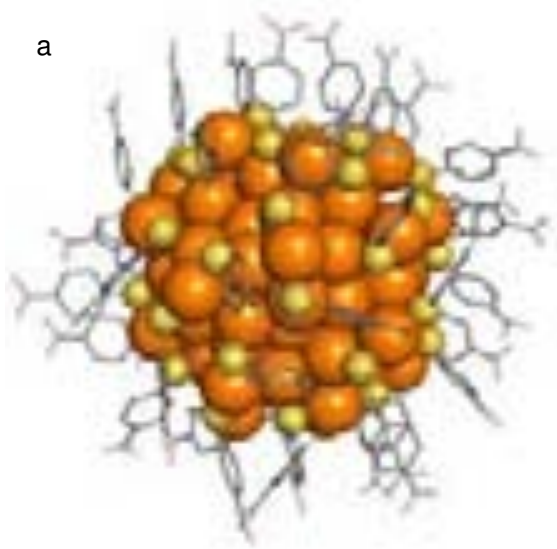

b

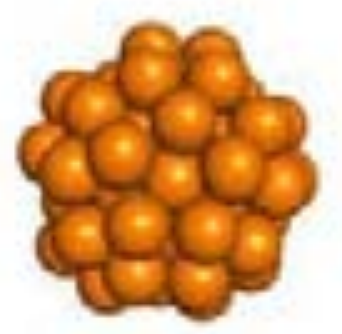

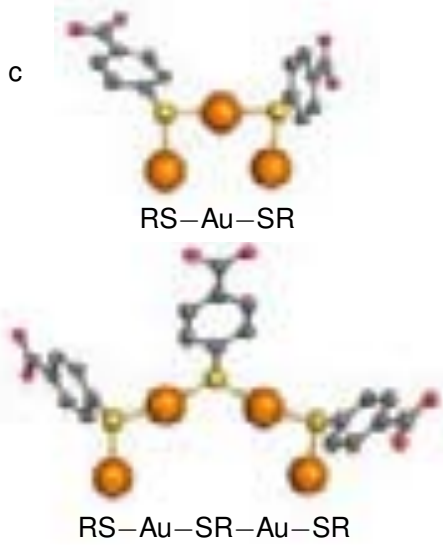

Figura 3.4: Cluster de $\mathrm{Au}_{102}(p-\mathrm{MBA})_{44}$. (a) Cluster completo. (b) Núcleo de $\mathrm{Au}_{79}$. (c) Diferentes tipos de ligandos; en cada caso se incluyen también 2 átomos del núcleo metálico aunque estos no participan del ligando como tal. Esferas anaranjadas: átomos de $\mathrm{Au}$, esferas amarillas: átomos de $\mathrm{S}$, cilindros grises: grupos $\mathrm{CH}_{2}$, cilindros y esferas rojos: átomos de O. Construido a partir de coordenadas cedidas por O. López-Acevedo.

sintetizadas en base a su tamaño, los métodos de Brust-Schiffrin han sido utilizados para la preparación de clusters de Au. El grupo de T. Tsukuda ha sido pionero en este campo, sobre todo en la aplicación de espectrometría de masas para el estudio de la composición de los clusters [67].

Un gran avance en el estudio de estos sistemas fue dado en el año 2007, cuando el grupo de R. Kornberg publicó la estructura de un cristal formado por clusters de Au cubiertos por ácido $p$-mercaptobenzoico, obtenida mediante difracción de rayos $\mathrm{X}$ ( $X$-ray diffraction, XRD) [53]. La fórmula de este cluster es $\mathrm{Au}_{102}(p-\mathrm{MBA})_{44}$ (Fig. 3.4a). Son preparados por el método de Brust-Schiffrin de una fase y consisten en un núcleo de 79 átomos $\mathrm{Au}$ formando un decaedro de Marks (Fig. 3.4b), cubierto por dos tipos de estructuras similares a las encontradas en los tiolatos de $\mathrm{Au}^{\mathrm{I}}$ : RS-Au-SR y RS-Au-SR-Au-SR (Fig. 3.4c).

Este hecho dio lugar al desarrollo de una interpretación de la estabilidad de estos clusters por el grupo de H. Häkkinen [16], en base al modelo de superátomos, que compara a estos clusters con los elementos de la tabla periódica e indica que las estructuras estables son aquellas cuya capa electrónica se encuentra cerrada (en analogía a los gases nobles). Un aspecto interesante de los cálculos sobre estos clusters en el marco de DFT está referido al estado de oxidación de los átomos de Au. Si bien se ha propuesto que los 79 átomos del núcleo se encuentran en estado metálico -con carga neutra $\left(\mathrm{Au}^{0}\right)$ - y los 23 átomos restantes en estado oxidado $\left(\mathrm{Au}^{\mathrm{I}}\right)$ [16], existe, en realidad, una distribución de carga en la partícula si se la analiza radialmente, que va desde una carga de Bader ${ }^{1}$ nula en el centro hasta $+0,13$ en la capa exterior [69].

Aunque el estudio de clusters metálicos es de larga data, las descripciones suponían

\footnotetext{
${ }^{1}$ El método de Bader descompone la densidad de carga electrónica del sistema en contribuciones individuales de cada átomo que compone el sistema [68]. Valores positivos indican pérdida de electrones y valores negativos indican ganancia de electrones.
} 
anteriormente que la capa protectora de tiol sobre los clusters no ejercía una influencia notable en el núcleo metálico [70]. Garzón et ál. [71] cuestionaron esta aproximación e informaron resultados de cálculos teóricos en los que se observa que una capa de tiol sobre un cluster de Au produce un desorden importante de los átomos del metal. Es decir, las moléculas de tiol no sólo cubren los núcleos de Au sino que cambian totalmente su estructura geométrica y electrónica. De este modo, al estudiar estos clusters hay que considerar tanto los átomos metálicos como las moléculas que los protegen. Esto se encuentra alineado a la reconstrucción superficial que ocurre en las SAMs de tiolatos sobre superficies planas de Au.

Otros clusters que han sido cristalizados y cuya estructura ha sido determinada son los que contienen $\mathrm{Au}_{25}\left(\mathrm{SCH}_{2} \mathrm{CH}_{2} \mathrm{Ph}\right)_{18}^{-}$[72] y $\mathrm{Au}_{38}\left(\mathrm{SC}_{2} \mathrm{H}_{4} \mathrm{Ph}\right)_{24}$ [73]. Es particularmente interesante que la estructura del cluster de $\mathrm{Au}_{38}(\mathrm{SR})_{24}$ fue predicha teóricamente [74], hecho que refuerza la validez de los cálculos computacionales.

Si bien se considera que la estructura superficial de las AuNPs debe ser similar a la encontrada en los clusters, aún no existe evidencia directa que confirme este postulado. Un paso importante en esta dirección ha sido presentado recientemente por el grupo de R. Jin, quienes informaron la preparación de AuNPs con una composición controlada, cuya fórmula es $\mathrm{Au}_{333}\left(\mathrm{SCH}_{2} \mathrm{CH}_{2} \mathrm{Ph}\right)_{72}$ y su tamaño, 2,2 nm [75].

En este trabajo, nos centraremos en el estudio de NPs de 2 a $4 \mathrm{~nm}$, en lugar de clusters. Los métodos más importantes para la preparación de AuNPs cubiertas con tiolatos son los métodos de síntesis de Brust-Schiffrin. La razón de la gran utilización de estos métodos puede atribuirse a los siguientes puntos: (i) es muy fácil su implementación en cualquier laboratorio; (ii) las NPs producidas poseen una distribución de tamaños estrecha cuya media se puede variar en un cierto rango ajustando la relación molar tiol:Au; (iii) las NPs pueden obtenerse en forma de polvo, lo que hace muy fácil su almacenamiento y posterior utilización; (iv) los productos son estables a lo largo del tiempo. La Fig. 3.5 muestra un esquema de los diferentes tioles utilizados en esta tesis.

\subsection{Método de Brust-Schiffrin de dos fases}

\subsubsection{Síntesis}

El método de Brust-Schiffrin de dos fases [14] es el método más extendido para la síntesis de AuNPs cubiertas con alcanotioles. El grupo de R. W. Murray ha estudiado esta síntesis ampliamente y ha sistematizado el método para controlar el tamaño de las NPs obtenidas en base a diferentes parámetros variables en la síntesis, como la relación molar tiol:Au, la temperatura y la velocidad de agregado del agente reductor [76].

Este método consiste en la reducción de un precursor de $\mathrm{Au}$, como ácido tetracloroáurico $\left(\mathrm{HAuCl}_{4}\right),{ }^{2}$ mediante un reductor fuerte, que generalmente es borohidruro de sodio $\left(\mathrm{NaBH}_{4}\right)$, en presencia de tioles de carácter hidrofóbico, como los alcanotioles. La solución acuosa del precursor de Au se coloca en contacto con un solvente orgánico de baja

\footnotetext{
${ }^{2}$ Como se explicó anteriormente, este método puede ser utilizado con distintos metales. Debido a que en este capítulo se utiliza $\mathrm{Au}$, describiremos los detalles del método utilizando este metal.
} 


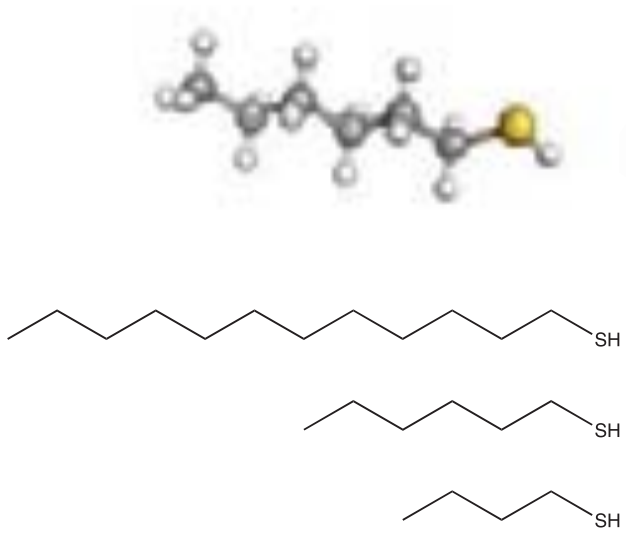

Alcanotioles

$\left(\mathrm{SC}_{n}\right)$

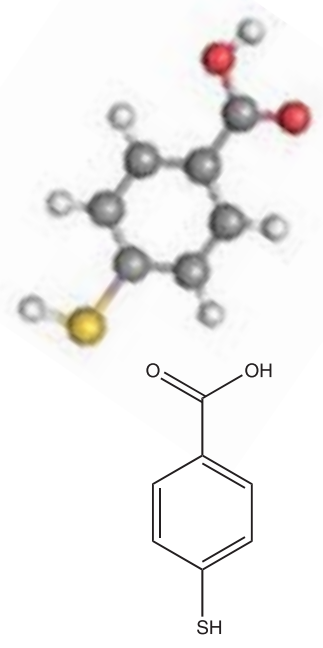

Ácido $p$-mercaptobenzoico $(p-\mathrm{MBA})$

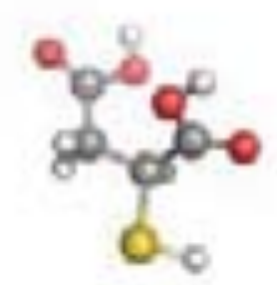<smiles>O=C(O)C[C@@H](S)C(=O)O</smiles>

Ácido tiomálico

(TMA)

Figura 3.5: Algunos de los tioles utilizados en la síntesis de AuNPs mediante el método de Brust-Schiffrin de una y dos fases.

polaridad (generalmente tolueno) donde se encuentra disuelta una sal de amonio cuaternaria $\left(\mathrm{NR}_{4} \mathrm{X}\right)$, que puede ser bromuro de tetraoctilamonio (ToABr) u otra con diferente largo de cadena hidrocarbonada. El catión de esta sal actúa como agente de transferencia de fase, produciendo el transporte de los iones $\left[\mathrm{AuCl}_{4}\right]^{-}$desde la fase acuosa a la fase orgánica. Posteriormente, se descarta la fase acuosa y la fase orgánica puede ser lavada con agua Milli-Q para eliminar el HBr que pueda permanecer, proveniente de la fase acuosa. En el siguiente gráfico se esquematiza el proceso de transferencia de fase [77]:

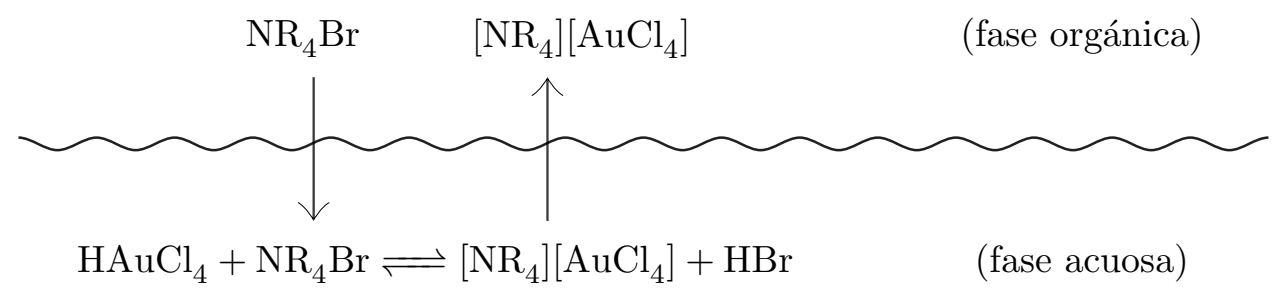

Una vez que se obtiene el precursor metálico en la fase orgánica, se agrega el tiol que se usará para proteger a las NPs que se sintetizarán. Estas moléculas producen una reducción de las especies de $\mathrm{Au}^{\mathrm{III}}$ a $\mathrm{Au}^{\mathrm{I}}$. Durante más de 15 años desde la publicación de este método de síntesis, era aceptado que el agregado de tioles producía la formación de especies poliméricas de $\left[\mathrm{Au}^{\mathrm{I}}-\mathrm{SR}\right]_{n}$ de acuerdo a las siguientes reacciones [78]: ${ }^{3}$

$$
\begin{aligned}
{\left[\mathrm{NR}_{4}\right]\left[\mathrm{AuX}_{4}\right]+3 \mathrm{RSH} } & \longrightarrow \mathrm{Au}^{\mathrm{I}}-\mathrm{SR}+\mathrm{RS}-\mathrm{SR}+\mathrm{NR}_{4} \mathrm{X}+3 \mathrm{HX} \\
n\left[\mathrm{Au}^{\mathrm{I}}-\mathrm{SR}\right] & \longrightarrow\left[\mathrm{Au}^{\mathrm{I}}-\mathrm{SR}\right]_{n}
\end{aligned}
$$

\footnotetext{
${ }^{3}$ Debido a que los iones bromuro de la sal de amonio pueden ser intercambiados con cloruros en la esfera de coordinación del $\mathrm{Au}^{\mathrm{III}}$, los complejos de $\mathrm{Au}$ en la fase orgánica son llamados simplemente $\left[\mathrm{AuX}_{4}\right]^{-}$.
} 
Sin embargo, experimentos recientes realizados por el grupo de R. B. Lennox [55], han demostrado que los precursores reales en la síntesis de NPs son pares iónicos de tetraalquilamonio y halogenuros de $\mathrm{Au}^{\mathrm{I}}$, en lugar de las especies poliméricas. Mediante medidas de espectroscopía UV-vis y de resonancia magnética nuclear protónica $\left({ }^{1} \mathrm{H} \mathrm{RMN}\right)$ encontraron que la estequiometría de la reacción es la siguiente:

$$
\left[\mathrm{NR}_{4}\right]\left[\mathrm{AuX}_{4}\right]+2 \mathrm{RSH} \longrightarrow\left[\mathrm{NR}_{4}\right]\left[\mathrm{AuX}_{2}\right]+\mathrm{RS}-\mathrm{SR}+2 \mathrm{HX}
$$

Posteriormente, el grupo de Y. J. Tong ha confirmado este hallazgo mediante experimentos de espectroscopía Raman y ha propuesto un mecanismo que indica que las especies de $\mathrm{Au}^{\mathrm{I}}$ se encuentran en la fase orgánica encapsuladas dentro de las micelas inversas formadas por los cationes de tetraalquilamonio [79]. Además, estos autores encontraron que si no se quita la fase acuosa del medio de reacción antes del agregado del tiol y la relación molar $\mathrm{RSH}: \mathrm{Au} \geq 2$, entonces los intermediarios en la síntesis están compuestos por una mezcla de $\left[\mathrm{NR}_{4}\right]\left[\mathrm{AuX}_{4}\right]$ y $\left[\mathrm{Au}^{\mathrm{I}}-\mathrm{SR}\right]_{n}[80]$. Condiciones similares fueron utilizadas por Whetten et ál. anteriormente, quienes propusieron un mecanismo como el dado por la Ec. 3.3 [81, 82]. Este comportamiento también fue comentado por Goulet y Lennox [55], quienes lo atribuyeron a la ruptura o la ausencia de los pares iónicos $\left[\mathrm{NR}_{4}\right]\left[\mathrm{AuX} \mathrm{X}_{4}\right]$. Por lo tanto, el agua (y, como veremos más adelante, los solventes polares en general) juegan un rol importante en esta síntesis.

Luego de la adición de tiol, el próximo paso es el agregado del reductor para producir las NPs. En general, se utiliza $\mathrm{NaBH}_{4}$ en un gran exceso respecto al metal $\left(\mathrm{NaBH}_{4}: \mathrm{Au}\right.$ $\sim$ 10:1). Este reactivo produce la reducción de las especies de $\mathrm{Au}^{\mathrm{I}}$ a $\mathrm{Au}^{0}$, creándose así núcleos de $\mathrm{Au}$ metálico en el interior de las micelas inversas [79]. A medida que estos aglomerados crecen, protegidos por tetraalquilamonio, las moléculas de tiol (ahora en forma de RS-SR o mezcla de ambos si la relación molar RSH:Au > 2) se adsorben en la superficie de estos núcleos limitando su crecimiento como NPs, es decir, en el rango de algunos nanómetros, evitando su aglomeración con otras partículas. De esta forma, se producen AuNPs protegidas por tiolato (Au@SR NPs). Este proceso puede esquematizarse de la siguiente manera:

$$
\mathrm{Au}^{\mathrm{I}} \stackrel{\mathrm{NaBH}_{4}}{\longrightarrow} \mathrm{Au}^{0} \stackrel{\mathrm{RS}-\mathrm{SR}}{\longrightarrow} \mathrm{Au} @ \mathrm{SR} \text { NPs }
$$

Una vez preparadas las NPs, es necesario su lavado para eliminar restos de reactivos utilizados en la síntesis, sobre todo moléculas de tiol libre. Para esto se reduce el volumen de tolueno mediante evaporación rotatoria sin aumentar la temperatura del baño por encima de $\sim 30^{\circ} \mathrm{C}$ para evitar la descomposición de las moléculas orgánicas. Luego, las partículas son dispersadas en etanol. Este solvente permite, por su polaridad, la disolución de las moléculas de tiol pero a la vez no forma suspensiones estables de las NPs. Al centrifugar esta mezcla a $\sim 2000 \times \mathrm{g}$ las NPs precipitan y se desecha el sobrenadante. Este proceso debe repetirse por lo menos 4 veces para eliminar la máxima cantidad posible de tiol libre. Finalmente las NPs se secan bajo corriente de nitrógeno obteniéndose un polvo de color marrón oscuro. A partir de aquí las NPs pueden almacenarse o utilizarse como si se tratara de un compuesto químico: pueden ser pesadas y, en solventes de baja polaridad, forman 
suspensiones muy estables que, a simple vista, tienen gran similitud con una solución. El solvente por excelencia para estas partículas es el tolueno.

En el caso de alcanotioles, es posible obtener NPs estables solamente si la longitud de la cadena hidrocarbonada es mayor o igual a 4 átomos de carbono $(n=4)$. Este comportamiento puede ser explicado considerando la longitud de la cadena hidrocarbonada de los tioles y su relación con las interacciones de van der Waals entre las moléculas protectoras, elementos claves en la estabilidad de las NPs. Si la relación tiol:metal utilizada es menor a 2, en el agregado de $\mathrm{NaBH}_{4}$ se produce la reducción tanto de especies de $\mathrm{Au}{ }^{\mathrm{I}}$ como de $\mathrm{Au}^{\mathrm{III}}$. El tamaño de las partículas puede ser controlado entre aproximadamente 2 y $5 \mathrm{~nm}$ variando la relación molar tiol:Au. Cuanto mayor es la relación tiol:Au, las NPs obtenidas son más pequeñas. Si esta relación molar es muy baja, la polidispersidad de las NPs preparadas es muy grande. Al realizar esta síntesis utilizando una relación tiol:Au = 1:8, las NPs obtenidas fueron de muy mala calidad, con una dispersión de tamaños elevada. La Fig. 3.6 muestra una comparación del tamaño entre las NPs preparadas mediante este método utilizando dodecanotiol $\left(\mathrm{Au} @ \mathrm{SC}_{12} \mathrm{NPs}\right)$, con diferentes relaciones molares $\mathrm{SC}_{12}: \mathrm{Au}$, junto con imágenes de HRTEM. Las distribuciones de tamaño evidencian el comportamiento discutido anteriormente. Los detalles de las síntesis se encuentran en el Apéndice B.

\subsubsection{Estudio de la composición química de las nanopartículas mediante espectroscopía de fotoelectrones generados por rayos $\mathrm{X}$}

En la Fig. 3.7 se muestran los espectros XPS de S $2 p$ y Au $4 f$ de Au@SC 12 NPs de $\langle D\rangle=3,0 \pm 0,9 \mathrm{~nm}$. En primer lugar, la señal de $\mathrm{S} 2 p$ presenta dos componentes: una en $162,2 \mathrm{eV}$ asignada a las especies tiolato y otra en $163,0 \mathrm{eV}$ que es asignada a moléculas de dodecanotiol libre o disulfuros (RS-SR). El ancho del pico correspondiente a Au $4 f$ es similar al obtenido para SAMs de tiolatos sobre $\mathrm{Au}(111)$. Por lo tanto, es posible ajustar este pico con solo una componente. En el caso de las NPs, la cantidad relativa de átomos de Au que están sobre la superficie -y, por lo tanto, en contacto con las moléculas de tiol- es muy grande. Por ejemplo, para una NP de $3 \mathrm{~nm}$ de diámetro, aproximadamente el $40 \%$ de los átomos se encuentran en la superficie [83]. Por este motivo, se esperaría que si los átomos de Au en contacto con moléculas de tiol tuvieran una densidad de carga positiva mayor a la de los átomos que están en el interior de la partícula, la señal de $\mathrm{Au} 4 f$ presentaría dos componentes: una correspondiente a Au metálico $(84,0 \mathrm{eV})$ y otra correspondiente a $\mathrm{Au}$ en un estado de oxidación mayor, a una energía de enlace mayor, producto del corrimiento químico (CS), discutido en la Sec. 2.5. En este aspecto, Zhang y Sham [84] informaron corrimientos hacia mayores energías de enlace en AuNPs cubiertas por alcanotiolatos. Similares resultados fueron publicados por Büttner et ál., al evaporar hexadecanotiol sobre AuNPs soportadas sobre carbono. Recientemente, MacDonald et ál. [85] encontraron un corrimiento de $\sim+0,2 \mathrm{eV}$ en clusters de $\mathrm{Au}_{144}(\mathrm{SR})_{60}$, donde diferentes componentes en la señal de $\mathrm{Au}$ uf fueron asignadas a distintos átomos de $\mathrm{Au}$ en las partículas en base a los resultados de EXAFS.

Estos análisis tienen aparejado, sin embargo, cierto grado de simplificación. Diversos 
a

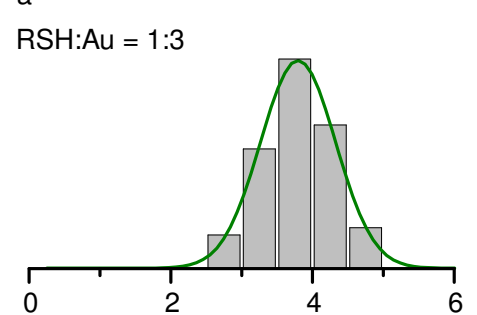

b

$\mathrm{RSH}: \mathrm{Au}=2: 1$

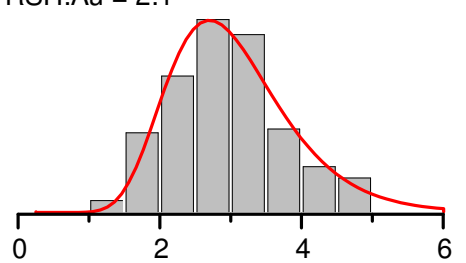

C

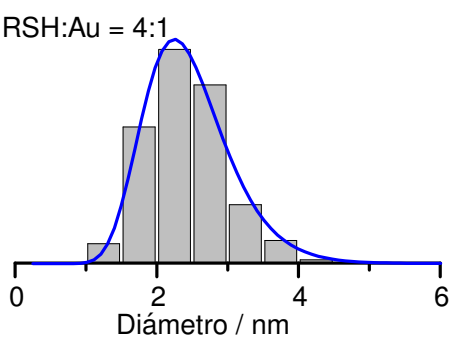

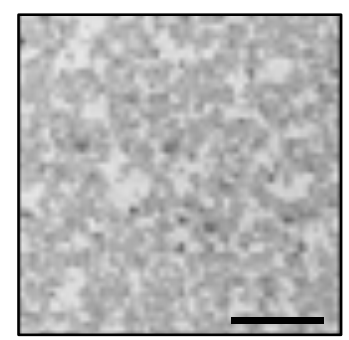
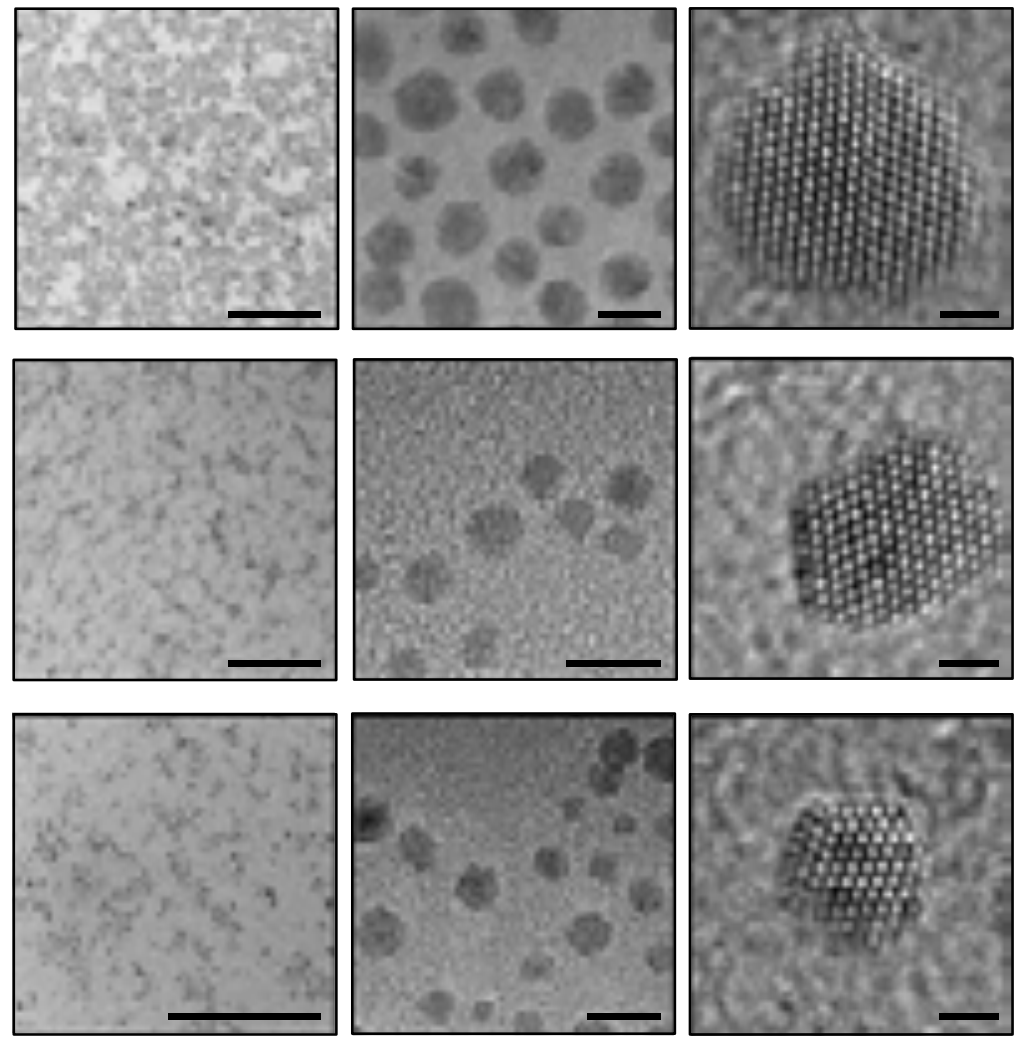

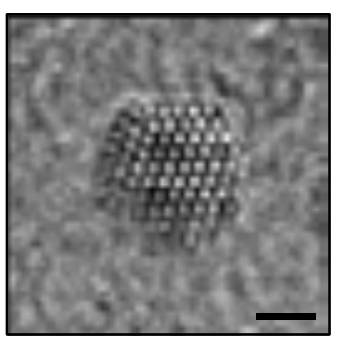

Figura 3.6: AuNPs protegidas con dodecanotiolato preparadas por el método bifásico de Brust-Schiffrin utilizando diferentes relaciones molares de tiol:Au. (a) Relación molar tiol: $\mathrm{Au}=1: 3$, temperatura ambiente, $\langle D\rangle=3,9 \pm 0,6 \mathrm{~nm}$. (b) Relación molar tiol: $\mathrm{Au}=$ 2:1, temperatura ambiente, $\langle D\rangle=3,0 \pm 0,9 \mathrm{~nm}$. (c) Relación molar tiol:Au $=4: 1,0^{\circ} \mathrm{C}$, $\langle D\rangle=2,5 \pm 0,6 \mathrm{~nm}$. Las imágenes de TEM de baja resolución fueron tomadas con el microscopio Phillips CM 200 UT operado a $200 \mathrm{kV}$ y las de HRTEM, con el microscopio OÅM operado a $300 \mathrm{kV}$. Escalas: imágenes a la izquierda: $100 \mathrm{~nm}$, imágenes al centro: $5 \mathrm{~nm}$, imágenes a la derecha: $1 \mathrm{~nm}$.

efectos pueden aparecer al analizar estas NPs mediante XPS, que deben ser considerados al realizar una correcta asignación de picos a una señal determinada. Estos causarán diferentes corrimientos en las energías de enlace y pueden ser divididos en tres tipos: efectos debidos a los átomos de la superficie (surface core-level shift, SCLS), efectos de estado final (final-state effects, FS) y efectos debido al entorno químico (CS). El primero produce corrimientos de $-0,3 \mathrm{a}-0,4 \mathrm{eV}$ en $\mathrm{Au}$ plano [86, 87]. Mientras que en el caso del Au plano, estudiado con una fuente de $\mathrm{Mg} \mathrm{K} \alpha$ y un ángulo de detección de $0^{\circ}$, la contribución de esta componente a la señal de $\mathrm{Au} 4 f$ es insignificante, en las NPs puede tomar gran importancia. El segundo efecto, FS, se produce debido a que al irradiar la muestra con fotones se eyectan electrones y se generan huecos (core-holes) en la muestra. Este defecto de carga negativa es recuperado mediante la conexión a tierra de la muestra. En una muestra de un metal masivo esta reposición se realiza en la escala de tiempo del 

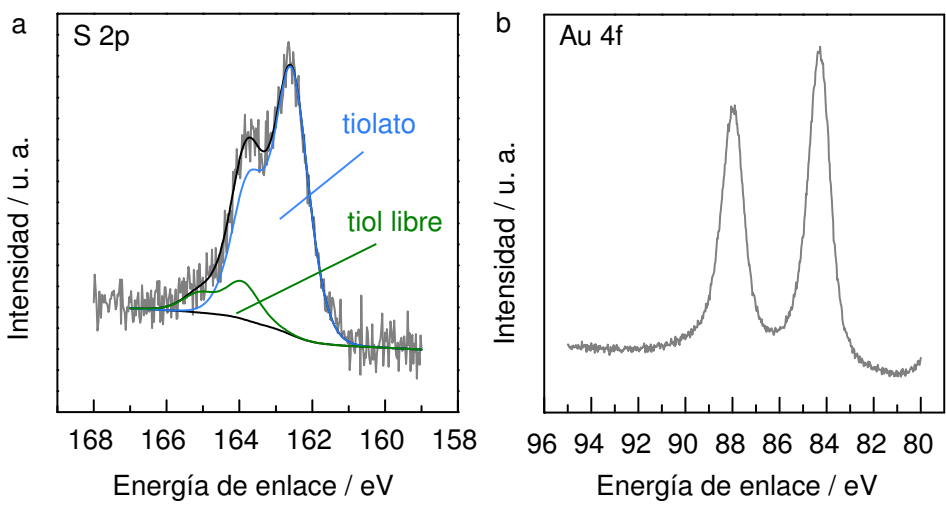

Figura 3.7: Espectros de XPS de AuNPs protegidas con dodecanotiolato $\left(\mathrm{Au} @ \mathrm{SC}_{12}\right.$ NPs), preparadas por el método bifásico de Brust-Schiffrin. (a) Señal de S $2 p$. (b) Señal de $\mathrm{Au} 4 f$.

proceso de fotoemisión (del orden de los femtosegundos). En las NPs protegidas por tioles, en cambio, se puede generar un exceso de carga positiva en el núcleo metálico debido a que la conexión eléctrica con el sustrato puede ser deficiente [88]. Esta carga positiva en las partículas produce un corrimiento en la energía de enlace hacia mayores valores. Por último, el CS es el efecto que nos interesa evaluar. Debido a que la densidad de carga positiva en los átomos de Au en la superficie es mayor por la unión tiolato, se espera que estos átomos presenten un corrimiento hacia mayores energías enlace. Considerando que en realidad hay una distribución de carga en las NPs, este efecto sería aún más difuso [69].

En el caso de superficies de $\mathrm{Au}(111)$, Chaudhuri et ál. [87] propusieron diferenciar 3 componentes en la señal de Au $4 f$ : una para los átomos en Au masivo, otra para los átomos de $\mathrm{Au}$ sin adsorbatos en la superficie y la tercera para los átomos de $\mathrm{Au}$ en contacto con una molécula de tiol, siguiendo el modelo de especies monoméricas de RS-Au adsorbidas sobre huecos $f c c$ de la superficie de $\mathrm{Au}(111)$ [89]. Resultados similares para hexanotiolato y dodecanotiolato fueron informados por Chesneau et ál. [90]. Más adelante, Grönbeck y Odelius [91] han estudiado los corrimientos químicos en los espectros de fotoemisión mediante DFT y propusieron que el único adsorbato consistente con los resultados de XPS de Chaudhuri et ál. son unidades del tipo RS-Au-SR, similares a las propuestas para los clusters de Au. Sin embargo, estos resultados han sido motivo de controversia en la literatura. Cossaro et ál. [54] argumentaron que no es posible relacionar directamente las intensidades de los picos de XPS con las poblaciones relativas de los diferentes átomos de $\mathrm{Au}$ debido a que cambios en el ángulo de colección de los fotoelectrones producen diferencias en los pesos relativos de las distintas componentes. Más aún, es posible que la adsorción de tiol sobre Au produzca diferentes cambios no solo en los átomos a los que se une sino también en otros átomos de la superficie. Es decir que la deconvolución de los espectros de Au $4 f$ para comprender la unión de las especies tiolato a los átomos de $\mathrm{Au}$ debe ser más compleja que la presentada en estos trabajos.

Los corrimientos en la señal de $\mathrm{Au} 4 f$ que hemos observado en las diferentes $\mathrm{Au} @ \mathrm{SC}_{12}$ 
NPs respecto a una superficie de $\mathrm{Au}(111)$, se encontraron en un rango de $+0,17 \mathrm{a}+0,27 \mathrm{eV}$ aproximadamente mientras que el ancho de los picos varió entre 1,05 y 1,14 eV, comparado con un ancho de $\sim 1,0 \mathrm{eV}$ para el $\mathrm{Au}(111)$. La relación de los corrimientos y ancho de los picos con el tamaño de las partículas no siguió un comportamiento determinado. Debido a lo comentado en los párrafos anteriores, no hemos realizado un análisis de las componentes de estos picos en relación a los diferentes estados químicos de los átomos presentes en las partículas. Este campo es motivo de estudio en el grupo de investigación en el presente y tiene como objetivo final el desacoplamiento de los distintos efectos que intervienen en las señales registradas.

\subsection{Método de Brust-Schiffrin de una fase}

El método de Brust-Schiffrin de una fase se emplea para la síntesis de NPs de metales nobles cubiertas con tioles solubles en soluciones acuosas [15]. Es un método más sencillo que el bifásico pero el número de variables que hay que controlar es mayor, lo que provoca que la reproducibilidad de este método sea menor que la del anterior. Esta ruta consiste en la reducción de $\mathrm{HAuCl}_{4}$ en un medio polar (agua/metanol, acetona, tetrahidrofurano (THF)) en presencia de tioles hidrofílicos. El reductor utilizado ampliamente es el $\mathrm{NaBH}_{4}$ y los tioles varían entre diferentes tipos. Este método de síntesis comienza con la disolución del $\mathrm{HAuCl}_{4}$ y el tiol en el solvente a utilizar. En este punto, el tiol produce la reducción de las especies de $\mathrm{Au}^{\mathrm{III}}$ a $\mathrm{Au}^{\mathrm{I}}$, formando especies oligoméricas y poliméricas de tiolato de $\mathrm{Au}^{\mathrm{I}}$. Este proceso se puede esquematizar mediante la siguientes reacciones [92]:

$$
\begin{aligned}
\mathrm{HAuCl}_{4}+3 \mathrm{RSH} & \longrightarrow \mathrm{Au}^{\mathrm{I}}-\mathrm{SR}+\mathrm{RS}-\mathrm{SR}+4 \mathrm{HCl} \\
n\left[\mathrm{Au}^{\mathrm{I}}-\mathrm{SR}\right] & \longrightarrow\left[\mathrm{Au}^{\mathrm{I}}-\mathrm{SR}\right]_{n}
\end{aligned}
$$

Luego, se agrega el $\mathrm{NaBH}_{4}$ para formar las NPs mediante la reducción del $\mathrm{Au}^{\mathrm{I}}$ a $\mathrm{Au}^{0}$.

$$
\left[\mathrm{Au}^{\mathrm{I}}-\mathrm{SR}\right]_{n} \stackrel{\mathrm{NaBH}_{4}}{\longrightarrow} \mathrm{Au} @ \mathrm{SR} \text { NPs }
$$

Se espera que las NPs formadas consistan en núcleos de átomos de Au, cuya superficies se encuentra protegida por tiolatos. Esto ha sido demostrado para el caso de AuNPs preparadas, p. ej., con ácido $p$-mercaptobenzoico ( $p$-MBA) como agente protector [53], obteniéndose AuNPs cubiertas por $p-\mathrm{MBA}$ en la forma tiolato (Au@ $p-\mathrm{MBA}$ NPs). La Fig. 3.8a muestra la distribución de tamaño de estas NPs preparadas utilizando una relación molar $p$-MBA:Au de 4:1 [53]. El diámetro medio de estas partículas resultó $\langle D\rangle=2,3 \pm 0,4 \mathrm{~nm}$. Estas NPs pueden dispersarse fácilmente en medio básico mientras que en medio neutro o ácido se aglomeran, pudiendo revertirse esto mediante aumento del pH, debido a la formación de enlaces de puente de hidrógeno entre las moléculas protectoras de las partículas. Esto puede evidenciarse por un cambio en la coloración de la suspensión de NPs de rojizo (medio básico) a violeta (medio ácido), dado por un corrimiento hacia mayores longitudes de onda en el pico de absorción correspondiente a la resonancia plasmónica superficial. Estos aglomerados también son visibles en las imágenes de TEM. En la Fig. 3.8b se muestra una imagen de una muestra preparada mediante 
a

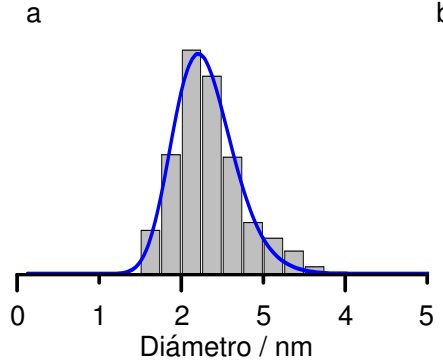

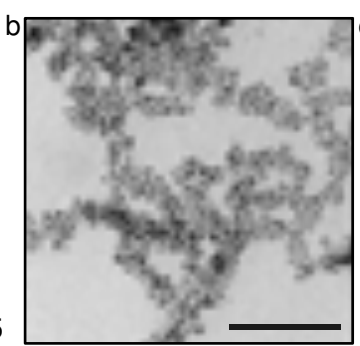

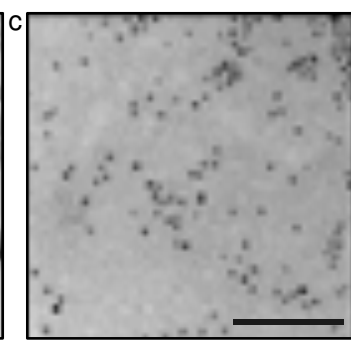

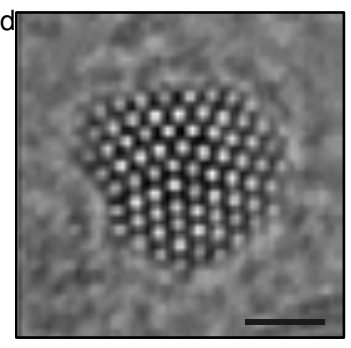

Figura 3.8: Distribución de tamaños e imágenes de TEM y HRTEM de Au@ $p-M B A$ NPs. (a) Distribución de tamaños de las NPs, $\langle D\rangle=2,3 \pm 0,4 \mathrm{~nm}$. (b) Imagen de TEM de una muestra de Au@p-MBA NPs desde agua, escala: $50 \mathrm{~nm}$. (c) Imagen de TEM de una muestra de Au@p-MBA NPs desde solución básica, escala: $50 \mathrm{~nm}$. (d) Imagen de HTEM de una Au@p-MBA NP, escala: 1 nm Las condiciones en que las imágenes fueron tomadas son iguales a las de la Fig. 3.6

deposición de algunas gotas de una suspensión acuosa de Au@p-MBA NPs de pH neutro mientras que la muestra correspondiente a la Fig. 3.8c fue preparada desde una suspensión alcalina $(\mathrm{NaOH} \sim 0,1 \mathrm{M})$. En la Fig. 3.8d se presenta una imagen de HRTEM de una NP de Au@p-MBA. Si bien estas partículas fueron preparadas siguiendo el protocolo publicado por Jadzinsky et ál. [53] las NPs obtenidas presentan un tamaño medio mayor a las informadas en el mencionado trabajo, $\mathrm{Au}_{102}(p-\mathrm{MBA})_{44}$. Esto puede deberse a diferencias en algunos parámetros durante la síntesis. Alternativamente, cuando los autores formaron cristales de NPs, puede haberse dado una selección de partículas de tamaño similar, siendo excluidas las de mayores tamaños.

En el espectro de S $2 p$ (Fig. 3.9a) puede observarse que estas NPs están compuestas principalmente por tiolato con una muy baja contribución de tiol libre, menor que el caso de las AuNPs cubiertas con dodecanotiolato. El espectro de Au $4 f$ es similar a los discutidos anteriormente, aunque presenta un mayor corrimiento en la energía de enlace $(+0,3 \mathrm{eV})$. El ancho del pico a media altura es de $1,14 \mathrm{eV}$. Si bien las características generales de estas partículas son similares a las de Au cubiertas con alcanotiolatos, su estabilidad es considerablemente menor. En el proceso de lavado mediante rutina de centrifugación/redispersión muchas partículas no pueden ser redispersadas y luego de un tiempo de sintetizadas las NPs se aglomeran.

Las reacciones involucradas en este método de síntesis son influenciadas por diversos factores como el pH, la fuerza iónica, la polaridad del medio, la solubilidad del tiol utilizado en la síntesis, etc. Esto se ve reflejado, por ejemplo, en los resultados encontrados al utilizar otro tiol como el ácido tiomálico (TMA) ${ }^{4}$. Particularmente, hemos estudiado en detalle la síntesis de NPs utilizando este tiol, ya que presenta resultados interesantes que serán discutidos en el siguiente capítulo. En ese caso, se produce una reducción parcial de las especies de $\mathrm{Au}^{\mathrm{I}}-\mathrm{SR}$ (intermediarios en la síntesis), formándose AuNPs cubiertas con tiomalato de $\mathrm{Au}^{\mathrm{I}}$ (Au@Au $-\mathrm{TM}$ NPs). Por esta razón, comentaremos brevemente algunos aspectos relevantes de los tiolatos de $\mathrm{Au}^{\mathrm{I}}$.

\footnotetext{
${ }^{4}$ Este tiol también es llamado ácido mercaptosuccínico (MSA).
} 

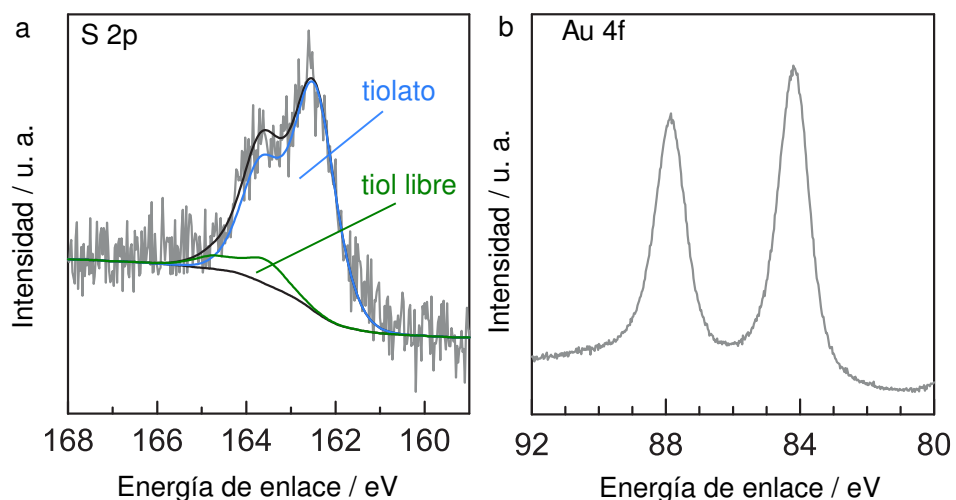

Figura 3.9: Espectros de XPS de AuNPs protegidas con $p$-MBA (Au@p-MBA NPs), preparadas por el método bifásico de Brust-Schiffrin de una fase. (a) Señal de S $2 p$. (b) Señal de Au $4 f$.

\subsection{Tiolatos de $\mathrm{Au}$}

Los tiolatos de $\mathrm{Au}^{\mathrm{I}}\left(\mathrm{Au} \mathrm{u}^{\mathrm{I}}-\mathrm{SR}\right)$ son interesantes por sus aplicaciones en medicina y biología [93]. Estos compuestos pueden tener diferentes tipos de estructuras pero en todas ellas se propone una composición oligomérica o polimérica en la que el esqueleto está formado por uniones del tipo $\mathrm{Au}-\mathrm{S}(\mathrm{R})-\mathrm{Au}-\mathrm{S}(\mathrm{R})$, por lo que podemos nombrarlos de la forma $\left[\mathrm{Au}{ }^{\mathrm{I}}-\mathrm{SR}\right]_{n}$. Es posible considerar que el azufre se encuentra con hibridación $s p^{3}$ con 2 de sus 4 orbitales híbridos participando en enlaces covalentes con los electrones $6 s$ del $\mathrm{Au}$ a aproximadamente $90^{\circ}$ [58]. Sin embargo, los enlaces $\mathrm{S}-\mathrm{Au}$ también incluyen contribuciones importantes de los electrones $d$ del Au. En estos compuestos, los átomos de $\mathrm{Au}$ interaccionan mediante atracciones débiles del tipo $5 d^{10}-5 d^{10}$ que se conocen como efectos aurofílicos y son muy importantes para comprender la estabilidad de estas sustancias. Estas interacciones son llamativas ya que se producen entre átomos con capas electrónicas cerradas e igual carga eléctrica [94]. Las distancias entre átomos de Au a las que estos efectos se producen van de 0,27 a $0,33 \mathrm{~nm}$.

Se han propuesto diferentes estructuras para estos compuestos que también pueden variar de acuerdo al estado de la muestra. En un cristal se ha propuesto una estructura del tipo de doble hélice para tiomalato de Au [95] mientras que se ha informado la existencia de compuestos bidimensionales agrupados en forma de capas, utilizando alcanotioles [96]. En los cálculos de estos compuestos basados en DFT, los valores de las diferentes propiedades convergen cuando el número $n$ de unidades que componen el oligómero es igual a 4 o 5 [97].

\subsection{Comportamiento de las nanopartículas de Au cubiertas por alcanotiolatos sobre grafeno}

En la última sección de este capítulo, discutiremos los resultados obtenidos a partir de la modificación de grafeno de una capa o unas pocas capas con las $\mathrm{Au} @ \mathrm{SC}_{12}$ NPs de 
$2,5 \pm 0,6 \mathrm{~nm}$, comentadas anteriormente.

La primera observación experimental de grafeno por A. K. Geim y K. S. Novoselov en el año 2004 [98] -acreedores del Premio Nobel de Física en 2010-produjo el inicio en la investigación en este material tanto por las importantes propiedades que presenta desde el punto de vista teórico como por la variedad de aplicaciones que este posee. La modificación de grafeno con NPs metálicas presenta, en principio, dos grandes campos de interés: el primero es referido a la utilización de grafeno como soporte para el estudio de NPs mediante microscopía electrónica. En esta técnica, comúnmente se utilizan grillas de $\mathrm{Au}$ o $\mathrm{Cu}$ cubiertas por una lámina de carbono amorfo con un espesor que va desde 4 a $40 \mathrm{~nm}$. Sobre estas grillas se depositan las NPs para su estudio mediante microscopía. Una limitación importante de este método está dada por el alto contraste que genera la lámina de carbono, dificultando la visualización de los átomos metálicos al realizar medidas de alta resolución. Por este motivo, el grafeno sería el material ideal para utilizarse como soporte debido a que este puede tener el mínimo espesor posible: una capa atómica. De hecho, su uso ha dado resultados muy interesantes ya que ha permitido observar, mediante HRTEM con corrección de aberración, la capa de citrato de sodio que cubre una AuNP de $\sim 8 \mathrm{~nm}$ de diámetro [99] y, recientemente, el seguimiento in situ de la síntesis de NPs de Pt mediante el encapsulamiento de líquido entre dos capas de grafeno [100]. Por otra parte, el Au es muy utilizado en aplicaciones del grafeno en sensores, catálisis electroquímica y contactos de circuitos [101], lo que hace importante el estudio de las interacciones Au-grafeno.

El grafeno utilizado en este trabajo fue preparado por J. M. Yuk, de la University of California at Berkeley, Estados Unidos. Se sintetizaron grandes áreas de grafeno mediante deposición química desde fase vapor (chemical vapor deposition, CVD) sobre una lámina de $\mathrm{Cu}$ de $25 \mu \mathrm{m}$ de espesor (99,8 \% Alfa Aesar, Ward Hill, MA), siguiendo el protocolo de la ref. [102]. Luego de la síntesis del grafeno, la lámina de $\mathrm{Cu}$ fue disuelta en una solución acuosa de persulfato de sodio por $3 \mathrm{~h}$ y las láminas de grafeno fueron transferidas a una grilla de TEM de Au cubierta por una lámina de carbono amorfo con agujeros. Las $\mathrm{Au} @ \mathrm{SC}_{12}$ NPs dispersadas en tolueno fueron depositadas en la grilla cubierta con grafeno y se evaporó el solvente a temperatura ambiente. Primeramente se examinaron las muestras en un microscopio electrónico convencional para luego estudiarlas en el microscopio TEAM 0.5 con corrección de aberración utilizando un voltaje de aceleración de $80 \mathrm{kV}$. Con voltajes superiores, la generación de vacancias en el grafeno es muy importante.

En la Fig. 3.11a se observa una imagen de las $\mathrm{Au} @ \mathrm{SC}_{12}$ NPs sobre grafeno. Es posible diferenciar dos zonas diferentes en el grafeno. Una zona correspondiente a grafeno de una monocapa y otra zona que corresponde a varias capas de grafeno o bien grafeno contaminado con carbono amorfo proveniente de la preparación del mismo o de la interacción del haz de electrones con materia orgánica presente en la muestra. Es notable que las AuNPs solo se sitúan en las zonas de multicapas de grafeno. Ninguna NP fue encontrada situada sobre grafeno de una capa. En la 3.11 b se observa el mismo fenómeno. Aquí las NPs se ubican preferentemente en los bordes de las láminas de grafeno o bien sobre multicapas, pero no en la zona de monocapa. Las imágenes presentadas son representativas de gran cantidad de imágenes obtenidas utilizando diferentes dosis de irradiación en dos 
a

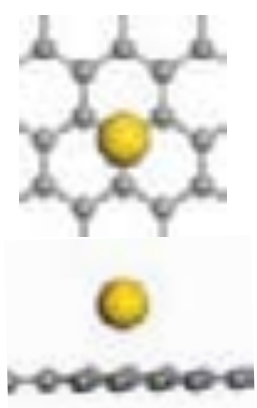

$E_{b} \approx 0,1 \mathrm{eV}$

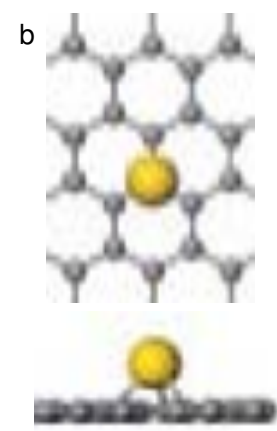

$E_{b} \approx 3 \mathrm{eV}$

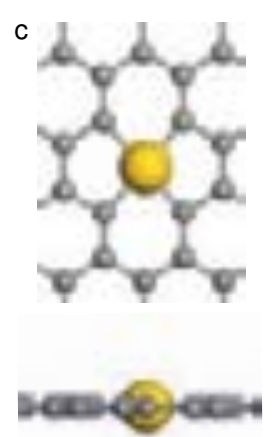

$E_{b} \approx 4 \mathrm{eV}$

Figura 3.10: Energías de adsorción de átomos de $\mathrm{Au}$ en diferentes sitios de grafeno. (a) Adátomo de Au, según ref. [103]. (b) Vacancia simple y (c) vacancia doble, según ref. [104].

microscopios diferentes (TEAM 0.5 y TEAM 1 de NCEM).$^{5}$

El comportamiento observado indicaría una mayor interacción entre la materia orgánica que protege las AuNPs y las multicapas de grafeno y el carbono amorfo. Alternativamente, puede interpretarse considerando las interacciones de los átomos de $\mathrm{Au}$ con las superficies de grafeno. La elección de esta aproximación tiene sus bases en dos fenómenos: (i) los tioles son dañados por efecto de la radiación electrónica, con lo que es probable que las NPs estén desprotegidas al ser observadas en el microscopio y (ii) el comportamiento que observamos es análogo al informado por Zan et ál. utilizando AuNPs desnudas [101].

La energía de adsorción de un adátomo de Au sobre grafeno es $\sim 0,1 \mathrm{eV}$ [103] (Fig. 3.10a), lo cual permitiría la difusión de los átomos a temperatura ambiente. Si, en cambio, un átomo de Au se ubica sobre una vacancia simple o doble del grafeno (Fig. 3.10b y c) la energía de adsorción es $\sim 3$ y 4 eV, respectivamente [104]. Al permanecer en las zonas con contaminación de materia orgánica o en los bordes, la coordinación de los átomos de Au es mayor, lo que restringe su posición a estas regiones. Estos resultados están de acuerdo con los informados por Zan et ál. [101], quienes estudiaron mediante TEM y STEM la evolución de AuNPs depositadas desde fase vapor sobre grafeno. Allí los autores proponen que los átomos de Au sólo pueden observarse en zonas de contaminación con materia orgánica o multicapas de grafeno donde las capas que se encuentran por debajo de la superficie tienen una influencia en la energía de adsorción de los átomos a la superficie de grafeno. Esto mismo había sido propuesto antes por los mismos autores en un trabajo en el que estudiaron la interacción de diferentes metales sobre grafeno, mediante STEM [105].

\footnotetext{
${ }^{5}$ El microscopio TEAM 1, no comentado en la parte experimental, es un microscopio similar al TEAM 0.5 pero que además cuenta con un corrector de aberración cromática y posee una lente objetivo SuperTwin.
} 

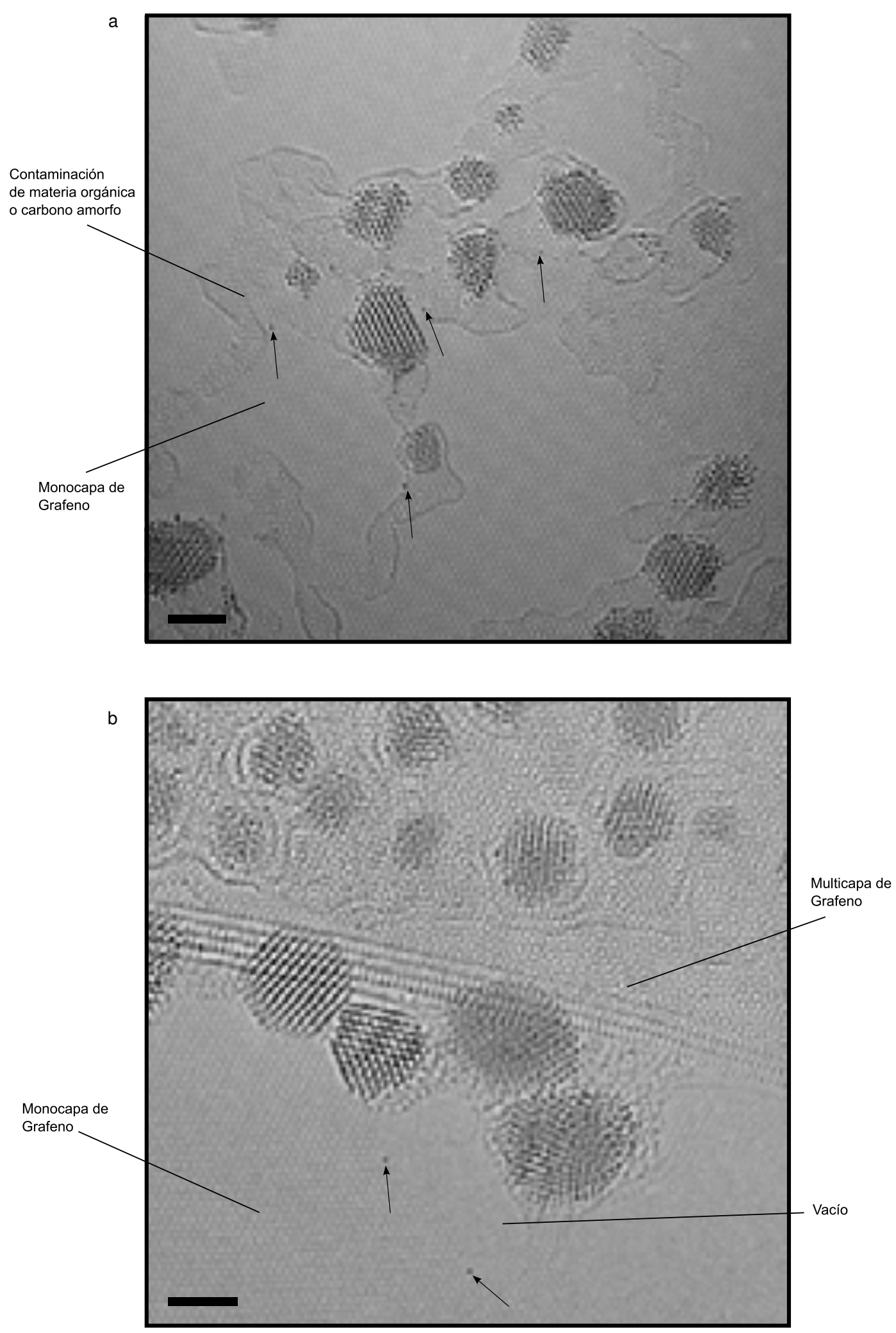

Figura 3.11: $\mathrm{Au} @ \mathrm{SC}_{12}$ NPs sobre grafeno. Las flechas indican átomos individuales. Escalas: $2 \mathrm{~nm}$. Estas imágenes (y las siguientes) fueron tomadas en condiciones de defoco en las que la función de transferencia de contraste es negativa y, por lo tanto, los átomos se observan con contraste negro sobre un fondo claro. 

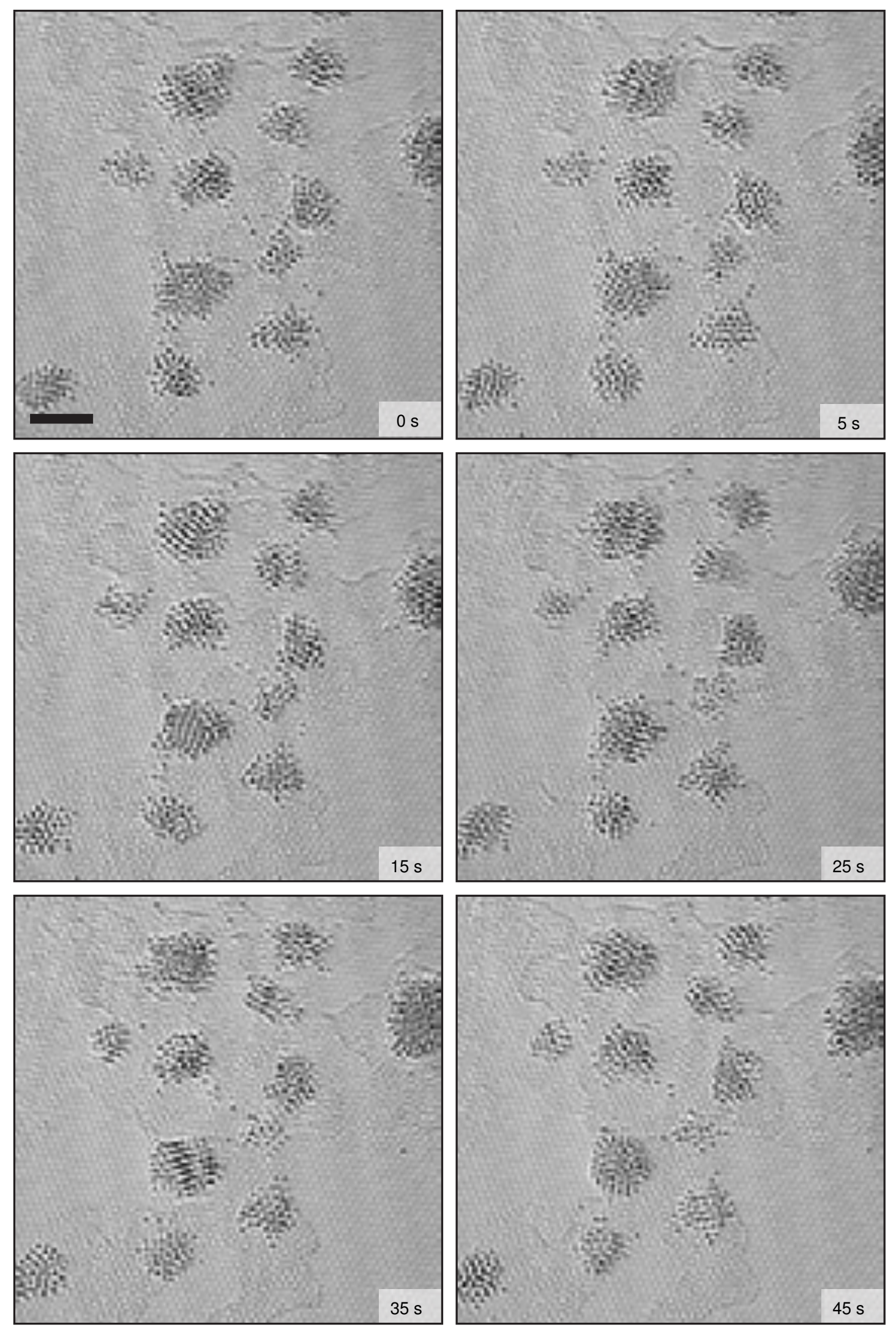

Figura 3.12: Evolución de nanopartículas de Au sobre grafeno. Escala: $2 \mathrm{~nm}$ (continúa en Fig. siguiente). 

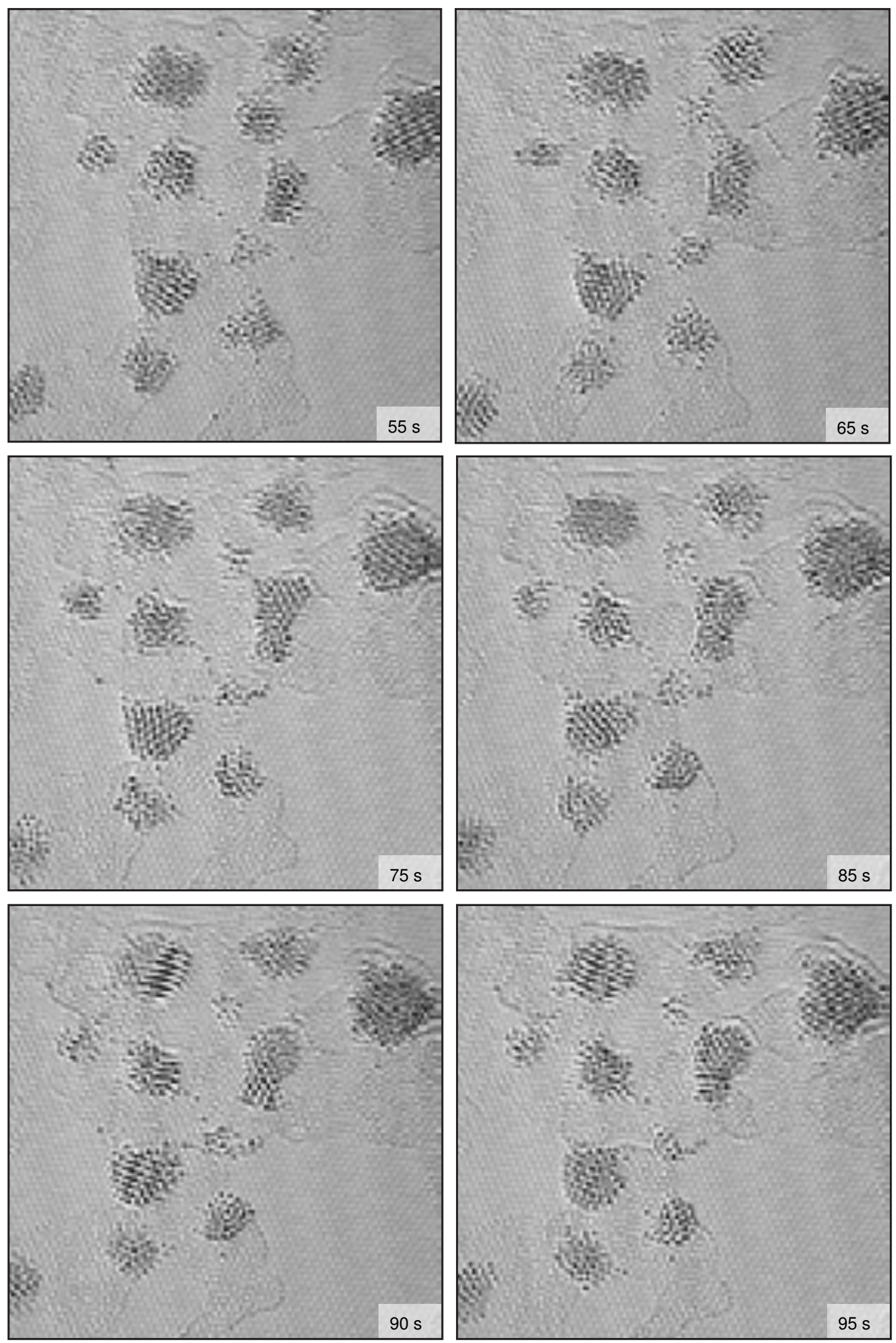

Figura 3.13: Evolución de nanopartículas de Au sobre grafeno. 
Otro aspecto interesante del estudio de las imágenes surge del análisis de series temporales de ellas. En las Figs. 3.12 y 3.13 se presentan imágenes tomadas con un intervalo de tiempo entre cada una (indicado en las imágenes). Dos observaciones son interesantes aquí. La primera se refiere a la evolución de cada NP a lo largo del tiempo: las NPs cambian su forman, rotan, existe gran movilidad de los átomos metálicos dentro de ellas, hay gran intercambio de átomos entre las diferentes partículas y en algunos casos estas se unen formando nuevas estructuras. Este fenómeno limita en gran medida la capacidad de estudio de estas estructuras mediante microscopía electrónica. Esto es producido por la trasferencia de energía de los electrones a los átomos metálicos, proceso conocido como daño por knock-on. Si bien para la energía utilizada $(80 \mathrm{kV})$ la energía máxima transferida por un electrón a un átomo de Au sería muy pequeña (véase Fig. 6.19) ${ }^{6}$, debido a que la interacción de los átomos de Au con el grafeno es muy baja y en este tamaño de NPs la mayoría de los átomos se encuentra en la superficie, con una baja coordinación, esta transferencia de energía puede provocar el movimiento de los átomos metálicos. En los sustratos de carbono amorfo comerciales de $\sim 4 \mathrm{~nm}$ de espesor el movimiento de las partículas bajo el haz de electrones es menor debido a la gran coordinación entre los átomos metálicos y el suporte. Esto se logra a expensas de un mayor contraste que interfiere en la imagen y dificulta la interpretación de la misma.

La segunda observación interesante respecta a los átomos individuales de Au que salen de la superficie de las NPs y permanecen en movimiento en las láminas de grafeno. Es interesante notar que los átomos también permanecen siempre en las zonas con carbono amorfo o de varias capas de grafeno o bien en los bordes de monocapas de grafeno, pero no se observan en el seno de las monocapas. Esto es razonable dada la baja energía de interacción de un adátomo de Au al grafeno y la poca densidad de vacancias disponibles en el grafeno a las que un átomo de Au podría unirse con mayor energía. Gan et ál. [106] estudiaron la difusión de átomos de Au a diferentes temperaturas mediante TEM a $200 \mathrm{kV}$ y determinaron un coeficiente de difusión térmica considerando una adsorción de Au obre vacancias de grafeno. Sin embargo, estos resultados fueron discutidos luego por Malola et ál. [104] quienes propusieron, en base a cálculos en el nivel de DFT, que las energías de difusión medidas deberían estar influidas por el método de medida, es decir que la difusión debería estar activada por el haz de electrones en lugar de la energía térmica solamente.

Diversos trabajos han utilizado la microscopía electrónica para estudiar la estructura de los átomos superficiales de NPs metálicas (p. ej. ref. [107, 108]). Los resultados presentados aquí muestran que esta técnica debe ser utilizada con mucha precaución en este tipo de estudios ya que la interacción del haz electrónico con los átomos metálicos puede causar severos daños que deben ser tenidos en cuenta al analizar los resultados. La disminución de la energía del haz de electrones y la dosis de irradiación ayudan a minimizar este problema a expensas de una disminución en la calidad de las imágenes obtenidas.

\footnotetext{
${ }^{6}$ En la Sec. 6.5 nos referiremos a este proceso con más detalle para el caso del Pd.
} 


\subsection{Conclusiones}

En este capítulo hemos discutido las características generales de diferentes sistemas en los que se presenta la interfase $\mathrm{Au}$-tiol, desde las SAMs de tiolatos sobre $\mathrm{Au}(111)$ hasta los tiolatos de $\mathrm{Au}^{\mathrm{I}}$. Mediante la presentación de resultados obtenidos en este trabajo, hemos introducido la problemática relacionada con la síntesis de AuNPs protegidas por tioles. Si bien muchos aspectos de estos métodos se creían conocidos, diversos trabajos han propuesto nuevas alternativas para comprender estos procesos [55, 79]. En esta dirección, es interesante observar que todos los clusters que fueron cristalizados y cuya estructura fue determinada mediante difracción de rayos X, han sido preparados mediante reducción de las especies intermediarias de $\left[\mathrm{Au}^{\mathrm{I}}-\mathrm{SR}\right]_{n}[53,72,73,109]$. Es decir, en ninguno de los casos se utilizó el método de Brust-Schiffrin de dos fases controlando las condiciones para que la síntesis se realizara sin la generación de las especies poliméricas, como en el proceso explicado por Lennox [55]. Debido a la similitud de las especies protectoras de estos clusters con los tiolatos de $\mathrm{Au}^{\mathrm{I}}$, la cristalización de clusters preparados en estas condiciones sería muy interesante para comparar la estructura de la interfase $\mathrm{Au}$-tiol obtenida por sendas rutas.

Las NPs preparadas por ambos métodos de Brust-Schiffrin presentan una estructura de átomos metálicos ordenados cubiertos por una capa de moléculas de tiolato con cierta cantidad de tiol libre. Las NPs preparas por el método bifásico presentan una estabilidad más prolongada y la regulación de su tamaño puede realizarse mediante la elección de la relación tiol:Au. El caso de las NPs preparadas por el método de una fase no es tan favorable ya que las partículas no presentan la misma estabilidad y la reproducibilidad del proceso de síntesis es más acotada debido a la gran cantidad de variables que influyen en su desarrollo. Más aún, en el próximo capítulo se estudiará en detalle un caso particular de este método donde aparecen nuevas complicaciones. El estudio del método de BrustSchiffrin de dos fases tiene particular importancia para la síntesis de PdNPs protegidas por alcanotioles (Cap. 6). Por otro lado, el método de Brust-Schiffrin de una fase se utiliza en el próximo capítulo utilizando TMA.

Hemos discutido la complejidad que existe en el análisis de los corrimientos químicos en los espectros de XPS de las NPs y la necesidad de desacoplar los diferentes efectos que intervienen en estos corrimientos y en el ensanchamiento de los picos de $\mathrm{Au} 4 f$.

Por último, hemos presentado los resultados obtenidos acerca del comportamiento de AuNPs protegidas por alcanotiolatos sobre grafeno. Los resultados -en concordancia con los informados recientemente en la bibliografía- muestran que las NPs y átomos de Au se ubican preferentemente en zonas con contaminación de materia orgánica o multicapas de grafeno donde la coordinación de los átomos de Au es mayor que sobre una monocapa de grafeno. Este resultado puede comprenderse en base a la baja energía de interacción entre el Au y el grafeno. Las medidas de la evolución de las NPs en el tiempo bajo el haz de electrones muestran la gran influencia que este tiene sobre su estructura y la dificultad que introduce el método de medida en el análisis de los resultados que puedan obtenerse. 


\section{Capítulo 4}

\section{Nanopartículas de Au protegidas por tiomalato de $\mathrm{Au}^{\mathrm{I}}$}

\subsection{Introducción}

Resulta particularmente interesante estudiar la síntesis de Brust-Schiffrin de una fase debido a que en esta ruta se producen tiolatos de $\mathrm{Au}$ como intermediarios, que luego son reducidos para producir las NPs, como discutimos en el capítulo anterior. Estos intermediarios tienen gran relación con las especies del tipo RS-Au-SR o RS-Au-SR-Au-SR que han sido encontradas como protectoras de los clusters de Au [16, 53, 72-74] y es posible que también cubran las AuNPs protegidas por tiolatos.

Uno de los tioles que puede utilizarse en esta síntesis es el ácido tiomálico (TMA) ${ }^{1}$ (Fig. 3.5). Los complejos formados por este tiol y Au dan lugar al tiomalato de $\mathrm{Au}, \mathrm{Au}^{\mathrm{I}}-\mathrm{TM}$. Este compuesto tiene un amplio espectro de aplicaciones en medicina entre las que se han informado propiedades para el tratamiento de la artritis reumatoidea [110] y propiedades antitumorales [111]. El nombre del medicamento que contiene tiomalato de Au es Myochrysine [93] y su estructura cristalina fue determinada por Bau [95] mediante difracción rayos X. Sin embargo, la toxicidad de los compuestos de Au ha limitado su uso, reemplazándose por nuevos productos. En este aspecto, la presencia de ácidos carboxílicos en las moléculas de TMA hace posible la modificación química de las NPs y abre interesantes posibilidades en cuanto a la distribución controlada de drogas y el ataque dirigido a cierto tipo células.

La síntesis de NPs con el método de Brust-Schiffrin de una fase utilizando TMA fue descrita por Chen y Kimura en el año 1999 [112]. En este trabajo, los autores proponen que las NPs obtenidas por este método (que utiliza $\mathrm{NaBH}_{4}$ como reductor en un exceso molar de 10:1 respecto al $\mathrm{Au}$ ) consisten en núcleos de $\mathrm{Au}^{0}$ cubiertos con moléculas de TMA (o TM, dependiendo del pH de la solución) en su forma de tiolato. Es decir que la estructura de estas NPs sería semejante a las obtenidas utilizando alcanotioles [14] o $p-$ MBA [53].

Sin embargo, Ackerson et ál. han informado que, con este método, existe una reducción

\footnotetext{
${ }^{1}$ Nos referiremos a la especie desprotonada con la abreviatura TM.
} 
parcial de los precursores de Au al agregar el reductor [113], utilizando la misma relación molar tiol:Au que Chen y Kimura y una relación equimolar de $\mathrm{NaBH}_{4}$ :Au. No obstante, la naturaleza de los productos obtenidos no ha sido descrita.

A continuación discutiremos los resultados que hemos obtenido utilizando las condiciones de síntesis originales [112]. Contrariamente a lo descrito por Chen y Kimura, proponemos un modelo alternativo para la descripción de estas NPs, que consiste en una estructura del tipo núcleo-coraza (core@shell) donde los núcleos están compuestos por Au metálico y se encuentran protegidos por especies poliméricas de $\mathrm{Au}$ I $-\mathrm{TM}$, producto de una reducción parcial de los precursores de la síntesis.

Primeramente, describiremos la síntesis de las NPs y la caracterización de su composición química mediante experimentos de XPS. Luego haremos un análisis de su estructura geométrica en base a los resultados obtenidos mediante EXAFS y SAXS, realizados en colaboración con el grupo del Dr. F. G. Requejo. El tamaño y estructura cristalina de las partículas será discutido en base a los resultados de TEM, realizados en colaboración con la Dra. E. Zelaya y de STEM, realizados en colaboración con el grupo del Dr. M. José-Yacamán.

\subsection{Características generales de las nanopartículas y com- posición química}

Para la síntesis de estas NPs se utilizó el método de Brust-Schiffrin de una fase [15] modificado por Chen y Kimura [112]. Primeramente, se mezclaron $\mathrm{HAuCl}_{4}$ y $\mathrm{TMA}$ en una solución de metanol/agua. Esta mezcla fue agitada por $5 \mathrm{~min}$, tiempo durante el cual solo parte del $\mathrm{HAuCl}_{4}$ es reducido por el TMA para formar $\mathrm{Au}^{\mathrm{I}}$-TMA, como lo revelan experimentos realizados posteriormente en el laboratorio (no comentados aquí). Luego se agregó el $\mathrm{NaBH}_{4}$ para reducir el metal y formar las NPs. El producto obtenido fue lavado con metanol/agua, metanol y etanol para eliminar las impurezas y los tioles libres. Se obtuvo un polvo color negro compuesto por NPs formadas por un núcleo de Au metálico cubierto por $\mathrm{Au}^{\mathrm{I}}-\mathrm{TM}$, como veremos más adelante. Los detalles de la síntesis se enumeran en el Apéndice B. El siguiente esquema representa el proceso de síntesis: ${ }^{2}$

$$
\mathrm{HAuCl}_{4}+\mathrm{TMA} \stackrel{\mathrm{MeOH} / \text { agua }}{\longrightarrow} \mathrm{HAuCl}_{4}+\mathrm{Au}^{\mathrm{I}}-\mathrm{TMA} \stackrel{+\mathrm{NaBH}_{4(\mathrm{ac})}}{\longrightarrow} \mathrm{Au} @ \mathrm{Au}^{\mathrm{I}}-\mathrm{TM} \text { NPS }
$$

El espectro UV-vis de las NPs disueltas en agua presenta un pico en $\lambda=520 \mathrm{~nm}$ (Fig. 4.1b), correspondiente a la resonancia plasmónica superficial (surface plasmon resonance, SPR) de las NPs, con una intensidad y posición característica de partículas con un tamaño $\leq 2 \mathrm{~nm}[76,112]$.

El estudio de la composición química de los productos de las síntesis de las NPs es un punto de fundamental importancia para mejorar las estrategias de preparación de mismas. Si bien esto puede parecer una obviedad al tratarse de una síntesis química, en muchos trabajos que se encuentran en la literatura es común la aplicación de un método de preparación de NPs (que en principio está bien establecido) sin realizar una adecuada

\footnotetext{
${ }^{2}$ Este es un esquema de reacción que no presenta ecuaciones balanceadas, al igual que otros en el texto.
} 

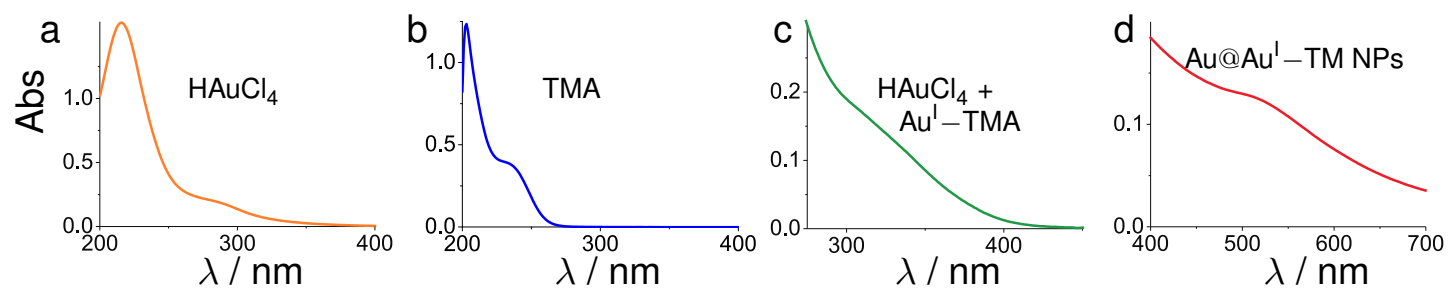

Figura 4.1: Espectros UV-vis de reactivos, intermediarios y productos de la síntesis de $\mathrm{Au} @ \mathrm{Au}^{\mathrm{I}}-\mathrm{TM}$ NPs. (a) Solución acuosa de $\mathrm{HAuCl}_{4}$ 0,085 mM. (b) Solución metanólica de TMA 0,13 mM. (c) Solución de $\mathrm{HAuCl}_{4}$ 0,07 mM + TMA 0,17 mM en $15 \%$ de agua, $85 \%$ de metanol. (d) $\mathrm{Au} @ \mathrm{Au}^{\mathrm{I}}$-TMA NPs luego de ser lavadas, dispersas en agua.

caracterización. Se asume en estos casos que su estructura y composición química es la misma que la descripta en los trabajos originales. Por ejemplo, en estudios realizados utilizando espectrometría de masas, se informó la ausencia de señal correspondiente a las NPs que se postularan, comprendidas por núcleos metálicos de $\mathrm{Au}_{55}$ cubiertos por moléculas de TMA [114]. Alternativamente a la presencia de NPs metálicas, los picos encontrados pueden atribuirse a oligómeros del tipo $\left[\mathrm{Au}{ }^{\mathrm{I}}-\mathrm{TMA}\right]_{n}$. Si bien este caso es extremo ya que se sospecha que no se han formado carozos metálicos, es posible que se formen tanto dominios metálicos como tiolatos de $\mathrm{Au}^{\mathrm{I}}$, como el caso reportado en la ref. [115]. Asimismo, la naturaleza y proporción de los productos obtenidos dependen sensiblemente de una cantidad importante de variables. Entre ellas se cuentan la temperatura, humedad ambiente, orden y velocidad de agregado de los reactivos, tiempo esperado en cada paso de la síntesis, velocidad de agitación, fuerza iónica y pH de la solución, nivel de humedad en los solventes orgánicos utilizados, limpieza del material, etc. Por lo tanto, es imprescindible realizar una caracterización exhaustiva de los productos obtenidos luego de cada síntesis.

La caracterización de la composición química de las NPs preparadas fue realizada mediante XPS. Para esto, una porción del polvo de las NPs preparadas fue dispersado en etanol y, utilizando esta suspensión, se depositaron varias gotas sobre una lámina de Pt. En las Fig. 4.2a, b pueden observarse los espectros XPS correspondientes a la señal de $\mathrm{Au}$ $4 f$ y S $2 p$ de estas NPs. Lo primero que llama la atención es que el ancho a media altura del pico de $\mathrm{Au} 4 f$ es de $1,4 \mathrm{eV}$, mayor al encontrado en Au masivo o AuNPs sintetizadas por el método de Brust-Schiffrin de dos fases $(\sim 1 \mathrm{eV})$. Por lo tanto, al deconvolucionar la señal de $\mathrm{Au} 4 f$ vemos que es necesaria la introducción de dos componentes. Luego de realizar el ajuste, se obtiene una componente ubicada en $84,0 \mathrm{eV}$, que contribuye en un $30 \%$ a la señal total y una segunda componente en $84,5 \mathrm{eV}$, que aporta el $70 \%$ restante. La componente en $84,0 \mathrm{eV}$ es asignada a $\mathrm{Au}^{0}$ mientras que la componente en $84,5 \mathrm{eV}$ es asignada a $\mathrm{Au}^{\mathrm{I}}[59]^{3}$. Por otra parte, la relación atómica de $\mathrm{S}_{\text {total }}: \mathrm{Au}^{\mathrm{I}}$ obtenida es muy cercana a la unidad. Esto significa que hay una correspondencia de 1 a 1 entre el número de átomos de azufre y las especies de $\mathrm{Au}^{\mathrm{I}}$. Estos resultados indican que el $\mathrm{Au}^{\mathrm{I}}$, responsable de la componente en $84,5 \mathrm{eV}$, se encuentra formando tiolatos de $\mathrm{Au}$ ( $\mathrm{Au}$ - TMA). La

\footnotetext{
${ }^{3}$ Tsukuda et ál. [56] informaron una energía de enlace de $86,0 \mathrm{eV}$ para $\mathrm{Au}{ }^{\mathrm{I}}-\mathrm{TM}$. Sin embargo, es probable que este valor esté afectado por una mala descarga a tierra de la muestra, lo que produce una acumulación de carga positiva y un corrimiento del pico hacia mayores energías de enlace.
} 

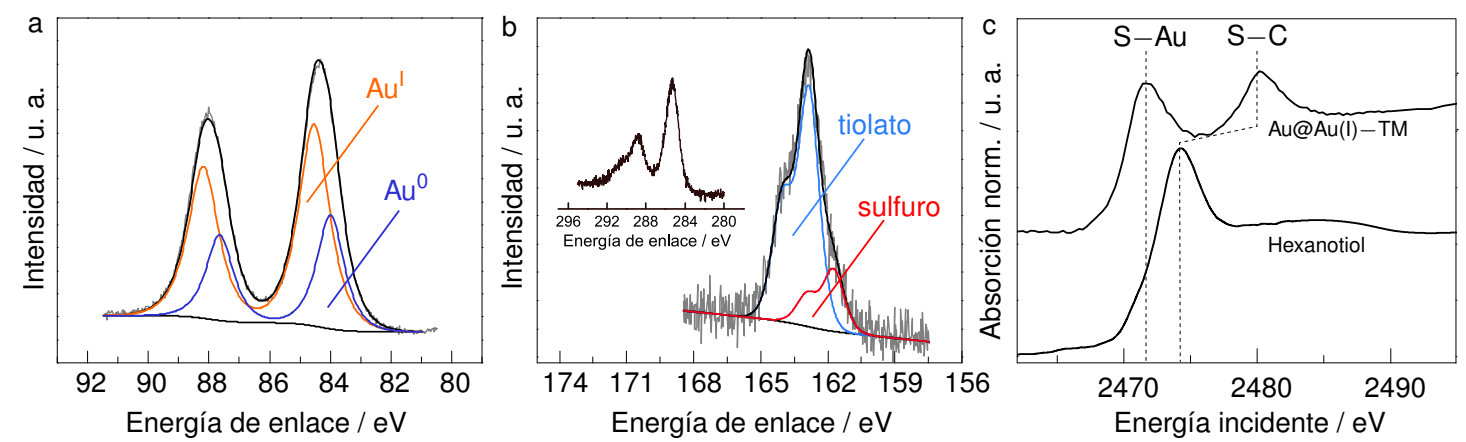

Figura 4.2: Espectros de XPS y XANES las Au@Au ${ }^{\mathrm{I}}-\mathrm{TM}$ NPs. (a) Espectro de XPS de Au $4 f$ de las Au@AuI-TM NPs. (b) Espectro de XPS de S $2 p$ de las Au@Au ${ }^{\mathrm{I}}-\mathrm{TM}$ NPs, inset: espectro de C 1s. (c) Espectro XANES del borde $K$ del S de las $\mathrm{Au} @ \mathrm{Au}^{\mathrm{I}}-\mathrm{TM}$ NPs y hexanotiol puro.

asignación de esta componente a especies de tiolatos de Au está en congruencia con los resultados de Bourg et ál., quienes informaron una componente de $\mathrm{Au} 4 f$ en 84,4 eV y una relación $\mathrm{S}: \mathrm{Au}=0,9$ para $\mathrm{Au}^{\mathrm{I}}-\mathrm{SC}_{4}$ [59]. En síntesis, hemos encontrado que las NPs están formadas por mayor cantidad de $\mathrm{Au}^{\mathrm{I}}-\mathrm{TM}$ que de $\mathrm{Au}^{0}$.

También resulta necesario introducir dos componentes en el espectro de $\mathrm{S} 2 p$ (Fig. $4.2 \mathrm{~b}$ ), para poder obtener un buen ajuste. De esta manera, se obtiene una componente ubicada en $161,8 \mathrm{eV}$ y la otra en $162,9 \mathrm{eV}$. Esta última corresponde a las especies tiolato (formando enlaces $\mathrm{S}-\mathrm{Au}$ ) en $\mathrm{Au}{ }^{\mathrm{I}}-\mathrm{TM}$. Ha sido propuesto que la energía de enlace a la que aparecen estas especies es mayor que la encontrada cuando se estudian SAMs de alcanotioles sobre $\mathrm{Au}(111)$ o NPs debido a que existe una reducción de la carga negativa en los átomos de $\mathrm{S}$ respecto a las especies de azufre quimisorbidas sobre $\mathrm{Au}$, por la estructura de los enlaces puente $\mathrm{S}-\mathrm{Au}-\mathrm{S}-\mathrm{Au}[59,116]$. Es probable que, en este caso, influya también el efecto inductivo del carboxilato más cercano al S, que puede retirar densidad electrónica del $\mathrm{S}$ generando en éste un defecto de carga negativa que se traduciría en un corrimiento en la señal del S $2 p$ hacia mayores energías de enlace. Por otro lado, la componente en $161,8 \mathrm{eV}$ es asignada a especies sulfuro [117]. Es posible comprender la presencia de sulfuros, que contribuyen en un $20 \%$ a la señal de S $2 p$, considerando la posibilidad de descomposición del TMA en la superficie de Au metálico, como ocurre con ciertos tioles [118], y cuyo mecanismo será motivo de futuras investigaciones. Por último, no se han encontrado especies de azufre en alto estado de oxidación, ya que no se observaron contribuciones en energías de enlace mayores a $167 \mathrm{eV}$.

Se ha descartado la presencia de moléculas de TMA no unidas a Au (tioles libres) mediante el análisis del espectro XANES en la región del borde $K$ del azufre. Estas medidas fueron realizadas en la línea SXS del LNLS, en condiciones de UHV. Debido a que las energías de enlace de los electrones S $2 p$ del tiolato de estas NPs coincide con la energía correspondiente a los electrones de las moléculas de tiol libre, no sería posible detectar por XPS la presencia de estas especies. Las muestras fueron preparadas mediante deposición de una suspensión de NPs en un sustrato de grafito pirolítico altamente orientado (highly oriented pyrolytic graphite, HOPG) y posterior secado mediante corriente de nitrógeno, 
previo al ingreso en la cámara de UHV. En la Fig. 4.2c se observa el espectro correspondiente a las NPs y a hexanotiol. El espectro de las NPs presenta dos picos separados por $7 \mathrm{eV}$, característico de uniones metal-tiolato. El pico a menor energía no se observa en el caso de tioles libres o NPs con cantidades considerables de tioles libres [84, 119, 120]. El segundo pico corresponde a excitaciones en el enlace $\mathrm{S}-\mathrm{C}$, y se encuentra centrado a mayores energías con respecto al observado en el caso de tioles libres, lo que hace también evidente la formación de uniones $\mathrm{S}-\mathrm{Au}[84,120]$. Si en las NPs hubiera TMA libre, se debería haber obtenido una señal similar a la encontrada para hexanotiol libre. Debido a que el pico observado para hexanotiol está relacionado a excitaciones en los estados correspondiente al enlace $\mathrm{S}-\mathrm{C}$, se espera que su forma sea independiente del tiol utilizado $[84,120]$.

\subsection{Estudio de la resistencia del $\mathrm{Au}^{\mathrm{I}}-\mathrm{TM}$ hacia la reducción}

Debido a la gran resistencia del $\mathrm{Au}{ }^{\mathrm{I}}-\mathrm{TM}$ hacia la reducción mediante un reductor fuerte como el $\mathrm{NaBH}_{4}$-comportamiento diferente al observado con alcanotioles o, inclusive, otros tioles hidrofílicos- es necesario el estudio de este proceso con más detalle. Para esto se realizaron dos experiencias diferentes. La primera consistió en la realización de un tratamiento de post reducción aplicado a las NPs ya sintetizadas y lavadas utilizando $\mathrm{NaBH}_{4}$. La segunda, se trata del estudio de reducción de $\mathrm{Au}^{\mathrm{I}}$ desde soluciones con los componentes utilizados en la síntesis de las NPs, mediante un potenciostato. Por último se analizará la variación de la energía libre asociada a los procesos de reducción de $\mathrm{Au}^{\mathrm{I}}-\mathrm{TM}$ en la síntesis de las NPs.

\subsubsection{Post reducción del $\mathrm{Au}{ }^{\mathrm{I}}-\mathrm{TM}$}

Con el objetivo de forzar la reducción de $\mathrm{Au}{ }^{\mathrm{I}}-\mathrm{TM}$ en las NPs, se ensayó una segunda reducción luego de sintetizar y lavar las NPs. Esto se llevo a cabo mediante el agregado de un exceso de $\mathrm{NaBH}_{4}$ a una porción de las NPs de $\mathrm{Au} @ \mathrm{Au}^{\mathrm{I}}-\mathrm{TM}$ dispersadas en agua. Los resultados de este tratamiento se presentan en la Fig. 4.3. En esta figura puede observarse que este proceso sólo produjo una reducción parcial de las especies de $\mathrm{Au} \mathrm{u}^{\mathrm{I}}$. Se incrementó la relación atómica de $\mathrm{Au}^{0}: \mathrm{Au}^{\mathrm{I}}$ y disminuyó la correspondiente a $\mathrm{S}_{\text {total }}$ : $\mathrm{Au} u_{\text {total }}$. El espectro de UV-vis de las NPs antes y después del proceso de post reducción se presenta en la Fig. 4.3 para su comparación. Este proceso produce un incremento en la intensidad del pico de SPR, lo que indica un mayor tamaño para las AuNPs. ${ }^{4}$ Por otra parte, la posición del pico permanece invariante, lo que indica que no hay una aglomeración significativa de las NPs.

Estos resultados son consistentes con los obtenidos recientemente por Shang et ál. [121] en la síntesis de AuNPs protegidas con ácido lipoico. Estos autores encontraron que las NPs preparadas presentaban fluorescencia en la zona de $700 \mathrm{~nm}$ al ser excitadas en $500 \mathrm{~nm}$ con un tiempo de vida largo (>100 ns), característico de compuestos del tipo $\mathrm{Au}^{\mathrm{I}}-\mathrm{SR}$.

\footnotetext{
${ }^{4}$ Si bien la intensidad del pico de SPR puede variar por diferencias en el entorno de la NP, en ambos casos el entorno es similar, lo que no produciría cambios significativos en el pico.
} 

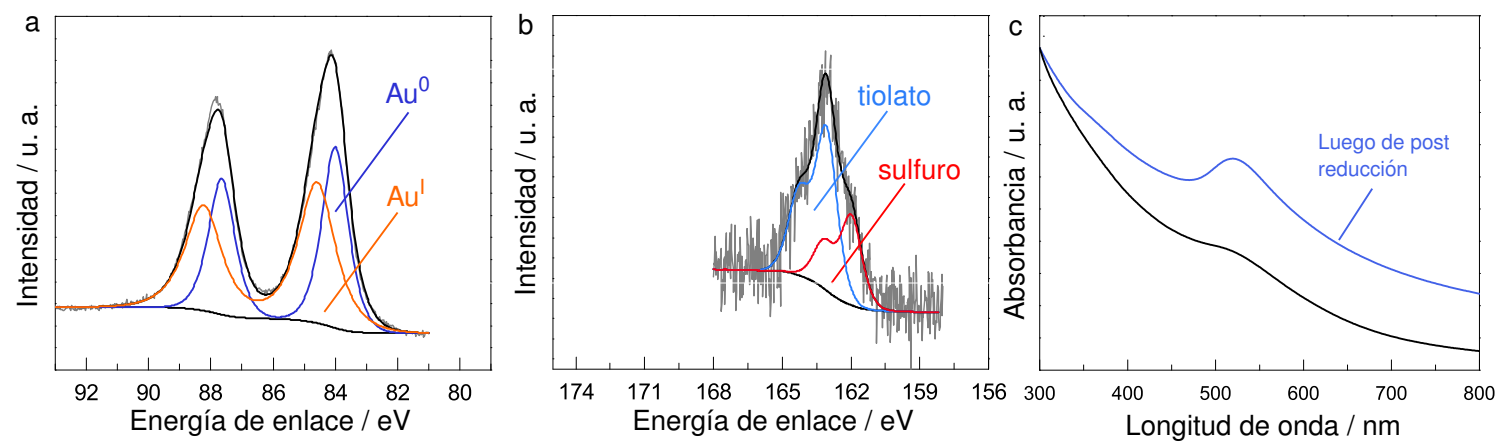

Figura 4.3: (a) Espectro XPS de $\mathrm{Au} 4 f$ de las $\mathrm{Au} @ \mathrm{Au}^{\mathrm{I}}-\mathrm{TM}$ luego del tratamiento de post reducción. (b) Espectro de S2p de $A u @ A u^{\mathrm{I}}-\mathrm{TM}$ luego del tratamiento de post reducción. (c) Comparación de los espectros UV-vis de las NPs antes (trazo negro) y después (trazo azul) de la post reducción

Este comportamiento fue atribuido a una reducción parcial del $\mathrm{Au}^{\mathrm{I}}$ por el $\mathrm{NaBH}_{4}$ utilizado, lo que produjo a una mezcla de clusters de $\mathrm{Au}^{0}$ y $\mathrm{Au}^{\mathrm{I}}$. Más aún, estos autores realizaron un tratamiento de post reducción después del cual observaron una disminución del $30 \%$ en la fluorescencia, lo que indica una menor cantidad especies $\mathrm{Au}^{\mathrm{I}}$

Si la estructura de las NPs preparadas fuera igual a la observada en las NPs sintetizadas por el método de Brust-Schiffrin de dos fases, las preparadas mediante el método de una fase utilizando $p$-MBA o a la descrita por Chen y Kimura [112], es decir, un núcleo metálico cubierto por una SAM de tiolatos, el proceso de post reducción no tendría ningún efecto significativo sobre las NPs. Los espectros XPS permanecerían invariantes al igual que el espectro de UV-Vis.

\subsubsection{Electrorreducción de Au sobre grafito}

Esta resistencia a la reducción también fue observada mediante experimentos de electrodeposición de Au. Utilizando una celda de tres electrodos con un electrodo cuasi reversible de hidrógeno como electrodo de referencia, un electrodo de platino de gran área como contra electrodo y un sustrato de HOPG como electrodo de trabajo, se realizó la electrodeposición de $\mathrm{Au}$ desde dos soluciones diferentes. La primera consistió en una solución acuosa de $\mathrm{HAuCl}_{4} 1,85 \mathrm{mM}$ mientras que la segunda consistió en una solución acuosa de $\mathrm{HAuCl}_{4}$ 1,85 mM + TMA 4,6 mM, preparada mediante mezcla de los dos componentes durante media hora de forma tal de formar Au $\mathrm{I}$-TMA. De esta manera, la relación molar TMA:Au es 2.5, al igual que en la síntesis de las NPs. Ambas soluciones fueron preparadas en $\mathrm{H}_{2} \mathrm{SO}_{4}$ 0,1 M -para evitar la hidrólisis de las especies de $\mathrm{Au}^{\mathrm{III}}$ - y desoxigenadas previamente a los experimentos mediante el burbujeo de nitrógeno purificado. Los valores de densidad de corriente fueron calculados en base al área geométrica del electrodo de trabajo mientras que los potenciales se encuentran referidos al electrodo de calomel saturado (ECS). Estas experiencias tienen un valor de comparación cualitativo con la síntesis debido a que las condiciones son diferentes.

En la Fig. 4.4 se muestran las curvas de densidad de corriente-potencial para las dos 


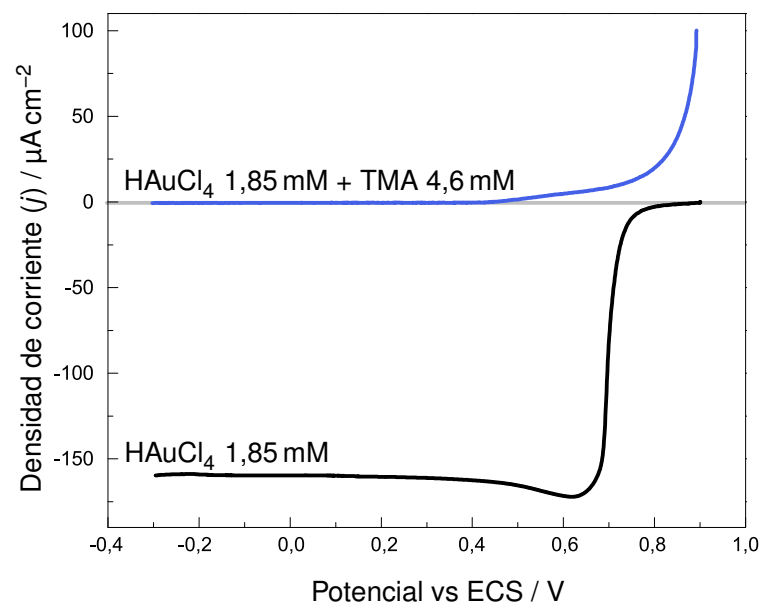

Figura 4.4: Diagrama de densidad de corriente vs. potencial para la electrodeposición de $\mathrm{Au}$ sobre $\mathrm{HOPG}$ desde una solución acuosa de $\mathrm{HAuCl}_{4} 1,85 \mathrm{mM}$ (línea negro) y desde una solución acuosa de $\mathrm{HAuCl}_{4}$ 1,85 mM + TMA 4,6 mM (línea azul). Ambas soluciones fueron preparadas en $\mathrm{H}_{2} \mathrm{SO}_{4}$ 0,1 M. Velocidad de barrido: $10 \mathrm{mV} \mathrm{s}^{-1}$.

soluciones empleadas. El barrido se comenzó en $0,9 \mathrm{~V}$ en la dirección negativa utilizando una velocidad de barrido de $10 \mathrm{mV} \mathrm{s}^{-1}$ y se continuó hasta $-0,30 \mathrm{~V}$, donde empieza a producirse la reacción de desprendimiento de hidrógeno (hydrogen evolution reaction, HER). Para la solución de $\mathrm{HAuCl}_{4}$ existe un pico de corriente negativa en $E=0,62 \mathrm{~V}$ y una meseta que se extiende desde $0,40 \mathrm{~V}$ hasta $-0,30 \mathrm{~V}$. Esta corriente límite corresponde a la electrodeposición de $\mathrm{Au}$ desde $\left[\mathrm{AuCl}_{4}\right]_{(\text {ac) }}^{-}$, de acuerdo a la siguiente reacción [122]:

$$
\left[\mathrm{AuCl}_{4}\right]_{(\mathrm{ac})}^{-}+3 \mathrm{e}^{-} \longrightarrow \mathrm{Au}_{(\mathrm{s})}+4 \mathrm{Cl}_{(\mathrm{aq})}^{-}
$$

cuyo potencial de reducción estándar es $E_{\mathrm{AuCl}_{4}^{-} / \mathrm{Au}^{0}}^{\circ}=1,002 \mathrm{~V}$ vs. electrodo normal de hidrógeno (ENH) [123]. La electrodeposición de Au sobre el electrodo de HOPG fue evidente a simple vista.

En el caso de la solución de $\mathrm{HAuCl}_{4}$ 1,85 mM + TMA 4,6 mM sólo se observa una corriente despreciable al realizar el mismo barrido. Al finalizar el proceso, no se observaron cambios en el HOPG. Estos resultados evidencian la gran dificultad para la reducción del $\mathrm{Au}{ }^{\mathrm{I}}$-TMA, en congruencia con los resultados obtenidos para las NPs. La corriente positiva que existe al inicio de barrido de potencial puede deberse a la oxidación de especies de $\mathrm{Au}^{\mathrm{I}}$ a $\mathrm{Au}{ }^{\mathrm{III}}$.

Sin embargo, un conflicto adicional puede existir en esta comparación. Recientemente, Barngrover y Aikens [124] han propuesto, mediante cálculos basados en DFT, que la reducción de $\mathrm{Au}^{\mathrm{I}}-\mathrm{SR}$ para formar $\mathrm{Au}^{0}$ mediante la adición de electrones - proceso que puede compararse con la aplicación de un potencial con un potenciostato, sin tener en cuenta el sustrato de HOPG- no es favorable desde el punto de vista del mecanismo y se requiere la adición de $\mathrm{BH}_{4}^{-}$a las especies de $\mathrm{Au}^{\mathrm{I}}$ para formar enlaces $\mathrm{Au}^{0}-\mathrm{Au}^{0}$. Es decir, aun cuando la reducción de $\mathrm{Au}^{\mathrm{I}}$-SR no sea posible de forma potenciostática, puede ser cinéticamente favorable mediante el uso de un reductor como $\mathrm{NaBH}_{4}$. 


\subsubsection{Variación de la energía libre asociada al proceso de reducción de $\mathrm{Au} \mathbf{u}^{\mathrm{I}}-\mathrm{TM}$}

El comportamiento observado durante la síntesis de las NPs, el proceso de post reducción y la electrodeposición de Au nos impulsa a estudiar los valores de energía libre asociados a estos procesos, desarrollados a continuación.

La formación de $\mathrm{Au} \mathrm{u}^{\mathrm{I}}-\mathrm{SR}$ puede representarse mediante la siguiente ecuación:

$$
\mathrm{Au}^{+}+\mathrm{RS}^{-} \longrightarrow \mathrm{Au}^{\mathrm{I}}-\mathrm{SR} \quad \Delta G_{f}^{\circ}=-R T \ln \left(K_{f, \mathrm{Au}^{\mathrm{I}}-\mathrm{SR}}\right)
$$

donde $\mathrm{SR}^{-}$representa en este caso los iones de tiomalato. El compuesto $\mathrm{Au}^{\mathrm{I}}$-SR es capaz de formar unidades oligoméricas:

$$
n\left[\mathrm{Au}^{\mathrm{I}}-\mathrm{SR}\right] \longrightarrow\left[\mathrm{Au}^{\mathrm{I}}-\mathrm{SR}\right]_{n} \quad \Delta G_{p}^{\circ}=-R T \ln \left(K_{p}\right)
$$

Mientras que se conoce el valor de la constante $K_{f, \mathrm{Au}^{\mathrm{I}}-\mathrm{SR}}$ para TMA [125], no fue informado el valor de $K_{p}$. Por esta razón, haremos algunas aproximaciones para estimarlo. $\mathrm{Si}$ la adición de una unidad monomérica $\mathrm{Au}{ }^{\mathrm{I}}$-SR al polímero implica la formación de un enlace $\mathrm{Au}-\mathrm{S}$ puente, ${ }^{5}$ es posible proponer que la liberación de un átomo de $\mathrm{Au}^{\mathrm{I}}$ requiere la ruptura de 2 enlaces $\mathrm{Au}-\mathrm{S}$. Si la ruptura de cada enlace está asociado a una constante con un valor de $1 / K_{f, \mathrm{Au}^{\mathrm{I}}-\mathrm{SR}}$, podemos describir aproximadamente el proceso que involucra la ruptura consecutiva de dos enlaces $\mathrm{Au}-\mathrm{S}$ mediante la constante $\left(1 / K_{f, \mathrm{Au}^{\mathrm{I}}-\mathrm{SR}}\right)^{2}$.

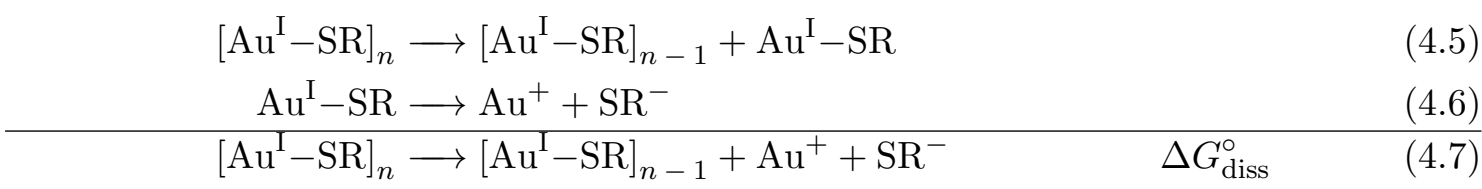

donde $\Delta G_{\text {diss }}^{\circ}=-R T \ln \left(1 / K_{f, \mathrm{Au}^{\mathrm{I}}-\mathrm{SR}}\right)^{2}$.

\section{Hemirreacción de reducción de $\mathrm{Au}^{\mathrm{I}}$}

Plantearemos, en primer lugar, la hemirreacción de reducción del $\mathrm{Au}^{\mathrm{I}}$ presente en $\left[\mathrm{Au}^{\mathrm{I}}-\mathrm{SR}\right]_{n}$.

$$
\begin{aligned}
& {\left[\mathrm{Au}^{\mathrm{I}}-\mathrm{SR}\right]_{n} \longrightarrow\left[\mathrm{Au}^{\mathrm{I}}-\mathrm{SR}\right]_{n-1}+\mathrm{Au}^{+}+\mathrm{SR}^{-} \quad \Delta G_{\text {diss }}^{\circ}} \\
& \mathrm{Au}^{+}+\mathrm{e}^{-} \longrightarrow \mathrm{Au}^{0} \quad \Delta G_{\mathrm{Au}^{+} / \mathrm{Au}^{0}}^{\circ} \\
& \begin{array}{cc}
\mathrm{RS}^{-}+\mathrm{H}^{+} \longrightarrow \mathrm{RSH} & \Delta G_{\mathrm{a}, 3}^{\circ} \\
\hline\left[\mathrm{Au}^{\mathrm{I}}-\mathrm{SR}\right]_{n}+\mathrm{e}^{-}+\mathrm{H}^{+} \longrightarrow\left[\mathrm{Au}^{\mathrm{I}}-\mathrm{SR}\right]_{n-1}+\mathrm{Au}^{0}+\mathrm{RSH} & \Delta G_{\mathrm{red}}^{\circ}
\end{array}
\end{aligned}
$$

donde $\Delta G_{\text {diss }}^{\circ}=-R T \ln \left(1 / K_{f, \mathrm{Au}^{\mathrm{I}}-\mathrm{SR}}\right)^{2}, \Delta G_{\mathrm{Au}^{+} / \mathrm{Au}^{0}}^{\circ}=-F E_{\mathrm{Au}^{+} / \mathrm{Au}^{0}}^{\circ} \mathrm{y} \Delta G_{\mathrm{a}, 3}^{\circ}=-R T \ln \left(1 / K_{\mathrm{a}, 3}\right)$. Por lo tanto,

$$
\begin{aligned}
\Delta G_{\text {red }}^{\circ} & =\Delta G_{\mathrm{diss}}^{\circ}+\Delta G_{\mathrm{Au}^{+} / \mathrm{Au}^{0}}^{\circ}+\Delta G_{\mathrm{a}, 3}^{\circ} \\
& =-R T\left(\ln \left(1 / K_{f, \mathrm{Au}^{\mathrm{I}}-\mathrm{SR}}\right)^{2}-F E_{\mathrm{Au}^{+} / \mathrm{Au}^{0}}^{\circ}-R T \ln \left(1 / K_{\mathrm{a}, 3}\right)\right.
\end{aligned}
$$

\footnotetext{
${ }^{5} \mathrm{La}$ estructura del polímero es $\cdots \mathrm{Au}-\mathrm{S}(\mathrm{R})-\mathrm{Au}-\mathrm{S}(\mathrm{R}) \cdots$.
} 
Para TMA, p $K_{\mathrm{a}, 1}=3,30, \mathrm{p} K_{\mathrm{a}, 2}=4,94$ y $\mathrm{p} K_{\mathrm{a}, 3}=10,64$ [126]. $K_{a, 1}$ y $K_{a, 2}$ son las constantes para los grupos carboxílicos mientras que $K_{a, 3}$ es la constante relacionada con la siguiente reacción:

$$
\mathrm{RSH} \rightleftharpoons \mathrm{RS}^{-}+\mathrm{H}^{+}
$$

La contante de formación $K_{f, \mathrm{Au}^{\mathrm{I}}-\mathrm{SR}}$ para $\mathrm{SR}=\mathrm{TMA}$, es $K_{f, \mathrm{Au}^{\mathrm{I}}-\mathrm{SR}}=1,86 \times 10^{10}[125]$ y el potencial de reducción estándar $E_{\mathrm{Au}^{+} / \mathrm{Au}^{0}}^{\circ}=1,692 \mathrm{~V}[123] .{ }^{6}$ Entonces, a $T=300 \mathrm{~K}$, resulta:

$$
\Delta G_{\mathrm{red}}^{\circ}=-1,07 \times 10^{5} \mathrm{~J} \mathrm{~mol}^{-1}
$$

Este valor de energía libre equivale a un potencial de reducción estándar $E_{\text {red }}^{\circ}=1,1 \mathrm{~V}$ vs. ENH (i. e. $E_{\text {red }}^{\circ}=0,86 \mathrm{~V}$ vs. ECS). Estos valores de energía libre y potencial de reducción estándar muestran que las especies de $\mathrm{Au}^{\mathrm{I}}$ son inestables aun en presencia de agentes reductores débiles. A continuación analizaremos la hemirreacción de oxidación de $\mathrm{NaBH}_{4}$, utilizado en la síntesis.

\section{Hemirreacción de oxidación de $\mathrm{NaBH}_{4}$}

Es conocido que el $\mathrm{NaBH}_{4}$ se hidroliza en agua siguiendo la siguiente reacción:

$$
\mathrm{NaBH}_{4}+4 \mathrm{H}_{2} \mathrm{O} \longrightarrow \mathrm{B}(\mathrm{OH})_{3}+\mathrm{NaOH}+4 \mathrm{H}_{2}
$$

El $\mathrm{p} K_{\mathrm{a}}$ del ácido bórico $\mathrm{B}(\mathrm{OH})_{3}$ a $20^{\circ} \mathrm{C}$ es 9,27 , entonces, a $\mathrm{pH}=8$ (valor luego de agregar el $\mathrm{NaBH}_{4}$ en la síntesis de las NPs), la especie de ácido bórico más importante es la especie protonada $\mathrm{B}(\mathrm{OH})_{3}$ en lugar de $\mathrm{B}(\mathrm{OH})_{4}^{-}$. Por lo tanto, la reacción de oxidación que consideraremos es la siguiente:

$$
\mathrm{BH}_{4}^{-}+3 \mathrm{H}_{2} \mathrm{O} \longrightarrow \mathrm{B}(\mathrm{OH})_{3}+7 \mathrm{H}^{+}+8 \mathrm{e}^{-} \quad \Delta G_{\mathrm{ox}}^{\circ}
$$

donde $\Delta G_{\mathrm{ox}}^{\circ}=n F E_{\mathrm{B}(\mathrm{OH})_{3} / \mathrm{BH}_{4}^{-}}^{\circ}=8 F \times(-0,481 \mathrm{~V})$. Por lo tanto,

$$
\Delta G_{\mathrm{ox}}^{\circ}=-3,71 \times 10^{5} \mathrm{~J} \mathrm{~mol}^{-1}
$$

\footnotetext{
${ }^{6}$ Cabe notar que el potencial reversible de las especies metálicas en solución en equilibrio con dominios metálicos con dimensiones nanométricas puede diferir del correspondiente al medido con metales masivos, debido a la gran energía superficial de las NPs [127]. En efecto, se han informado corrimientos en este potencial de hasta $850 \mathrm{mV}$ en experiencias de redisolución de AuNPs en presencia de halogenuros [128]. Sin embargo, las condiciones en las hemos preparado las NPs distan de las utilizadas en el citado trabajo. De hecho, el anterior análisis no tiene en cuenta la posibilidad de efectos tales como la pasivación, los que pueden ser más importantes en NPs que en los metales masivos [129]. Así, las partículas pueden compensar el incremento en la energía superficial mediante adsorción de agentes pasivantes (p. ej. O, H, $\mathrm{OH})$. Aun considerando estos corrimientos, no se producen cambios significativos en el análisis realizado en esta sección, por lo que utilizaremos el valor asociado al metal masivo.
} 


\section{Reacción rédox completa}

La reacción global de óxido-reducción, teniendo en cuenta las dos hemirreacciones discutidas anteriormente, resulta:

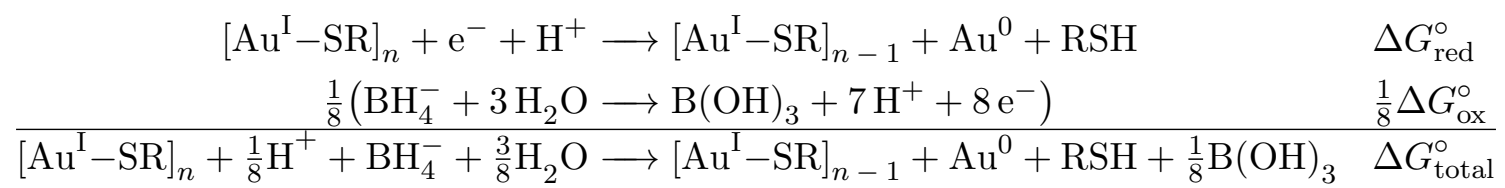

donde $\Delta G_{\text {total }}^{\circ}=\Delta G_{\text {red }}^{\circ}+\frac{1}{8} \Delta G_{\text {ox }}^{\circ}$. Por lo tanto, obtenemos:

$$
\Delta G_{\text {total }}^{\circ}=-1,53 \times 10^{5} \mathrm{~J} \mathrm{~mol}^{-1}
$$

Este valor de energía libre para la reacción global de reducción de un mol de átomos de $\mathrm{Au}^{\mathrm{I}}$ (desde $\mathrm{Au}^{\mathrm{I}}-\mathrm{TMA}$ ) utilizando $\mathrm{NaBH}_{4}$, muestra que este proceso es termodinámicamente favorable en condiciones estándar. Tanto en la síntesis como en el tratamiento de post reducción realizados en este trabajo, las reacciones fueron llevadas a cabo utilizando un gran exceso de $\mathrm{NaBH}_{4}$. Por otro lado, en la experiencia de electrorreducción utilizando un potenciostato, el potencial aplicado fue lo suficientemente negativo como para producir la reducción de $\mathrm{Au}^{\mathrm{I}}$-TMA. Por lo tanto, es probable que la reducción parcial de estas especies se deba a un obstáculo cinético, en lugar de termodinámico.

\subsection{Estructura geométrica de las nanopartículas}

Para estudiar la estructura de las NPs, se realizaron medidas de EXAFS, SAXS, HRTEM y STEM. Comenzaremos por la descripción de los resultados obtenidos mediante la caracterización por EXAFS, llevada a cabo en la línea XAFS-1 del LNLS. Las medidas corresponden al borde $L_{3}$ del $\mathrm{Au}(7112 \mathrm{eV})$, a temperatura ambiente, en modo transmisión y utilizando una celda para líquidos donde se introdujo una suspensión concentrada de las NPs. En la Fig. 4.5 se presenta la transformada de Fourier del espectro medido para las NPs de $\mathrm{Au} @ \mathrm{Au}^{\mathrm{I}}$-TMA antes y después del tratamiento de post reducción y para una lámina de $\mathrm{Au}$, utilizada como referencia. Con el objetivo de descartar la posibilidad de que las especies de $\mathrm{Au}^{\mathrm{I}}$ estén unidas a través de los grupos carboxilatos del TM, se realizó un primer ajuste del espectro utilizando oxígeno. Sin embargo, el ajuste no fue bueno y las distancias obtenidas fueron mayores que las esperadas para enlaces $\mathrm{Au}-\mathrm{O}$ (entre $0,193 \mathrm{~nm}$ y $0,207 \mathrm{~nm}[130,131]$ ). De esta forma se descartó la presencia de complejos de $\mathrm{Au}^{\mathrm{I}}$ formando enlaces con los grupos carboxilatos del TM. Por otro lado, el ajuste utilizando una capa de átomos de azufre resultó más apropiado y se obtuvieron distancias $\mathrm{Au}-\mathrm{S}$ de $0,231 \pm 0,003 \mathrm{~nm}$, en muy buena concordancia con los resultados publicados previamente para $\mathrm{Au}$ I $-\mathrm{TM}$. Bau [95] informó distancias $\mathrm{Au}-\mathrm{S}$ de 0,2289 $\pm 0,0008 \mathrm{~nm}$ y $2,285 \pm 0,007 \mathrm{~nm}$ obtenidas mediante XRD, para un cristal de $\mathrm{Au}^{\mathrm{I}}-\mathrm{TM}$; anteriormente, mediante EXAFS, Elder et ál. [132] determinaron distancias de 0,230 nm para $\mathrm{Au}^{\mathrm{I}}-\mathrm{TM}$ en estado sólido y líquido mientras que Mazid et ál. [133] informaron distancias Au-S de $0,237 \mathrm{~nm}$. Además, estas distancias también están en congruencia con los valores obtenidos 


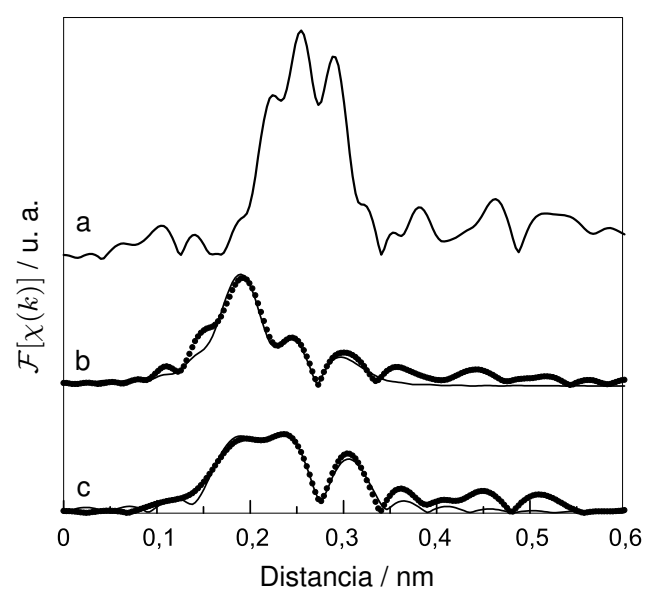

Figura 4.5: Transformada de Fourier del espectro EXAFS del borde $L_{3}$ del Au. (a) Lámina de Au. (b) Au@AuI-TM NPs. (c) NPs luego de la post reducción. En los gráficos b y c, las líneas punteadas corresponden a los datos experimentales mientras que las líneas sólidas corresponden a los ajustes

experimentalmente $[53,72,73,85]$ y calculados desde primeros principios $[16,134-136]$ para las estructuras tipo $\mathrm{RS}-\mathrm{Au}-\mathrm{SR}$, propuestos como las especies que recubren las AuNPs protegidas con tiolatos, comentadas en la Sec. 3.3. Se consideró una contribución de una segunda capa, formada por átomos de $\mathrm{Au}$, para ajustar la región del espectro entre 0,14 y $0,35 \mathrm{~nm}$, que está asociada con las distancias $\mathrm{Au}-\mathrm{Au}$ del núcleo metálico. Estos resultados están de acuerdo con las dos componentes encontradas en el espectro XPS del Au $4 f$.

El número de coordinación promedio $(N)$ puede ser utilizado para estimar el tamaño de NPs metálicas con diámetros menores a $5 \mathrm{~nm}$, si se conoce su forma [137]. Para NPs esféricas, $N$ decrece al decrecer el tamaño de la partícula hasta el límite de 5,53, que corresponde al número de coordinación promedio para un cuboctaedro ideal de $\mathrm{Au}_{13}$. En el caso de las NPs de Au@Au ${ }^{\mathrm{I}}-\mathrm{TMA}$ se obtuvo un valor menor, $N \approx 4,4$, lo que indica que las NPs no están compuestas solamente por Au metálico. Para poder explicar este valor de $N$ tan bajo es necesario plantear la presencia de Au en otra fase, diferente a $\mathrm{Au}$ metálico. Este resultado puede ser producido por una fase de átomos de $\mathrm{Au}^{\mathrm{I}}$ cuya primera capa de coordinación está formada por átomos de S. Mientras que los átomos dentro de la fase metálica se encuentran rodeados por 12 átomos de $\mathrm{Au}$, los átomos de $\mathrm{Au}^{\mathrm{I}}$, ubicados en la segunda fase, contribuirán con 0 al valor del número de coordinación promedio $\mathrm{Au}-\mathrm{Au}$.

De esta forma, a partir de los resultados de XPS y EXAFS podemos concluir que las NPs están formadas por $\mathrm{Au}^{\mathrm{I}}$-TMA con una pequeña cantidad de sulfuro y Au metálico.

Posteriormente al tratamiento de post reducción, se observó un incremento en el número de coordinación de $\mathrm{Au}-\mathrm{Au}$ y una disminución del correspondiente a Au-S. Mientras que la relación atómica de $\mathrm{S}_{\text {total }}$ : Au $\mathrm{u}_{\text {total }}$, estimada mediante XPS, decreció como consecuencia de la post reducción, la distancia $\mathrm{Au}-\mathrm{S}$ se mantuvo invariante. Estos cambios indican que la cantidad de Au metálico aumentó a expensas de las especies de $\mathrm{Au}$ I-TMA. En la Tabla 4.1 se encuentran los parámetros obtenidos de las medidas de EXAFS para las NPs antes y después del tratamiento de post reducción. 
Tabla 4.1: Parámetros estructurales de $A u @ A u^{\mathrm{I}}-\mathrm{TM}$ NPs antes y después del tratamiento de post reducción, obtenidos por EXAFS. Número de coordinación promedio $(N)$, distancia de enlace $(d)$, y factor de Debye-Waller $\left(\sigma^{2}\right)$.

\begin{tabular}{|c|c|c|c|c|}
\hline Muestra & Capa & $N$ & $d / \mathrm{nm}$ & $\sigma^{2} / 10^{-4} \mathrm{~nm}^{2}$ \\
\hline \multirow{2}{*}{$\mathrm{Au} @ A u^{\mathrm{I}}-\mathrm{TM} \mathrm{NPs}$} & $\mathrm{Au}-\mathrm{S}$ & $1,2 \pm 0,3$ & $0,231 \pm 0,003$ & $0,5 \pm 0,1$ \\
\hline & $\mathrm{Au}-\mathrm{Au}$ & $4,4 \pm 0,8$ & $0,283 \pm 0,003$ & $5 \pm 1$ \\
\hline \multirow{2}{*}{$\begin{array}{c}A u @ A u^{\mathrm{I}}-\mathrm{TM} \text { NPs (post } \\
\text { reducción) }\end{array}$} & $\mathrm{Au}-\mathrm{S}$ & $0,6 \pm 0,2$ & $0,231 \pm 0,003$ & $0,30 \pm 0,05$ \\
\hline & $\mathrm{Au}-\mathrm{Au}$ & $6,5 \pm 0,8$ & $0,284 \pm 0,005$ & $1,1 \pm 0,5$ \\
\hline
\end{tabular}

Luego de haber establecido la composición química y los parámetros estructurales de los dos dominios presentes en las NPs mediante el empleo de XPS y EXAFS, a continuación estudiaremos la distribución geométrica de los dominios de $\mathrm{Au}^{0}$ y $\mathrm{Au}^{\mathrm{I}}-\mathrm{TMA}$, mediante SAXS. Las medidas fueron realizadas en la línea SAXS-2 del LNLS en muestras de las NPs diluidas en agua, a temperatura ambiente, utilizando una celda de líquidos. Las curvas de SAXS para las NPs antes y después de la post reducción se presentan en la Fig. 4.6. El mejor ajuste a los datos experimentales fue obtenido considerando un modelo con dos densidades electrónicas: una densidad constante atribuida al Au metálico y una distribución gaussiana para una capa asociada al Au $\mathrm{A}^{\mathrm{I}}$ TMA. Se introdujo una distribución log-normal para el radio del núcleo de $\mathrm{Au}^{0}$ en la rutina de ajuste, para tener en cuenta la polidispersidad de las NPs [45]. Los valores obtenidos para los diferentes parámetros se encuentran en la Tabla 4.2. La función utilizada en el ajuste describe fielmente los datos experimentales en la región de altos valores del vector de dispersión $q$ (desde 0,85 a $\left.5 \mathrm{~nm}^{-1}\right) .{ }^{7}$ Estos resultados indican que un posible modelo para la geometría de las partículas sintetizadas consiste en un núcleo de Au metálico de $\sim 1 \mathrm{~nm}$ de diámetro, rodeado por una capa polimérica de $\mathrm{Au}^{\mathrm{I}}-\mathrm{TM}$ con un radio de giro de $\sim 2 \mathrm{~nm}$, por lo tanto, podemos nombrar a estas partículas como $\mathrm{Au} @ \mathrm{Au}^{\mathrm{I}}-\mathrm{TM}$ NPs. Este modelo resulta más factible que un modelo en el que los núcleos metálicos se encuentran inmersos en una fase masiva de $\mathrm{Au}^{\mathrm{I}}-\mathrm{TM}$. La desviación de la curva de ajuste de los datos experimentales en la región de bajos valores de $q$ puede ser atribuida a la formación de agregados de NPs de $\mathrm{Au} @ \mathrm{Au}^{\mathrm{I}}-\mathrm{TM}$. Esta agregación no cambia luego del proceso de post reducción, cuando el tamaño de los núcleos de Au se duplica.

Estos resultados resultan congruentes con los obtenidos por Chen y Kimura [112], quienes encontraron, mediante XRD, un tamaño de 1,02 nm para las NPs sintetizadas de igual manera (con una relación molar de TMA:Au de 2,5:1). La diferencia reside en que, mientras estos autores han descrito que estos núcleos de Au están cubiertos por una SAM de TM, nuestros resultados indican que lo que cubre a las NPs es una compleja capa de $\mathrm{Au} \mathrm{I}^{\mathrm{I}}$ TM. Estos datos también concuerdan con los resultados de los espectros UV-vis, discutidos anteriormente.

\footnotetext{
${ }^{7} q=4 \pi / \lambda \sin (\epsilon / 2)$, donde $\lambda$ es la longitud de onda de los rayos X incidentes y $\epsilon$, el ángulo de dispersión.
} 
Tabla 4.2: Parámetros obtenidos del ajuste de las curvas de SAXS. Radio medio del núcleo de $\mathrm{Au}\langle R\rangle$ calculado a partir de la distribución log-normal y radio de giro $\left(R_{\mathrm{g}}\right)$ de la capa de $\mathrm{Au}^{\mathrm{I}}-\mathrm{TM}$.

\begin{tabular}{|c|c|c|}
\hline Muestra & $\langle R\rangle / \mathrm{nm}$ & $R_{\mathrm{g}} \mathrm{Au}^{\mathrm{I}}-\mathrm{TM} / \mathrm{nm}$ \\
\hline $\mathrm{Au} @ A u^{\mathrm{I}}-\mathrm{TMA}$ NPs & $0,51 \pm 0,07$ & $2,02 \pm 0,04$ \\
\hline $\begin{array}{c}\mathrm{Au} @ \mathrm{Au}^{\mathrm{I}}-\mathrm{TMA} \text { NPs (post } \\
\text { reducción) }\end{array}$ & $1,3 \pm 0,1$ & $3,9 \pm 0,3$ \\
\hline
\end{tabular}
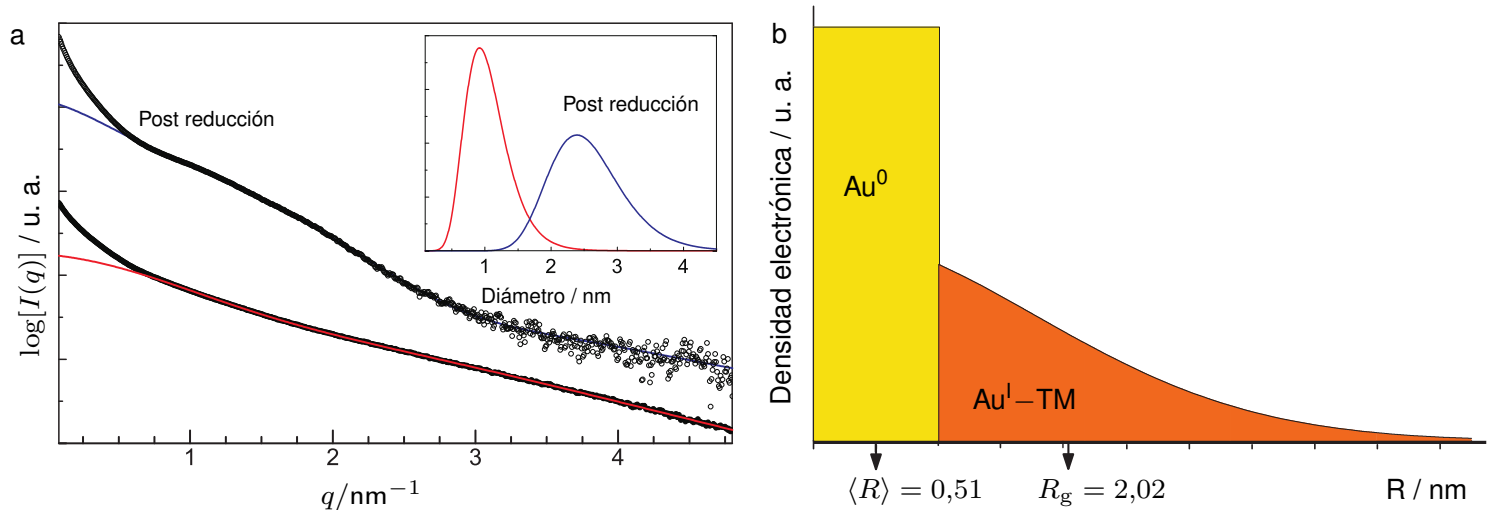

Figura 4.6: (a) Curvas de SAXS para $\mathrm{Au} @ \mathrm{Au}^{\mathrm{I}}-\mathrm{TM}$ NPs antes y después del tratamiento de post reducción junto con las cruvas de ajuste de trazo rojo y azul, respectivamente. Inset: Distribuciones de tamaño de los núcleos metálicos. (b) Esquema de la distribución de densidad electrónica propuesta para el ajuste de los datos de SAXS.

\subsection{Tamaño de las nanopartículas}

\subsubsection{Microscopía electrónica de transmisión (TEM)}

Las $\mathrm{Au} @ \mathrm{Au}^{\mathrm{I}}-\mathrm{TM}$ NPs fueron estudiadas también mediante TEM. En la Fig. $4.8 \mathrm{~b}^{8}$ se presenta una imagen de campo claro tomada con el microscopio Phillips CM 200 UT con un voltaje de aceleración de $200 \mathrm{kV}$. La muestra fue preparada mediante deposición de varias gotas de una suspensión sobre una grilla de $\mathrm{Cu}$ cubierta con una lámina de carbono amorfo de un lado y una de Formvar del otro (UltraThin Carbon Type A, TedPella). La muestra fue depositada del lado del Formvar ya que este es menos hidrofóbico que el carbono, lo que facilita la dispersión de las partículas hidrofílicas. Inesperadamente, el diámetro medio de estas partículas, obtenido del análisis de las imágenes de TEM, es de $\langle D\rangle=4 \pm 1 \mathrm{~nm}$, bastante mayor al obtenido por SAXS y al esperado en base al espectro UV-vis (Fig. 4.8). Sin embargo, este comportamiento está relacionado con la estructura propuesta para estas NPs (núcleo de $\mathrm{Au}$ rodeado por $\mathrm{Au} \mathrm{u}^{\mathrm{I}}-\mathrm{TM}$ ) y el efecto que puede

\footnotetext{
${ }^{8}$ Esta figura se presenta en una de las subsecciones siguientes debido a que a partir de ella se discuten otros resultados.
} 
producir el haz de electrones sobre ellas. En este aspecto, Kim et ál. [96] realizaron la síntesis de NPs mediante la irradiación de alcanotiolatos de $\mathrm{Au}\left(\mathrm{Au}^{\mathrm{I}}-\mathrm{SR}\right)$ con un haz de electrones de un TEM. En ese trabajo, los autores prepararon $\mathrm{Au}^{\mathrm{I}}-\mathrm{SC}_{18}$ y lo depositaron en una grilla de TEM. Al irradiar esta muestra utilizando un voltaje de aceleración de $300 \mathrm{kV}$, observaron la generación de NPs de $\sim 2 \mathrm{~nm}$. Además, determinaron que el tamaño de las NPs producidas depende de la energía de los electrones utilizados. Con voltajes de aceleración de $80 \mathrm{kV}$, el tamaño de las NPs sintetizadas fue de 5,0 nm mientras que con $200 \mathrm{kV}, 2,0 \mathrm{~nm}$. Por otro lado, el tamaño de las NPs aumenta al reducir el largo de la cadena hidrocarbonada del tiol. En nuestro caso, el $\mathrm{Au}^{\mathrm{I}}$ de la capa de $\mathrm{Au}^{\mathrm{I}}-\mathrm{TM}$ de las NPs puede ser reducido mediante el haz de electrones, incrementando el tamaño de los núcleos metálicos de las NPs, daño conocido como radiólisis [40].

Por lo tanto, el tamaño determinado por TEM está relacionado al Au metálico presente en la síntesis original y también al Au metálico generado mediante la reducción de $\mathrm{Au}^{\mathrm{I}}$ por el haz de electrones. Este resultado es consistente con el tamaño observado por el grupo de Kimura, utilizando una relación TMA:Au de 3:1 [138]. En este trabajo, los autores obtuvieron un diámetro $\langle D\rangle=3,4 \pm 0,8 \mathrm{~nm}$ (medido mediante TEM), mayor al que habían publicado anteriormente a partir de XRD $(1,02 \mathrm{~nm})$, utilizando una relación TMA:Au similar (2.5:1) [112]. Se puede comprender esta discrepancia en los valores teniendo en cuenta las diferencias en los métodos de caracterización utilizados en cada caso.

\subsubsection{Microscopía electrónica de barrido por transmisión (HAADF-STEM)}

El estudio de estas NPs mediante HAADF-STEM con corrección de aberración resulta muy interesante, debido a que en esta configuración la intensidad registrada es aproximadamente proporcional a $Z^{2}$, lo que permite la visualización de los átomos de Au presente en las capas de $\mathrm{Au}^{\mathrm{I}}-\mathrm{TM}$. Esto puede apreciarse en la Fig. 4.7. Los átomos de Au presentes en la capa de $\mathrm{Au}$ I $-\mathrm{TM}$ se observan rodeando las NPs. Debe tenerse en cuenta que la configuración de las NPs depositadas en la grilla de TEM e irradiadas por el cañón de electrones puede ser muy diferente a lo que ocurre cuando estas se encuentran dispersas en agua. Lo interesante de estas imágenes es que muestran de forma directa la diferencia con las AuNPs protegidas con una monocapa de tiolato $(\mathrm{Au} @ \mathrm{SR})$, como las presentadas en la ref. [139]. En esas NPs todo el Au presente se encuentra formando los núcleos metálicos y no se observa esta gran intensidad rodeando las partículas.

Es interesante notar que el daño por radiación producido por STEM parece ser menor al causado por TEM: los núcleos metálicos son menores y puede observarse Au rodeando las partículas, es decir no todo el Au fue reducido por el haz de electrones agrandando los núcleos. Si bien la corriente de electrones por unidad de área es mucho mayor en el caso de STEM, la irradiación en este caso es puntual (haz de $\sim 0,1 \mathrm{~nm}$ ) en lugar de afectar a gran parte de la muestra al mismo tiempo, como en el caso del haz paralelo que se utiliza en TEM.

En base a algunos de los resultados descritos anteriormente obtenidos con las diferentes técnicas, podría proponerse que la estructura de los productos sintetizados es en realidad la de muy pequeños clusters (10 - 30 átomos) formados por átomos de Au y moléculas 
a

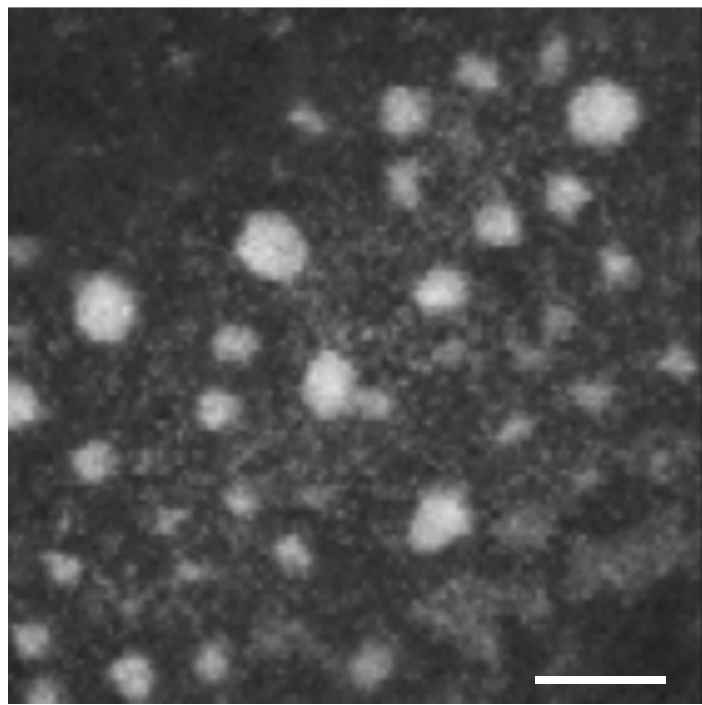

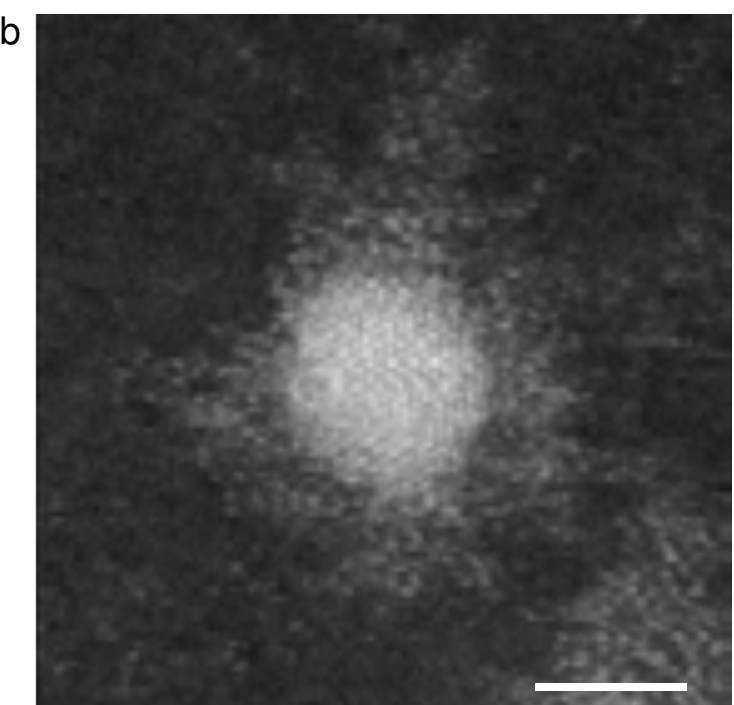

Figura 4.7: Imágenes de HAADF-STEM de Au@Au ${ }^{I}-T M$ NPs. (a) Imagen donde se observan distintas NPs. Notar que el tamaño de las partículas es en general menor al observado por TEM. Escala: $5 \mathrm{~nm}$. (b) Imagen de una NP donde se observa claramente un núcleo de $\mathrm{Au}$ cristalino rodeado por átomos de $\mathrm{Au}$ que forman parte del $\mathrm{Au}^{\mathrm{I}}-\mathrm{TM}$. Escala: $2 \mathrm{~nm}$

de TMA, como los preparados por Tsukuda et ál. [56, 140] que, si bien tienen la misma estequiometría que los complejos de $\left[\mathrm{Au}^{\mathrm{I}}-\mathrm{SR}\right]_{n}$, sus propiedades son diferentes a estos y se caracterizan como clusters. Sin embargo, si este fuera el caso, las imágenes de HAADFSTEM obtenidas serían significativamente diferentes. En lugar de observarse núcleos de Au rodeados de una estructura desordenada donde se encuentran átomos de Au, se obtendrían imágenes de estos clusters separados sin intensidad entre medio de ellos donde sólo estaría el fondo oscuro del carbono amorfo.

\subsubsection{Comparación entre el tamaño determinado mediante microscopía electrónica y dispersión de rayos $\mathrm{X}$ a bajo ángulo}

La discrepancia en el tamaño medido por los diferentes métodos muestra la necesidad de la combinación de distintas herramientas para poder comprender de mejor manera la estructura de las NPs. En la Fig. 4.8, se muestra una comparación entre la distribución de tamaños obtenida por TEM y la obtenida por SAXS para Au@Au ${ }^{\mathrm{I}}-\mathrm{TM}$ NPs. Además, hemos incluido en la misma figura los resultados obtenidos para AuNPs preparadas por el método de Brust-Schiffrin de dos fases cubiertas por dodecanotiolato ( $\left.\mathrm{Au} @ \mathrm{SC}_{12} \mathrm{NPs}\right)$, discutidas en la Sec. 3.4. A partir de la información experimental, es evidente que el hecho de que la composición química y estructura de estas NPs no sea la misma produce que las diferencias observadas en las distribuciones de tamaño medidas por ambas técnicas

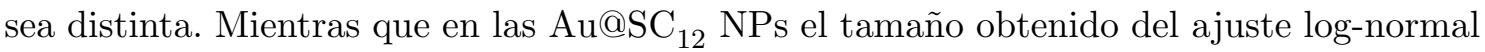
del histograma realizado a partir de las medidas de TEM $(\langle D\rangle=3,9 \pm 0,6 \mathrm{~nm})$ es muy cercano al obtenido por SAXs $(\langle D\rangle=3,6 \pm 0,4 \mathrm{~nm})$, en las Au@AuI-TM NPs la diferencia 
es notable: por TEM el valor obtenido es $\langle D\rangle=4 \pm 1 \mathrm{~nm}$ mientras que por SAXS este valor es de $\langle D\rangle=1,02 \pm 0,07 \mathrm{~nm}$.

Para comprender el origen de estas discrepancias, hay que tener en cuenta, en primer lugar, el tipo de técnica empleada. SAXS es una técnica promedio: todas las partículas dispersas en la solución afectarán al tamaño medido. Por otro lado TEM es una técnica local, cada partícula se cuenta individualmente y el alcance no es el mismo. En las muestras siempre existen partículas muy pequeñas $(D<1 \mathrm{~nm})$ que no se observan en las medidas de TEM convencional pero sí contribuyen en las medidas de SAXS. Esta puede ser la razón de la pequeña diferencia observada para las $\mathrm{Au} @ \mathrm{SC}_{12} \mathrm{NPs}(0,3 \mathrm{~nm})$ entre las dos técnicas. Por otro lado, la interacción de los rayos X y los electrones con la muestra también influye en el tamaño observado. Los electrones producen la reducción de las especies de $\mathrm{Au}^{\mathrm{I}}$ aumentando el tamaño medido en las $\mathrm{Au} @ \mathrm{Au}^{\mathrm{I}}$-TM NPs, mientras que en las $\mathrm{Au} @ \mathrm{SC}_{12}$ NPs este efecto no se produce ya que todo el Au se encontraría formando el núcleo metálico.

Hemos visto entonces que para validar un método de síntesis de NPs, es necesario conocer su composición química para poder comprender el tamaño obtenido por diferentes métodos. Más aún, es fundamental la combinación de diferentes técnicas de caracterización del tamaño. Entre ellas, las siguientes son las más utilizadas: TEM, SAXS, XRD, EXAFS, STM, dispersión de luz y cromatografía de exclusión por tamaño.

\subsection{Estructura cristalina de las nanopartículas}

Las NPs analizadas presentan estructura cristalina. Esto puede observase en el patrón de difracción de electrones de área selecta (selected area diffraction, SAD) y la imagen de campo oscuro (Fig. 4.9a, b) tomada seleccionado una porción de las reflexiones (111) y (200) con la apertura objetivo. El patrón de difracción obtenido es típico para una estructura cristalina $f c c$. Esta estructura no es la más estable para este tamaño de AuNPs a temperaturas cercanas a la temperatura ambiente, según lo predicen cálculos de termodinámica desde primeros principios [141]. Estos resultados muestran que estructuras icosaédricas y decaédricas son preferidas en este rango de tamaño. Sin embargo, hay que tener en cuenta que en estas aproximaciones no se tiene en cuenta la presencia del tiol como molécula protectora y que las condiciones bajo el haz de electrones pueden ser muy diferentes a las utilizadas en dichos cálculos. Más aún, específicamente estas NPs están siendo afectadas permanentemente por el haz de electrones que reduce las especies de $\mathrm{Au}^{\mathrm{I}}$ agrandando los núcleos metálicos.

La imagen de HRTEM de una partícula, tomada en la dirección [100] evidencia también la estructura $f c c$ de las mismas (Fig. 4.9c, d). Para interpretar las imágenes de HRTEM, se puede realizar una simulación de las mismas a partir de la construcción de un modelo, que para estas NPs puede considerarse un octaedro truncado (OT). Este es uno de modelos posibles para NPs monocristalinas con una estructura $f c c$. El OT expone caras cuadradas $\{100\}$ y hexagonales $\{111\}$ al exterior, y la serie completa se construye incrementando la cantidad de átomos $\mathcal{N}$ en las NPs, siendo $\mathcal{N}=16 n^{3}+15 n^{2}+6 n+1$, para $n=1,2,3,4, \ldots$ [142]. Es decir, $\mathcal{N}=38,201,586,1289, \ldots$ En la Fig. 4.10 se presentan los dos OT que hemos considerado para las simulaciones. 

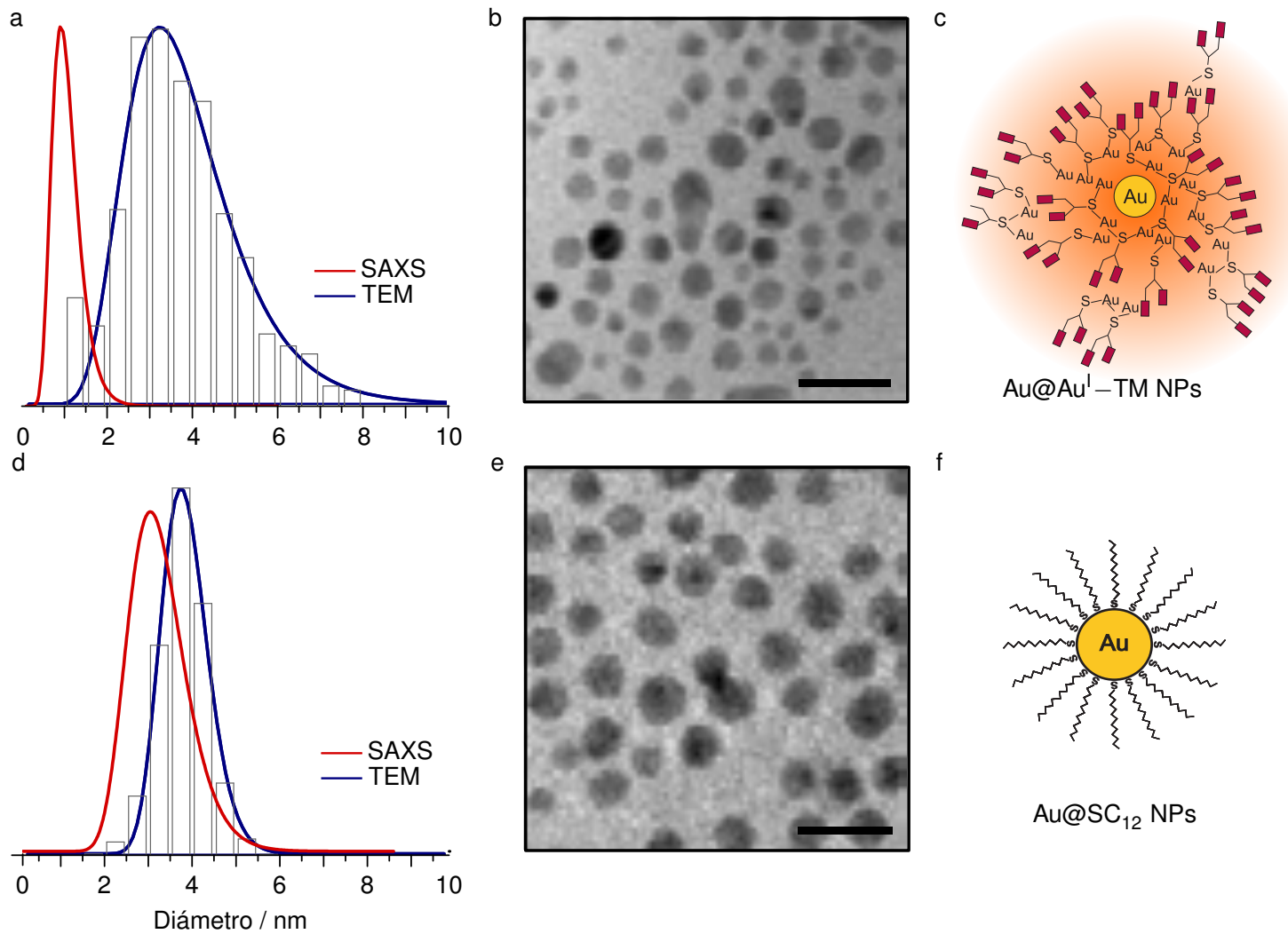

$\mathrm{Au} @ \mathrm{SC}_{12}$ NPs

Figura 4.8: Comparación entre el tamaño determinado por SAXS y TEM para NPs de $\mathrm{Au} @ \mathrm{Au}^{\mathrm{I}}-\mathrm{TM}$ y Au@SC $\mathrm{SC}_{12}$. (a, d) Distribución de tamaños determinada por SAXS y TEM para NPs de Au@Au ${ }^{\mathrm{I}}-\mathrm{TM}$ y Au@SC ${ }_{12}$, respectivamente. (b, e) Imagen de TEM de NPs de $\mathrm{Au} @ A u^{\mathrm{I}}-\mathrm{TM}$ y Au@SC ${ }_{12}$, respectivamente. Escalas: 10 nm. (c, f) Esquema de ambos tipos de NPs.

Las simulaciones se realizaron utilizando el software $j e m s^{9}$, que permite simular las condiciones experimentales utilizadas en la caracterización de la muestra. Se utilizó el método de simulación multislice. El mejor ajuste de las simulaciones a las imágenes experimentales fue obtenido mediante la rotación de los octaedros truncados $2^{\circ}$ respecto al eje de zona $f c c$ [110]. Las imágenes obtenidas se muestran en la Fig. 4.11.

\subsection{Estabilidad de las nanopartículas}

Una muestra de las $\mathrm{Au} @ A u^{\mathrm{I}}-\mathrm{TM}$ NPs dispersadas en agua fue almacenada durante 7 meses a $4{ }^{\circ} \mathrm{C}$. En la Fig. 4.12 se muestran los espectros XPS de Au $4 f$ y S $2 p$ de las NPs luego de dicho período. La señal de Au $4 f$ presenta las mismas componentes que en las muestras recién preparadas (Fig. 4.2), con la misma relación molar de $\mathrm{Au}^{\mathrm{I}}: \mathrm{Au}^{0}$. La señal de S $2 p$ presenta además una componente adicional en la zona de 167 a $168 \mathrm{eV}$. Esta señal corresponde a especies de $\mathrm{S}$ de alto estado de oxidación como sulfonatos [143], producidos

\footnotetext{
${ }^{9}$ P. A. Stadelmann. Jems software. http://cimewww.epfl.ch/people/stadelmann/jemsWebSite/jems.html.
} 

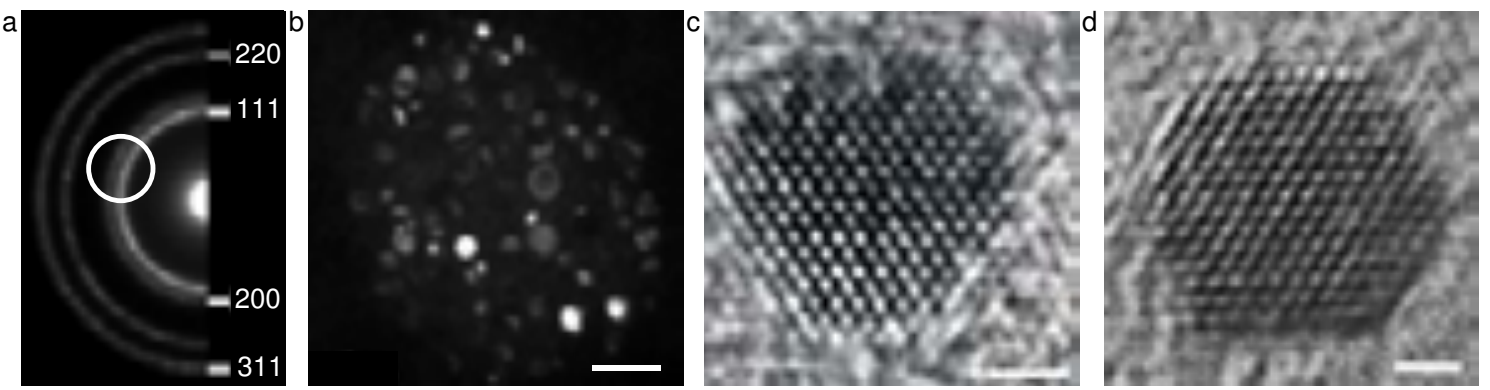

Figura 4.9: Estructura cristalina de las $A u @ A u^{I}-T M$. (a) Patrón de difracción de electrones de $A u @ A u^{I}-T M$ NPs. (b) Imagen de campo oscuro de $A u @ A u^{I}-T M$ NPs, escala: $10 \mathrm{~nm}$. (c, d) Imágenes de HRTEM de Au@Au-TM NPs de dos tamaños diferentes, escala: $1 \mathrm{~nm}$. Estas imágenes fueron filtradas para aumentar el contraste de las columnas atómicas.
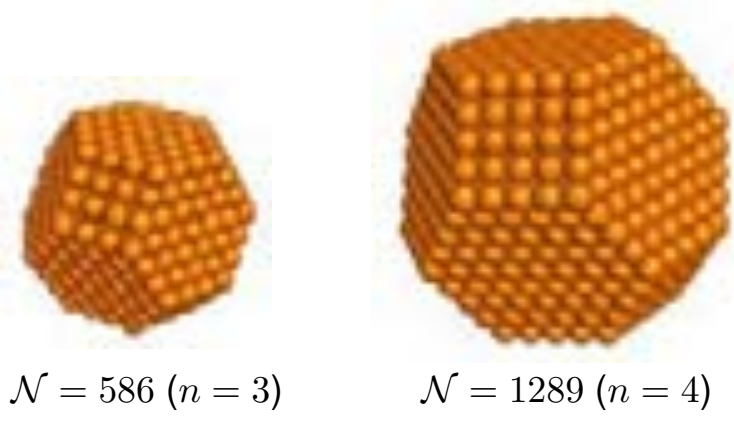

Figura 4.10: Octaedros truncados utilizados para la simulación de las imágenes de HRTEM. Construidos a partir de coordenadas cedidas por O. A. Oviedo.

durante el tiempo de almacenamiento de las partículas. La relación de intensidades indica que el $20 \%$ del azufre original fue oxidado durante este período de tiempo.

\subsection{Nanopartículas bimetálicas de Au-Ag preparadas a par- tir de nanopartículas de Au protegidas por tiomalato de $\mathrm{Au}$}

Debido a que en el proceso de post reducción detallado anteriormente sólo fue posible una reducción de aproximadamente el $50 \%$ de la cantidad total de Au presente en las NPs, se propone aquí una estrategia diferente.

En esta sección demostraremos que el obstáculo observado para la reducción de las especies poliméricas $\left[\mathrm{Au}^{\mathrm{I}}-\mathrm{TM}\right]_{n}$, puede ser superado ampliamente mediante la adición de cationes capaces de competir con el $\mathrm{Au}^{\mathrm{I}}$ en el enlace con las especies tiolato.

Los experimentos realizados consisten en la dispersión de las Au@AuI-TM NPs en una solución que se utiliza para realizar la deposición de Ag sobre Au a subpotenciales (UPD) [144]. Esta solución consta de la cupla rédox quinhidrona (Q/QH2) en una concentración 

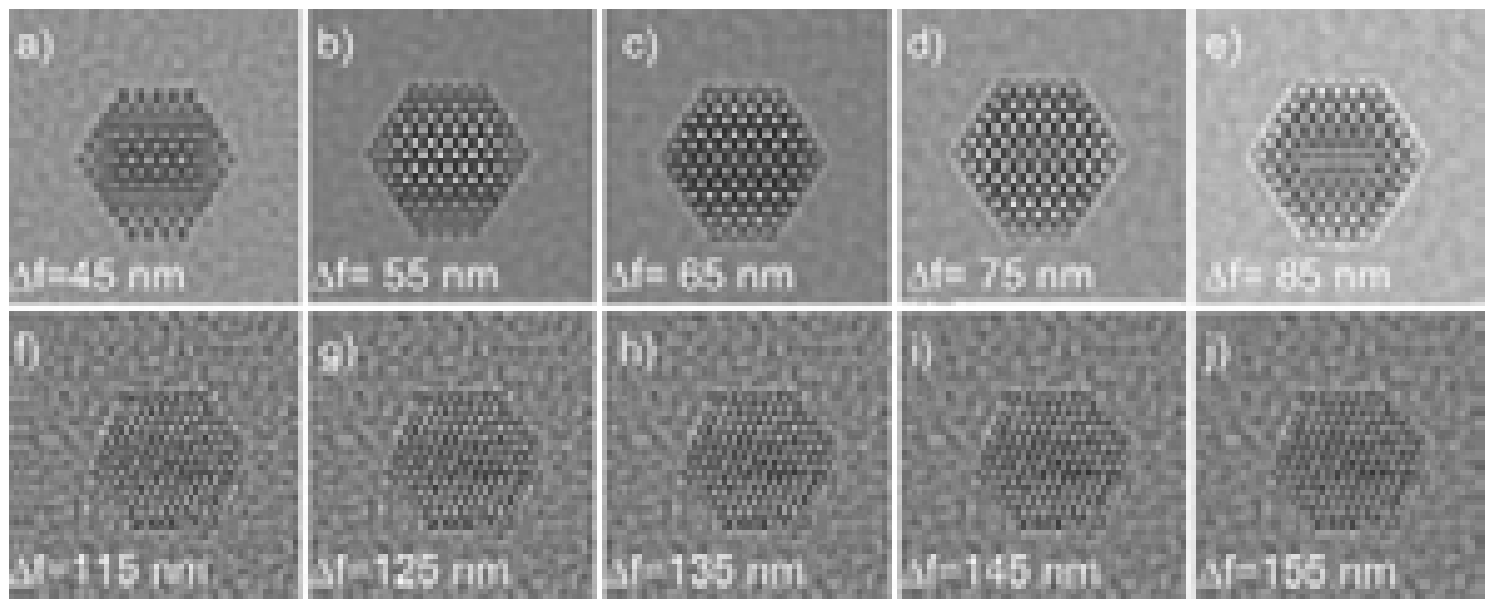

Figura 4.11: Simulaciones de las imágenes de HRTEM en el eje de zona $f c c$ [110] a partir de los octaedros truncados de: $(\mathbf{a}-\mathbf{e}) \mathcal{N}=586$ átomos; $(\mathbf{f}-\mathbf{j}) \mathcal{N}=1289$ átomos. Cada figura incluye el valor del defoco $(\Delta f)$. Las imágenes fueron simuladas considerando los parámetros del microscopio Phillips CM 200.
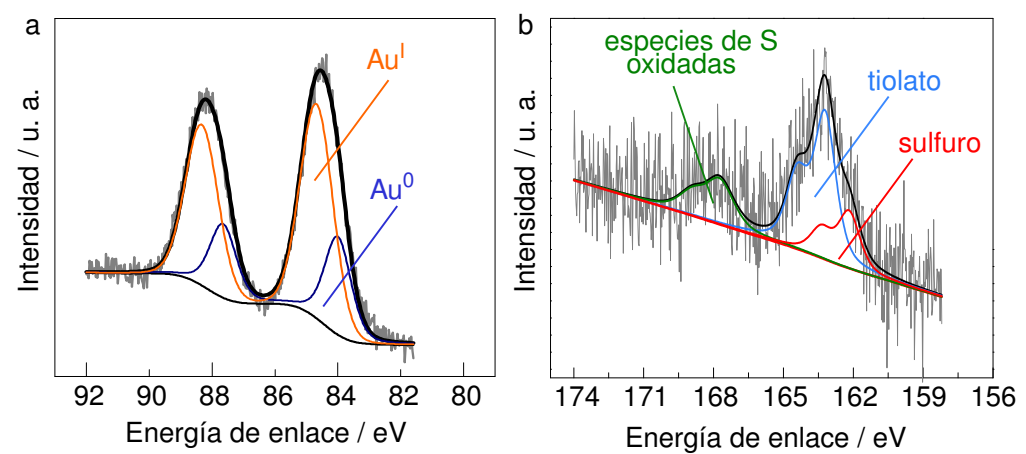

Figura 4.12: Espectros XPS de las Au@Au - TM NPs luego de 7 meses de ser preparadas. (a) Espectro XPS de Au $4 f$. (b) Espectro XPS de S $2 p$.

$1 \mathrm{mM}$, que consiste en una mezcla equimolar de $p$-benzoquinona e hidroquinona, iones $\mathrm{Ag}^{+}$en una concentración $1 \mathrm{mM} \mathrm{y} \mathrm{H}_{2} \mathrm{SO}_{4}$ 0,1 M. Si se coloca un sustrato de Au masivo en contacto con esta solución, se produce la deposición de 1 monocapa de Ag sobre la superficie del Au mediante el control del potencial del metal en la zona de subpotenciales [144].

En la Fig. 4.13 se muestran los espectros UV-vis de las $\mathrm{Au} @ \mathrm{Au}^{\mathrm{I}}-\mathrm{TM}$ NPs en diferentes soluciones. Puede observarse que no se evidencia ningún cambio al colocar las NPs en contacto con una solución de Q/QH2 $+\mathrm{H}_{2} \mathrm{SO}_{4}$ o solo iones $\mathrm{Ag}^{+}$. Sin embargo, cuando se colocan las NPs en contacto con una solución que contiene los tres componentes, se observa el incremento del pico en $\sim 520 \mathrm{~nm}$, correspondiente a la resonancia plasmónica superficial. El incremento en la intensidad de este pico indica un aumento en el tamaño de las NPs. Este aumento es producido por la reducción de los átomos de Au presentes inicialmente en el polímero.

El comportamiento descrito a través del espectro UV-vis es congruente con los resul- 


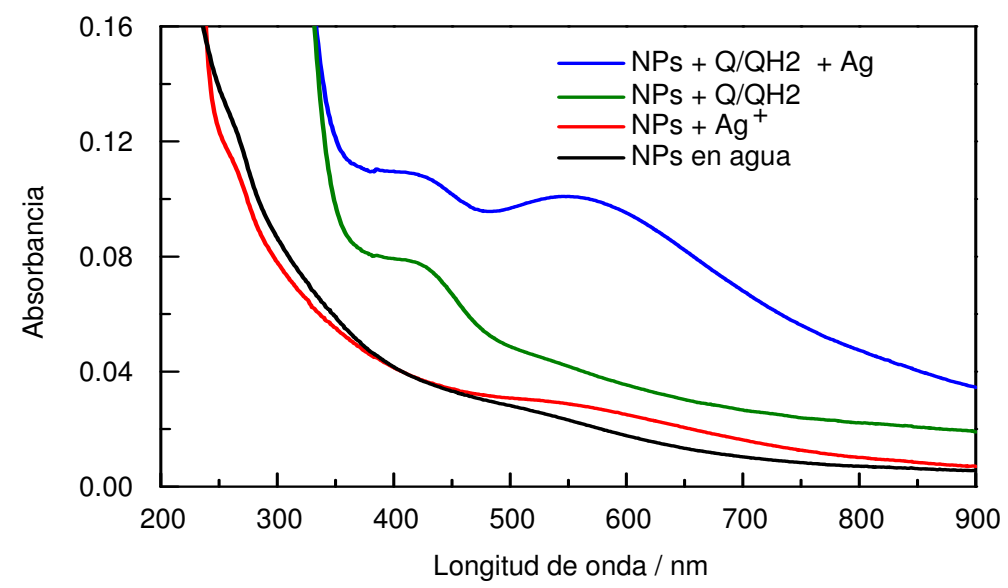

Figura 4.13: Espectros UV-vis de diferentes muestras. Línea negra: $0,01 \mathrm{mg} / \mathrm{mL}$ de $\mathrm{Au} @ A u^{\mathrm{I}}-\mathrm{TM}$ NPs en agua. Línea roja: $0,01 \mathrm{mg} / \mathrm{mL} \mathrm{Au} @ \mathrm{Au}-\mathrm{I} M \mathrm{NPs}+\mathrm{Ag}_{2} \mathrm{SO}_{4}$ 0,5 mM. Línea verde: Au@AuI-TM NPs + Q/QH2 1 mM. Linea azul: Au@Au - TM NPs + $\mathrm{Q} / \mathrm{QH} 21 \mathrm{mM}+\mathrm{Ag}_{2} \mathrm{SO}_{4} 0,5 \mathrm{mM}$.
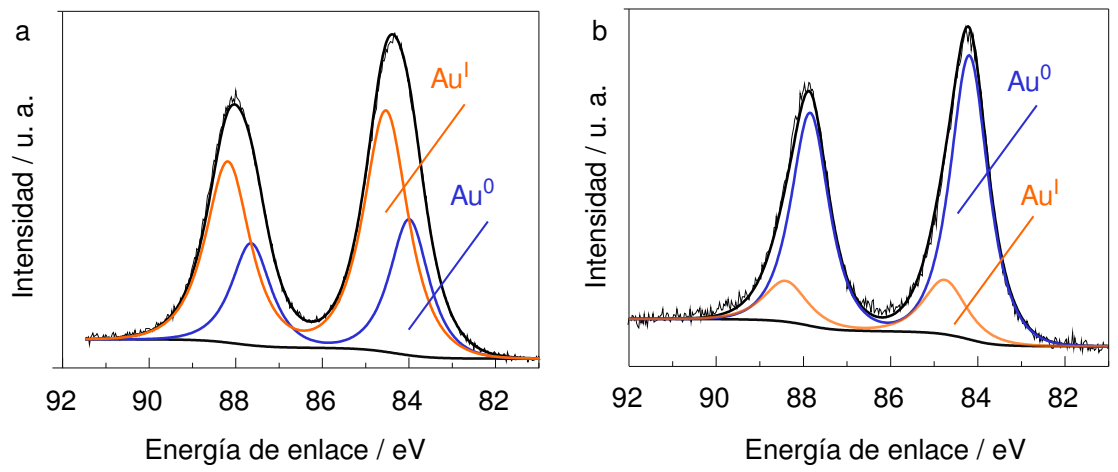

Figura 4.14: Señal de $\mathrm{Au} 4 f$ de (a) $\mathrm{Au} @ \mathrm{Au}^{\mathrm{I}}-\mathrm{TM}$ NPs tal como fueron preparadas y (b) luego de la modificación con $\mathrm{Ag}^{+}$y Q/QH2.

tados de XPS, mostrados en la Fig. 4.14. En esta figura se observa el espectro XPS de Au $4 f$ de las NPs antes y después del tratamiento con la solución de indicada. Mientras que las NPs originales están compuestas por $70 \%$ de $\mathrm{Au}^{\mathrm{I}}$ y $30 \%$ de $\mathrm{Au}^{0}$, luego del tratamiento, las NPs tienen una composición de $20 \%$ de $\mathrm{Au}^{\mathrm{I}}$ y $80 \%$ de $\mathrm{Au}^{0}$. Es decir, se logró la reducción de una cantidad $\mathrm{Au}^{\mathrm{I}}$ mucho mayor que con el tratamiento de post reducción. Es interesante notar que en ese tratamiento el reductor utilizado $\left(\mathrm{NaBH}_{4}\right)$ es más fuerte que en el comentado aquí (Q/QH2). La diferencia radica en la inclusión de iones $\mathrm{Ag}^{+}$en el medio de reacción.

En la Fig. 4.15 se presenta un esquema de un mecanismo propuesto para explicar el proceso observado. Primeramente, los iones $\mathrm{Ag}^{+}$compiten con el $\mathrm{Au}$ por la unión con las especies tiolato. Aunque la constante de estabilidad de los complejos de $\mathrm{Au}^{\mathrm{I}}$ es mayor que la de $\mathrm{Ag}^{\mathrm{I}}$, los cationes $\mathrm{Ag}^{+}$se encuentran en exceso con respecto a los cationes $\mathrm{Au}^{\mathrm{I}}$. Cuando los iones $\mathrm{Au}^{\mathrm{I}}$ se liberan de los ligandos de TMA, pueden ser reducidos sobre la superficie de los núcleos de Au originales ya que el potencial de la cupla rédox al $\mathrm{pH}$ 

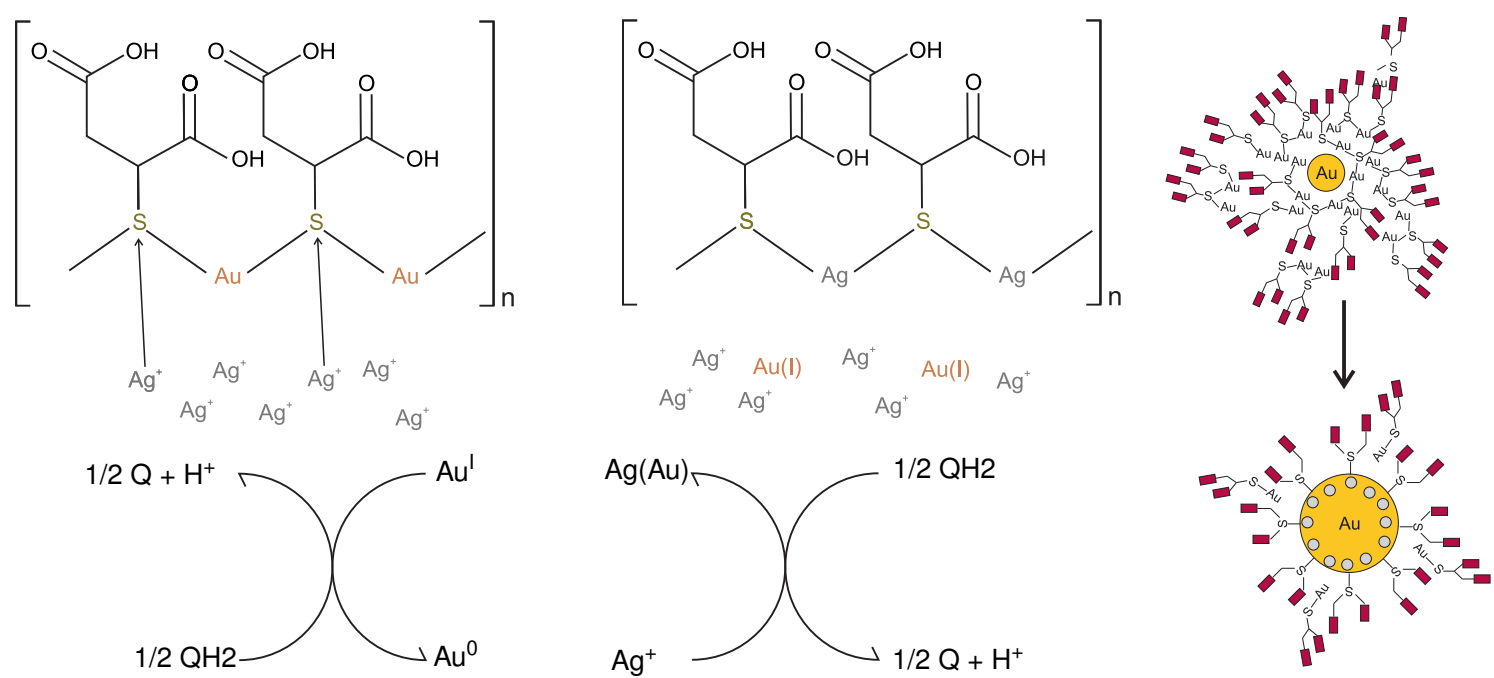

Figura 4.15: Esquema de reacción propuesto para la reducción de $\mathrm{Au}{ }^{\mathrm{I}}-\mathrm{TM}$ mediante $\mathrm{Ag}^{+}$y Q/QH2.

utilizado $(\sim 0,65 \mathrm{~V}$ vs. ENH) es suficiente para producir esta reacción. Simultáneamente, los iones de $\mathrm{Ag}^{+}$libres pueden ser depositados a subpotenciales sobre la superficie de Au. Debido al potencial de la cupla rédox, la Ag puede depositarse sólo a subpotenciales, i. e. no puede depositarse en forma masiva. De esta forma, se obtienen NPs bimetálicas de $\mathrm{Au}-\mathrm{Ag}$.

\subsection{Conclusiones}

Como hemos discutido anteriormente, las especies poliméricas de $\mathrm{Au}{ }^{\mathrm{I}}-\mathrm{SR}$ han sido propuestas como precursores en las diferentes rutas de síntesis de NPs de Au protegidas con tiolatos $[78,81,92,145]$. Aunque recientemente se ha encontrado que las especies precursoras en la síntesis de Brust-Schiffrin de dos fases no son tiolatos de Au, estos intermediarios sí existen cuando la síntesis se realiza en un solvente polar [55, 79]. El estudio realizado en este capítulo aporta grandes evidencias a favor de este argumento ya que hemos demostrado, de manera consistente, mediante diferentes técnicas experimentales, la presencia de $\mathrm{Au}^{\mathrm{I}}-\mathrm{SR}$ en las NPs sintetizadas.

Por otro lado, ha sido propuesto que las NPs protegidas con una monocapa de tiolatos están cubiertas por unidades del tipo $\mathrm{RS}-\mathrm{Au}$ - SR [16, 53, 72-74] y además estas estructuras han sido encontradas en las SAMs de tiolatos sobre Au [60, 61, 146]. La naturaleza de estas especies está íntimamente relacionada con la de los complejos moleculares de $\left[\mathrm{Au}^{\mathrm{I}}-\mathrm{SR}\right]_{n}$ [58]. Por lo tanto, las NPs de $\mathrm{Au} @ \mathrm{Au}^{\mathrm{I}}-\mathrm{TM}$ podrían ser consideradas de naturaleza intermedia entre los tiolatos de Au y las NPs protegidas por una monocapa de tiolatos, que en lugar de proceder hacia la reducción total del $\mathrm{Au}^{\mathrm{I}}$ para formar núcleos de $\mathrm{Au}$ protegidos por una capa de tiolato, quedan atrapadas en una estructura compuesta por núcleos de $\mathrm{Au}$ metálico cubiertos por capas poliméricas de $\mathrm{Au}$ - TM. La naturaleza del tiol y el solvente utilizado deben jugar un rol importante en la obtención de este tipo 
de NPs, ya que al utilizar otros tioles u otros solventes, se produce la reducción total [53, 81, 145], es decir, la reducción de $\mathrm{Au}^{\mathrm{I}}-\mathrm{SR}$ mediante $\mathrm{NaBH}_{4}$ produce NPs metálicas. Goulet y Lennox han propuesto que, debido a la baja solubilidad de los tiolatos de $\mathrm{Au}$, la reducción de estos es, en realidad, una reacción heterogénea, lo que puede dar lugar a productos compuestos por mezclas entre $\mathrm{Au}^{0}$ y $\mathrm{Au}^{\mathrm{I}}-\mathrm{SR}$ [55].

En un esquema de reacción posible para la síntesis de estas NPs, el precursor de $\mathrm{Au}\left(\mathrm{HAuCl}_{4}\right)$ es reducido en primer lugar por el TMA, produciendo oligómeros del tipo $\left[\mathrm{Au}^{\mathrm{I}}-\mathrm{TM}\right]_{n}$ (Ec. 4.18 y 4.19). Debido a que el TMA es utilizado en defecto respecto al $\mathrm{HAuCl}_{4}$ (considerando una relación estequiométrica de 3:1), parte del $\mathrm{HAuCl}_{4}$ permanece en exceso. Luego, este exceso de $\mathrm{HAuCl}_{4}$ y el $\left[\mathrm{Au}^{\mathrm{I}}-\mathrm{TMA}\right]_{n}$ reaccionan con $\mathrm{NaBH}_{4}$ donde se produce una reducción parcial de las especies de $\mathrm{Au}^{\mathrm{I}}$ y se forman las NPs de $\mathrm{Au} @ \mathrm{Au}^{\mathrm{I}}-\mathrm{TM}$ (Ec. 4.20). Estas NPs están compuestas por aproximadamente $30 \%$ de $\mathrm{Au}^{0}$ y $70 \%$ de $\mathrm{Au}^{\mathrm{I}}$.

$$
\begin{aligned}
& \mathrm{HAuCl}_{4}+3 \mathrm{RSH} \longrightarrow \mathrm{Au}^{\mathrm{I}}-\mathrm{RS}+\mathrm{RS}-\mathrm{SR}+4 \mathrm{HCl} \\
& n\left[\mathrm{Au}^{\mathrm{I}}-\mathrm{RS}\right] \longrightarrow\left[\mathrm{Au}^{\mathrm{I}}-\mathrm{RS}\right]_{n} \\
& \mathrm{HAuCl}_{4}+\left[\mathrm{Au}^{\mathrm{I}}-\mathrm{RS}\right]_{n} \stackrel{\mathrm{NaBH}_{4}}{\longrightarrow} \mathrm{Au} @ \mathrm{Au}^{\mathrm{I}}-\mathrm{SR} \text { NPs }
\end{aligned}
$$

donde RSH $=$ TMA.

Se podría argumentar que la formación de $\mathrm{Au}^{0}$ proviene de la reducción del exceso de $\mathrm{HAuCl}_{4}$ solamente y todo el $\mathrm{Au}^{\mathrm{I}}$-TMA producido es observado luego cubriendo las NPs. Sin embargo, en síntesis utilizando una relación molar de TMA:Au = 12.5:1, hemos observado resultados similares a los que discutimos en este capítulo mediante caracterización por XPS y UV-vis.

Luego de sintetizadas y lavadas, las NPs fueron sometidas a un segundo tratamiento de reducción. Esta post reducción produjo un aumento en la cantidad relativa de Au metálico pero la reducción no fue total. Tanto las NPs preparadas inicialmente como las tratadas con la post reducción pueden considerarse como intermediarios en la síntesis de AuNPs cubiertas por tiolatos. Si fuera posible llegar a una reducción completa de la capa de $\mathrm{Au}^{\mathrm{I}}-\mathrm{TM}$, el producto final sería equivalente a esas NPs.

Es probable que al formarse inicialmente los núcleos de Au metálico, en la síntesis de las NPs a través de la reducción del polímero, estos sean cubiertos por el polímero gradualmente limitando y finalmente bloqueando el crecimiento de los mismos. Por otro lado, puede ocurrir que en el caso particular del TMA, la fragmentación del polímero por el $\mathrm{BH}_{4}^{-}$para crear enlaces $\mathrm{Au}-\mathrm{Au}$ se encuentre limitada impidiendo la reducción total de las especies de $\mathrm{Au}^{\mathrm{I}}$ [124]. Un estudio detallado del mecanismo de formación de estas $\mathrm{Au} @ \mathrm{Au}^{\mathrm{I}}-\mathrm{TM}$ NPs y del efecto de las distintos parámetros en la composición del producto final, así como la preparación de NPs cubiertas por TM mediante intercambio de ligandos en partículas previamente sintetizadas, puede ser muy interesante para comprender más precisamente no solo esta síntesis en particular sino las diferentes síntesis de NPs protegidas por tioles.

Por último, se presentó un procedimiento para la reducción del tiomalato de Au mediante la inmersión de las NPs en una solución de Q/QH2 y iones Ag. De esta forma se sintetizaron Au-Ag NPs. 
En la Fig. 4.16 presentamos un esquema en el que se compara los dos métodos de Brust-Schiffrin para la síntesis de NPs, construido en base a los trabajos publicado en la literatura, mayormente discutidos en el capítulo anterior, junto con los resultados desarrollados en el presente capítulo.
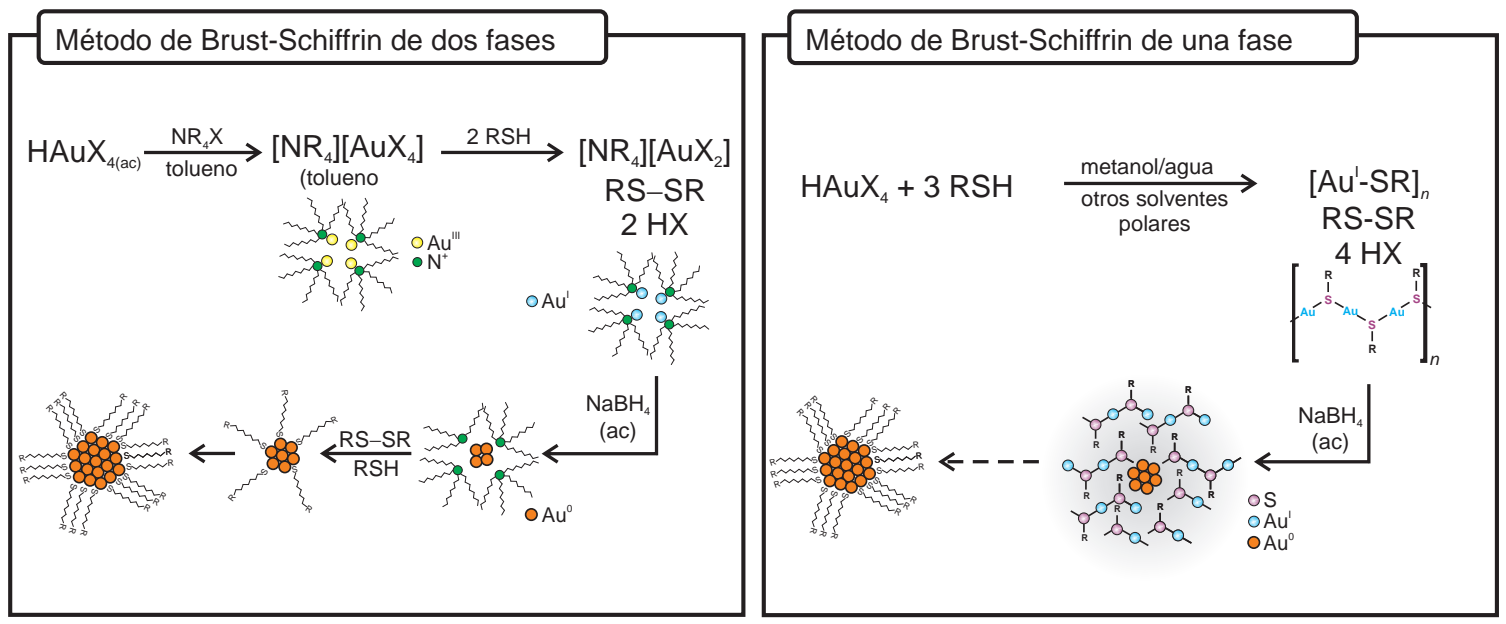

Figura 4.16: Esquema de las reacciones involucradas en los dos métodos de Brust-Schiffrin para su comparación. En el método de una fase, al agregar el reductor se producen núcleos metálicos cubiertos por especies de $\mathrm{Au}^{\mathrm{I}}-\mathrm{SR}$. La reacción continúa hacia la formación de las NPs en algunos casos (ciertos tioles y condiciones de síntesis) pero en otros se detiene en este punto (como el caso discutido en este capítulo). 


\section{Parte III}

\section{Interfase Pd-tiol}





\section{Capítulo 5}

\section{Adsorción de alcanotioles sobre superficies planas de Pd}

\subsection{Introducción}

Aunque hay ciertos aspectos de la interfase $\mathrm{Au} /$ tiol que aún resta comprender, la profundidad en el conocimiento de este sistema dista mucho del estado actual del sistema $\mathrm{Pd} /$ tiol. Un ejemplo de este punto lo da el conocimiento teórico de ambos. Mientras que existen diversos modelos para la interfase $\mathrm{Au} /$ tiol y han sido ampliamente estudiados desde primeros principios [17] aún en NPs [16, 74, 134], la estructura electrónica de un solo modelo ha sido publicada en el caso de la interfase $\mathrm{Pd} /$ tiol [147].

Los tioles forman SAMs sobre superficies de Pd, y estos sistemas (comprendiendo tanto superficies planas como NPs) revisten utilidad en diferentes aplicaciones como protectores hacia la corrosión química [148], sensores de gases [12], catalizadores [149], dispositivos de uso en biotecnología [150], etc. La mayoría de los estudios centrados en la aplicación de estos sistemas a un fin específico no se detienen a comprender en detalle los mecanismos responsables de su función, dados por su composición y estructura. Más aún, incluso en estudios recientes, la composición de los sistemas estudiados se describe de forma imprecisa y algunas veces errada, al tratar de asemejarla a lo encontrado en los sistemas de Au/tiol.

Esto indica que el estudio de la composición y estructura de distintos sistemas que involucran la interfase $\mathrm{Pd} /$ tiol resulta muy interesante. Si sumamos a este aspecto el hecho de que la adsorción de tioles sobre Pd presenta un comportamiento más complejo que sobre $\mathrm{Au}$, el atractivo de este sistema es todavía mayor.

El primer grupo en estudiar de manera detallada la formación de SAMs de tioles sobre superficies planas de Pd fue el grupo de G. Whitesides, en 2003 [151]. En este artículo se estudiaron, mediante XPS y FTIR, sustratos de Pd policristalino modificados con alcanotioles desde solución. Los autores propusieron un modelo que consiste en una capa mixta de alcanotiolatos y sulfuro de Pd. Entre el Pd metálico y una capa densa de alcanotiolatos se ubica una capa de $\mathrm{PdS}_{\mathrm{x}}$ que debe ser formada mediante ruptura de enlaces $\mathrm{S}-\mathrm{C}$ de los alcanotioles en la superficie de Pd. La evolución de las SAMs de alcanotioles sobre $\mathrm{Pd}$ en contacto con el aire a lo largo del tiempo también fue estudiada mediante 
XPS, encontrándose que el azufre se oxida casi totalmente a especies como sulfonatos en 5 días. Esto muestra que la estabilidad de estas SAMs en aire es menor que el caso de las análogas sobre $\mathrm{Au}$ [143] o $\mathrm{Cu}$ [152] donde la estabilidad se extiende por semanas.

En algunas de las aplicaciones de sistemas que incluyen la interfase Pd/tiol (sobre todo en NPs), resulta necesario la limpieza de la superficie para poder exponer el metal a, por ejemplo, las especies que intervienen en una reacción química. Es decir, los tioles son indispensables en parte del proceso de síntesis del sistema pero interfieren negativamente durante la utilización de los mismos. Existen diversos métodos para limpiar estos sistemas como el tratamiento térmico o mediante oxidantes fuertes como ozono [153]. Sin embargo, estos tienen la desventaja de modificar la estructura del sistema (p. ej. el tamaño en el caso de las NPs) y el estado de oxidación del metal. Una opción para superar este problema se encuentra en la electrodesorción mediante polarización por aplicación de potenciales negativos. Este método consiste en desorber los tioles mediante la aplicación de un potencial lo suficientemente negativo. Es interesante entonces estudiar la estabilidad electroquímica de las SAMs de alcanotioles sobre Pd. Williams y Gorman, en el año 2007 [154], han abarcado este estudio en SAMs de alcanotioles sobre Pd. A diferencia de las SAMs de alcanotioles sobre $\mathrm{Au}$ o Ag donde la electrodesorción reductiva se puede estudiar mediante la integración del pico observado en una voltamperometría cíclica [155], no es posible en el caso del Pd ya que la desorción ocurre a potenciales más negativos que el correspondiente a la reacción de desprendimiento de hidrógeno (HER). Por lo tanto, los autores utilizan la cupla rédox de ferro/ferricianuro como sonda para estudiar la electrodesorción de alcanotioles sobre Pd en soluciones etanólicas básicas. Los resultados demuestran que la ventana de potencial en la que estas SAMs son estables es menor que en el caso de Au. Sin embargo, como veremos más adelante, la utilización de una cupla como sonda de un proceso de desorción de una SAM de una superficie presenta ciertos problemas.

En este capítulo describiremos los resultados acerca de la formación de SAMs de tioles sobre $\mathrm{Pd}$ en relación a la naturaleza química de la interfase tiol/Pd plano para luego centrarnos en el estudio de su estabilidad electroquímica mediante un método alternativo al utilizado previamente para este sistema. Luego, discutiremos resultados de diferentes modelos planteados para las SAMs de tioles sobre Pd, derivados de cálculos basados en la teoría del funcional de densidad (DFT) y termodinámica estadística desde primeros principios, realizados por la Dra. Pilar Carro, de la Universidad de La Laguna, España. Mediante el análisis de los resultados experimentales y los cálculos computacionales propondremos un esquema para explicar el motivo por el cual las SAMs de alcanotioles sobre Pd están compuestas por una estructura mixta constituida por sulfuro de Pd y alcanotiolatos.

\subsection{Preparación de los sustratos de paladio}

Para estudiar la adsorción de moléculas sobre un metal es imprescindible contar con una superficie bien definida. En este aspecto, los sustratos por excelencia son los monocristales, que consisten en un cristal único cortado de manera tal de exponer una determinada cara cristalina hacia el exterior. Estos sustratos tienen la desventaja de ser muy costosos y requieren facilidades especiales para la preparación de las superficies. Para el trabajo en 
contacto con soluciones acuosas y en experimentos electroquímicos, una alternativa para obtener superficies con caras cristalinas bien definidas es la utilización de películas delgadas de metales a las que se les realiza un tratamiento térmico. Así, pueden obtenerse superficies con una orientación cristalográfica preferencial en cierta dirección.

Un ejemplo de estos sustratos son las películas delgadas de $\mathrm{Au}$, con orientación preferencial de las caras (111), preparadas por recocido. Los sustratos de Au utilizados en este trabajo fueron provistos por la firma Arrandee ${ }^{1}$, y son desarrollados originalmente para nanoscopías. Estos sustratos miden $(12 \times 12) \mathrm{mm}^{2}$ y soportan una película de $\mathrm{Au}$ de $250 \pm 50 \mathrm{~nm}$ de espesor. Esta película se obtiene por evaporación sobre una placa de vidrio borosilicato de $0,7 \mathrm{~mm}$ de espesor que contiene una capa de $\mathrm{Cr}$ de $2,5 \pm 1,5 \mathrm{~nm}$ de espesor para aumentar la adherencia del $\mathrm{Au}$ al vidrio. Las películas de Au obtenidas por evaporación son policristalinas. Por lo tanto, para obtener películas con una orientación preferencial de las caras (111), es necesario someterlas a un tratamiento térmico llamado recocido (flame annealing). Este procedimiento consiste en calentar el sustrato de $\mathrm{Au}$ con un mechero de hidrógeno o butano hasta alcanzar una temperatura aproximada de $650^{\circ} \mathrm{C}$. De esta manera, es posible obtener terrazas de $\mathrm{Au}(111)$ de aproximadamente $(100 \times 100) \mathrm{nm}^{2}$. El proceso de recocido es simple y es posible contar con varios sustratos para realizar diferentes experiencias en forma simultánea. Estos sustratos de Au se pueden lavar con solución "piraña" (véase Sec. 2.1) para asegurar una superficie libre de contaminantes. Los sustratos de $\mathrm{Au}(111)$ fueron utilizados para electrodepositar Pd y obtener así las superficies sobre las que se estudió la adsorción de tioles. La electrodeposición de Pd se realizó desde una solución de $\mathrm{PdCl}_{2} 1 \mathrm{mM}+\mathrm{HCl} 2 \mathrm{mM}+\mathrm{H}_{2} \mathrm{SO}_{4}$ 0,1 M, utilizando una celda electroquímica de tres electrodos. Como electrodo de referencia se utilizó un electrodo de calomel saturado (ECS) y como contra electrodo, una lámina de Pt de alta área. Se aplicó una función lineal de potencial de $1 \mathrm{mV} \mathrm{s}^{-1}$ desde 0,80 hasta $0,40 \mathrm{~V}$ y luego de se mantuvo este potencial constante por $10 \mathrm{~min}$. De esta forma se deposita la primera capa de Pd a subpotenciales (underpotential deposition, UPD) y las siguientes capas en la zona de deposición a sobrepotenciales (overpotential deposition, OPD), como se muestra en la Fig. 5.1. En esta figura, similar a las publicadas anteriormente [156, 157], se muestra el voltamperograma completo, que comprende tanto la deposición (reducción) como la redisolución (oxidación) del Pd. La densidad total de carga depositada equivale a la formación de aproximadamente 50 monocapas de Pd. En estas condiciones, se obtienen terrazas de Pd con una orientación preferencial (111), como se observa a partir de la imagen de STM y el patrón de difracción de rayos X (XRD) de polvo en la Fig. 5.2. Luego de la electrodeposición, los sustratos fueron lavados, primero con $\mathrm{H}_{2} \mathrm{SO}_{4} 0,1 \mathrm{M}$, luego con agua Milli-Q y finalmente con etanol, luego de lo cual fueron secados bajo corriente de nitrógeno.

La limpieza de los sustratos fue controlada mediante voltamperometría cíclica y XPS, mostrados en la Fig. 5.3. Del espectro, es evidente la ausencia de contaminantes $\left(\mathrm{Cl}^{-}, \mathrm{S}\right.$, $\mathrm{SO}_{4}^{2-}$ ). Sólo existe una pequeña cantidad de carbono proveniente de contaminación atmosférica como consecuencia del proceso de transferencia desde la celda electroquímica a la cámara de UHV. No resulta evidente la presencia de óxidos de Pd. Sin embargo, este

\footnotetext{
${ }^{1}$ Arrandee, Werther, Alemania, http://www. arrandee.com/.
} 


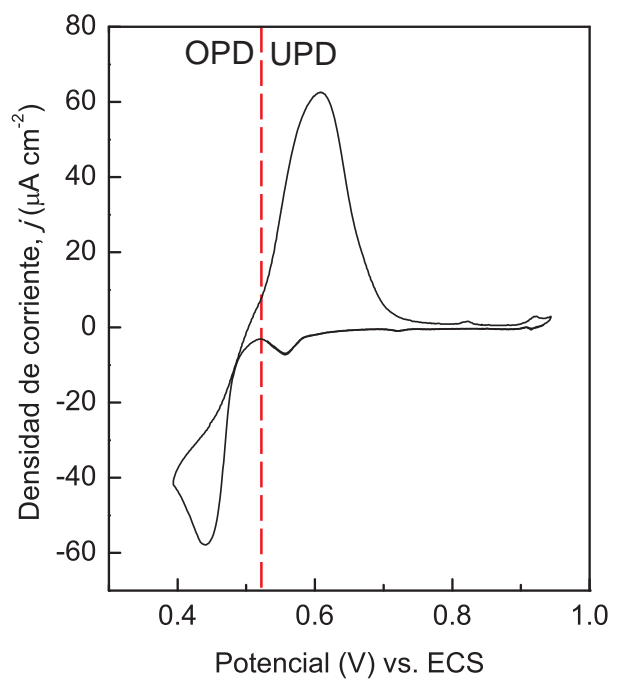

Figura 5.1: Voltamperograma típico de electrodeposición y redisolución de $\mathrm{Pd}$ sobre $\mathrm{Au}(111)$ desde una solución de $\mathrm{PdCl}_{2} 1 \mathrm{mM}+\mathrm{HCl} 2 \mathrm{mM}+\mathrm{H}_{2} \mathrm{SO}_{4}$ 0,1 M a $1 \mathrm{mV} \mathrm{s}^{-1}$. La linea punteada muestra la división entre la zona de deposición a subpotenciales (UPD) y sobrepotenciales (OPD).
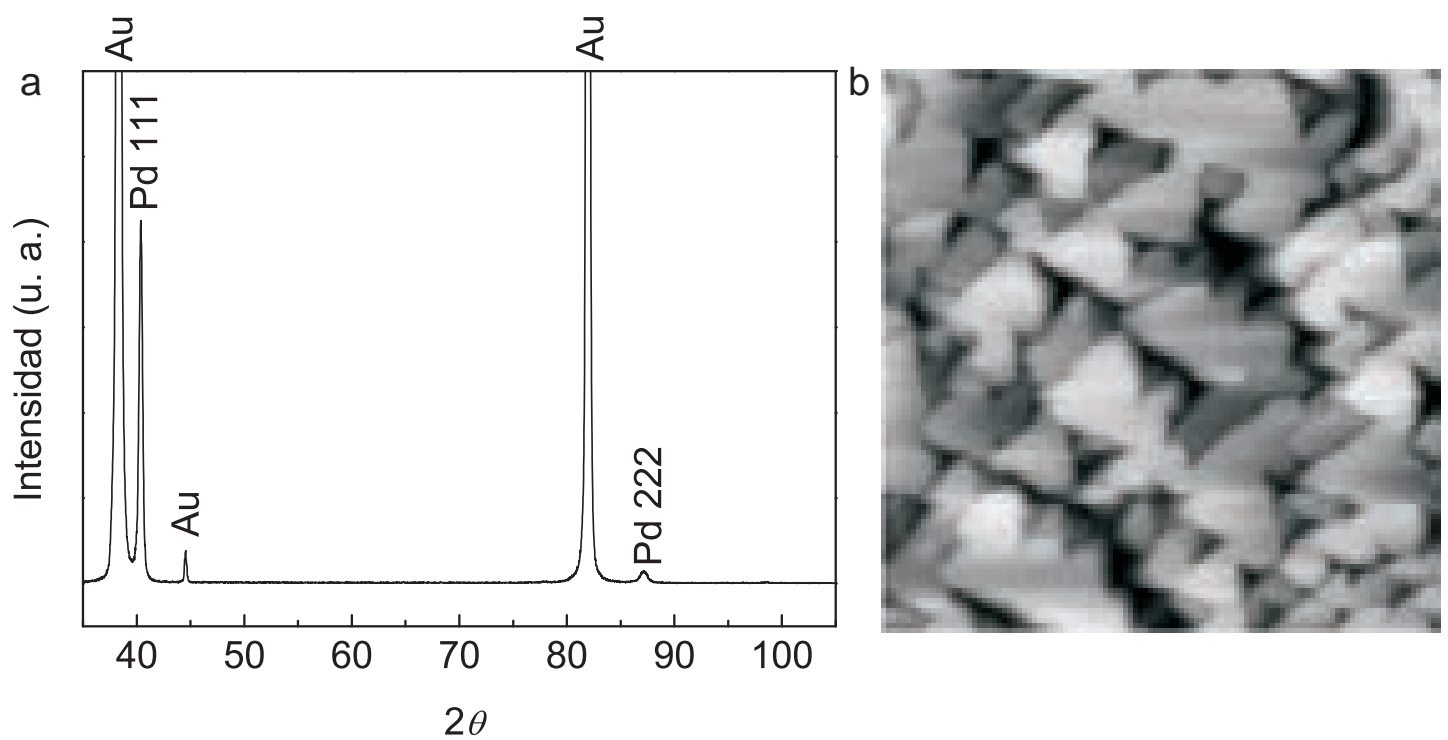

Figura 5.2: (a) Patrón de XRD por el método de polvo de una película de Pd electrodepositada sobre $\mathrm{Au}(111)$. Se observa la orientación preferencial en la dirección [111]. (b) Imagen de STM de la película de Pd de $(200 \times 200) \mathrm{nm}^{2}$. Se observan terrazas triangulares, típicas de la orientación (111). 

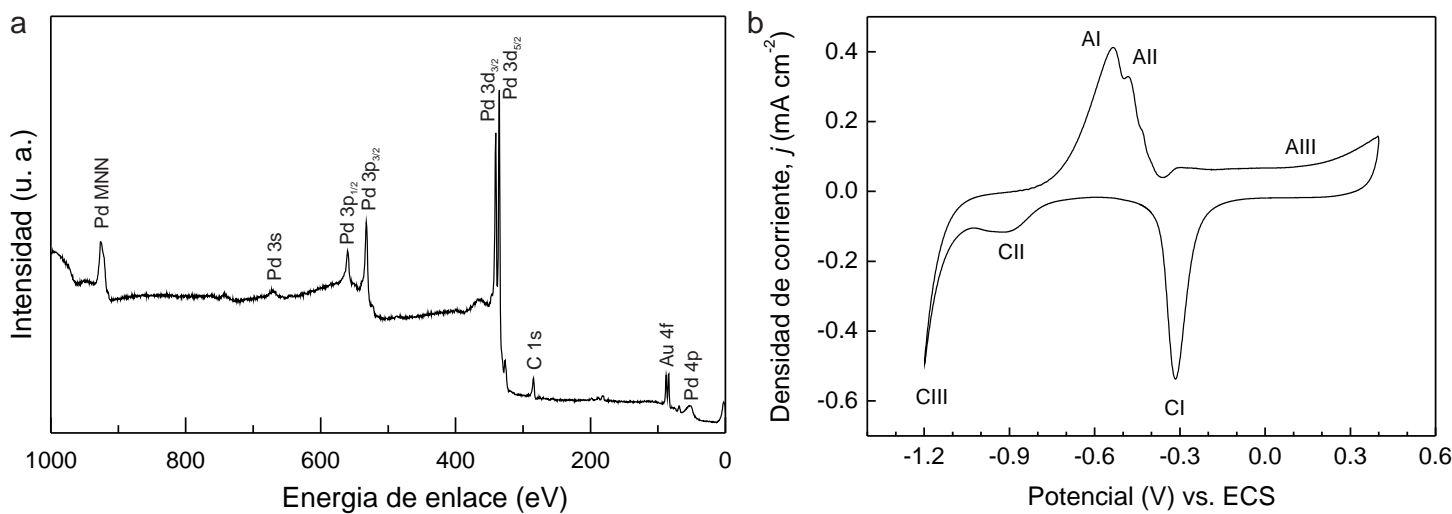

Figura 5.3: (a) Espectro XPS de Pd electrodepositado sobre Au. (b) Voltamperometría cíclica de $\mathrm{Pd}$ en $\mathrm{NaOH}$ 0,1 M, velocidad de barrido: $100 \mathrm{mV} \mathrm{s}^{-1}$.

metal tiene gran tendencia a adsorber oxígeno en la superficie que puede dar lugar a la formación de óxidos superficiales. De todas maneras, aunque esto ocurra, ha sido recientemente demostrado que al adsorber alcanotioles desde soluciones etanólicas, la superficie es limpiada por esta solución, generando una superficie de Pd metálica sobre la que es posible la adsorción de alcanotioles [158]. Más aún, medidas del potencial a circuito abierto (open circuit potential, OCP) de un electrodo de $\mathrm{Pd}$ en una solución de etanol $1 \mathrm{M}$ en $\mathrm{NaOH}$ 0,1 M indican que al introducir en la solución un tiol con una concentración final $\sim 0,4 \mathrm{mM}$ el potencial alcanzado (entre $-0,28$ y $-0,35 \mathrm{~V}$ ) corresponde a la zona donde el Pd se encuentra reducido, en equivalencia a lo observado en Pt [159]. En la Fig. 5.3b se muestra un voltamperograma estacionario de un sustrato de $\mathrm{Pd}$ en $\mathrm{NaOH} 0,1 \mathrm{M}$, preparado por electrodeposición. Este voltamperograma fue adquirido luego de comenzar el barrido de potencial en $-0,4 \mathrm{~V}$ en la dirección negativa hasta alcanzar $-1,2 \mathrm{~V}$ y luego ciclar repetidamente el potencial entre $-1,2$ y $0,4 \mathrm{~V}$. En el barrido positivo la superficie de $\mathrm{Pd}$ comienza a oxidarse en $\sim 0 \mathrm{~V}$ y la oxidación continúa a mayores potenciales (pico AIII). En el barrido negativo, la capa de óxido de Pd se reduce, dando lugar al pico de reducción en $-0,35 \mathrm{~V}(\mathrm{CI})$. El pequeño pico observado en el barrido negativo entre $-0,8 \mathrm{y}$ -1,0 V (CII) es asignado a la reacción de adsorción de H [160], mientras que la HER se hace evidente a partir de $-1,1 \mathrm{~V}$ (CIII) $[23,160]$ y está superpuesta con la absorción de H. En el barrido positivo, se observa la electro-oxidación del H absorbido (AI) y adsorbido (AII) que originan los picos anchos y superpuestos alrededor de $-0,6 \mathrm{~V}$ [23].

\subsection{Preparación de las superficies cubiertas con alcanotioles}

La adsorción de alcanotioles sobre $\mathrm{Pd}$ se realizó en fase líquida utilizando moléculas de diferentes largo de cadena: propanotiol $\left(\mathrm{SC}_{3}\right)$, hexanotiol $\left(\mathrm{SC}_{6}\right)$, nonanotiol $\left(\mathrm{SC}_{9}\right)$ y dodecanotiol $\left(\mathrm{SC}_{12}\right)$. Los alcanotioles fueron utilizados directamente como fueron recibidos (Fluka), sin purificación adicional. Las monocapas se prepararon mediante inmersión de los sustratos de Pd en soluciones etanólicas de los tioles $50 \mu \mathrm{M}$ durante un mínimo de $18 \mathrm{~h}$. Luego de la preparación, las muestras fueron lavadas cuidadosamente en etanol con 
el objetivo de remover las moléculas de tioles fisisorbidas.

\subsection{Caracterización de las superficies de paladio modifica- das con alcanotioles}

\subsubsection{Caracterización mediante XPS}

En primer lugar, es interesante comparar el espectro de XPS de S $2 p$ de un sustrato de $\mathrm{Pd}$ modificado con alcanotioles con el espectro obtenido en el caso de un sustrato de $\mathrm{Au}$ modificado con las mismas moléculas (Cap. 3). Para el Au, la señal de S $2 p$ está compuesta, básicamente, por una componente en $\sim 162 \mathrm{eV}$ asignada a la especie tiolato, como discutimos anteriormente. En el caso de $\mathrm{Pd}$, sin embargo, la estructura es más compleja. En la Fig. 5.4 se observan los espectros de $\mathrm{S} 2 p$ y $\mathrm{Pd} 3 d$ de un sustrato de $\mathrm{Pd}$ luego de ser incubado en solución de propanotiol y dodecanotiol durante $18 \mathrm{~h}$ y lavados con etanol. En la señal de S $2 p$ se observa la presencia de tres componentes en $162,1 \mathrm{eV}, 162,9 \mathrm{eV}$ y 164,1 eV (Fig. 5.4a,b). En la Tabla 5.1 se muestran los porcentajes de los diferentes componentes y su comparación con los resultados informados por Love et ál. [151].

El cubrimiento total de especies de azufre $\left(\theta_{\mathrm{S}}\right)$ obtenido desde el análisis del espectro de XPS es de $\theta_{\mathrm{S}} \approx 0,8$. Esto pone en evidencia que la cantidad de especies azufradas es mucho mayor que en el caso de SAMs de alcanotiolatos sobre $\mathrm{Au}(111)$ y $\mathrm{Ag}(111)$, para los que se han informado valores de $\theta_{\mathrm{S}}=0,33$ y $\theta_{\mathrm{S}}=0,44$, respectivamente $[17,155,161,162]$.

La gran cantidad de especies de azufre indica que las especies moleculares de tiolato deben coexistir con una capa de sulfuro proveniente de la descomposición del alcanotiolato [151]. Por lo tanto, los resultados se han interpretado siguiendo el trabajo de Love et ál. [151]: los alcanotiolatos (componente en 162,9 eV) se ubican en sitios sobre una capa diluida de sulfuro $(162,1 \mathrm{eV})$ adsorbida sobre la superficie metálica. La asignación de una especie química determinada a la pequeña componente en $164,1 \mathrm{eV}$ es más complicada ya que esta puede corresponder a moléculas fisisorbidas de disulfuro [151] o alcanotioles [117]. Sin embargo, muestras lavadas exhaustivamente en etanol y luego medidas nuevamente mediante XPS, no exhibieron cambios en la intensidad de la componente en $164,1 \mathrm{eV}$. Por lo tanto, es posible que esta señal no esté asociada a especies débilmente adsorbidas. Entonces, la posibilidad de asignar esta componente a S elemental no debe ser descartada, considerando que el S elemental sobre metales está asociado a mayores energías de enlace que las encontradas para sulfuro o tiolato [163].

La señal de Pd luego de la adsorción de tioles presenta una pequeño corrimiento hacia mayores energías de enlace, comparada con la correspondiente a una superficie limpia de $\mathrm{Pd}$, lo que indica un cierto grado de oxidación del metal (Fig. 5.4c). Este corrimiento puede ser atribuido a la contribución de los átomos de Pd superficiales, considerando que el cubrimiento de especies azufradas está en el orden de la submonocapa. Hay que tener en cuenta que el seno del sustrato de $\mathrm{Pd}$, no afectado por la presencia de tioles en la superficie, representa una gran contribución a la señal de $\mathrm{Pd} 3 d$, debido a las condiciones experimentales en las que se adquirió este espectro.

Para el caso de los sustratos de Pd modificados con dodecanotiol, se observó una señal 

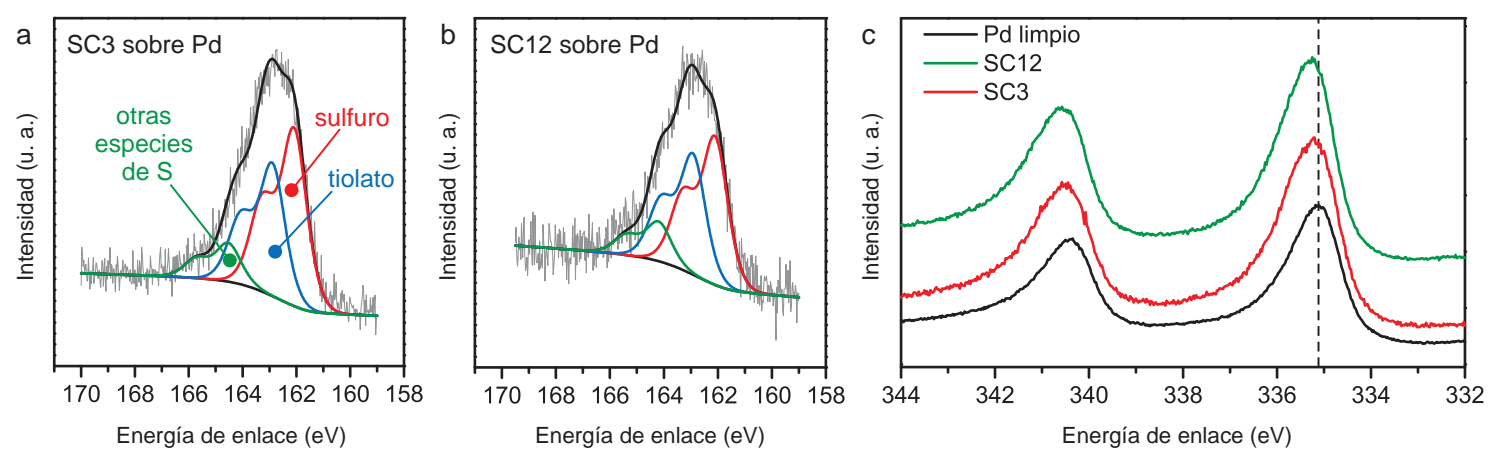

Figura 5.4: (a) Espectro de la región del S $2 p$ de $\mathrm{Pd}$ modificado con propanotiol $\left(\mathrm{SC}_{3}\right)$. (b) Espectro de la región del S $2 p$ de $\mathrm{Pd}$ modificado con dodecanotiol $\left(\mathrm{SC}_{12}\right)$. (c) Espectro de la región del $\mathrm{Pd} 3 d$ de $\mathrm{Pd}$ limpio y $\mathrm{Pd}$ modificado con $\mathrm{SC}_{3}$ y $\mathrm{SC}_{12}$. La línea punteada muestra la energía de enlace correspondiente al Pd limpio.

Tabla 5.1: Asignación de las diferentes componentes de la señal de S $2 p$ para alcanotiolatos sobre Pd y energía de enlace de las mismas.

\begin{tabular}{lccc}
\hline & Sulfuro & Tiolato & $\begin{array}{c}-\mathrm{S}-\mathrm{S}-, \mathrm{S}_{\mathrm{n}}, \\
\text { tioles fisisorbidos }\end{array}$ \\
\hline $\mathrm{BE} / \mathrm{eV}$ (ref. [151]) & $162,3(44,4 \%)$ & $163,2(40,2 \%)$ & $164,9(15,4 \%)$ \\
$\mathrm{BE} \mathrm{/} \mathrm{eV} \mathrm{(esta} \mathrm{tesis)}$ & $162,1 \pm 0,1(48 \%)$ & $162,9 \pm 0,1(39 \%)$ & $164,1 \pm 0,2(13 \%)$ \\
\hline
\end{tabular}

intensa de $\mathrm{C} 1 s$ (alta relación C:S) consistente con la presencia de la cadena hidrocarbonada. Para el caso de la pequeña señal obtenida con propanotiol esto no resulta evidente ya que se encuentra en el orden de la cantidad de carbono proveniente de contaminación atmosférica. En el caso de dodecanotiol la relación atómica C:S obtenida fue $\sim 11: 1$, mientras que para dodecanotiol sobre Au, la relación S:C es mayor a 15:1. Este resultado es también un indicativo de la ruptura de la cadena hidrocarbonada y la presencia de sulfuro en la superficie. El valor obtenido para $\mathrm{Au}$ es mayor que la relación estequiométrica para dodecanotiol (12:1), en principio, por dos razones. La primera es que en los experimentos de XPS siempre existe carbono proveniente de contaminación de la muestra (carbono adventicio). La segunda razón es que los fotoelectrones provenientes del C $1 s$ de la cadena hidrocarbonada del tiol son atenuados en menor medida que los fotoelectrones del S $2 p$.

Como puede observarse en la Fig. 5.4, se obtuvieron resultados similares para la señal de S $2 p$ y Pd $3 d$ en el caso de propanotiol y dodecanotiol sobre $\mathrm{Pd}$, es decir que la naturaleza de la interfase alcanotiol/Pd parece no tener una dependencia marcada con la longitud de la cadena hidrocarbonada. Los datos de XPS permiten concluir que la adsorción de alcanotioles sobre Pd produce una compleja interfase que consiste en sulfuro y tiolatos con una pequeña cantidad de especies de azufre oxidado. 


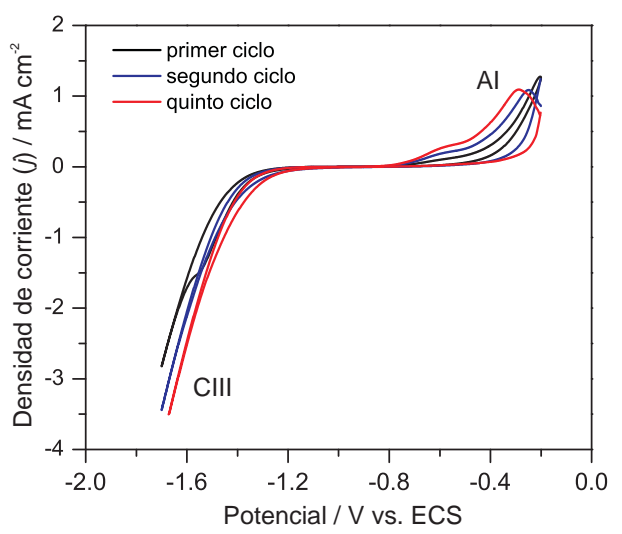

Figura 5.5: Voltamperograma de electrodo de Pd modificado con dodecanotiol. El barrido de potencial se realizó entre $-1,20$ y $-1,70 \mathrm{~V}$ a $50 \mathrm{mV} \mathrm{s}^{-1}$.

\subsubsection{Caracterización mediante voltamperometría cíclica}

La presencia de una capa de tiolatos sobre la superficie de Pd está reflejada en el primer ciclo del voltamperograma tomado en $\mathrm{NaOH}$ 0,1 M (Fig. 5.5). Podemos observar que la capacidad de la doble capa en el rango de potencial entre $-1,20$ y $-0,50 \mathrm{~V}$ es mucho menor que la de Pd limpio. La HER (CIII en la Fig. 5.3b) está desplazada en la dirección negativa, indicando que la reacción se encuentra obstaculizada. De igual manera, la oxidación del hidrógeno absorbido está reprimida y la pequeña corriente negativa relacionada a la adsorción de hidrógeno desaparece. Esto significa que el transporte de moléculas de agua es dificultoso a través de las cadenas hidrocarbonadas hidrofóbicas, por lo que existe una población insignificante de adátomos de hidrógeno en la superficie que puedan difundir hacia el interior de la red de Pd. Sin embargo, luego de repetidos ciclos, la HER se desarrolla a potenciales más positivos y la corriente relacionada con la oxidación de hidrógeno (AI) comienza a incrementarse, sugiriendo que ocurre una desorción o un desorden inducido por el potencial de la capa de tiol, en la zona más negativa de potencial alcanzada.

Se han estudiado las propiedades de barrera de la compleja capa formada sobre la superficie de Pd mediante la medida de la capacidad de la interfase $(C)$ y el estudio del comportamiento de una cupla rédox en solución. Es conocido que cuando se adsorben alcanotioles de cadena larga sobre metales, la capacidad de estos electrodos en soluciones electrolíticas disminuye aproximadamente un orden de magnitud, comparada con la de un electrodo del mismo metal desnudo [164]. La capacidad es aproximadamente constante con el potencial y puede ser obtenida mediante el cociente de la densidad de corriente $(j)$ y la velocidad de barrido $(v)$ en un rango de potencial donde no ocurran procesos faradaicos [19, 165-167]. Aunque la electroquímica del Pd en medio básico es muy compleja e implica muchos procesos de oxidación y reducción (Fig. 5.3b), es posible realizar una estimación de la capacidad de la doble capa eléctrica mediante voltamperometría cíclica. Se realizó un barrido de potencial a $50 \mathrm{mV} \mathrm{s}^{-1}$ entre $-0,40 \mathrm{y}-0,60 \mathrm{~V}$, donde la capacidad de interfase es prácticamente constante y se encuentra cerca del potencial de carga cero del Pd en electrolitos básicos [22]. Con el objeto de comparar, también se realizaron medidas de 
Tabla 5.2: Capacidad de la interfase y cubrimiento total de especies de azufre $\left(\theta_{\mathrm{S}}\right)$ de electrodos de $\mathrm{Pd}$ y $\mathrm{Au}$ limpios y luego de su modificación con $\mathrm{Na}_{2} \mathrm{~S}$ (adsorción de sulfuro), propanotiol $\left(\mathrm{SC}_{3}\right)$ y dodecanotiol $\left(\mathrm{SC}_{12}\right)$.

\begin{tabular}{lccccc}
\hline \multirow{2}{*}{ adsorbato } & \multicolumn{2}{c}{ capacidad $/ \mu \mathrm{F} \mathrm{cm}^{-2}$} & & \multicolumn{2}{c}{$\theta_{\mathrm{S}}$} \\
\cline { 2 - 3 } \cline { 5 - 6 } & $\mathrm{Au}$ & $\mathrm{Pd}$ & & $\mathrm{Au}$ & $\mathrm{Pd}$ \\
\hline limpio & $26 \pm 5$ & $123 \pm 8$ & & 0 & 0 \\
$\mathrm{Na}_{2} \mathrm{~S}$ & $21 \pm 3$ & $26 \pm 3$ & & $1 / 3$ to $2 / 3$ & $0,8 \pm 0,1$ \\
$\mathrm{SC}_{3}$ & $6 \pm 1$ & $10 \pm 2$ & & 0,33 & $0,78 \pm 0,09$ \\
$\mathrm{SC}_{12}$ & $2,5 \pm 0,8$ & $5 \pm 2$ & & 0,33 & $0,76 \pm 0,09$ \\
\hline
\end{tabular}

capacidad en sustratos de $\mathrm{Au}(111)$ limpios y modificados con alcanotioles y en electrodos de $\mathrm{Pd}$ modificados con $\mathrm{Na}_{2} \mathrm{~S}$ (Tabla 5.2).

Como ya fue informado para el caso de $\mathrm{Au}[166,168]$, es evidente que las capas adsorbidas de propanotiol y dodecanotiol disminuyen significativamente la capacidad del electrodo de Pd. También se observa la dependencia de la capacidad con el largo de cadena del tiol utilizado, siendo menor en el caso de dodecanotiol que en el de propanotiol. Sin embargo, las capacidades en el caso de tioles de cadena corta son a veces mayores que las esperadas para una capa dieléctrica perfecta de espesor equivalente. Esto indica una permeabilidad parcial de los iones del electrolito a través de las cadenas hidrocarbonadas cortas de estos tioles. En efecto, las monocapas de alcanotiolatos de cadena corta contienen diferentes tipos de defectos como filas faltantes (missing rows), donde algunas moléculas están ausentes o desordenadas [169] y límites de dominio, donde los alcanotiolatos adsorbidos presentan un fuerte desorden [170]. Debido a que la disminución de la capacidad al adsorber distintos alcanotioles sobre Pd está relacionada con la presencia de una capa de baja constante dieléctrica sobre el electrodo, los pequeños valores de capacidad obtenidos para los electrodos modificados con alcanotioles son atribuidos a la presencia de las cadenas hidrocarbonadas de dichas moléculas.

Contrariamente a lo encontrado para SAMs de alcanotiolatos sobre Au o Ag [155], no se observa pico de electrodesorción en los barridos hacia potenciales negativos, como el mostrado en la Fig. 5.5, en correspondencia con los resultados publicados previamente [154]. Por lo tanto, se ha estudiado el proceso de electrodesorción combinando medidas de capacidad de interfase y XPS luego de polarizar los electrodos de Pd modificados con alcanotioles a diferentes potenciales.

Antes de pasar al estudio detallado de la estabilidad electroquímica de las SAMs de alcanotioles sobre $\mathrm{Pd}$, describiremos los experimentos de transferencia de carga, que dan otro indicio de la presencia de la capa de alcanotiolatos.

\subsubsection{Transferencia de carga a través de la capa de sulfuro-tiolato}

Con el objetivo de estudiar el bloqueo a la transferencia de carga por parte de la compleja capa de sulfuro-tiolato, se midió la respuesta voltamperométrica de una cupla rédox en 
solución, que no penetra la monocapa de alcanotiol [171, 172]. Se utilizó la cupla rédox ferro/ferricianuro en el sustrato de Pd modificado con dodecanotiol antes y después de realizar el tratamiento de electrodesorción mediante la aplicación de potenciales negativos. La reacción correspondiente a la cupla rédox mencionada, es la siguiente:

$$
\left[\mathrm{Fe}(\mathrm{CN})_{6}\right]^{3-}+\mathrm{e}^{-} \rightleftharpoons\left[\mathrm{Fe}(\mathrm{CN})_{6}\right]^{4-}
$$

La voltamperometría cíclica se realizó en una celda electroquímica, en solución de $\mathrm{K}_{4} \mathrm{Fe}(\mathrm{CN})_{6} 10 \mathrm{mM}$ en $\mathrm{KNO}_{3} 1 \mathrm{M}$. Los voltamperogramas obtenidos se muestran en la Fig. 5.6. La capa formada por la adsorción de dodecanotiol tiene un efecto de bloqueo hacia la transferencia de carga. Solamente se observa una pequeña corriente positiva que crece cuasi exponencialmente con el sobrepotencial aplicado. Es interesante notar también que no existe una meseta o pico de corriente, que podrían ser relacionados a procesos limitados por transferencia de materia. Es posible inferir entonces que la pequeña señal positiva registrada corresponde mayormente a corriente de tunelamiento a través de la capa formada por el dodecanotiol [166]. Esto demuestra que se ha formado una capa densa de alcanotiolatos sobre el Pd, similar las SAMs de dodecanotiolato sobre Au [170, 171].

Luego de desorber las especies azufradas adsorbidas sobre el Pd, se alcanzó el comportamiento típico de la cupla rédox. Esto puede deberse a que se han desorbido totalmente las especies hidrocarbonadas de la superficie obteniéndose un electrodo limpio. Sin embargo, si existe una desorción parcial de los adsorbatos, es posible obtener un comportamiento similar al de un arreglo de ultramicroelectrodos, representado por las porciones de Pd limpio separadas mediante las zonas de Pd modificado con alcanotioles. En este caso, si las capas difusionales de las porciones limpias son mayores que la distancia entre los ultramicroelectrodos, estas se solapan y el área sensada es entonces mayor al área limpia del electrodo. Dependiendo de la velocidad de barrido y los tamaños relativos de las superficies limpias y cubiertas, es posible obtener el comportamiento de un electrodo completamente limpio aún cuando exista una desorción parcial [19]. Por otra parte, se pueden encontrar algunos problemas en la caracterización de la monocapas de tioles sobre Pd mediante la cupla rédox de ferro/ferricianuro debido a la redisolución del Pd en la zona anódica y la consiguiente desorción oxidativa del tiol [173]. Por estos motivos, no hemos utilizado esta cupla rédox como sonda del grado de cubrimiento de tiol sobre Pd, contrariamente a lo realizado por Williams y Gorman [154]. No obstante, en el caso de la monocapa de dodecanotiol completa, la utilización de la cupla nos da una evidencia importante acerca de la ausencia de defectos en la capa y del grado de compactación de la misma. En este sistema, la oxidación de $\mathrm{Pd}$ no interfiere en la caracterización de la interfase tiol/Pd debido a que el acceso del electrolito a la superficie metálica es insignificante.

Una cupla que cumple con el requisito de que las reacciones de oxidación y reducción se ubiquen en un rango de potencial donde no haya procesos faradaicos asociados al $\mathrm{Pd}$ o las moléculas adsorbidas es la cupla de $\left[\mathrm{Ru}\left(\mathrm{NH}_{3}\right)_{6}\right]^{3+} /\left[\mathrm{Ru}\left(\mathrm{NH}_{3}\right)_{6}\right]^{2+}$, que puede estudiarse en el rango de potencial de $-0,6$ a 0,0 V [166]. En este trabajo, en lugar de utilizar una cupla rédox para seguir el proceso de desorción, hemos utilizado la medida de capacidad de interfase, como se detalla en la siguiente sección. 


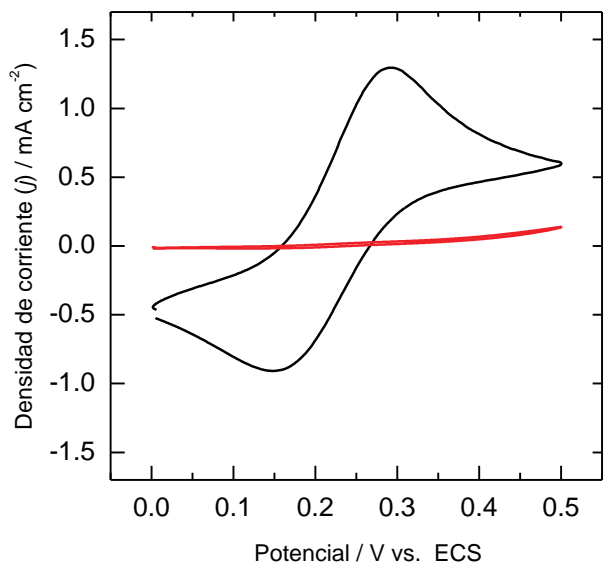

Figura 5.6: Voltamperograma de un electrodo de Pd modificado con dodecanotiol en $\mathrm{K}_{4} \mathrm{Fe}(\mathrm{CN})_{6} 10 \mathrm{mM}+\mathrm{KNO}_{3} 1 \mathrm{M}$. Velocidad de barrido: $100 \mathrm{mV} \mathrm{s}^{-1}$. Trazo rojo: electrodo de Pd luego de ser modificado con dodecanotiol, trazo negro: luego de electrodesorción mediante aplicación de un potencial $E_{c}=-1,7 \mathrm{~V}$ durante $30 \mathrm{~s}$.

\subsection{Estudio electroquímico de la estabilidad de la capa de sulfuro-tiolato}

Para estudiar el proceso de electrodesorción de las especies hidrocarbonadas sobre Pd, se midió la capacidad de los electrodos de $\mathrm{Pd}$ en $\mathrm{NaOH}$ 0,1 M luego de: (i) realizar un barrido de potencial desde $-0,40 \mathrm{~V}$ hasta diferentes potenciales más negativos $\left(E_{c}\right)$ a $50 \mathrm{mV} \mathrm{s}^{-1}$, (ii) polarizar el electrodo por $30 \mathrm{~s}$ a $E_{c}$ y (iii) realizar un barrido de potencial entre $-0,40 \mathrm{y}-0,60 \mathrm{~V}$ a $50 \mathrm{mV} \mathrm{s}^{-1}$ hasta alcanzar un voltamperograma estacionario. En estos experimentos $E_{c}$ se varió progresivamente en la dirección negativa. En la Fig. 5.7 se muestran los voltamperogramas obtenido luego de polarizar un electrodo de $\mathrm{Pd}$ modificado con propanotiol a diferentes potenciales. Es claro que en el rango de potencial entre $-0,60$ y $-1,20 \mathrm{~V}$, la corriente de carga de la doble capa eléctrica permanece baja (i. e. la superficie de $\mathrm{Pd}$ permanece bloqueada), pero cuando $E_{c}<-1,40 \mathrm{~V}$ se da un incremento de la corriente de doble capa, que indica que los alcanotiolatos son desorbidos de la superficie.

Es posible correlacionar la magnitud del incremento en la capacidad de la interfase con la disminución del cubrimiento de especies orgánicas sobre la superficie del electrodo y así calcular un cubrimiento remanente $\left(\theta_{\text {rem }}\right)$. Este cubrimiento puede ser estimado directamente de las medidas de capacidad mediante la siguiente ecuación [165, 174]:

$$
\theta_{\text {rem }}=\frac{C_{\mathrm{Pd}}-C_{E_{c}}}{C_{\mathrm{Pd}}-C_{\max }}
$$

donde $C_{\mathrm{Pd}}$ es la capacidad del electrodo de $\mathrm{Pd}$ limpio, $C_{\max }$ es la capacidad del electrodo luego de ser modificado con el alcanotiol y $C_{E_{c}}$ es la capacidad del electrodo luego de ser polarizado al potencial $E_{c}$. Es importante notar que $\theta_{\text {rem }}$ no representa el cubrimiento real sino que es una cantidad relacionada al cubrimiento máximo obtenido para los distintos alcanotioles sobre Pd. Es decir, la ecuación 5.2 normaliza el cubrimiento en cada punto 


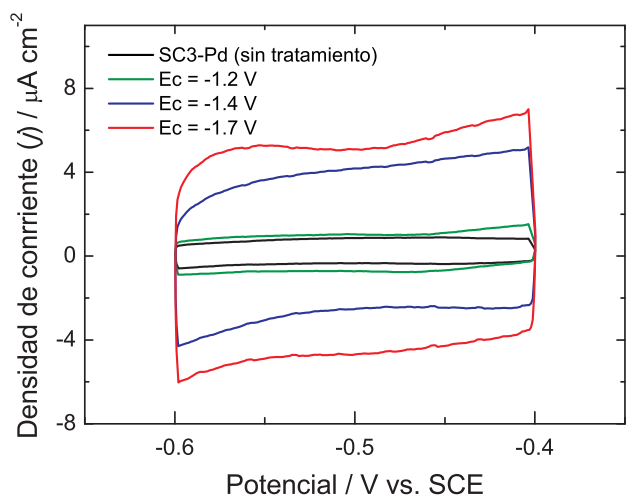

Figura 5.7: Voltamperogramas de un electrodo de $\mathrm{Pd}$ cubierto con propanotiol $\left(\mathrm{SC}_{3}\right)$ tal como fue preparado y luego de polarizar a diferentes potenciales $\left(E_{c}\right)$ en $\mathrm{NaOH} 0,1 \mathrm{M}$, vel. de barrido: $50 \mathrm{mV} / \mathrm{s}$.

respecto al cubrimiento en el electrodo antes de aplicarle algún potencial.

El la Fig. 5.8 se muestra el cubrimiento remanente en función del potencial aplicado $E_{c}$ para electrodos de Pd modificados con propanotiol, hexanotiol, nonanotiol y dodecanotiol. Se realizó una regresión no lineal para ajustar una función sigmoidea a los puntos experimentales. Los puntos de inflexión de estas curvas podrían compararse con los potenciales de desorción de los alcanotiolatos adsorbidos sobre, p. ej., Au y Ag, obtenidos de los picos de electrodesorción reductiva. Se observa que no existe una correlación marcada entre la longitud de cadena del tiol y el potencial de desorción, contrariamente al caso de los otros metales mencionados. ${ }^{2}$ También se incluyen en la Fig. 5.8 los datos de cubrimiento obtenidos mediante el análisis de la relación S:Pd de los espectros de XPS, para el caso de propanotiol y dodecanotiol. Es evidente que a $-1,7 \mathrm{~V}$ prácticamente todas las especies de azufre fueron desorbidas. La cantidad de azufre residual en el caso de dodecanotiol es mayor que en el de propanotiol, posiblemente debido a la menor solubilidad de la especies desorbidas que permanecen fisisorbidas sobre la superficie de Pd.

La desorción de la capa de sulfuro-tiolato fue seguida en detalle mediante experimentos de XPS. En la Fig. 5.9 se presentan los espectros de S $2 p$ tomados luego de polarizar un electrodo de $\mathrm{Pd}$ modificado con propanotiol a diferentes $E_{c}$. Se evidencia en estos espectros una disminución del cubrimiento de especies de azufre $\left(\theta_{\mathrm{S}}\right)$ desde 0,8 a 0,05 a medida que $E_{c}$ se mueve hacia potenciales más negativos. Existe también una desorción preferencial de la componente de tiolato $(162,9 \mathrm{eV})$ primeramente. En la Fig. 5.9 la señal asignada a tiolato se corre hacia mayores energías de enlace a medida que el cubrimiento disminuye. Esto puede ser atribuido al hecho de que la superficie cambia desde una compleja capa de sulfuro-tiolato a una superficie de $\mathrm{Pd}$ con menor contenido de especies azufradas. Simultáneamente se produce la formación de especies oxidadas (166 a 168 eV). Esto sugiere que los procesos de electrodesorción en el $\mathrm{Pd}$ deben proceder en diferentes pasos. Sin embargo, la comprensión de mecanismo preciso para la desorción de la capa de sulfurotiolato del $\mathrm{Pd}$, requiere un estudio más detallado de este proceso. También es evidente

\footnotetext{
${ }^{2}$ En la Sec. 5.8 describiremos estas diferencias.
} 


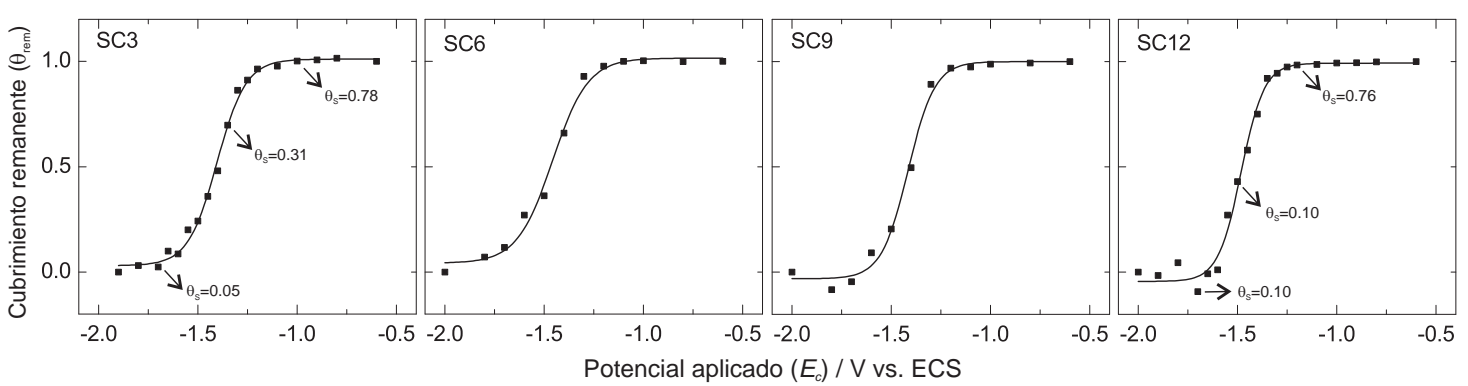

Figura 5.8: Cubrimiento remanente de sulfuro-tiolato $\left(\theta_{\text {rem }}\right)$ en función del potencial aplicado para tioles de diferente largo de cadena: propanotiol $\left(\mathrm{SC}_{3}\right)$, hexanotiol $\left(\mathrm{SC}_{6}\right)$, nonanotiol $\left(\mathrm{SC}_{9}\right)$ y dodecanotiol $\left(\mathrm{SC}_{12}\right)$. Para $\mathrm{SC}_{3}$ y $\mathrm{SC}_{12}$, se incluye también el cubrimiento de especies de azufre $\left(\theta_{\mathrm{S}}\right)$ obtenido mediante XPS, luego de aplicar diferentes potenciales $E_{c}$.

que la cantidad de azufre residual $\left(\theta_{\mathrm{S}} \approx 0,05-0,10\right)$ consiste mayormente en sulfuro y especies oxidadas de azufre. En este aspecto, ha sido informado que especies monoméricas de azufre fuertemente quimisorbidas en bordes de escalón, permanecen adsorbidas luego de la electrodesorción de azufre de terrazas de $\mathrm{Au}(111)$ [175]. Mediante el análisis del espectro de $\mathrm{Pd} 3 d$ se observó que, luego de la desorción, el Pd recupera casi completamente el carácter metálico.

\subsection{Adsorción de azufre sobre Pd}

El hecho de que el potencial de desorción mediante aplicación de potenciales negativos de los alcanotioles adsorbidos sobre Pd no dependa significativamente del largo de la cadena hidrocarbonada, sugiere que la presencia de la capa de sulfuro metálico juega un rol importante en la estabilización de la capa adsorbida. Por lo tanto, se han preparado y estudiado superficies de Pd modificadas con sulfuro mediante la inmersión de estos sustratos en soluciones acuosas diluidas de $\mathrm{Na}_{2} \mathrm{~S}$ por corto tiempo. Los datos de XPS de la señal de S $2 p$ y Pd $3 d$, mostrados en la Fig. 5.10 son consistentes con la formación de una capa adsorbida de azufre sobre $\mathrm{Pd}$. El corrimiento de la señal de $\mathrm{Pd} 3 d$ hacia mayores energías de enlace es de aproximadamente $0,5 \mathrm{eV}$, como fue publicado anteriormente [176]. Este corrimiento es mayor que el encontrado en el caso de superficies de Pd cubiertas con dodecanotiol (Fig. 5.4). La presencia de las componentes en 161,6 y 162,4 eV son asignadas a $\mathrm{PdS}$ y $\mathrm{PdS}_{2}$, respectivamente, mientras que la componente en $163,3 \mathrm{eV}$ es asignada a especies $S_{n}[176]$. Una pequeña cantidad de azufre oxidado está también presente, revelado por la señal en $165,2 \mathrm{eV}$.

El comportamiento electroquímico de esta capa de azufre fue estudiado en condiciones similares a las descritas anteriormente para los alcanotioles. La Fig. 5.11a muestra un voltamperograma típico de una superficie de Pd modificada con aproximadamente 1 monocapa de azufre, en $\mathrm{NaOH}$ 0,1 M. Se puede observar que la reacción de adsorción de hidrógeno (pico CII) se encuentra bloqueada y también la densidad de corriente correspondiente a la reducción de $\mathrm{PdO}$ es menor que en el caso de Pd limpio, como es esperado para 


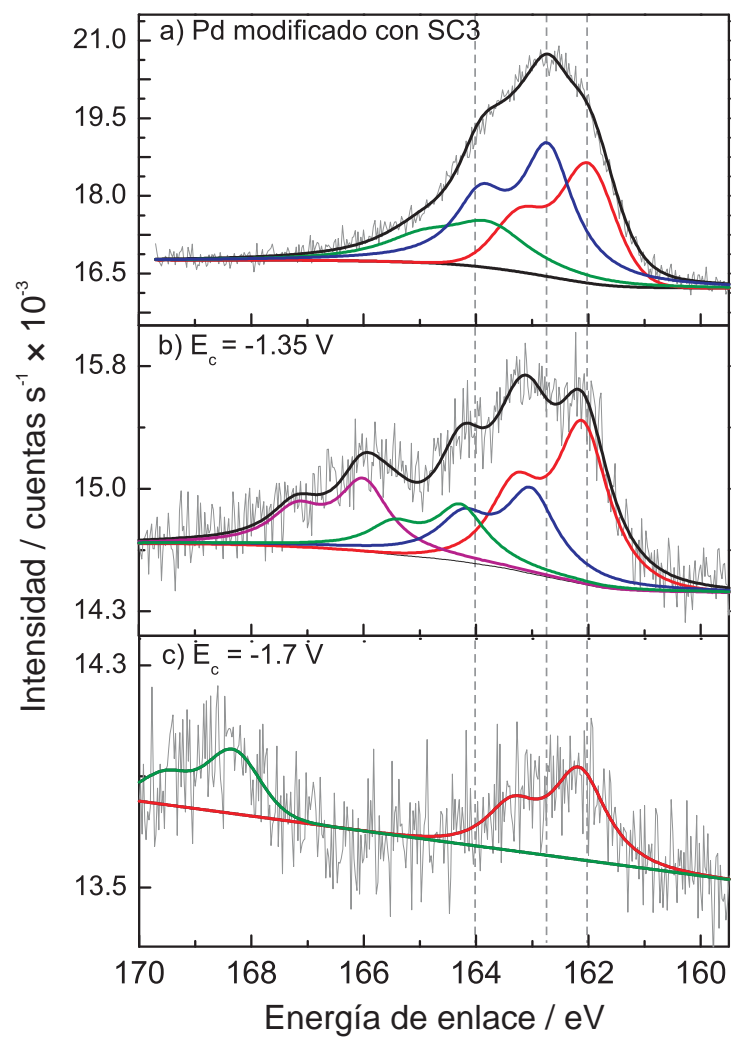

Figura 5.9: Espectros XPS de $\mathrm{S} 2 p$ de propanotiol $\left(\mathrm{SC}_{3}\right)$ adsorbido sobre $\mathrm{Pd}$. (a) Luego de su preparación. (b) Luego de aplicar un potencial $E_{c}=-1,35 \mathrm{~V}$. (c) Luego de aplicar un potencial $E_{c}=-1,7 \mathrm{~V}$.

electrodos envenenados con azufre [177]. Un pico anódico adicional (AIV) es observado en la región de formación de $\mathrm{PdO}$. Este pico es debido a la desorción oxidativa de las especies de azufre quimisorbidas $[177,178]$.

La especie de azufre más importante en solución acuosa de $\mathrm{NaOH}$ 0,1 M es $\mathrm{SH}^{-}$. Por lo tanto, el proceso de adsorción puede ser escrito como:

$$
\mathrm{Pd}+\mathrm{HS}^{-}+\mathrm{OH}^{-} \longrightarrow \mathrm{PdS}_{\mathrm{ads}}+2 \mathrm{e}^{-}+\mathrm{H}_{2} \mathrm{O}
$$

La reacción de desorción reductiva es la inversa de la reacción de adsorción. El hecho de que el proceso de adsorción de hidrógeno esté bloqueado en el electrodo de $\mathrm{Pd}$ modificado con azufre fue utilizado como una sonda electroquímica para estudiar la desorción del azufre sobre $\mathrm{Pd}$. Un electrodo de $\mathrm{Pd}$ modificado con azufre fue polarizado a diferentes potenciales $E_{c}$ por $1 \mathrm{~min}$ y luego se estudió la reacción de adsorción de hidrógeno mediante voltamperometría cíclica entre $-0,40$ y $-1,00 \mathrm{~V}$. En la Fig. $5.11 \mathrm{~b}$ se muestran los voltamperogramas obtenidos luego de polarizar un electrodo de $\mathrm{Pd}$ modificado con azufre a diferentes $E_{c}$. Se observa que luego de la polarización a $-1,30 \mathrm{~V}$, la reacción de adsorción de hidrógeno (pico CII en la Fig. 5.11a y 5.3b) permanece bloqueada. Sólo luego de polarizar a $-1,35 \mathrm{~V}$ la reacción de adsorción de hidrógeno aparece en el voltamperograma, indicando que la desorción de las especies de azufre comienza en esa región de potencial. 

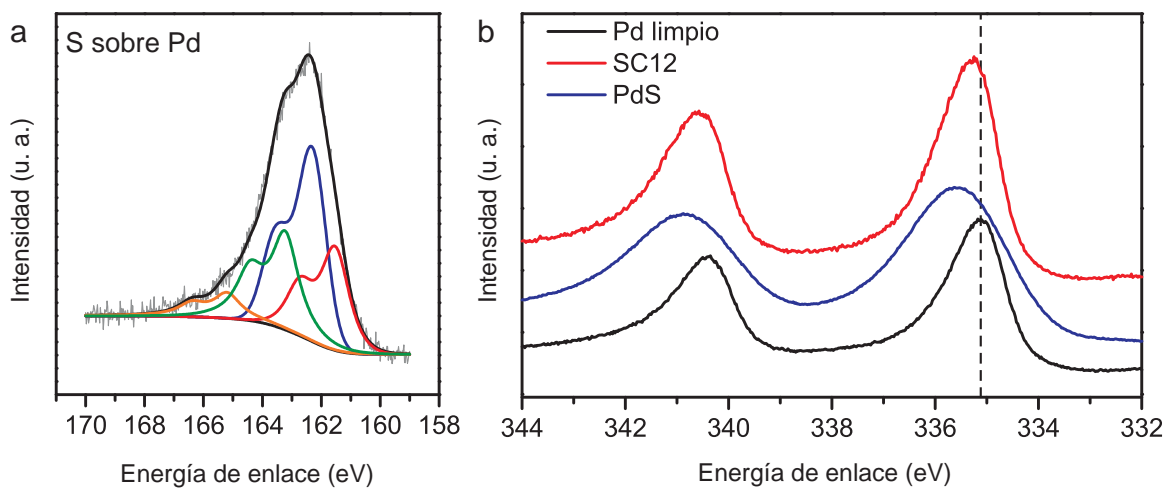

Figura 5.10: Espectros XPS de superficies de Pd modificadas con sulfuro. (a) Espectro XPS de S $2 p$ de sustrato de Pd luego de la modificación con $\mathrm{Na}_{2} \mathrm{~S}$. (b) Espectro XPS de $\mathrm{Pd} 3 d$ de sustrato de $\mathrm{Pd}$ limpio y luego de la modificación con $\mathrm{Na}_{2} \mathrm{~S}$. También se incluye el espectro de $\mathrm{SC}_{12}$ sobre $\mathrm{Pd}$, para comparación.

La desorción de azufre también fue estudiada mediante medidas de XPS (Fig. 5.11b), considerando las componentes principales de la señal de S $2 p$. Puede notarse que la desorción de azufre comienza en $-1,20 \mathrm{~V}$ y, a $-1,70 \mathrm{~V}$, el electrodo está prácticamente limpio. Las diferencias entre los datos de XPS y electroquímicos pueden ser atribuidas al hecho de que pequeñas diferencias en el cubrimiento pueden no ser detectadas mediante las medidas electroquímicas. Sin embargo, estos datos indican que el azufre sobre Pd es electrodesorbido en la misma región de potencial que las capas de sulfuro-alcanotiolatos sobre Pd. Este resultado sugiere que el comportamiento electroquímico de los alcanotioles sobre Pd está fuertemente dominado por el azufre, y no por las cadenas hidrocarbonadas como en otros metales. Este mecanismo es consistente con el comportamiento observado para alcanotioles sobre Pd, cuyos potenciales de desorción solo dependen ligeramente del largo de cadena hidrocarbonada. Estos resultados están en correspondencia con los resultados encontrados por Love, et ál. [148] quienes utilizaron SAMs formadas desde alcanotioles sobre Pd como protectores para el grabado (etching) de superficies metálicas modificadas por microcontact printing $(\mu \mathrm{CP}) .^{3}$ Estos autores atribuyeron la elevada resistencia de las capas de tioles sobre $\mathrm{Pd}$ hacia la corrosión química a la naturaleza de la interfase $\mathrm{Pd} / \mathrm{S}$, restando importancia al efecto de la cadena hidrocarbonada. Más aún, encontraron que al modificar un sustrato de $\mathrm{Pd}$ con $\mathrm{Na}_{2} \mathrm{~S}$ los resultados eran comparables a los obtenidos con alcanotioles, a diferencia de lo encontrado en Au donde una capa de sulfuro no produce ninguna protección del metal hacía la corrosión.

\footnotetext{
${ }^{3}$ Esta es una técnica de litografía que consiste en crear una plantilla con un patrón determinado y utilizar, como tinta, un tiol. Este sello se coloca sobre la superficie del metal elegido y entonces se forma una SAM del tiol sobre el metal solamente en las zonas donde el sello está en contacto con el sustrato. De esta forma se obtiene una superficie modificada con una capa que sigue un patrón determinado.
} 

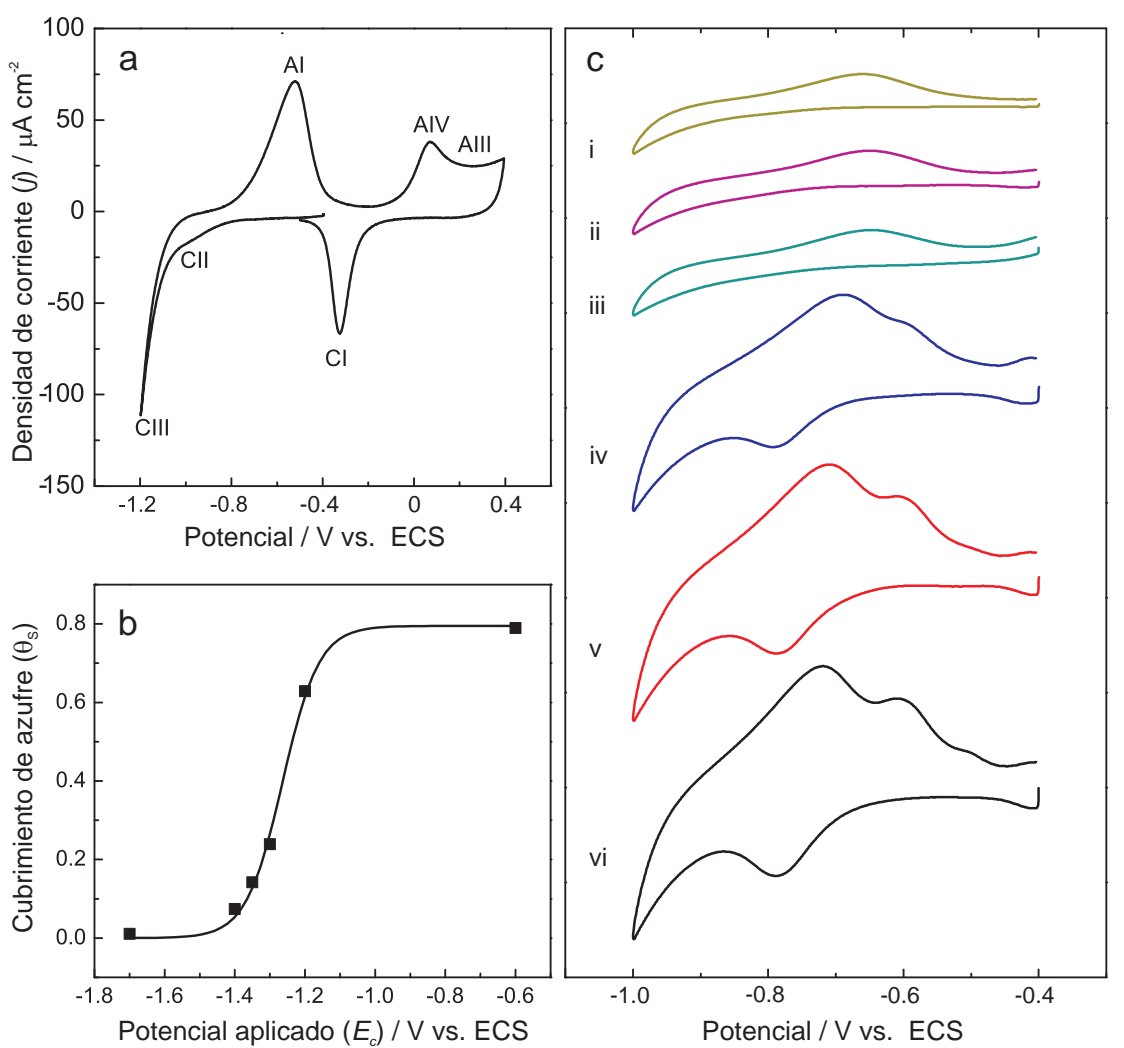

Figura 5.11: Adsorción de sulfuro sobre Pd. (a) Voltamperograma de un electrodo de Pd incubado durante 1 min en solución de $\mathrm{Na}_{2} \mathrm{~S} 60 \mu \mathrm{M}+\mathrm{NaOH}$ 0,1 M. Velocidad de ba-

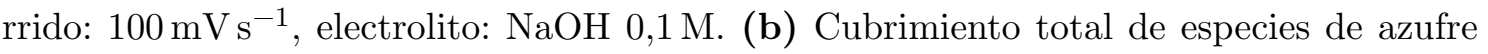
$\left(\theta_{\mathrm{S}}\right)$ calculado a partir de los datos de XPS de un electrodo preparado de la misma forma que en a luego de ser polarizado durante 1 min a diferentes potenciales $\left(E_{c}\right)$. (c) Voltamperogramas de un electrodo de $\mathrm{Pd}$ incubado ídem a y luego polarizado durante 1 min a diferentes potenciales $E_{c}$ : (i) sin polarizar, (ii) $-1,20 \mathrm{~V}$, (iii) $-1,30 \mathrm{~V}$, (iv) $-1,35 \mathrm{~V}$, (v)

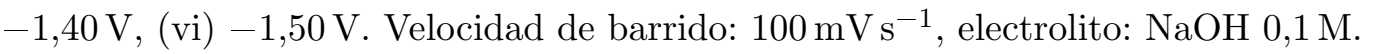

\subsection{Adsorción de alcanotioles sobre superficies de Pd-Au}

La preparación de películas ultradelgadas de Pd sobre Au para el estudio de la adsorción de alcanotioles sobre estas superficies es interesante, en principio, por dos motivos. El primero está relacionado con el estudio mediante XPS. En este caso, prácticamente todos los átomos de Pd estarán en contacto con los adsorbatos y, por lo tanto, no tendremos influencia de señal proveniente del seno del metal. En segundo lugar, la modificación de una superficie metálica con un segundo metal produce una superficie cuyas propiedades electrónicas pueden ser diferentes. En este aspecto, resulta interesante estudiar la influencia de las capas de Pd ubicadas bajo la superficie en la adsorción de alcanotioles desde solución. 


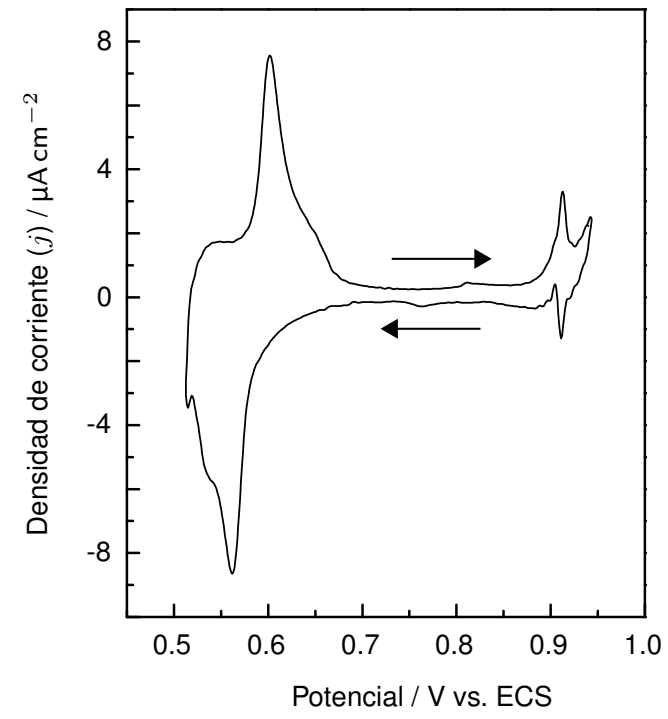

Figura 5.12: Voltamperograma de deposición a subpotenciales (UPD) y redisolución de Pd sobre $\mathrm{Au}(111)$ a $1 \mathrm{mV} \mathrm{s}^{-1}$ en solución acuosa de $\mathrm{PdCl}_{2} 1 \mathrm{mM}+\mathrm{HCl} 2 \mathrm{mM}+\mathrm{H}_{2} \mathrm{SO}_{4}$ $0,1 \mathrm{M}$.

\subsubsection{Preparación de los sustratos}

Los sustratos de $\mathrm{Au}$ modificados con $\mathrm{Pd}$ fueron preparados mediante electrodeposición a subpotenciales (UPD) de Pd sobre sustratos de $\mathrm{Au}(111)$, como los utilizados con Pd masivo. La electrodeposición de aproximadamente 1 monocapa de $\mathrm{Pd}$ se realizó desde una solución acuosa de $\mathrm{PdCl}_{2} 1 \mathrm{mM}+\mathrm{HCl} 2 \mathrm{mM}+\mathrm{H}_{2} \mathrm{SO}_{4}$ 0,1 M utilizando una celda electroquímica de 3 electrodos, siguiendo el protocolo de Kibler et ál. [156]. Se aplicó una función lineal de potencial de $1 \mathrm{mV} \mathrm{s}^{-1}$ desde $+0,80$ hasta aproximadamente $+0,52 \mathrm{~V}$, potencial luego del cual comienza la deposición de $\mathrm{Pd}$ a sobrepotenciales (véase Fig. 5.1). A ese potencial, se retiró el electrodo de trabajo de la celda y luego se despolarizó el mismo. La Fig. 5.12 muestra un ciclo completo de deposición y disolución de Pd en la zona de UPD.

\subsubsection{Composición química superficial}

El cubrimiento de Pd sobre $\mathrm{Au}(111)$ fue determinado mediante XPS. Para esto es necesario realizar la deconvolución de los picos de $\mathrm{Pd} 3 d$ y Au $4 d$ ya que se encuentran en la misma zona de energías de enlace. En la Fig. 5.13 se muestra la deconvolución de un espectro que corresponde a un cubrimiento de 1.2 monocapas.

La Fig. 5.14 muestra los espectros de XPS de S $2 p$ y Pd $3 d$ correspondientes a un sustrato de $\mathrm{Au}(111)$ sobre el que se depositó Pd con un cubrimiento de 1,2 ML junto con el de Pd masivo, para su comparación. Se presentan los espectros obtenidos luego de la adsorción de propanotiol, desde una solución $50 \mu \mathrm{M}$ realizada de igual manera que sobre $\mathrm{Pd}$ masivo (Sec. 5.3). La señal de S $2 p$ debe ser descompuesta en 3 componentes, interpretadas de igual manera que en el caso de las superficies monometálicas: una componente en 


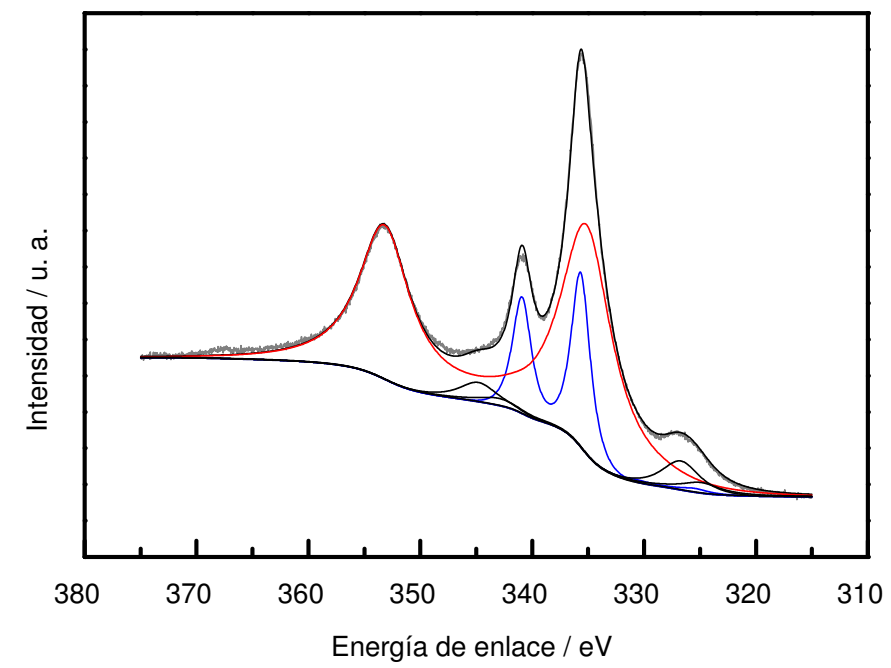

Figura 5.13: Espectro de $\mathrm{Pd} 3 d$ y Au $4 d$ de Pd electrodepositado sobre $\mathrm{Au}(111)$ en la zona de subpotenciales. La señal en azul corresponde al Pd $3 d$ mientras que la roja corresponde al Au 4d. Los demás picos son los satélites de ambas señales (véase Sec. 2.5.3).

$162,1 \mathrm{eV}$ que corresponde a sulfuro, otra en $162,9 \mathrm{eV}$, correspondiente a tiolato y una tercera componente de muy baja intensidad en $164 \mathrm{eV}$ asignada a especies de mayor estado de oxidación. El cubrimiento total de especies de tiolato + sulfuro es $\sim 0,37$ ML y además se observa cierta presencia de especies oxidadas. Se puede notar que la cantidad relativa de sulfuro en este sustrato disminuye considerablemente. Mientras que en las muestras de Pd masivo la relación tiolato:sulfuro es aproximadamente 0,8, en estas muestras la relación pasa a ser $\sim 1,4$. Esto indica, en principio, dos cosas. La primera es que aun con este cubrimiento de $\mathrm{Pd}$, se produjo la disociación del enlace $\mathrm{S}-\mathrm{C}$, generándose sulfuro. La segunda, que con solo 0,15 ML de sulfuro fue posible la adsorción de tiolato sobre esta superficie, es decir, sin ruptura de enlace $\mathrm{S}-\mathrm{C}$, en contraste con las 0,4 ML encontradas en $\mathrm{Pd}$ masivo. Este resultado indica que las capas de Pd que se encuentran por debajo de la primer capa atómica deben tener un rol importante en la formación de la capa de sulfuro. Este comportamiento se encuentra en concordancia con los resultados de DFT detallados en la próxima sección.

En la Fig. 5.14b se muestran los espectros de Pd $3 d$ de diferentes sistemas: superficie limpia de Pd masivo, superficie limpia de 1,2 ML de Pd sobre $\mathrm{Au}(111)$ y los mismos sistemas luego de la adsorción de propanotiol. Como comentamos en la Sec. 5.4.1, al realizar la adsorción de alcanotioles sobre Pd masivo, se observó un corrimiento de la señal de $\mathrm{Pd} 3 d$, que fue interpretado en relación a la alta densidad de carga de los átomos de Pd en la superficie debido a la presencia de sulfuro. En el caso de 1,2 ML de Pd este efecto es mucho más notorio. Esto se debe a que, en este caso, prácticamente todos los átomos de $\mathrm{Pd}$ se encuentran en contacto con la capa mixta de sulfuro-tiolato, a diferencia del Pd masivo, donde la contribución de los átomos de Pd en el seno del metal a la señal de $\mathrm{Pd} 3 d$ es mayoritaria. Nótese que en la superficie bimetálica esta zona del espectro tiene la contribución de la señal de Pd $3 d$ y Au $4 d$ (Fig. 5.13). Sin embargo, la posición del pico 

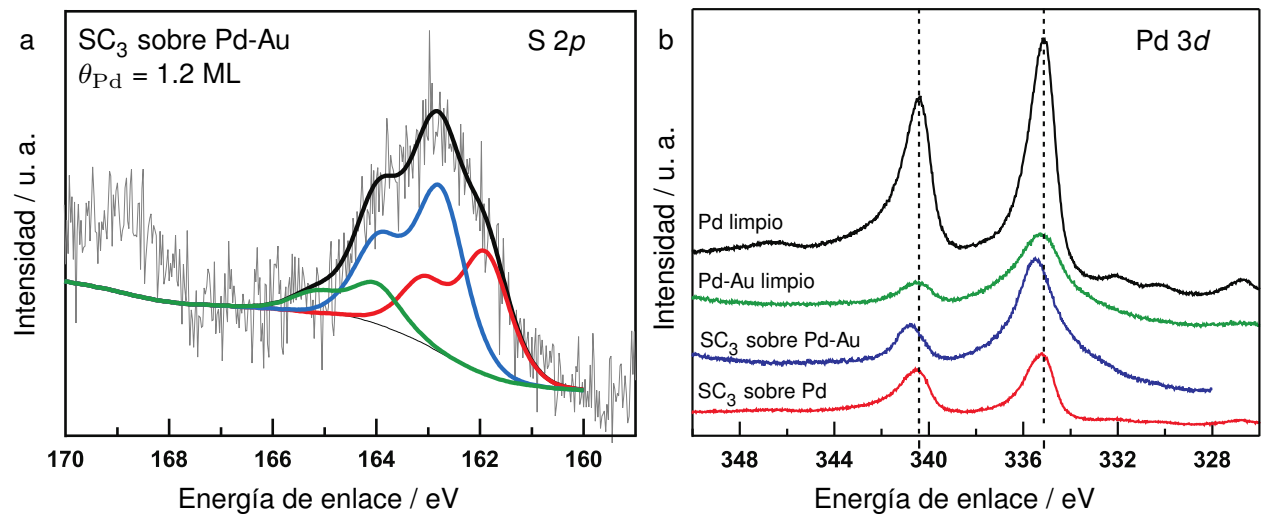

Figura 5.14: Espectros de XPS de diferentes superficies modificadas con Pd. (a) Espectro XPS de S 2p. (b) Espectro XPS de Pd $3 d$.

de $\mathrm{Pd} 3 d_{3 / 2}(\sim 340 \mathrm{eV})$ no es afectada considerablemente por esta superposición y puede utilizarse para la mencionada comparación cualitativa.

\subsection{Discusión general de los resultados experimentales}

Los resultados de XPS y electroquímicos confirman la presencia de una compleja capa de sulfuro-tiolato adsorbida sobre Pd. Mientras que el cubrimiento total de las especies de azufre es $\theta_{\mathrm{S}} \approx 0,8$, las intensidades relativas de las diferentes componentes de la señal de $\mathrm{S} 2 p$ dan como resultado cubrimientos superficiales de sulfuro $\theta_{\text {sulfuro }} \approx 0,4$ y tiolato $\theta_{\text {tiolato }} \approx 0,3$. Este último valor es cercano al encontrado para SAMs de tiolatos sobre $\mathrm{Au}\left(\theta_{\text {tiolato }} \approx 0,33\right)$, lo que explica las propiedades de barrera encontradas mediante las medidas electroquímicas. El valor de $\theta_{\text {sulfuro }} \approx 0,4$ es consistente con la formación de una capa diluida de sulfuro de paladio [151]. La presencia de Pd en mayor estado de oxidación, revelada por el corrimiento de señal de XPS de Pd $3 d$ (comportamiento no observado en el caso de $\mathrm{Au}$ ), debe ser explicada por la presencia de la capa de sulfuro cercana a la superficie del metal [176]. Este efecto es todavía más notorio en el caso de las superficies bimetálicas de Pd-Au.

Las medidas de capacidad de la doble capa indican que la capa de sulfuro-tiolato permanece estable en un amplio rango de potencial, contrariamente a lo encontrado por Williams y Gorman para alcanotioles sobre Pd en soluciones metanólicas alcalinas [154]. Esta discrepancia puede deberse a que estos autores utilizaron la cupla rédox de ferro/ferricianuro como sonda para calcular el cubrimiento remanente luego de aplicar diferentes potenciales $E_{c}$. De esta forma, al realizar un voltamperograma de la cupla, se puede producir una desorción oxidativa parcial de la capa de tioles lo que produciría una disminución aparente del rango de estabilidad de los tioles sobre Pd. Más aún, como se explicó anteriormente, al desorber parcialmente la capa de tioles, la cupla puede recuperar el perfil correspondiente al electrodo limpio debido a la generación de un arreglo de ultramicroelectrodos donde sus capas difusionales se solapan. Nuestros resultados en relación a la desorción de la capa de sulfuro-tiolato en soluciones acuosas de $\mathrm{NaOH} 0,1 \mathrm{M}$ indican 


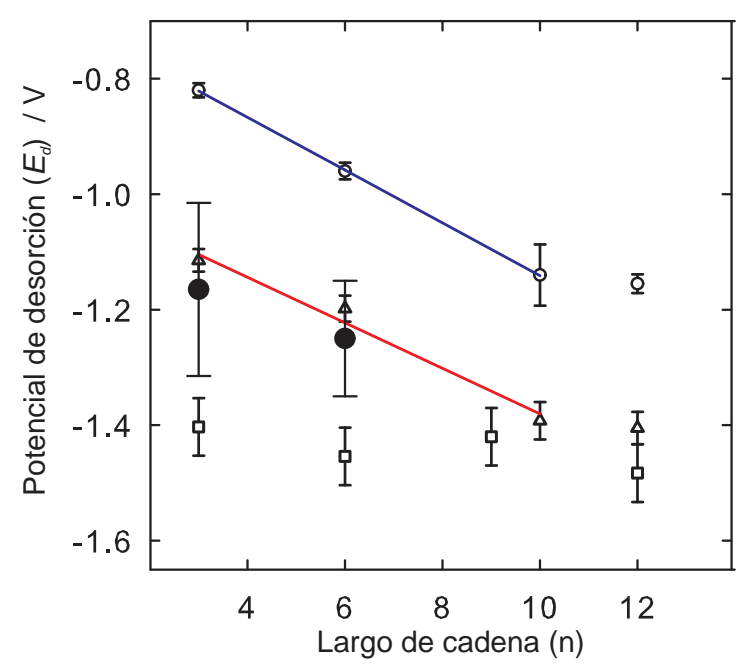

Figura 5.15: Potenciales de desorción para alcanotioles de distinto largo de cadena ( $n$ carbonos) en diferentes metales. (o y trazo azul): $\mathrm{Au},(\triangle \mathrm{y}$ trazo rojo): $\mathrm{Ag},(\bullet): \mathrm{Ni}[181]$, $(\square): \mathrm{Pd}$.

que esta se produce en un rango de potenciales $\sim 0,6 \mathrm{~V}$ más negativo que el potencial informado para el caso de alcanotioles de cadena corta sobre $\mathrm{Au}$ [179], y 0,3 V más negativo que en el caso de $\mathrm{Ag}[155,180]$ y Ni [181]. Estas diferencias se tornan menores para alcanotioles de cadena más larga debido a la débil dependencia del potencial de desorción con el largo de cadena, observada en el caso del Pd. Esto es un indicativo fuerte de que la capa de sulfuro de paladio debe jugar un rol preponderante en la estabilización de la compleja capa de sulfuro-tiolato en soluciones acuosas alcalinas. En la Fig. 5.15 se presentan los potenciales de desorción de alcanotioles con diferente largo de cadena hidrocarbonada sobre distintos metales.

La posibilidad de una remoción prácticamente completa de la capa de sulfuro-tiolato mediante métodos electroquímicos reductivos es muy interesante ya que abre un camino simple para la preparación de NPs desnudas de Pd soportadas sobre carbono desde NPs de Pd protegidas con alcanotioles. Esto puede ser realizado mediante la adsorción de NPs de Pd protegidas con alcanotioles sobre sustratos de carbono, desde soluciones de hexano, seguido por una limpieza electroquímica de los compuestos de azufre en solución acuosa, como lo publicado para AuNPs cubiertas por alcanotiolatos [182]. Por otro lado, el amplio rango de estabilidad de la capa de sulfuro-tiolato sobre Pd indica que el Pd puede ser una plataforma apropiada para la fabricación de sensores y biosensores basados en ambientes acuosos.

En la siguiente sección describiremos los resultados del estudio de la capa de sulfurotiolato adsorbida sobre Pd mediante cálculos computacionales desde primeros principios. 


\subsection{Estudio teórico de la adsorción de tioles sobre Pd}

La utilización de cálculos computacionales desde primeros principios permite tanto comprender los resultados experimentales como predecir el comportamiento de nuevos sistemas. El estudio teórico de las monocapas autoensambladas de tioles sobre metales ha sido ampliamente explorado, sobre todo utilizando $\mathrm{Au}(111)$ y AuNPs como sustratos sobre los que se adsorben distintos tipos de tioles, como hemos discutido en el Cap. 3 (véase las refs. $[17,58]$ para una revisión del estudio teórico del sistema Au-tiol). El sistema Pd-tiol, sin embargo, ha sido estudiado en menor medida desde el punto de vista teórico.

Majumder, en 2008, ha sido el primero en estudiar la adsorción de tioles sobre Pd mediante cálculos desde primeros principios [147]. En este trabajo el autor estudió, mediante DFT, el comportamiento de metanotiol y 2-mercapto tiofeno en la adsorción sobre $\operatorname{Pd}(111)$. Uno de los resultados más importantes de este trabajo es que la adsorción de metanotiol sobre $\mathrm{Pd}$ se realiza mediante el mecanismo disociativo (ruptura de enlace $\mathrm{S}-\mathrm{H}$ ) mientras que la adsorción de 2-mercapto tiofeno se realiza sin ruptura de este enlace, haciendo que la energía de interacción con el metal sea menor. Esto indica, como es esperado, que el entorno electrónico del S tiene una gran influencia en la interacción de los tioles con el Pd. Más adelante, en el año 2010, Karhánek et ál. publicaron dos trabajos en los que incluyeron, además del Pd, los otros metales del grupo (Ni y Pt) [183, 184]. Ninguno de estos trabajos, sin embargo, tuvo en cuenta en los cálculos la posibilidad de la presencia de sulfuro, encontrado experimentalmente, lo que hace que su alcance en la comparación con resultados experimentales sea limitado. Dada la escasa disponibilidad de estudios teóricos del sistema $\mathrm{Pd} /$ tiol en la bibliografía y teniendo en cuenta los resultados experimentales tan diferentes a los de la interfase $\mathrm{Au} / \mathrm{tiol}$, resulta interesante abordar el estudio de este sistema con el objetivo de explorar, mediante cálculos computacionales, estructuras comparables con los datos experimentales.

En esta sección discutiremos los resultados de los cálculos computacionales a partir de primeros principios de diferentes estructuras superficiales referidas a la adsorción de tioles sobre $\operatorname{Pd}(111)$. Este estudio teórico se divide en dos partes. En primer lugar se plantearon diferentes estructuras que comprenden tiolato, sulfuro y sulfuro-tiolato sobre $\operatorname{Pd}(111)$, basadas en resultados experimentales y teóricos publicados previamente, cuya estructura geométrica y electrónica fue optimizada en el marco de DFT (véase Cap. 2.11). De estas estructuras optimizadas se obtuvieron tanto datos geométricos (longitud y ángulos de enlaces) como de energía de enlace adsorbato-metal y distribuciones de cargas.

Sin embargo, los cálculos realizados de esta manera no tienen en cuenta las condiciones ambientales como la temperatura $(T=0 \mathrm{~K})$, por lo que su comparación con ciertos datos experimentales resulta limitada. Por lo tanto, en segundo lugar, se realizó un análisis de la estabilidad de estas estructuras en el marco de la termodinámica estadística desde primeros principios, que tiene como finalidad utilizar los datos de los sistemas microscópicos a $T=0 \mathrm{~K}$, obtenidos por DFT, para predecir los resultados de los equivalentes sistemas macroscópicos que se encuentran a cierta presión $p$ y temperatura $T$. Se puede encontrar una descripción de este método en los artículos de Reuter y Scheffler [185, 186] y en los trabajos sobre su aplicación a diferentes sistemas [187-190]. Básicamente, consiste en 
calcular, para cada estructura superficial optimizada, su energía libre superficial, considerando que esta se encuentra en equilibrio con un reservorio de los átomos/moléculas que actúan como adsorbatos en fase gaseosa. De esta manera es posible construir un diagrama que relacione la energía libre superficial de cada estructura con el potencial químico de las especies de nuestro interés en la fase gaseosa. Si conocemos la dependencia del potencial químico con la temperatura $T$ y presión $p$ de estas especies, resulta clara la posibilidad de relacionar estos cálculos con datos experimentales. El siguiente esquema (adaptado de ref. [191]) expone los diferentes pasos para llegar a un diagrama donde relacionemos la estabilidad de las estructuras con la temperatura y presión de las especies que se adsorben sobre la superfice del metal:

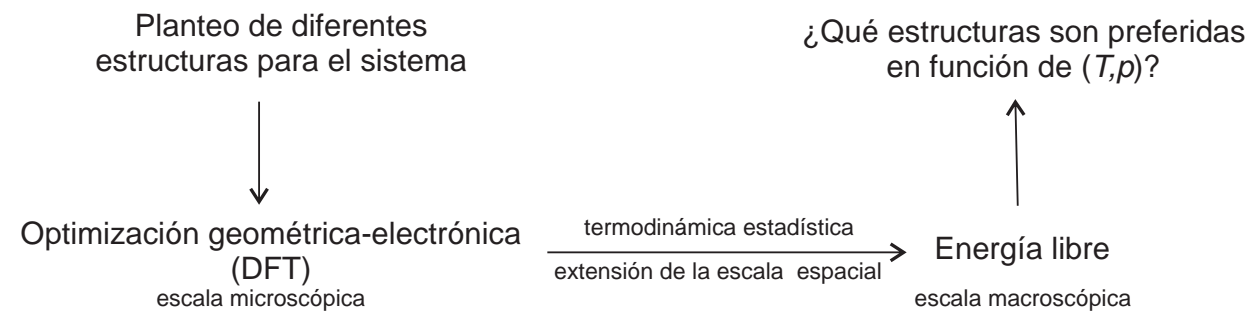

\subsubsection{Características de los modelos propuestos y parámetros estructu- rales obtenidos}

Para estudiar la adsorción de alcanotioles sobre $\mathrm{Pd}(111)$ se propusieron 5 modelos, en base a los resultados experimentales de XPS presentados anteriormente y publicados previamente en la literatura. Estos modelos consisten en monocapas de metanotiolato, monocapas de sulfuro y monocapas mixtas de sulfuro-tiolato. El modelo $\mathbf{1}$ consiste en una monocapa de metanotiolato $(\mathrm{MT})^{4}$ con un cubrimiento $\theta_{\mathrm{MT}}=1 / 3$, situados sobre huecos $f c c$ de $\operatorname{Pd}(111)$, que es la posición más estable para este sistema [147]. La red formada es $\operatorname{Pd}(111)-(\sqrt{3} \times \sqrt{3}) \mathrm{R}_{30}-\mathrm{MT}{ }^{5}$ El modelo 2 corresponde a una capa de átomos de $\mathrm{S}$ situados sobre huecos $f c c$, formando la red $\operatorname{Pd}(111)-(\sqrt{3} \times \sqrt{3}) \mathrm{R} 30^{\circ}-\mathrm{S}$ con un cubrimiento $\theta_{\mathrm{S}}=1 / 3$ [192]. El modelo 3 consiste en una red de $\operatorname{Pd}(111)-(\sqrt{7} \times \sqrt{7}) \mathrm{R} 19,1^{\circ}-\mathrm{S}$ [193], propuesta como la estructura superficial de $\mathrm{S} / \mathrm{Pd}(111)$ más estable [194]. En este modelo, la capa de $\mathrm{Pd}$ externa está formada por una estructura mixta de $\mathrm{Pd}-\mathrm{S}\left(\mathrm{Pd}_{5} \mathrm{~S}_{3}\right)$ con una arreglo compacto de pentágonos de $\mathrm{Pd}$ rodeando un átomo de $\mathrm{S}$ y con un cubrimiento de azufre de $\theta_{\mathrm{S}}=3 / 7$. La celda unidad del modelo 4 consta de dos MT situados sobre la superficie del modelo 3 con un cubrimiento de metanotiolato $\theta_{\mathrm{MT}}=2 / 7$, lo que produce la red $\operatorname{Pd}(111)-(\sqrt{7} \times \sqrt{7}) \mathrm{R} 19,1^{\circ}-(\mathrm{S}+\mathrm{MT})$. Las especies de MT se encuentran adsorbidas en posiciones hueco-puente (hollow-bridge) entre dos átomos de $\mathrm{Pd}$. En el modelo 5, los átomos de $\mathrm{S}$ fueron incorporados entre las dos capas más superficiales de $\mathrm{Pd}$ [195] con el mismo cubrimiento que el de los modelos 3 y 4.

\footnotetext{
${ }^{4}$ En la presente sección utilizaremos la abreviatura MT para referirnos tanto a la molécula de metanotiol $\left(\mathrm{CH}_{3} \mathrm{SH}\right)$, el anión metanotiolato $\left(\mathrm{CH}_{3} \mathrm{~S}^{-}\right)$o el radical metanotiil $\left(\mathrm{CH}_{3} \mathrm{~S}^{*}\right)$, según las circunstancias.

${ }^{5}$ Por simplicidad, más adelante obviaremos la parte del sustrato en la nomenclatura de las redes, dejando sólo la parte del adsorbato.
} 

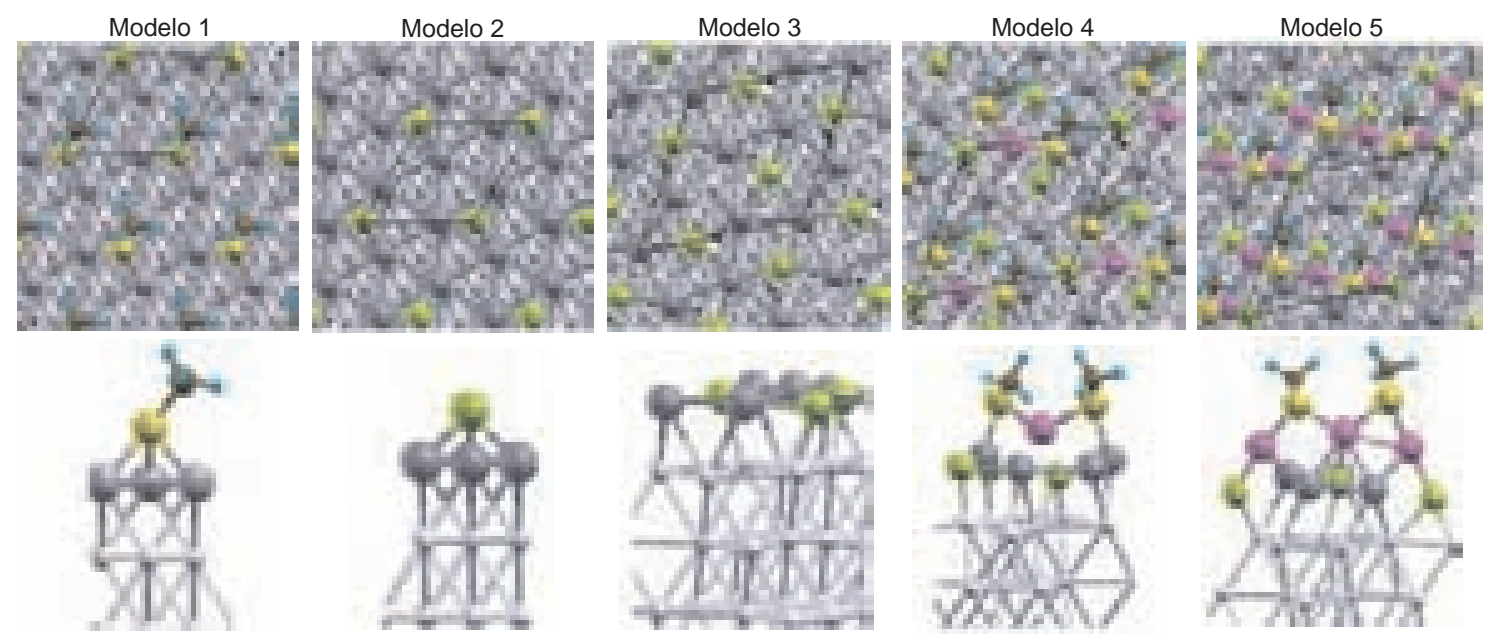

Figura 5.16: Estructuras optimizadas de los diferentes modelos propuestos para la adsorción de azufre y metanotiol sobre $\operatorname{Pd}(111)$. S: verde; S en metanotiol: amarillo; C: marrón; $\mathrm{H}$ : cian; adátomo de $\mathrm{Pd}$ : violeta; capa superficial de $\mathrm{Pd}$ : gris oscuro; segunda y restantes capas de Pd: gris claro.

Estas estructuras fueron optimizadas mediante DFT, obteniéndose las estructuras mostradas en la Fig. 5.16. En particular, es interesante notar los resultados de la optimización de las estructuras correspondientes a los modelos 4 y 5. En la Fig. 5.17 se muestra la comparación entre la estructura inicial y la optimizada para estos modelos. Al optimizar la geometría de la estructura del modelo 4 , se reconstruye completamente la capa de $\operatorname{Pd}_{5} \mathrm{~S}_{3}$ y un átomo de Pd se transforma finalmente en un adátomo que une dos MT. Esta unidad $\mathrm{MT}-\mathrm{Pd}_{\mathrm{ad}}-\mathrm{MT}$ es similar a las propuestas para la adsorción de tioles sobre Au (véase Fig. 3.4) $[16,53,134,196]$. En el modelo $\mathbf{5}$, la posición de los átomos de $\mathrm{S}$ bajo la superficie (subsurface) induce una distorsión estructural importante en la superficie de $\operatorname{Pd}(111)$. En la estructura inicial, las moléculas de MT se encuentran adsorbidas en una posición cuasi puente y promueven una fuerte reconstrucción de las capas externas de $\mathrm{Pd}$ y $\mathrm{S}$, dando lugar a una capa de $\mathrm{Pd}_{4} \mathrm{~S}_{3}$ y tres adátomos de $\mathrm{Pd}$. Este modelo recuerda el modelo de cadenas de tioles unidos por adátomos de $\mathrm{Au}(\mathrm{RS}-\mathrm{Au}-\mathrm{SR})$ propuesto para tioles sobre $\mathrm{Au}[196]$.

En la Tabla 5.3 se presentan los parámetros estructurales de los diferentes modelos, obtenidos de los cálculos de DFT. Las energías de enlace $\left(E_{\mathrm{b}}\right)$ para MT y S adsorbido sobre $\mathrm{Pd}(111)$ se calcularon mediante las siguientes ecuaciones. En el caso del modelo 1:

$$
E_{b}^{\mathrm{MT}}=\frac{1}{N_{\mathrm{MT}}}\left(E_{\text {total }}-E_{\mathrm{Pd}}-E_{\mathrm{MT}}\right)
$$

En el caso de los modelos 2 y $\mathbf{3}$, se utilizó la siguiente ecuación:

$$
E_{b}^{\mathrm{S}}=\frac{1}{N_{\mathrm{S}}}\left(E_{\text {total }}-E_{\mathrm{Pd}}-E_{\mathrm{S}}\right)
$$




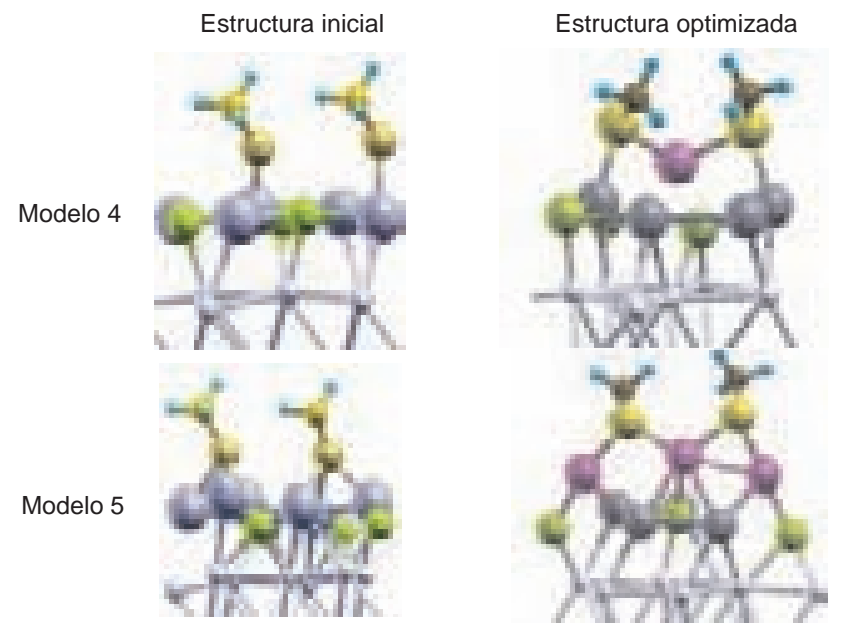

Figura 5.17: Estructuras iniciales y optimizadas de los modelos 4 y 5. S: verde; $\mathrm{S}$ en metanotiol: amarillo; C: marrón; H: cian; adátomo de Pd: violeta; capa superficial de Pd: gris oscuro; segunda y restantes capas de Pd: gris claro.

Tabla 5.3: Parámetros estructurales para los diferentes modelos (1-5) obtenidos de los cálculos de DFT. Cubrimientos del metal y los adsorbatos $\left(\theta_{\mathrm{Pd}}, \theta_{\mathrm{MT}}, \theta_{\mathrm{S}}\right)$; distancia interatómica promedio $\left(d_{\mathrm{Pd}-\mathrm{S}}, d_{\mathrm{S}-\mathrm{C}}\right)$; ángulo $\alpha$ inclinación entre el enlace $\mathrm{S}-\mathrm{C}$ y la normal a la superficie; energías de enlace $\left(E_{b}\right)$ de los adsorbatos al metal.

\begin{tabular}{|c|c|c|c|c|c|c|c|c|c|}
\hline \multirow[t]{2}{*}{ Modelo - Red } & \multirow[t]{2}{*}{$\theta_{\mathrm{Pd}}$} & \multirow[t]{2}{*}{$\theta_{\mathrm{MT}}$} & \multirow[t]{2}{*}{$\theta_{\mathrm{S}}$} & \multicolumn{2}{|c|}{$E_{b} / \mathrm{eV}$} & \multirow{2}{*}{$\frac{\mathrm{S}}{d_{\mathrm{Pd}-\mathrm{S}} / \mathrm{nm}}$} & \multicolumn{3}{|c|}{ MT } \\
\hline & & & & $\mathrm{S}$ & MT & & $d_{\mathrm{Pd}-\mathrm{S}} / \mathrm{nm}$ & $d_{\mathrm{S}-\mathrm{C}} / \mathrm{nm}$ & $\alpha /^{\circ}$ \\
\hline $1-(\sqrt{3} \times \sqrt{3}) \mathrm{R}^{2} 0^{\circ}-\mathrm{MT}$ & 0 & $1 / 3$ & 0 & - & $-2,67$ & - & 0,235 & 0,186 & 37 \\
\hline $2-(\sqrt{3} \times \sqrt{3}) \mathrm{R} 30^{\circ}-\mathrm{S}$ & 0 & 0 & $1 / 3$ & $-4,98$ & - & 0,225 & - & - & - \\
\hline $3-(\sqrt{7} \times \sqrt{7}) \mathrm{R} 19,1^{\circ}-\mathrm{S}$ & $5 / 7$ & 0 & $3 / 7$ & $-5,50$ & - & 0,236 & - & - & - \\
\hline $4-(\sqrt{7} \times \sqrt{7}) \mathrm{R} 19,1^{\circ}-(\mathrm{S}+\mathrm{MT})$ & $5 / 7$ & $2 / 7$ & $3 / 7$ & $-5,70$ & $-2,62$ & 0,247 & 0,238 & 0,182 & 54 \\
\hline $5-(\sqrt{7} \times \sqrt{7}) \mathrm{R} 19,1^{\circ}-\left(\mathrm{S}_{\mathrm{sub}}+\mathrm{MT}\right)$ & $7 / 7$ & $2 / 7$ & $3 / 7$ & $-5,58$ & $-3,22$ & 0,245 & 0,233 & 0,183 & 58 \\
\hline
\end{tabular}

Finalmente, para los modelos $\mathbf{4}$ y $\mathbf{5}$, se utilizaron las siguientes ecuaciones:

$$
\begin{gathered}
E_{b}^{\mathrm{MT}}=\frac{1}{N_{\mathrm{MT}}}\left(E_{\text {total }}-E_{\mathrm{Pd} @ \mathrm{~S}}-E_{\mathrm{MT}}\right) \\
E_{b}^{\mathrm{S}}=\frac{1}{N_{\mathrm{S}}}\left(E_{\mathrm{Pd} @ \mathrm{~S}}-E_{\mathrm{Pd}}-E_{\mathrm{S}}\right)
\end{gathered}
$$

donde $E_{\mathrm{MT}}, E_{\mathrm{S}}, E_{\mathrm{Pd}}, E_{\mathrm{Pd} @ \text { S }}$ representan las energías totales del radical MT libre, del átomo de $\mathrm{S}$ libre, de la superficie de $\mathrm{Pd}(111)$ relajada y de la superficie de $\mathrm{S} / \mathrm{Pd}(111)$ relajada, respectivamente.

Los resultados mostrados en la Tabla 5.3 indican que los valores de $E_{b}$ obtenidos para el S son el doble que los estimados para moléculas de MT adsorbidas tanto sobre Pd(111) como $\operatorname{Pd}(111)$ modificado con S. Por otro lado, es interesante notar que las energías de enlace de MT sobre estas superficies son mayores que las estimadas para la adsorción de MT sobre superficies de Au sin reconstruir $\left(E_{b}=-1,82 \mathrm{eV}\right)$ y superficies reconstruidas con adátomos de $\mathrm{Au}\left(E_{b}=-2,20 \mathrm{a}-2,61 \mathrm{eV}\right)$ [17]. 


\subsubsection{Estabilidad termodinámica de los diferentes modelos}

Se determinó la estabilidad de diferentes estructuras superficiales de S/MT sobre $\mathrm{Pd}(111)$ mediante el estudio de la energía libre superficial y su comparación con la de una superficie limpia del metal. Esto se realizó en el marco de la termodinámica estadística desde primeros principios, siguiendo resultados previos para la adsorción de tioles sobre Au [188-190]. Se tuvo en cuenta que los tioles adsorbidos pueden ser fragmentados por la superficie de $\operatorname{Pd}(111)$, generando S adsorbido, según fue discutido anteriormente desde los datos de XPS. La composición y geometría superficial más estable será la que minimice la energía libre superficial $\gamma(T, P)$, la cual se define de la siguiente manera [187]:

$$
\gamma(T, p)=\frac{1}{A}\left(G_{\text {total }}-N_{\mathrm{Pd}} g_{\mathrm{Pd}}-N_{\mathrm{S}} \mu_{\mathrm{S}}-N_{\mathrm{MT}} \mu_{\mathrm{MT}}\right)-\gamma_{\text {clean }}^{\mathrm{U}}
$$

donde $A$ es el área superficial, $G_{\text {total }}$ es la energía libre de Gibbs del sistema, $g_{\mathrm{Pd}}$ es la energía libre de Gibbs por átomo de Pd en el metal masivo ${ }^{6}$ y $\mu_{\mathrm{S}}$ y $\mu_{\mathrm{MT}}$ son los potenciales químicos de los adsorbatos azufre y metanotiol, respectivamente, en equilibrio con los mismos componentes en fase gaseosa. $N_{\mathrm{Pd}}, N_{\mathrm{S}}$ y $N_{\mathrm{MT}}$ son la cantidad de átomos de $\mathrm{Pd}$ y especies adsorbidas en la supercelda y $\gamma_{\text {clean }}^{\mathrm{U}}$ es la energía libre superficial de la superficie de $\operatorname{Pd}(111)$ sin reconstruir, que debe ser sustraída debido a que la supercelda contiene dos superficies, una con adsorbato y capaz de relajarse durante la optimización y otra sin adsorbato y con las posiciones de sus átomos fijas en el espacio. La energía libre de Gibbs se define como:

$$
G(T, p)=E_{\text {total }}+F_{\text {vib }}+F_{\text {conf }}+p V
$$

donde $E_{\text {total }}$ es la energía total, $F_{\text {vib }}$ es la energía libre vibracional, $F_{\text {conf }}$ es la energía libre configuracional y $p V$ es el término expansivo. Sin embargo, para nuestros sistemas, es posible considerar que el único sumando que contribuye significativamente con $G(T, p)$ es $E_{\text {total }}$, que se obtiene directamente de los cálculos de DFT [186]. Por lo tanto, la energía libre de Gibbs del sistema $\left(G_{\text {total }}\right)$ es estimada de la energía total del sistema adsorbatosustrato a $T=0 \mathrm{~K}\left(E_{\text {total }}\right)$ y la energía libre de Gibbs por átomo de $\mathrm{Pd}\left(g_{\mathrm{Pd}}\right)$ es calculada como la energía total de un átomo de $\operatorname{Pd}$ masivo $\left(E_{\text {bulk }}^{\mathrm{Pd}}\right)$.

La energía libre superficial de la superficie de Pd limpia se calcula construyendo una supercelda sin adsorbatos y se define como:

$$
\gamma_{\text {clean }}(T, p)=\frac{1}{A}\left(G_{\text {total }}^{\text {clean }}-N_{\text {Pd }}^{\text {clean }} E_{\text {bulk }}^{\mathrm{Pd}}\right)-\gamma_{\text {clean }}^{\mathrm{U}}
$$

donde $G_{\mathrm{Pd}}^{\text {clean }}$ es aproximada de la energía total de la supercelda $\left(E_{\text {total }}^{\text {clean }}\right)$, y $N_{\mathrm{Pd}}^{\text {clean }}$ es el número de átomos de $\mathrm{Pd}$ en la supercelda.

Debido a que lo que nos interesa es la diferencia entre la energía libre superficial de las estructuras con adsorbatos que proponemos, $\gamma(T, p)$, y la energía libre superficial de una superficie de $\operatorname{Pd}(111)$ limpia, $\gamma_{\text {clean }}(T, p)$, es conveniente definir una energía libre de

\footnotetext{
${ }^{6}$ En estas ecuaciones, $G$ mayúscula se refiere a una energía libre por supercelda mientas que $g$ minúscula se refiere a una energía libre por átomo.
} 
Gibbs de adsorción de la siguiente manera:

$$
\begin{aligned}
\Delta G_{\mathrm{ads}} & =\gamma(T, p)-\gamma_{\text {clean }}(T, p) \\
& =\frac{1}{A}\left(G_{\text {total }}-N_{\mathrm{Pd}} g_{\mathrm{Pd}}-N_{\mathrm{S}} \mu_{\mathrm{S}}-N_{\mathrm{MT}} \mu_{\mathrm{MT}}\right)-\frac{1}{A}\left(G_{\mathrm{Pd}}^{\text {clean }}-N_{\mathrm{Pd}}^{\text {clean }} g_{\mathrm{Pd}}\right)
\end{aligned}
$$

donde los términos $\gamma_{\text {clean }}^{\mathrm{U}}$ se cancelan debido a que tienen la misma contribución en cada supercelda. De esta forma, $\Delta G_{\text {ads }}$ evalúa el costo de crear una superficie con adsorbatos respecto a la creación de una superficie limpia. Por lo tanto, para una superficie de $\operatorname{Pd}(111)$ limpia, obtenemos $\Delta G_{\text {ads }}=0$ y las estructuras más estables que la superficie limpia tendrán un valor de $\Delta G_{\text {ads }}<0$. La estructura más estable será la que tenga el valor más negativo de $\Delta G_{\text {ads }}$.

Como comentamos en el Cap. 3, la adsorción de tioles sobre Au requiere la ruptura del enlace $\mathrm{S}-\mathrm{H}$ del tiol. Sin embargo, esto no ocurre en el caso de metanotiol sobre $\mathrm{Au}(111)$ (libre de defectos), según lo muestran resultados experimentales [197] y teóricos [198]. Por lo tanto, los datos del potencial químico del metanotiol serán referidos a los valores del dimetil disulfuro $\left(\mathrm{CH}_{3} \mathrm{~S}\right)_{2}$, el cual sí se adsorbe sobre $\mathrm{Au}(111)$ formando una monocapa de metanotiolato [199]. El potencial químico de la molécula $\left(\mathrm{CH}_{3} \mathrm{~S}\right)_{2}$ está relacionado al de MT y al del S mediante la siguiente ecuación:

$$
\frac{1}{2} \mu_{\left(\mathrm{CH}_{3} \mathrm{~S}\right)_{2}}=\mu_{\mathrm{MT}}=\mu_{\mathrm{S}}+\mu_{\mathrm{C}}+\frac{3}{2} \mu_{\mathrm{H}_{2}}
$$

debido a que consideramos que las especies se encuentran en equilibrio termodinámico y están relacionadas mediante las siguientes ecuaciones:

$$
\frac{1}{2}\left(\mathrm{CH}_{3} \mathrm{~S}\right)_{2} \rightleftharpoons \mathrm{CH}_{3} \mathrm{~S} \rightleftharpoons \mathrm{S}+\mathrm{C}+\frac{3}{2} \mathrm{H}_{2}
$$

Las especies involucradas en la ecuación 5.13 fueron encontradas en estudios previos de reacciones similares sobre superficies de Pd [200-204].

Las moléculas de $\left(\mathrm{CH}_{3} \mathrm{~S}\right)_{2}$, en fase gaseosa, actúan como un reservorio intercambiando moléculas con la superficie a una determinada presión y temperatura. Se define entonces el potencial químico del MT respecto a la molécula de $\left(\mathrm{CH}_{3} \mathrm{~S}\right)_{2}$ :

$$
\mu_{\mathrm{MT}}(T, p)=\frac{1}{2} E_{\left(\mathrm{CH}_{3} \mathrm{~S}\right)_{2}}+\frac{1}{2} E_{\left(\mathrm{CH}_{3} \mathrm{~S}\right)_{2}}^{\mathrm{ZPE}}+\Delta \mu_{\mathrm{MT}}(T, p)
$$

La energía total $E_{\left(\mathrm{CH}_{3} \mathrm{~S}\right)_{2}}$ y la energía de punto cero (zero-point energy) $E_{\left(\mathrm{CH}_{3} \mathrm{~S}\right)_{2}}^{\mathrm{ZPE}}$ de la molécula de dimetil disulfuro en fase gaseosa fueron calculadas mediante el empleo de una supercelda cúbica de $8 \mathrm{~nm}^{3} . \Delta \mu_{\mathrm{MT}}(T, p)$ contiene la dependencia con la presión $\left(p_{\left(\mathrm{CH}_{3} \mathrm{~S}\right)_{2}}\right)$ y temperatura $(T)$ experimental mediante la ecuación:

$$
\Delta \mu_{\mathrm{MT}}(T, p)=\frac{1}{2} \mu_{\left(\mathrm{CH}_{3} \mathrm{~S}\right)_{2}}^{\ominus}\left(T, p^{\circ}\right)+\frac{1}{2} k T \ln \left(\frac{p_{\left(\mathrm{CH}_{3} \mathrm{~S}\right)_{2}}}{p^{\circ}}\right)
$$

donde $k$ es la constante de Boltzmann y $\mu_{\left(\mathrm{CH}_{3} \mathrm{~S}\right)_{2}}^{\ominus}\left(T, p^{\circ}\right)$ es el potencial químico relativo a la presión estándar $p^{\circ}$ y donde la energía de punto cero y la energía electrónica son iguales a cero, estimado en términos de la función de partición molecular (véase Apéndice A). Para $T=300 \mathrm{~K}$ y $p^{\circ}=10^{5} \mathrm{~Pa}, \mu_{\left(\mathrm{CH}_{3} \mathrm{~S}\right)_{2}}^{\ominus}\left(T, p^{\circ}\right)_{\text {gas }}=-0,9094 \mathrm{eV}$. 
Para calcular el potencial químico de la molécula de hidrógeno, se utilizó la siguiente ecuación:

$$
\mu_{\mathrm{H}_{2}}(T, p)=E_{\mathrm{H}_{2}}+E_{\mathrm{H}_{2}}^{\mathrm{ZPE}}+\mu_{\mathrm{H}_{2}}^{\ominus}\left(T, p^{\circ}\right)+k T \ln \left(\frac{p_{\mathrm{H}_{2}}}{p^{\circ}}\right)
$$

La energía total $E_{\mathrm{H}_{2}}$ y la de punto cero $E_{\mathrm{H}_{2}}^{\mathrm{ZPE}}$ fueron estimadas mediante DFT, y $\mu_{\mathrm{H}_{2}}^{\ominus}$ se obtuvo de tablas de datos termodinámicos. En los cálculos se utilizó $T=300 \mathrm{~K}$ y $p_{\mathrm{H}_{2}}=5 \times 10^{-7}$ atm. Este valor es razonable teniendo en cuenta los niveles de $\mathrm{H}_{2}$ en un recipiente con etanol en contacto con la atmósfera. El potencial químico del carbono fue fijado en $\mu_{\mathrm{C}}=-11,8 \mathrm{eV}$. A este valor, la fase de $\mathrm{Pd} / \mathrm{C}$ no es formada, ya que se necesita $\mu_{\mathrm{C}}=-8,8 \mathrm{eV}$ para iniciar la deposición de carbono [205, 206].

Las definiciones del potencial químico en las ecuaciones 5.13 y 5.15 permiten escribir una expresión para la energía libre de Gibbs de adsorción $\Delta G_{\text {ads }}$ como función del potencial químico del metanotiol en fase gaseosa $\Delta \mu_{\mathrm{MT}}$ mediante la siguiente ecuación:

$$
\begin{aligned}
\Delta G_{\mathrm{ads}}= & \frac{1}{A}\left[E_{\text {total }}-N_{\mathrm{Pd}} E_{\mathrm{Pd}}^{\text {bulk }}+N_{\mathrm{S}}\left(\mu_{\mathrm{C}}+\frac{3}{2} \mu_{\mathrm{H}_{2}}-\frac{1}{2} E_{\left(\mathrm{CH}_{3} \mathrm{~S}\right)_{2}}-\frac{1}{2} E_{\left(\mathrm{CH}_{3} \mathrm{~S}\right)_{2}}^{\mathrm{ZPE}}-\Delta \mu_{\mathrm{MT}}\right)\right. \\
& \left.-N_{\mathrm{MT}}\left(\frac{1}{2} E_{\left(\mathrm{CH}_{3} \mathrm{~S}\right)_{2}}+\frac{1}{2} E_{\left(\mathrm{CH}_{3} \mathrm{~S}\right)_{2}}^{\mathrm{ZPE}}+\Delta \mu_{\mathrm{MT}}\right)-\left(E_{\text {total }}^{\text {clean }}-N_{\mathrm{Pd}}^{\text {clean }} E_{\text {bulk }}^{\mathrm{Pd}}\right)\right]
\end{aligned}
$$

Reordenando la ecuación obtenemos:

$$
\begin{aligned}
\Delta G_{\mathrm{ads}}=\frac{1}{A}\left[E_{\text {total }}-E_{\text {total }}^{\text {clean }}-\left(N_{\mathrm{Pd}}-N_{\mathrm{Pd}}^{\text {clean }}\right) E_{\mathrm{Pd}}^{\text {bulk }}+N_{\mathrm{S}}\left(\mu_{\mathrm{C}}+\frac{3}{2} \mu_{\mathrm{H}_{2}}\right)\right. \\
\left.\quad-\frac{1}{2}\left(N_{\mathrm{S}}+N_{\mathrm{MT}}\right)\left(E_{\left(\mathrm{CH}_{3} \mathrm{~S}\right)_{2}}+E_{\left(\mathrm{CH}_{3} \mathrm{~S}\right)_{2}}^{\mathrm{ZPE}}\right)\right]-\frac{1}{A}\left(N_{\mathrm{S}}+N_{\mathrm{MT}}\right) \Delta \mu_{\mathrm{MT}}
\end{aligned}
$$

En la Fig. 5.18 se representa la energía libre de Gibbs de adsorción $\left(\Delta G_{\text {ads }}\right)$ para las diferentes estructuras superficiales consideradas, en función del potencial químico del MT $\left(\Delta \mu_{\mathrm{MT}}\right)$, calculada con la ecuación 5.19. Comenzaremos el análisis general en base a la Fig. 5.18a. Los otros dos gráficos presentan los resultados para diferentes valores de potenciales químicos de $\mathrm{H}_{2}$ y C. Aunque surgen algunas diferencias en el rango de estabilidad de las diferentes fases con cambios en estos valores, el comportamiento general es similar. En estos gráficos, el valor de $\Delta G_{\text {ads }}=0$ corresponde a la superficie de $\operatorname{Pd}(111)$ limpia, representada como una linea punteada horizontal paralela al eje de abscisas, por ser independiente del potencial químico del MT. Por otro lado, las diferentes estructuras superficiales de S y/o MT sobre $\operatorname{Pd}(111)$ dan como resultado lineas rectas de $\Delta G_{\text {ads }}$ en función de $\Delta \mu_{\mathrm{MT}}$ con diferentes pendientes. A bajos potenciales químicos $\left(\Delta \mu_{\mathrm{MT}} \rightarrow-\infty\right)$ las estructuras de S/MT exhiben valores de energía libre de adsorción positivos, reflejando que estas estructuras son inestables con respecto a la superficie limpia. Sin embargo, cuando $\Delta \mu_{\mathrm{MT}}=$ $-5,40 \mathrm{eV}$, la red de $(\sqrt{3} \times \sqrt{3}) \mathrm{R} 30^{\circ}-\mathrm{S}$ (modelo 2) comienza a ser más estable que la superficie limpia de $\operatorname{Pd}(111)$. La estructura del modelo $\mathbf{1}$, red de $(\sqrt{3} \times \sqrt{3}) \mathrm{R} 30^{\circ}-\mathrm{MT}$, es más estable que la superficie de Pd limpia sólo cuando $\Delta \mu_{\mathrm{MT}} \geq-2,2 \mathrm{eV}$. Por lo tanto, esta superficie no debería formarse sobre $\mathrm{Pd}(111)$ ya que la red de $(\sqrt{7} \times \sqrt{7}) \mathrm{R} 19,1^{\circ}-\mathrm{S}$ (modelo 
3 ) está favorecida termodinámicamente. Sin embargo, la ruptura del enlace $\mathrm{S}-\mathrm{C}$ no es un proceso con una energía de activación baja, por lo que la red de $(\sqrt{3} \times \sqrt{3}) \mathrm{R} 30^{\circ}$-MT podría existir como un sistema estabilizado cinéticamente. No obstante, aún no existe evidencia experimental de la formación de estructuras de alcanotiolatos -libres de azufre elemental o sulfuro- sobre $\operatorname{Pd}(111)$.

El rango de potencial químico donde la estructura de $(\sqrt{3} \times \sqrt{3}) \mathrm{R} 30^{\circ}-\mathrm{S}$ es termodinámicamente estable se extiende hasta $\Delta \mu_{\mathrm{MT}}=-4,60 \mathrm{eV}$, donde ocurre una transición formando la estructura de $(\sqrt{7} \times \sqrt{7}) \mathrm{R} 19,1^{\circ}-\mathrm{S}$ (modelo 3). Esta estructura es estable hasta $\Delta \mu_{\mathrm{MT}}=-1,2 \mathrm{eV}$, donde comienzan a dominar el diagrama de fases las estructuras de $(\sqrt{7} \times \sqrt{7}) \mathrm{R} 19,1^{\circ}-(\mathrm{S}+\mathrm{MT})$, correspondientes a los modelos 4 (S sobre la superficie) y $\mathbf{5}$ (S bajo la superficie). Esto significa que las capas de MT sobre Pd son estables solamente cuando la superficie de $\mathrm{Pd}$ es pasivada por átomos de S. La diferencia en estabilidad entre las estructuras de los modelos 4 y 5 es sólo $5,6 \mathrm{meV}^{-2}$. Esta diferencia de energía se encuentra en el mismo orden que la energía térmica. Por lo tanto, cualquiera de estas dos estructuras puede ser esperada. Es interesante notar que la adsorción simultánea de $\mathrm{S}$ y MT reconstruye fuertemente la superficie de $\mathrm{Pd}$ (Fig. 5.16). Debe notarse que los cubrimientos encontrados experimentalmente de $\theta_{\text {sulfuro }} \approx 0,4$ y $\theta_{\text {tiolato }} \approx 0,3$ (véase Sec. 5.4.1) pueden ser consistentes también con la presencia de una capa de $(\sqrt{3} \times \sqrt{3}) \mathrm{R} 30^{\circ}-\mathrm{S}$ $+(\sqrt{3} \times \sqrt{3}) \mathrm{R} 30^{\circ}-\mathrm{MT}\left(\theta_{\mathrm{S}}=0,66\right)$. Sin embargo, los cálculos de DFT y el análisis termodinámico indican que esta estructura superficial es menos estable que las correspondientes a los modelos 4 y $\mathbf{5}$. El gráfico de $\Delta G_{\text {ads }}$ vs. $\Delta \mu_{\mathrm{MT}}$ para este sistema da como resultado una recta prácticamente paralela a las de los modelos $\mathbf{4}$ y $\mathbf{5}$ pero corrida aproximadamente $50 \mathrm{meV} \AA^{-2}$ hacia valores más positivos de $\Delta G_{\text {ads }}$.

Finalmente, se observa que un cambio importante en la presión de hidrógeno $\left(p_{\mathrm{H}_{2}}\right)$ desde $5 \times 10^{-7} \mathrm{~atm}$ (Fig. 5.18a) hasta $1 \times 10^{-9}$ atm (Fig. 5.18b) resulta en pequeños cambios en los diagramas de estabilidad. Por otro lado, el incremento en el potencial químico del carbono $\left(\mu_{\mathrm{C}}\right)$ desde $-11,8 \mathrm{eV}$ (Fig. 5.18a,b) hasta $-9,0 \mathrm{eV}$ (Fig. 5.18c) -valor cercano al cual el C comienza a ser incorporado dentro del Pd [205]-, dificulta la formación de las fases de S, pero no tiene un efecto notorio sobre la zona de estabilidad de las fases de $(\sqrt{7} \times \sqrt{7}) \mathrm{R} 19,1^{\circ}-(\mathrm{S}+\mathrm{MT})$.

\subsubsection{Análisis de la estructura electrónica}

Para poder comprender el mecanismo por el cual las estructuras experimentales encontradas pueden ser formadas sobre la superficie de $\mathrm{Pd}$, es necesario estudiar con más detalle los cambios que se producen en la estructura electrónica del sistema al adsorber las distintas especies sobre el metal. En este aspecto, para obtener más detalles de la interacción entre el metanotiol y el Pd, se estudió la densidad de estados (DOS) de los diferentes modelos y especies consideradas y se realiza a continuación una interpretación de la interacción adsorbato-sustrato en términos de la aproximación de orbitales de frontera [207].

Se ha encontrado -tanto mediante estudios experimentales como cálculos computacionales- que, en general, la energía de adsorción de especies sobre la superficie de metales de transición varía con la posición del centro de la banda $d$ del metal $\left(\epsilon_{d}\right)$ relativa al nivel 


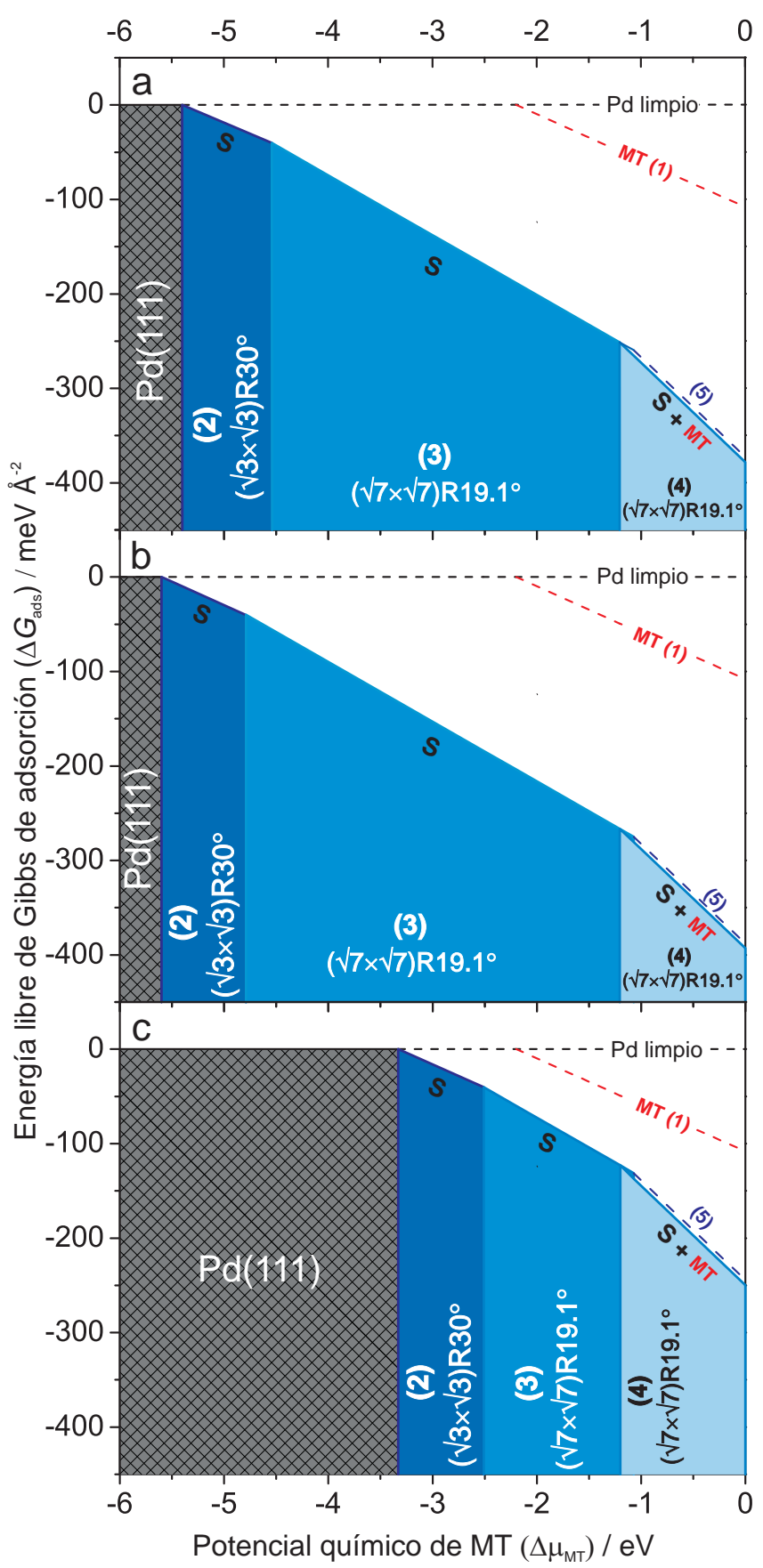

Figura 5.18: Energía libre de Gibbs de adsorción $\left(\Delta G_{\mathrm{ads}}\right)$ de las diferentes estructuras sobre $\operatorname{Pd}(111)$ en función del potencial químico de metanotiol (MT) $\left(\Delta \mu_{\mathrm{MT}}\right)$. (a) $T=$ $300 \mathrm{~K}, p_{\mathrm{H}_{2}}=5 \times 10^{-7} \mathrm{~atm}, \mu_{\mathrm{C}}=-11,8 \mathrm{eV}$. (b) $T=300 \mathrm{~K}, p_{\mathrm{H}_{2}}=1 \times 10^{-9} \mathrm{~atm}, \mu_{\mathrm{C}}=$ $-11,8 \mathrm{eV}$. (c) $\mathrm{T}=300 \mathrm{~K}, p_{\mathrm{H}_{2}}=5 \times 10^{-7} \mathrm{~atm}, \mu_{\mathrm{C}}=-9 \mathrm{eV}$. Los números en la figura indican el modelo. En línea punteada se muestran los modelos cuya $\gamma$ es mayor que la de otros modelos para el mismo $\Delta \mu$. La diferencia en $\Delta G_{\text {ads }}$ entre los modelos 4 (S sobre la superficie) y $\mathbf{5}$ (S bajo la superficie) es $5,6 \mathrm{meV}^{-2}$. 


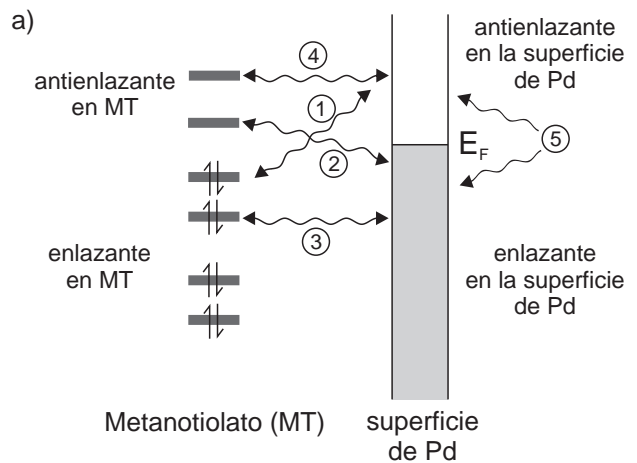

b)

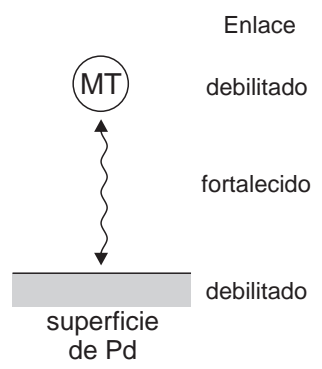

Figura 5.19: (a) Esquema de las interacciones entre el adsorbato y la superficie en términos del análisis de orbitales de frontera. (b) Efectos de las interacciones en los enlaces entre el adsorbato y la superficie, dentro del adsorbato y dentro de la superficie. Adaptado de ref. [207].

de Fermi. Cuanto más cercano se encuentre $\epsilon_{d}$ al nivel de Fermi, mayor será la interacción entre el metal y el adsorbato. En los metales de transición $3 d, 4 d$ y $5 d$ se observa que al moverse hacia la izquierda en la tabla periódica desde el $\mathrm{Cu}, \mathrm{Ag}$ y $\mathrm{Au}, \epsilon_{d}$ se corre hacia mayores energías, acercándose al nivel de Fermi [208]. En términos del análisis de orbitales de frontera es posible considerar distintas interacciones entre el adsorbato y la superficie metálica, esquematizadas en la Fig. 5.19a. Las interacciones más importantes son las señaladas en la figura como (1) y (2). En general estas interacciones involucran la transferencia electrónica entre los dos sistemas, lo cual favorece la interacción entre ambos. Sin embargo también puede ocurrir la transferencia de carga hacia orbitales antienlazantes, lo que genera un debilitamiento de enlaces dentro del adsorbato y dentro de la superficie y puede producir ruptura de enlaces [207]. Es decir que la quimisorción se realiza a expensas de un debilitamiento tanto de las interacciones metal-metal como de las interacciones dentro de las moléculas de adsorbato (Fig. 5.19b). Por lo tanto, también la reactividad de los metales es mayor cuanto más cercano esté el centro de la banda $d$ al nivel de Fermi. La interacción (3) es en general una interacción desestabilizadora, como ocurre entre átomos o moléculas (p. ej. la unión de dos átomos de He). En el caso de un adsorbato sobre una superficie, puede ocurrir que esta interacción resulte en una interacción enlazante si la interacción generada produce un estado por encima del nivel se Fermi de la superficie, con lo que los electrones pueden ser transferidos desde este estado antienlazante hacia el metal. La interacción (4) se produce entre dos estados desocupados. Es claro que en los sistemas moleculares esta interacción no tendría ningún efecto en el enlace. En el caso de la superficie, sin embargo, puede ocurrir que el estado generado se ubique por debajo del nivel de Fermi del metal y entonces puede ocurrir una migración electrónica desde el metal hacia este nuevo estado enlazante. Por último, la interacción de segundo orden (5) se produce como compensación de los movimientos en los estados electrónicos de la superficie como consecuencia de las interacciones primarias.

En las Fig. 5.20a y b se muestran los gráficos de la DOS correspondientes al sustrato de $\operatorname{Pd}(111)$ limpio y al radical MT en el vacío, respectivamente. Al pasar al modelo 1 
(Fig. 5.20c), la interacción entre el metanotiol y el Pd reduce la población electrónica de la banda $d$ en las cercanías del nivel de Fermi y se produce además un ensanchamiento de la banda $d$. Al estudiar la quimisorción de especies sobre metales de transición, si bien aumenta la energía de adsorción cuanto más cercana al nivel de Fermi se encuentre la banda $d$ del metal -como acabamos de comentar-, se produce también un compromiso entre quimisorción y ruptura de enlaces en el adsorbato. Esto es lo que se observa en el modelo $\mathbf{1}$, donde se produce una transferencia electrónica entre la banda $d$ del metal y orbitales antienlazantes $\left(\pi^{*}\right)$ del enlace $\mathrm{S}-\mathrm{C}$ del metanotiol adsorbido (interacción (2) en la Fig. 5.19a). Este fenómeno resulta en la elongación del enlace $\mathrm{S}-\mathrm{C}\left(d_{\mathrm{S}-\mathrm{C}}=0,186 \mathrm{~nm}\right)$ con respecto al radical $\mathrm{MT}$ en el vacío $\left(d_{\mathrm{S}-\mathrm{C}}=0,179 \mathrm{~nm}\right)$ y en la acumulación de carga negativa en el átomo de carbono luego de la adsorción del tiol (Tabla 5.3 y 5.4). El exceso de carga negativa en el átomo de $\mathrm{S}$ del metanotiolato adsorbido es mayor que la que se encuentra en la mayoría de los modelos de adsorción de tioles sobre Au [17,69] donde no se observa disociación del enlace S-C. Las cargas en los distintos elementos de los sistemas estudiados fueron calculadas mediante el método de análisis de Bader, utilizado para determinar la carga asociada a cada átomo en una molécula o un sólido. Es interesante notar que en los modelos 4 y $\mathbf{5}$ se diferencia la carga asociada a los adátomos (ad.) de la correspondiente a la capa de átomos de Pd que no fue distorsionada en gran medida. Los adátomos de $\mathrm{Pd}$ (en color violeta en la Fig. 5.17) poseen una carga positiva bastante mayor que los átomos de Pd superficiales (en color gris oscuro en la Fig. 5.17). Este defecto de densidad electrónica es mayor que en el caso de los adátomos de Au en las SAMs de tioles sobre $\mathrm{Au}(111)$ [17] o NPs [69], lo que demuestra la gran influencia de la capa de sulfuro, donde se acumula gran parte de esta carga negativa. Por otro lado, en el modelo $\mathbf{5}$ existen dos tipos de metanotiolato no equivalentes, lo que se hace evidente por la carga negativa acumulada en el átomo de C (Tabla 5.4).

Continuando con el análisis de la DOS, en la Fig. 5.20d,e se evidencia el efecto de la adsorción de $\mathrm{S}$ sobre Pd. Nótese el solapamiento entre los niveles $s, p$ del $\mathrm{S}$ y los $d$ del Pd y una gran disminución de la población electrónica en los estados cercanos al nivel de Fermi. De esta forma, el centro de la banda $d\left(\epsilon_{d}\right)$ se corre hacia valores más negativos de energía (Tabla 5.4). Este mismo comportamiento es observado en los modelos 4 y 5. El corrimiento de la banda $d$ del Pd hacia menores energías (mayores energías de enlace) hace que su reactivad disminuya. Por lo tanto, la superficie de $\mathrm{Pd}(111)$ modificada con $\mathrm{S}$ es más inerte hacia la disociación del metanotiol, en relación a la superficie de $\operatorname{Pd}(111)$ limpia. Esta superficie ya no es capaz de romper enlaces $\mathrm{S}-\mathrm{C}$ y se vuelve posible entonces la adsorción de metanotiolato.

Es interesante notar que luego de la adsorción de S sobre $\mathrm{Pd}(111)$, el centro de la banda $d$ se corre hacia valores más cercanos al encontrado en el análisis de la DOS de una superficie de $\mathrm{Au}(111)$ limpia o modificada con metanotiol (Fig. 5.21), donde es bien conocido que no existe ruptura del enlace $\mathrm{S}-\mathrm{C}$ (al menos con alcanotioles y ciertos tioles hidrofílicos). En esta figura se observa que el centro de la banda $d$ del Au se encuentra a menores valores de energía que en el caso del $\mathrm{Pd}$, como es esperado por las posiciones relativas de estos elementos en la tabla periódica [208]. Una superficie más noble que la de $\operatorname{Pd}(111)$ limpio, similar en reactividad a la del $\mathrm{Au}(111)$, es obtenida entonces luego de 
Tabla 5.4: Posición del centro de la banda $d$ con respecto al nivel de Fermi $\left(\epsilon_{d}\right)$ y cargas de Bader calculadas para los diferentes modelos.

\begin{tabular}{cccccc}
\hline modelo & \multirow{2}{*}{$\epsilon_{\mathrm{d}} / \mathrm{eV}$} & \multicolumn{4}{c}{ carga de Bader / $\mathrm{e}^{-}$} \\
\cline { 3 - 5 } & & $\mathrm{Pd}$ & \multicolumn{2}{c}{$\mathrm{MT}$} & \\
\cline { 3 - 5 } \cline { 3 - 4 } & & (capa superf.) & $\mathrm{S}$ & $\mathrm{C}$ & $\mathrm{S}$ \\
\hline $\mathbf{1}$ & $-1,75$ & $+0,06$ & $-0,20$ & $-0,03$ & - \\
$\mathbf{2}$ & $-1,85$ & $+0,09$ & - & - & $-0,22$ \\
$\mathbf{3}$ & $-1,83$ & $+0,21$ & - & - & $-0,42$ \\
$\mathbf{4}$ & $-1,83$ & $+0,36$ (ad.) & $-0,16$ & $-0,06$ & $-0,39$ \\
& & $+0,21$ & & & \\
$\mathbf{5}$ & $-1,83$ & $+0,44$ (ad.) & $-0,17$ & $-0,10$ & $-0,40$ \\
& & $+0,14$ & & $-0,04$ & \\
\hline
\end{tabular}

la adsorción de S sobre $\mathrm{Pd}(111)$.

\subsubsection{Comparación entre resultados experimentales y cálculos compu- tacionales}

En la Tabla 5.5 se presenta una comparación entre los cubrimientos de las especies azufradas obtenidos mediante XPS de propanotiol adsorbido sobre Pd (discutido en la Sec. 5.4.1) y los correspondientes a los modelos 4 y $\mathbf{5}$ propuestos para el estudio mediante DFT y termodinámica. Si bien se puede argumentar que esta comparación no es válida debido a que las fuerzas intermoleculares de van der Waals - no tenidas en cuenta en los cálculos teóricos- podrían aumentar la estabilidad de diferentes estructuras de tioles sobre el metal, para el caso de tioles de cadena corta como el propanotiol las fuerzas de van der Waals esperadas son débiles ( $\sim-0,063 \mathrm{eV}$ por unidad de metileno) [159].

La presión de disulfuro de dimetilo en fase gaseosa o su concentración en solución para cada potencial químico $\Delta \mu$ de la Fig. 5.18 pueden ser calculados mediante las ecuaciones A.36 y A.42, respectivamente, desarrolladas en el Apéndice A. De esta manera, se pueden relacionar los diagramas de $\Delta G_{\text {ads }}$ vs. $\Delta \mu$ con condiciones experimentales. Este cálculo indica que la transición entre la red de $(\sqrt{7} \times \sqrt{7}) \mathrm{R} 19,1^{\circ}-\mathrm{S}$ (modelo 3 ) y las redes de $(\sqrt{7} \times \sqrt{7}) \mathrm{R} 19,1^{\circ}-(\mathrm{S}+\mathrm{MT})$ (modelos 4 y 5 ), que ocurre a $\Delta \mu=-1,2 \mathrm{eV}$, equivale a una presión de $\left(\mathrm{CH}_{3} \mathrm{~S}\right)_{2}$ en fase gaseosa $\sim 2 \times 10^{-27}$ atm o una concentración de $\left(\mathrm{CH}_{3} \mathrm{~S}\right)_{2} \sim 3 \times 10^{-24} \mathrm{M}$ en una solución etanólica. Este resultado indica que no sería posible, en principio, alcanzar experimentalmente una fase de adsorbatos $\mathrm{S}$ sin metanotiolato o metanotiolato solo sobre Pd, mediante la adsorción de metanotiol. Por lo tanto, las estructuras superficiales accesibles experimentalmente, estables termodinámicamente, son las que comprenden tiolatos adsorbidos sobre una capa de sulfuro. Sin embargo, podría obtenerse alguna de las otras configuraciones propuestas si estas existieran como estructuras atrapadas cinéticamente.

Por otro lado, es posible relacionar la energía de enlace $E_{b}$ calculada para tiol y sulfuro sobre Pd (Tabla 5.3) con los potenciales de electrodesorción de la capa de sulfuro-tiolato sobre Pd (discutido en la Sec. 5.5). Como primera aproximación, el potencial de desorción es más negativo cuanto mayor es la energía de enlace [155]. En la Tabla 5.3 puede notarse 


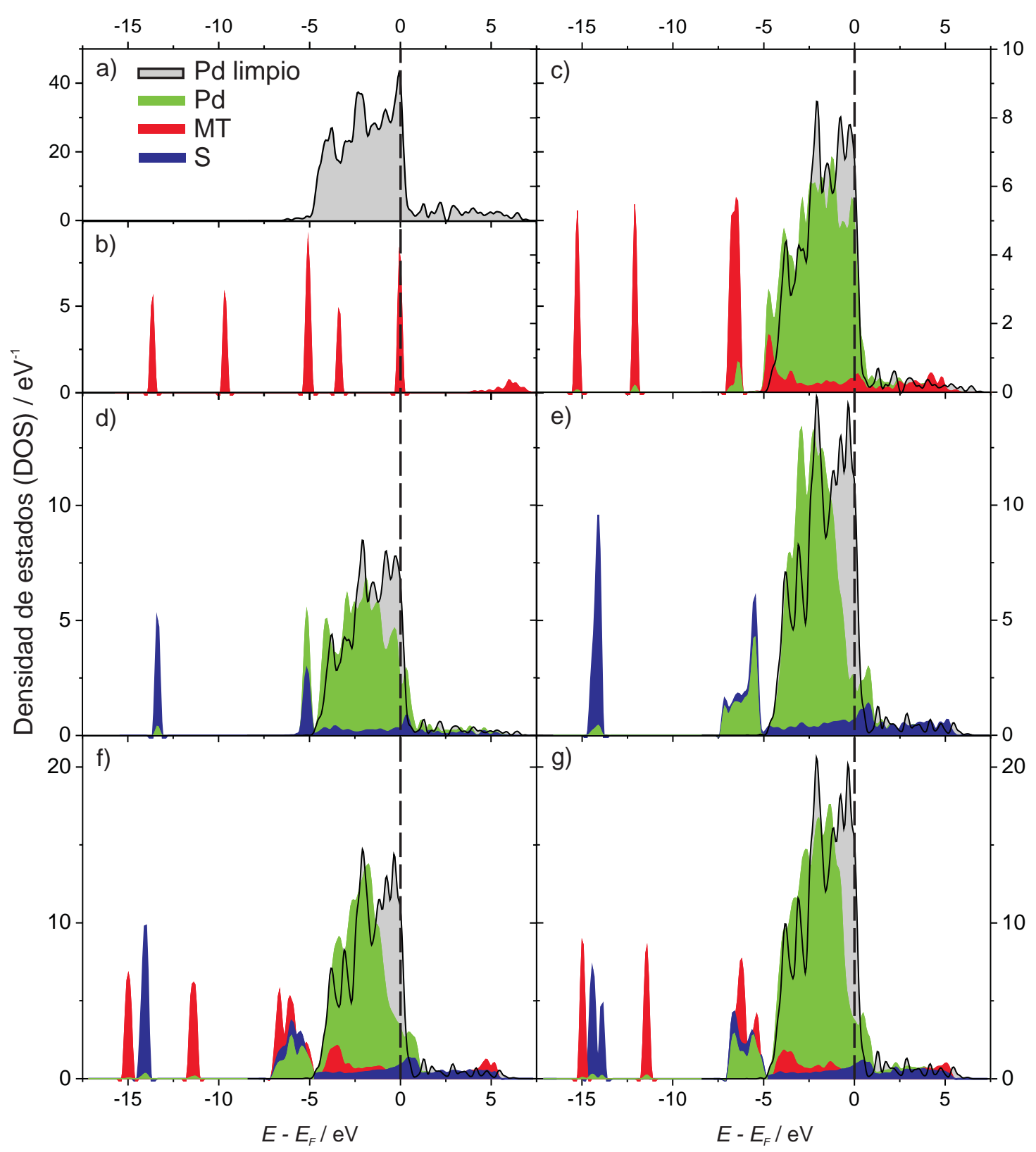

Figura 5.20: Densidad de estados (DOS) de los diferentes modelos estudiados comparado con Pd limpio y metanotiol libre. (a) $\mathrm{Pd}(111)$ limpio; (b) metanotiol aislado; (c) modelo 1 ; (d) modelo 2 ; (e) modelo 3 ; (f) modelo $4 ;$ (g) modelo 5 . Gris: estados $d$ de la capa superficial de $\mathrm{Pd}$ limpio; verde: estados $d$ de la capa superficial de $\mathrm{Pd}$; rojo: estados $s$ y $p$ de MT; azul: estados $s$ y $p$ de S. 


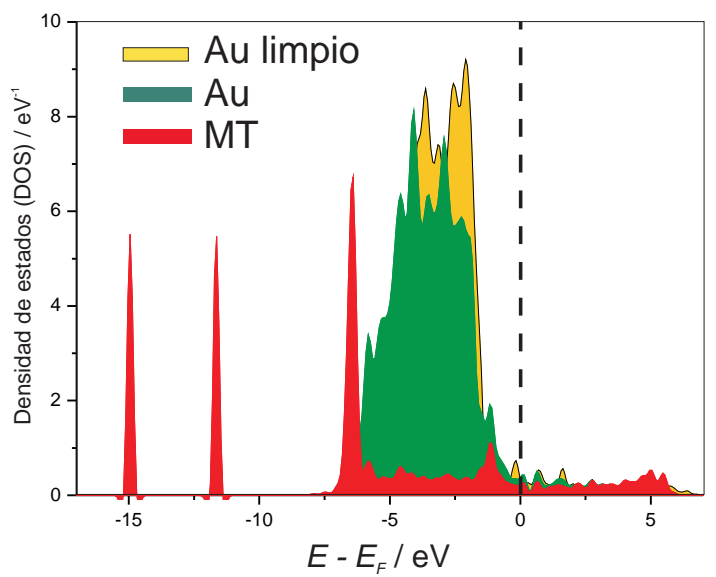

Figura 5.21: Densidad de estados del sistema $(\sqrt{3} \times \sqrt{3}) \mathrm{R} 30^{\circ}-\mathrm{MT}$ sobre $\mathrm{Au}(111)$ y $\mathrm{Au}(111)$ limpio. Amarillo: capa externa de átomos de $\mathrm{Au}$ limpio $(d)$, verde: capa externa de átomos de Au en el sistema MT-Au(111) (d), rojo: MT ( $s$ y $p$ ).

que en los modelos 4 y $\mathbf{5}$, la energía de enlace para metanotiol $\left(E_{b}=-2,62 \mathrm{a}-3,22 \mathrm{eV}\right)$ es mayor que la de metanotiol sobre la superficie de $\mathrm{Au}(111)$ sin reconstruir $\left(E_{b}=-1,82 \mathrm{eV}\right)$ o reconstruida $\left(E_{b}=-2,20 \mathrm{a}-2,61 \mathrm{eV}\right)$ [17]. No debe olvidarse que al desorber la capa de sulfuro-tiolato hay que tener en cuenta también la energía de adsorción del sulfuro sobre Pd, cuyos valores son considerablemente más altos que los del tiol. La tendencia de estos resultados está de acuerdo con los resultados experimentales para la electrodesorción donde se observó un incremento en la estabilidad electroquímica de los sustratos de Pd modificados con alcanotioles comparado con el comportamiento de Au modificado con alcanotiolatos $[155] .{ }^{7}$ Por otro lado, como ya fue comentado, estos resultados no concuerdan con los publicados por Williams y Gorman, quienes encontraron que los tioles sobre Pd poseen un rango de estabilidad menor que sobre $\mathrm{Au}$ [154].

Finalmente, se propone un esquema para la adsorción de tioles sobre superficies de $\operatorname{Pd}(111)$. Luego de la adsorción de tiolato sobre la superficie se produce una transferencia electrónica desde la banda $d$ del $\mathrm{Pd}$ hacia el adsorbato, lo que provoca una elongación y posterior ruptura del enlace S-C. Se forma entonces una estructura de sulfuro sobre la superficie de Pd, más estable termodinámicamente que la estructura de tiolato sobre $\operatorname{Pd}(111)$. El sistema continúa incorporando sulfuro, utilizando las moléculas adsorbidas de tiolato como reservorio de $\mathrm{S}$, hasta que la barrera energética para la ruptura del enlace $\mathrm{S}-\mathrm{C}$ se vuelve muy alta debido a los cambios en la densidad de estados del Pd y, entonces, los tiolatos pueden ser adsorbidos sobre la superficie de Pd modificada con $\mathrm{S}$, sin ulterior ruptura del enlace $\mathrm{S}-\mathrm{C}$.

\footnotetext{
${ }^{7} \mathrm{Al}$ realizar este análisis también hay que considerar la energía necesaria para introducir un electrón en el sistema tiolato-metal y la energía de interacción del solvente con los diferentes metales [155]. No obstante, en el caso del Au y Pd, la diferencia más notable se encuentra en las energías de enlace. Por otro lado, debido a que en el Pd la desorción ocurre a potenciales donde también ocurre la HER, es probable que el mecanismo de desorción sea diferente que en el caso de los otros metales como Au y Ag.
} 
Tabla 5.5: Comparación entre los cubrimientos de sulfuro, tiolato y $\mathrm{S}$ total obtenidos mediante XPS (adsorción de propanotiol sobre Pd) y los resultantes de los modelos propuestos para los cálculos de DFT. S total es la suma del cubrimiento de sulfuro y tiolato. Los porcentajes se calcularon teniendo en cuenta todas las especies azufradas.

\begin{tabular}{lcc}
\hline & XPS: $\mathrm{SC}_{3}$ & Modelos: $\mathbf{4}$ y $\mathbf{5}$ \\
\hline sulfuro & $48 \% ; 0,4 \mathrm{ML}$ & $3 / 7=0,43 \mathrm{ML}$ \\
tiolato & $39 \% ; 0,3 \mathrm{ML}$ & $2 / 7=0,29 \mathrm{ML}$ \\
S total & $0,7 \mathrm{ML}$ & $5 / 7=0,71 \mathrm{ML}$ \\
\hline
\end{tabular}

\subsection{Conclusiones}

Los resultados presentados en este capítulo muestran la gran diferencia que existe en la composición de las monocapas autoensambladas de alcanotioles sobre Pd comparadas con sus análogas sobre Au. Esto fue estudiado mediante diversos métodos, tanto experimentales como teóricos.

Los resultados de XPS pueden resumirse en 4 incisos: (i) La relación atómica S:Pd hallada es aproximadamente el doble de la relación S:Au en sistemas similares. (ii) La señal de S $2 p$ tiene una estructura más compleja que la encontrada en el caso de tioles sobre $\mathrm{Au}$, poniendo en evidencia una capa de sulfuro además de la monocapa de alcanotiolatos y (iii) La señal de Pd $3 d$ de los sistemas con tioles muestran algún grado de oxidación del metal, mientras que en el Au no se observa este comportamiento. Esto se encuentra en congruencia con los valores calculados para las cargas de Bader de los diferentes metales. Mientras que para SAMs de tiolatos sobre $\mathrm{Au}(111)$, la carga de Bader de los adátomos de $\mathrm{Au}$ se encuentra entre $+0,05$ y $+0,15$, dependiendo del modelo considerado [17], los valores para el Pd pueden llegar a $+0,44$ (Tabla 5.4). (iv) La relación atómica C:S hallada no es consistente con un modelo de alcanotiolatos libres de sulfuro sobre Pd.

Mediante distintos experimentos electroquímicos (medidas de capacidad de interfase y comportamiento de una cupla rédox) se encontró que la capacidad de bloqueo a la transferencia de carga de las monocapas de alcanotiolatos preparadas son similares a la encontrada en las SAMs de alcanotiolatos sobre Au. Por otra parte se demostró que el rango de estabilidad de la compleja capa de sulfuro-tiolato sobre Pd es más amplio que en el caso del Au. En particular, la electrodesorción de esta capa en $\mathrm{NaOH}$ 0,1 M se produce a potenciales más negativos que en el caso del Au. Además se observó que este potencial es prácticamente independiente de la longitud de la cadena hidrocarbonada del alcanotiol, indicando que la capa de sulfuro ejerce un rol preponderante en la estabilidad de estos sistemas. Por último, se estudió la adsorción de sulfuro sobre Pd a modo de comparación con la adsorción de tioles, debido a la presencia de la capa de sulfuro encontrada en el caso de la adsorción de tioles sobre Pd. En este sistema se encontró que la electrodesorción reductiva ocurre en la misma zona de potencial que en el caso de los sustratos de $\mathrm{Pd}$ modificados con alcanotioles, lo cual refuerza la importancia del sulfuro en la estabilidad de la capa de sulfuro-tiolato. 
Mediante los cálculos realizados en el marco de DFT se optimizaron las estructuras de 5 modelos diferentes para tiolato, sulfuro y sulfuro-tiolato sobre $\operatorname{Pd}(111)$. Un resultado interesante en este aspecto es la importante reconstrucción de la superficie de $\mathrm{Pd}(111)$ observada al adsorber simultáneamente azufre y tiolato sobre el metal (modelos 4 y 5 ). Estas estructuras recuerdan a las propuestas para la adsorción de tiolatos sobre $\mathrm{Au}(111)$ y NPs. Es interesante comentar que las estructuras fueron encontradas directamente a partir de la optimización mediante DFT de las estructuras iniciales propuestas. Luego se evaluó la estabilidad de las estructuras optimizadas y para esto se realizó un análisis en el marco de la termodinámica estadística a partir de primeros principios. Esta aproximación permite obtener datos termodinámicos a temperaturas y presiones determinadas, a partir de los resultados arrojados por DFT a $T=0 \mathrm{~K}$. Mediante este método se estudió la variación de la energía libre superficial de los distintos modelos en función del potencial químico (y en definitiva de la presión y temperatura) de un reservorio de moléculas que contienen azufre en fase gaseosa. Se pueden enumerar tres resultados más importantes de este análisis y que apoyan los resultados experimentales comentados. El primero consiste en el hecho de que la estructura de una monocapa de tiolato sobre $\operatorname{Pd}(111)$ (libre de sulfuro) es termodinámicamente menos estable que las estructuras de sulfuro o sulfuro-tiolato para todo el rango de potenciales químicos del tiol. En segundo lugar, a las temperaturas accesibles experimentalmente, ${ }^{8}$ las estructuras más estables termodinámicamente corresponden a las compuestas por sulfuro y tiolato, tal como fuera encontrado experimentalmente. Los dos modelos propuestos con esta composición ( 4 y 5 ) presentan una energía libre superficial del mismo orden. Los resultados de XPS obtenidos para una monocapa de Pd sobre $\mathrm{Au}(111)$ muestran que la cantidad relativa de sulfuro en este sistema es menor que el caso de Pd masivo. Esto se encuentra en concordancia con las estructuras de los modelos 4 y $\mathbf{5}$ ya que, en ambos modelos, la capa de sulfuro interacciona fuertemente con átomos de $\mathrm{Pd}$ de la primera y segunda capa atómica.

Por último, es necesario comentar que, si bien la estructura de alcanotiolatos sobre $\operatorname{Pd}(111)$ es inestable en todo el rango de potencial químico estudiado, podría ser posible encontrar esta estructura experimentalmente si se encuentran las condiciones para atrapar cinéticamente este sistema. Un ejemplo posible para estas condiciones puede ser la adsorción de tioles a bajas temperaturas.

En último término, se estudió la estructura electrónica de los diferentes modelos propuestos. Los resultados encontrados en este análisis resultan muy interesantes ya que permiten relacionar las estructuras encontradas con los cambios producidos en la densidad de estados electrónicos de la superficie del metal. En primer lugar, al comparar la densidad de estados del Pd con la del Au, se observa que la banda de electrones $d$ del primero se encuentra muy cercana al nivel de Fermi y crece bruscamente en esta región. La banda $d$ de $\mathrm{Au}$, en cambio, se ubica a menores energías (mayores energías de enlace). Debido a que la reactividad de los metales (capacidad de transferencia de carga con los adsorbatos) está relacionada con la posición de la banda $d$, como fue explicado anteriormente, es muy probable la posibilidad de ruptura del enlace $\mathrm{S}-\mathrm{C}$ por parte de la superficie del $\operatorname{Pd}(111)$,

\footnotetext{
${ }^{8}$ No tiene sentido físico considerar temperaturas muy elevadas debido a que el rango de estabilidad térmica de los tioles es limitado.
} 
lo cual no sucede en el caso del $\mathrm{Au}(111)$ (al menos con alcanotioles). La población de la banda $d$ del $\operatorname{Pd}(111)$ disminuye en la zona cercana al nivel de Fermi luego de que se adsorbe azufre sobre su superficie. Esto produce que el centro de la banda $d$ se corra hacia menores energías y, por lo tanto, la reactividad de esta nueva superficie disminuye. Esto hace posible la ulterior adsorción de tioles como tiolatos sobre esta superficie, dado que la barrera energética para la ruptura del enlace $\mathrm{S}-\mathrm{C}$ ya no puede ser alcanzada. El cambio en la estructura electrónica del $\operatorname{Pd}(111)$ explica por qué no se produce una sulfidización masiva del metal y, en cambio, el cubrimiento de sulfuro es del orden de la submonocapa. 


\section{Capítulo 6}

\section{Nanopartículas de Pd protegidas por alcanotioles}

\subsection{Introducción}

Como ya fue discutido en el caso del Au, el estudio de la estructura y composición de las NPs y su relación con el método de síntesis empleado es de gran interés tanto para ampliar los conocimientos básicos de las NPs como para mejorar su uso en diversas aplicaciones como sensores y catalizadores. El caso particular de las PdNPs protegidas con alcanotioles resulta muy atrayente por dos motivos. En primer lugar, este metal posee importantes propiedades catalíticas, como es ampliamente conocido. Si se lo utiliza en forma de NPs no sólo se aumenta considerablemente su relación superficie:volumen sino que también se pueden variar sus propiedades electrónicas debido a la disminución del tamaño a la escala nanométrica y sintonizar así sus propiedades catalíticas. Existen, además, estudios que han demostrado que al cubrir las PdNPs con alcanotioles se puede aumentar la selectividad de estos catalizadores en determinadas reacciones. En segundo lugar, resulta un sistema del que existen pocos estudios detallados acerca de su composición química y su estructura, aunque ha sido utilizado en diversas aplicaciones. Estos escasos estudios muestran que estas partículas tienen una composición diferente a sus análogas de Au, lo que las hace aún más interesantes.

En referencia a las aplicaciones, es ampliamente conocido el uso de PdNPs como catalizadores en diversas reacciones químicas. Ejemplos recientes en los que se utilizan PdNPs protegidas con tioles son el trabajo de Carnello et ál. [209], quienes reutilizaron varias veces PdNPs cubiertas con ácido 11-mercapto-undecanoico para acelerar reacciones de acoplamiento de Suzuki, donde se disminuyen los costos de las sales de Pd o complejos de organo-paladio. Por otro lado, Lu et ál. [210] publicaron el uso de PdNPs cubiertas por tioles como excelentes catalizadores para las reacciones de Heck. En diferentes trabajos de Marshall et ál., se demostró que los alcanotioles como protectores de PdNPs (y Pd plano) incrementan la selectividad en la formación de 1-epoxibutano a partir de 1-epoxi-3-buteno desde $11 \%$ a $94 \%$ en condiciones de reacción equivalentes a un catalizador de Pd desnudo. A pesar de que el azufre fue siempre considerado un envenenador de catalizadores, 
estos autores demostraron que la velocidad de reacción hacia los productos en un catalizador cubierto con tiol es sólo ligeramente menor que en el caso de un catalizador desnudo $[149,211]$. Las moléculas de tioles son sólo un ejemplo de este campo, en el que se estudia la modulación de la reactividad y selectividad de la superficie metálica mediante la adición de adsorbatos [212].

Debido a la gran capacidad del $\mathrm{Pd}$ para absorber hidrógeno formando $\mathrm{PdH}_{x}$, surgen diversas aplicaciones entre las que se destaca su uso en sensores. Al absorber hidrógeno en la red del Pd, distintas propiedades del metal cambian, entre ellas, la conductividad. Esto dio origen a los sensores de hidrógeno basados en el cambio en la conductividad de películas delgadas al absorber el gas: la resistencia aumenta al aumentar la cantidad de hidrógeno adsorbido. Sin embargo, los sensores más interesantes son los formados por PdNPs. El volumen de las NPs aumenta al incrementarse la cantidad de hidrógeno absorbido y, en una película de NPs depositada sobre una superficie, la conductividad entre dos extremos de esta aumenta debido a que existe mayor contacto entre las partículas [153]. Este tipo de sensores fue introducido por el grupo de R. M. Penner [213] y estudiado ampliamente por el grupo de F. P. Zamborini [12]. Para construir estos sensores, se han utilizado ampliamente PdNPs cubiertas con alcanotioles, preparadas por el método de Brust-Schiffrin [153, 214] y por intercambio de ligandos en PdNPs cubiertas con alquilaminas [215]. Un problema que se presenta en estos sistemas es la necesidad de remover el agente protector de las NPs luego de ser sintetizadas para facilitar la difusión de $\mathrm{H}_{2}$ hacia la superficie de las partículas donde se produce el hidrógeno atómico que finalmente difundirá en el metal. Esto ha sido realizado mediante tratamiento térmico o mediante un oxidante fuerte como ozono, lo que trae aparejado los problemas comentados en la introducción del capítulo anterior. La comprensión de la estructura y composición superficial de las PdNPs resulta fundamental para su utilización en estos sensores, tanto para idear métodos para su limpieza como para comprender mejor el mecanismo de detección.

Del mismo modo que ocurre con la formación de SAMs de tioles sobre Pd plano, cuando se considera la superficie de PdNPs cubiertas por tioles, en la literatura se observa la misma descripción incompleta de su química [149, 215-217]. Recientemente, Moreno et ál. [215] informaron la preparación de PdNPs de $3.0 \mathrm{~nm}$-preparadas por el método bifásico de Brust-Schiffrin utilizando hexanotiol- para su utilización en la detección de hidrógeno. Estas partículas fueron descritas simplemente como núcleos metálicos cubiertos por una monocapa de alcanotiolatos, en analogía a las AuNPs. Se asumió que el reemplazo de aminas por tioles es dominado por la fuerza del enlace Pd-SR sin tener en cuenta la posibilidad de formación de una capa de sulfuro. Ramallo-López et ál. [218] describieron las PdNPs preparadas por un método de Brust-Schiffrin de una fase modificado, como NPs de sulfuro de paladio. Por otro lado, Zelakiewicz et ál. [219] sintetizaron PdNPs cubiertas con octanotiol mediante el método bifásico de Brust-Schiffrin y, en base resultados de ${ }^{13} \mathrm{C}_{1} \mathrm{RMN}$ y espectroscopía infrarroja, propusieron un modelo en el que los núcleos de $\mathrm{Pd}$ metálico se encuentran cubiertos por una monocapa de dialquil disulfuro. Más adelante, Sun et ál. plantearon un modelo de núcleos de $\mathrm{Pd}^{0}$ inmersos en una matriz de sulfuro de paladio [220]. Por otro lado, anteriormente a estos trabajos, Murayama et ál. describieron a estas partículas -a partir de resultados de EXAFS, TEM y XRD- como núcleos metálicos 
cubiertos por una capa de sulfuro y, sobre este, una monocapa de alcanotiolatos [221], en referencia al modelo propuesto por Love et ál. para tioles sobre Pd plano [151].

Los ejemplos anteriores indican que existe una necesidad clara de una comprensión más profunda de la interfase formada cuando las PdNPs son protegidas por especies derivadas de tioles. En este capítulo nos ocuparemos de estudiar la naturaleza química de las PdNPs protegidas por alcanotioles sintetizadas por diferentes vías y luego compararemos su estructura interna con la de NPs protegidas por alquilaminas. En primer término discutiremos diferentes aspectos relacionados a los pasos involucrados en la síntesis de las NPs y luego detallaremos los resultados obtenidos mediante diferentes técnicas que nos permiten obtener información acerca de la estructura y composición química de las NPs y su relación con la síntesis empleada. Las técnicas utilizadas incluyen espectroscopía UV-vis y FTIR, EXAFS -realizado en colaboración con el grupo del Dr. F. G. Requejo- y XPS. Finalmente discutiremos otros aspectos estructurales, derivados del estudio mediante HRTEM con corrección de aberración -realizado en NCEM, Berkeley, de STEM con corrección de aberración -realizado en colaboración con el grupo del Dr. M. José-Yacamán, de la University of Texas at San Antonio- y de cálculos de dinámica de Langevin realizados por el grupo del Dr. M. M. Mariscal, de la Universidad Nacional de Córdoba. También discutiremos la incidencia del daño inducido por radiación en la caracterización de las NPs.

\subsection{Síntesis de las nanopartículas}

En esta sección describiremos la síntesis de PdNPs protegidas por alcanotioles, preparadas mediante dos métodos diferentes: el método bifásico de Brust-Schiffrin [14], ya comentado para el caso de AuNPs (Sec. 3.4) y el método de reemplazo de ligandos en PdNPs protegidas por alquilaminas, sintetizadas por el método de Leff [222]. Los detalles pueden encontrarse en el Apéndice B.

El método de Brust-Schiffrin fue utilizado por primera vez con Pd por Chen et ál. [223] y estudiado luego con más detalle por Zamborini et ál. [65]. En esta ruta de síntesis, las especies de $\mathrm{Pd}^{\mathrm{II}}$-que forman complejos de $\left[\mathrm{PdCl}_{4}\right]^{2-}$ - son transferidas desde la fase acuosa hacia la fase orgánica (tolueno) mediante $\mathrm{ToABr}$, como se muestra en el esquema de la Fig. 6.1. Los aniones metálicos se encuentran dentro de micelas inversas formadas por la sal de amonio en el solvente orgánico [79]. Debido a que los iones bromuro pueden ser intercambiados con cloruros en la esfera de coordinación del $\mathrm{Pd}^{\mathrm{II}}$, los complejos de $\mathrm{Pd}$ en la fase orgánica son llamados simplemente $\left[\mathrm{PdX}_{4}\right]^{2-}$, como en el caso del Au. Contrariamente a lo que ocurre cuando este método es utilizado para la síntesis de AuNPs, los tioles no producen la reducción de las especies metálicas: el paladio permanece como $\mathrm{Pd}^{\mathrm{II}}$ luego del agregado de tioles al medio de reacción. Como se discutió en el Cap. 3, resultados experimentales recientes han demostrado que los precursores reales en el método bifásico son pares iónicos de tetraalquilamonio y haluros de $\mathrm{Au}^{\mathrm{I}}$, [ $\left.\mathrm{NR}_{4}\right]\left[\mathrm{AuX}_{2}\right]$ [55]. Sin embargo, en el caso de $\mathrm{Pd}$, cuando los tioles están en contacto con las especies de $\mathrm{Pd}^{\mathrm{II}}$ disueltas en tolueno se forman complejos del tipo $\mathrm{Pd}^{\mathrm{II}}-\mathrm{RSH}$ [65]. En las síntesis que se realizó en este trabajo, se utilizó una relación molar tiol: $\mathrm{Pd}=0,5: 1$, menor que la requerida para formar estequiométricamente los complejos de $\mathrm{Pd}^{\mathrm{II}}-\mathrm{RSH}$. Por lo tanto, las especies de 
$\left[\mathrm{PdX}_{4}\right]^{2-}$ también están presentes en la fase orgánica cuando se agrega el agente reductor, $\mathrm{NaBH}_{4}$, como se muestra en la Fig. 6.1. Luego de agregar el tiol, la mezcla se agita por $1 \mathrm{~h}$ más y se agrega el $\mathrm{NaBH}_{4}$ en un exceso molar de 10:1 respecto al metal, para formar las NPs. La solución se vuelve negra rápidamente. Luego de agitar por $3 \mathrm{~h}$, se descarta la fase acuosa y se reduce el volumen de la fase orgánica mediante evaporación en rotavapor a temperatura ambiente. Las partículas se lavan 4 veces con acetonitrilo mediante rutina de centrifugación/redispersión. En este trabajo se utilizó dodecanotiol y se obtuvieron PdNPs protegidas con un capa mixta de sulfuro y dodecanotiol ( $\mathrm{Pd} @ \mathrm{~S}-\mathrm{SC}_{12} \mathrm{NPs}$ ), como veremos más adelante.

Los espectros UV-vis observados en la Fig. 6.1 se correlacionan muy bien con los informados anteriormente para PdNPs [65, 217, 223]. La ausencia de picos en la zona de 300 a $500 \mathrm{~nm}$, relacionados con complejos de $\mathrm{Pd}^{\mathrm{II}}-\mathrm{RSH}[65,224,225]$ indica que no hay cantidades significativas de estas especies en la solución que contiene las $\mathrm{Pd} @ \mathrm{~S}-\mathrm{SC}_{12}$ NPs.

El efecto de la relación molar tiol:Pd utilizada se detalla en la Fig. 6.2. Allí se muestran los espectros UV-vis y fotografías de mezclas de $\mathrm{Pd}^{\mathrm{II}}$ y dodecanotiol en diferentes proporciones y las mismas muestras luego del agregado del agente reductor. Se observa que la reducción de los complejos de $\mathrm{Pd}^{\mathrm{II}}$ se produce totalmente para dar lugar a las NPs, sólo cuando la relación molar tiol:Pd es menor a 1. En los otros casos, se obtiene una mezcla de PdNPs y $\mathrm{Pd}^{\mathrm{II}}-\mathrm{RSH}$ o solamente $\mathrm{Pd}^{\mathrm{II}}-\mathrm{RSH}$.

La misma ruta de síntesis fue empleada con el objetivo de preparar PdNPs protegidas con propanotiol ( $\mathrm{Pd} @ \mathrm{~S}-\mathrm{SC}_{3} \mathrm{NPs}$ ) y hexanotiol (Pd@S-SC $\mathrm{S}_{6} \mathrm{NPs}$ ). Mientras que las $\mathrm{Pd} @ \mathrm{~S}-\mathrm{SC}_{6}$ NPs presentaron características similares a las $\mathrm{Pd} @ \mathrm{~S}-\mathrm{SC}_{12}$ NPs, no fue posible obtener las $\mathrm{Pd} @ \mathrm{SC}_{3} \mathrm{NPs}$, ya que las mismas se aglomeraron luego de la síntesis, al igual que en el caso del $\mathrm{Au}$ (Sec. 3.4).

Por último, es interesante considerar el efecto de la temperatura en los productos resultantes de la síntesis de las NPs. Fue demostrado que cuando la temperatura es incrementada en la síntesis de NPs con tioles, las especies de tiolato adsorbidas sobre el $\mathrm{Pd}^{0}$ no son estables y se produce una descomposición del ligando, lo que resulta en una sulfidización de las PdNPs [224]. Consecuentemente, para obtener $\mathrm{Pd}^{0}$ en alguna medida, la preparación de las PdNPs debe ser llevada a cabo a temperatura ambiente o menor [209]. Además, la purificación debe ser realizada evitando la exposición a altas temperaturas, ya que puede ocurrir la desorción de las especies de tiolato o la ruptura de enlaces $\mathrm{S}-\mathrm{C}$.

La segunda ruta empleada para la síntesis de PdNPs ha sido la del intercambio de ligandos en PdNPs protegidas con alquilaminas $\left(\mathrm{RNH}_{2}\right)$, previamente sintetizadas. Estas partículas fueron preparadas por el método de Leff [222], que consiste en la reducción de $\mathrm{Pd}^{\mathrm{II}}$ por $\mathrm{NaBH}_{4}$ en presencia de alquilaminas (Fig. 6.1). El primer paso en este método -desarrollado originalmente para AuNPs- es el mismo que en la síntesis de Brust-Schiffrin. La diferencia ocurre luego de que el $\left[\mathrm{PdX}_{4}\right]^{2-}$ es transferido a la fase orgánica, ya que se agrega alquilamina al medio de reacción sin quitar la fase acuosa proveniente de la sal metálica. Por lo tanto, se produce una emulsión de tolueno/agua, favorecida por las aminas protonadas debido a la acidez del medio acuoso, llevándose la síntesis a cabo en estas condiciones. Luego, se agrega el $\mathrm{NaBH}_{4}$ y se obtienen las PdNPs protegidas con alquilaminas. En este trabajo se utilizó dodecilamina, obteniéndose entonces PdNPs protegidas 

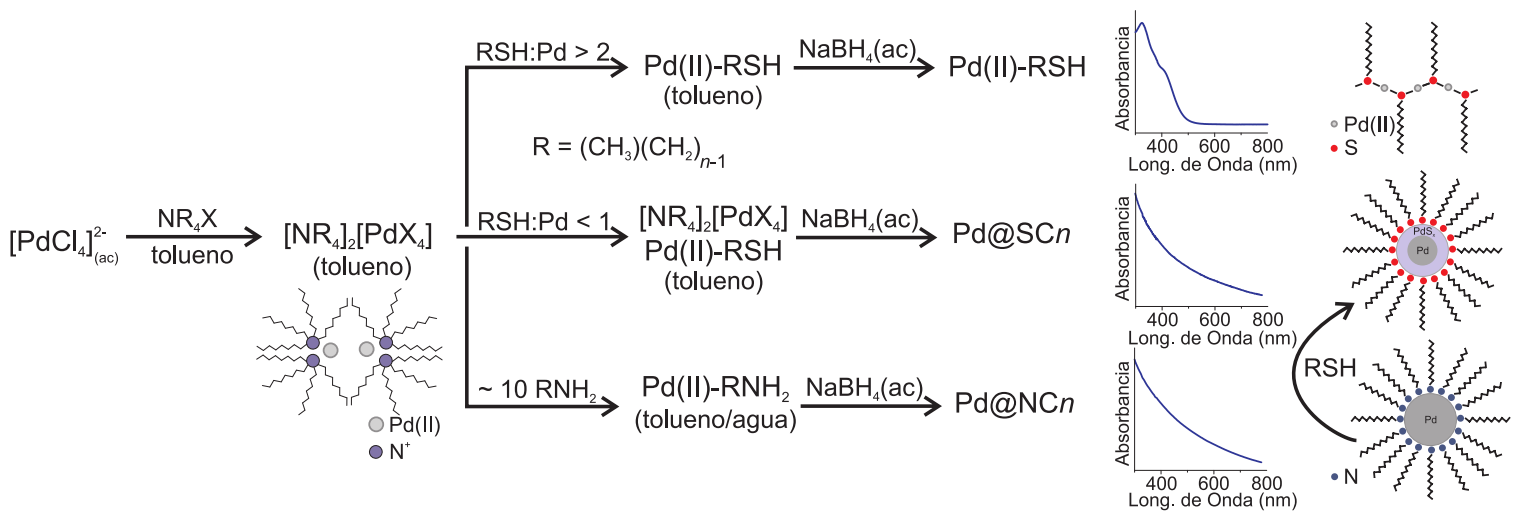

Figura 6.1: Esquema de las diferentes rutas para la síntesis de PdNPs y complejos de $\mathrm{Pd}^{\mathrm{II}}-\mathrm{RSH}$. Los espectros UV-vis de los diferentes productos también se incluyen. En este trabajo se analiza el caso de $\mathrm{SC}_{n}=\mathrm{SC}_{12}$ y $\mathrm{NC}_{n}=\mathrm{NC}_{12}$. Los dibujos son solo representaciones esquemáticas de los productos e intermediarios.

con dodecilamina ( $\left.\mathrm{Pd} @ \mathrm{NC}_{12} \mathrm{NPs}\right)$. Comúnmente estas NPs son descritas en la literatura como núcleos de $\mathrm{Pd}^{0}$ cubiertos por alquilaminas [214, 215], como se esquematizó en la Fig. 6.1. Sin embargo, debido a que la energía de interacción entre las moléculas de aminas y el Pd no es tan grande como en el caso de los tioles, estas NPs son más susceptibles que las Pd@S-SC 12 NPs de ser oxidadas por el oxígeno presente en la solución. Por esta razón es esperable la presencia de cierta cantidad de óxido de paladio en estas partículas.

Luego de lavar las Pd@NC 12 NPs, estas fueron dispersadas en tolueno, en contacto con dodecanotiol (tiol:Pd $\sim 1: 1$ ) durante $12 \mathrm{~h}$ aproximadamente, para realizar el intercambio de ligandos de aminas por tioles. Así, se obtuvieron PdNPs protegidas por una mezcla de dodecilamina y dodecanotiol $\left(\mathrm{Pd} @ \mathrm{NC}_{12}-\mathrm{SC}_{12} \mathrm{NPs}\right)$.

\subsection{Naturaleza química de las nanopartículas}

\subsubsection{Distribución de tamaños}

Para poder estudiar cualquier propiedad de las NPs o caracterizar su estructura química mediante cualquier técnica, es necesario, primero, conocer su distribución de tamaños. Para esto, se estudiaron las Pd@S-SC 12 NPs y Pd@NC N $_{12}$ NPs mediante HAADF-STEM, a baja resolución y se calculó su distribución de tamaños analizando distintas imágenes mediante el algoritmo de distribución de tamaños del programa Digital Micrograph, como fue explicado en la Sec. 2.10. En la Fig. 6.3 se muestran imágenes representativas de estas NPs y sus distribuciones de tamaños. Las imágenes fueron tomadas en el microscopio JEOL JEM-ARM200F con corrección de aberración operado a $200 \mathrm{kV}$, en colaboración con G. Casillas.

Como se explicó en la Sec. 2.9, en la configuración de HAADF-STEM la intensidad de la señal es proporcional al cuadrado del número atómico $\left(\propto Z^{2}\right)$ de los elementos en la muestra (Ec. 2.41). En consecuencia, los átomos de Pd de las NPs $(Z=46)$ aparecen con contraste blanco en la imagen, rodeados por un fondo negro que corresponde al soporte de 


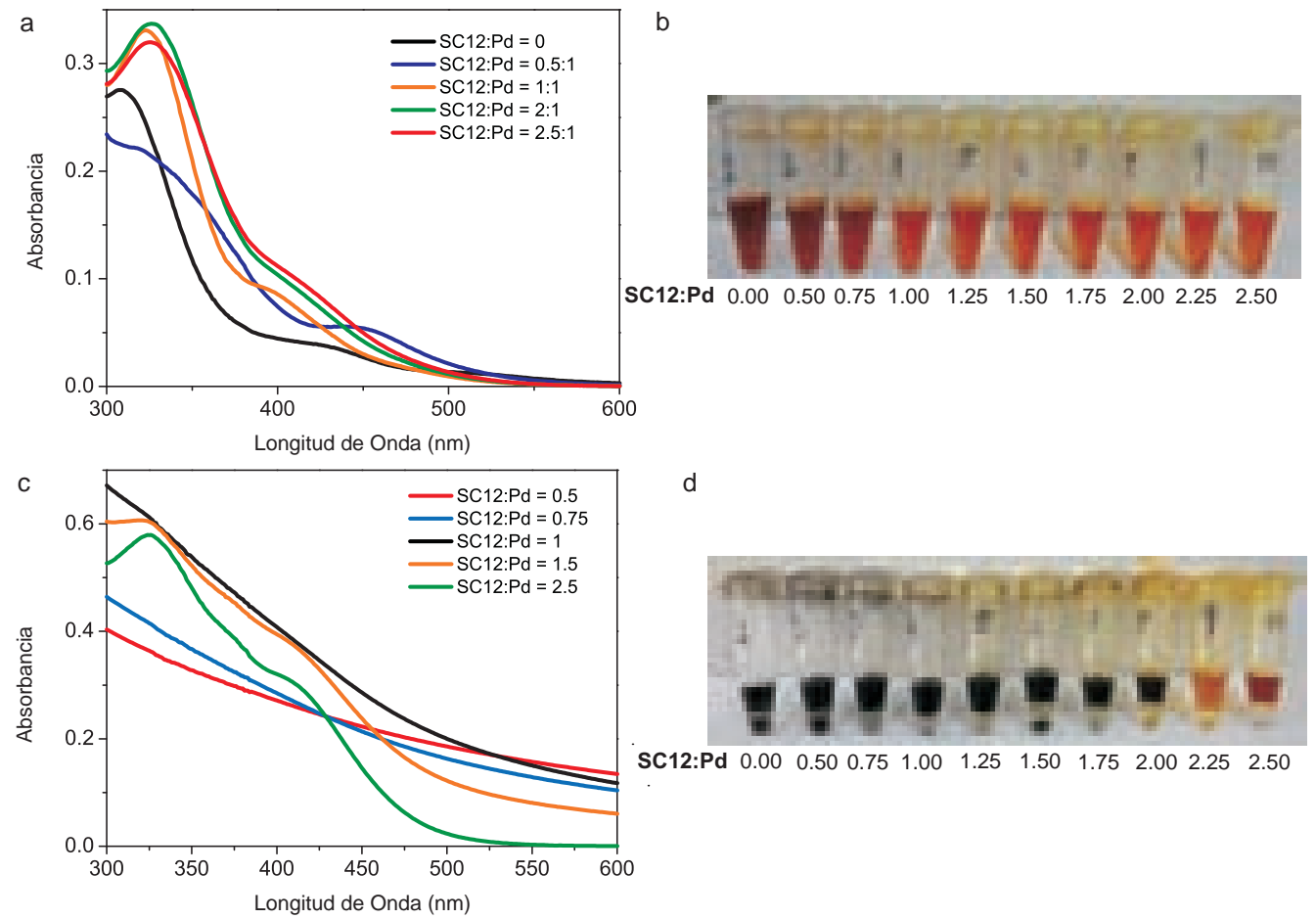

Figura 6.2: Experimentos realizados para estudiar el efecto de la relación molar tiol:Pd en los productos obtenidos durante la síntesis de NPs. (a) Espectros UV-vis de $\mathrm{Pd}^{\mathrm{II}}$ con diferentes cantidades de dodecanotiol $\left(\mathrm{SC}_{12}\right)$ obtenidos $2 \mathrm{~h}$ después de la adición de $\mathrm{SC}_{12}$. $\mathrm{El}\left[\mathrm{PdCl}_{4}\right]^{2-}$ fue transferido desde la fase acuosa a la fase orgánica y, luego de descartar la fase acuosa, se agregó $\mathrm{SC}_{12}$. Las muestras fueron diluidas en tolueno para alcanzar una concentración 0,05 mM de $\mathrm{Pd}^{\mathrm{II}}$. Algunas muestras no fueron incluidas en los espectros para facilitar la visualización. El espectro correspondiente a $\left[\mathrm{PdX}_{4}\right]^{2-}$ sin tiol $\left(\mathrm{SC}_{12}: \mathrm{Pd}=\right.$ 0 ) presenta un pico en $\sim 310 \mathrm{~nm}$ y un hombro en $\sim 430 \mathrm{~nm}$. Cuando el $\mathrm{SC}_{12}$ es agregado, los espectros cambian hasta que la relación molar $\mathrm{SC}_{12}$ : $\mathrm{Pd}$ es mayor a 1:1. Para la relación usada en este trabajo $(0,5: 1)$, una mezcla de complejos de $\mathrm{Pd}^{\mathrm{II}}-\mathrm{RSH}$ y $\left[\mathrm{PdX}_{4}\right]^{2-}$ sería responsable del espectro observado. (b) Fotografías de las muestras estudiadas en a, antes de la dilución. (c) Espectros UV-vis de las muestras anteriores, $18 \mathrm{~h}$ después de la adición de $\mathrm{NaBH}_{4}$. Las muestras fueron diluidas 1/400. Luego de agregar el $\mathrm{NaBH}_{4}$, todas las muestras se tornaron inmediatamente negras. Sin embargo, para el caso de $\mathrm{SC}_{12}$ : $\mathrm{Pd}>2: 1$, luego de algunas horas, las soluciones retornaron al color anaranjado inicial y el espectro UV-vis final fue similar al obtenido antes de la adición del agente reductor. Para las muestras con $\mathrm{SC}_{12}$ : $\mathrm{Pd}<1: 1$, las soluciones permanecieron de color negro y el espectro no mostró ningún pico en la zona de 300 a $500 \mathrm{~nm}$. No obstante, para los casos de 1:1 $<\mathrm{SC}_{12}$ :Pd $<2: 1$, se observaron picos en esa misma zona, evidenciando la presencia de complejos de $\mathrm{Pd}^{\mathrm{II}}-\mathrm{RSH}$. Esas muestras permanecieron negras con una leve coloración anaranjada, indicando una mezcla de PdNPs y complejos de Pd ${ }^{\mathrm{II}}-\mathrm{RSH}$. (d) Fotografía de las muestras estudiadas en $\mathbf{c}$, antes de la dilución. En el fondo de cada tubo se observa la fase acuosa proveniente del $\mathrm{NaBH}_{4}$. 

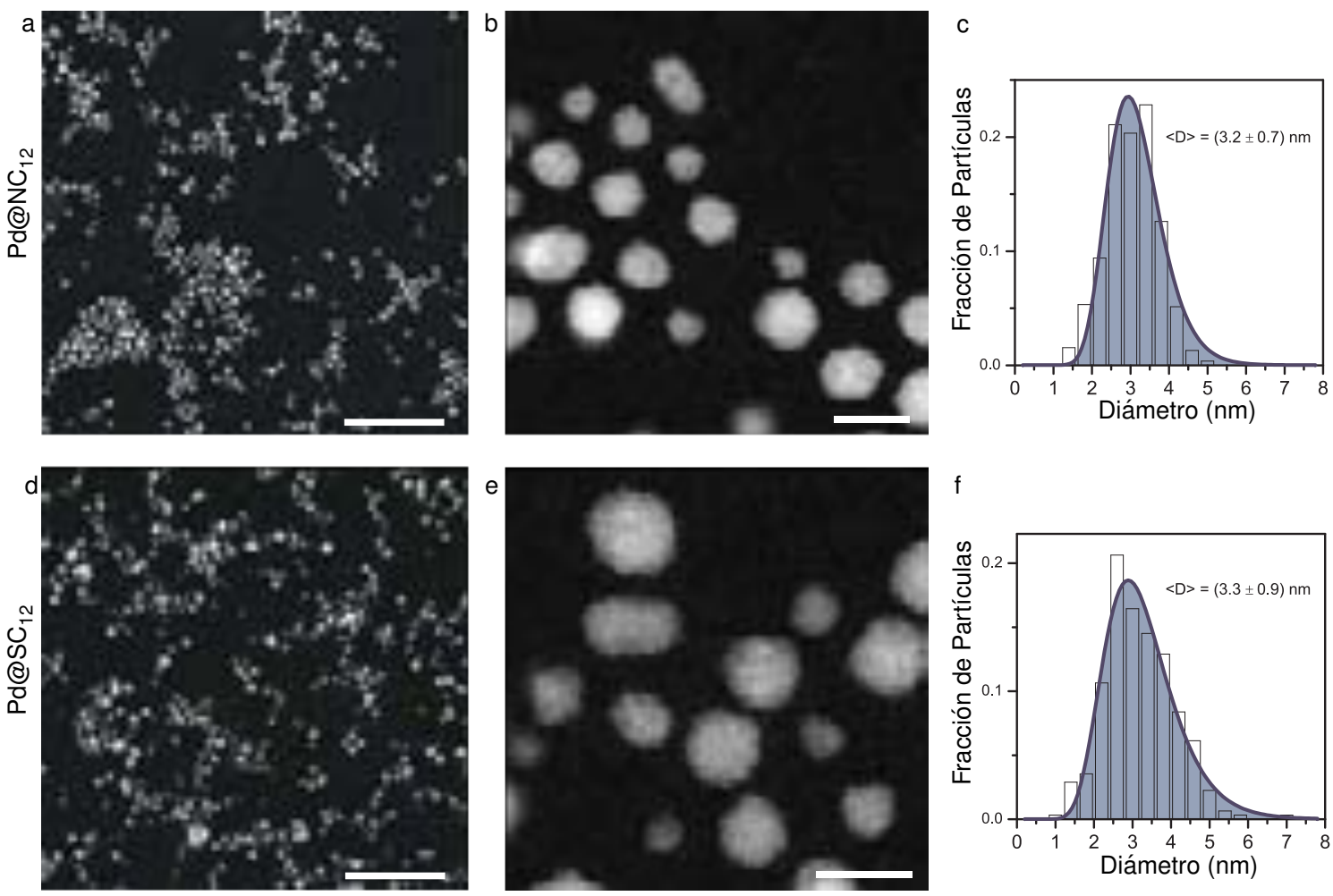

Figura 6.3: Imágenes representativas de HAADF-STEM de (a, b) $\mathrm{Pd}_{\mathrm{NC}_{12}} \mathrm{NPs}_{\mathrm{y}}$ (d, e) $\mathrm{Pd} @ \mathrm{~S}-\mathrm{SC}_{12}$ NPs. Escalas figuras a y d: $50 \mathrm{~nm}$, figuras b y e: $5 \mathrm{~nm}$. Histogramas de distribución de tamaños y curva de ajuste log-normal de (c) Pd@NC $\mathrm{N}_{12} \mathrm{NPs}_{\text {y }}$ (d) $\mathrm{Pd} @ \mathrm{~S}-\mathrm{SC}_{12}$ NPs.

carbono amorfo $(Z=6)$. Estos resultados no están de acuerdo con el modelo propuesto por Sun et ál., para Pd@S-SC ${ }_{12}$ NPs preparadas de manera similar [220]. Como se comentó en la introducción de este capítulo, en ese trabajo los autores proponen que núcleos de $\mathrm{Pd}^{0}$ están inmersos en una matriz de sulfuro de paladio. Si ese fuera el caso, el fondo de las imágenes de HAADF-STEM debería ser más brillante que el de la Fig. 6.3 debido a la presencia de átomos de $\mathrm{Pd}$ alrededor de las NPs, de forma similar a lo observado para el caso de las NPs de $A u @ A u^{I}-T M$, en la Fig. 4.7. Por lo tanto, se puede afirmar que los átomos de $\mathrm{Pd}$ se encuentran restringidos en una región de tamaño bien definido - de alrededor de $3 \mathrm{~nm}-$ en lugar de estar dispersos en una fase extendida de sulfuro de paladio.

\subsubsection{Caracterización del agente protector de las nanopartículas de $\mathrm{Pd} @ \mathrm{~S}-\mathrm{SC}_{12}$}

El estudio de las NPs mediante espectroscopía FTIR puede dar una evidencia clara acerca de la presencia y la estructura de la capa de moléculas utilizada para su protección. En la Fig. 6.4 se muestra un espectro FTIR típico de Pd@S-SC ${ }_{12}$ NPs, tomado en la zona de 600 a $3000 \mathrm{~cm}^{-1}$. En él se observa la banda de estiramiento simétrico $\left(\nu_{\mathrm{s}} \mathrm{CH}_{2}\right)$, y antisimétrico $\left(\nu_{\mathrm{as}} \mathrm{CH}_{2}\right)$-características de los metilenos- en 2850 y $2921 \mathrm{~cm}^{-1}$, respectivamente. Esto 
demuestra que las cadenas alquílicas están presentes en las NPs y se encuentran extendidas con conformación trans zigzag. Estas bandas han sido utilizadas en estudios previos de espectroscopia infrarroja en SAMs de alcanotioles sobre Pd plano, para determinar la orientación de las cadenas [151].

En trabajos anteriores, la posición de las bandas características de los metilenos ha sido utilizada como una medida de las interacciones laterales cadena-cadena y, por lo tanto, del grado de organización de las cadenas alquílicas que forman los autoensamblados [226, 227]. Estos trabajos se basan en los resultados obtenidos por Snyder et ál., quienes estudiaron la posición de la bandas en cadenas de polimetilenos ( $n$-alcanos y polietileno) en estado sólido y líquido [228]. Estos autores encontraron que la banda $\nu_{\mathrm{as}} \mathrm{CH}_{2}$ en muestras en estado cristalino $\left(2920 \mathrm{~cm}^{-1}\right)$ se ubica a un número de onda $8 \mathrm{~cm}^{-1}$ menor que las mismas en estado líquido $\left(2928 \mathrm{~cm}^{-1}\right)$, mientras que en la banda $\nu_{\mathrm{s}} \mathrm{CH}_{2}$, la diferencia entre la muestra en estado cristalino $\left(2850 \mathrm{~cm}^{-1}\right)$ y líquido $\left(2856 \mathrm{~cm}^{-1}\right)$ es de $6 \mathrm{~cm}^{-1}$ [226, 228]. En el caso de SAMs de alcanotiolatos sobre Au, Porter et ál. estudiaron el efecto del largo de cadena del tiol en la posición de las bandas de los metilenos y, por ende, en el grado de orden de las monocapas [226]. Estos autores encontraron que a medida que se aumenta el largo de la cadena hidrocarbonada, la posición de las bandas de los metilenos se aproxima al valor informado para las muestras cristalinas, i. e. la estructura incrementa su orden. En la Fig. 6.4 se observa que la banda $\nu_{\text {as }} \mathrm{CH}_{2}=2921 \mathrm{~cm}^{-1}$ se encuentra prácticamente en el mismo valor informado para una superficie de $\mathrm{Pd}$ plano modificada con dodecanotiol $\left(2920 \mathrm{~cm}^{-1}\right)$ [151], AuNPs cubiertas con dodecanotiol $\left(2920 \mathrm{~cm}^{-1}\right)$ [229] y una superficie de Au plano modificada con dodecanotiol $\left(2920,5 \mathrm{~cm}^{-1}\right)$ [227]. Esto significa que el grado de organización de las cadenas alquílicas es comparable entre las PdNPs, las AuNPs y el Au y Pd plano. Debe notarse, sin embargo, que el grado de organización de las cadenas es también susceptible a la forma en que se prepara la muestra para adquirir el espectro. La concentración de la suspensión de partículas utilizada para depositar la muestra y la velocidad de evaporación del solvente luego de depositar la suspensión pueden producir variaciones en la organización colectiva de las cadenas alquílicas.

La banda observada en $2954 \mathrm{~cm}^{-1}$ y el hombro en $\sim 2872 \mathrm{~cm}^{-1}$ corresponden a los modos de estiramiento antisimétrico $\left(\nu_{\mathrm{as}} \mathrm{CH}_{3}\right)$ y simétrico $\left(\nu_{\mathrm{s}} \mathrm{CH}_{3}\right)$ del grupo metilo, respectivamente. Estas bandas son prácticamente invariantes con respecto a la formación de SAMs en la superficie de la partícula [229]. En el caso de tioles libres, una banda correspondiente al estiramiento del enlace $\mathrm{S}-\mathrm{H}$ es usualmente observada en la región espectral de 2550 a $2600 \mathrm{~cm}^{-1}$. Este modo vibracional aparece en $2575 \mathrm{~cm}^{-1}$ para dodecanotiol libre [230]. Consecuentemente, la ausencia de absorción en esta región indica que ha ocurrido una ruptura del enlace $\mathrm{S}-\mathrm{H}$ del dodecanotiol y los tioles se encuentran en forma de tiolatos en las Pd@S-SC 12 NPs [229, 230]. Sin embargo, hay que tener en cuenta que esta señal es muy débil y puede no ser detectada en muestras diluidas o películas delgadas [231].

En la región de 1300 a $1500 \mathrm{~cm}^{-1}$, la intensa banda observada en $\sim 1463 \mathrm{~cm}^{-1}$ es asignada al modo de flexión de los metilenos, conocido como modo tijera $\left(\delta_{\mathrm{s}} \mathrm{CH}_{2}\right)$. El modo de flexión simétrica del grupo metilo $\left(\delta_{\mathrm{s}} \mathrm{CH}_{3}\right)$, también conocido como modo paraguas, aparece en $\sim 1376 \mathrm{~cm}^{-1}$. Por otro lado, la serie de picos observados entre 1000 y $1150 \mathrm{~cm}^{-1}$ son asignados a modos de vibración del esqueleto $\mathrm{C}-\mathrm{C}-\mathrm{C}$, mientras que las bandas en 


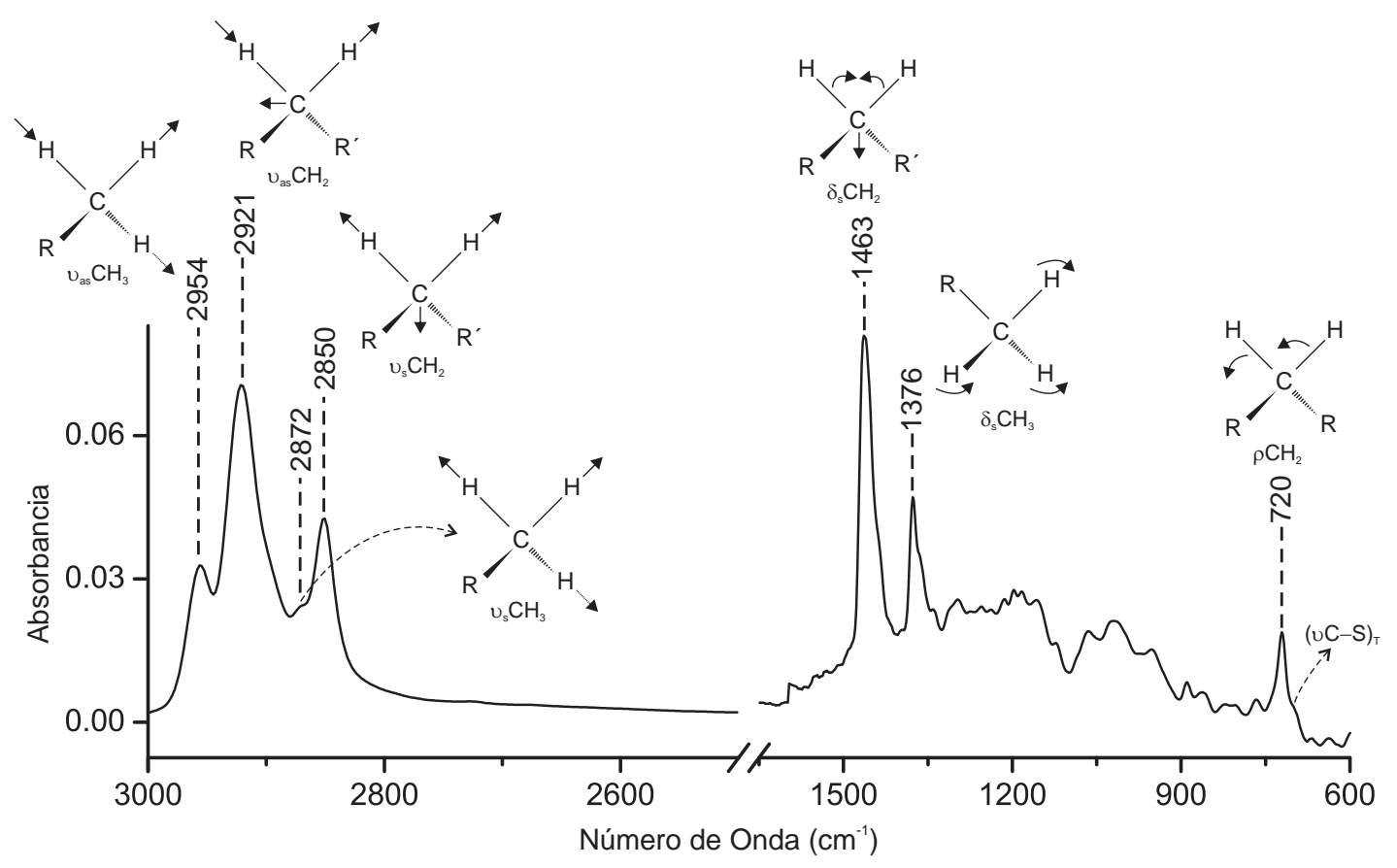

Figura 6.4: Espectro FTIR de Pd@S-SC $\mathrm{S}_{12}$ NPs. La absorbancia en la región entre 1650 y $600 \mathrm{~cm}^{-1}$ fue multiplicada por un factor 4 . Se incluyen además los esquemas de los modos de vibración correspondientes a las bandas principales del espectro, según ref. [231].

la región de 700 a $980 \mathrm{~cm}^{-1}$ son asignadas a los modos de balanceo de las cadenas de metilenos (rocking, $\rho \mathrm{CH}_{2}$ ), con una banda principal en $720 \mathrm{~cm}^{-1}$. Nótese que esta banda es lo suficientemente intensa como para ocultar parcialmente la información conformacional de los enlaces $\mathrm{C}-\mathrm{C}$ adyacentes al enlace $\mathrm{C}-\mathrm{S}$, que puede obtenerse del análisis de la banda de estiramiento del enlace $\mathrm{C}-\mathrm{S}(\nu \mathrm{C}-\mathrm{S})$.

Para alcanotioles de cadena corta en fase gaseosa o líquida, la región del espectro vibracional entre 600 y $750 \mathrm{~cm}^{-1}$ presenta dos bandas de $\nu \mathrm{C}-\mathrm{S}$. Estas corresponden a diferentes confórmeros, llamados TT y GT, donde la primera letra describe la conformación (trans o gauche) alrededor del enlace $\mathrm{C}-\mathrm{C}$ adyacente al enlace $\mathrm{C}-\mathrm{S}$, y la segunda letra describe la conformación alrededor del enlace $\mathrm{C}-\mathrm{S}$. Para propanotiol, el confórmero GT tiene una banda $(\nu \mathrm{C}-\mathrm{S})_{\mathrm{G}}$ en $655 \mathrm{~cm}^{-1}$ mientras que para el confórmero $\mathrm{TT}$, la banda $(\nu \mathrm{C}-\mathrm{S})_{\mathrm{T}}$ aparece en $706 \mathrm{~cm}^{-1}$ [232]. En el análisis del espectro de la Fig. 6.4 se encuentra que la banda $(\nu \mathrm{C}-\mathrm{S})_{\mathrm{G}}$ es indetectable. Sin embargo, existe un hombro significativamente intenso en $700 \mathrm{~cm}^{-1}$ que puede ser asignado a la vibración de estiramiento de enlaces $\mathrm{C}-\mathrm{S}$ adyacentes a unidades de metilenos en conformación trans, $(\nu \mathrm{C}-\mathrm{S})_{\mathrm{T}}$. Si bien la población de confórmeros trans ha sido estimada para AuNPs protegidas con hexanotiolatos [233], la banda de rocking es más intensa en el caso de especies derivadas de dodecanotiol [229], lo que hace más dificultoso el análisis cuantitativo en esta región.

Contrariamente a nuestros resultados, se ha encontrado en el espectro infrarrojo de PdNPs protegidas con octanotiol marcado con ${ }^{13} \mathrm{C}_{1}$, una conformación gauche del $100 \%$, que ha sido interpretada considerando dioctil disulfuro como especie protectora [219]. 


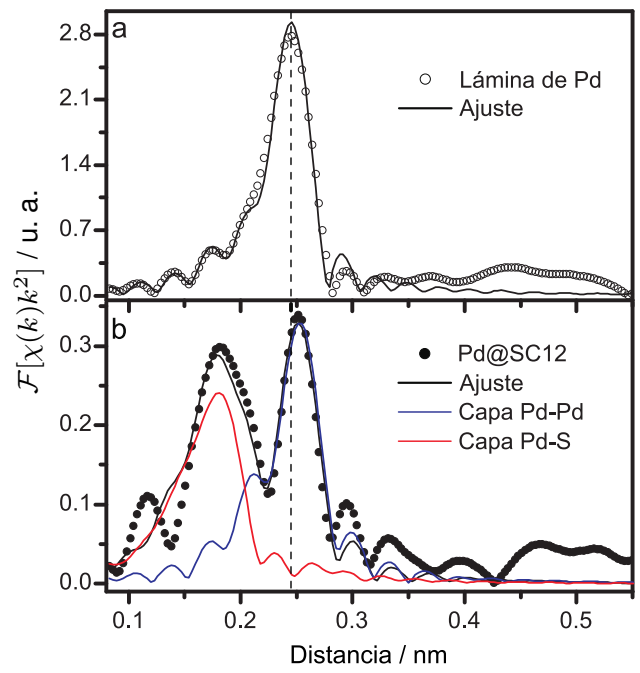

Figura 6.5: Transformada de Fourier (FT) experimental y ajustes correspondientes de la señal de EXAFS para (a) lámina de Pd y (b) Pd@S-SC ${ }_{12}$ NPs.

Aunque no fue posible extraer información cuantitativa respecto a la abundancia relativa de los isómeros rotacionales, nuestros espectros son similares a los obtenidos con AuNPs protegidas con alcanotiolatos [229], en lugar de los informados por Zelakiewicz et ál. [219]. Si bien los protocolos de síntesis utilizados son muy similares, la naturaleza de las especies protectoras y su conformación dominante parecen ser diferentes. Por otra parte, el dialquilo disulfuro no puede ser desechado como una molécula protectora posible basándose en la ausencia de la señal debida al enlace $\mathrm{S}-\mathrm{S}$, usualmente encontrado a $575 \mathrm{~cm}^{-1}$, ya que estas vibraciones son muy débiles [234]. Este punto, sin embargo, se discutirá en base a los datos de XPS.

\subsubsection{Aspectos estructurales de las nanopartículas}

Para estudiar la estructura y la composición química de las PdNPs discutiremos los resultados obtenidos utilizando EXAFS y XPS. Mientras que EXAFS entrega información estructural de los sistemas estudiados, XPS da información respecto a la naturaleza química de los elementos de la muestra y de las propiedades electrónicas de la misma.

Los experimentos de EXAFS en el borde $K$ del Pd $(24350 \mathrm{eV})$ fueron realizados utilizando un espectrómetro de absorción de rayos X RIGAKU R-XAS Looper en modo transmisión. Una muestra seca de $\mathrm{Pd} @ S-\mathrm{SC}_{12}$ NPs fue montada en un porta muestra de acrílico. El espesor de la muestra proporcionó un salto en el borde K del Pd de aproximadamente 0,75 . La calibración de la escala de energía fue realizada utilizando una lámina de Pd.

En la Fig. 6.5 se observa la transformada de Fourier (FT) de los datos de EXAFS correspondientes a las $\mathrm{Pd} @ \mathrm{~S}-\mathrm{SC}_{12}$ NPs. Este espectro exhibe dos contribuciones importantes entre 0,12 y $0,28 \mathrm{~nm}$. Mientras que la primera es asignada al enlace $\mathrm{Pd}-\mathrm{S}$, la segunda 
Tabla 6.1: Parámetros estructurales de Pd@S-SC 12 NPs obtenidos por EXAFS. Número de coordinación promedio $(N)$, longitud de enlace $(d)$, umbral de corrección de energía $\left(\Delta E_{0}\right)$ y factor de Debye-Waller $\left(\sigma^{2}\right)$.

\begin{tabular}{lcccc}
\hline & \multicolumn{2}{c}{$\mathrm{Pd} @ \mathrm{~S}-\mathrm{SC}_{12} \mathrm{NPs}$} & & lámina de $\mathrm{Pd}$ \\
\cline { 2 - 3 } \cline { 5 - 5 } & capa $\mathrm{Pd}-\mathrm{Pd}$ & capa $\mathrm{Pd}-\mathrm{S}$ & & capa $\mathrm{Pd}-\mathrm{Pd}$ \\
\hline$N$ & $1,8 \pm 0,6$ & $1,3 \pm 0,5$ & & 12 \\
$\Delta E_{0} / \mathrm{eV}$ & $7 \pm 7$ & $7 \pm 2$ & & $-1 \pm 2$ \\
$\sigma^{2} / 10^{-5} \mathrm{~nm}^{2}$ & $6 \pm 2$ & $7 \pm 4$ & & $4,4 \pm 0,6$ \\
$d / \mathrm{nm}$ & $0,275 \pm 0,001$ & $0,229 \pm 0,003$ & & $0,273 \pm 0,001$ \\
\hline
\end{tabular}

corresponde a una capa de coordinación Pd-Pd [218, 220, 221, 235].

Para analizar la región de primeros vecinos, se realizó un ajuste no lineal utilizando el paquete IFEFFIT [36, 236], integrado a las interfases de usuario ATHENA y ARTEMIS. Los parámetros ajustados para cada capa de coordinación propuesta en el modelo fueron: el número de coordinación promedio $(N)$, la longitud de enlace $(d)$, la corrección del umbral de energía $\left(\Delta E_{0}\right)$ y el factor de Debye-Waller $\left(\sigma^{2}\right)$. Para realizar el ajuste se propusieron dos capas diferentes, una para tener en cuenta la contribución $\mathrm{Pd}-\mathrm{Pd}$ y la otra correspondiente a la capa de $\mathrm{Pd}-\mathrm{S}$. Estas contribuciones fueron calculadas utilizando el código FEEF [237] desde las estructuras cristalográficas del Pd metálico y sulfuro de paladio.

Debido a que el azufre de la muestra sufrió daño inducido por radiación (generación de especies de alto estado de oxidación, véase Fig. 6.6), la deconvolución de esta señal en contribuciones de diferentes distancias $\mathrm{Pd}-\mathrm{S}$, provenientes de diferentes especies de azufre, no sería confiable. Por lo tanto, la capa de $\mathrm{Pd}-\mathrm{S}$ fue ajustada considerando solo una especie, aunque podría estar formada por diferentes compuestos (p. ej., sulfuro y tiolato).

Los resultados del análisis de los datos de EXAFS mostrados en la Fig. 6.5 son resumidos en la Tabla 6.1.

El pequeño valor de $N(1,8 \pm 0,6)$ para la contribución $\mathrm{Pd}-\mathrm{Pd}$ no puede ser explicado considerando la formación de pequeñas partículas de Pd. En cambio, se necesita otra fase sin $\mathrm{Pd}$ como primeros vecinos para poder explicar tal valor de $N$. Este caso es similar al de $\mathrm{Au} @ A u^{I}-T M$ NPs, estudiado en el Cap. 4. La distancia Pd-Pd obtenida en el ajuste de las Pd@S-SC 12 NPs $(0,275 \pm 0,001 \mathrm{~nm})$ es mayor que la obtenida para Pd masivo $(0,273 \pm 0,001 \mathrm{~nm})$. Resultados similares para distancias Pd-Pd en PdNPs protegidas con tioles han sido informados anteriormente [220, 221]. Este aumento en el parámetro de red ha sido atribuido a la presencia de azufre en las NPs. Sin embargo, es probable que la expansión de la red pueda deberse a la absorción de hidrógeno atómico durante la síntesis de las partículas (proveniente del $\mathrm{BH}_{4}^{-}$), cuya desorción sería impedida por la ulterior adsorción de S/tiolato sobre la superficie de las NPs, lo que limitaría la recombinación de átomos de $\mathrm{H}$ para dar $\mathrm{H}_{2}$.

Los datos de EXAFS están de acuerdo con estudios previos de PdNPs. Sin embargo, 


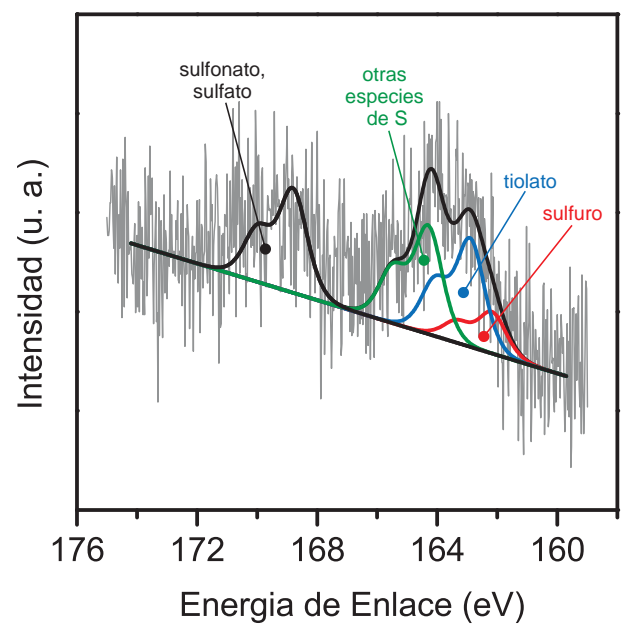

Figura 6.6: Espectro XPS de S $2 p$ de $\mathrm{Pd} @ \mathrm{~S}-\mathrm{SC}_{12}$ NPs luego del experimento de EXAFS. Notar la contribución importante de especies de alto estado de oxidación $(\sim 168,5 \mathrm{eV})$. Observar la Fig. 6.7a para una comparación con una muestra sin daño.

el bajo valor de $N$ ha sido interpretado mediante dos modelos diferentes. El primero propone la presencia de núcleos de $\mathrm{Pd}^{0}$ inmersos en una fase de sulfuro de paladio, que fue descartado en base a los datos de HAADF-STEM [220]. El segundo propone un modelo del tipo núcleo de $\mathrm{Pd}$-coraza de $\mathrm{PdS}_{x}$ cubierta por tiolatos, en analogía a las superficies de Pd planas modificadas con tioles [221, 235]. Sin embargo, los datos de EXAFS no proporcionan mayores detalles referidos a la química de la interfase $\mathrm{S} / \mathrm{Pd}$, o a los procesos que ocurren durante la formación de las NPs. Por lo tanto, seguiremos el estudio de estas NPs mediante XPS.

\subsubsection{Composición química de las nanopartículas}

Con el objetivo de estudiar la composición de las Pd@S-SC $\mathrm{S}_{12} \mathrm{NPs}$, hemos analizado estas NPs mediante XPS y hemos comparado estos resultados con $\mathrm{Pd} @ \mathrm{NC}_{12}-\mathrm{SC}_{12}$ y Au@SC 12 NPs y con SAMs de dodecanotiol sobre superficies planas de Pd y Au. Para diferenciar la composición superficial de las NPs de su composición masiva, hemos comparados los resultados obtenidos en el laboratorio con los adquiridos utilizando radiación de luz sincrotrón de menor energía. Finalmente hemos caracterizado la estructura electrónica de las NPs mediante el análisis del espectro fotoelectrónico de la banda de electrones de valencia.

En los espectros de XPS del S $2 p$ de Pd@S-SC 12 NPs se observa una señal ancha $\mathrm{a} \sim 162,5 \mathrm{eV}$ (Fig. 6.7a). El primer aspecto que sobresale en el análisis de estas NPs mediante XPS es la relación atómica de azufre total a paladio ( $\mathrm{S}: \mathrm{Pd}=0,7 \pm 0,1)$, que es el doble del valor obtenido para la relación azufre total a oro (S:Au) en $\mathrm{Au} @ \mathrm{SC}_{12} \mathrm{NPs}_{\text {de }}$ tamaño similar. El mismo factor se obtiene al analizar la relación (S:Pd)/(S:Au), derivada del estudio de SAMs de alcanotioles sobre Pd plano (Cap. 5) y sobre Au plano (Cap. 3). Este valor indica que existe un exceso de azufre en la superficie de las Pd@S-SC 12 NPs en relación con la cantidad esperada en sistemas en los que las especies protectoras son 
solo alcanotiolatos (como el caso del Au). Este exceso de azufre también fue informado por Zamborini et ál., quienes, mediante análisis termogravimétrico, encontraron un mayor contenido orgánico que el predicho para el modelo simple de adsorción de tiolatos [65]. Basados en estos resultados, es posible descartar los modelos simples de interfases Pdtiolato, publicados en años recientes para este sistema [149, 215, 217].

El ajuste del pico de $\mathrm{S} 2 p$ da como resultado dos componentes principales, en 162,1 y $162,9 \mathrm{eV}$ y una componente pequeña en $164,1 \mathrm{eV}$ (Fig. 6.7a). La asignación de las componentes fue realizada como se explicó en el capítulo anterior, para SAMs de alcanotioles sobre Pd masivo. La componente en $162,9 \mathrm{eV}$ se asigna a tiolato, la que se encuentra en $162,1 \mathrm{eV}$ se asigna a sulfuro y la de $164,1 \mathrm{eV}$ a moléculas fisisorbidas de disulfuro o alcanotioles. Estos resultados no están de acuerdo con los datos informados para PdNPs protegidas con $n$-octadecanotiol preparadas por el método bifásico, para las cuales se encontraron energías de enlace para S $2 p$ entre 161,4 y 161,7 eV [238].

Con el propósito de facilitar la comparación, en la Fig. 6.7 se muestran también los espectros de $\mathrm{S} 2 p$ de superficies extendidas de Pd modificadas con dodecanotiol (Fig. 6.7b), ya discutidas en el capítulo anterior. Es evidente que las componentes en los espectros de las superficies de Pd planas y NPs modificadas con tioles son muy similares, y claramente diferentes al caso de $\mathrm{Au} @ \mathrm{SC}_{12}$ NPs (Fig. 6.7d) y al de SAMs de tiolatos sobre $\mathrm{Au}(111)$ (Fig. 3.3). Estos resultados ponen en evidencia que las especies de azufre presentes en ambas superficies de Pd (planas y NPs de $3 \mathrm{~nm}$ ) son de naturaleza similar. Si los principales ligandos fueran dialquil disulfuros, como fue propuesto anteriormente [219], la componente en 163 a $164 \mathrm{eV}$ debería dominar la señal S $2 p$, lo que claramente no sucede en el caso de las Pd@S-SC 12 NPs (Fig. 6.7a). Por otra parte, si ese fuera el caso, la relación S:Pd

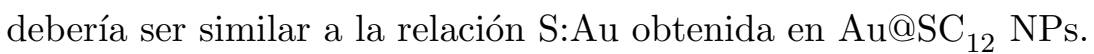

Las NPs preparadas por intercambio de ligandos de $\mathrm{Pd} @ \mathrm{NC}_{12}$ NPs con dodecanotiol también fueron estudiadas mediante XPS. Las moléculas de dodecilamina fueron intercambiadas parcialmente por moléculas de dodecanotiol, resultando en partículas con una mezcla de agentes protectores $\left(\mathrm{Pd} @ \mathrm{NC}_{12}-\mathrm{SC}_{12} \mathrm{NPs}\right)$. Esto fue revelado por XPS, ya que se encontró cierta cantidad de nitrógeno luego del intercambio de ligandos. En la Fig. 6.7c se puede observar que estas NPs tienen una composición muy similar a las de $\mathrm{Pd} @ \mathrm{~S}-\mathrm{SC}_{12}$, preparadas por el método bifásico. Los datos cuantitativos de estos sistemas se muestran en la Tabla 6.2. A pesar de que la relación total S:Pd es menor comparada con las $\mathrm{Pd} @ \mathrm{~S}-\mathrm{SC}_{12} \mathrm{NPs}$, debido a un intercambio de ligandos incompleto, las contribuciones a la señal de $\mathrm{S} 2 p$ muestran la presencia de sulfuro en estas partículas. Esto hace evidente la ruptura del enlace $\mathrm{S}-\mathrm{C}$ por el $\mathrm{Pd}^{0}$ luego de la adsorción del tiol. Aunque estas dos rutas de síntesis para obtener PdNPs cubiertas con tioles son completamente diferentes, la composición final de las NPs es muy similar.

El análisis de la relación atómica de C:S también aporta evidencia a favor de la idea de que las especies que cubren las PdNPs no son sólo tiolatos. En el caso de las Pd@S-SC 12 NPs, la relación atómica C:S es aproximadamente 11,5:1, mientras que para $\mathrm{Au} @ \mathrm{SC}_{12}$ NPs de tamaño similar, es mayor a 14:1. El valor obtenido para Au es mayor que la relación estequiométrica para dodecanotiol (12:1) por los mismos motivos comentados en la Sec. 5.4 para Pd plano. Este resultado no es consistente con dialquil disulfuros o 
Tabla 6.2: Contribución relativa de las diferentes componentes a la señal de $\mathrm{S} 2 p$ para SAMs de dodecanotiol sobre Pd plano, Pd@S-SC 12 NPs y Pd@NC ${ }_{12}-\mathrm{SC}_{12}$ NPs.

\begin{tabular}{lccc}
\hline & Pd plano & $\begin{array}{c}\mathrm{Pd} @ \mathrm{~S}-\mathrm{SC}_{12} \\
\mathrm{NPs}\end{array}$ & $\begin{array}{c}\mathrm{Pd} @ \mathrm{NC}_{12}-\mathrm{SC}_{12} \\
\mathrm{NPs}\end{array}$ \\
\hline \% sulfuro & $48 \pm 3$ & $46 \pm 2$ & $37 \pm 3$ \\
$\%$ tiolato & $39 \pm 4$ & $42 \pm 3$ & $44 \pm 4$ \\
$\%$-S-S-, $\mathrm{S}_{\mathrm{n}}$, tioles fisisorbidos & $13 \pm 2$ & $12 \pm 3$ & $19 \pm 6$ \\
\hline
\end{tabular}
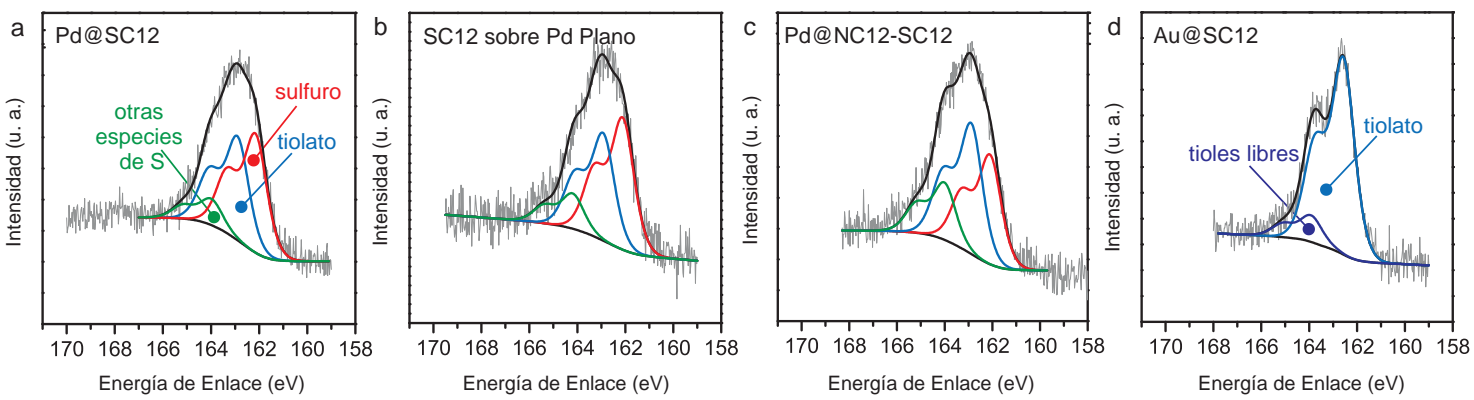

Figura 6.7: Espectros XPS de S $2 p$ de diferentes sistemas Pd-tiol para su comparación. (a) $\mathrm{Pd} @ \mathrm{~S}-\mathrm{SC}_{12} \mathrm{NPs}$ preparadas por el método bifásico de Brust-Schiffrin, (b) Pd plano modificado con dodecanotiol, (c) $\mathrm{Pd} @ \mathrm{NC}_{12}-\mathrm{SC}_{12} \mathrm{NPs}$ preparadas mediante intercambio de ligandos de PdNPs@NC 12 con dodecanotiol, (d) $\mathrm{Au}_{\mathrm{PSC}_{12}} \mathrm{NPs}_{\mathrm{s}}\langle D\rangle=3,0 \pm 0,9 \mathrm{~nm}$ preparadas por el método bifásico de Brust-Schiffrin.

simplemente alcanotiolatos como especies protectoras, pero se aproxima razonablemente al valor esperado para una capa mixta de sulfuro + tiolato.

El análisis de la señal de Pd $3 d$ es también importante para entender el estado químico de las especies de azufre en la superficie de las PdNPs. Si se compara con una superficie plana de Pd limpia, las muestras preparadas en presencia de tioles exhiben un corrimiento de aproximadamente $1 \mathrm{eV}$ hacia mayores energías de enlace, indicando una oxidación parcial del $\mathrm{Pd}$, que ha sido relacionada a la presencia de $\mathrm{PdS}_{x}$ en la interfase [239], como ya fue discutido para el caso de Pd plano. Sin embargo, en las NPs, el análisis de los corrimientos químicos es más complejo ya que es muy difícil desacoplarlos de los corrimientos por carga y otros fenómenos relacionados con el tamaño y la gran relación superficie a volumen de estos sistemas. El corrimiento observado en las $\mathrm{Pd} @ \mathrm{~S}-\mathrm{SC}_{12}$ NPs puede deberse a diversos efectos que fueron propuestos para explicar desplazamientos de hasta $\sim 1 \mathrm{eV}$, parte de los cuales fueron comentados para el caso de las AuNPs en la Sec. 3.4.2 [88, 240-243]. Sin embargo, en las AuNPs protegidas con tiolatos no se observa un corrimiento tan grande en la señal de $\mathrm{Au} 4 f$ y tampoco se evidencian cambios en esta señal en Au plano modificado con dodecanotiol (sí observado en la señal de Pd $3 d$ de Pd plano, Fig. 5.4). Esto indica que en el caso de las PdNPs este corrimiento podría ser producido por el exceso de densidad de carga positiva sobre los átomos de Pd por la presencia de sulfuro. Sin embargo, su análisis cuantitativo requiere una aproximación más compleja, de igual manera que con las 

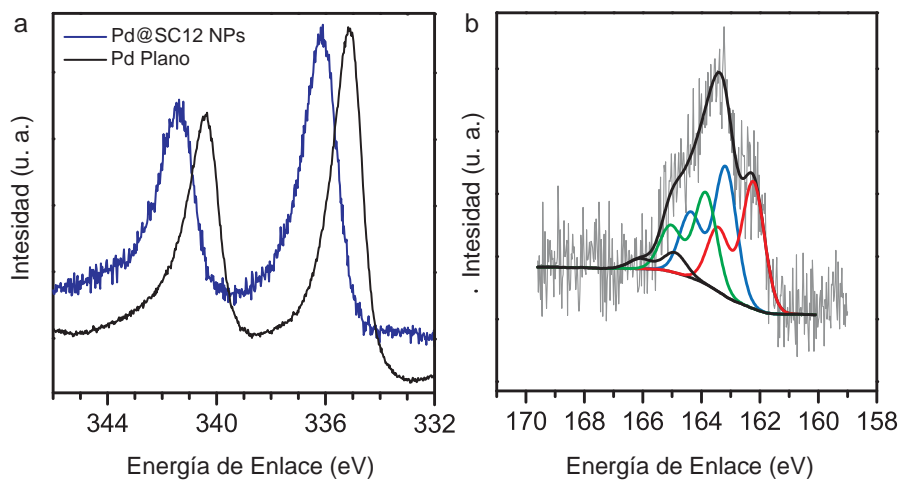

Figura 6.8: Espectros XPS de $\mathrm{Pd} @ \mathrm{~S}-\mathrm{SC}_{12}$ NPs. (a) Señal de Pd $3 d$ de $\mathrm{Pd} @ \mathrm{~S}-\mathrm{SC}_{12}$ NPs y Pd limpio, electrodepositado sobre Au. (b) Señal de S $2 p$ de Pd@S-SC 12 NPs, obtenido con una fuente de luz sincrotrón $250 \mathrm{eV}$.

AuNPs. En la Fig. 6.8a se muestra el espectro de Pd $3 d$ de $\mathrm{Pd} @ \mathrm{~S}-\mathrm{SC}_{12}$ NPs comparado con el de Pd limpio electrodepositado sobre Au.

Para estudiar la distribución de especies en una muestra en función de la profundidad desde la superficie mediante XPS, se pueden seguir dos rutas diferentes. La primera consiste en variar el ángulo de detección de los fotoelectrones (take-off-angle). La segunda consiste en variar la energía cinética $\left(E_{K}\right)$ de los fotoelectrones generados. Para estudiar la distribución de las diferentes especies de sulfuro en las NPs, variar el take-off-angle no tiene un efecto claro, ya que la orientación de las partículas en el sustrato es al azar. Por lo tanto, es necesario variar la energía cinética de los fotoelectrones generados. Para poder conseguir esta variación es necesario variar la energía de los rayos $\mathrm{X}$ incidentes $h \nu$ (véase Ec. 2.4), hecho que es factible con una fuente de luz sincrotrón. Para este estudio utilizamos la línea SGM del Laboratório Nacional de Luz Síncrotron (LNLS), de Campinas, Brasil. Se eligió una energía incidente de $250 \mathrm{eV}$ para el análisis de la señal de $\mathrm{S} 2 p$. Esta energía produce fotoelectrones con una energía cinética marcadamente menor que los producidos en el laboratorio con una fuente de $\mathrm{Mg} K \alpha(1253,6 \mathrm{eV})$. La longitud de atenuación efectiva (EAL) de los fotoelectrones S $2 p$ emitidos debido a la incidencia de radiación proveniente de la fuente de $\mathrm{Mg} K \alpha$ en una fase metálica es aproximadamente $1,3 \mathrm{~nm}$, mientras que el EAL para los fotoelectrones producidos con radiación de $250 \mathrm{eV}$ es aproximadamente $0,3 \mathrm{~nm}$ (véase Ec. 2.12). Es evidente entonces que la utilización de una energía incidente más baja otorga una mayor sensibilidad superficial.

Mediante la deconvolución del espectro tomado con $250 \mathrm{eV}$ de energía incidente (Fig. $6.8 \mathrm{~b})$, se observó la misma relación de areas tiolato:sulfuro $(\sim 1: 1)$ que la encontrada con la fuente de $\operatorname{Mg} K \alpha(\sim 0,9: 1)$, dentro del error experimental. Si el sulfuro estuviera homogéneamente distribuido en las $\mathrm{Pd} @ \mathrm{~S}-\mathrm{SC}_{12} \mathrm{NPs}$, su contribución relativa a la señal de S $2 p$ debería ser menor en el caso de 250 eV de energía incidente. Por lo tanto, se puede inferir que las especies tiolato y sulfuro se encuentran en la superficie de las NPs. De esta forma se descarta la idea de sulfuro homogéneamente distribuido en las NPs.

A modo de resumen podemos concluir que, independientemente de la ruta utilizada en 


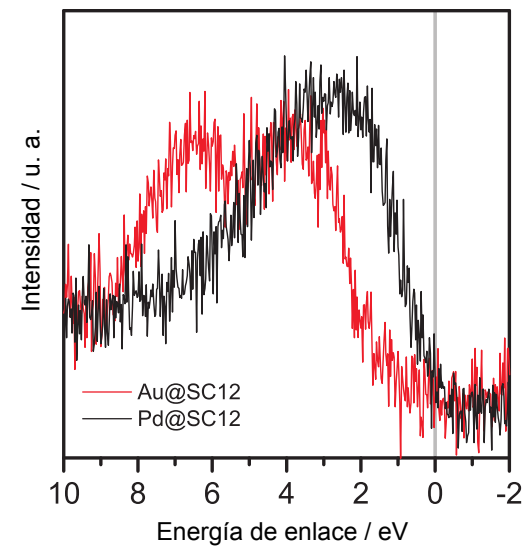

Figura 6.9: Espectro de la banda de valencia de $\mathrm{Pd} @ \mathrm{~S}-\mathrm{SC}_{12} \mathrm{NPs}$ y $\mathrm{Au} @ \mathrm{SC}_{12} \mathrm{NPs}$. La intensidad fue normalizada por la área de los picos de $\mathrm{Pd} 3 d$ y Au $4 f$, respectivamente.

la síntesis de PdNPs protegidas con tiolatos y de la naturaleza de la superficie (plana o NPs), se encuentran cantidades comparables de tiolato y sulfuro como constituyentes de los sistemas. De forma adicional, las especies de azufre se localizan en la superficie de las NPs. Es importante notar que esta última conclusión no podría haber sido alcanzada a partir de los datos de EXAFS o XPS convencional solamente.

Como ya fue comentado, XPS es una sonda muy útil no sólo de la composición química de la muestra, sino también de su estructura electrónica. El espectro de la banda de valencia está fuertemente relacionado con la densidad de estados electrónicos (DOS) del material estudiado. Entonces, el estudio del espectro de la banda de valencia puede entregar datos valiosos sobre el comportamiento de los metales hacia la adsorción de diferentes especies, debido a relación entre la reactividad de los metales de transición y la población electrónica de la banda de electrones $d$ (Sec. 5.9.3). Los metales con una banda $d$ cuyo centro se encuentra cerca del nivel de Fermi son capaces de romper enlaces de los adsorbatos en su superficie. La Fig. 6.9 muestra la banda de valencia de Pd@S $\mathrm{SC}_{12}$ NPs y Au@SC $\mathrm{AP}_{12}$ NPs, tomada con fuente de $\operatorname{Mg} K \alpha$. Como puede observarse, el centro de la banda de valencia de las $\mathrm{Au} @ \mathrm{SC}_{12} \mathrm{NPs}$ está localizado a un energía de enlace mayor que el de $\mathrm{Pd} @ \mathrm{~S}-\mathrm{SC}_{12}$ NPs, hecho relacionando con la gran reactividad del Pd comparada con la del Au. Estos resultados están de acuerdo con los cálculos para Au y Pd, discutidos en la Sec. 5.9.3.

\subsubsection{Esquema del proceso de síntesis}

Analizadas la composición química y las características electrónicas de las PdNPs, es posible plantear un esquema de reacción para el proceso de síntesis de PdNPs protegidas por tioles teniendo en cuenta la similitud con el sistema plano y los cálculos de DOS discutidos en el capítulo anterior. En el caso de las NPs preparadas por intercambio de dodecilamina por dodecanotiol, los procesos deberían ser similares a los observados en la formación de SAMs de tiolatos sobre superficies planas de Pd. Las moléculas de tiol reemplazan las moléculas de aminas y se aproximan a la superficie de Pd. Luego de la 
adsorción de tioles sobre la PdNP, existe una transferencia de densidad electrónica desde la banda $d$ del metal a los orbitales antienlazantes de las moléculas de tiol, que debilitan el enlace S-C, lo elongan y finalmente lo disocian, produciendo adsorbatos sulfuro. En este punto, la superficie de la partícula no es más activa hacia la descomposición del tiol en sulfuro, ya que el centro de la DOS se ha corrido hacia mayores energías de enlace, por una disminución de la población electrónica cerca del nivel de Fermi. De esta forma, los alcanotioles que se aproximan a la superficie pueden ser adsorbidos como tiolatos, sin ruptura del enlace S-C. La reducción de la población electrónica en las cercanías del nivel de Fermi explica por qué las PdNPs no están completamente sulfidizadas.

Debido a que las $\mathrm{Pd} @ \mathrm{NC}_{12}-\mathrm{SC}_{12} \mathrm{NPs}$ presentan las mismas especies azufradas que las encontradas en las NPs preparadas por el método bifásico de Brust-Schiffrin, es razonable proponer un mecanismo similar para los pasos finales en la formación de las $\mathrm{Pd} @ \mathrm{~S}-\mathrm{SC}_{12}$ NPs. Este método comienza con la adición de alcanotioles a la fase orgánica, que convierte parcialmente los halogenuros de $\mathrm{Pd}^{\mathrm{II}}$ en complejos de $\mathrm{Pd}^{\mathrm{II}}-\mathrm{RSH}$. Luego de la adición del agente reductor, se forman los núcleos de $\mathrm{Pd}^{0}$ y las pequeñas partículas metálicas crecen dentro de las micelas inversas formadas por la sal de amonio cuaternaria. Luego, las moléculas de dodecanotiol alcanzan la superficie de estas partículas que son capaces de disociar el enlace $\mathrm{S}-\mathrm{C}$ y, desde este punto, la reacción continuaría de la misma manera que en la ruta anterior. Esta síntesis solamente da como resultado NPs estables si el Pd ${ }^{\mathrm{II}}$ está en exceso estequiométrico respecto a los tioles, como fue explicado anteriormente.

Más estudios son necesarios para elucidar cada paso en la síntesis de las PdNPs protegidas por tioles preparadas por el método de Brust-Schiffrin, como los publicados recientemente para el caso de $\mathrm{Au}, \mathrm{Ag}$ y $\mathrm{Cu}[55,79,80]$. Lo expuesto aquí es solo un esquema realizado en base a la unificación de los resultados mostrados en este capítulo y en los anteriores.

\subsection{Influencia del ligando en el orden de los átomos metáli- cos de las nanopartículas de Pd}

Una vez descritas las características de la química de las PdNPs, estudiaremos la influencia del agente protector sobre su estructura interna. Para esto centraremos nuestro análisis en las PdNPs protegidas por alcanotioles $\left(\mathrm{Pd} @ \mathrm{~S}-\mathrm{SC}_{12} \mathrm{NPs}\right)$ y por alquilaminas $\left(\mathrm{Pd} @ \mathrm{NC}_{12}\right.$ NPs).

En la Fig. 6.10, se observa la gran diferencia en el orden de los átomos metálicos de las PdNPs protegidas con dodecanotiol comparadas con las protegidas con dodecilamina. En las últimas (Fig. 6.10a, b, c), se observa una estructura ordenada que, en el caso particular de esta figura, se trata de una partícula decaédrica. En las Pd@S-SC $\mathrm{S}_{12} \mathrm{NPs}$ (Fig. 6.10d, e, f) no es posible observar este tipo de estructuras y no fue posible distinguir ninguna red cristalina en las imágenes tomadas, bajo diferentes condiciones de defoco. Todas las partículas observadas presentaron una estructura similar a la mostrada en la Fig. 6.10e.

Estas imágenes ponen en clara evidencia el hecho de que la estructura de las PdNPs es afectada en gran medida por las moléculas que las protegen. Los primeros trabajos en encontrar estructuras amorfas y cristalinas en PdNPs protegidas por tioles fueron los de 

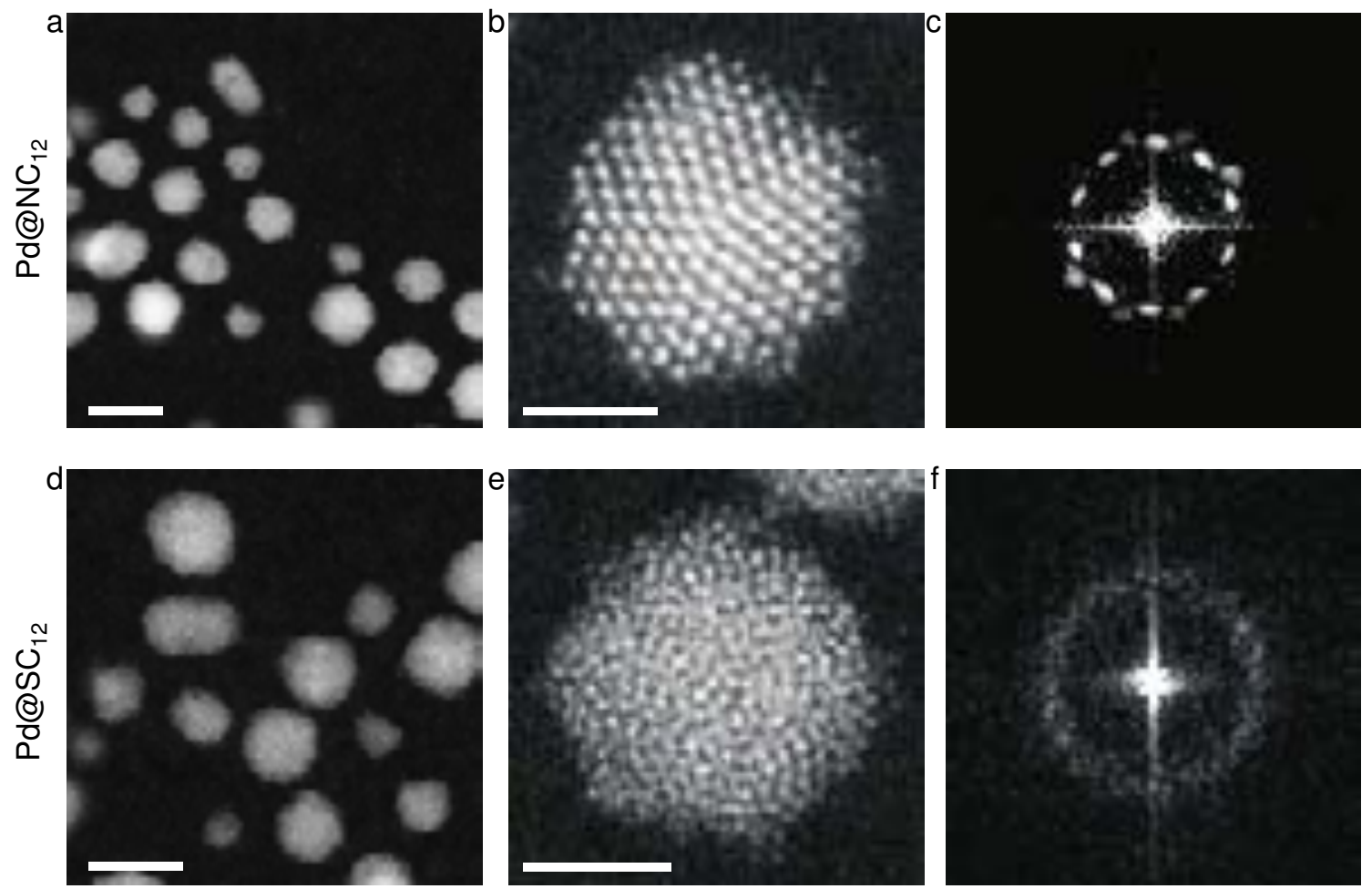

Figura 6.10: Imágenes representativas de HAADF-STEM con corrección de aberración de: (a, b) Pd@NC ${ }_{12}$ NPs. Escalas: $5 \mathrm{~nm}$ y $1 \mathrm{~nm}$, respectivamente. (d, e) Pd@S-SC 12 NPs. Escalas: $5 \mathrm{~nm}$ y $1 \mathrm{~nm}$, respectivamente. (c, f) Transformadas de Fourier de las imágenes b y e, respectivamente. Imágenes tomadas con el microscopio JEOL ARM200F con un voltaje de aceleración de $200 \mathrm{kV}$, en colaboración con G. Casillas.

Hou et ál. [239, 244]. Estos autores sintetizaron PdNPs protegidas con polivinilpirrolidona (PVP) mediante el uso de un reductor fuerte $\left(\mathrm{NaBH}_{4}\right)$ y uno débil (etanol) y luego modificaron las NPs preparadas con dodecanotiol. Encontraron que las NPs producidas mediante el reductor fuerte presentaban una estructura amorfa mientras que las preparadas mediante el reductor débil exhibían una estructura cristalina. Según los autores, el motivo de esta diferencia radica en la velocidad de reducción de los precursores para generar Pd metálico: con $\mathrm{NaBH}_{4}$ la reducción es rápida y las NPs se forman sin poder relajar su estructura; en el caso de etanol, al proceder la reducción lentamente, los átomos de Pd tienen el tiempo suficiente para formar estructuras ordenadas. Es decir que no se le atribuye ningún efecto al ligando utilizado.

En un estudio reciente utilizando HRTEM, se estudió la modulación de la cristalinidad de las PdNPs mediante el cambio de la molécula protectora. Mientras que las NPs sintetizadas con oleilamina como ligando presentaron una estructura cristalina, al sustituir esta molécula por trioctilfosfina su cristalinidad disminuyó considerablemente [245]. Este comportamiento se atribuyó a la magnitud de la interacción entre el ligando y el metal. Mientras que la oleilamina interacciona débilmente con el $\mathrm{Pd}$, la trioctilfosfina se enlaza más fuertemente al metal. Sin embargo, las simulaciones presentadas no tienen en cuenta 
de forma explícita al ligando. En otro estudio publicado recientemente, se realizó la síntesis de PdNPs protegidas con didodecil sulfuro para su uso en catálisis para la generación de agua oxigenada [246]. Estas NPs presentaron una estructura cristalina, evidente en las imágenes de HRTEM. Sin embargo, al intercambiar este ligando por un tiol (ácido mercaptoacético) se observó la pérdida del orden en la estructura de los átomos metálicos de las NPs. En el caso del didodecil sulfuro, la unión que se produce entre el S y el Pd está dada sólo por los pares de electrones libres en el S, con lo cual la energía de esta interacción es muy débil. En el caso de un tiol, en cambio, como discutimos anteriormente, se produce un enlace covalente con el metal. Más aún, con Pd es posible también la formación de sulfuro de paladio, donde la interacción entre los elementos es todavía mayor.

Por otro lado, en el trabajo ya comentado en la introducción de este capítulo donde se estudiaron PdNPs protegidas con ácido 11-mercapto-undecanoico, se encontró que la cristalinidad de las NPs obtenidas depende fuertemente de la temperatura durante su síntesis [209]. Mediante HRTEM, se determinó que cuanto menor es la temperatura utilizada en la síntesis de las PdNPs, mayor es la cristalinidad de las NPs obtenidas. Si bien los autores interpretaron este comportamiento en la misma línea que Hou et ál, i.e bajas temperaturas disminuyen la velocidad de las reacciones y favorecen un empaquetamiento más ordenado de los átomos de $\mathrm{Pd}$, es probable que la naturaleza del ligando que protege las NPs en uno u otro caso sea diferente. Es decir, a bajas temperaturas la formación de las monocapas autoensambladas de tiolatos sobre Pd puede no seguir el mismo comportamiento que el observado a temperatura ambiente y, por lo tanto, la energía de interacción entre los ligandos y el metal puede variar.

En síntesis, los experimentos que han encontrado diferencias en la estructura cristalina de las PdNPs han sido interpretados mediante dos rutas diferentes. La primera se basa en la diferencia en la velocidad de reducción de los iones de $\mathrm{Pd}^{\mathrm{II}}$ para formar las NPs: reducciones rápidas producen estructuras desordenadas y reducciones lentas, estructuras metálicas ordenadas. La segunda interpretación indica que las diferencias en el orden de los átomos metálicos de las NPs se deben a la magnitud de la interacción entre el ligando y el metal: ligandos que interaccionan fuertemente con el Pd producen estructuras amorfas y ligandos que interaccionan débilmente con el metal dan como resultado estructuras metálicas ordenadas.

En esta sección analizaremos nuestros resultados experimentales en base a simulaciones computacionales mediante dinámica de Langevin, cuyos resultados serán interpretados en base a simulaciones de imágenes de HRTEM y cuantificados a través de la función de distribución de pares (pair distribution function, PDF, $g(r)$ ). Esta función indica la probabilidad de encontrar un átomo de $\mathrm{Pd}$ a cierta distancia del primero.

Se eligieron 3 geometrías diferentes para describir los núcleos metálicos de las PdNPs: un octaedro (Oh) de 891 átomos, un decaedro de Marks (Dh) de 584 átomos y un icosaedro (Ih) de 923 átomos. Los octaedros se construyen en base a una estructura $f c c$ de $\mathrm{Pd}$ cortada de manera de exponer 4 caras $\{111\}$ (Fig. 6.11a). Las decaedros están compuestas por subunidades tetraédricas unidas mediante planos espejo, exponiendo caras $\{111\}$ al exterior y poseen una estructura no cristalográfica con simetría de rotación de quinto grado alrededor del eje [110]. Debido a la geometría de estas partículas, no es posible formarlas 
a

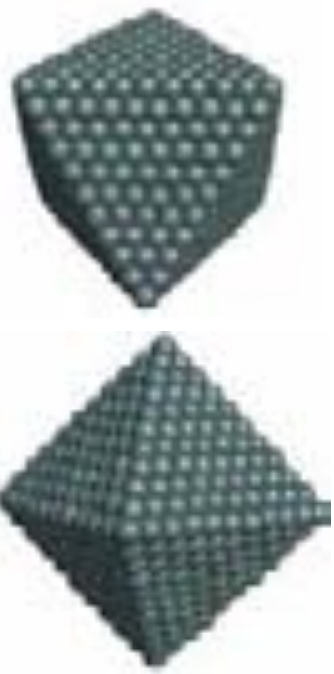

Octaedro (Oh)
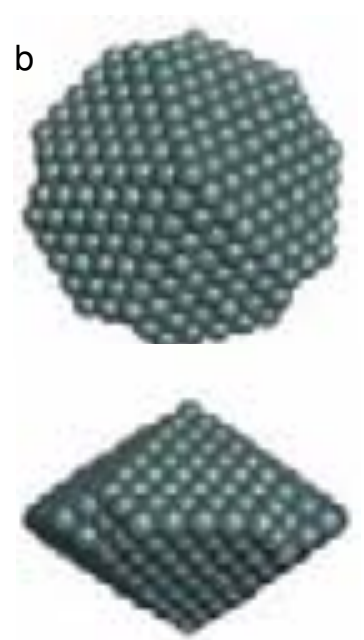

Decaedro de Marks (Dh)
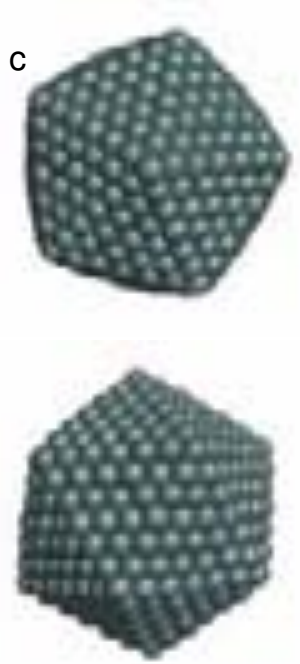

Icosaedro (Ih)

Figura 6.11: Diferentes geometrías utilizadas para describir los núcleos de Pd en las NPs simuladas.

mediante estructuras $f c c$ sin distorsiones, por lo que se deben producir defectos o bien acumular deformaciones de la red $f c c$. En los decaedros de Marks, los vértices donde se unen 4 caras $\{111\}$ del decaedro son reemplazados por caras $\{111\}$ entrantes (Fig. 6.11b) [142]. Por último, los icosaedros se componen a partir de 20 unidades tetraédricas y también están sujetos a deformaciones de la red $f c c$. Exponen al exterior solamente caras $\{111\}$ (Fig. 6.11c).

Estos núcleos de $\mathrm{Pd}$ fueron cubiertos con 4 adsorbatos diferentes: 1-butilamina $\left(\mathrm{NC}_{4}\right)$, sulfuro $(\mathrm{S})$, butanotiolato $\left(\mathrm{SC}_{4}\right)$ y sulfuro + butanotiolato (S-SC4). Se construyeron los sistemas y se realizaron las simulaciones de dinámica de Langevin. Estos cálculos fueron realizados por J. Olmos-Azar y M. M. Mariscal, de la Universidad Nacional de Córdoba, Argentina.

Las interacciones consideradas en estos sistemas son: interacciones metal-metal, metalmolécula, metal-sulfuro, molécula-molécula, molécula-sulfuro, sulfuro-sulfuro e intramoleculares. Para las interacciones metálicas se utilizó el potencial de muchos cuerpos TightBinding, en la aproximación de segundos momentos (TB-SMA). Las interacciones moléculamolécula, intramoleculares, molécula-sulfuro y sulfuro-sulfuro fueron representadas en la aproximación del campo de fuerza universal (universal force field, UFF). Para las interacciones sulfuro-metal, se utilizó el potencial de Morse. Para representar las interacciones molécula-metal (tiolato y amina) se utilizó el potencial desarrollado en la ref. [247]. En el citado trabajo pueden encontrarse los detalles del método de simulación.

Los parámetros necesarios para los potenciales utilizados fueron ajustados a partir de cálculos en el nivel de teoría de DFT realizados sobre Pd(111), como los descritos en la Sec. 5.9, utilizando el código CASTEP. Estos parámetros son: la profundidad del pozo de potencial $\left(D_{e}\right)$, la distancia de equilibrio $\mathrm{S}-\mathrm{Pd}$ o $\mathrm{N}-\mathrm{Pd}\left(r_{e}\right)$, la constante de 
Tabla 6.3: Parámetros obtenidos para el ajuste del potencial Pd-tiolato y Pd-amina. Energía de adsorción $\left(E_{b}\right)$, profundidad del pozo de potencial $\left(D_{e}\right)$, distancia de equilibrio $\mathrm{S}-\mathrm{Pd}$ o $\mathrm{N}-\mathrm{Pd}\left(r_{e}\right)$, constante de anarmonicidad $(\alpha)$ y orden de enlace (BO).

\begin{tabular}{ccccccc}
\hline Interacción & Sitio de adsorción & $E_{b} / \mathrm{eV}$ & $D_{e} / \mathrm{eV}$ & $r_{e} / \mathrm{nm}$ & $\alpha / \mathrm{nm}^{-} 1$ & $\mathrm{BO}$ \\
\hline \multirow{3}{*}{ Pd-tiolato } & on top & $-3,00$ & 1,006932 & 0,2251 & 14,7 & 1,00 \\
& bridge & $-2,96$ & 0,667994 & 0,2456 & 14,7 & 2,01 \\
& hollow-fcc & $-3,50$ & 0,729014 & 0,2320 & 14,7 & 3,00 \\
\hline \multirow{2}{*}{ Pd-amina } & on top & $-0,16$ & 0,005109 & 0,2435 & 14,7 & 1,19 \\
& hollow-fcc & $-0,14$ & 0,002877 & 0,2879 & 14,7 & 2,81 \\
\hline
\end{tabular}

anarmonicidad $(\alpha)$ y la energía de adsorción $\left(E_{b}\right)$. Para el caso del sulfuro en un hueco tetraédrico (hollow-fcc), los valores obtenidos son: $D_{e}=1,274611 \mathrm{eV}, r_{e}=0,22898 \mathrm{~nm}$, $\alpha=14,7 \mathrm{~nm}^{-1}$ y $E_{b}=-6,10 \mathrm{eV}$. Para el butanotiolato se consideraron 3 sitios de adsorción: posición puente entre dos átomos de $\mathrm{Pd}$ (bridge), sitio hollow-fcc y sobre un átomo de Pd (on top). En el caso de la butilamina se consideraron dos posiciones: on top y hollowfcc. En la Tabla 6.3 se muestran los parámetros obtenidos para la interacción Pd-tiolato y Pd-amina. Los valores de $D_{e}$ fueron optimizados a partir de los datos de $r_{e}$, de manera tal de reproducir los valores de $E_{b}$ calculados por DFT.

En las NPs desnudas, la estructura se encuentra ordenada, y la PDF presenta máximos bien definidos que representan las distancias entre vecinos de los átomos de Pd. En el caso de los sistemas con azufre (sulfuro o tiol) esta función fue estudiada, además de la partícula completa, en diferentes profundidades: desde el centro hasta un radio de $0,3 \mathrm{~nm}$, en un casquete esférico entre 0,3 y $0,6 \mathrm{~nm}$ y en un casquete esférico entre 0,6 y $0,9 \mathrm{~nm}$ (Fig. 6.12). De esta forma, es posible obtener una idea de la distancia hasta la cual el ligando sobre la superficie de las partículas ejerce un efecto en el grado de orden de los átomos metálicos.

La simulación de las imágenes de HRTEM y sus patrones de difracción (DF) fue realizada utilizando el programa SimulaTEM [248] con el método multislice. Solamente los átomos de $\mathrm{Pd}$ fueron considerados en la simulación. Se utilizó un voltaje de aceleración de $300 \mathrm{kV}$, aberración esférica $C_{3}=-20 \mu \mathrm{m}$, extensión del defoco (defocus spread) de 0,1 mrad y se dividieron las partículas en capas (slices) de 0,2 nm. Estas condiciones son las correspondientes a un microscopio con corrección de aberración esférica. Se realizó una simulación de una serie focal y se presenta aquí la imagen correspondiente al defoco $\left(C_{1}\right)$ para el cual los átomos de $\mathrm{Pd}$ aparecen brillantes (white-atom condition).

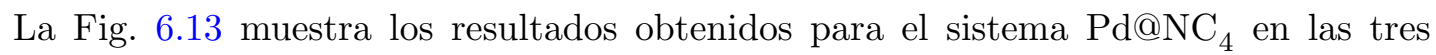
geometrías de núcleos de Pd luego de 2 ns de simulación. La PDF de las NPs desnudas y protegidas con $\mathrm{NC}_{4}$ no presentan diferencias notables, prácticamente coinciden en todo el rango de distancias estudiado. Este resultado es congruente con lo que observado en las imágenes simuladas de HRTEM y sus patrones de difracción: las NPs retienen su estructura ordenada luego de adsorber las moléculas orgánicas sobre su superficie, lo cual está de acuerdo también con las imágenes de HAADF-STEM (Fig. 6.10). Este comportamiento es 


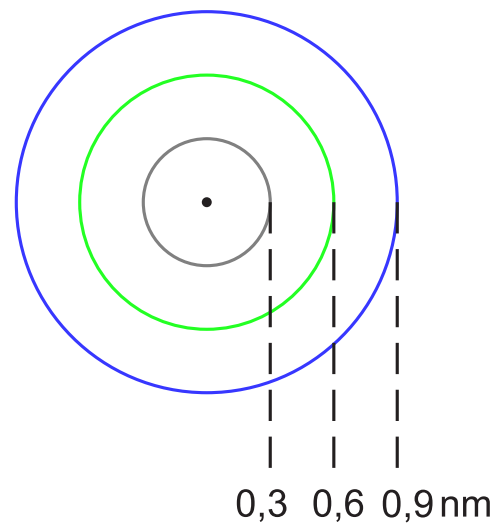

Figura 6.12: Diferentes casquetes en los que se calculó la función de distribución de pares en las NPs.

esperable, considerando la baja energía de interacción entre las aminas y el $\mathrm{Pd}$ (de $-0,14$ $\mathrm{a}-0,16 \mathrm{eV})$.

Al modificar las PdNPs con átomos de $\mathrm{S}$, observamos que las partículas se cubren con estos átomos que, finalmente, representarían un sulfuro en la superficie de Pd (Fig. 6.14). En las tres geometrías de núcleos estudiados se evidencia una gran modificación del orden de los átomos metálicos. Esto puede observarse en los modelos presentados en la figura así como también en las imágenes simuladas de HRTEM y los gráficos de la función de distribución de pares. Estos gráficos fueron realizados tanto para la partícula completa como para los diferentes casquetes esquematizados en la Fig. 6.12. Para el octaedro y el icosaedro, parte de la estructura original del núcleo de Pd es retenida parcialmente en el centro de la partícula (hasta un radio de $0,3 \mathrm{~nm}$ ) pero esta no se conserva en los siguientes estratos, como se observa a partir de la pérdida de los máximos desde los segundos vecinos en los gráficos de PDF. En el caso del decaedro de Marks, aún en el centro de la partícula el orden original de los átomos se pierde. Este gran cambio en la estructura de los núcleos metálicos, producida por la incorporación de átomos de $\mathrm{S}$ es también clara en las imágenes de HRTEM simuladas: no es posible observar un orden en los átomos de Pd. Los DP simulados muestran un patrón típico de una estructura amorfa. Los átomos de $\mathrm{S}$ entonces inducen un gran desorden en la estructura metálica de los núcleos de $\mathrm{Pd}$, comportamiento que puede ser comprendido considerando la alta energía de enlace del $\mathrm{S}$ al metal $(-6,10 \mathrm{eV})$.

$\mathrm{Al}$ adsorber $\mathrm{SC}_{4}$ sobre las partículas de $\mathrm{Pd}$ se observa la generación de sólo un leve desorden en la partícula de carácter principalmente superficial. Esto puede notarse claramente en las imágenes de HRTEM simuladas, presentadas en la Fig. 6.15. Mientras el centro de los núcleos metálicos conservan el orden original de las partículas desnudas, este se pierde en las cercanías de la superficie, sobre todo en la unión de distintas caras $\{111\}$. El comportamiento es similar en las tres configuraciones iniciales consideradas. En las AuNPs protegidas con alcanotiolatos se observa un efecto análogo (aunque quizás menor) en la superficie de los núcleos metálicos [139]. Esto es razonable considerando que la energía de interacción tiol-metal es comparable.

Hay que tener en cuenta que la estructura anterior $\left(\mathrm{Pd} @ \mathrm{SC}_{4}\right)$ no corresponde a la en- 
contrada experimentalmente. Por esto, consideramos la estructura formada por $\mathrm{Pd} @ \mathrm{~S}-\mathrm{SC}_{4}$, más cercana a la descrita en base a resultados experimentales en este capítulo (Fig. 6.16). En el decaedro de Marks y el icosaedro, los resultados observados son muy similares a los sistemas correspondientes de Pd@S: el orden en las núcleos metálicos se pierde y esto se evidencia tanto en las imágenes de HRTEM simuladas como en los gráficos de PDF. La estructura octaédrica, sin embargo, muestra un comportamiento inesperado. En este sistema, solo hay un desorden superficial y la estructura cristalina inicial se conserva en casi toda la partícula. Este resultado puede ser comprendido en base al cubrimiento total de especies de azufre en las NPs simuladas. Debido a la forma en que se optimiza el cubrimiento en el método de simulación utilizado, este es aproximadamente el mismo en los tres sistemas ( $\mathrm{S}, \mathrm{SC}_{4}$ y $\left.\mathrm{S}-\mathrm{SC}_{4}\right)$. A partir de los resultados de XPS, hemos observado que el cubrimiento en las $\mathrm{Pd} @ \mathrm{~S}-\mathrm{SC}_{12}$ NPs es aproximadamente el doble que en las $\mathrm{Au} @ \mathrm{SC}_{12}$ NPs de igual tamaño. Esto significa que el cubrimiento en las simulaciones se encuentra subestimado; es esperable que en los sistemas reales el cubrimiento de $\mathrm{S}_{\text {y }} \mathrm{SC}_{4}$ sea mayor. Este defecto en el cubrimiento superficial puede ser más notable en el caso de estructuras muy compactas como es el caso del octaedro $\mathrm{Pd}_{891}$. Sin embargo, estas simulaciones tienen una validez cualitativa para la comparación con los resultados experimentales y los ajustes necesarios para aproximarse más al sistema real son objeto de investigaciones que serán realizadas en el futuro.

Finalmente, en la Fig. 6.17 se presenta, a modo de comparación, el modelo de la estructura final simulada y la imagen de HRTEM simulada para el decaedro de Marks protegido por los 4 diferentes ligandos considerados: $\mathrm{NC}_{4}, \mathrm{~S}, \mathrm{SC}_{4}$ y $\mathrm{S}-\mathrm{SC}_{4}$. Hemos elegido esta geometría para la comparación debido a que coincide con la imagen de STEM de la partícula de $\mathrm{Pd} @ \mathrm{NC}_{12}$ mostrada anteriormente. Puede notarse en esta figura que la incorporación de azufre como adsorbato en la superficie de las partículas de $\mathrm{Pd}$ produce un gran desorden en los átomos metálicos que componen las NPs, mientas que los núcleos de $\mathrm{Pd}$ cubiertos con aminas no presentan cambios notables en su estructura y los cubiertos por alcanotioles solamente sólo exhiben desorden superficial. Debido a que hemos encontrado experimentalmente que las PdNPs cubiertas por alcanotioles están cubiertas por sulfuro y tiolato, resulta claro que el gran desorden observado en los núcleos metálicos, mostrado en las imágenes de HAADF-STEM (Fig. 6.10) y HRTEM (Fig. 6.18) es debido a la presencia del sulfuro en las NPs y el efecto producido por el tiol es de mucho menor escala. Este hecho se encuentra en concordancia con lo observado en las AuNPs protegidas por alcanotioles de similar tamaño, las cuales exhiben una estructura metálica ordenada y sólo están cubiertas por alcanotiolatos (sin presencia de sulfuro) (véase Sec. 3.4). La gran energía de enlace de los átomos de $\mathrm{S}$ (del sulfuro) al $\mathrm{Pd}$ debe ser la responsable de la magnitud del desorden causado en los núcleos metálicos. Es interesante notar que esta interacción $(\sim 6 \mathrm{eV})$ es mayor que la correspondiente a los enlaces $\mathrm{Pd}-\mathrm{Pd}$, la cual tiene un valor de $\sim 3,7 \mathrm{eV}$. 


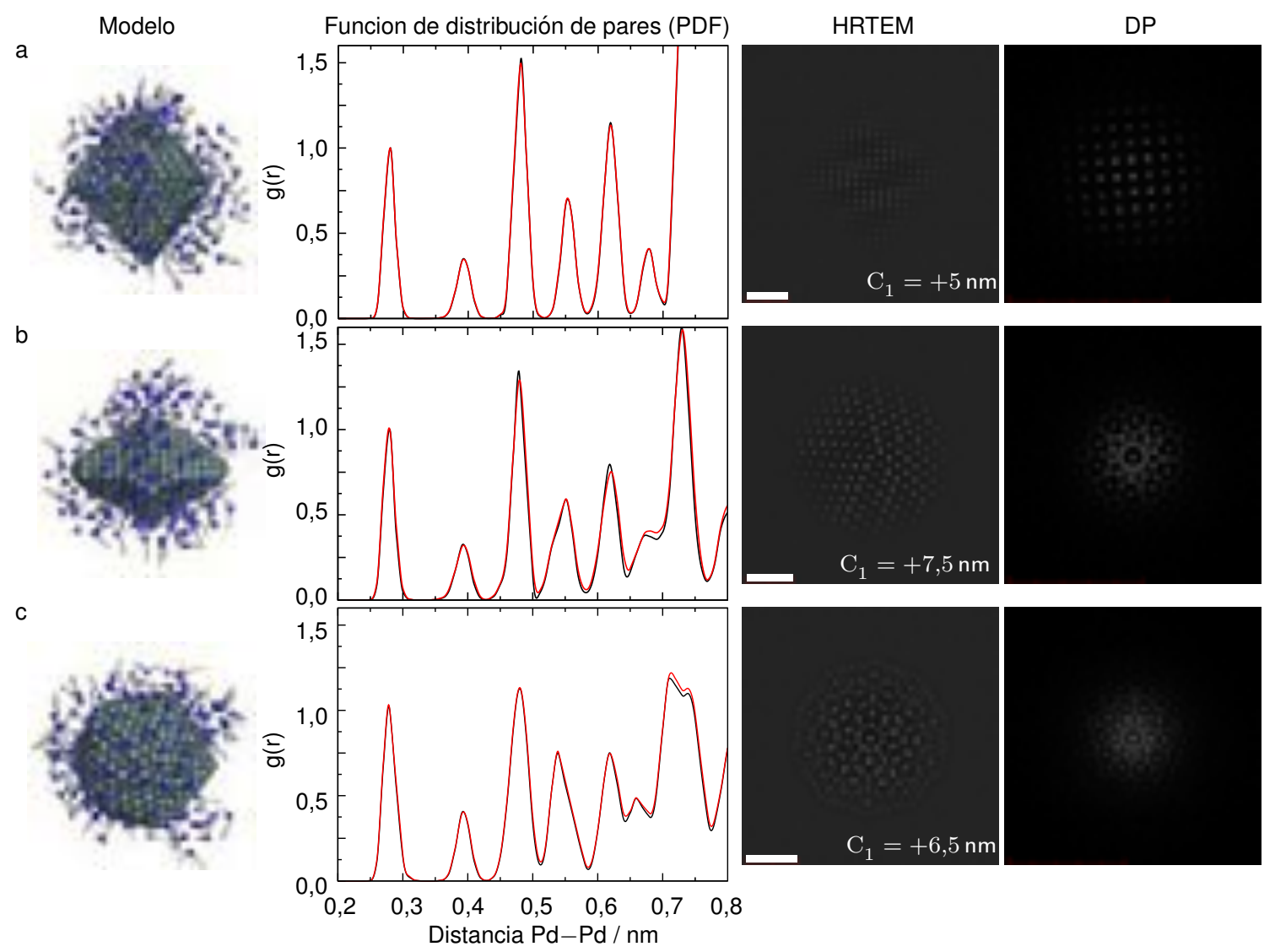

Figura 6.13: Simulación de nanopartículas de $\mathrm{Pd}$ protegidas con butilamina $\left(\mathrm{Pd}_{\mathrm{N}} \mathrm{NC}_{4}\right.$ NPs) utilizando diferentes núcleos de Pd. (a): Octaedro (Oh) $\mathrm{Pd}_{891}$. (b): Decaedro de Marks (Dh) $\mathrm{Pd}_{584}$. (c): Icosaedro (Ih) $\mathrm{Pd}_{923}$. Se presenta: el modelo de la estructura optimizada (Pd: esferas grises, $\mathrm{N}$ : esferas azules, grupos $\mathrm{CH}_{2}$ y $\mathrm{CH}_{3}$ : cilindros grises), la función de distribución de pares (trazo negro: PdNP desnuda, trazo rojo: $\mathrm{Pd}_{\mathrm{N}} \mathrm{NC}_{4} \mathrm{NP}$ completa), la simulación de imágenes de HRTEM de los núcleos de Pd (escala: $1 \mathrm{~nm}$ ) y su correspondiente patrón de difracción (DP). Para el octaedro, la simulación se realizó en el eje de zona $f c c$ [100]; para el decaedro, en el eje de zona que coincide con el eje de rotación de quinto grado al igual que para el icosaedro 
a

b

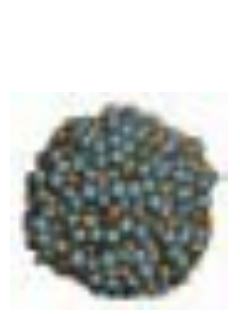

Modelo
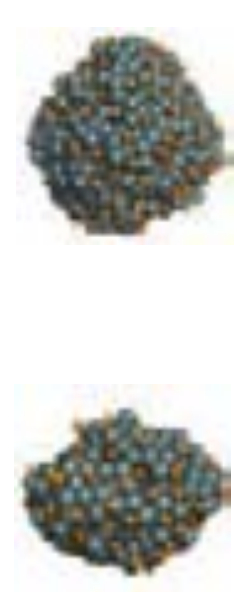

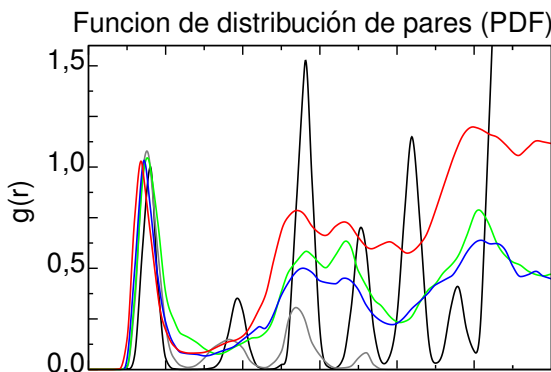

HRTEM

DP
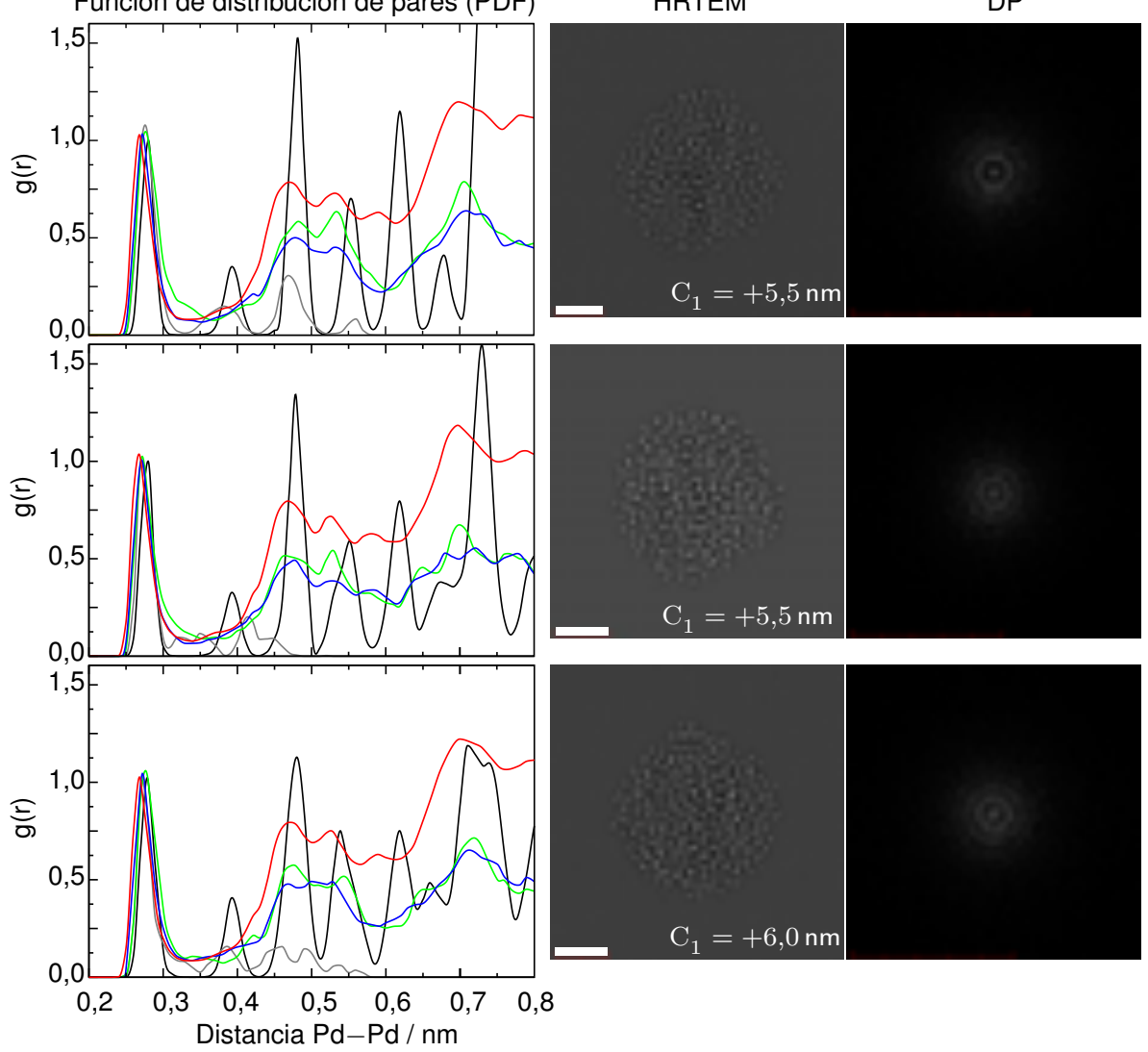

Figura 6.14: Simulación de nanopartículas de Pd protegidas con sulfuro (Pd@S NPs) utilizando diferentes núcleos de $\mathrm{Pd}$. (a): Octaedro $(\mathrm{Oh}) \mathrm{Pd}_{891}$. (b): Decaedro de Marks (Dh) $\mathrm{Pd}_{584}$. (c): Icosaedro (Ih) $\mathrm{Pd}_{923}$. Se presenta: el modelo de la estructura optimizada (Pd: esferas grises, S: esferas anaranjadas), la función de distribución de pares (trazo negro: PdNP desnuda, trazo gris: dentro de esfera de radio de $0,3 \mathrm{~nm}$, trazo verde: dentro de un casquete entre 0,3 y $0,6 \mathrm{~nm}$, trazo azul: dentro de un casquete entre 0,6 y $0,9 \mathrm{~nm}$, trazo rojo: Pd@S NP completa), la simulación de imágenes de HRTEM de los núcleos de Pd (escala: $1 \mathrm{~nm}$ ) y su correspondiente patrón de difracción (DP). 


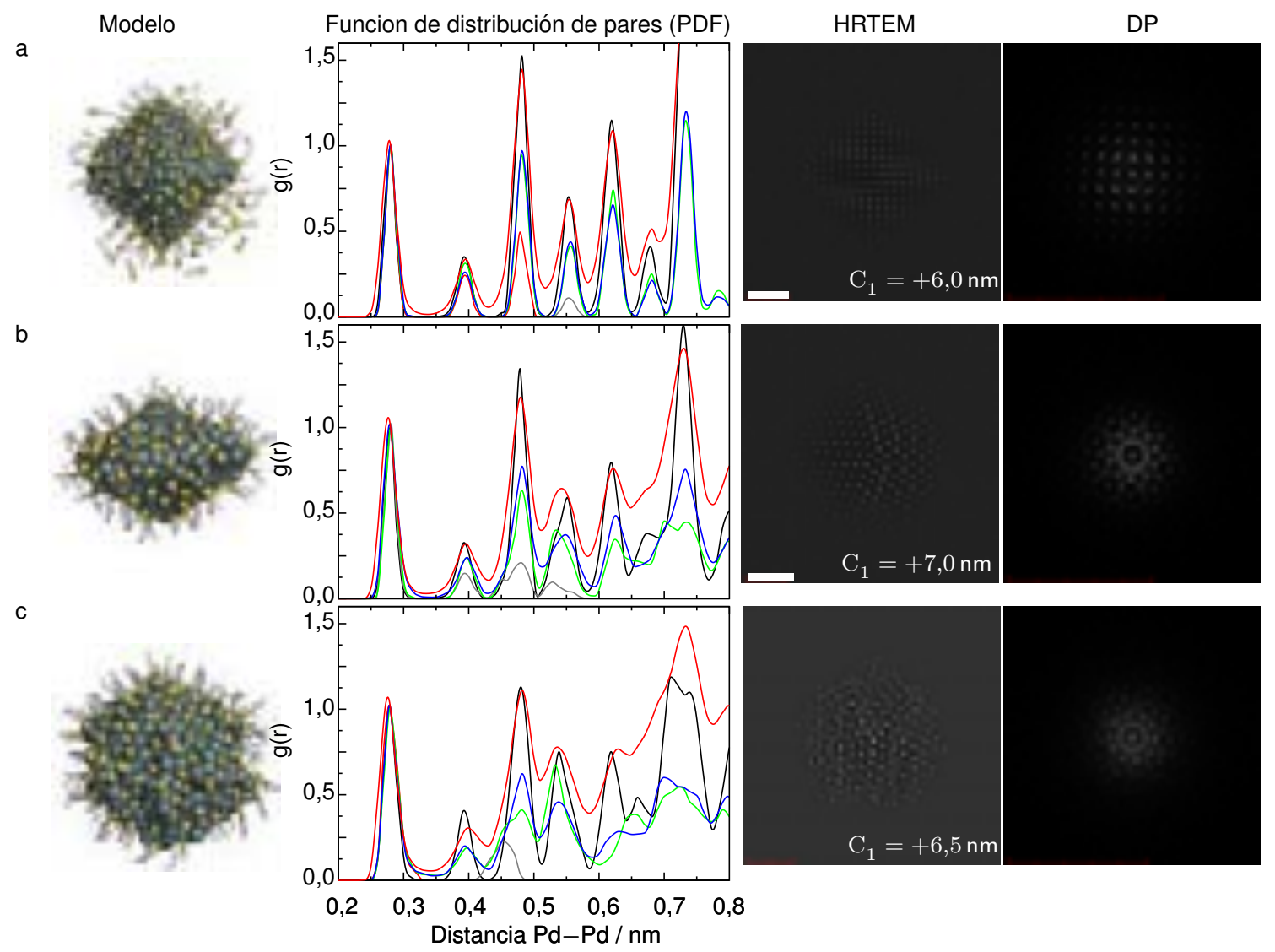

Figura 6.15: Simulación de nanopartículas de $\mathrm{Pd}$ protegidas con butanotiolato $\left(\mathrm{Pd} @ \mathrm{SC}_{4}\right.$ NPs) utilizando diferentes núcleos de Pd. (a): Octaedro (Oh) $\mathrm{Pd}_{891}$. (b): Decaedro de Marks (Dh) $\mathrm{Pd}_{584}$. (c): Icosaedro (Ih) $\mathrm{Pd}_{923}$. Se presenta: el modelo de la estructura optimizada (Pd: esferas grises, $\mathrm{S}$ : esferas amarillas, grupos $\mathrm{CH}_{2}$ y $\mathrm{CH}_{3}$ : cilindros grises), la función de distribución de pares (trazo negro: PdNP desnuda, trazo gris: dentro de esfera de radio de $0,3 \mathrm{~nm}$, trazo verde: dentro de un casquete entre 0,3 y $0,6 \mathrm{~nm}$, trazo azul: dentro

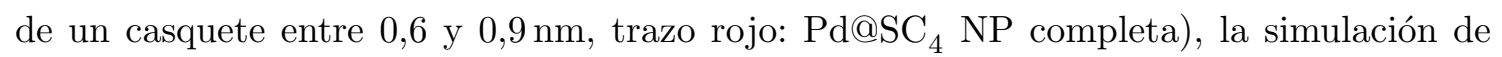
imágenes de HRTEM de los núcleos de Pd (escala: $1 \mathrm{~nm}$ ) y su correspondiente patrón de difracción (DP). 


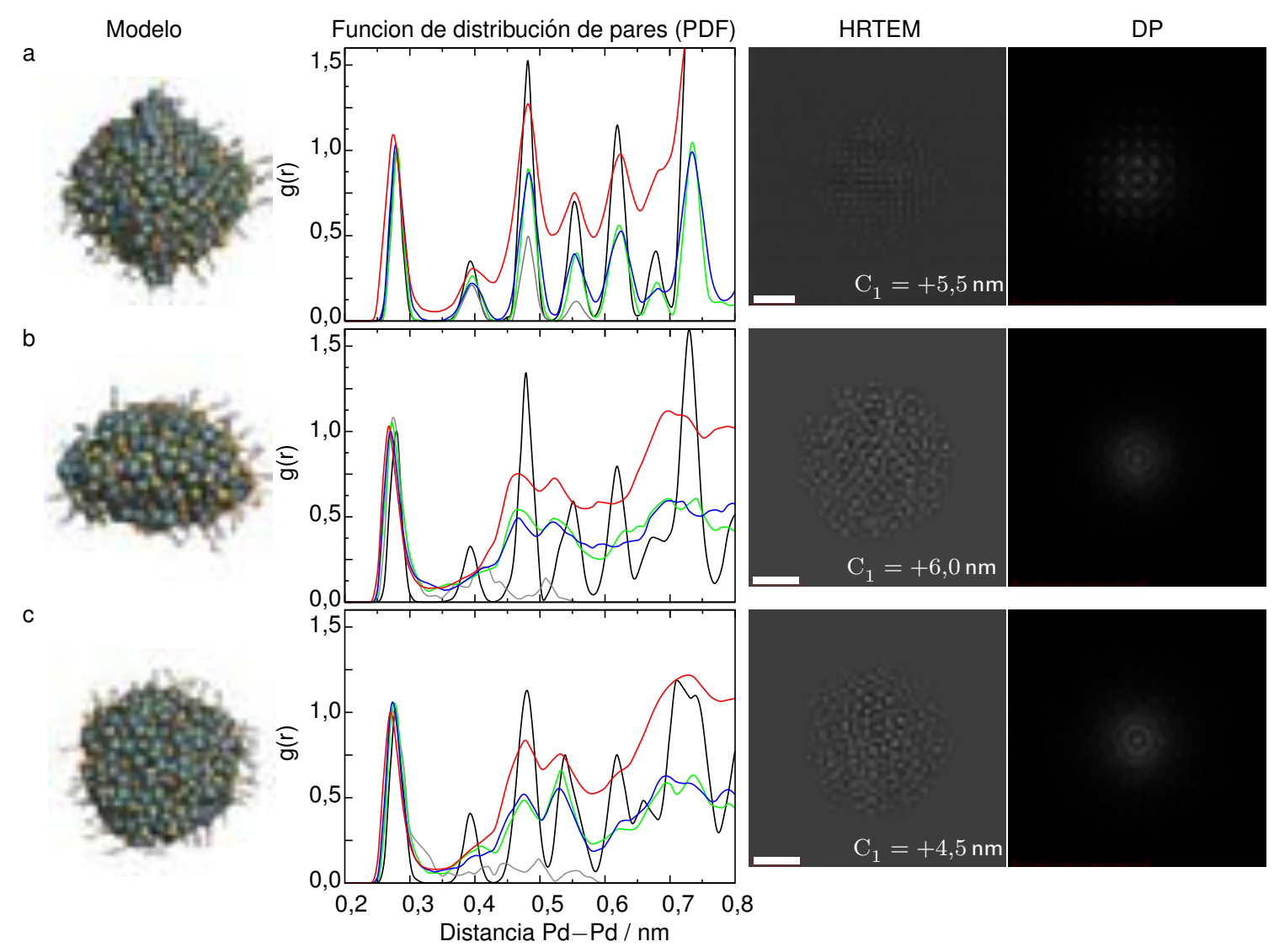

Figura 6.16: Simulación de nanopartículas de Pd protegidas con sulfuro y butanotiolato $\left(\mathrm{Pd} @ \mathrm{~S}-\mathrm{SC}_{4} \mathrm{NPs}\right)$ utilizando diferentes núcleos de $\mathrm{Pd}$. (a): Octaedro (Oh) $\mathrm{Pd}_{891}$. (b): Decaedro de Marks (Dh) $\mathrm{Pd}_{584}$. (c): Icosaedro (Ih) $\mathrm{Pd}_{923}$. Se presenta: el modelo de la estructura optimizada (Pd: esferas grises, $\mathrm{S}$ de sulfuro: esferas anaranjadas, $\mathrm{S}$ de tiol: esferas amarillas, grupos $\mathrm{CH}_{2}$ y $\mathrm{CH}_{3}$ : cilindros grises), la función de distribución de pares (trazo negro: PdNP desnuda, trazo gris: dentro de esfera de radio de $0,3 \mathrm{~nm}$, trazo verde: dentro de un casquete entre 0,3 y $0,6 \mathrm{~nm}$, trazo azul: dentro de un casquete entre $0,6 \mathrm{y}$ 0,9 nm, trazo rojo: $\mathrm{Pd} @ \mathrm{~S}-\mathrm{SC}_{4} \mathrm{NP}$ completa), la simulación de imágenes de HRTEM de los núcleos de $\mathrm{Pd}$ (escala: $1 \mathrm{~nm}$ ) y su correspondiente patrón de difracción (DP). 


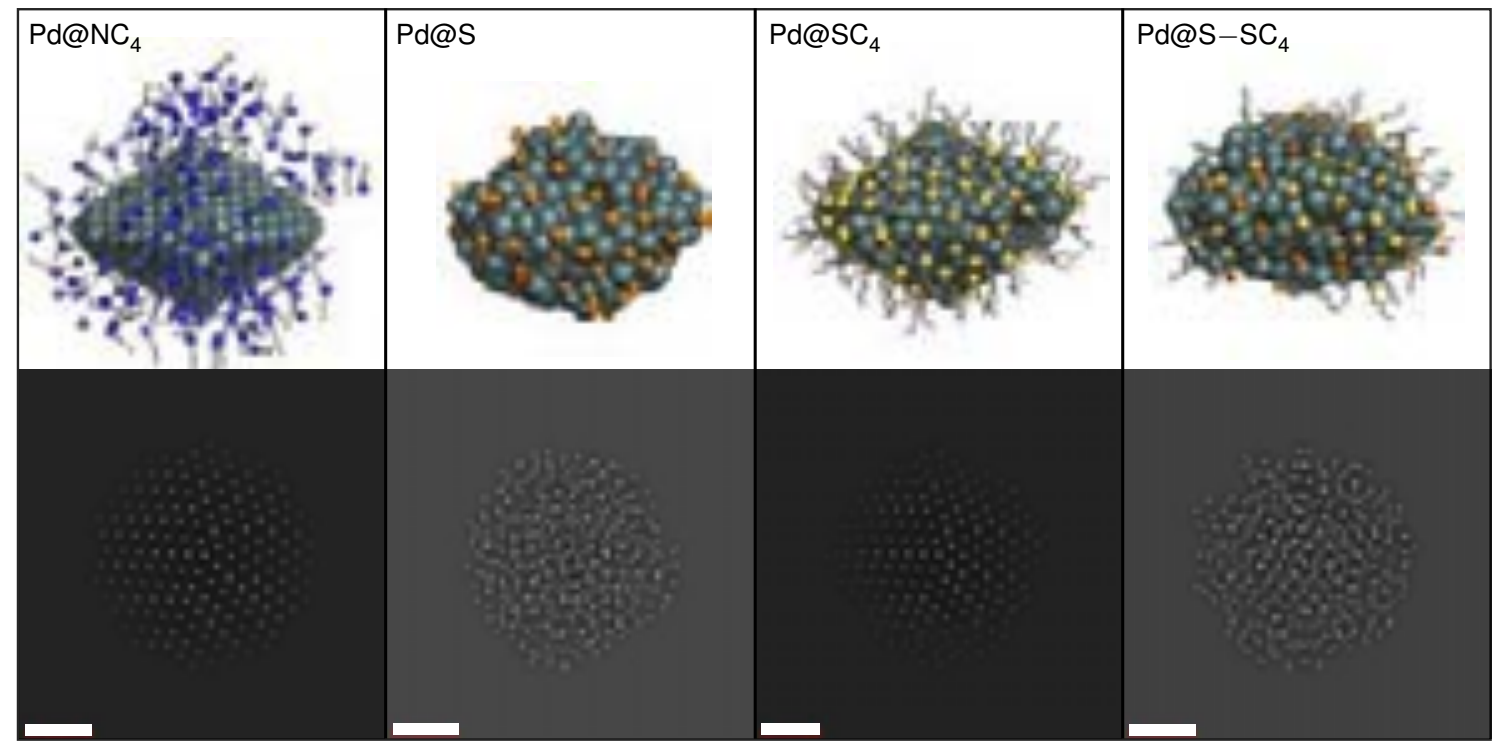

Figura 6.17: Comparación de las simulaciones de PdNPs con diferentes adsorbatos. Se presenta el modelo de la estructura final de la dinámica de Langevin y la simulación de la imagen de HRTEM correspondiente. Escalas: $1 \mathrm{~nm}$.

\subsection{Efecto del daño por radiación en la caracterización de las nanopartículas mediante microscopía electrónica}

Hemos estudiado las Pd@S-SC 12 NPs mediante HRTEM con corrección de aberración esférica utilizando el microscopio TEAM 0.5 operado a $300 \mathrm{kV}$ en NCEM, Berkeley. Como veremos a continuación, las NPs muestran también una estructura amorfa pero sufren daño inducido por el haz de electrones que ordena la estructura metálica de las NPs.

La Fig. 6.18 muestra las imágenes obtenidas luego de diferentes tiempos de irradiación. En la primera imagen $(t=0 \mathrm{~s})$ se observa una estructura amorfa tanto en la imagen de HRTEM como en en la transformada de Fourier de la misma, tal como se esperaba a partir de las imágenes de HAADF-STEM analizadas anteriormente. Sin embargo, si se continúa irradiando una partícula con el haz de electrones pueden notarse grandes cambios en la misma, como lo evidencian las siguientes imágenes en la figura. Finalmente, luego de aproximadamente 2 min de irradiación, prácticamente toda la partícula adquirió una estructura cristalina. En la Fig. 6.18 a $t=137 \mathrm{~s}$, puede observarse una NP levemente rotada de la dirección [100], típica de una estructura $f c c$. Es decir, el haz de electrones produjo el ordenamiento de los átomos en la partícula para dar lugar a un monocristal. Este comportamiento puede comprenderse mediante el análisis del daño inducido por radiación.

En principio, tres tipos de daños por radiación de electrones pueden afectar a las Pd@S-SC ${ }_{12}$ NPs: daño por ionización o radiólisis, daño por calentamiento y daño por knock-on [40]. El daño por ionización o radiólisis produce la ruptura de enlaces y genera cambios químicos en la muestra, como los observados para las Au@AuI-TM NPs en el Cap. 4. Este tipo de daño aumenta al disminuir la energía del haz de electrones incidentes, dado que la sección eficaz de ionización (dada por la ley de Bethe) es aproximadamente 


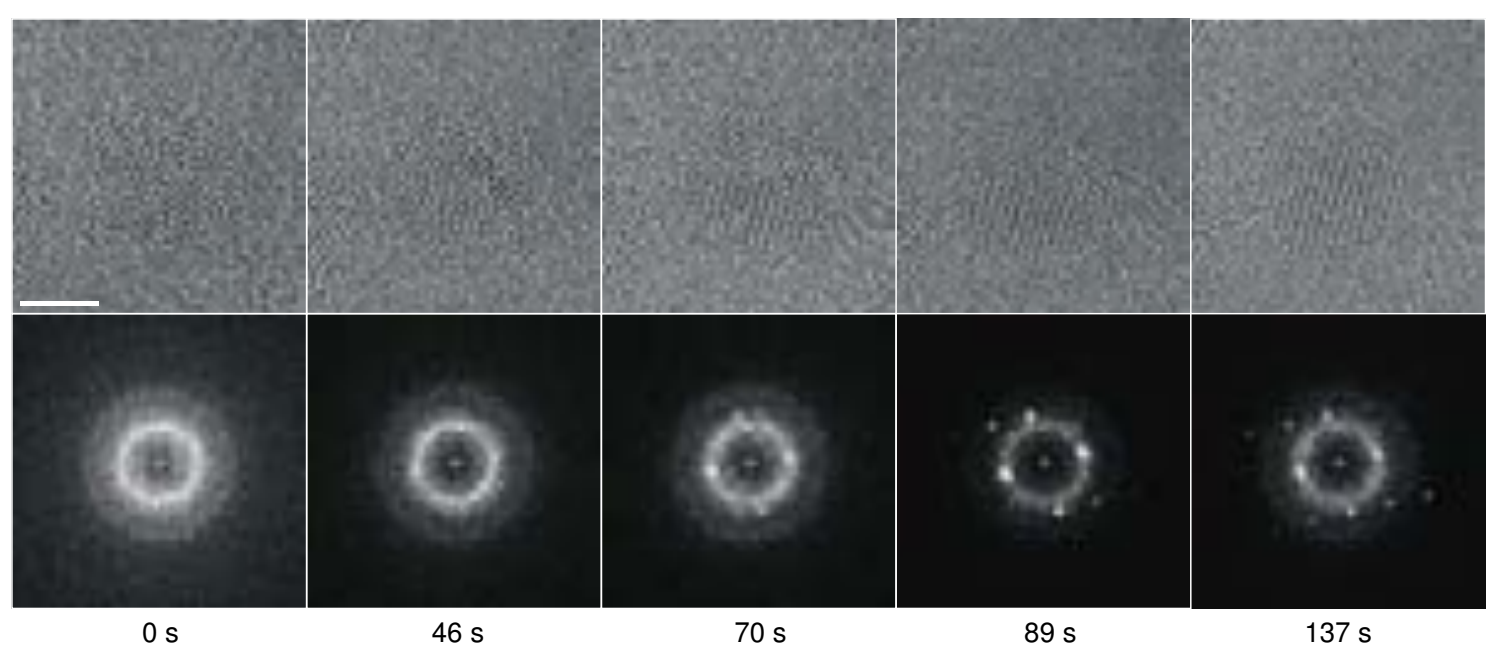

Figura 6.18: Evolución de las $\mathrm{Pd} @ \mathrm{~S}-\mathrm{SC}_{12} \mathrm{NPs}$ bajo un haz de electrones. Imágenes de HRTEM con corrección de aberración de Pd@S-SC 12 NPs y sus correspondientes transformadas de Fourier, a diferentes tiempos de irradiación con cañón de electrones a $300 \mathrm{kV}$. Dosis $=3,7 \times 10^{5} \mathrm{e}^{-} \mathrm{nm}^{-2} \mathrm{~s}^{-1}$. Escala: $2 \mathrm{~nm}$.

inversamente proporcional al cuadrado de la velocidad de los electrones en el haz [249]. Por otro lado, al incidir sobre la muestra electrones de alta energía, se excitan los fonones de la misma lo que produce su calentamiento. Este efecto produce daño, en general, en las muestras con baja conducción térmica. El daño por knock-on se debe al desplazamiento de átomos en la muestra por transferencia directa de la energía del haz. Aunque la dispersión de electrones por parte de un átomo puede considerarse elástica en muchas situaciones (Rutherford scattering) esto es válido sólo para ángulos de dispersión pequeños [44]. La energía que pierde el haz de electrones por transferencia hacia un núcleo atómico está dada por la siguiente ecuación:

$$
E=E_{\max } \sin ^{2}\left(\frac{\theta}{2}\right)=\frac{1}{2} E_{\max }(1-\cos \theta)
$$

donde $E_{\max }$ es la máxima energía que puede ser transferida cuando el ángulo de dispersión del electrón es $\theta=180^{\circ}$ y se cumple que:

$$
E_{\max }=\frac{E_{0}\left(E_{0}+2 m_{0} c^{2} \times 6,24 \times 10^{15}\right)}{E_{0}+\frac{1}{2}\left(1+m_{0} / M\right)^{2} M c^{2} \times 6,24 \times 10^{15}}
$$

donde $E_{\max }$ están en eV, $E_{0}$ es la energía del haz de electrones incidente (en $\mathrm{keV}$ ), $m_{0}$ es la masa del electrón en reposo (en $\mathrm{kg}$ ), $M$ es la masa del átomo (en $\mathrm{kg}$ ) y $c$ es la velocidad de la luz (en $\mathrm{ms}^{-1}$ ) [44]. En la Fig. 6.19 se encuentra graficada esta ecuación para distintos elementos. Si consideramos que la energía promedio para desplazar un átomo dentro del material masivo es $E_{d} \approx 25 \mathrm{eV}$ [40], entonces, para una dada energía incidente $E_{0}$, todos los elementos cuyas curvas de $E_{\max }$ estén por encima de este valor podrán ser desplazados por el haz de electrones incidentes. $E_{\max }$ aumenta con $E_{0}$ pero decrece con la masa atómica, i. e. los átomos más livianos son desplazados más fácilmente que los 

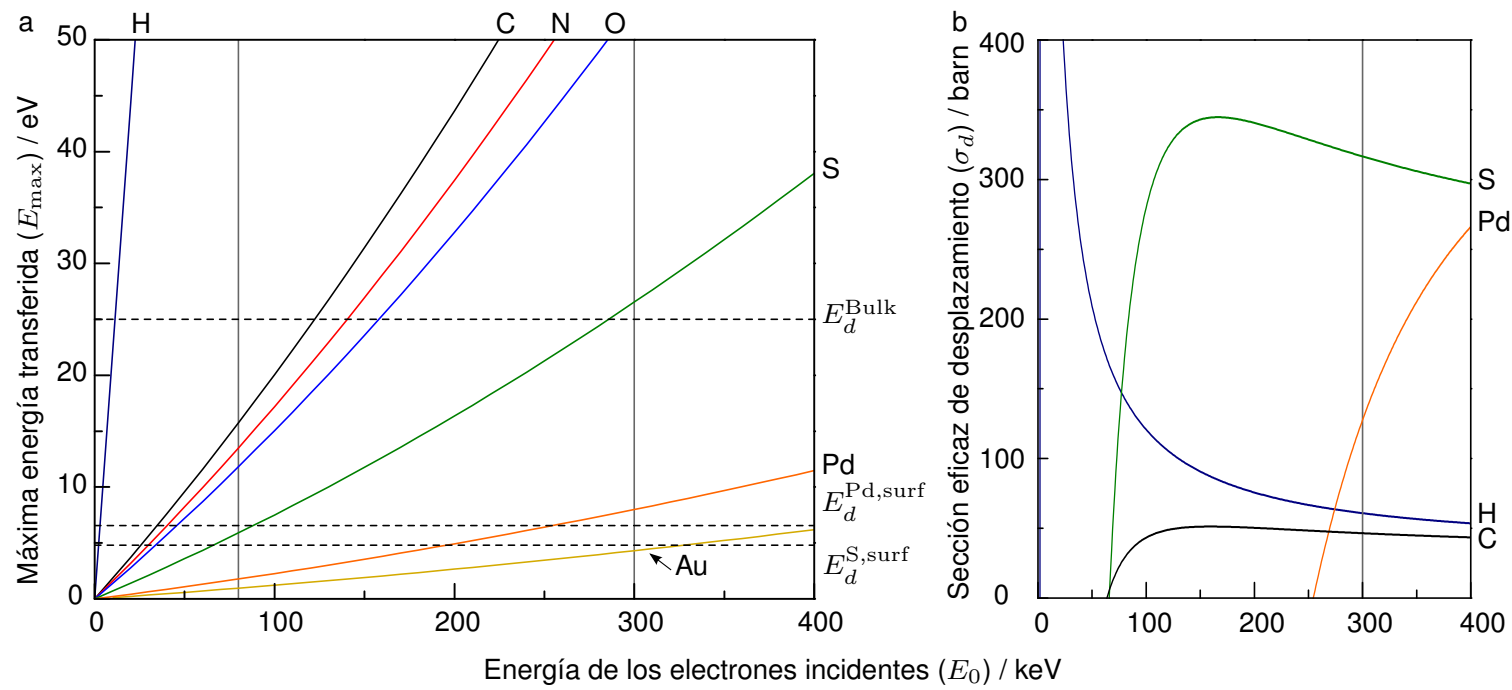

Figura 6.19: (a) Energía máxima transferida $\left(E_{\max }\right)$ sobre distintos elementos mediante dispersión a $180^{\circ}$ en función de la energía de los electrones incidentes $\left(E_{0}\right)$, calculada con la Ec. 6.2. Las líneas horizontales en $25,6,6$ y 4,8 eV corresponden a la energía promedio de desplazamiento de átomos desde el masivo $\left(E_{d}^{\text {Bulk }}\right)$, desde la superficie para $\operatorname{Pd}\left(E_{d}^{\mathrm{Pd} \text {,surf }}\right)$ y desde la superficie para $\mathrm{S}\left(E_{d}^{\mathrm{S}, \text { surf }}\right)$, respectivamente. (b) Sección eficaz de desplazamiento de átomos de la superficie $\left(\sigma_{d}\right)$ en función de $E_{0}$ para distintos elementos, calculada con la Ec. 6.3

átomos pesados. Sin embargo, la energía para desplazar átomos que se encuentran en la superficie del material es, en general, menor y, por la tanto, este proceso se diferencia del anterior con el nombre de sputtering [40]. Egerton et ál. [44] propusieron considerar como energía de desplazamiento para el sputtering una energía promedio de enlace en la superficie calculada como $\frac{5}{3} E_{\text {sub }}$, donde $E_{\text {sub }}$ es la energía de sublimación del elemento. Los valores de estas energías se encuentra tabulados, p. ej., en la ref. [250]. De esta forma, si $E_{\max }$ excede a $E_{d}=\frac{5}{3} E_{\mathrm{sub}}$, la dispersión de electrones a altos ángulos puede causar el desplazamiento de los átomos de la superficie. En la Fig. 6.19a incluimos los valores de energía de desplazamiento de átomos de la superficies para el $\mathrm{S}\left(E_{d}^{\mathrm{S}, \text { surf }}\right)$ y el $\mathrm{Pd}\left(E_{d}^{\mathrm{Pd}, \text { surf }}\right)$ como líneas punteadas horizontales.

Resulta evidente entonces que para una energía incidente $E_{0}=300 \mathrm{keV}$, como la utilizada para la adquisición de las imágenes mostradas en la Fig. 6.18, la energía máxima transferible a los átomos de $\mathrm{S}\left(E_{\max }=26,1 \mathrm{eV}\right)$ excede en gran medida la energía mínima necesaria para el desplazamiento de átomos de $\mathrm{S}$ en la superficie $\left(E_{d}^{\mathrm{S} \text {,surf }}=4,8 \mathrm{eV}\right)$. En el caso del Pd, esta diferencia es mucho menor. Para este elemento, $E_{\max }=7,9 \mathrm{eV}$ a $300 \mathrm{keV}$ de energía incidente, mientras que $E_{d}^{\mathrm{Pd} \text {,surf }}=6,6 \mathrm{eV}$. Es decir, con un haz de electrones operado a un voltaje de aceleración de $300 \mathrm{kV}$, es posible el desplazamiento de átomos de $\mathrm{S}$ dentro de un material masivo y en gran medida desde la superficie mientras que sólo es posible el desplazamiento de átomos de Pd de la superficie.

Sin embargo, para evaluar este fenómeno hay que analizar la sección eficaz de despla- 
zamiento $\left(\sigma_{d}\right)$ de los átomos de la superficie, que varía para cada elemento y cada energía incidente. Una buena aproximación para el cálculo de $\sigma_{d}$ es la expresión para la dispersión de Rutherford (Ec. 2.41) integrada entre $E_{\max }$ y $E_{d}$ [44]:

$$
\sigma_{d}=\frac{1-v^{2} / c^{2}}{v^{4} / c^{4}} \pi Z^{2} r_{0}^{2}\left(\frac{E_{\max }}{E_{\mathrm{d}}}-1\right) \times 10^{28}
$$

donde $v$ es la velocidad de los electrones incidentes, $Z$ es el número atómico, $r_{0}=$ $\left(4 \pi \epsilon_{0}\right)^{-1}\left(e^{2} / m_{0} c^{2}\right)=2,8179 \times 10^{-15} \mathrm{~m}$ es el radio clásico del electrón, $E_{\max }$ es la energía máxima transferida al átomo por el electrón, calculada con la Ec. 6.2 y $E_{\mathrm{d}}$ es la energía mínima para el desplazamiento por sputtering. Los valores de $\sigma_{d}$ se obtienen en barn $=$ $10^{-24} \mathrm{~cm}^{2}$. Los valores par H, C, S y Pd calculados con esta ecuación se encuentra graficados en la Fig. 6.19b. Para un haz de $300 \mathrm{kV}$, la sección eficaz de desplazamiento de átomos de la superficie tiene los siguientes valores: para $\mathrm{S}, \sigma_{d} \approx 317$ barn y para $\mathrm{Pd}, \sigma_{d} \approx 128$ barn. Si consideramos una cara compacta de un metal como la $\{111\}$, la densidad de átomos ( $\rho_{\text {surf }}$ ) es aproximadamente $10^{15} \mathrm{~cm}^{-2}$. Por lo tanto, podemos calcular el rendimiento de sputtering $(Y)$, que equivale a la cantidad de átomos desplazados por cada electrón incidente, como $Y=\sigma_{d} \rho_{\text {surf }}$. Utilizando esta ecuación obtenemos los valores de $Y_{\mathrm{S}}=3,17 \times 10^{-7}$ y $Y_{\mathrm{Pd}}=1,28 \times 10^{-7}$. Considerando la dosis utilizada de $3,7 \times 10^{5} \mathrm{e}^{-} \mathrm{nm}^{-2} \mathrm{~s}^{-1}$ y una superficie para la NP de $\sim 9 \mathrm{~nm}^{2}$, se desplazan $\sim 1$ átomo de $\mathrm{S}$ y $\sim 0,4$ átomos de $\mathrm{Pd}$ de la NP por segundo, si todos estos átomos se encuentran en la superficie. Esto produciría el desplazamiento $\sim 150$ átomos de $\mathrm{S}$ y $\sim 60$ de Pd luego de una irradiación por $\sim 140$ s. Sin embargo, considerando el modelo que hemos propuesto para estas NPs, la superficie debe ser muy rica en átomos de S en lugar de Pd. Por lo tanto, se espera que el desplazamiento de átomos de $\mathrm{S}$ respecto al de $\mathrm{Pd}$ sea mayor al dado por los cálculos anteriores. En estos cálculos hemos considerado átomos de azufre elemental, sin tener en cuenta que algunos de estos están unidos a la cadena hidrocarbonada. Además, la energía mínima de desplazamiento considerada es la energía de sublimación si la muestra estuviera formada por ese único elemento. Sin embargo, los cálculos realizados sirven para tener una idea cualitativa de estos procesos en cada uno de los elementos considerados.

A partir del análisis realizado, y considerando solamente el daño por knock-on (más precisamente sputtering), podemos proponer un mecanismo que explique la generación de una estructura cristalina en las $\mathrm{Pd} @ \mathrm{~S}-\mathrm{SC}_{12} \mathrm{NPs}$ a partir de la irradiación de la muestra con un haz de electrones paralelo con una energía de $300 \mathrm{keV}$. Al irradiar la muestra, la energía transferida por los electrones incidentes sobre los átomos de $\mathrm{S}$ es suficiente para eyectar estos átomos de las NPs. Estos electrones también pueden desplazar átomos de Pd, pero en menor medida. Las cadenas hidrocarbonadas también son destruidas por este tipo de daño en menor medida (ver las curvas correspondientes a H y C en la Fig. 6.19a, b) pero son muy susceptibles al daño por calentamiento y radiólisis. Las NPs entonces se van enriqueciendo en la cantidad relativa de Pd y el efecto que tenía inicialmente el S en la estructura cristalina de la misma, va desapareciendo. De esta forma, las NPs compuestas prácticamente sólo de $\mathrm{Pd}$ y sometidas a una temperatura local que puede ser diferente a la temperatura ambiente producto del calentamiento por el haz de electrones, pueden reorganizar su estructura interna y presentar una estructura ordenada. Por otro lado, puede existir un daño del tipo de radiólisis que produzca la reducción de los átomos de $\mathrm{Pd}$ 

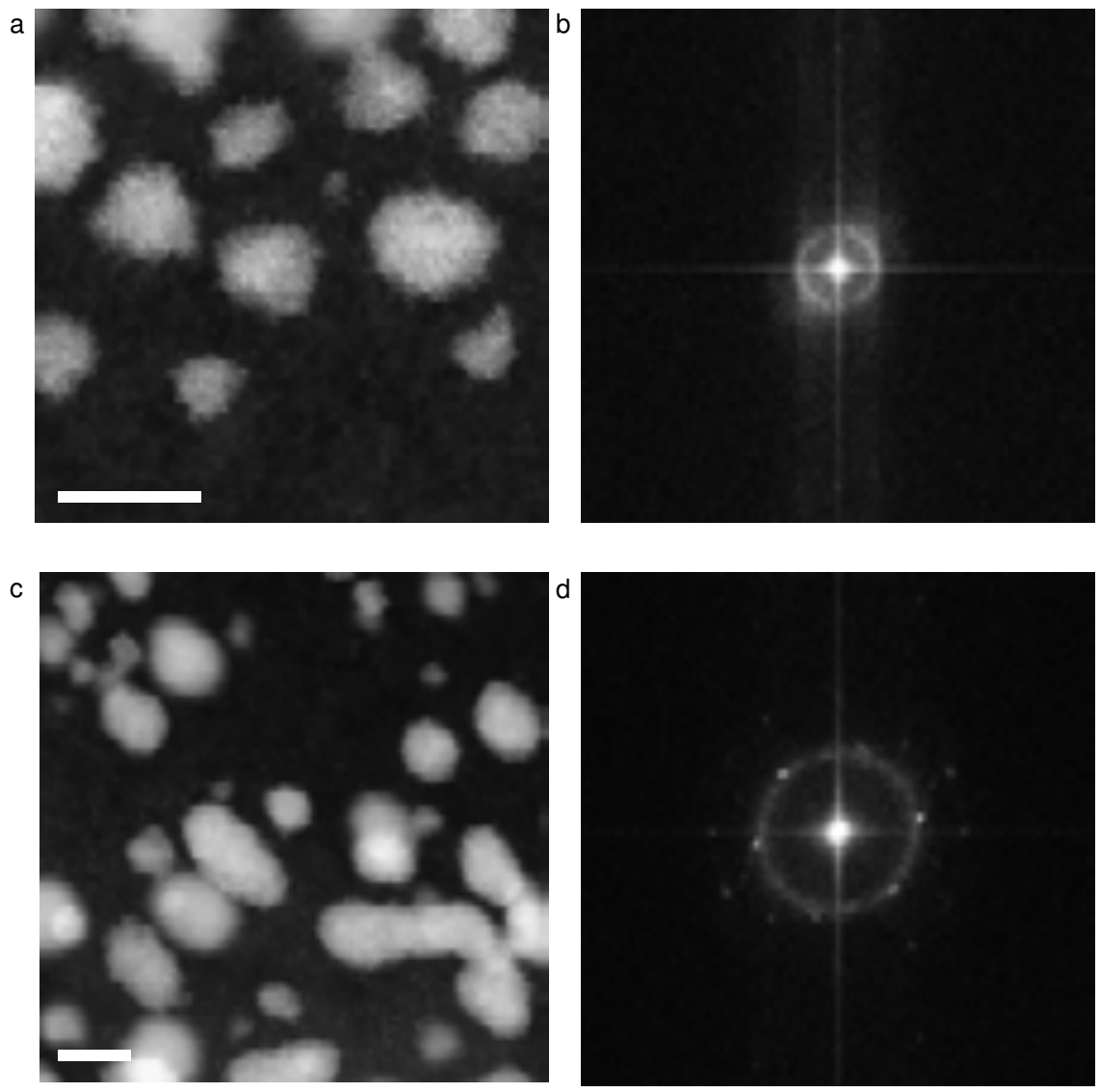

Figura 6.20: Efecto del daño por radiación sobre $\mathrm{Pd} @ \mathrm{~S}-\mathrm{SC}_{12}$ NPs estudiado por HAADF-STEM. (a, b) Imagen de HAADF-STEM y su transformada de Fourier antes de irradiar la muestra con un haz paralelo. (c, d) Imagen de la misma muestra y su transformada de Fourier luego de irradiarla con un haz paralelo (modo TEM). Escalas: $5 \mathrm{~nm}$.

oxidados presentes en las NPs. Este mismo comportamiento fue encontrado utilizando un microscopio JEOL 2010F, con un haz de electrones de $200 \mathrm{keV}$ (imágenes no mostradas aquí), energía con la cual no es posible desplazar átomos de Pd de las NPs pero sí, átomos de S (Fig. 6.19a, b).

En el caso de HAADF-STEM, no se observó esta cristalización de las partículas aun luego de irradiarlas durante un tiempo prologado con el haz de electrones convergente. Es decir, las imágenes mostradas en la Fig. 6.10d y 6.20a permanecieron invariantes bajo los efectos del haz durante el tiempo en que fueron estudiadas. Sin embargo, si se irradia estas NPs con un haz de electrones paralelo (modo TEM) y luego se observa su estructura con el haz convergente (modo STEM) nuevamente, se obtienen estructuras de átomos metálicos ordenados, como la que se muestra en las Fig. 6.20c, d. Esta imagen fue obtenida luego de irradiar durante 5 min la muestra con un haz de electrones paralelo. Este comportamiento indica que la naturaleza del haz de electrones utilizado (haz convergente o paralelo) tiene una gran influencia en el daño producido sobre la muestra. Esto es 
particularmente llamativo considerando que en modo STEM la dosis de electrones es de $\sim 3 \times 10^{8} \mathrm{e}^{-} \mathrm{nm}^{-2} \mathrm{~s}^{-1}$ (concentrado en un área de $7 \times 10^{-3} \mathrm{~nm}^{2}$ ) mientras que en TEM es de $3,7 \times 10^{5} \mathrm{e}^{-} \mathrm{nm}^{-2} \mathrm{~s}^{-1}$.

De esta forma, nuevamente hemos presentado un ejemplo en el que la observación de NPs en un microscopio electrónico distorsiona la estructura inicial de la muestra. Estos daños producidos por el haz de electrones deben ser tenidos en cuenta al caracterizar este tipo de muestras ya que pueden dar lugar a interpretaciones erróneas de las imágenes observadas.

\subsection{Conclusiones}

En este capítulo hemos estudiado la composición química y estructura de las PdNPs protegidas por alcanotioles. Hemos discutido los aspectos relevantes del proceso de síntesis de estas NPs por diferentes vías y la composición química de las mismas, obtenidas utilizando diversas técnicas sensibles a las distintas porciones de las partículas (XPS, EXAFS, FTIR, UV-vis). Por otro lado, hemos estudiado la estructura interna de las NPs y la influencia del agente protector en el orden de los átomos metálicos que la componen, tanto mediante técnicas experimentales (HRTEM y STEM) como simulaciones computacionales (dinámica de Langevin). Todo lo analizado respecto a las PdNPs fue contrastado con los sistemas con los mismos componentes pero en estructuras planas (SAMs de alcanotioles sobre Pd plano) y los sistemas equivalentes compuestos por el metal modelo (AuNPs protegidas por alcanotiolatos).

Respecto a la composición química de las $\mathrm{Pd} @ \mathrm{~S}-\mathrm{SC}_{12} \mathrm{NPs}$, hemos encontrado que tiene gran similitud con la descrita en el Cap. 5 para superficies planas de Pd modificadas con alcanotioles: los núcleos de Pd metálico se encuentran protegidos por una submonocapa de sulfuro y otra de alcanotiolatos con una pequeña cantidad de azufre en mayor estado de oxidación. Estos resultados fueron obtenidos a partir del análisis en conjunto de los datos de EXAFS, XPS y FTIR. Estas capas protectoras son de naturaleza superficial en las PdNPs no evidenciándose penetración de los átomos de $\mathrm{S}$ a partes muy internas de las partículas, como lo muestran los resultados de XPS utilizando radiación de luz sincrotrón de baja energía.

Las PdNPs obtenidas mediante intercambio de ligandos de alquilamina por alcanotioles exhiben una composición química similar a las PdNPs sintetizadas por el método de BrustSchiffrin. Este hecho, sumado al análisis de la banda de valencia de las Pd@S-SC 12 NPs y la discusión en este aspecto realizada para Pd plano (Sec. 5.9.3) nos permite inferir que en la síntesis Brust-Schiffrin se generan núcleos de $\mathrm{Pd}^{0}$ y luego las moléculas de alcanotioles se adsorben sobre su superficie y se produce la ruptura de enlaces $\mathrm{S}-\mathrm{C}$, lo que da origen al sulfuro presente en las partículas. Las moléculas de alcanotioles que se adsorben luego sobre las PdNPs pasivadas por los átomos de S no pueden ser disociadas y se adsorbe entonces una capa de alcanotiolatos.

De esta forma el modelo propuesto es similar al introducido por Murayama et ál. [221], en base a resultados de EXAFS, XRD y TEM. Nuestros resultados apoyan este modelo y aportan más detalles respecto a la relación entre las PdNPs y el sistema análogo plano. Por 
otro lado, se presenta gran cantidad de evidencia que muestra la incompatibilidad de los otros modelos propuestos con anterioridad y posterioridad al modelo de Murayama para describir las NPs utilizadas en este trabajo. El modelo de Sun et ál. de pequeños núcleos de $\mathrm{Pd}^{0}$ embebidos en una matriz de sulfuro de $\mathrm{Pd}$ [220] es inconsistente con las imágenes de HAADF-STEM obtenidas; el modelo de Zelakiewicz et ál. quienes proponen que las PdNPs están protegidas por moléculas de disulfuro de dialquilo [219] no se corresponde con los resultados de FTIR ni con los de XPS; los modelos análogos al de AuNPs protegidas por alcanotiolatos resultan incompatibles con los resultados de XPS y EXAFS [149, 215]; el modelo en el que se describe a las PdNPs completamente sulfidizadas [218], es incongruente con los resultados obtenidos mediante XPS utilizando radiación de luz sincrotrón.

En las imágenes de HAADF-STEM hemos observado una clara diferencia en el orden de los átomos de $\mathrm{Pd}$ en el núcleo metálico de las NPs protegidas por alquilaminas de las protegidas por alcanotioles. Mientras las primeras exhiben una estructura ordenada, las segundas presentan una estructura amorfa. Este comportamiento fue estudiado mediante simulaciones de dinámica de Langevin. Se propusieron 4 estructuras diferentes para estudiar el efecto de los diferentes posibles agentes protectores de las NPs en su estructura interna. Hemos demostrado que la capa de sulfuro presente en las PdNPs protegidas por sulfuro + tiolato ejerce un efecto muy importante en el desorden de los átomos metálicos. Este efecto es causado por la magnitud de la energía de enlace entre los átomos de $\mathrm{S}$ y Pd. Las simulaciones apoyan entonces el modelo de núcleos de Pd metálico cubiertos por sulfuro y tiolato. Si las PdNPs estuvieran cubiertas sólo por moléculas de tiolato, las imágenes de HRTEM y STEM evidenciarían una estructura metálica ordenada, como la obtenida en las simulaciones para la configuración hipotética de $\mathrm{Pd} @ \mathrm{SC}_{4}$.

Por otro lado, hemos estudiado el efecto que produce la radiación de electrones sobre la organización de los átomos metálicos en las $\mathrm{Pd} @ \mathrm{~S}-\mathrm{SC}_{12}$ NPs. Mediante HRTEM hemos encontrado que los electrones producen la cristalización de las PdNPs. Este efecto no fue observado en la irradiación mediante un haz de electrones convergente (modo STEM), solo con un haz de electrones paralelo (modo TEM). Esto indica que no sólo la dosis y el voltaje de aceleración del haz es importante al analizar el daño que este puede causar sobre la muestra.

En resumen, además de proponer un modelo para las PdNPs protegidas por alcanotioles en base a gran cantidad de evidencia experimental y de simulaciones tanto en las NPs como en la superficie de Pd plano hemos demostrado una vez más la necesidad de la combinación de diferentes técnicas para poder avanzar sobre la comprensión de este tipo de problemas. Además hemos discutido el daño que pueden producir sobre las muestras, diferentes técnicas ampliamente utilizadas en la caracterización de estos sistemas (como HRTEM y absorción de rayos X). La única forma de poder conocer estos daños es estudiar los sistemas mediante diferentes técnicas y conocer, en primera instancia, su composición química. Es importante conocer estos daños tanto para poder minimizarlos como para analizar los datos obtenidos correctamente. Estos resultados pueden ser interesantes no solo para conocer más detalles de las NPs metálicas y la relación de su composición y estructura con el método de síntesis sino también para su utilización en diferentes aplicaciones. 


\section{Parte IV}

\section{Parte final}





\section{Capítulo 7}

\section{Conclusiones generales y perspectivas}

En este trabajo de tesis hemos estudiado diferentes sistemas en los que se encuentra presente la interfase Au-tiol y Pd-tiol, cuyo estudio tiene interés, sobre todo, en la preparación de nanopartículas metálicas. Estos sistemas se extendieron desde las monocapas autoensambladas (SAMs) de tioles sobre superficies metálicas planas hasta las especies poliméricas de tiolatos metálicos. El problema se abordó mediante el estudio en conjunto de estas estructuras, proceso que permitió encontrar elementos en común entre ellas y sin el cual no hubiera sido posible el análisis puntual de cada caso.

Con respecto a la interfase $\mathrm{Au}$-tiol, hemos contrastado los resultados obtenidos mediante los dos métodos de síntesis de nanopartículas de Brust-Schiffrin: el método bifásico y el método de una fase. En este aspecto, hemos demostrado que las partículas preparadas con uno u otro método pueden tener características muy diferentes en relación a su composición química como también a su estructura. Esto indica que el mecanismo involucrado en la obtención de las nanopartículas metálicas y la naturaleza del tiol utilizado tienen gran influencia en el producto obtenido. Por otro lado, hemos estudiado la evolución de las nanopartículas de Au sobre grafeno. Hemos observado que las nanopartículas se ubican preferentemente sobre multicapas de grafeno o zonas con carbono amorfo. Además, hemos mostrado la gran influencia del haz de electrones sobre la estructura de estas partículas. Los resultados presentados en el Capítulo 4 muestran un ejemplo de la aplicación del método de Brust-Schiffrin de una fase. Allí discutimos los resultados obtenidos en la síntesis de nanopartículas de Au en presencia de ácido tiomálico. Contrariamente a lo que ocurre con alcanotioles en la síntesis bifásica, o con ciertos tioles en la síntesis monofásica, con este tiol ocurre una reducción parcial de los intermediarios de reacción que, por tratarse del método de una fase, consisten en tiolatos de $\mathrm{Au}(\mathrm{Au}-\mathrm{SR})$. Esta reducción incompleta produce núcleos de $\mathrm{Au}$ metálico rodeados por tiomalato de oro $(\mathrm{Au}-\mathrm{I} M)$ en una estructura del tipo carozo-coraza (core-shell) a la que llamamos $\mathrm{Au} @ \mathrm{Au}^{\mathrm{I}}$-TM. Adicionalmente, hemos propuesto que, debido a la relación entre el tiolato de oro encontrado en estas nanopartículas y las especies propuestas como protectoras en clusters de Au cubiertos por tioles, las nanopartículas de $\mathrm{Au} @ \mathrm{Au}^{\mathrm{I}}-\mathrm{TM}$ podrían ser consideradas de naturaleza inter- 
media entre los tiolatos de Au y las partículas protegidas por una monocapa de tiolatos. Estas, en lugar de evolucionar hacia la reducción total del $\mathrm{Au}{ }^{\mathrm{I}}$ para formar partículas de $\mathrm{Au}$ protegidas por una capa de tiolato, quedan atrapadas en una estructura compuesta por núcleos de Au metálico cubiertos por capas poliméricas de $\mathrm{Au}^{\mathrm{I}}-\mathrm{TM}$. Por último, presentamos un procedimiento para la reducción del tiomalato de Au mediante la inmersión de las nanopartículas en una solución de $p$-benzoquinona/hidroquinona y iones $\mathrm{Ag}^{+}$para formar nanopartículas bimetálicas. La descripción de la estructura y composición de las nanopartículas utilizadas fue posible gracias al estudio del sistema mediante diferentes técnicas, enfoque que fue utilizado a lo largo de todo este trabajo. La complejidad de estos sistemas y su sensibilidad en relación a los posibles daños asociados con las diferentes técnicas de caracterización utilizadas, hace indispensable su estudio desde diferentes perspectivas.

El aporte más importante en lo que respecta a la interfase Au-tiol está referido a la caracterización de la naturaleza química de las nanopartículas cubiertas por tioles en las que se produce una reducción parcial de los intermediarios de reacción. Si bien este comportamiento ha sido planteado especulativamente en trabajos anteriores como un hecho posible para comprender las propiedades de lo productos obtenidos, su caracterización completa mediante diferentes métodos, no ha sido informada anteriormente en la bibliografía.

En lo que respecta a la interfase Pd-tiol, debido a la poca información disponible en la literatura, comenzamos por el estudio de la adsorción de alcanotioles sobre superficies planas de $\mathrm{Pd}$. Hemos obtenido resultados de espectroscopía de fotoelectrones generados por rayos X (XPS) similares a los reportados anteriormente, que proponen que las interfases formadas están compuestas por una capa de sulfuro de Pd sobre la que se adsorben alcanotiolatos. Hemos profundizado el análisis de los resultados de XPS para calcular los cubrimientos relativos de las especies de azufre sobre Pd. Adicionalmente, hemos estudiado la adsorción de tioles sobre superficies bimetálicas de $\mathrm{Pd}-\mathrm{Au}(111)$. En estas superficies, la cantidad de sulfuro encontrada fue menor que en las superficies monometálicas, lo que indica la influencia de las capas de Pd internas en la composición de la superficie.

Un aspecto central en el estudio de las capas formadas por adsorción de alcanotioles sobre Pd plano fue el análisis de su estabilidad en soluciones acuosas alcalinas. Esto no fue posible mediante el análisis de los picos de electrodesorción reductiva -utilizado en otros metales, como $\mathrm{Au} \mathrm{y} \mathrm{Ag-} \mathrm{debido} \mathrm{a} \mathrm{que} \mathrm{no} \mathrm{se} \mathrm{observan} \mathrm{en} \mathrm{el} \mathrm{caso} \mathrm{del} \mathrm{Pd} \mathrm{por} \mathrm{encontrarse,} \mathrm{el}$ proceso de desorción, solapado con las reacciones de adsorción, absorción y desprendimiento de hidrógeno. Por tal motivo, hemos analizado la capacidad de interfase de los sustratos de Pd modificados con diferentes alcanotioles, luego de aplicarles distintos potenciales. En estos experimentos encontramos que la electrodesorción de la capa de sulfuro-tiolato en soluciones alcalinas se produce a potenciales más negativos que en el caso del Au. Además se observó que este potencial es prácticamente independiente de la longitud de la cadena hidrocarbonada del alcanotiol, indicando que la capa de sulfuro ejerce un rol preponderante en la estabilidad de estos sistemas. De hecho, la electrodesorción reductiva de una capa de sulfuro formada sobre Pd ocurre en la misma zona de potencial que en el caso de los sustratos de Pd modificados con alcanotioles.

Los cálculos realizados sobre estos sistemas, basados en la teoría del funcional de 
densidad y la termodinámica estadística desde primeros principios, mostraron que una capa mixta de sulfuro y tiolato es la estructura más estable en las condiciones experimentales, en lugar de una capa compuesta sólo por tiolato o sulfuro. Las estructuras propuestas para esta capa muestran una gran reconstrucción de la superficie de Pd y la formación de estructuras del tipo RS-Pd-SR, similares a las propuestas para clusters y superficies planas de $\mathrm{Au}$, comentadas en el Capítulo 4. Además, mediante el estudio de la estructura electrónica de estos sistemas, hemos propuesto un mecanismo que explica el origen del sulfuro en estos sistemas, basado en el análisis de la interacción adsorbato-sustrato.

En el siguiente paso para la interfase Pd-tiol, hemos estudiado las nanopartículas de Pd cubiertas por dodecanotiol. Presentamos los detalles de la síntesis de estas partículas mediante el método de Brust-Schiffrin de dos fases y estudiamos la naturaleza de los productos mediante una variedad de técnicas, analizando asimismo cómo influyen las condiciones experimentales durante la preparación de las muestras.

A diferencia del $\mathrm{Au}$, sólo es posible la síntesis de estas nanopartículas si la relación molar tiol:Pd es menor a la unidad. En los otros casos se obtienen productos donde existe una mezcla de nanopartículas y complejos formados entre $\mathrm{Pd}^{\mathrm{II}}$ y las moléculas de tiol o bien solo estos complejos. Los resultados presentados muestran la gran similitud en la composición química de estas nanopartículas con las superficies de Pd plano, lo que indica que la superficie de ambos sistemas debe ser similar. Esta composición también coincide con la hallada en nanopartículas preparadas por intercambio de ligandos. La utilización de radiación de luz sincrotrón en estudios de XPS permitió definir el carácter superficial de las especies de azufre en estas partículas, descartando así los modelos que han propuesto una sulfidización completa de las mismas. Los diferentes modelos planteados con anterioridad para estas nanopartículas han sido contrastados con los resultados obtenidos en este trabajo. El modelo que hemos propuestos consta de un núcleo de Pd metálico sobre el que se adsorben átomos de $\mathrm{S}$ en la forma de sulfuro, con cubrimientos en el orden de submonocapas y, sobre esta capa, se ubican los alcanotiolatos. Hemos planteado también un posible esquema de reacción para la síntesis de estas nanopartículas en base a los productos obtenidos y al análisis de la estructura electrónica de las superficies planas de Pd.

Luego, hemos realizado un estudio de la influencia de las moléculas protectoras en el orden de los átomos metálicos que componen las nanopartículas en base al análisis de imágenes de STEM. Hemos observado que las nanopartículas cubiertas con tioles presentan una estructura desordenada mientras que átomos metálicos en las partículas protegidas con aminas poseen un orden establecido. Hemos interpretado estas diferencias en base a simulaciones atomísticas de dinámica de Langevin. Los resultados indican que el desorden de los átomos es causado por la presencia de la capa de sulfuro en estas partículas debido a la gran energía de enlace de estas especies al Pd. Este es otro ejemplo donde se evidencia la importancia de la capa de sulfuro en las propiedades de estas nanopartículas. Hemos estudiado también el daño producido por un haz de electrones sobre estas nanopartículas y hemos propuesto un mecanismo por el cual pueden observarse estructuras cristalinas en las nanopartículas de Pd protegidas por tioles al ser analizadas mediante microscopía electrónica. 
En forma más general, podemos concluir que aunque muchos de estos sistemas se creían muy bien conocidos, diversos trabajos recientes, comentados a lo largo del texto, y algunos resultados presentados en este manuscrito han demostrado lo contrario. Hemos aportado algunos detalles nuevos acerca de la composición química y estructura de estos sistemas y aún resta mucho trabajo a realizar para llegar a una comprensión más detallada de ellos. Hemos mostrado también la necesidad de atacar estos problemas mediante la utilización de diferentes técnicas experimentales y teóricas en forma conjunta. Por último, hemos comentado en diferentes partes del texto los distintos daños relacionados con las técnicas de caracterización utilizadas.

Debido al interés por estudiar el comportamiento general de estos sistemas más que el detalle particular de pocos casos, el análisis de ellos puede haber sido incompleto. Por lo tanto, resultaría interesante continuar la investigación en distintos campos, como los que se comentan a continuación.

Sería interesante realizar un estudio más detallado de los procesos que ocurren luego del agregado del reductor, en la síntesis de las nanopartículas de $\mathrm{Au} @ \mathrm{Au}^{\mathrm{I}}-\mathrm{TM}$. Este estudio podría ser desarrollado mediante técnicas in situ que permitan analizar características electrónicas y químicas (como absorción de rayos X) y estructurales (como la dispersión de rayos $\mathrm{X}$ a bajo ángulo). Estudios de este tipo han sido realizados sobre nanopartículas cubiertas con citrato [5] pero, según nuestro conocimiento, aún no fueron aplicados a la síntesis de Brust-Schiffrin. Algunas preguntas para responder en estos sistemas serían las siguientes. ¿Las especies $\left[\mathrm{Au}^{\mathrm{I}}-\mathrm{TMA}\right]_{n}$ son reducidas parcialmente, o se produce la reducción total de ellas en una primera etapa y luego el sistema evoluciona hacia la situación inicial? ¿Cuál es la influencia del borohidruro de sodio y el oxígeno presente en el medio de reacción en los productos finales obtenidos?. Por otro lado, sería interesante estudiar el mecanismo por el cual es generado el sulfuro presente en estas nanopartículas, que muy probablemente provenga de la descomposición de ácido tiomálico en la superficie de los núcleos de $\mathrm{Au}$.

En el sistema de Pd metálico sería muy interesante la realización de cálculos de dinámica molecular ab initio referidos al proceso de adsorción de las moléculas de tiol en la superficie de Pd. De esta manera, sería posible el seguimiento de la estructura electrónica y geométrica de la interfase Pd-tiol a lo largo del tiempo de simulación, lo que haría posible una correlación entre estas dos medidas para una interpretación más detallada de todo este proceso. Otro aspecto interesante para estudiar en este sistema es la adsorción de alcanotioles sobre un monocristal de $\mathrm{Pd}(111)$ desde fase gaseosa para el estudio de su composición química superficial y su estructura electrónica mediante XPS de alta resolución, utilizando fotones de baja energía para aumentar la sensibilidad superficial. Esto permitiría un control muy preciso del estado inicial de la superficie de Pd, antes del agregado del tiol, como así también de la temperatura en todo el proceso, desde la preparación de la muestra hasta el análisis superficial. Además, al tener una superficie bien definida, resultaría también interesante el estudio de las estructuras superficiales del tiol mediante microscopía de barrido de efecto túnel (STM). Por último, el estudio de este sistema mediante XPS a alta presión permitiría el seguimiento in situ del proceso de adsorción de tioles sobre Pd, mediante el estudio de la composición química (análisis del espectro de niveles internos) 
y la estructura electrónica (espectro de la banda de valencia). Esto sería especialmente interesante para obtener más detalles de los estadios iniciales del proceso de adsorción. Un problema aparejado a estos experimentos es que la utilización de tioles en las cámaras de ultra alto vacío es muchas veces evitado debido a la dificultad en su eliminación luego de la preparación de la muestra. Este inconveniente es más importante al incrementarse el largo de las cadenas hidrocarbonadas. Por este motivo, estos experimentos solo pueden llevarse a cabo utilizando tioles de cadena corta, como propanotiol.

Respecto a las nanopartículas de Pd, sería muy interesante estudiar en detalle la relación entre la razón tiol:Pd utilizada y los productos obtenidos, aspecto muy cercano a lo comentado antes para las nanopartículas de $\mathrm{Au} @ \mathrm{Au} \mathrm{u}^{\mathrm{I}}-\mathrm{TM}$. Otro aspecto interesante por estudiar es la relación entre los productos obtenidos y la temperatura a la que se realiza la síntesis. En el caso de bajas temperaturas se ha informado la formación de nanopartículas de mayor cristalinidad que aquellas preparadas a temperatura ambiente [209], lo que sugiere que no se formó sulfuro de Pd. Por otra parte, a través del análisis de nanopartículas preparadas a temperaturas mayores que la ambiente se ha informado la sulfidización completa de estos materiales [218, 224]. 


\section{Apéndice A}

\section{Cálculo del potencial químico a partir de la función de partición}

En el Cap. 5 se realizó un estudio de la estabilidad de diferentes estructuras de alcanotioles y azufre sobre $\operatorname{Pd}(111)$ en función del potencial químico de tioles en un reservorio. Para poder relacionar los valores de potencial químico con valores de presión y temperatura (realizado en la Sec. 5.9.4) es necesario conocer el potencial químico del dimetil disulfuro $\left(\mathrm{CH}_{3} \mathrm{~S}\right)_{2}$ en el estado estándar. En este apéndice desarrollaremos las ecuaciones necesarias para llegar a una expresión para la obtención de este potencial químico en fase gaseosa y en solución.

\section{A.1 Potencial químico de $\left(\mathrm{CH}_{3} \mathrm{~S}\right)_{2}$ en fase gaseosa}

El potencial químico $\mu$ en estado estándar por molécula para el dimetil disulfuro fue calculado a partir de la función de partición, considerando un gas poliatómico ideal, en el ensamble canónico:

$$
\mu=\left(\frac{\partial A}{\partial N}\right)_{T, V}=-k T\left(\frac{\partial \ln Q}{\partial N}\right)_{T, V}
$$

donde $A=-k T \ln Q$ es la energía libre de Helmholtz, $k$ es la constante de Boltzmann y $Q(N, V, T)$ es la función de partición del ensamble canónico. Para un sistema de $N$ moléculas independientes e indistiguibles, que cumplan con la condición de que el número de estados moleculares disponibles es mucho mayor que $N$, se cumple [251]:

$$
Q(N, V, T)=\frac{1}{N !}[q(V, T)]^{N}
$$

donde $q(V, T)$ es la función de partición molecular. Entonces,

$$
\mu=-k T\left[\frac{\partial \ln \left(q^{N} / N !\right)}{\partial N}\right]_{T, V}
$$

Utilizando la aproximación de Stirling para $N$ ! se obtiene:

$$
\ln \left(q^{N} / N !\right)=N \ln q-N \ln N+N
$$


y sustituyendo este valor en la Ec. A.3, obtenemos:

$$
\begin{aligned}
\mu & =-k T(\ln q-\ln N+1-1) \\
& =-k T \ln \left(\frac{q}{N}\right)
\end{aligned}
$$

Si se multiplica y divide por el volumen $V$ y se aplica la ecuación de estado para un gas ideal $p V=N k T$ :

$$
\begin{aligned}
\mu & =-k T \ln \left(\frac{q}{V} \frac{V}{N}\right) \\
& =-k T \ln \left[\left(\frac{q}{V}\right) \frac{k T}{p}\right]
\end{aligned}
$$

Como la presión siempre se expresa referida la presión del estado estándar $p^{\circ}$, resulta conveniente multiplicar y dividir por $p^{\circ}$ :

$$
\mu=-k T \ln \left[\left(\frac{q}{V}\right) \frac{k T}{p} \frac{p^{\circ}}{p^{\circ}}\right]
$$

reordenando:

$$
\mu=-k T\left[\left(\frac{q}{V}\right) \frac{k T}{p^{\circ}}\right]+k T \ln \left(\frac{p}{p^{\circ}}\right)
$$

Si comparamos esta ecuación con la ecuación para el potencial químico de un gas ideal:

$$
\mu(T, p)=\mu^{\circ}\left(T, p^{\circ}\right)+k T \ln \left(\frac{p}{p^{\circ}}\right)
$$

resulta evidente que:

$$
\mu^{\circ}\left(T, p^{\circ}\right)=-k T \ln \left[\left(\frac{q}{V}\right) \frac{k T}{p^{\circ}}\right]
$$

Para el caso del dimetil disulfuro $\left(\mathrm{CH}_{3} \mathrm{~S}\right)_{2}$, la ecuación correspondiente sería:

$$
\mu_{\left(\mathrm{CH}_{3} \mathrm{~S}\right)_{2}}^{\circ}\left(T, p^{\circ}\right)_{\text {gas }}=-k T \ln \left[\left(\frac{q}{V}\right) \frac{k T}{p^{\circ}}\right]
$$

Por lo tanto, lo siguiente consiste en encontrar una expresión para la evaluación de $(q / V)$. Teniendo en cuenta que:

$$
q(V, T)=\sum_{j} e^{\epsilon_{j} / k T}
$$

una aproximación importante consiste en expresar cada energía del nivel $j\left(\epsilon_{j}\right)$ como una suma de contribuciones separadas de energías traslacional $(t)$, rotacional $(r)$, vibracional $(v)$ y electrónica $(e)$. Esto es posible debido a que el Hamiltoniano para una molécula, es por lo menos, aproximadamente separable y sólo es válido si se considera accesible un solo estado electrónico (en este caso el fundamental):

$$
\begin{gathered}
H=H_{t}+H_{r}+H_{v}+H_{e} \\
\epsilon=\epsilon_{t}+\epsilon_{r}+\epsilon_{v}+\epsilon_{e}
\end{gathered}
$$


De esta forma entonces podemos expresar la función de partición molecular de la siguiente manera:

$$
q=q_{t} q_{r} q_{v} q_{e}
$$

Por lo tanto, debemos encontrar las expresiones para $q_{t}, q_{r}, q_{v}$ y $q_{e}$.

A partir de los posibles estados energéticos para una partícula en una caja tridimensional, obtenidos a partir de la resolución de la ecuación de Schrödinger, es posible obtener una expresión para la función de partición molecular traslacional, considerando el movimiento del centro de masa de la molécula con 3 grados de libertad [251]:

$$
q_{t}(V, T)=\left[\frac{2 \pi\left(\sum_{i} m_{i}\right) k T}{h^{2}}\right]^{3 / 2} V
$$

donde $\sum_{i} m_{i}$ es suma de las masas de todos los átomos de la molécula para dar la masa molecular $(m)$ y $h$ es la constante de Planck.

Debido a la complejidad de un tratamiento cuántico para la evaluación de los niveles energéticos rotacionales, consideramos el caso clásico que resulta apropiado para la molécula de nuestro interés [251]. Entonces, la función de partición molecular rotacional se define como:

$$
q_{r}(T)=\frac{\pi^{1 / 2}}{\sigma}\left(\frac{8 \pi^{2} I_{A} k T}{h^{2}}\right)^{1 / 2}\left(\frac{8 \pi^{2} I_{B} k T}{h^{2}}\right)^{1 / 2}\left(\frac{8 \pi^{2} I_{C} k T}{h^{2}}\right)^{1 / 2}
$$

donde $I$ es el momento de inercia alrededor del centro de masa de la molécula y $\sigma$ es el número de simetría que se introduce para corregir el conteo repetido de configuraciones indistinguibles [251]. Para el caso de $\left(\mathrm{CH}_{3} \mathrm{~S}\right)_{2}, \sigma=2$. La Ec. A.16 se puede escribir también de la siguiente manera:

$$
q_{r}(T)=\frac{\pi^{1 / 2}}{\sigma}\left(\frac{T^{3}}{\Theta_{A} \Theta_{B} \Theta_{C}}\right)^{1 / 2}
$$

donde $\Theta_{A, B, C}$ es la temperatura característica de la rotación y se define como:

$$
\Theta_{A, B, C}=\frac{h^{2}}{8 \pi^{2} I_{A, B, C} k}
$$

Para la molécula de $\left(\mathrm{CH}_{3} \mathrm{~S}\right)_{2}$, se utilizaron los siguientes valores obtenidos de los cálculos de DFT: $\Theta_{A}=0,53683 \mathrm{~K}, \Theta_{B}=0,12641 \mathrm{~K}, \Theta_{C}=0,10519 \mathrm{~K}$.

Si utilizamos la aproximación del oscilador armónico, la energía de vibración de un modo normal en el nivel $v$ es igual a [252]:

$$
\epsilon_{v_{v}}=\left(v+\frac{1}{2}\right) h \nu
$$

Por lo tanto, la función de partición vibracional de un modo normal de vibración es la siguiente [251]:

$$
q_{v_{m . n .}}=\sum_{v=0}^{\infty} e^{-\epsilon_{v_{v}} / k T}=\sum_{v=0}^{\infty} e^{-\left(v+\frac{1}{2}\right) h \nu / k T}=e^{-\frac{1}{2} h \nu / k T} \sum_{v=0}^{\infty}\left(e^{-h \nu / k T}\right)^{v}
$$


Mediante el desarrollo en serie $\sum_{n=0}^{\infty} x^{n}=\frac{1}{1-x}$ para $|x|<1$, con $x=e^{-h \nu / k T}$ y $n=v$ obtenemos:

$$
q_{v_{m . n .}}=\frac{e^{-\frac{1}{2} h \nu / k T}}{1-e^{-h \nu / k T}}
$$

Si consideramos ahora la energía vibracional $\epsilon_{v}$ de una molécula no lineal que contiene $\mathcal{N}$ átomos, la energía de vibración está dada por la siguiente expresión:

$$
\epsilon_{v}=\sum_{i=1}^{3 \mathcal{N}-6}\left(v_{i}+\frac{1}{2}\right) h \nu_{i}
$$

donde $\nu_{i}$ es la frecuencia del $i$-ésimo modo normal de vibración de la molécula y $v_{i}$ es su número cuántico. Si comparamos esta ecuación con la Ec. A.19, vemos que la energía vibracional de la molécula es la suma de las energías independientes de cada modo normal. Entonces, la función de partición vibracional será el producto de las funciones de partición de cada modo normal [251, 252]:

$$
q_{v}(T)=q_{v_{1}} q_{v_{2}} \ldots q_{v_{3 \mathcal{N}-6}}=\prod_{i=1}^{3 \mathcal{N}-6} \frac{e^{-h \nu_{i} / 2 k T}}{1-e^{-h \nu_{i} / k T}}
$$

Las $3 \mathcal{N}-6=24$ frecuencias vibracionales calculadas para $\left(\mathrm{CH}_{3} \mathrm{~S}\right)_{2}$ son las siguientes (en $\mathrm{meV}): 382,41 ; 382,06 ; 380,05 ; 379,67 ; 370,18 ; 369,35 ; 177,33 ; 177,01 ; 175,13 ; 174,29 ; 159,6$; 158,$85 ; 122,68 ; 115,0 ; 114,58 ; 114,57 ; 82,21 ; 82,03 ; 61,41 ; 32,09,31,76 ; 19,94 ; 16,91 ; 14,93$.

La función de partición electrónica puede ser escrita de la siguiente forma [253]:

$$
q_{e}(T)=\sum_{j=0}^{\infty} \omega_{e_{j}} e^{-\epsilon_{e_{j}} / k t}
$$

donde $\omega_{e_{j}}$ y $\epsilon_{e_{j}}$ son la degeneración y la energía del estado $j$-ésimo, respectivamente. Para la mayoría de las moléculas $\epsilon_{e_{1}} \gg k T$ a temperaturas cercanas a la temperatura ambiente. Por lo tanto, consideramos sólo el estado fundamental (no degenerado para este caso) y obtenemos la siguiente expresión:

$$
q_{e}(T)=e^{-\epsilon_{e_{0}} / k t}
$$

Combinando las ecuaciones A.14, A.15, A.17, A.23 y A.25, obtenemos la expresión $\operatorname{para}(q / V)$ :

$$
\frac{q}{V}=\left[\left(\frac{2 \pi m k T}{h^{2}}\right)^{3 / 2}\right]\left[\frac{\pi^{1 / 2}}{\sigma}\left(\frac{T^{3}}{\Theta_{A} \Theta_{B} \Theta_{C}}\right)^{1 / 2}\right]\left[\prod_{i=1}^{3 \mathcal{N}-6} \frac{e^{-h \nu_{i} / 2 k T}}{1-e^{-h \nu_{i} / k T}}\right] e^{-\epsilon_{e_{0}} / k t}
$$

Debido a que:

$$
\mu_{\mathrm{MT}}=\frac{1}{2} \mu_{\left(\mathrm{CH}_{3} \mathrm{~S}\right)_{2}}
$$

y a partir de la Ec. A.11, obtenemos:

$$
\mu_{\mathrm{MT}}(T, p)=-\frac{1}{2} k T \ln \left[\left(\frac{q}{V}\right) \frac{k T}{p^{\circ}}\right]+\frac{1}{2} k T \ln \left(\frac{p_{\left(\mathrm{CH}_{3} \mathrm{~S}\right)_{2}}}{p^{\circ}}\right)
$$


De esta forma, podemos introducir la Ec. A.26 en la Ec. A.28 para calcular el potencial químico del metanotiol:

$$
\begin{array}{r}
\mu_{\mathrm{MT}}(T, p)= \\
-\frac{1}{2} k T \ln \left\{\left[\left(\frac{2 \pi m k T}{h^{2}}\right)^{3 / 2}\right]\left[\frac{\pi^{1 / 2}}{\sigma}\left(\frac{T^{3}}{\Theta_{A} \Theta_{B} \Theta_{C}}\right)^{1 / 2}\right]\left[\prod_{i=1}^{3 \mathcal{N}-6} \frac{e^{-h \nu_{i} / 2 k T}}{1-e^{-h \nu_{i} / k T}}\right] e^{-\epsilon_{e_{0}} / k t} \frac{k T}{p^{\circ}}\right\} \\
+\frac{1}{2} k T \ln \left(\frac{p_{\left(\mathrm{CH}_{3} \mathrm{~S}\right)_{2}}}{p^{\circ}}\right)
\end{array}
$$

Resolviendo el logaritmo del producto como la suma de logaritmos, obtenemos:

$$
\begin{aligned}
& \mu_{\mathrm{MT}}(T, p)=-\frac{1}{2} k T \ln \left[\left(\frac{2 \pi m k T}{h^{2}}\right)^{3 / 2} \frac{k T}{p^{\circ}}\right]-\frac{1}{2} k T \ln \left[\frac{\pi^{1 / 2}}{\sigma}\left(\frac{T^{3}}{\Theta_{A} \Theta_{B} \Theta_{C}}\right)^{1 / 2}\right] \\
&+\frac{1}{2} \sum_{i=1}^{3 \mathcal{N}-6}\left(\frac{h \nu_{i}}{2}\right)+\frac{1}{2} k T \sum_{i=1}^{3 \mathcal{N}-6} \ln \left(1-e^{-h \nu_{i} / k T}\right)+\frac{\epsilon_{e_{0}}}{2} \\
&+\frac{1}{2} k T \ln \left(\frac{p_{\left(\mathrm{CH}_{3} \mathrm{~S}\right)_{2}}}{p^{\circ}}\right)
\end{aligned}
$$

donde los siguientes datos son obtenidos a partir de los cálculos de DFT:

$$
\begin{aligned}
\sum_{i=1}^{3 \mathcal{N}-6}\left(\frac{h \nu_{i}}{2}\right) & =E_{\left(\mathrm{CH}_{3} \mathrm{~S}\right)_{2}}^{\mathrm{ZPE}} \equiv \text { energía de punto cero (zero-point energy) } \\
\epsilon_{e_{0}} & =E_{\left(\mathrm{CH}_{3} \mathrm{~S}\right)_{2}} \equiv \text { energía electrónica total }
\end{aligned}
$$

Por lo tanto:

$$
\begin{aligned}
\mu_{\mathrm{MT}}(T, p) & =\frac{1}{2} \mu_{\left(\mathrm{CH}_{3} \mathrm{~S}\right)_{2}}^{\circ}(T=0 \mathrm{~K})+\frac{1}{2} \mu_{\left(\mathrm{CH}_{3} \mathrm{~S}\right)_{2}}^{\ominus}\left(T, p^{\circ}\right)+\frac{1}{2} k T \ln \left(\frac{p_{\left(\mathrm{CH}_{3} \mathrm{~S}\right)_{2}}}{p^{\circ}}\right) \\
& =\frac{1}{2} E_{\left(\mathrm{CH}_{3} \mathrm{~S}\right)_{2}}+\frac{1}{2} E_{\left(\mathrm{CH}_{3} \mathrm{~S}\right)_{2}}^{\mathrm{ZPE}}+\frac{1}{2} \mu_{\left(\mathrm{CH}_{3} \mathrm{~S}\right)_{2}}^{\ominus}\left(T, p^{\circ}\right)+\frac{1}{2} k T \ln \left(\frac{p_{\left(\mathrm{CH}_{3} \mathrm{~S}\right)_{2}}}{p^{\circ}}\right)
\end{aligned}
$$

donde se definió un potencial químico del estado estándar $\mu^{\ominus}$ para diferenciarlo de $\mu^{\circ}$, utilizado anteriormente. Este potencial químico considera solamente los términos de $\mu^{\circ}$ que dependen de la temperatura $T$. Es decir que en este nuevo estado estándar la energía de punto cero y la energía electrónica son iguales a cero. Se define de la siguiente manera:

$$
\begin{array}{r}
\mu_{\left(\mathrm{CH}_{3} \mathrm{~S}\right)_{2}}^{\ominus}\left(T, p^{\circ}\right)=-k T \ln \left[\left(\frac{2 \pi m k T}{h^{2}}\right)^{3 / 2} \frac{k T}{p^{\circ}}\right]-k T \ln \left[\frac{\pi^{1 / 2}}{\sigma}\left(\frac{T^{3}}{\Theta_{A} \Theta_{B} \Theta_{C}}\right)^{1 / 2}\right] \\
+k T \sum_{i=1}^{3 \mathcal{N}-6} \ln \left(1-e^{-h \nu_{i} / k T}\right)
\end{array}
$$

En este punto, es posible definir la cantidad $\Delta \mu_{\mathrm{MT}}$ que considera las contribuciones al potencial químico de los grados de libertad traslacionales, vibracionales y rotacionales que dependen de la temperatura y la presión:

$$
\Delta \mu_{\mathrm{MT}}(T, p)=\frac{1}{2} \mu_{\left(\mathrm{CH}_{3} \mathrm{~S}\right)_{2}}^{\ominus}\left(T, p^{\circ}\right)+\frac{1}{2} k T \ln \left(\frac{p_{\left(\mathrm{CH}_{3} \mathrm{~S}\right)_{2}}}{p^{\circ}}\right)
$$


De esta manera, es posible entonces calcular el potencial químico del metanotiol mediante la siguiente expresión:

$$
\mu_{\mathrm{MT}}(T, p)=\frac{1}{2} E_{\left(\mathrm{CH}_{3} \mathrm{~S}\right)_{2}}+\frac{1}{2} E_{\left(\mathrm{CH}_{3} \mathrm{~S}\right)_{2}}^{\mathrm{ZPE}}+\Delta \mu_{\mathrm{MT}}(T, p)
$$

La definición de $\mu_{\left(\mathrm{CH}_{3} \mathrm{~S}\right)_{2}}^{\ominus}\left(T, p^{\circ}\right)$, permite calcularlo a partir de valores de entalpía y entropía encontrados en tablas de termoquímica, en lugar de hacerlo mediante la Ec. A.35, ya que:

$$
\mu_{\left(\mathrm{CH}_{3} \mathrm{~S}\right)_{2}}^{\ominus}\left(T, p^{\circ}\right)=\mu_{\left(\mathrm{CH}_{3} \mathrm{~S}\right)_{2}}\left(T, p^{\circ}\right)-\mu_{\left(\mathrm{CH}_{3} \mathrm{~S}\right)_{2}}\left(T=0 \mathrm{~K}, p^{\circ}\right)
$$

Sin embargo, en este trabajo $\mu_{\left(\mathrm{CH}_{3} \mathrm{~S}\right)_{2}}^{\ominus}\left(T, p^{\circ}\right)$ fue calculado a partir de la Ec. A.35. Para $T=300 \mathrm{~K}$ y $p^{\circ}=10^{5} \mathrm{~Pa}$ se obtiene un valor de $\mu_{\left(\mathrm{CH}_{3} \mathrm{~S}\right)_{2}}^{\ominus}\left(T, p^{\circ}\right)_{\text {gas }}=-0,813 \mathrm{eV}$. Con este valor se pueden relacionar los datos de $\Delta \mu_{\mathrm{MT}}(T, p)$ con valores de presión y temperatura, utilizando la Ec. A.36, como se realizó en la Sec. 5.9.

\section{A.2 Potencial químico de $\left(\mathrm{CH}_{3} \mathrm{~S}\right)_{2}$ en solución}

Adicionalmente, se calculó el potencial químico del $\left(\mathrm{CH}_{3} \mathrm{~S}\right)_{2}$ en el estado estándar en solución, al que tomamos como la sustancia pura $\left(\mu_{\left(\mathrm{CH}_{3} \mathrm{~S}\right)_{2}}^{\ominus}(T, p)_{\text {liq }}=\mu_{\left(\mathrm{CH}_{3} \mathrm{~S}\right)_{2}}^{*}(T, p)_{\text {liq }}\right)$, para relacionar los cálculos teóricos con los experimentos de adsorción desde solución. A partir de la definición del potencial químico por molécula de una sustancia pura $i$, podemos escribir:

$$
\mu_{i}^{*} \equiv\left(\frac{\partial G}{\partial N_{i}}\right)_{T, p} \equiv G_{i}=H_{i}-T S_{i}
$$

donde $G_{i}$ es la energía libre de Gibbs por molécula de la sustancia pura $i, H_{i}$ es la entalpía por molécula de la sustancia $i$ y $S_{i}$ es la entropía por molécula de la sustancia $i$. Entonces, a partir de A.39, podemos relacionar los potenciales químicos del $\left(\mathrm{CH}_{3} \mathrm{~S}\right)_{2}$ en fase gaseosa y en fase líquida de la siguiente manera:

$$
\mu_{\left(\mathrm{CH}_{3} \mathrm{~S}\right)_{2}}^{*}(T, p)_{\text {liq }}=\mu_{\left(\mathrm{CH}_{3} \mathrm{~S}\right)_{2}}^{\ominus}\left(T, p^{\circ}\right)_{\text {gas }}+\left(H_{\text {liq }}^{\ominus}-H_{\text {gas }}^{\ominus}\right)-T\left(S_{\text {liq }}^{\ominus}-S_{\text {gas }}^{\ominus}\right)
$$

De esta forma, podemos aproximar esta ecuación para utilizar los datos disponibles en la bibliografía de las entalpías de formación de $\left(\mathrm{CH}_{3} \mathrm{~S}\right)_{2}$ en fase líquida y gaseosa [123] y de las entropías estándar de sulfuro de dimetilo, $\left(\mathrm{CH}_{3}\right)_{2} \mathrm{~S}$, en fase líquida y gaseosa [254]:

$$
\mu_{\left(\mathrm{CH}_{3} \mathrm{~S}\right)_{2}}^{*}(T, p)_{\text {liq }} \approx \mu_{\left(\mathrm{CH}_{3} \mathrm{~S}\right)_{2}}^{\ominus}\left(T, p^{\circ}\right)_{\text {gas }}+\left(\Delta_{\mathrm{f}} H_{\text {liq }}^{\ominus}-\Delta_{\mathrm{f}} H_{\text {gas }}^{\ominus}\right)-T\left(S_{\text {liq }}^{\ominus}-S_{\text {gas }}^{\ominus}\right)
$$

A $T=300 \mathrm{~K}$ se obtiene $\mu_{\left(\mathrm{CH}_{3} \mathrm{~S}\right)_{2} \text {, liq }}^{*}=-0,928 \mathrm{eV}$. Por lo tanto, considerando una solución ideal:

$$
\Delta \mu_{\mathrm{MT}}(T, p)_{\text {liq }}=\frac{1}{2} \mu_{\left(\mathrm{CH}_{3} \mathrm{~S}\right)_{2}}^{*}(T, p)_{\text {liq }}+\frac{1}{2} k T \ln \left(x_{\left(\mathrm{CH}_{3} \mathrm{~S}\right)_{2}}\right)
$$

En una solución etanólica de dimetil disulfuro diluida, como la utilizada típicamente para la adsorción de tioles en solución desde disulfuro $\left(1 \times 10^{-3} \mathrm{M}\right)$ [199], la fracción molar $x$ puede aproximarse de la siguente manera:

$$
x=\frac{n_{\mathrm{MT}} / V}{n_{\mathrm{MT}} / V+n_{\mathrm{EtOH}} / V} \approx \frac{n_{\mathrm{MT}} / V}{n_{\mathrm{EtOH}} / V}
$$


donde $n$ es el número de moles de cada especie y $V$ es el volumen de la solución (en $\mathrm{dm}^{3}$ ). Se aproxima el número de moles de etanol como el obtenido en estado puro $\left(n_{\mathrm{EtOH}} / V=\right.$ $\left.17,13 \mathrm{~mol} \mathrm{dm}^{-3}\right)$. 


\section{Apéndice B}

\section{Detalles experimentales de las síntesis de nanopartículas}

En este Apéndice describiremos los detalles experimentales de todas síntesis de NPs discutidas en este trabajo. Para las síntesis de AuNPs se utilizó $\mathrm{HAuCl}_{4}$ comercial (Aldrich, puriss) o el sintetizado en el laboratorio (véase Sec. 2.1.4).

\section{B.1 Síntesis de nanopartículas de Au cubiertas con dodeca- notiol (Au@SC $\mathrm{SP}_{12}$ NP)}

Este método fue discutido en el Cap. 3. Las $\mathrm{Au} @ \mathrm{SC}_{12}$ NPs fueron preparadas mediante el método bifásico de Brust-Schiffrin [14], siguiendo las modificaciones introducidas por Murray [76]. Las 3 muestras comentadas en el Cap. 3 tienen ciertas diferencias en su síntesis, por lo que se describe cada una por separado.

\section{B.1.1 Nanopartículas de $\mathrm{Au} @ \mathrm{SC}_{12}$ de $\langle D\rangle=3,9 \pm 0,6 \mathrm{~nm}$}

Esta síntesis se realizó a temperatura ambiente en un balón de vidrio. Se agregaron 0,4 mmol de $\mathrm{HAuCl}_{4}$ a $40 \mathrm{~mL}$ de una solución $25 \mathrm{mM}$ de ToABr (Aldrich, $99 \%$ ) en tolueno (relación molar ToABr:Au = 2,5:1). Se mezclaron las dos fases mediante agitación magnética vigorosa para favorecer la transferencia del $\mathrm{HAuCl}_{4}$ a la fase orgánica. Una vez que esta fase tomó color anaranjado rojizo y la fase acuosa se volvió incolora, se descartó la última y se agregaron 0,13 mmol de dodecanotiol (Aldrich, $97 \%$ ) en la fase orgánica utilizando una micro pipeta Hamilton (relación molar $\mathrm{SC}_{12}: \mathrm{Au}=1: 3$ ). El color de la solución no cambió considerablemente luego del agregado del tiol. Se continuó agitando esta solución por unos minutos y se agregaron $4 \mathrm{mmol}$ de $\mathrm{NaBH}_{4}$ desde una solución acuosa preparada justo antes de su uso (relación molar $\mathrm{NaBH}_{4}: \mathrm{Au}=10: 1$ ). La fase orgánica se volvió marrón oscura y la mezcla de reacción se agitó por $3 \mathrm{~h}$. Se descartó la fase acuosa proveniente de la solución de $\mathrm{NaBH}_{4}$ y se redujo el volumen de la fase orgánica mediante evaporación rotatoria $\mathrm{a} \sim 30^{\circ} \mathrm{C}$. El sólido marrón obtenido se dispersó en etanol absoluto y esta dispersión se sometió a ultrasonido por unos minutos para disolver los productos 
indeseados y las moléculas de tioles libres. Luego, se centrifugó la suspensión a $\sim 2000 \times \mathrm{g}$ para decantar las NPs. Se desechó el sobrenadante y se agregó etanol nuevamente. Este proceso se repitió 4 veces en total. Finalmente, se secaron las partículas bajo corriente de nitrógeno. Las partículas preparadas se disolvieron en tolueno y se almacenaron a $4{ }^{\circ} \mathrm{C}$ hasta su uso.

\section{B.1.2 Nanopartículas de $\mathrm{Au} @ \mathrm{SC}_{12}$ de $\langle D\rangle=3,0 \pm 0,9 \mathrm{~nm}$}

Esta síntesis se realizó seguiendo el mismo protocolo que la anterior. Las cantidades utilizadas fueron $0,4 \mathrm{mmol}$ de $\mathrm{HAuCl}_{4}, 25 \mathrm{~mL}$ de una solución $40 \mathrm{mM}$ de ToABr en tolueno (relación molar ToABr:Au = 2.5:1), 0,8 mmol de dodecanotiol (relación molar $\mathrm{SC}_{12}: \mathrm{Au}=$ 2:1) y 4 mmol de $\mathrm{NaBH}_{4}$ (relación molar $\mathrm{NaBH}_{4}: \mathrm{Au}=10: 1$ ). La solución se volvió color amarillo pálido a los pocos minutos del agregado del tiol debido a la reducción de Au ${ }^{\text {III }}$ $\mathrm{Au}^{\mathrm{I}}$. El lavado y almacenamiento de las partículas se realizó de igual manera a la explicada más arriba.

\section{B.1.3 Nanopartículas de $\mathrm{Au} @ \mathrm{SC}_{12}$ de $\langle D\rangle=2,5 \pm 0,6 \mathrm{~nm}$}

La síntesis de estas NPs fue realizada a $0{ }^{\circ} \mathrm{C}$, sumergiendo el balón donde se desarrolló la síntesis en un baño de hielo. El procedimiento es similar a los anteriores, utilizando las siguientes cantidades: $0,2 \mathrm{mmol}$ de $\mathrm{HAuCl}_{4}, 14,5 \mathrm{~mL}$ de una solución $34,3 \mathrm{mM}$ de ToABr en tolueno (relación molar ToABr:Au = 2.5:1), 0,8 mmol de dodecanotiol (relación molar $\left.\mathrm{SC}_{12}: \mathrm{Au}=4: 1\right)$ y 2 mmol de $\mathrm{NaBH}_{4}$ (relación molar $\mathrm{NaBH}_{4}: \mathrm{Au}=10: 1$ ). El lavado de estas partículas fue similar al realizado en las anteriores síntesis.

\section{B.2 Síntesis de nanopartículas de Au cubiertas con ácido $p$-mercaptobenzoico (Au@p-MBA NPs)}

Este método fue discutido en el Cap. 3. Para sintetizar estas NPs se utilizó el método Brust-Schiffrin de una fase [15] con las modificaciones de Jadzinsky et ál. [53]. La síntesis se realizó en una solución $27 \%$ de metanol y $73 \%$ de agua. Se preparó una solución de $\mathrm{HAuCl}_{4}$ 20,8 mM y una solución de $p$-MBA (Aldrich, 90\%) $20 \mathrm{mM}$ en $\mathrm{NaOH} 60 \mathrm{mM}$. Se mezclaron volúmenes correspondientes de cada solución, agua y metanol de manera tal de obtener $20 \mathrm{~mL}$ de una solución con una concentración final de $\mathrm{HAuCl}_{4} 1 \mathrm{mM}$ y $p$-MBA $4 \mathrm{mM}$. Esta solución se agitó durante aproximadamente $10 \mathrm{~h}$. En este proceso se forman las especies poliméricas de $\left[\mathrm{Au}^{\mathrm{I}}-p-\mathrm{MBA}\right]_{n}$ que producen que la solución tome un color amarillo pálido con cierto grado de turbidez producido por la baja solubilidad de los tiolatos de Au. Por último, se agregaron $444 \mu \mathrm{L}$ de una solución acuosa de $\mathrm{NaBH}_{4}$ $150 \mathrm{mM}$ (relación molar $\mathrm{NaBH}_{4}: \mathrm{Au}=3.3: 1$ ). Las NPs fueron lavadas con etanol mediante centrifugación/redispersión. 


\section{B.3 Síntesis de nanopartículas de de Au cubiertas con tio- malato de Au (Au@Au ${ }^{\mathrm{I}}-\mathrm{TM}$ NPs)}

Este método fue discutido en el Cap. 4. Para la síntesis de estas NPs se utilizó el método de Brust-Schiffrin de una fase [15] modificado por Chen y Kimura [112]. Se utilizó $\mathrm{HAuCl}_{4}$ sintetizado en el laboratorio y TMA (Fluka, $99 \%$ ). 19,7 mL de la solución acuosa de $\mathrm{HAuCl}_{4}$ (0,50 mmol) fueron mezclados con $100 \mathrm{~mL}$ de metanol. Luego, se agregaron 1,25 mmol de TMA (relación molar TMA:Au $=2,5: 1$ ) y se agitó por $5 \mathrm{~min}$. La solución se volvió color amarillo pálido debido a la reducción de $\mathrm{Au}^{\mathrm{III}} \mathrm{Au}^{\mathrm{I}}$, y el $\mathrm{pH}$ medido fue de 1,7. Posteriormente, se agregaron $10 \mathrm{~mL}$ de una solución $0,5 \mathrm{M}_{\text {de }} \mathrm{NaBH}_{4}$ (Fluka, $96 \%$ ). El valor del $\mathrm{pH}$ de la solución se incrementó hasta 8 , la solución se volvió marrón oscura inmediatamente y se observó la generación de un precipitado en la mezcla de reacción. La suspensión se agitó por $1 \mathrm{~h}$ y luego se centrifugó, se eliminó el sobrenadante y las partículas se lavaron mediante la rutina de centrifugación/redispersión con una mezcla $80 \%$ metanol, $20 \%$ agua 2 veces para eliminar las impurezas inorgánicas (sodio, cloruros, especies con boro). Seguidamente, se lavaron 3 veces con metanol para eliminar las moléculas de tiol libre. Finalmente, las NPs fueron redispersadas en etanol y secadas bajo corriente de nitrógeno. Las NPs fueron almacenadas en forma de polvo hasta su uso. Estas partículas son dispersables en agua fácilmente.

\section{B.4 Síntesis de nanopartículas de Pd cubiertas con dodeca- notiol (Pd@SC 12 NPs)}

Este método fue discutido en el Cap. 6. Las NPs fueron sintetizadas mediante el método de Brust-Schiffrin [14] modificado por Zamborini et ál. [65]. Se realizaron diferentes síntesis, utilizando distintas cantidades de reactivos, aunque la misma proporción entre ellos y condiciones de síntesis similares a las comentadas para las AuNPs. Se disolvió $\mathrm{PdCl}_{2}$ (Aldrich, purum) en agua con un exceso molar de $\mathrm{HCl}$ de 4:1 para formar $\left[\mathrm{PdCl}_{4}\right]^{2-}$, el cual fue transferido a la fase tolueno mediante $\mathrm{ToABr}$ con agitación fuerte (relación molar ToABr:Pd = 1.5:1). La fase tolueno se tornó color rojo fuerte al transferir todo el $\left[\mathrm{PdCl}_{4}\right]^{2-}$ mientras que la fase acuosa se volvió incolora. Se descartó la fase acuosa y se agregó dodecanotiol (Aldrich, $97 \%$ ). La razón molar de RSH:Pd utilizada para la síntesis de las NPs fue de 0,5:1. Luego de agitar la mezcla por $1 \mathrm{~h}$, se agregó una solución de $\mathrm{NaBH}_{4}$ (Aldrich, $99 \%$ ) de preparación reciente en una relación molar $\mathrm{NaBH}_{4}: \mathrm{Pd}$ de 10:1

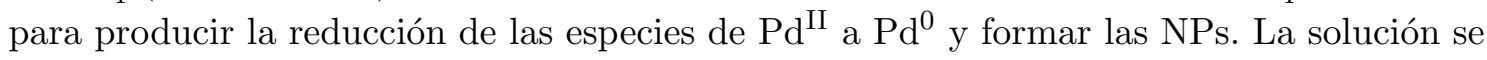
tornó negra inmediatamente. Luego de agitar durante otras $3 \mathrm{~h}$, se descartó la fase acuosa proveniente de la solución de $\mathrm{NaBH}_{4}$ y se redujo el volumen de tolueno en rotavapor a temperatura ambiente. Las partículas fueron lavadas con acetonitrilo mediante una rutina de centrifugación/redispersión repetida 4 veces. 


\section{B.5 Síntesis de nanopartículas de Pd cubiertas con dodecil- amina $\left(\mathrm{Pd} @ \mathrm{NC}_{12}\right.$ NPs)}

Este método fue discutido en el Cap. 6. Estas NPs fueron sintetizadas mediante el método de Leff, originalmente desarrollado para la síntesis de NPs de Au [214, 222]. Se disolvieron $0,4 \mathrm{mmol}$ de $\mathrm{K}_{2} \mathrm{PdCl}_{4}$ (Aldrich, purum) y se transfirieron a $25 \mathrm{~mL}$ tolueno como en el caso anterior (relación molar ToABr:Pd = 2.3:1). Seguidamente, sin quitar la fase acuosa, se agregaron 4,4 mmol de dodecilamina (Aldrich, $98 \%$ ). La relación molar de $\mathrm{NC}_{12}: \mathrm{Pd}$ utilizada fue 11:1. En este punto se formó una emulsión blanca, lechosa, seguramente debido a la formación de un complejo entre las especies metálicas y las aminas protonadas. Luego de $10 \mathrm{~min}$, se agregaron $10 \mathrm{~mL}$ de una solución acuosa que contenía $6 \mathrm{mmol}$ de $\mathrm{NaBH}_{4}$ (relación molar $\mathrm{NaBH}_{4}: \mathrm{Pd}=15: 1$ ). La suspensión se volvió límpida y marrón oscura gradualmente y fue agitada por $20 \mathrm{~h}$ más. Finalmente, la fase acuosa fue descartada y se redujo el volumen de la fase tolueno mediante rotavapor. Las NPs fueron precipitadas con etanol, centrifugadas y lavadas otras 3 veces con etanol mediante centrifugación/redispersión. En este caso se evitó utilizar el ultrasonido ya que este produce cierta aglomeración de las NPs debido a la baja energía de enlace de las moléculas de aminas a la superficie de Pd. 


\section{Apéndice $\mathrm{C}$}

\section{Abreviaturas, siglas, acrónimos y constantes físicas}

\section{C.1 Abreviaturas, siglas y acrónimos}

AuNPs Nanopartículas de Au

Cap. Capítulo

ECS Electrodo de calomel saturado

ENH Electrodo normal de hidrógeno

EXAFS Extended X-ray absorption fine structure

FT Fourier transform, transformada de Fourier

FTIR Fourier transform infrared spectrosocpy, espectroscopía infrarroja por transformada de Fourier

HAADF high-angle annular dark field (detector), (detector) anular de campo oscuro de alto ángulo

HRTEM High-resolution transmission electron microscopy, microscopía electrónica de transmisión de alta resolución

HOPG Highly oriented pyrolytic graphite, grafito pirolítico altamente orientado

MT Metanotiol

NP Nanopartícula

NPs Nanopartículas

OPD Overpotential deposition, deposición a sobrepotenciales

$p$-MBA $\quad p$-Mercaptobenzoic acid, ácido p-mercaptobenzoico

PdNPs Nanopartículas de Pd

ref. Referencia

SAM Monocapa autoensamblada

SAMs Monocapas autoensambladas

$\mathrm{SC}_{1} \quad$ Metanotiol

$\mathrm{SC}_{3} \quad$ Propanotiol

$\mathrm{SC}_{6} \quad$ Hexanotiol

$\mathrm{SC}_{9} \quad$ Nonanotiol 
$\mathrm{SC}_{12} \quad$ Dodecanotiol

Sec. Sección

SPR Surface plasmon resonance, resonancia plasmónica superficial

STEM Scanning transmission electron microscopy, microscopía electrónica barrido por transmisión

STM Scanning tunnelling microscopy, microscopía de barrido de efecto túnel

TEM Transmission electron microscopy, microscopía electrónica de transmisión

TM Thiomalate, tiomalato

TMA Thiomalic acid, ácido tiomálico

$\mathrm{ToABr}$ Tetraoctylammonium bromide, bromuro de tetraoctilamonio

UHV Ultra-high vacuum, ultra alto vacío

UV-Vis Espectroscopía ultravioleta-visible

XANES X-ray absorption near edge spectroscopy

XPS X-ray photoelectron spectroscopy, espectroscopía de fotoelectrones generados por rayos $\mathrm{X}$

\section{C.2 Constantes físicas}

\begin{tabular}{lll}
\hline Cantidad & Símbolo & Valor \\
\hline Velocidad de la luz & $c$ & $2,9979246 \times 10^{8} \mathrm{~m} \mathrm{~s}^{-1}$ \\
Carga del electrón & $e$ & $-1,602177 \times 10^{-19} \mathrm{C}$ \\
Constante de Faraday & $F$ & $96485 \mathrm{C} \mathrm{mol}^{-1}$ \\
Constante de Planck & $h$ & $6,6260690 \times 10^{-34} \mathrm{~J} \mathrm{~s}$ \\
Constante de Boltzmann & $k$ & $1,3806488 \times 10^{-23} \mathrm{~J} \mathrm{~K}^{-1}$ \\
Masa del electrón en reposo & $m_{0}$ & $9,1093829 \times 10^{-31} \mathrm{Kg}$ \\
Constante universal de los gases & $R$ & $8,3144621 \mathrm{~J} \mathrm{~K}^{-1} \mathrm{~mol}^{-1}$ \\
\hline
\end{tabular}




\section{Apéndice D}

\section{Trabajos publicados}

Las siguientes publicaciones contienen parte de los resultados desarrollados en esta tesis.

- Electrochemical and X-ray Photoelectron Spectroscopy Characterization of Alkanethiols Adsorbed on Palladium Surfaces.

G. Corthey, A. A. Rubert, G. A. Benitez, M. H. Fonticelli, R. C. Salvarezza.

J. Phys. Chem. C 2009, 113, 6735-6742.

- Synthesis and Characterization of Gold@Gold(I)-Thiomalate Core@Shell Nanoparticles.

G. Corthey, L. J. Giovanetti, J. M. Ramallo-López, E. Zelaya, A. A. Rubert, G. A. Benitez, F. G. Requejo, M. H. Fonticelli, R. C. Salvarezza.

ACS Nano 2010, 4, 3413-3421.

- The Complex Thiol-Palladium Interface: a Theoretical and Experimental Study.

P. Carro, G. Corthey, A. A. Rubert, G. A. Benitez, M. H. Fonticelli, R. C. Salvarezza. Langmuir 2010, 26, 14655-14662.

- New Insights into the Chemistry of Thiolate-Protected Palladium Nanoparticles. G. Corthey, A. A. Rubert, A. L. Picone, G. Casillas, L. J. Giovanetti, J. M. RamalloLópez, E. Zelaya, G. A. Benitez, F. G. Requejo, M. José-Yacamán, R. C. Salvarezza, M. H. Fonticelli.

J. Phys. Chem. C 2012, 116, 9830-9837.

- The Chemistry of the Sulfur-Gold Interface: in Search of a Unified Model.

E. Pensa, E. Cortés, G. Corthey, P. Carro, C. Vericat, M. H. Fonticelli, G. Benítez, A. A. Rubert, R. C. Salvarezza.

Acc. Chem. Res. 2012, 45, 1183-1192 


\section{Bibliografía}

[1] Daniel, M.-C.; Astruc, D. Gold Nanoparticles: Assembly, Supramolecular Chemistry, Quantum-Size-Related Properties, and Applications toward Biology, Catalysis, and Nanotechnology. Chem. Rev. 2004, 104, 293-346, Enlace.

[2] Faraday, M. The Bakerian Lecture: Experimental Relations of Gold (and Other Metals) to Light. Phil. Trans. R. Soc. London 1857, 147, 145-181.

[3] Thomas, J. M. Colloidal Metals: Past, Present and Future. Pure Appl. Chem. 1988, $60,1517-1528$.

[4] Turkevich, J.; Stevenson, P. C.; Hillier, J. A Study of the Nucleation and Growth Processes in the Synthesis of Colloidal Gold. Discuss. Faraday Soc. 1951, 11, 55-75, Enlace.

[5] Polte, J.; Ahner, T. T.; Delissen, F.; Sokolov, S.; Emmerling, F.; Thünemann, A. F.; Kraehnert, R. Mechanism of Gold Nanoparticle Formation in the Classical Citrate Synthesis Method Derived from Coupled In Situ XANES and SAXS Evaluation. $J$. Am. Chem. Soc. 2010, 132, 1296-1301, Enlace.

[6] Boisselier, E.; Astruc, D. Gold Nanoparticles in Nanomedicine: Preparations, Imaging, Diagnostics, Therapies and Toxicity. Chem. Soc. Rev. 2009, 38, 1759-1782, Enlace.

[7] Azzazy, H. M.; Mansour, M. M.; Kazmierczak, S. C. Nanodiagnostics: A New Frontier for Clinical Laboratory Medicine. Clin. Chem. 2006, 52, 1238-1246, Enlace.

[8] Peng, G.; Tisch, U.; Adams, O.; Hakim, M.; Shehada, N.; Broza, Y.; Billan, S.; Abdah-Bortnyak, R.; Kuten, A.; Haick, H. Diagnosing Lung Cancer in Exhaled Breath Using Gold Nanoparticles. Nat. Nanotechnol. 2009, 4, 669-673, Enlace.

[9] Haruta, M.; Kobayashi, T.; Sano, H.; Yamada, N. Novel Gold Catalysts for the Oxidation of Carbon Monoxide at a Temperature far Below $0{ }^{\circ} \mathrm{C}$. Chem. Lett. 1987, 16, 405-408, Enlace.

[10] Wieckowski, A., Savinova, E. R., Vayenas, C. G., (comps.) Catalysis and Electrocatalysis at Nanoparticle Surfaces; Marcel Dekker: New York, 2003. 
[11] Lopez-Acevedo, O.; Kacprzak, K. A.; Akola, J.; Häkkinen, H. Quantum Size Effects in Ambient CO Oxidation Catalysed by Ligand-Protected Gold Clusters. Nat. Chem. 2010, 2, 329-334, Enlace.

[12] Ibañez, F. J.; Zamborini, F. P. Chemiresistive Sensing with Chemically Modified Metal and Alloy Nanoparticles. Small 2012, 8, 174-202, Enlace.

[13] Saha, K.; Agasti, S. S.; Kim, C.; Li, X.; Rotello, V. M. Gold Nanoparticles in Chemical and Biological Sensing. Chem. Rev. 2012, 112, 2739-2779, Enlace.

[14] Brust, M.; Walker, M.; Bethell, D.; Schiffrin, D. J.; Whyman, R. Synthesis of thiolderivatised gold nanoparticles in a two-phase Liquid-Liquid system. J. Chem. Soc., Chem. Commun. 1994, 801-802, Enlace.

[15] Brust, M.; Fink, J.; Bethell, D.; Schiffrin, D. J.; Kiely, C. Synthesis and reactions of functionalised gold nanoparticles. J. Chem. Soc., Chem. Commun. 1995, 1655-1656, Enlace.

[16] Walter, M.; Akola, J.; Lopez-Acevedo, O.; Jadzinsky, P. D.; Calero, G.; Ackerson, C. J.; Whetten, R. L.; Grönbeck, H.; Häkkinen, H. A unified view of ligandprotected gold clusters as superatom complexes. Proc. Natl. Acad. Sci. U. S. A. 2008, 105, 9157-9162, Enlace.

[17] Vericat, C.; Vela, M. E.; Benitez, G.; Carro, P.; Salvarezza, R. C. Self-Assembled Monolayers of Thiols and Dithiols on Gold: New Challenges for a Well-Known System. Chem. Soc. Rev. 2010, 39, 1805-1834, Enlace.

[18] Block, B. P. Gold Powder and Potassium Tetrabromoaurate (III). Inorg. Synth. 1953, 4, 14-17.

[19] Bard, A. J.; Faulkner, L. R. Electrochemical Methods: Fundamentals and Applications, 2da ed.; John Wiley \& Sons: New York, 2001.

[20] Michri, A.; Pshchenichnikov, A. G.; Burshtein, R. Determining the actual surface area of smooth gold electrodes. Elektrokhimiya 1972, 8, 351-352.

[21] Kittel, C. Introducción a la física del estado sólido, 8a ed.; John Wiley \& Sons: Hoboken, NJ, 2005.

[22] Grdeń, M.; Łukaszewski, M.; Jerkiewicz, G.; Czerwiński, A. Electrochemical behaviour of palladium electrode: Oxidation, electrodissolution and ionic adsorption. Electrochim. Acta 2008, 53, 7583-7598, Enlace.

[23] Bolzán, A. Phenomenological aspects related to the electrochemical behaviour of smooth palladium electrodes in alkaline solutions. J. Electroanal. Chem. 1995, 380, 127-138, Enlace. 
[24] Fadley, C. S. Basic Concepts of X-ray Photoelectron Spectroscopy. En Electron spectroscopy: theory, techniques and applications; Brundle, C. R., Baker, A. D., (comps.); Academic Press: London, 1978; Vol. 2.

[25] Fadley, C. S. Atomic-level characterization of materials with core- and valence-level photoemission: basic phenomena and future directions. Surf. Interface Anal. 2008, 40, 1579-1605, Enlace.

[26] Hüfner, S. Photoelectron Spectroscopy: Principles and Applications; Springer: Berlin, 1996.

[27] Waterhouse, G.; Bowmaker, G.; Metson, J. Oxidation of a polycrystalline silver foil by reaction with ozone. Appl. Surf. Sci. 2001, 183, 191-204, Enlace.

[28] Yeh, J.; Lindau, I. Atomic Subshell Photoionization Cross Sections and Asymmetry Parameters: $1 \leq \mathrm{Z} \leq 103$. At. Data Nucl. Data Tables 1985, 32, 1-155, Enlace.

[29] Wagner, C. D.; Riggs, W. M.; Davis, L. E.; Moulder, J. F.; Muilenberg, G. E. Handbook of $x$-ray photoelectron spectroscopy: a reference book of standard data for use in $x$-ray photoelectron spectroscopy; Physical Electronics Division, Perkin-Elmer Corp.: Eden Prairie, MN, 1979.

[30] Attwood, D. Soft X-Rays and Extreme Ultraviolet Radiation: Principles and Applications; Cambridge University Press: Cambridge, 1999.

[31] Watts, J. F.; Wolstenholme, J. An Introduction to Surface Analysis by XPS and AES; John Wiley \& Sons: West Sussex, 2003.

[32] Jablonski, A.; Powell, C. J. The electron attenuation length revisited. Surface science reports 2002, 47, 33-91, Enlace.

[33] Cumpson, P. J.; Seah, M. P. Elastic Scattering Corrections in AES and XPS. II. Estimating Attenuation Lengths and Conditions Required for their Valid Use in Overlayer/Substrate Experiments. Surf. Interface Anal. 1997, 25, 430-446, Enlace.

[34] Powell, C. J.; Jablonsky, A. NIST Electron Effective-Attenuation-Length Database - Version 1.3; National Institute of Standars and Technology: Gaithersburg, MD, 2011.

[35] Ramallo-López, J. M.; Requejo, F. G. X-ray absorption fine structure studies of fundamental properties of nanostructures. En Recent Advances in Nanoscience; Mariscal, M. M., Dassie, S. A., (comps.); Research Signpost: Kerala, 2007.

[36] Ravel, B.; Newville, M. ATHENA, ARTEMIS, HEPHAESTUS: Data Analysis for X-Ray Absorption Spectroscopy Using IFEFFIT. J. Synchrotron Radiat. 2005, 12, 537-541, Enlace.

[37] Glatter, O. Small angle x-ray scattering; Academic Press: London, 1982. 
[38] Paquete Fit2D. Enlace.

[39] Ekspong, G., Frängsmy, T., (comps.) Nobel Lectures in Physics 1981-1990; World Scientific Publishing Co: Singapore, 1993.

[40] Williams, D. B.; Carter, C. B. Transmission Electron Microscopy: A Textbook for Materials Science, 2da ed.; Springer: New York, 2009.

[41] Erni, R. Aberration-corrected Imaging in Transmission Electron Microscopy: An Introduction; Imperial College Press: London, 2010.

[42] Lentzen, M. Contrast Transfer and Resolution Limits for Sub-Angstrom HighResolution Transmission Electron Microscopy. Microsc. Microanal. 2008, 14, 16-26, Enlace.

[43] O'Keefe, M.; Hetherington, C.; Wang, Y.; Nelson, E.; Turner, J.; Kisielowski, C.; Malm, J.-O.; Mueller, R.; Ringnalda, J.; Pan, M.; Thust, A. Sub-Ångstrom highresolution transmission electron microscopy at $300 \mathrm{keV}$. Ultramicroscopy 2001, 89, 215-241, Enlace.

[44] Egerton, R.; McLeod, R.; Wang, F.; Malac, M. Basic questions related to electroninduced sputtering in the TEM. Ultramicroscopy 2010, 110, 991-997, Enlace.

[45] Granqvist, C. G.; Buhrman, R. A. Ultrafine metal particles. J. Appl. Phys. 1976, 47, 2200-2219.

[46] Levine, I. N. Química Cuántica; Pearson Educación: Madrid, 2001.

[47] Sánchez, C. G. Estudio teórico de la interfase electroquímica mediante cálculos a partir de primeros principios. Tesis Doctoral, Universidad Nacional de Córdoba, Córdoba, Argentina, 2000.

[48] Kresse, G.; Joubert, D. From ultrasoft pseudopotentials to the projector augmentedwave method. Phys. Rev. B 1999, 59, 1758-1775, Enlace.

[49] Kresse, G.; Furthmüller, J. Efficient iterative schemes for ab initio total-energy calculations using a plane-wave basis set. Phys. Rev. B 1996, 54, 11169-11186, Enlace.

[50] Perdew, J. P.; Wang, Y. Accurate and simple analytic representation of the electrongas correlation energy. Phys. Rev. B 1992, 45, 13244-13249, Enlace.

[51] Kresse, G.; Hafner, J. Ab initio molecular dynamics for liquid metals. Phys. Rev. B 1993, 47, 558-561, Enlace.

[52] Blöchl, P. E. Projector augmented-wave method. Phys. Rev. B 1994, 50, 1795317979, Enlace.

[53] Jadzinsky, P. D.; Calero, G.; Ackerson, C. J.; Bushnell, D. A.; Kornberg, R. D. Structure of a Thiol Monolayer-Protected Gold Nanoparticle at $1.1 \AA$ Resolution. Science 2007, 318, 430-433, Enlace. 
[54] Cossaro, A.; Floreano, L.; Verdini, A.; Casalis, L.; Morgante, A. Comment on "Local Methylthiolate Adsorption Geometry on $\mathrm{Au}(111)$ from Photoemission Core-Level Shifts". Phys. Rev. Lett. 2009, 103, 119601, Enlace.

[55] Goulet, P. J. G.; Lennox, R. B. New Insights into Brust-Schiffrin Metal Nanoparticle Synthesis. J. Am. Chem. Soc. 2010, 132, 9582-9584, Enlace.

[56] Negishi, Y.; Nobusada, K.; Tsukuda, T. Glutathione-Protected Gold Clusters Revisited: Bridging the Gap between Gold(I)-Thiolate Complexes and Thiolate-Protected Gold Nanocrystals. J. Am. Chem. Soc. 2005, 127, 5261-5270, Enlace.

[57] Love, J.; Estroff, L.; Kriebel, J.; Nuzzo, R.; Whitesides, G. Self-Assembled Monolayers of Thiolates on Metals as a Form of Nanotechnology. Chem. Rev. 2005, 105, 1103-1170, Enlace.

[58] Häkkinen, H. The gold-sulfur interface at the nanoscale. Nat. Chem. 2012, 4, 443455, Enlace.

[59] Bourg, M.-C.; Badia, A.; Lennox, R. B. Gold-Sulfur Bonding in 2D and 3D SelfAssembled Monolayers: XPS Characterization. J. Phys. Chem. B 2000, 104, 65626567, Enlace.

[60] Maksymovych, P.; Sorescu, D. C.; Yates, J. T. Gold-Adatom-Mediated Bonding in Self-Assembled Short-Chain Alkanethiolate Species on the Au(111) Surface. Phys. Rev. Lett. 2006, 97, 146103, Enlace.

[61] Cossaro, A.; Mazzarello, R.; Rousseau, R.; Casalis, L.; Verdini, A.; Kohlmeyer, A.; Floreano, L.; Scandolo, S.; Morgante, A.; Klein, M. L.; Scoles, G. X-ray Diffraction and Computation Yield the Structure of Alkanethiols on Gold(111). Science 2008, 321, 943-946, Enlace.

[62] Heath, J. R.; Knobler, C. M.; Leff, D. V. Pressure/Temperature Phase Diagrams and Superlattices of Organically Functionalized Metal Nanocrystal Monolayers: The Influence of Particle Size, Size Distribution, and Surface Passivant. J. Phys. Chem. $B$ 1997, 101, 189-197, Enlace.

[63] Kang, S. Y.; Kim, K. Comparative Study of Dodecanethiol-Derivatized Silver Nanoparticles Prepared in One-Phase and Two-Phase Systems. Langmuir 1998, 14 , 226-230, Enlace.

[64] Garitaonandia, J. S.; Insausti, M.; Goikolea, E.; Suzuki, M.; Cashion, J. D.; Kawamura, N.; Ohsawa, H.; Gil de Muro, I.; Suzuki, K.; Plazaola, F.; Rojo, T. Chemically Induced Permanent Magnetism in $\mathrm{Au}, \mathrm{Ag}$, and $\mathrm{Cu}$ Nanoparticles: Localization of the Magnetism by Element Selective Techniques. Nano Lett. 2008, 8, 661-667, Enlace.

[65] Zamborini, F.; Gross, S.; Murray, R. Synthesis, Characterization, Reactivity, and Electrochemistry of Palladium Monolayer Protected Clusters. Langmuir 2001, 17, 481-488, Enlace. 
[66] Castro, E. G.; Salvatierra, R. V.; Schreiner, W. H.; Oliveira, M. M.; Zarbin, A. J. G. Dodecanethiol-Stabilized Platinum Nanoparticles Obtained by a Two-Phase Method: Synthesis, Characterization, Mechanism of Formation, and Electrocatalytic Properties. Chem. Mater. 2009, 22, 360-370, Enlace.

[67] Negishi, Y.; Takasugi, Y.; Sato, S.; Yao, H.; Kimura, K.; Tsukuda, T. MagicNumbered $\mathrm{Au}_{n}$ Clusters Protected by Glutathione Monolayers $(n=18,21,25$, 28, 32, 39): Isolation and Spectroscopic Characterization. J. Am. Chem. Soc. 2004, 126, 6518-6519, Enlace.

[68] Bader, R. Atoms in molecules; Oxford University Press: New York, 1990.

[69] Lopez-Acevedo, O.; Clayborne, P. A.; Häkkinen, H. Electronic structure of gold, aluminum, and gallium superatom complexes. Phys. Rev. B 2011, 84, 035434, Enlace.

[70] Häkkinen, H.; Barnett, R. N.; Landman, U. Electronic Structure of Passivated $\mathrm{Au}_{38}\left(\mathrm{SCH}_{3}\right)_{24}$ Nanocrystal. Phys. Rev. Lett. 1999, 82, 3264-3267, Enlace.

[71] Garzón, I. L.; Rovira, C.; Michaelian, K.; Beltrán, M. R.; Ordejón, P.; Junquera, J.; Sánchez-Portal, D.; Artacho, E.; Soler, J. M. Do Thiols Merely Passivate Gold Nanoclusters? Phys. Rev. Lett. 2000, 85, 5250, Enlace.

[72] Heaven, M. W.; Dass, A.; White, P. S.; Holt, K. M.; Murray, R. W. Crystal Structure of the Gold Nanoparticle $\left[\mathrm{N}_{(}\left(\mathrm{C}_{8} \mathrm{H}_{17}\right)_{4}\right]\left[\mathrm{Au}_{25}\left(\mathrm{SCH}_{2} \mathrm{CH}_{2} \mathrm{Ph}\right)_{18}\right]$. J. Am. Chem. Soc. 2008, 130, 3754-3755, Enlace.

[73] Qian, H.; Eckenhoff, W. T.; Zhu, Y.; Pintauer, T.; Jin, R. Total Structure Determination of Thiolate-Protected $\mathrm{Au}_{38}$ Nanoparticles. J. Am. Chem. Soc. 2010, 132, 8280-8281, Enlace.

[74] Lopez-Acevedo, O.; Tsunoyama, H.; Tsukuda, T.; Häkkinen, H.; Aikens, C. M. Chirality and Electronic Structure of the Thiolate-Protected $\mathrm{Au}_{38}$ Nanocluster. J. Am. Chem. Soc. 2010, 132, 8210-8218, Enlace.

[75] Qian, H.; Zhu, Y.; Jin, R. Atomically precise gold nanocrystal molecules with surface plasmon resonance. Proc. Natl. Acad. Sci. U. S. A. 2012, En prensa. DOI: 0.1073/pnas.1115307109, Enlace.

[76] Hostetler, M.; Wingate, J.; Zhong, C.-J.; Harris, J.; Vachet, R.; Clark, M.; Londono, J.; Green, S.; Stokes, J.; Wignall, G.; Glish, G.; Porter, M.; Evans, N.; Murray, R. Alkanethiolate Gold Cluster Molecules with Core Diameters from 1.5 to 5.2 nm: Core and Monolayer Properties as a Function of Core Size. Langmuir 1998, 14, 17-30, Enlace.

[77] Starks, C. M. Phase-transfer catalysis. I. Heterogeneous reactions involving anion transfer by quaternary ammonium and phosphonium salts. J. Am. Chem. Soc. 1971, 93, 195-199, Enlace. 
[78] Templeton, A. C.; Wuelfing, W. P.; Murray, R. W. Monolayer-Protected Cluster Molecules. Acc. Chem. Res. 2000, 33, 27-36, Enlace.

[79] Li, Y.; Zaluzhna, O.; Xu, B.; Gao, Y.; Modest, J. M.; Tong, Y. J. Mechanistic Insights into the Brust-Schiffrin Two-Phase Synthesis of Organo-Chalcogenate-Protected Metal Nanoparticles. J. Am. Chem. Soc. 2011, 133, 2092-2095, Enlace.

[80] Li, Y.; Zaluzhna, O.; Tong, Y. J. Critical Role of Water and the Structure of Inverse Micelles in the Brust-Schiffrin Synthesis of Metal Nanoparticles. Langmuir 2011, 27, 7366-7370, Enlace.

[81] Schaaff, T. G.; Shafigullin, M. N.; Khoury, J. T.; Vezmar, I.; Whetten, R. L.; Cullen, W. G.; First, P. N.; Gutierrez-Wing, C.; Ascensio, J.; Jose-Yacaman, M. J. Isolation of Smaller Nanocrystal Au Molecules: Robust Quantum Effects in Optical Spectra. J. Phys. Chem. B 1997, 101, 7885-7891, Enlace.

[82] Alvarez, M.; Khoury, J.; Schaaff, T.; Shafigullin, M.; Vezmar, I.; Whetten, R. Critical sizes in the growth of Au clusters. Chem. Phys. Lett. 1997, 266, 91-98, Enlace.

[83] Leff, D. V.; Ohara, P. C.; Heath, J. R.; Gelbart, W. M. Thermodynamic Control of Gold Nanocrystal Size: Experiment and Theory. J. Phys. Chem. 1995, 99, 70367041, Enlace.

[84] Zhang, P.; Sham, T. K. X-Ray Studies of the Structure and Electronic Behavior of Alkanethiolate-Capped Gold Nanoparticles: The Interplay of Size and Surface Effects. Phys. Rev. Lett. 2003, 90, 245502, Enlace.

[85] MacDonald, M.; Zhang, P.; Qian, H.; Jin, R. Site-Specific and Size-Dependent Bonding of Compositionally Precise Gold- Thiolate Nanoparticles from X-ray Spectroscopy. J. Phys. Chem. Lett. 2010, 1, 1821-1825, Enlace.

[86] Citrin, P. H.; Wertheim, G. K. Photoemission from surface-atom core levels, surface densities of states, and metal-atom clusters: A unified picture. Phys. Rev. B 1983, 27, 3176-3200, Enlace.

[87] Chaudhuri, A.; Lerotholi, T. J.; Jackson, D. C.; Woodruff, D. P.; Dhanak, V. Local Methylthiolate Adsorption Geometry on $\mathrm{Au}(111)$ from Photoemission Core-Level Shifts. Phys. Rev. Lett. 2009, 102, 126101, Enlace.

[88] Moriarty, P. Comment on "X-Ray Studies of the Structure and Electronic Behavior of Alkanethiolate-Capped Gold Nanoparticles: The Interplay of Size and Surface Effects". Phys. Rev. Lett. 2004, 92, 109601, Enlace.

[89] Yu, M.; Bovet, N.; Satterley, C. J.; Bengió, S.; Lovelock, K. R. J.; Milligan, P. K.; Jones, R. G.; Woodruff, D. P.; Dhanak, V. True Nature of an Archetypal SelfAssembly System: Mobile Au-Thiolate Species on $\mathrm{Au}(111)$. Phys. Rev. Lett. 2006, 97, 166102, Enlace. 
[90] Chesneau, F.; Zhao, J.; Shen, C.; Buck, M.; Zharnikov, M. Adsorption of Long-Chain Alkanethiols on $\mathrm{Au}(111)$ : A Look from the Substrate by High Resolution X-ray Photoelectron Spectroscopy. J. Phys. Chem. C 2010, 114, 7112-7119, Enlace.

[91] Grönbeck, H.; Odelius, M. Photoemission core-level shifts reveal the thiolate-Au(111) interface. Phys. Rev. B 2010, 82, 085416, Enlace.

[92] Brinas, R. P.; Hu, M.; Qian, L.; Lymar, E. S.; Hainfeld, J. F. Gold Nanoparticle Size Controlled by Polymeric Au(I) Thiolate Precursor Size. J. Am. Chem. Soc. 2008, 130, 975-982, Enlace.

[93] Shaw, C. F. Gold-Based Therapeutic Agents. Chem. Rev. 1999, 99, 2589-2600, Enlace.

[94] Crespo, O. Gold-Gold Interactions. En Modern Supramolecular Gold Chemistry; Laguna, A., (comp.); John Wiley \& Sons: Weinheim, 2008.

[95] Bau, R. Crystal Structure of the Antiarthritic Drug Gold Thiomalate (Myochrysine): A Double-Helical Geometry in the Solid State. J. Am. Chem. Soc. 1998, 120, 93809381, Enlace.

[96] Kim, J.-U.; Cha, S.-H.; Shin, K.; Jho, J. Y.; Lee, J.-C. Synthesis of Gold Nanoparticles from Gold(I)-Alkanethiolate Complexes with Supramolecular Structures through Electron Beam Irradiation in TEM. J. Am. Chem. Soc. 2005, 127, 99629963, Enlace.

[97] Barngrover, B. M.; Aikens, C. M. Incremental Binding Energies of Gold(I) and Silver(I) Thiolate Clusters. J. Phys. Chem. A 2011, 115, 11818-11823, Enlace.

[98] Novoselov, K. S.; Geim, A. K.; Morozov, S. V.; Jiang, D.; Zhang, Y.; Dubonos, S. V.; Grigorieva, I. V.; Firsov, A. A. Electric Field Effect in Atomically Thin Carbon Films. Science 2004, 306, 666 -669, Enlace.

[99] Lee, Z.; Jeon, K.-J.; Dato, A.; Erni, R.; Richardson, T. J.; Frenklach, M.; Radmilovic, V. Direct Imaging of Soft-Hard Interfaces Enabled by Graphene. Nano Lett. 2009, 9, 3365-3369, Enlace.

[100] Yuk, J. M.; Park, J.; Ercius, P.; Kim, K.; Hellebusch, D. J.; Crommie, M. F.; Lee, J. Y.; Zettl, A.; Alivisatos, A. P. High-Resolution EM of Colloidal Nanocrystal Growth Using Graphene Liquid Cells. Science 2012, 336, 61-64, Enlace.

[101] Zan, R.; Bangert, U.; Ramasse, Q.; Novoselov, K. S. Evolution of Gold Nanostructures on Graphene. Small 2011, 7, 2868-2872, Enlace.

[102] Li, X.; Cai, W.; An, J.; Kim, S.; Nah, J.; Yang, D.; Piner, R.; Velamakanni, A.; Jung, I.; Tutuc, E.; Banerjee, S. K.; Colombo, L.; Ruoff, R. S. Large-Area Synthesis of High-Quality and Uniform Graphene Films on Copper Foils. Science 2009, 324, 1312-1314, Enlace. 
[103] Chan, K. T.; Neaton, J. B.; Cohen, M. L. First-principles study of metal adatom adsorption on graphene. Phys. Rev. B 2008, 77, 235430, Enlace.

[104] Malola, S.; Häkkinen, H.; Koskinen, P. Gold in graphene: In-plane adsorption and diffusion. Appl. Phys. Lett. 2009, 94, 043106, Enlace.

[105] Zan, R.; Bangert, U.; Ramasse, Q.; Novoselov, K. S. Metal-Graphene Interaction Studied via Atomic Resolution Scanning Transmission Electron Microscopy. Nano Lett. 2011, 11, 1087-1092, Enlace.

[106] Gan, Y.; Sun, L.; Banhart, F. One- and Two-Dimensional Diffusion of Metal Atoms in Graphene. Small 2008, 4, 587-591, Enlace.

[107] Wang, Z. W.; Palmer, R. E. Mass Spectrometry and Dynamics of Gold Adatoms Observed on the Surface of Size-Selected Au Nanoclusters. Nano Lett. 2012, 12, 91-95, Enlace.

[108] Wang, Z. W.; Toikkanen, O.; Quinn, B. M.; Palmer, R. E. Real-Space Observation of Prolate Monolayer-Protected $\mathrm{Au}_{38}$ Clusters Using Aberration-Corrected Scanning Transmission Electron Microscopy. Small 2011, 7, 1542-1545, Enlace.

[109] Zhu, M.; Aikens, C. M.; Hollander, F. J.; Schatz, G. C.; Jin, R. Correlating the Crystal Structure of A Thiol-Protected $\mathrm{Au}_{25}$ Cluster and Optical Properties. $J$. Am. Chem. Soc. 2008, 130, 5883-5885, Enlace.

[110] van Vollenhoven, R. F. Treatment of rheumatoid arthritis: state of the art 2009. Nat. Rev. Rheumatol. 2009, 5, 531-541, Enlace.

[111] Tiekink, E. R. T. Gold derivatives for the treatment of cancer. Crit. Rev. Oncol./Hemat. 2002, 42, 225-248, Enlace.

[112] Chen, S.; Kimura, K. Synthesis and Characterization of Carboxylate-Modified Gold Nanoparticle Powders Dispersible in Water. Langmuir 1999, 15, 1075-1082, Enlace.

[113] Ackerson, C. J.; Jadzinsky, P. D.; Kornberg, R. D. Thiolate Ligands for Synthesis of Water-Soluble Gold Clusters. J. Am. Chem. Soc. 2005, 127, 6550-6551, Enlace.

[114] Helfrich, A.; Bettmer, J. Analysis of gold nanoparticles using ICP-MS-based hyphenated and complementary ESI-MS techniques. Int. J. Mass Spectrom. 2011, 30\%, 92-98, Enlace.

[115] Menard, L. D.; Xu, H.; Gao, S.-P.; Twesten, R. D.; Harper, A. S.; Song, Y.; Wang, G.; Douglas, A. D.; Yang, J. C.; Frenkel, A. I.; Murray, R. W.; Nuzzo, R. G. Metal Core Bonding Motifs of Monodisperse Icosahedral $\mathrm{Au}_{13}$ and Larger Au MonolayerProtected Clusters As Revealed by X-ray Absorption Spectroscopy and Transmission Electron Microscopy. J. Phys. Chem. B 2006, 110, 14564-14573, Enlace. 
[116] Walton, R. A. The x-ray photoelectron spectra of metal complexes of sulfurcontaining ligands: sulfur 2p binding energies. Coord. Chem. Rev. 1980, 31, 183-220, Enlace.

[117] Zhong, C.-J.; Brush, R. C.; Anderegg, J.; Porter, M. D. Organosulfur Monolayers at Gold Surfaces: Reexamination of the Case for Sulfide Adsorption and Implications to the Formation of Monolayers from Thiols and Disulfides. Langmuir 1999, 15, 518-525, Enlace.

[118] Ramírez, E. A.; Cortés, E.; Rubert, A. A.; Carro, P.; Benítez, G.; Vela, M. E.; Salvarezza, R. C. Complex Surface Chemistry of 4-Mercaptopyridine Self-Assembled Monolayers on $\mathrm{Au}(111)$. Langmuir 2012, 28, 6839-6847, Enlace.

[119] Vairavamurthy, A. Using X-ray absorption to probe sulfur oxidation states in complex molecules. Spectrochim. Acta, Part A 1998, 54, 2009-2017, Enlace.

[120] Ramallo-Lopez, J. M.; Giovanetti, L. J.; Requejo, F. G.; Isaacs, S. R.; Shon, Y. S.; Salmeron, M. Molecular Conformation Changes in Alkylthiol Ligands as a Function of Size in Gold Nanoparticles: X-Ray Absorption Studies. Phys. Rev. B 2006, 74, 073410, Enlace.

[121] Shang, L.; Azadfar, N.; Stockmar, F.; Send, W.; Trouillet, V.; Bruns, M.; Gerthsen, D.; Nienhaus, G. U. One-Pot Synthesis of Near-Infrared Fluorescent Gold Clusters for Cellular Fluorescence Lifetime Imaging. Small 2011, 7, 2614-2620, Enlace.

[122] Martin, H.; Carro, P.; Hernandez Creus, A.; Gonzalez, S.; Andreasen, G.; Salvarezza, R. C.; Arvia, A. J. The Influence of Adsorbates on the Growth Mode of Gold Islands Electrodeposited on the Basal Plane of Graphite. Langmuir 2000, 16, 29152923, Enlace.

[123] Lide, D. R., (comp.) CRC Handbook of Chemistry and Physics, 90th Edition (CDROM Version 2010); CRC Press/Taylor and Francis: Boca Raton, FL, 2009.

[124] Barngrover, B. M.; Aikens, C. M. Electron and Hydride Addition to Gold(I) Thiolate Oligomers: Implications for Gold-Thiolate Nanoparticle Growth Mechanisms. J. Phys. Chem. Lett. 2011, 2, 990-994, Enlace.

[125] Zucconi, T. D.; Janauer, G. E.; Donahe, S.; Lewkowicz, C. Acid dissociation and metal complex formation constants of penicillamine, cysteine, and antiarthritic gold complexes at simulated biological conditions. J. Pharm. Sci. 1979, 68, 426-432, Enlace.

[126] Cheney, G. E.; Fernando, Q.; Freiser, H. Some Metal Chelates of Mercaptosuccinic Acid. J. Phys. Chem. 1959, 63, 2055-2057, Enlace.

[127] Plieth, W. J. Electrochemical properties of small clusters of metal atoms and their role in the surface enhanced Raman scattering. J. Phys. Chem. 1982, 86, 3166-3170, Enlace. 
[128] Masitas, R. A.; Zamborini, F. P. Oxidation of Highly Unstable $<4$ nm Diameter Gold Nanoparticles $850 \mathrm{mV}$ Negative of the Bulk Oxidation Potential. J. Am. Chem. Soc. 2012, 134, 5014-5017, Enlace.

[129] Redmond, P. L.; Hallock, A. J.; Brus, L. E. Electrochemical Ostwald Ripening of Colloidal Ag Particles on Conductive Substrates. Nano Lett. 2004, 5, 131-135, Enlace.

[130] Baker, T. A.; Friend, C. M.; Kaxiras, E. Atomic Oxygen Adsorption on Au(111) Surfaces with Defects. J. Phys. Chem. C 2009, 113, 3232-3238, Enlace.

[131] Jones, P. G.; Rumpel, H.; Schwarzmann, E.; Sheldrick, G. M.; Paulus, H. Gold(III) oxide. Acta Crystallogr., Sect. B: Struct. Sci. 1979, 35, 1435-1437, Enlace.

[132] Elder, R. C.; Ludwig, K.; Cooper, J. N.; Eidsness, M. K. EXAFS and WAXS Structure Determination for an Antiarthritic Drug, Sodium Gold(I) Thiomalate. J. Am. Chem. Soc. 1985, 107, 5024-5025, Enlace.

[133] Mazid, M. A.; Razi, M. T.; Sadler, P. J.; Greaves, G. N.; Gurman, S. J.; Koch, M. H. J.; Phillips, J. C. An EXAFS study of gold co-ordination in the anti-arthritic drugs Myocrisin and Solganol. J. Chem. Soc., Chem. Commun. 1980, 1261-1263, Enlace.

[134] Li, Y.; Galli, G.; Gygi, F. Electronic Structure of Thiolate-Covered Gold Nanoparticles: $\mathrm{Au}_{102}(\mathrm{MBA})_{44}$. ACS Nano 2008, 2, 1896-1902, Enlace.

[135] Akola, J.; Walter, M.; Whetten, R. L.; Hakkinen, H.; Gronbeck, H. On the Structure of Thiolate-Protected $\mathrm{Au}_{25}$. J. Am. Chem. Soc. 2008, 130, 3756-3757, Enlace.

[136] Lopez-Acevedo, O.; Akola, J.; Whetten, R. L.; Grönbeck, H.; Häkkinen, H. Structure and Bonding in the Ubiquitous Icosahedral Metallic Gold Cluster $\mathrm{Au}_{144}(\mathrm{SR})_{60} . J$. Phys. Chem. C 2009, 113, 5035-5038, Enlace.

[137] Ramallo-López, J.; Requejo, F.; Craievich, A.; Wei, J.; Avalos-Borja, M.; Iglesia, E. Complementary methods for cluster size distribution measurements: supported platinum nanoclusters in methane reforming catalysts. J. Mol. Catal. A: Chem. 2005, 228, 299-307, Enlace.

[138] Yao, H.; Kojima, H.; Sato, S.; Kimura, K. Interparticle Spacing Control in the Superlattices of Carboxylic Acid-Capped Gold Nanoparticles by Hydrogen-Bonding Mediation. Langmuir 2004, 20, 10317-10323, Enlace.

[139] Mariscal, M. M.; Olmos-Asar, J. A.; Gutierrez-Wing, C.; Mayoral, A.; Yacaman, M. J. On the atomic structure of thiol-protected gold nanoparticles: a combined experimental and theoretical study. Phys. Chem. Chem. Phys. 2010, 12, 1178511790, Enlace. 
[140] Negishi, Y.; Takasugi, Y.; Sato, S.; Yao, H.; Kimura, K.; Tsukuda, T. Kinetic Stabilization of Growing Gold Clusters by Passivation with Thiolates. J. Phys. Chem. $B$ 2006, 110, 12218-12221, Enlace.

[141] Barnard, A. S.; Young, N. P.; Kirkland, A. I.; van Huis, M. A.; Xu, H. Nanogold: A Quantitative Phase Map. ACS Nano 2009, 3, 1431-1436, Enlace.

[142] Wales, D. J. Energy Landscapes; Cambridge University Press: Cambridge, 2003.

[143] Vericat, C.; Benitez, G. A.; Grumelli, D. E.; Vela, M. E.; Salvarezza, R. C. Thiolcapped gold: from planar to irregular surfaces. J. Phys.: Condens. Matter 2008, 20, 184004, Enlace.

[144] Fonticelli, M. H.; Corthey, G.; Benitez, G. A.; Salvarezza, R. C.; Giovanetti, L. J.; Requejo, F. G.; Shon, Y. S. Preparation of Ultrathin Thiolate-Covered Bimetallic Systems: From Extended Planar to Nanoparticle Surfaces. J. Phys. Chem. C 2007, 111, 9359-9364, Enlace.

[145] Corbierre, M. K.; Lennox, R. B. Preparation of Thiol-Capped Gold Nanoparticles by Chemical Reduction of Soluble Au(I)-Thiolates. Chem. Mater. 2005, 17, 5691-5696, Enlace.

[146] Grönbeck, H.; Häkkinen, H.; Whetten, R. L. Gold-Thiolate Complexes Form a Unique $\mathrm{c}(4 \times 2)$ Structure on $\mathrm{Au}(111)$. J. Phys. Chem. C 2008, 112, 15940-15942, Enlace.

[147] Majumder, C. Adsorption of Thiols on the Pd(111) Surface: A First Principles Study. Langmuir 2008, 24, 10838-10842, Enlace.

[148] Love, J. C.; Wolfe, D. B.; Chabinyc, M. L.; Paul, K. E.; Whitesides, G. M. SelfAssembled Monolayers of Alkanethiolates on Palladium Are Good Etch Resists. $J$. Am. Chem. Soc. 2002, 124, 1576-1577, Enlace.

[149] Marshall, S. T.; O'Brien, M.; Oetter, B.; Corpuz, A.; Richards, R. M.; Schwartz, D. K.; Medlin, J. W. Controlled Selectivity for Palladium Catalysts Using Self-Assembled Monolayers. Nat. Mater. 2010, 9, 853-858, Enlace.

[150] Jiang, X.; Bruzewicz, D.; Thant, M.; Whitesides, G. Palladium as a Substrate for Self-Assembled Monolayers Used in Biotechnology. Anal. Chem. 2004, 76, 61166121, Enlace.

[151] Love, J.; Wolfe, D.; Haasch, R.; Chabinyc, M.; Paul, K.; Whitesides, G.; Nuzzo, R. Formation and Structure of Self-Assembled Monolayers of Alkanethiolates on Palladium. J. Am. Chem. Soc. 2003, 125, 2597-2609, Enlace.

[152] Laibinis, P. E.; Whitesides, G. M.; Allara, D. L.; Tao, Y. T.; Parikh, A. N.; Nuzzo, R. G. Comparison of the structures and wetting properties of self-assembled monolayers of n-alkanethiols on the coinage metal surfaces, copper, silver, and gold. J. Am. Chem. Soc. 1991, 113, 7152-7167, Enlace. 
[153] Ibañez, F.; Zamborini, F. Ozone- and Thermally Activated Films of Palladium Monolayer-Protected Clusters for Chemiresistive Hydrogen Sensing. Langmuir 2006, 22, 9789-9796, Enlace.

[154] Williams, J.; Gorman, C. Alkanethiol Reductive Desorption from Self-Assembled Monolayers on Gold, Platinum, and Palladium Substrates. J. Phys. Chem. C 2007, 111, 12804-12810, Enlace.

[155] Azzaroni, O.; Vela, M. E.; Andreasen, G.; Carro, P.; Salvarezza, R. C. Electrodesorption Potentials of Self-Assembled Alkanethiolate Monolayers on $\operatorname{Ag}(111)$ and $\mathrm{Au}(111)$. An Electrochemical, Scanning Tunneling Microscopy and Density Functional Theory Study. J. Phys. Chem. B 2002, 106, 12267-12273, Enlace.

[156] Kibler, L. A.; Kleinert, M.; Randler, R.; Kolb, D. M. Initial stages of Pd deposition on $\mathrm{Au}(\mathrm{hkl})$ Part I: Pd on Au(111). Surf. Sci. 1999, 443, 19-30, Enlace.

[157] Quayum, M.; Ye, S.; Uosaki, K. Mechanism for nucleation and growth of electrochemical palladium deposition on an $\mathrm{Au}(111)$ electrode. J. Electroanal. Chem. 2002, 520, 126-132, Enlace.

[158] Macfie, G.; Simpson, L. V.; McColl, D.; Cardosi, M. F. Mechanism of 2Mercaptoethanesulphonate Adsorption onto Sputtered Palladium Films: Influence of Surface Oxide Species. J. Phys. Chem. C 2012, 116, 9930-9941, Enlace.

[159] Floridia Addato, M. A.; Rubert, A. A.; Benítez, G. A.; Fonticelli, M. H.; Carrasco, J.; Carro, P.; Salvarezza, R. C. Alkanethiol Adsorption on Platinum: Chain Length Effects on the Quality of Self-Assembled Monolayers. J. Phys. Chem. C 2011, 115, 17788-17798, Enlace.

[160] Martin, M.; Lasia, A. Study of the hydrogen absorption in Pd in alkaline solution. Electrochim. Acta 2008, 53, 6317-6322, Enlace.

[161] Ulman, A. Formation and Structure of Self-Assembled Monolayers. Chem. Rev. 1996, 96, 1533-1554, Enlace.

[162] Yu, M.; Driver, S. M.; Woodruff, D. P. Scanning Tunneling Microscopy Investigation of the Structure of Methanethiolate on $\mathrm{Ag}(111)$. Langmuir 2005, 21, 7285-7291, Enlace.

[163] Vericat, C.; Vela, M. E.; Andreasen, G.; Salvarezza, R. C.; Vázquez, L.; MartínGago, J. A. Sulfur-Substrate Interactions in Spontaneously Formed Sulfur Adlayers on $\mathrm{Au}(111)$. Langmuir 2001, 17, 4919-4924, Enlace.

[164] Laredo, T.; Leitch, J.; Chen, M.; Burgess, I. J.; Dutcher, J. R.; Lipkowski, J. Measurement of the Charge Number Per Adsorbed Molecule and Packing Densities of Self-Assembled Long-Chain Monolayers of Thiols. Langmuir 2007, 23, 6205-6211, Enlace. 
[165] Damaskin, B. B.; Petrii, O. A.; Batrakov, V. V. Adsorption of organic compounds on electrodes; Plenum Press: New York, 1981.

[166] Finklea, H. O., Electrochemistry of organized monolayers of thiols and related molecules on electrodes. En Electronalytical Chemistry; Bard, A. J., Rubinstein, I., (comps.); Marcel Dekker: New York, 1996; Vol. 19.

[167] Torrelles, X.; Vericat, C.; Vela, M. E.; Fonticelli, M. H.; Daza Millone, M. A.; Felici, R.; Lee, T.-L.; Zegenhagen, J.; Muñoz, G.; Martín-Gago, J. A.; Salvarezza, R. C. Two-Site Adsorption Model for the $(\sqrt{3} \times \sqrt{3})$ R30 Dodecanethiolate Lattice on $\mathrm{Au}(111)$ Surfaces. J. Phys. Chem. B 2006, 110, 5586-5594, Enlace.

[168] Widrig, C. A.; Chung, C.; Porter, M. D. The electrochemical desorption of nalkanethiol monolayers from polycrystalline $\mathrm{Au}$ and $\mathrm{Ag}$ electrodes. J. Electroanal. Chem. 1991, 310, 335-359, Enlace.

[169] Hagenström, H.; Schneeweiss, M. A.; Kolb, D. M. Modification of a Au(111) Electrode with Ethanethiol. 1. Adlayer Structure and Electrochemistry. Langmuir 1999, 15, 2435-2443, Enlace.

[170] Benítez, G.; Vericat, C.; Tanco, S.; Remes Lenicov, F.; Castez, M. F.; Vela, M. E.; Salvarezza, R. C. Role of Surface Heterogeneity and Molecular Interactions in the Charge-Transfer Process through Self-Assembled Thiolate Monolayers on $\mathrm{Au}(111)$. Langmuir 2004, 20, 5030-5037, Enlace.

[171] Sabatani, E.; Rubinstein, I. Organized self-assembling monolayers on electrodes. 2. Monolayer-based ultramicroelectrodes for the study of very rapid electrode kinetics. J. Phys. Chem. 1987, 91, 6663-6669, Enlace.

[172] Flynn, N. T.; Tran, T. N. T.; Cima, M. J.; Langer, R. Long-Term Stability of SelfAssembled Monolayers in Biological Media. Langmuir 2003, 19, 10909-10915, Enlace.

[173] Soreta, T. R.; Strutwolf, J.; O'Sullivan, C. K. Electrochemically Deposited Palladium as a Substrate for Self-Assembled Monolayers. Langmuir 2007, 23, 10823-10830, Enlace.

[174] Lemay, D. M.; Shepherd, J. L. Electrochemical fabrication of a heterogeneous binary SAM on polycrystalline Au. Electrochim. Acta 2008, 54, 388-393, Enlace.

[175] Vericat, C.; Vela, M. E.; Benitez, G. A.; Gago, J. A. M.; Torrelles, X.; Salvarezza, R. C. Surface characterization of sulfur and alkanethiol self-assembled monolayers on $\mathrm{Au}(111)$. J. Phys.: Condens. Matter 2006, 18, R867-R900, Enlace.

[176] Rodriguez, J. A.; Chaturvedi, S.; Jirsak, T. The bonding of sulfur to Pd surfaces: photoemission and molecular-orbital studies. Chem. Phys. Lett. 1998, 296, 421-428, Enlace. 
[177] Qian, S. Y.; Conway, B. E.; Jerkiewicz, G. Comparative effects of adsorbed S-species on $\mathrm{H}$ sorption into $\mathrm{Pd}$ from $\mathrm{UPD}$ and $\mathrm{OPD} \mathrm{H}$ : a kinetic analysis. Int. J. Hydrogen Energy 2000, 25, 539-550, Enlace.

[178] Casella, I. G.; Guascito, M. R.; Desimoni, E. Sulfide measurements by flow injection analysis and ion chromatography with electrochemical detection. Anal. Chim. Acta 2000, 409, 27-34, Enlace.

[179] Vela, M. E.; Martin, H.; Vericat, C.; Andreasen, G.; Hernández Creus, A.; Salvarezza, R. C. Electrodesorption Kinetics and Molecular Interactions in Well-Ordered Thiol Adlayers On Au(111). J. Phys. Chem. B 2000, 104, 11878-11882, Enlace.

[180] Hatchett, D.; Uibel, R.; Stevenson, K.; Harris, J.; White, H. Electrochemical Measurement of the Free Energy of Adsorption of n-Alkanethiolates at $\operatorname{Ag}(111)$. J. Am. Chem. Soc. 1998, 120, 1062-1069, Enlace.

[181] Bengió, S.; Fonticelli, M.; Benítez, G.; Creus, A. H.; Carro, P.; Ascolani, H.; Zampieri, G.; Blum, B.; Salvarezza, R. C. Electrochemical Self-Assembly of Alkanethiolate Molecules on Ni(111) and Polycrystalline Ni Surfaces. J. Phys. Chem. B 2005, 109, 23450-23460, Enlace.

[182] Grumelli, D.; Vericat, C.; Benitez, G.; Vela, M.; Salvarezza, R.; Giovanetti, L.; Ramallo-Lopez, J.; Requejo, F.; Craievich, A.; Shon, Y. Thiol-Capped Gold Nanoparticles on Graphite: Spontaneous Adsorption and Electrochemically Induced Release. J. Phys. Chem. C 2007, 111, 7179-7184, Enlace.

[183] Karhánek, D.; Bučko, T.; Hafner, J. A density functional study of the adsorption of methane-thiol on the (111) surfaces of the Ni-group metals: I. Molecular and dissociative adsorption. J. Phys.: Condens. Matter 2010, 22, 265005, Enlace.

[184] Karhánek, D.; Bučko, T.; Hafner, J. A density-functional study of the adsorption of methane-thiol on the (111) surfaces of the Ni-group metals: II. Vibrational spectroscopy. J. Phys.: Condens. Matter 2010, 22, 265006, Enlace.

[185] Reuter, K.; Stampfl, C.; Scheffler, M. Ab initio atomistic thermodynamics and statistical mechanics of surface properties and functions. En Handbook of Materials Modeling, Vol. 1: Fundamental Models and Methods.; Yip, S., (comp.); Springer: Dordrecht, 2004.

[186] Rogal, J.; Reuter, K. Ab initio atomistic thermodynamics for surfaces: A primer. En Experiment, Modeling and Simulation of Gas-Surface Interactions for Reactive Flows; Educational Notes RTO-EN-AVT-142: Neuilly-sur-Seine, 2007.

[187] Reuter, K.; Scheffler, M. Composition, structure, and stability of $\mathrm{RuO}_{2}(110)$ as a function of oxygen pressure. Phys. Rev. B 2001, 65, 035406, Enlace.

[188] Torres, D.; Carro, P.; Salvarezza, R. C.; Illas, F. Evidence for the Formation of Different Energetically Similar Atomic Structures in $\mathrm{Ag}(111)-(\sqrt{7} \times \sqrt{7}) \mathrm{R} 19,1^{\circ}-\mathrm{CH}_{3} \mathrm{~S}$. Phys. Rev. Lett. 2006, 97, 226103-4, Enlace. 
[189] Carro, P.; Salvarezza, R.; Torres, D.; Illas, F. On the Thermodynamic Stability of $(\sqrt{3} \times \sqrt{3})$ R30 ${ }^{\circ}$ Methanethiolate Lattice on Reconstructed $\mathrm{Au}(111)$ Surface Models. J. Phys. Chem. C 2008, 112, 19121-19124, Enlace.

[190] Carro, P.; Creus, A. H.; Muñoz, A.; Salvarezza, R. C. On the Thermodynamic Stability of $\alpha, \omega$-Alkanedithiols Self-Assembled Monolayers on Unreconstructed and Reconstructed $\mathrm{Au}(111)$. Langmuir 2010, 26, 9589-9595, Enlace.

[191] Beret, E. C.; Ghiringhelli, L. M. Ab Initio Atomistic Thermodynamics. 2011; Handson Tutorial Workshop 2011 on Ab Initio Molecular Simulations, Berlin., Enlace.

[192] Alfonso, D. R. First-principles study of sulfur overlayers on $\operatorname{Pd}(111)$ surface. Surf. Sci. 2005, 596, 229-241, Enlace.

[193] Liu, W.; Mitchell, K. A. R.; Berndt, W. The structure of the $\operatorname{Pd}(111)-(\sqrt{7} \times$ $\sqrt{7}) \mathrm{R} 19,1^{\circ}$-S surface: comparison with the corresponding $\mathrm{P} / \mathrm{Rh}(111)$ surface. Surf. Sci. 1997, 393, L119-L125, Enlace.

[194] Alfonso, D. R. First-principles studies of the $(\sqrt{7} \times \sqrt{7}) \mathrm{R} 19,1^{\circ}$ structure of sulfur on the $\operatorname{Pd}\left(\begin{array}{ll}1 & 1\end{array}\right)$ surface. Surf. Sci. 2007, 601, 4899-4909, Enlace.

[195] Alfonso, D. R. Initial incorporation of sulfur into the Pd(1 11 ) surface: A theoretical study. Surf. Sci. 2006, 600, 4508-4516, Enlace.

[196] Jiang, D.-e.; Tiago, M. L.; Luo, W.; Dai, S. The "Staple" Motif: A Key to Stability of Thiolate-Protected Gold Nanoclusters. J. Am. Chem. Soc. 2008, 130, 2777-2779, Enlace.

[197] Rzeźnicka, I. I.; Lee, J.; Maksymovych, P.; Yates, J. T. Nondissociative Chemisorption of Short Chain Alkanethiols on $\mathrm{Au}(111)$. J. Phys. Chem. B 2005, 109, 15992-15996, Enlace.

[198] Zhou, J.-G.; Hagelberg, F. Do Methanethiol Adsorbates on the Au(111) Surface Dissociate? Phys. Rev. Lett. 2006, 97, 045505, Enlace.

[199] Mehring, P.; Beimborn, A.; Westphal, C. The structural formation of methylthiolate SAMs on $\mathrm{Au}\left(\begin{array}{lll}1 & 1 & 1\end{array}\right)$ for short deposition times from solution. Appl. Surf. Sci. 2010, 256, 7265-7269, Enlace.

[200] Shah, N.; Panjala, D.; Huffman, G. P. Hydrogen Production by Catalytic Decomposition of Methane. Energy Fuels 2001, 15, 1528-1534, Enlace.

[201] Dropsch, H.; Baerns, M. Interaction of methane with supported Pd catalysts studied by adsorption microcalorimetry and TPD/TPSR techniques. Appl. Catal. A 1997, 165, 159-169, Enlace.

[202] Spiess, F.-J.; Suib, S. L.; Irie, K.; Hayashi, Y.; Matsumoto, H. Metal effect and flow rate effect in the hydrogen production from methane. Catal. Today 2004, 89, 35-45, Enlace. 
[203] Takenaka, S.; Shigeta, Y.; Tanabe, E.; Otsuka, K. Methane Decomposition into Hydrogen and Carbon Nanofibers over Supported Pd-Ni Catalysts: Characterization of the Catalysts during the Reaction. J. Phys. Chem. B 2004, 108, 7656-7664, Enlace.

[204] Lin, Y.-M.; Rei, M.-H. Process development for generating high purity hydrogen by using supported palladium membrane reactor as steam reformer. Int. J. Hydrogen Energy 2000, 25, 211-219, Enlace.

[205] Teschner, D.; Révay, Z.; Borsodi, J.; Hävecker, M.; Knop-Gericke, A.; Schlögl, R.; Milroy, D.; Jackson, S. D.; Torres, D.; Sautet, P. Understanding Palladium Hydrogenation Catalysts: When the Nature of the Reactive Molecule Controls the Nature of the Catalyst Active Phase. Angew. Chem., Int. Ed. 2008, 47, 9274-9278, Enlace.

[206] Wrobel, R. J.; Becker, S. Carbon and sulphur on Pd(111) and Pt(111): Experimental problems during cleaning of the substrates and impact of sulphur on the redox properties of $\mathrm{CeO}_{x}$ in the $\mathrm{CeO}_{x} / \mathrm{Pd}(111)$ system. Vacuum 2010, 84, 1258-1265, Enlace.

[207] Hoffmann, R. Solids and Surfaces: A Chemist's View of Bonding in Extended Structures; VCH Publishers: New York, 1988.

[208] Hammer, B.; Nørskov, J. K. Theoretical surface science and catalysis-calculations and concepts. Adv. Catal. 2000, 45, 71-129, Enlace.

[209] Cargnello, M.; Wieder, N. L.; Canton, P.; Montini, T.; Giambastiani, G.; Benedetti, A.; Gorte, R. J.; Fornasiero, P. A Versatile Approach to the Synthesis of Functionalized Thiol-Protected Palladium Nanoparticles. Chem. Mater. 2011, 23, 3961-3969, Enlace.

[210] Lu, C.-H.; Chang, F.-C. Polyhedral Oligomeric Silsesquioxane-Encapsulating Amorphous Palladium Nanoclusters as Catalysts for Heck Reactions. ACS Catal. 2011, 1, 481-488, Enlace.

[211] Marshall, S. T.; Schwartz, D. K.; Medlin, J. W. Adsorption of Oxygenates on Alkanethiol-Functionalized Pd(111) Surfaces: Mechanistic Insights into the Role of Self-Assembled Monolayers on Catalysis. Langmuir 2011, 27, 6731-6737, Enlace.

[212] Marshall, S. T.; Medlin, J. W. Surface-level mechanistic studies of adsorbateadsorbate interactions in heterogeneous catalysis by metals. Surf. Sci. Rep. 2011, 66, 173-184, Enlace.

[213] Favier, F.; Walter, E. C.; Zach, M. P.; Benter, T.; Penner, R. M. Hydrogen Sensors and Switches from Electrodeposited Palladium Mesowire Arrays. Science 2001, 293, 2227-2231, Enlace.

[214] Ibañez, F. J.; Zamborini, F. P. Reactivity of Hydrogen with Solid-State Films of Alkylamine- and Tetraoctylammonium Bromide-Stabilized Pd, PdAg, and PdAu 
Nanoparticles for Sensing and Catalysis Applications. J. Am. Chem. Soc. 2008, 130, 622-633, Enlace.

[215] Moreno, M.; Ibañez, F. J.; Jasinski, J. B.; Zamborini, F. P. Hydrogen Reactivity of Palladium Nanoparticles Coated with Mixed Monolayers of Alkyl Thiols and Alkyl Amines for Sensing and Catalysis Applications. J. Am. Chem. Soc. 2011, 133, 43894397, Enlace.

[216] Novakova, E. K.; McLaughlin, L.; Burch, R.; Crawford, P.; Griffin, K.; Hardacre, C.; Hu, P.; Rooney, D. W. Palladium-Catalyzed Liquid-Phase Hydrogenation/Hydrogenolysis of Disulfides. J. Catal. 2007, 249, 93-101, Enlace.

[217] Sadeghmoghaddam, E.; Lam, C.; Choi, D.; Shon, Y.-S. Synthesis and Catalytic Properties of Alkanethiolate-Capped Pd Nanoparticles Generated from Sodium SDodecylthiosulfate. J. Mater. Chem. 2010, 21, 307-312, Enlace.

[218] Ramallo-López, J.; Giovanetti, L.; Craievich, A.; Vicentin, F.; Marín-Almazo, M.; José-Yacaman, M.; Requejo, F. XAFS, SAXS and HREM Characterization of Pd Nanoparticles Capped With n-Alkyl Thiol Molecules. Phys. B 2007, 389, 150-154, Enlace.

[219] Zelakiewicz, B. S.; Lica, G. C.; Deacon, M. L.; Tong, Y. ${ }^{13}$ C NMR and Infrared Evidence of a Dioctyl-Disulfide Structure on Octanethiol-Protected Palladium Nanoparticle Surfaces. J. Am. Chem. Soc. 2004, 126, 10053-10058, Enlace.

[220] Sun, Y.; Frenkel, A. I.; Isseroff, R.; Shonbrun, C.; Forman, M.; Shin, K.; Koga, T.; White, H.; Zhang, L.; Zhu, Y.; Rafailovich, M. H.; Sokolov, J. C. Characterization of Palladium Nanoparticles by Using X-ray Reflectivity, EXAFS, and Electron Microscopy. Langmuir 2006, 22, 807-816, Enlace.

[221] Murayama, H.; Ichikuni, N.; Negishi, Y.; Nagata, T.; Tsukuda, T. EXAFS study on interfacial structure between $\mathrm{Pd}$ cluster and $n$-octadecanethiolate monolayer: formation of mixed Pd-S interlayer. Chem. Phys. Lett. 2003, 376, 26-32, Enlace.

[222] Leff, D. V.; Brandt, L.; Heath, J. R. Synthesis and Characterization of Hydrophobic, Organically-Soluble Gold Nanocrystals Functionalized with Primary Amines. Langmuir 1996, 12, 4723-4730, Enlace.

[223] Chen, S.; Huang, K.; Stearns, J. A. Alkanethiolate-Protected Palladium Nanoparticles. Chem. Mater. 2000, 12, 540-547, Enlace.

[224] Yang, Z.; Klabunde, K. J.; Sorensen, C. M. From Monodisperse Sulfurized Palladium Nanoparticles to Tiara Pd(II) Thiolate Clusters: Influence of Thiol Ligand on Thermal Treatment of a Palladium(II)-Amine System. J. Phys. Chem. C 2007, 111, 18143-18147, Enlace.

[225] Yang, Z.; Smetana, A. B.; Sorensen, C. M.; Klabunde, K. J. Synthesis and Characterization of a New Tiara $\mathrm{Pd}(\mathrm{II})$ Thiolate Complex, $\left[\mathrm{Pd}\left(\mathrm{SC}_{12} \mathrm{H}_{25}\right)_{2}\right]_{6}$, and its 
Solution-Phase Thermolysis to Prepare Nearly Monodisperse Palladium Sulfide Nanoparticles. Inorg. Chem. 2007, 46, 2427-2431, Enlace.

[226] Porter, M. D.; Bright, T. B.; Allara, D. L.; Chidsey, C. E. D. Spontaneously organized molecular assemblies. 4. Structural characterization of $n$-alkyl thiol monolayers on gold by optical ellipsometry, infrared spectroscopy, and electrochemistry. J. Am. Chem. Soc. 1987, 109, 3559-3568, Enlace.

[227] Grumelli, D.; Méndez De Leo, L. P.; Bonazzola, C.; Zamlynny, V.; Calvo, E. J.; Salvarezza, R. C. Methylene Blue Incorporation into Alkanethiol SAMs on Au(111): Effect of Hydrocarbon Chain Ordering. Langmuir 2010, 26, 8226-8232, Enlace.

[228] Snyder, R. G.; Strauss, H. L.; Elliger, C. A. Carbon-hydrogen stretching modes and the structure of $n$-alkyl chains. 1. Long, disordered chains. J. Phys. Chem. 1982, 86, 5145-5150, Enlace.

[229] Hostetler, M.; Stokes, J.; Murray, R. Infrared Spectroscopy of Three-Dimensional Self-Assembled Monolayers: $N$-Alkanethiolate Monolayers on Gold Cluster Compounds. Langmuir 1996, 12, 3604-3612, Enlace.

[230] Manna, A.; Imae, T.; Yogo, T.; Aoi, K.; Okazaki, M. Synthesis of Gold Nanoparticles in a Winsor II Type Microemulsion and Their Characterization. J. Colloid Interface Sci. 2002, 256, 297-303, Enlace.

[231] Silverstein, R. M.; Webster, F. X.; Kiemle, D. J. Spectrometric identification of organic compounds, 7a ed.; John Wiley \& Sons: Hoboken, NJ, 2005.

[232] Hayashi, M.; Shiro, Y.; Murata, H. The Vibrational Assignment and Rotational Isomerism of n-Propyl Mercaptan. Bull. Chem. Soc. Jpn. 1966, 39, 112-117, Enlace.

[233] Schaaff, T. G.; Shafigullin, M. N.; Khoury, J. T.; Vezmar, I.; Whetten, R. L. Properties of a Ubiquitous $29 \mathrm{kDa}$ Au:SR Cluster Compound. J. Phys. Chem. B 2001, 105, 8785-8796, Enlace.

[234] Li, Y.; Zaluzhna, O.; Tong, Y. J. Identification of a Source of Size Polydispersity and its Solution in Brust-Schiffrin Metal Nanoparticle Synthesis. Chem. Commun. 2011, 47, 6033-6035, Enlace.

[235] Litrán, R.; Sampedro, B.; Rojas, T. C.; Multigner, M.; Sánchez-López, J. C.; Crespo, P.; López-Cartes, C.; García, M. A.; Hernando, A.; Fernández, A. Magnetic and Microstructural Analysis of Palladium Nanoparticles with Different Capping Systems. Phys. Rev. B 2006, 73, 054404, Enlace.

[236] Newville, M. IFEFFIT: Interactive XAFS Analysis and FEFF Fitting. J. Synchrotron Radiat. 2001, 8, 322-324, Enlace.

[237] Ankudinov, A. L.; Ravel, B.; Rehr, J. J.; Conradson, S. D. Real-Space MultipleScattering Calculation and Interpretation of X-Ray-Absorption Near-Edge Structure. Phys. Rev. B 1998, 58, 7565-7576, Enlace. 
[238] Shen, C. M.; Su, Y. K.; Yang, H. T.; Yang, T. Z.; Gao, H. J. Synthesis and characterization of $n$-octadecayl mercaptan-protected palladium nanoparticles. Chem. Phys. Lett. 2003, 373, 39-45, Enlace.

[239] Lu, W.; Wang, B.; Wang, K.; Wang, X.; Hou, J. G. Synthesis and Characterization of Crystalline and Amorphous Palladium Nanoparticles. Langmuir 2003, 19, 58875891, Enlace.

[240] Cook, S. C.; Padmos, J. D.; Zhang, P. Surface structural characteristics and tunable electronic properties of wet-chemically prepared Pd nanoparticles. J. Chem. Phys. 2008, 128, 154705-11, Enlace.

[241] Wertheim, G. K.; DiCenzo, S. B.; Buchanan, D. N. E. Noble- and transition-metal clusters: The $d$ bands of silver and palladium. Phys. Rev. B 1986, 33, 5384-5390, Enlace.

[242] Mason, M. G. Electronic structure of supported small metal clusters. Phys. Rev. B 1983, 27, 748-762, Enlace.

[243] Richter, B.; Kuhlenbeck, H.; Freund, H.-J.; Bagus, P. S. Cluster Core-Level BindingEnergy Shifts: The Role of Lattice Strain. Phys. Rev. Lett. 2004, 93, 026805, Enlace.

[244] Hou, J. G.; Wang, B.; Yang, J.; Wang, K.; Lu, W.; Li, Z.; Wang, H.; Chen, D. M.; Zhu, Q. Disorder and Suppression of Quantum Confinement Effects in Pd Nanoparticles. Phys. Rev. Lett. 2003, 90, 246803, Enlace.

[245] Liu, Y.; Wang, C.; Wei, Y.; Zhu, L.; Li, D.; Jiang, J. S.; Markovic, N. M.; Stamenkovic, V. R.; Sun, S. Surfactant-Induced Postsynthetic Modulation of Pd Nanoparticle Crystallinity. Nano Lett. 2011, 11, 1614-1617, Enlace.

[246] Kim, J.-H.; Park, J.-S.; Chung, H.-W.; Boote, B. W.; Lee, T. R. Palladium nanoshells coated with self-assembled monolayers and their catalytic properties. RSC Advances 2012, 2, 3968-3977, Enlace.

[247] Olmos-Asar, J. A.; Rapallo, A.; Mariscal, M. M. Development of a semiempirical potential for simulations of Thiol-Gold interfaces. Application to Thiol-Protected gold nanoparticles. Phys. Chem. Chem. Phys. 2011, 13, 6500, Enlace.

[248] Gómez-Rodríguez, A.; Beltrán-del Río, L.; Herrera-Becerra, R. SimulaTEM: Multislice simulations for general objects. Ultramicroscopy 2010, 110, 95-104, Enlace.

[249] Spence, J. C. H. High-Resolution Electron Microscopy, 3ra ed.; Oxford University Press: New York, 2003.

[250] Kudriavtsev, Y.; Villegas, A.; Godines, A.; Asomoza, R. Calculation of the surface binding energy for ion sputtered particles. Appl. Surf. Sci. 2005, 239, 273-278, Enlace. 
[251] Hill, T. L. An Introduction to Statistical Thermodynamics; Courier Dover Publications: New York, 1986.

[252] Levine, I. N. Fisicoquímica, 5ta ed.; McGraw-Hill: Madrid, 2004; Vol. 2.

[253] McQuarrie, D. A.; Simon, J. D. Molecular Thermodynamics; University Science Books: Sausalito, CA, 1999.

[254] Osborne, D. W.; Doescher, R. N.; Yost, D. M. The Heat Capacity, Heats of Fusion and Vaporization, Vapor Pressure and Entropy of Dimethyl Sulfide. J. Am. Chem. Soc. 1942, 64, 169-172, Enlace. 